\title{
Wind Study for High Altitude Platform Design
}

(NASA-RP-1044) WIND STUDY FOR HTGH ALTITUDE
PLATPORM DESIGN (NASA) 288 P HC A13/MF AOI
CSCL O4B

N $80-12661$

Unclas

H $1 / 47 \quad 41462$

Thomas W. Strganac

DECEMBER 1979

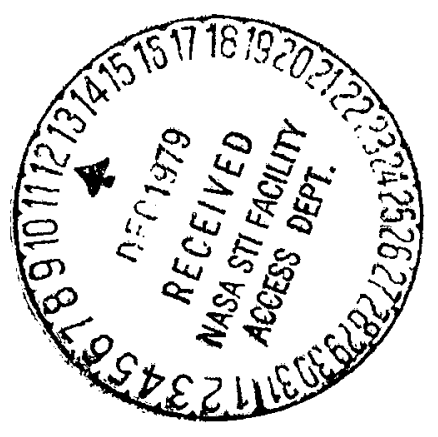

N/Sก 
NASA Reference Publication 1044

\section{Wind Study for High Altitude Platform Design}

Thomas W. Strganac

Wrallops Flight Center

Wullops Island, Virginia

Scientific and Technical

Information Branch

1979 


\section{CONTENTS}

Page

SUMMARY. . . . . . . . . . . . . . . .

INTRODUCTION . . . . . . . . . . . . . . . . . . . . . . . . . . . . . . 2

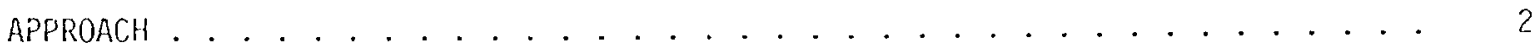

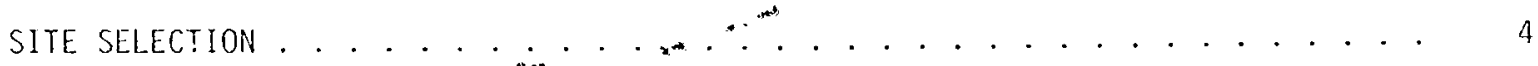

DATA PRESENTATIOH. . . . . . . . . . . . . . . . . . . . . . . 6

QUALIFICATION OF DATA. . . . . . . . . . . . . . . . . . . . . . . . . . . . . . . 9

CONCLUSIONS. . . . . . . . . . . . . . . . . . . . . . . . 10

Geographical area coverage . . . . . . . . . . . . . . . . . . . . . 10

Site operation. . . . . . . . . . . . . . . . . . . . . . . 12

Maximum and minimum wind speeds . . . . . . . . . . . . . . . . . . . . 13

Average wind speeds. . . . . . . . . . . . . . . . . . . . . . 13

Operating altitude regime. . . . . . . . . . . . . . . . . . . . . . . 14

APPENDIX . . . . . . . . . . . . . . . . . . . . . . . 15

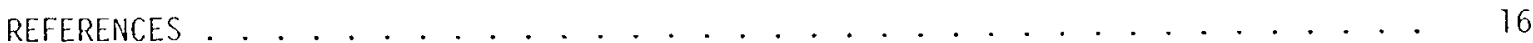

SECTION A - UNITED STATES. . . . . . . . . . . . . . . . . . . . . . . . 17

A-1 Wind profiles - selected prime sites. . . . . . . . . . . . . . . . . . . 18

A-2 Maps - sample count per site. . . . . . . . . . . . . . . . . . . . . . . 32

A-3 Maps - mean wind speed and standard deviation . . . . . . . . . . . . . 48

A-4 Maps - wind roses per prime site. . . . . . . . . . . . . . . . . . . . 64

A-5 Maps - percent occurrence of winds less than 30 knots . . . . . . . . . 80

A-6 Maps - percent occurrence of winds less than 40 knots . . . . . . . . . . 96

A-7 Maps - percent occurrence of winds less than 50 knots. . . . . . . . . 112

A-8 Maps - percent occurrence of winds less than 75 knots . . . . . . . . . 128

SECTICN B - EUROPEAN . . . . . . . . . . . . . . . . . . . . . . . . 144

B 1 Wind profiles - selected prime sites. . . . . . . . . . . . . . . . 145

B-2 Maps - sample count per site. . . . . . . . . . . . . . . . . . . 160

B-3 Maps - mean wind speed and standard deviation . . . . . . . . . . . . . . 168

B-4 Maps - wind roses per prime site. . . . . . . . . . . . . . . . . . . 176

B-5 Maps - percent occurrence of winds less than 30 knots. . . . . . . . . . 184

B-6 Maps - percent occurrence of winds less than 40 knots . . . . . . . . . . 192

B-7 Maps - percent occurrence of winds less than 50 knots . . . . . . . . . . 200

B-8 Maps - percent oc urrence of winds less than 75 knots . . . . . . . . . 208 
SECTION C - PACIFIC. . . . . . . . . . . . . . . . . 216

$C-1$ Wind profiles - selected prime sites.............. 217

C-2 Maps - sample count per site. . . . . . . . . . . . . . . 228

C-3 Maps - mean wind speed and startard deviation............. . . . 236

C-4 Maps - wind roses per prime site. . . . . . . . . . . . . . 244

C-5 Maps - percent occurrence of winds less than 30 knots . . . . . . . . 252

C-6 Maps - percent occurrence of winds less than 40 knots......... 260

C-7 Maps - percent occurrence of winds less than 50 knots . . . . . . 268

C-8 Maps - percent occurrence of winds less than 75 knots....... 276 


\section{WIND STUDY FOR HIGH ALTITUDE PLATFORM DESIGN}

Thomas W. Strganac

Wallops Flight Center

SUMMARY

A study of upper winds ranging from $100 \mathrm{mb}$ to $25 \mathrm{mb}$ pressure altitude has been performed to define the mission operating altitudes for purposes of high altitude platform design. Four areas of interest have been investigated: the contiguous United States to address the National Aeronaltics and Space Administration (NASA)/Wallops Flight Center High Altitude Powered Plitf rm (HAPP) requirements; and the Norwegian area, the Mediterranean area, and the Pacific area from Alaska to Japan with surrounding areas for addressing the Navy's high iltitude platform (HI SPOT) concepts. A preliminary study conducted using wind data at. Wa: sps Flight Center established guidelines for this study. The National Oceanic a, ....spheric Administration's (NOAA) National Climatic Center was contracted for qual : : jite selection and representation of compiled data as specified by the NASA Waliops F, ight Certer Lighter-Than-Air Program office.

Sites were selected by the National clinatic Center, based on adequate rawinsonde coverage, geographic dispersion and climate characteristics, to best represent each of the four area's conditions. Several years of rawinsonde data were compiled and presented in the following formats: wind profiles from surface to $10 \mathrm{mb}$ pressure altitude (31 $\mathrm{km}$ ); and maps of the four geographical areas depicting mean scalar speeds, standard deviation, sample size, and wind roses presenting wind directions and mea speed per direction. In addition, the data were provided in maps unique for design purposes depicting the frequency of wind speeds occurring less than predetermined design speeds of 30,40 , 50, and 75 knots.

The results of this study show that high altitude winds are at a minimum between the altitudes of 18 and $22 \mathrm{~km}$ dependent on time of year. For these altitudes, based on a 95 percent statistical occurrence, resu'ts show that in the United States annual wind speeds are less than 50 knots with the exception of the winter period; for the winter the winds are less than 50 knots at 86 percent of the sites. The foreign areas studied appear 0 be more seasonaily limited. W'ind speeds are less than 50 knots greater than 80 percent of the time during the non-winter months and 45 percent of the time during the winter months. Conditions can be improved with a change in altitude, latitude, or season. 


\section{INTRODUCTION}

A study has been conducted to characterize upper winds - primarily magnitudes - for use as guidelines in high altitude platform design. This effort addresses the probabilities for flight operation at the potential mission operating altitudes for assumed design speeds on a seasonal basis. NASA/Wallops Flight Center has been investigating the feasibility of a HAPP concept - a long Juration, remotely piloted, geostationary platform - with power supplied by microwave transmission. Both heavier-than-air and lighterthan-air concepts exist for use as communication, surveillance, remote sensing, dilu in situ measurement piatforms. Preliminary studies (refs. 1 and 2) have indicated the potential feasibility of the HAPP concept; however, further environmenta definition of the winds has been stressed due to the criticalness of power plant and platform design. The dependency upon transmitted power from a ground fixed beam source requires station keeping capabilities, and since the propulsion (power) requiremencs for stationary operation increase as a cube of the wind velocity, the definition of winds for altitudes of minimum conditions is essential to the success of HAPP concepts. In addition to NASA's HAPP concept requirements the needs for the Navy's high altitude platform (HI SPOT) concept - a long duration, remotely piioted. solar power system - have been addressed at the Navy's request due to their similar dependency on upper winds for design.

NASA's Wallops Flight Center contracted with NOAA's National Climatic Center to provide qualified site selection and to compile and present data in a prescribed method. All available rawinsnnde data from these selected sites (from the surface to $10 \mathrm{mb}$ altitude) were compiled and analyzed to characterize the horizontal wind field. The following geographical areas of interest were investigated: the contiguous united States for NASA HAPP activities; and both the European area, including the Norwegian and Mediterranean Seas, and the Pacific area from Alaska to Japan with surrounding areas for the Navy's HI SPOT concepts. The results of this effort are presented here including site selection and its basis, wind profiles for sites, maps detailing various statistical parameters, discussions of the data's validity, and concilasions regarding the expected wind environment for both the NASA and Navy high altitude platform concepts.

\section{APPROACH}

Wallops Flight Center conducted a preliminary in-house study to provide detailed information on the upper winds at wallops Flight Center. The data were provided using a standard winds aloft format (ref. 3) inciuding percentage of winds per direction, percentage of winds per speed group (1-9 knots, 10-19 knots, etc.), and statistical information (mean, std. deviation, etc.) for nine years of daily measurements at established standaru altitudes ranging from suriace to a pressure altitude of $4 \mathrm{mb}$. Based upon this 


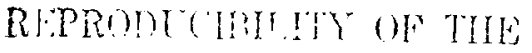

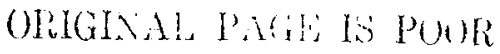

initial effort, the NASA/Wallops Flight Center Lighter-Than-Air Program Office developed a working plan which provided guidelines for a follow-on effort to include the United States and foreign areas of interest. The major components of the study were: site selection, data compilation, presentation, and qualification.

A large coverage was desired; therefore, site selection was of extreme importance as resources limited the number of locations which could be investigated. To this end the study guidelines required sites to be selected based on the upper wind characteristics for the following four geographical areas of interest: the United States (including Alaska); the Pacific area (including the Sea of Japan and Sea of Okhotsk); the Norwegian Sea with immediate surroundings; and the Mediterranean Sea with immediate surroundings. The number of sites selected for each area was dependent only on fulfiliment of requirements to represent the upper wind conditions per geographical area. Other possible site selection method alternatives were considered including: selection based on potential use per site; using an array of sites which provides overall high altitude platform coverage per locales of interest; or use of all wind reporting stations. The selection based on potential use per site was not used since these sites have not yet been defined. Using the array format was not acceptable as it would not necessarily represent the desired unique wind condition expectations in a geographical area but might instead provide a number of sites with similar conditions. Using all reporting stations was rejected due to being impractical on a cost and time basis.

Winds aloft summaries, consisting of several years (approximately twenty years dependent on site) of twice daily rawinsonde soundings, were used for the data base. Since the primary purpose of this wind study was to establish the minimum speed operating altitudes and design requirements for high altitude platforms, all maps and profiles were developed to support this; primary interest was placed on wind magnitudes from the surface to $31 \mathrm{~km}$ with directional information being only minimally addressed.

To define the potential mission operating altitudes for high altitude vehicles, wind profiles were desired consisting of mean wind speed and expected theoretical standard deviations versus altitude. Bised on these wind profiles from surface to $31 \mathrm{~km}$ for all selected sites, a definition of the potential operating regime wolld be established with respect to seasons and further emphasis would be placed on this regime. The remainder of the study would consist of reprisentation of the wind data in map form. Maps, representing the operating regime for the separate areas of interest and providing a breakdown of the annua" conditions, would include the fcllowing: mean wind speed, wind roses representing directions, and the proportion of occurrences below predetermined operating speeds. The maps would provide contours of constant parameters depicting probable conditions in the areas of interest based on the selected sites. Potertial design operating speeds of $30,40,50$, and 75 knots were selected for parametric anlalys is of upper wind operating conditions. The analysis provides proportions of historical occurrence of 
winds less than the established value $(30,40,50$, and 75 knots) as well as theoretical confidence intervals providing reliability of these proportions. Wind direction data would be presented in the form of wind roses indicating the historical occurrence from each direction and the respective mean speed.

The National climatic Center, based on their expertise and experience, was contracted to perform this study task as directed by NASA/Wallops Flight Center. The National climatic Center records and archives data for all meteorological stations including in.. formation from the U. S. Weather Service, Navy, Air Force, plus foreign operated sices, and its climatology experience would provide the basis for reliable site selection.

Upon completion of the site selection and data representation by the National climatic Center, Wallops Fight Center would provide conclusions pertaining to the potential mission operating environment for high altitude platform concepts.

\section{SITE SELECTION}

Using the mean scalar wind chart for the winter season, as described in reference 4 , the National Climatic Center selected sites based on: (1) adequate sampling of upper winds per site; (2) dispersion of sites throughout the geographical area of interest; and (3) representation of the unique upper winds per geographical area.

TABLE I. -UNITEO STATES SITE SELECTION

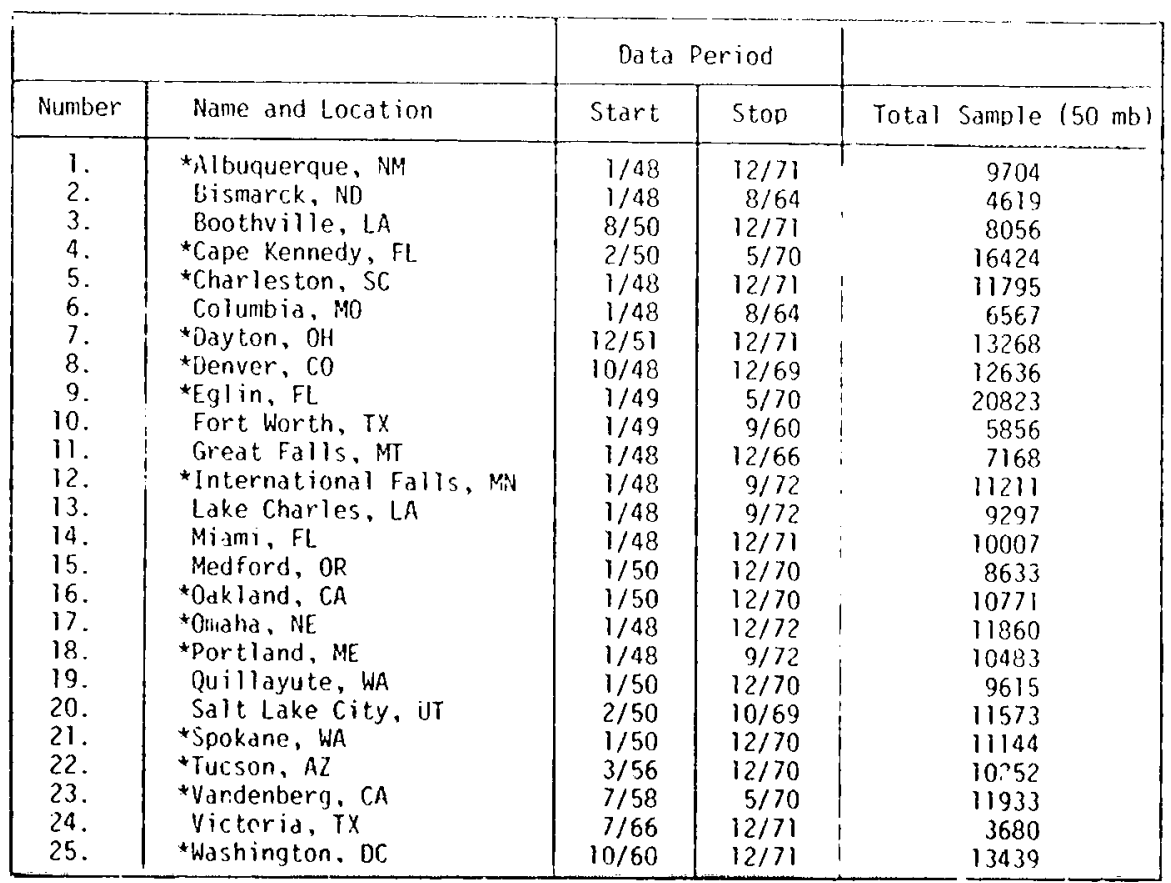

\section{* Prime site}




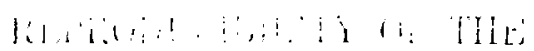

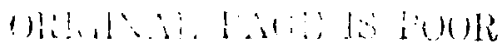

During this selection the National Crimatic Center determined that the Norwegian Sea and Mediterranean areas should be combined due to high altitude climatological similarities. For similar reasons Alaskan sites were added to the Pacific area. Data were provided in existing winds aloft summaries; the tables provide a listing of data periods as well as the total recorded sample size for the $50 \mathrm{mb}$ level. Tables I, II, and III provide a listing of all stations selected for the Uniced States, European and Pacific locales respectively. Initially 14 U. S. Sites, 15 European sites, and 11 Pacific sites were selected as prime sites. However, during data compilation and map analysis, additional sites were required due to the discontinuity of the data of one or more of the selected prime sites when compared with the overall pattern described by the network of prime sites. The National Climatic Center, based on experience of expected climatological conditions, determined that these discontinuities could result from sampling size, instrumentation, data reduction efforts, or data transmission errors. Supplemental sites in the vicinit; of the questionable stations wero added to support the analysis. A total of 25 U. S. sites, 21 European sites, and 23 Pacific sites were used in the compilation of the results.

TABLE II.-EUROPEAN SITE SELECTION

\begin{tabular}{|c|c|c|c|c|}
\hline \multirow[b]{2}{*}{ Number } & \multirow[b]{2}{*}{ ilame and Location } & \multicolumn{2}{|c|}{ Data Period } & \multirow[b]{2}{*}{ Iotal Samole $(50 \mathrm{mb})$} \\
\hline & & Start & Stop & \\
\hline 1. & Apeppo, Syria & $7 / 57$ & $6 / 67$ & 396 \\
\hline 2. & *Alger, Algeria & $1 / 49$ & $8 / 67$ & 904 \\
\hline 3. & *Bet Dagan, Israel & $2 / 56$ & $2 / 67$ & 653 \\
\hline 4. & *Brindisi, italy & $1 / 64$ & $2 / 71$ & 5216 \\
\hline 5. & Chaumont, France & $7 / 53$ & $8 / 59$ & 3306 \\
\hline 6. & *Essen, Germany & $7 / 65$ & $10 / 71$ & 3341 \\
\hline 7. & Iraklion, Greece & $1 / 64$ & $12 / 72$ & 3656 \\
\hline 8. & \$zmir, Turkey & $1 / 61$ & $12 / 67$ & 136 \\
\hline 9. & Ian Mayen, Norway & $1 / 64$ & $12 / 72$ & 3656 \\
\hline 10. & * Jokioinen, Finland & $1 / 49$ & $11 / 63$ & 2554 \\
\hline 11. & *Keflavik, Iceland & $10 / 51$ & $9 / 61$ & 8942 \\
\hline 12. & *Kobenhavn, Denmark & $.0 / 49$ & $10 / 71$ & 6110 \\
\hline 13. & Lvov, USSR & $2 / 47$ & $9 / 67$ & 1122. \\
\hline 14. & *Matruh, Egypt & $2 / 55$ & $6 / 66$ & 68 \\
\hline 15. & *Milano, Italy & $7 / 57$ & $2 / 71$ & 5866 \\
\hline 16. & Nicosia, Cyprus & $1 / 56$ & $12 / 67$ & 1252 \\
\hline 17. & *Odessa, USSR & $12 / 46$ & $9 / 67$ & 1223 \\
\hline 18. & *Tharshavn, Faeroe Islands & $11 / 49$ & $10 / 71$ & 2432 \\
\hline 19. & *Tripoli, Libya & $4 / 49$ & $7 / 63$ & 6516 \\
\hline 20. & *Valentia, Ireland & $1 / 60$ & $10 / 71$ & 1345 \\
\hline 21. & +Yerevan, USSR & $2 / 49$ & $12 / 67$ & 414 \\
\hline
\end{tabular}

* Prime Site 
TABLE III.-PACIFIC SITE SELECTION

\begin{tabular}{|c|c|c|c|c|}
\hline \multirow[b]{2}{*}{ Number } & & \multicolumn{2}{|c|}{ Data Period } & \multirow{2}{*}{ Total Sample $(50 \mathrm{mb})$} \\
\hline & Name and Location & Start & Stop & \\
\hline $\begin{array}{l}1 . \\
2 . \\
3 . \\
4 . \\
5 . \\
6 . \\
7 . \\
8 . \\
9 . \\
10 . \\
11 . \\
12 . \\
13 . \\
14 . \\
15 . \\
16 . \\
17 . \\
18 . \\
19 . \\
20 . \\
21 . \\
22 . \\
23 .\end{array}$ & $\begin{array}{l}\text { Adak, Alaska } \\
\text { Akita, Japan } \\
\text { *Aleksandrovsk, USSR } \\
\text { *Anchorage, Alaska } \\
\text { *Ayan, USSR } \\
\text { Barrow, Alaska } \\
\text { Barter, Alaska } \\
\text { Buhta Ugolnaja, USSR } \\
\text { Fairbanks, Alaska } \\
\text { Kodiak, Alaska } \\
\text { *Korf, USSR } \\
\text { Mosuipo, Korea } \\
\text { *Mys Vasilyeva, USSR } \\
\text { Nagayevo, USSR } \\
\text { Nikol Skoye, IJSSR } \\
\text { *Mone, Alaska } \\
\text { *Osan, Korea } \\
\text { *Sapporn, Japan } \\
\text { *Shemya, Alaska } \\
\text { Shionomisaki, Japan } \\
\text { *Vladivostok, USSR } \\
\text { Wakkanai, Japan } \\
\text { * Wajima, Japan } \\
\end{array}$ & $\begin{array}{r}1 / 46 \\
1 / 56 \\
9 / 51 \\
1 / 48 \\
8 / 50 \\
1 / 62 \\
1 / 68 \\
4 / 55 \\
1 / 48 \\
1 / 46 \\
1 / 52 \\
7 / 54 \\
7 / 53 \\
3 / 50 \\
8 / 57 \\
1 / 48 \\
10 / 50 \\
1 / 56 \\
6 / 46 \\
1 / 56 \\
10 / 46 \\
1 / 56 \\
1 / 56\end{array}$ & $\begin{array}{r}2 / 64 \\
12 / 65 \\
12 / 65 \\
10 / 72 \\
12 / 65 \\
12 / 66 \\
12 / 72 \\
12 / 65 \\
6 / 70 \\
8 / 62 \\
12 / 65 \\
12 / 70 \\
12 / 65 \\
12 / 65 \\
12 / 65 \\
4 / 69 \\
12 / 70 \\
12 / 65 \\
2 / 64 \\
12 / 65 \\
6 / 71 \\
12 / 65 \\
12 / 65\end{array}$ & $\begin{array}{r}3581 \\
4794 \\
371 \\
11200 \\
126 \\
2192 \\
2194 \\
\text { None } \\
9713 \\
4335 \\
1141 \\
7855 \\
30 \\
278 \\
429 \\
8766 \\
17230 \\
4846 \\
3821 \\
4986 \\
3024 \\
4399 \\
4711\end{array}$ \\
\hline
\end{tabular}

\section{DATA PRESENTATION}

The data are presented in three separate parts: Section A (beginning on page 17) (page 216) presents the pacific arean B (page 144) presents the European area; and Section $i$ subsets: (1) wind profiles - selected Each section consists of the following identical on maps); (3) mean speed and standard prime sites only; (2) sample count ("N" count contours); (4) wind roses (maps ind deariation (maps with constant mean speed winds < 30 knots (maps with constant (7) proportions < 50 knots; and (8) proptage contours); (6) proportions < 40 knots;

The study is presented in a seasonat forntions < 75 knots. are presented by winter; March. April, and fornat such that December, January, and February profiles (subsets $A-1, B-1$, and $C-1$ ) - provided, and May are represented by spring; etc. Wind mean speed, the mean speed plus and minus one standard provided for the prime sites only - present the the 99 percentile at all standard pressure one standard deviation, the 95 percentile, and $\mathrm{mb}$. The Appendix is provided as easy reference level to geopotential altitude in meters and feet. number of data levels due to differences and feet. Foreign sites contained a fewer based on the assumption that the data 
mean speed:

standard deviation:

(for mean speed \pm 1 o)

95 percentile:

y̆ÿ percentile:

where:
$\bar{V}=\left[\frac{\Sigma V}{n}\right]_{\text {LEVEL }}$

$\sigma=\left[\sqrt{\frac{\sum(V-\bar{V})^{2}}{n-1}}\right]_{\text {LEVEL }}$

95 percent value $=(\bar{V}+1.645 \sigma)$

LEVEL

99 percent value $=(\bar{V}+2.326 \sigma)$

LEVEL

$\bar{V}=$ mean speed ( $=V$ in profiles).

$\mathrm{n}=$ sample size ( $\mathrm{N}$ in profiles).

$\sigma=$ standard deviation ( $=S$ in profiles).

The profiles may be interpreted as describing the number of sccurrences of wind magnitudes less than the established percent contour. For example, theoretically 99 percent of ali recorded wind values are less than the values indicated on the 99 percentile profile. In addition, empirical 84.13 percent values (shown as asterisks on profiles) calculated from the recorded data in the wind summaries are presented in the pressure altitude regime 100 to $25 \mathrm{mb}$. The wind summaries used contained percent of occurrence for the following speed classt-: 1-9 knots, 10-19 knots, 20-29 knots. 30-39 knots, 40-49 knots, 50-59 knots, 60-74 knots, 75-99 knots, 100-149 knots, 150-199 knots, and $\geq 200$ knots. The empirical 84.13 percent values were computed by summing the percent values in these speed class intervals and interpolating for 84.13 percent if required. Since in theory $\bar{V}+\sigma=84.13$ percent, the normality assumption can be validated by comparing the empirical 84.13 percent values with the mean speed plus 1 o profile. NASA selected the regime from 100 to $25 \mathrm{mb}$ pressure altitute to be closely examined as a result of the indicated 1 ull in winds shown on the profiles. Eight altitude levels - 100, 80, 70, 6n, $50,40,30$, and $25 \mathrm{mb}$ - were used for the United States; foreign sites included the levels of $100,70,50$, and $30 \mathrm{mb}$ becalise: of differences in established record keeping procedures.

All maps provide information for a particular locale (U. S., Europe, Pacific) for one scason and one altitude. The first maps of each section (subsets A-2, B-2, and C-2) contain sample count values for all selected sites. The sample counts in many cases support the need for the additional sites (indicated by smaller characters on the maps) to supplenient the prime sites. The next series of maps (subsets $A-3, B-3$, and $C-3$ ) 
characterize the mean speed for each area. Isotachs (contours of constant speed) were constructed by using the site to site values and interpolating between sites where necessary. As the study progressed support sites were added as required because of the discontinuity of some prime site data to other prime site data; the contours do not reflect the discontinuous data. The contours provide a geographic breakdown for each map of the conditions to be expected. Contours for standard deviation are not presented; however, the computed standard deviation is indicated below the mean value for each site. Maps containing 16 point wind roses for the prime sites indicate percent occurrence per direction and the mean speed for that direction. These maps are located in subset 4 of sections $A, B$, and $C$. The length of the line indicates the percentage of historical occurrence of the direction the winds came from; and the numerical values associated with each of the 16 compass points indicate the mean speed of occurrences for only that direction.

The remainder of the maps (subsets 5, 6, 7, and 8) for each section provide contours of constant proportions (presented as percentages) of wind magnitudes less than predetermined values. The proportions were based on actual occurrence of wind magnitudes iess than 30, 40, 50 and 75 knots. These values were selected by wallops Flight Center to best represent an envelope of possible operating sueed for the high altitude platform concepts. Values less than 30 knots (10 and 20 knots) were not used since proportions would be extremely low and non-representative for high altitude vehicle design. Values yreater than 75 knots were not selected since design speeds of that order were deened unrealistic. Confidence intervals of 95 percent and 99 percent for the proportions were computed based on the assumption of a normal data distribution. These confidence intervals provide a measure of estimating how accurate the sample proportion is to the true proportion. Assuming a normal distribution of data, these intervals were calculated as follows:

confidence interval: $\quad P_{a}= \pm z_{a} \sqrt{\frac{p(1-p)}{n}}$

where $z_{a}=1.96$ for $95 ; z_{a}=2.58$ for 99 percent.

$\mathrm{P}_{\mathrm{a}}=$ theoreticai true proportion.

$\mathrm{p}=$ observed proportion.

$n$ = sample size.

These intervals are interpreted such that:

$p-z_{a} \sqrt{\frac{p(1-p)}{n}}<p_{a}<p+z_{a} \sqrt{\frac{p(1-p)}{n}}$ 
In words, a confidence interval is a statistical lieasure of the true proportion based on: (1) normal distribution, (2) sample size, and (3) observed proportion.

To simplify interprectation of these maps, only contours of constant theoretical proportion were prepared. The plus/minus vaiues for the 95 percent and 99 percent confidence intervals are tabulated on the maps below the associated observed proportions for each site.

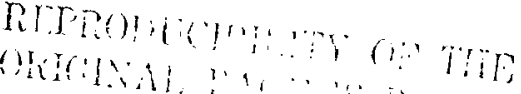

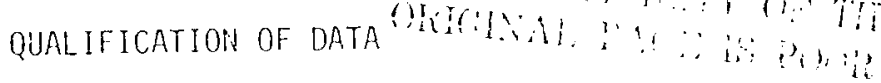

Areas of immediate concern are assumption of nomality, validity of represented data, and quality of rawinsonde techniques. As previously reported, cheoretical and actual observed values for mean speed plus one standard deviation (84.13 percent) were compared to provide a measure of the validit: of the normality assumption. In addition, theoretical 95 percent and 99 percent values have been compared to the actual 95 percent and 99 percent values. Results of the comparisons are: (1) approximately 10 percent difference (average value) between the theoretical and actual values for the 95 percent profiles; and (2) approximately 35 percent difference between theoretical and actual profiles in the extremes (99 percent). In most cases the actual values were greater than the theoretical values. Contributing factors to the deviations observeu are: (1) few wina magnitudes recorded at extremes; (2) large recording intervals of data $(10 \mathrm{knot}$ intervals - 0 to 60 knots, 50 knot intervals - 100 to 200 knots); and (3) 1 inear interpolation of the actual 84.13 percent, 95 percent, and 99 percent values. For example, 7t Albuquerque, New Mexico (50 mb pressure altitude level-winter season), based on the mean speed and standard deviation the 84.13 percent, 95 percent, and 99 percent values are $26.4,33$, and 40 knots, respectively. However, the values as determined by $l i n e a r l y$ interpolating the recorded data are $25.6,37$, and 58 knots for 84.13 , 35 , and 99 percent, respectively. In some cases these deviations can be theoretically justified by relating the sample count to the comparison. Questionable site data were qualified in this study by the addition of sites in the general vicinity of the site in question.

Other available formats of wind data exist which include: the serially complete data, which includes basic rawinsonde data as presented in this study but completed by the theoretical aadition of missing samples; and grid point data, which is map form, computer enhanced rawinsonde data presented in an array forma $i$ using latitude and longitude as coordinates. However, since this study was conducted on a seasonal and not a daily basis, it was felt that the basic rawinsonde data would be adequate.

The quality of rawinsonde data has been questioned and reviewed. The National climatic center indicates that problems existing with basic rawinsonde data are: (1) missing data; (2) addition of standard pressure levels (different sample sizes); and (3) accuracy of the ground meteorological detector (GMO) measurement system. Missing 
data results from: (1) transmission problems from rawinsonde to GMD; (2) transmission problems from site to record center; (3) failure in rawinsonde; and (4) rawinsunde forced out of the GMD receiving range. The addition of standard pressure levels results in a discontinuity of data resulting from sample size. The $70 \mathrm{mb}$ pressure altitude level was added as a standard recording level several years after the others had been established. A slight discontinuity due to sample size is reflected on some profiles presented in this report. Independent tests (refs. 5 and 6 ) have been conductad comparing GMD measurements to radar trackings. These tests show that wind speeds obtained using the GMD are slower on the average by $2-4$ knots than radar outside the jet stream region.

\section{CONCLUSIONS}

Analysis of this data has been performed to cetermine the wind environmental impact upon the design of the high altitude platforms. Seasonal and altitude variations have been analyzed. The results for all areas will be presented as follows: (1) geographical area coverage; (2) site operation; (3) maximum and minimum wind speeds (for seasonal operation); (4) average wind speeds; and (5) the operating altitude regime. These conclusions only address the wind magnitudes; the maps with wind roses, located in subset 4 of sections $A, B$, and $C$, provide direction data for informational purposes only.

The conclusions concerning site operation and maximum and minimum wind speeds ( 2 and 3 above) are presented as an alternate method of analyzing the rawinsonde data to determine the potential for operating at mission altitudes; these conclusions were determined from direct analysis of the prime site wind summaries. However, sites added to support questionable prime sites are not reflected in these conclusions. Therefore, the percent of platform operation based on geographical area is better since the questionable prime site data was omitted in the contours as justif $-d$ by the added support sites. In the United States, platform oneration based on 100 percent of site operation is similar to the platfcrm operation based on 100 percent geographical area since the added sites verified the questionable prine sites. However, as seen in the following conclusions, the foreign areas do not reflect this agreement between percent of operation based on geographical area and the percent of prime site operation due to the support sites substantiating the discontinuity.

\section{Geographical Area Coverage}

The percent of platform operation (time) for 100 percent geogiaphical area coverage has been determined using the maps (subsets 5, 6, 7, and 8) of proportions of winds less than $30,40,50$, and $75:$ i.ots for the pressure alticude levels 100 to 25 rib. These maps 
were analyzed per season and geographical area, and the altitude of minimum wind conditions was determined; at this altitude the proportion contour with the lowest value (worst case) which described any part of the geographical area (United States, etc.) of interest was used as the basis for the conclusions regarding the percent of operation for 100 percent geographical ared coverage.

In cases where the contour fully describes the worst case for the altitude of minimum wind conditions, the value of that contour was recorded. However, in cases where a sizable pertion of geographical area extends beyond this contour the particular situation was assessed based on the presented wind conditions. These results are presented in Table IV. The altitudes of minimum wind conditions will be discussed in a separate section.

Signiricant findings for mission altitude operation are:

United States:

- 98 percent (or higher) non-winter operation; 35 percent winter operation for a design speed of 50 knots.

. 95 percent non-winter operation; 75 percent winter operation for a design speed of 40 knots.

European Ared:

- 85 percent (or higher) non-winter operation; 45 percent winter operation for a design speed of 50 knots (Norwegian Sea area).

- 95 percent (or higher) non-winter operation; 80 percent winter operation for à design speed of 50 knots (Mediterranean Sea area).

TABLE IV.-PERCENT OF OPERATION FOR 100', GEOGRAPHICAL AREA COVERRGE

\begin{tabular}{|c|c|c|c|c|c|c|}
\hline \multirow[t]{2}{*}{ Design Speed } & \multirow[t]{2}{*}{ Season } & \multicolumn{5}{|c|}{ Percent of Time Per Area } \\
\hline & & U.S. & $\begin{array}{c}\text { Norwegian } \\
\text { Sea }\end{array}$ & $\begin{array}{c}\text { Mediterranean } \\
\text { Sed }\end{array}$ & $\begin{array}{l}\text { Sed of } \\
\text { Japan }\end{array}$ & $\begin{array}{l}\text { Sed of } \\
\text { Okhotsk }\end{array}$ \\
\hline 30 knots & $\begin{array}{l}\text { Winter } \\
\text { Spring } \\
\text { Summer } \\
\text { Fall }\end{array}$ & $\begin{array}{l}60 \\
90 \\
98 \\
90\end{array}$ & $\begin{array}{l}20 \\
60 \\
90 \\
55 \\
\end{array}$ & $\begin{array}{l}50 \\
80 \\
85 \\
80\end{array}$ & $\begin{array}{l}30 \\
80 \\
95 \\
70 \\
\end{array}$ & $\begin{array}{l}10 \\
80 \\
98 \\
50\end{array}$ \\
\hline $40 \mathrm{knots}$ & $\begin{array}{l}\text { Winter } \\
\text { Spring } \\
\text { Summer } \\
\text { Fall }\end{array}$ & $\begin{array}{l}75 \\
95 \\
99.6 \\
95\end{array}$ & $\begin{array}{l}30 \\
70 \\
75 \\
75\end{array}$ & $\begin{array}{l}70 \\
90 \\
95 \\
90\end{array}$ & $\begin{array}{l}50 \\
90 \\
98 \\
70\end{array}$ & $\begin{array}{l}40 \\
90 \\
913 \\
70\end{array}$ \\
\hline 50 knots & $\begin{array}{l}\text { Winter } \\
\text { Spring } \\
\text { Summer } \\
\text { Fall }\end{array}$ & $\begin{array}{l}35 \\
98 \\
99.6 \\
98\end{array}$ & $\begin{array}{l}45 \\
85 \\
783 \\
90\end{array}$ & $\begin{array}{l}80 \\
95 \\
98 \\
95\end{array}$ & $\begin{array}{l}70 \\
90 \\
99 \\
90\end{array}$ & $\begin{array}{l}60 \\
95 \\
99 \\
80\end{array}$ \\
\hline 75 knots & $\begin{array}{l}\text { Winter } \\
\text { Spring } \\
\text { Suminer } \\
\text { Fall }\end{array}$ & $\begin{array}{l}95 \\
99.2 \\
99.7 \\
99.5\end{array}$ & $\begin{array}{l}90 \\
95 \\
99 \\
98 \\
\end{array}$ & $\begin{array}{l}96 \\
99 \\
99 \\
99\end{array}$ & $\begin{array}{l}90 \\
98 \\
99 \\
9 \cdot 9\end{array}$ & $\begin{array}{l}90 \\
98 \\
99 \\
39\end{array}$ \\
\hline
\end{tabular}


Pacific Area:

- 90 percent (or higher) non-winter operation; 70 percent winter operation for a desiugn speed of 50 knots (Sed of Japan area).

- 80 percent (or higher) non-winter operation; 60 percent winter operation for a design speed of 50 knots (Sea of Okhotsk area).

Tabie $V$ presents the percent of platform operation at design speed of 30 and 50 knots for a percent of geographical area in the United States. These conclusions were obtained by examining the proportion maps (oniy subsets 5 and 7 of Section A) as done for the preceding conclusions regarding 100 percent geographical area but measuring the percent of geographical area for various percents of operation.

TABLE V. -PERCENT OF OPERATION FOR PERCENT OF U.S. AREA COVERAGE

\begin{tabular}{|c|c|c|c|}
\hline Design Speed & Season & $\begin{array}{c}\text { Approxillate Percent of } \\
\text { Geographical Ared }\end{array}$ & Percent of Time \\
\hline \multirow[t]{4}{*}{30 knots } & Winter & $\begin{array}{l}80 \\
50 \\
20\end{array}$ & $\begin{array}{l}70 \\
80 \\
90\end{array}$ \\
\hline & Spring & $\begin{array}{l}65 \\
10\end{array}$ & $\begin{array}{l}95 \\
97.5\end{array}$ \\
\hline & Summer & $\begin{array}{l}90 \\
80\end{array}$ & $\begin{array}{r}98.5 \\
99.5\end{array}$ \\
\hline & Fall & $\begin{array}{l}75 \\
20\end{array}$ & $\begin{array}{l}95 \\
97.5\end{array}$ \\
\hline \multirow[t]{4}{*}{50 knots } & inter & $\begin{array}{l}93 \\
80 \\
55 \\
35\end{array}$ & $\begin{array}{l}85 \\
90 \\
+5 \\
97.5\end{array}$ \\
\hline & Spring & $\begin{array}{l}99 \\
65\end{array}$ & $\begin{array}{l}98 \\
99\end{array}$ \\
\hline & Sunmer & 45 & 100 \\
\hline & Fall & $\begin{array}{l}99 \\
75 \\
35\end{array}$ & $\begin{array}{l}98 \\
99 \\
99.5\end{array}$ \\
\hline
\end{tabular}

Site Operation

All of the selected prime sites were used to determine the percent of annual site operation per geographical area. Significant findings, based on a 95 percent theoretical occurrence, are as follows:

United States:

- 100 percent non-winter operation; 86 percent winter operation for a design speed of 50 knots.

- 100 percent $r$-n-winter operation; 43 percent winter operation for a design speed of 40 knots. 


\section{European Ared:}

- 100 percent non-winter operation; 85 percent winter operation for a design speed of 80 knots.

Pacific Area:

- 100 percent non-winter operation; 80 percent winter operation for a clesign speed of 75 knots.

Based on a 99 percent theoretical occurrence a design speed of 55 knots would provide 100 percent non-winter operation and 50 percent winter operation for the United states. As menlioned this data does reflect the discontinuities particularly in foreign areas and therefore should not be considered as representative as the area coverage results.

Maximum and Minimum Wind Speeds

All of the prime sites used in the United States, European area, and the Parific area have been analyzed at all potential mission operating altitudes to determine the maximum and minimum 95 percentile wind speeds (plus 99 percentile for the 1). S.) at the altitude of the minimum wind conditions per season. The maximum and minimum values represent the range of the sites with the largest value to the smallest value per geographical area. These results reflect all prime site data including those sites determined to be discontinuous; therefore, the maximums indicated - especially in the foreign areas - are higher than the more realistic values provided by the analyzed maps (Table IV). Table VI provides this seasonal maximum and minimum information.

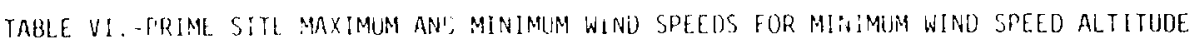

\begin{tabular}{|c|c|c|c|c|c|c|c|c|}
\hline \multirow[t]{3}{*}{ Sedson } & \multicolumn{4}{|c|}{ United States } & \multirow{2}{*}{\multicolumn{2}{|c|}{$\frac{\text { Pacific Ared }}{95}$}} & \multirow{2}{*}{\multicolumn{2}{|c|}{ European Area }} \\
\hline & \multicolumn{2}{|c|}{$95 *$} & \multicolumn{2}{|c|}{$99 . *$} & & & & \\
\hline & $\operatorname{Max}$. & Min. & Max. & Min. & $\operatorname{Max}$. & Min. & $\operatorname{Mdx}$. & Min. \\
\hline $\begin{array}{l}\text { Winter } \\
\text { Spring } \\
\text { Summer } \\
\text { Fall }\end{array}$ & $\begin{array}{l}66 \\
34 \\
32 \\
35\end{array}$ & $\begin{array}{l}30 \\
21 \\
14 \\
21\end{array}$ & $\begin{array}{l}81 \\
42 \\
37 \\
42\end{array}$ & $\begin{array}{l}34 \\
26 \\
17 \\
25\end{array}$ & $\begin{array}{l}86 \\
45 \\
32 \\
72\end{array}$ & $\begin{array}{l}50 \\
20 \\
15 \\
26\end{array}$ & $\begin{array}{l}94 \\
68 \\
68 \\
76\end{array}$ & $\begin{array}{l}38 \\
25 \\
14 \\
23\end{array}$ \\
\hline Annual & 66 & 30 & 81 & 34 & 86 & 50 & 34 & 38 \\
\hline
\end{tabular}

\footnotetext{
* Refers to theoretical occurrences.
}

\section{Average : lind Speeds}

The maps of llean speeds - subset 3 of Sections A, B, and C - were used to determine the seasonal maximuml averages per 100 percent geographical ared. These values were determined by surveying the maps for the altitude of minimum winds per season; the contour with the highest value (worst case) which described any part of the geographical 
area was recorded. However, in cases vitere a sizable portion of geographical area extends beyond this contour, th situation was assessed based on the presented conditions. Table VII provides a complete seasonal and arsd breakdown.

TABLE VII. -ALERAGE WIND SPEZDS (MAXIMUM PER AREA)

\begin{tabular}{|l|c|c|c|c|}
\hline Seuson & Ui.ited States & $\begin{array}{c}\text { Pacific Area } \\
\text { (Total) }\end{array}$ & $\begin{array}{c}\text { Norwegian } \\
\text { Sea }\end{array}$ & $\begin{array}{c}\text { Mediterranean } \\
\text { Sea }\end{array}$ \\
\hline Winter & 30 & 50 & 45 & 30 \\
Spring & 15 & 20 & 30 & 15 \\
Summer & 25 & 15 & 15 & 20 \\
Fall & 15 & 30 & 30 & 20 \\
\hline
\end{tabular}

Operating Altitude Regime

The minimum wind speed altitude per site is dependent on its geographic location. The dititudes indicated below represent a majority of the sites per geographical area; however, at some locations a higher altitude (30 mb pressure altitude level) for non-summer applications or a lower (100 mb pressure altitude level) for summer applications will provide a small improvement for the wind speed conditions. As seen by the wind profiles, the minimum wind altitudes vary from site to site and season to season; in seneral, the range of the minimum wind altitudes involves more than one pressure altitude level. A change in latitude will also improve conditions. For example, minimum conditions for the United States change such that the low latitude provides minimum winds in the winter and the high latitude provides minimum winds in the summer. In general, the wind speed altitudes are ds follows:

- $40 \mathrm{mb}$ to $50 \mathrm{mb}(2 \mathrm{~km}$ to $22 \mathrm{~km})$ for non-summer applications.

- $60 \mathrm{mb}$ to $80 \mathrm{mb}(18 \mathrm{~km}$ to $19 \mathrm{~km})$ for summer applications.

This study has presented an analys is of the upper air winds to krovide probabilities for high altitude platform operation at mission altitudes on a seasonal basis. This ef fort has therefore oniy addressed the long term overall sizing issue and not the finer definition of the wind structure needed for answering the mission operating issues. A follow-on effort would be to define the operating scenarios from the surface to mission operating altitudes. This effort should take into consideration the deployment and retrieval requirements (launch, ascent, recovery) as well as the short term finer effects of the winds on the on-station requirements for HAPP operation. The previously mentioned serially complete and grid data could be used since the scenarios would require a finer analysis of the winds with respect to short periods of time (days/hours as compared to seasons). In addition to the operational issues, the follow-on effort would provide data for support of the wind study presented in this report, and together woula provide the total wind environment influencing high altitude platform operation. 


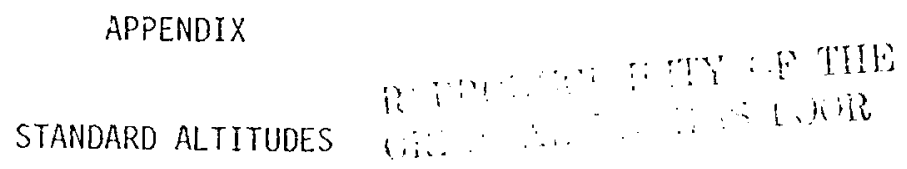

\section{Pressure}

(Millibars)

SFC

1000

950

900

850

800

750

700

650

600

550

500

450

400

350

300

250

200

175

150

125

100

80

70

60

50

40

30

25

20

15

10
Geopotential

$\begin{array}{cr}\text { (Meters) } & \text { (Feet) } \\ 0 & 0 \\ 111 & 364 \\ 540 & 1773 \\ 988 & 3243 \\ 1457 & 4781 \\ 1949 & 6394 \\ 2466 & 8091 \\ 3012 & 9882 \\ 3590 & 11780 \\ 4207 & 13801 \\ 4865 & 15962 \\ 5574 & 18289 \\ 6344 & 20812 \\ 7185 & 23574 \\ 8117 & 26631 \\ 9164 & 36065 \\ 10363 & 33999 \\ 11784 & 38662 \\ 12631 & 41440 \\ 13603 & 44647 \\ 14675 & 48440 \\ 16180 & 53083 \\ 17595 & 57726 \\ 18442 & 60504 \\ 19437 & 63711 \\ 20576 & 67507 \\ 22000 & 72177 \\ 23849 & 78244 \\ 25029 & 82115 \\ 26481 & 86881 \\ 28368 & 92071 \\ 31055 & 101885\end{array}$


1. Sinko, James B.: High Altitude Powered Platform $C 5$ nd Feasibility Study. Stanford Research institute, SRI Project 5655-502: '.

2. Kuhner, M. B.; Earhart, R. W.; Madigan, J. A.; and Ruck, G. T.: Applications of a High Altitude Powered Platform (HAPP). Battelle Columbus Laboratories, BCL-OA-TFR$77-5,1977$.

3. Monthly and Annual Winds Aloft Summary (WBAN 120) - Wallops Island, VA. National Weather Records Center, Job. No. 13713, Aug. 14, 1972.

4. Crutcher, Harold L.; and Bailey, Morton H.: Upper Winds Statistics Charts of the Northern Hemisphere (50 mb level, provisional). Volume III, NAVWEPS 50-1C-535, 1962.

5. Sandlin, Roy W., Jr.; and Armijo, Elias H.: An Analysis of AN/FPS-16 Radar and AN/ GMD-1B Rawinsonde Data Differences. ERDA-115, 1964.

6. Barr, William C.; and Peterson, Arnold C.: Wind Measuring Accuracy Test of Meteorological Systems, ECOM-5831, 1977. 
SECTION A

UNITED STATES 
ALBUGUERQUE
$*=84,1 \%$ LEVEL

WINTER

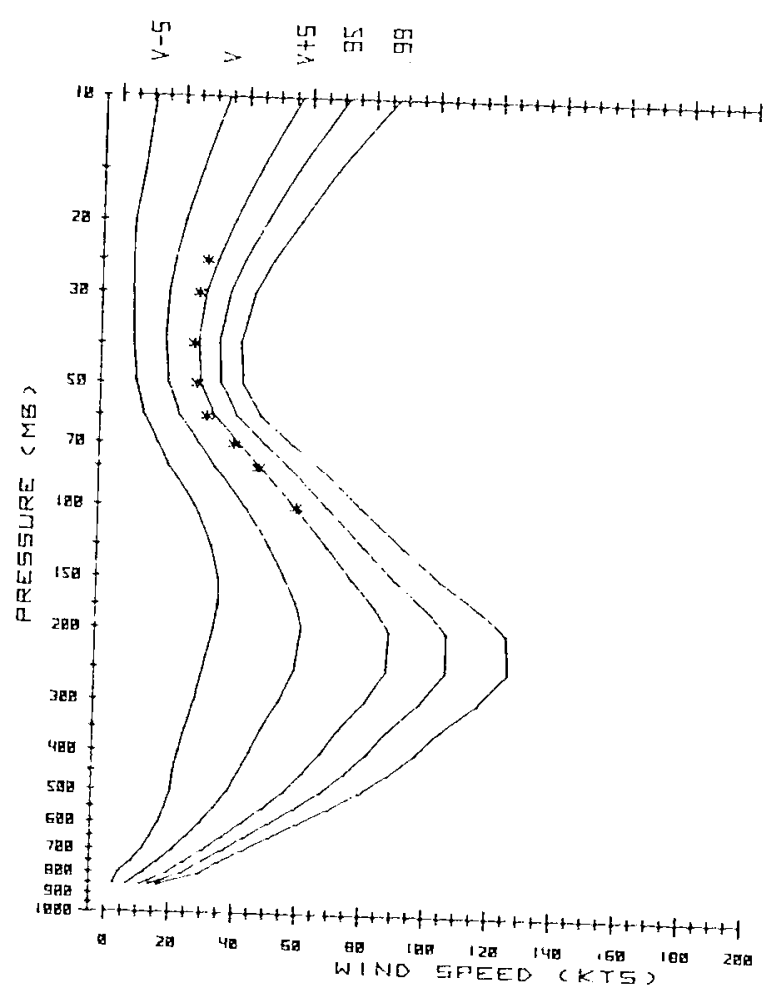

ALELULIEREUE

$*=64.1 \%$ LEVEL

SPR ING

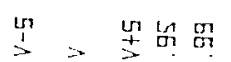

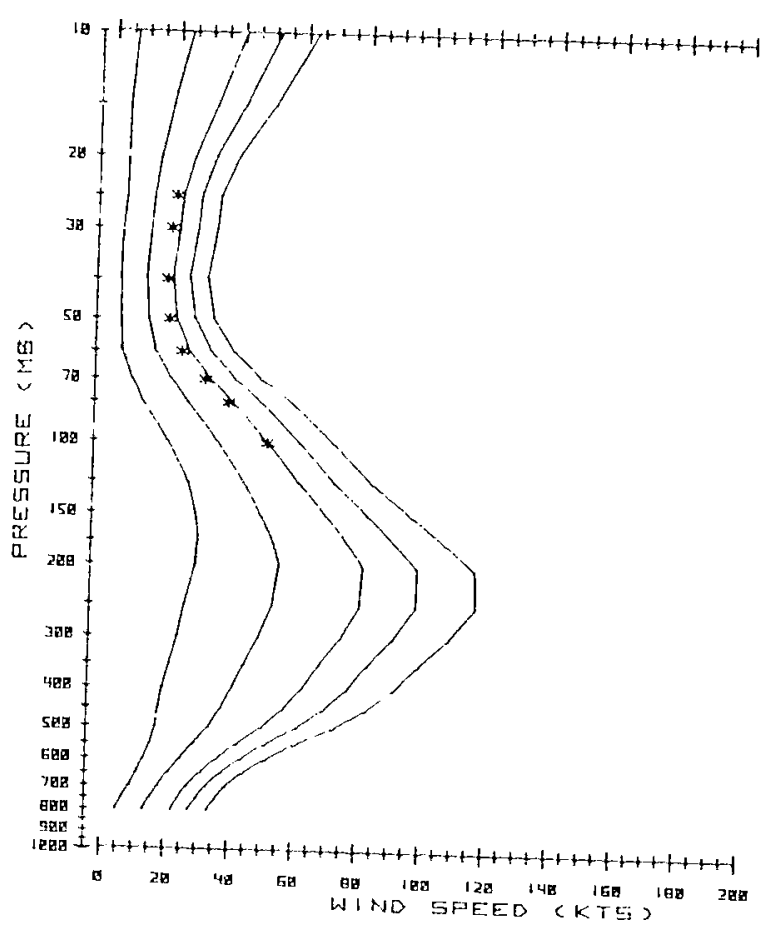

RLGUQLERESIE

$*=941 \%$ !. VVEL

SUMMER

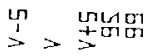

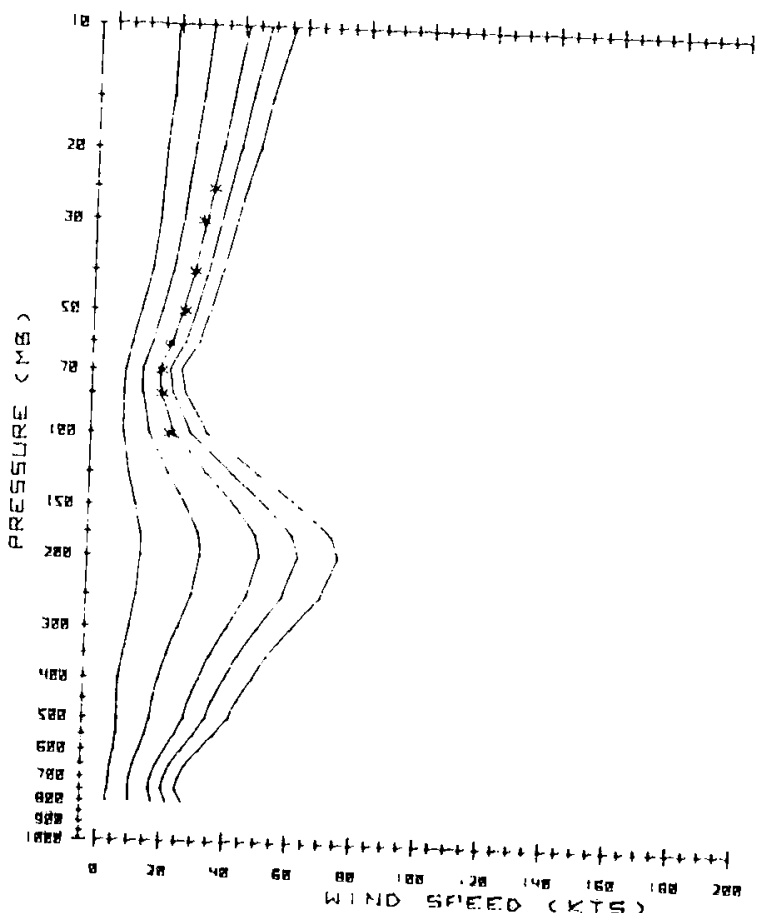

A!_BLIQLIERQUE

* = 84 1\% LEVEL

FALL

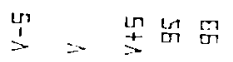

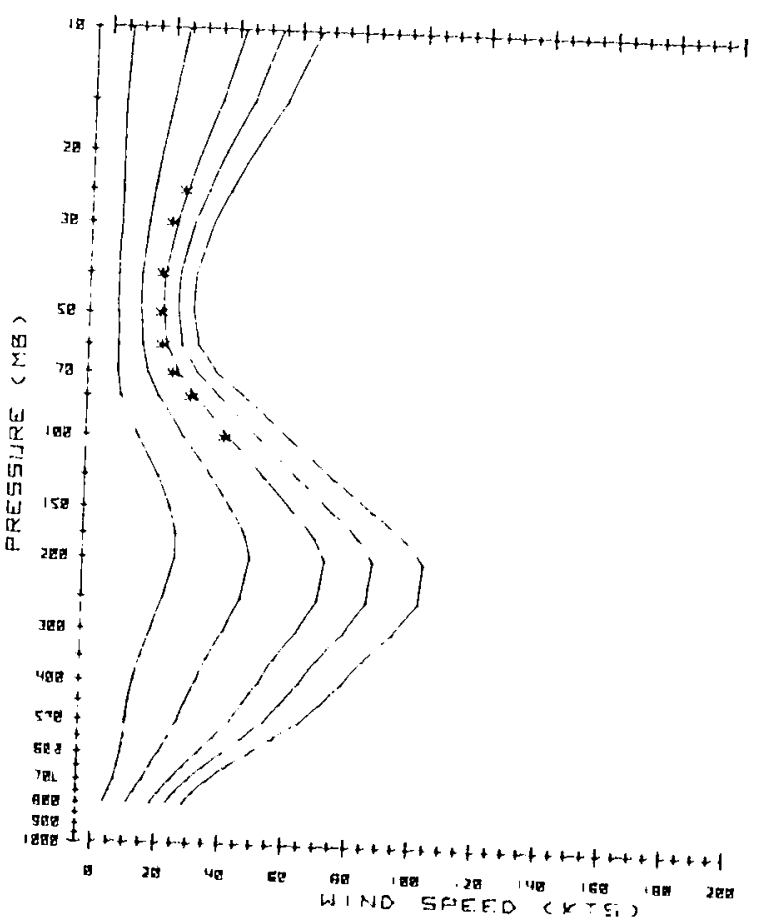



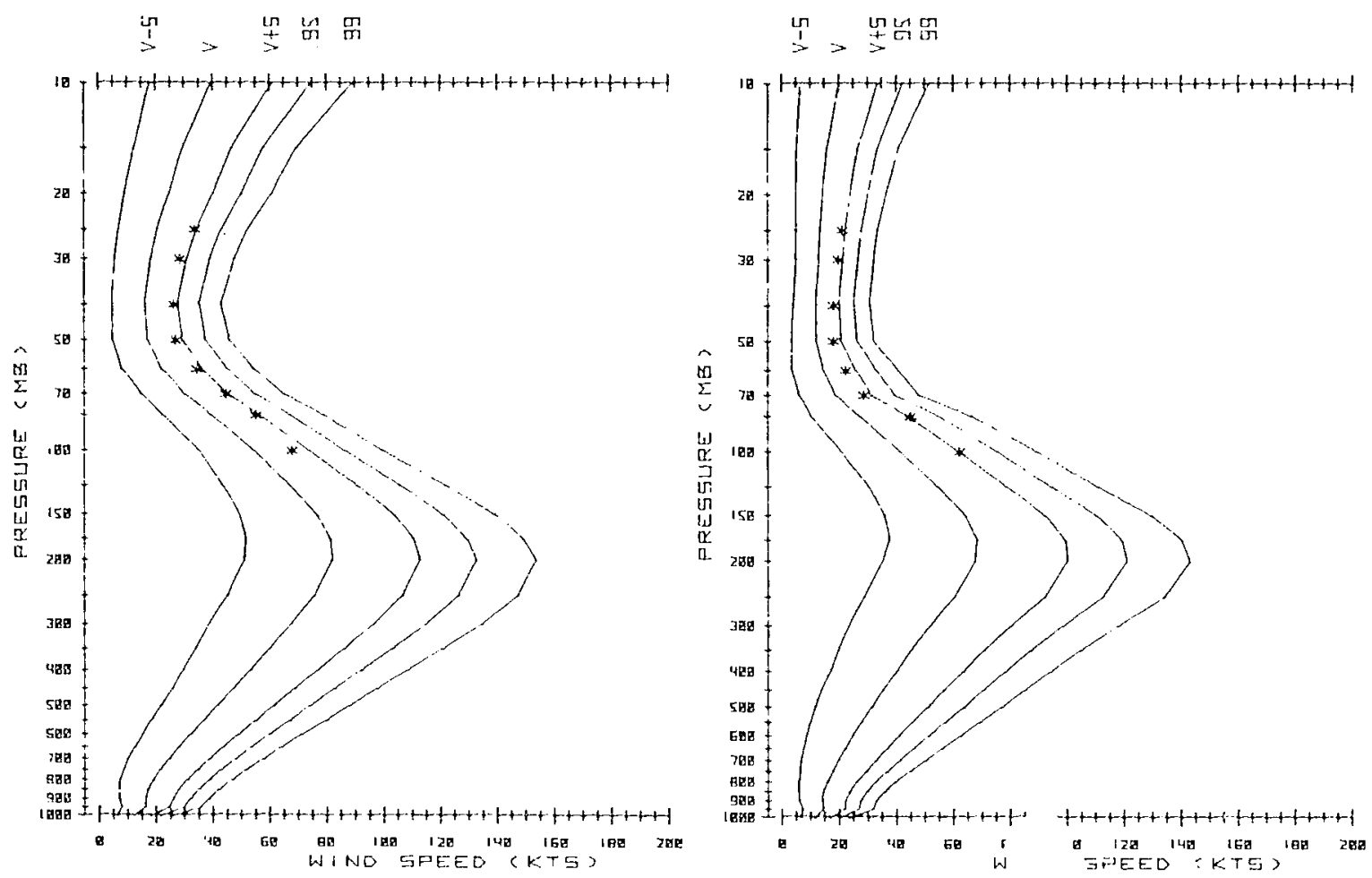

CAPE KENNEDY
$*=84 \% \%$ LEVEL

SUMHER

CAPE KENNEDY

FALL

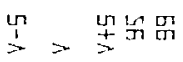

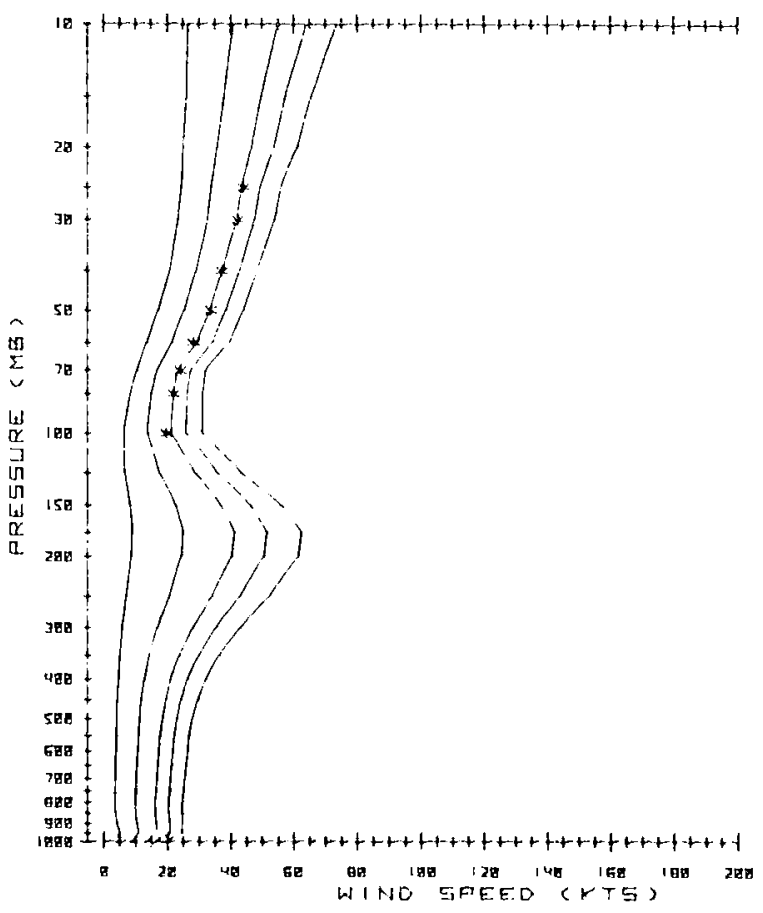

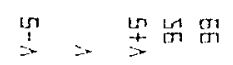

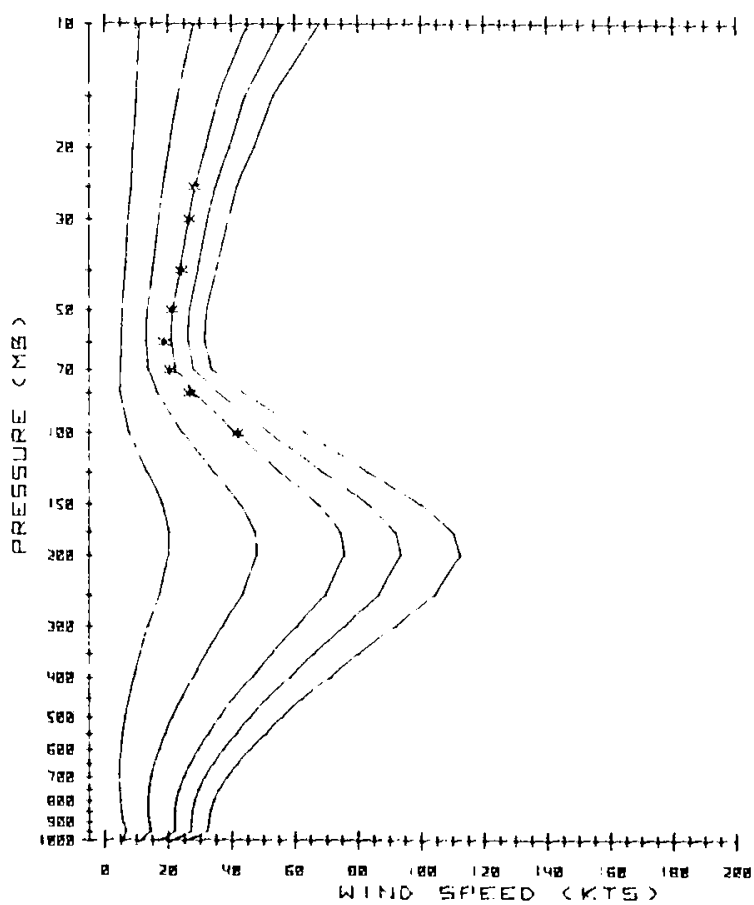



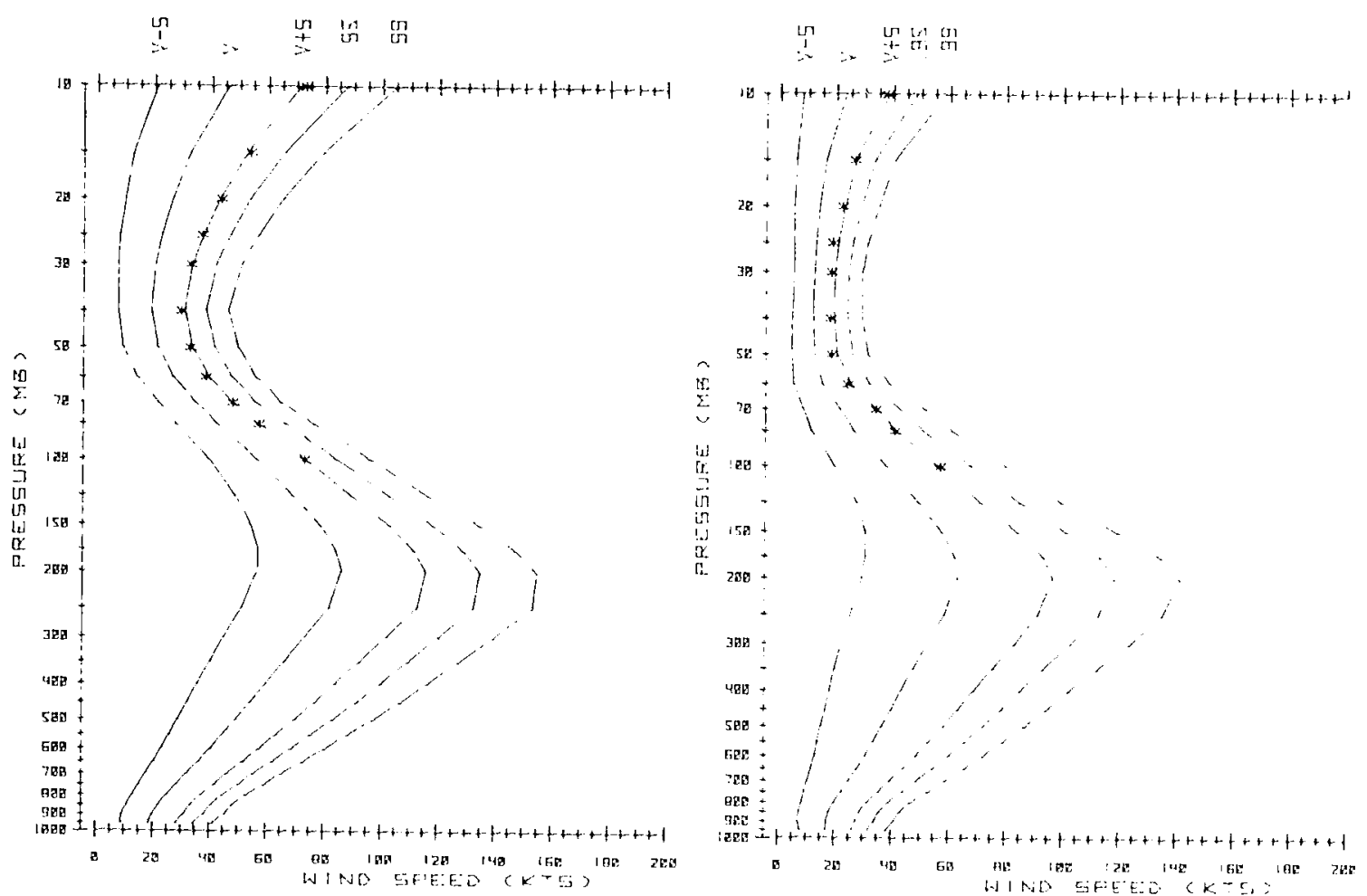

CHARLESTON $*=$ EU 1\% LEVEL

S!IMMER

CHAKLESTON

* = Bu I\% LEVE:

FFILI

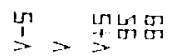
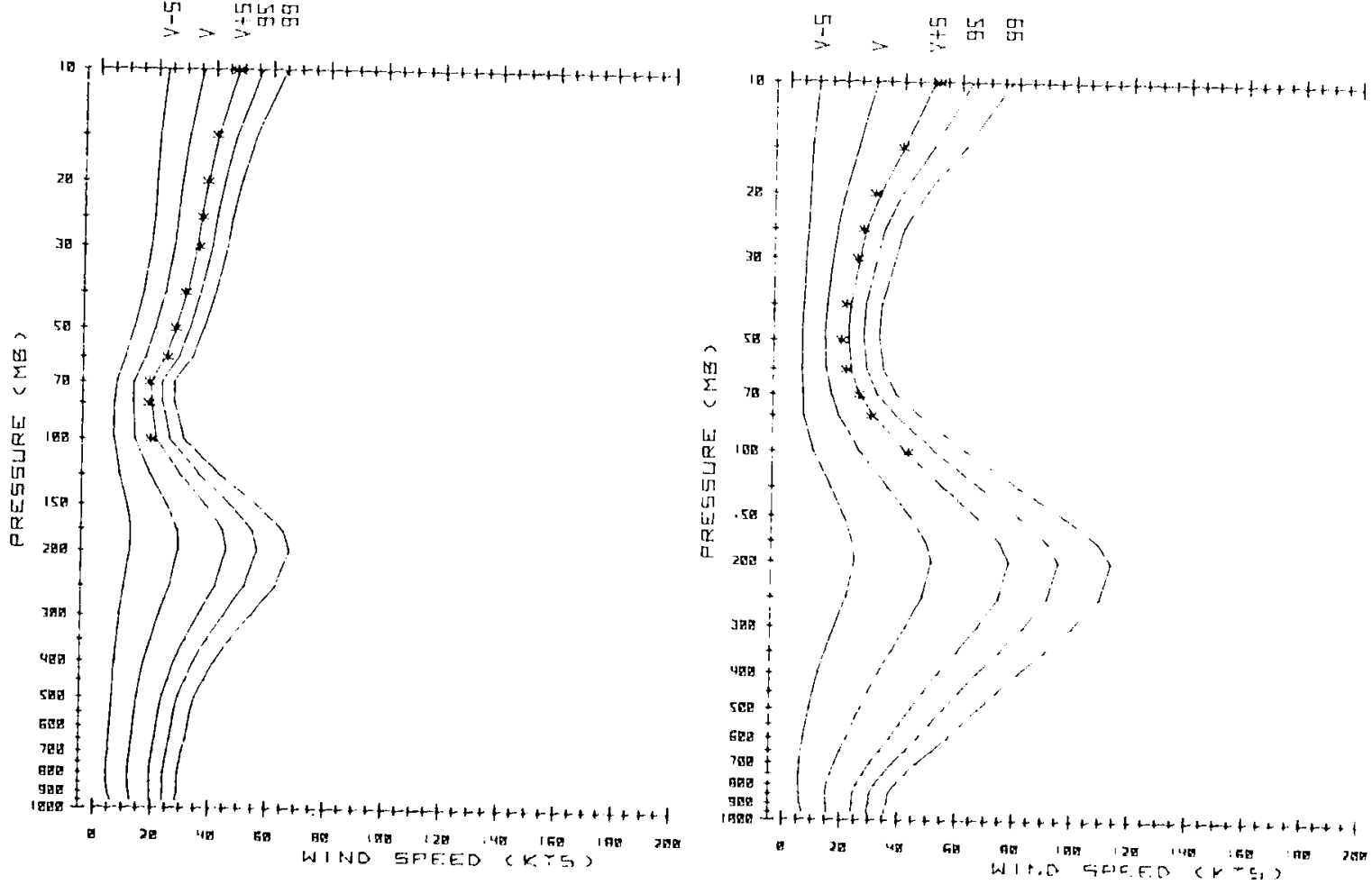


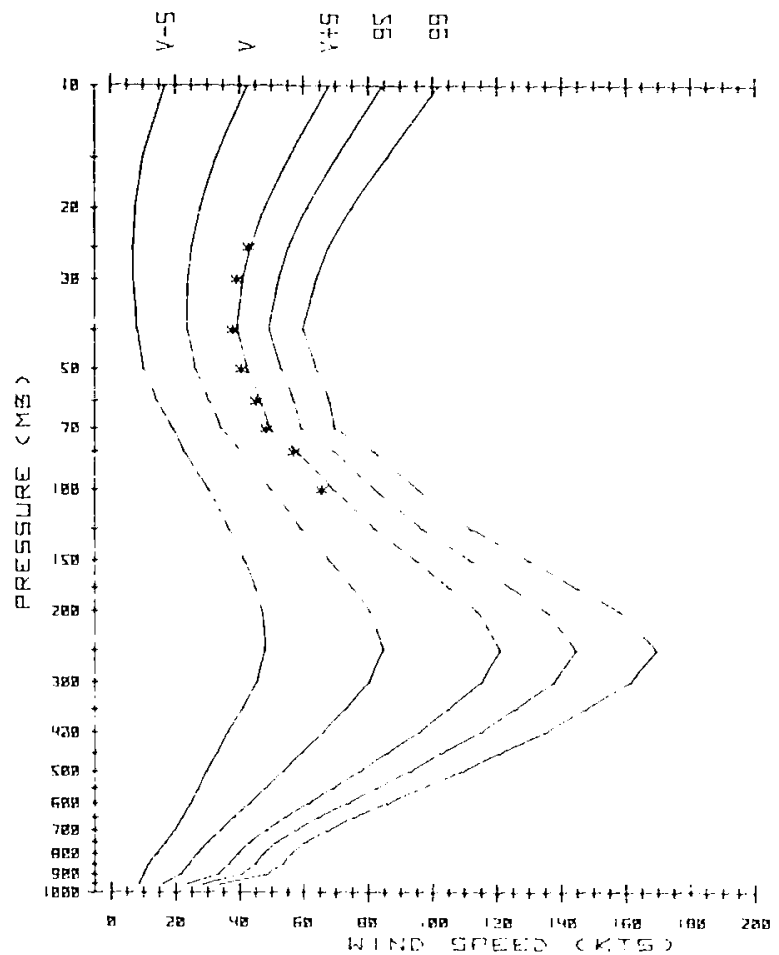

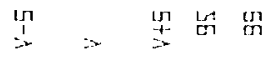
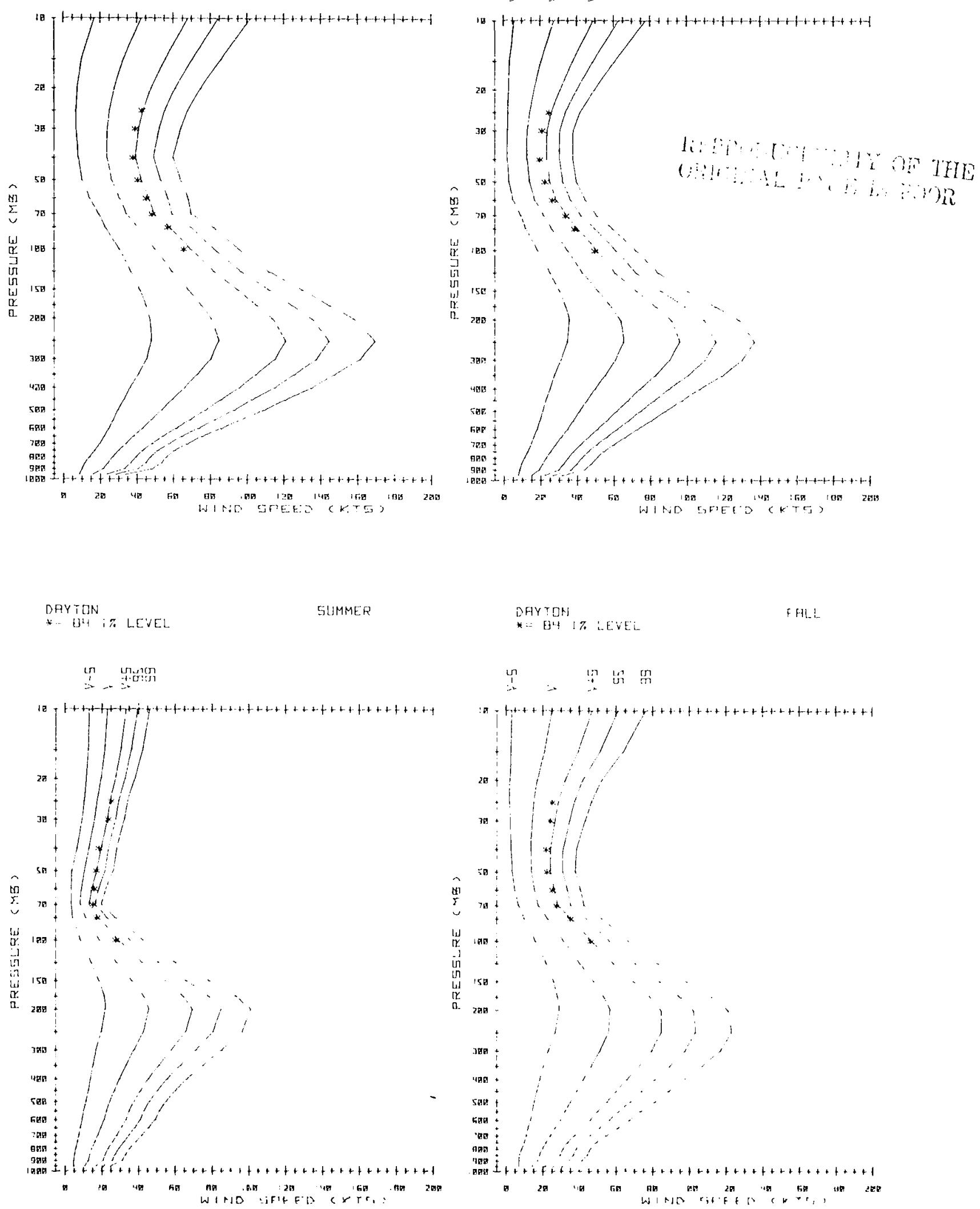
DENVER

$*=B 4$ I\% LEVEL

WINTER

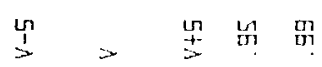

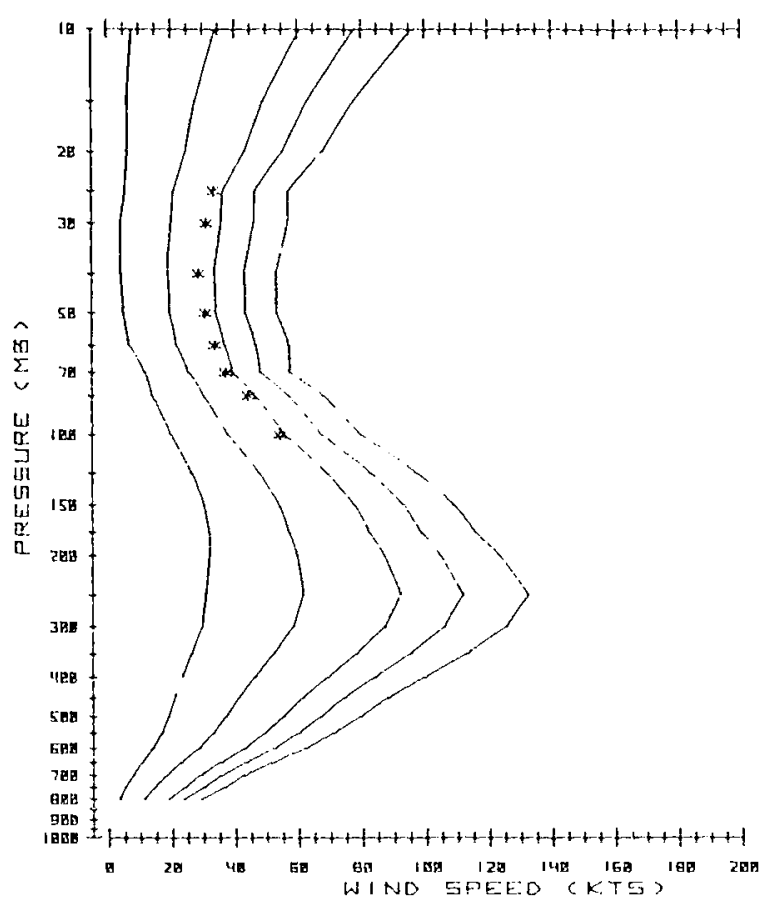

DENVER

* $=041 \%$ LEVEL

SLMMER

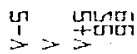

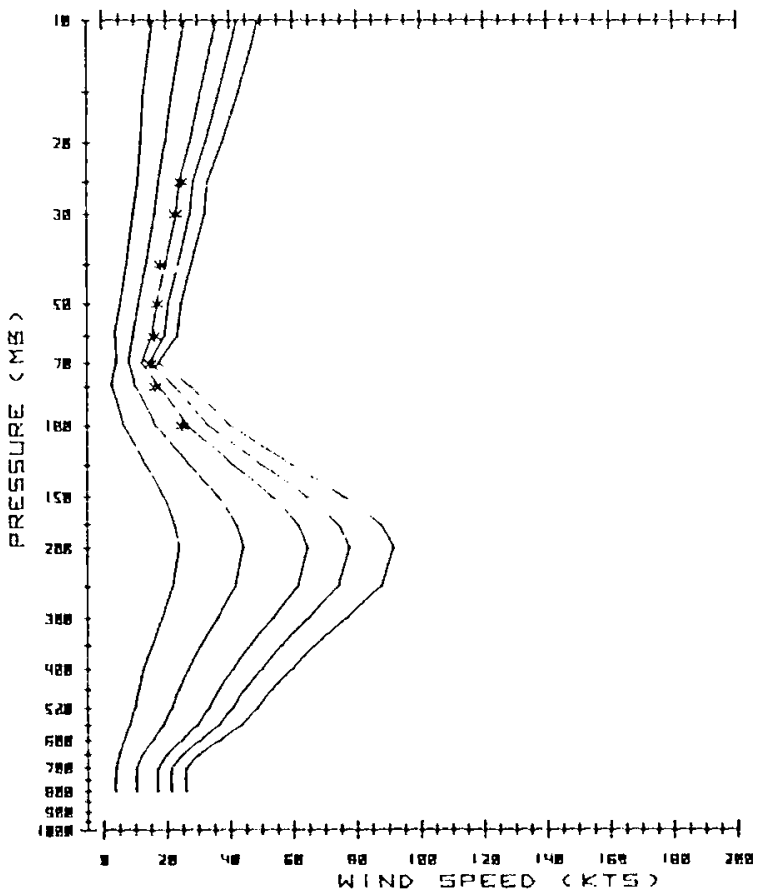

DENVER
$*=$ BU $^{2}$ I\% LEVEI

5PRING

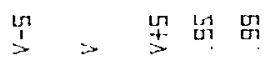

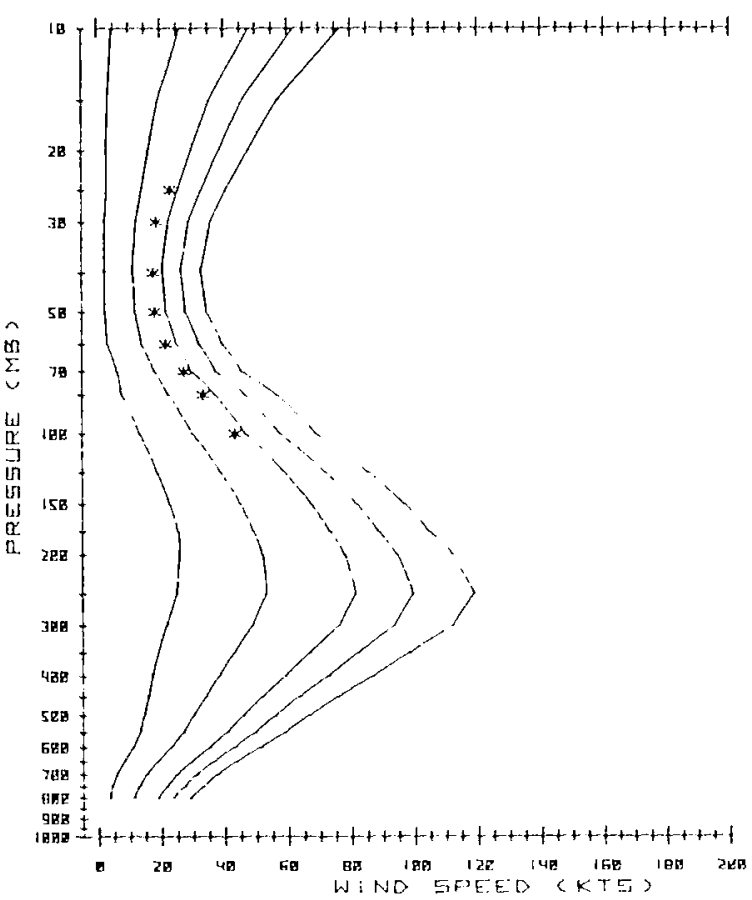

DENVER
$*=B^{4} \mid \pi$ LEVEL

FALL

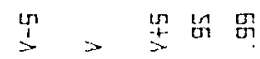

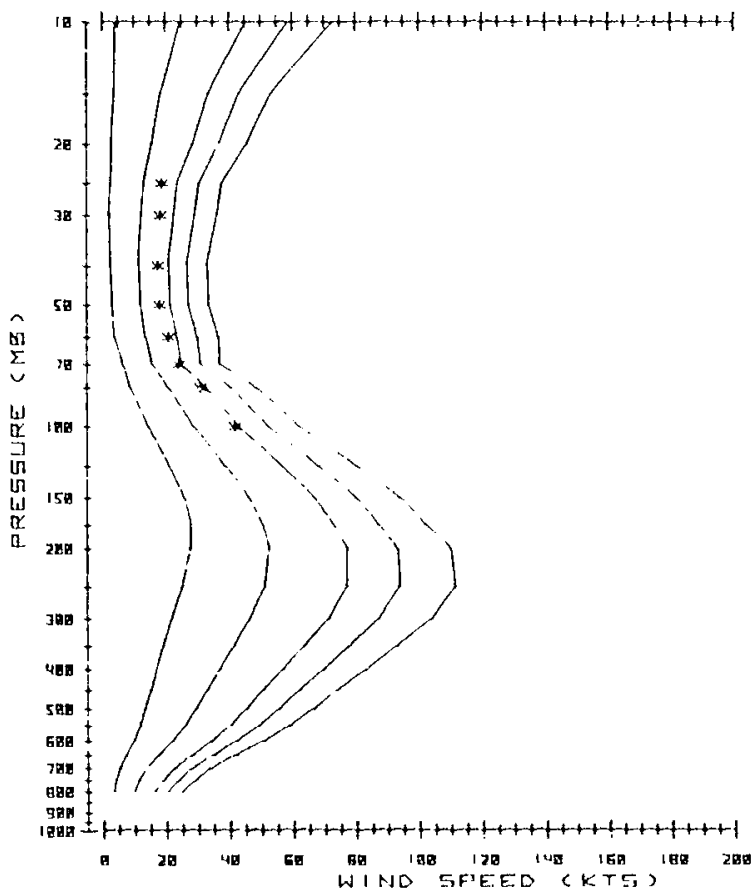


EET.IN

* G G IA LEVE:

WINTER

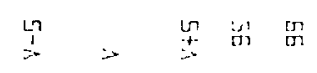

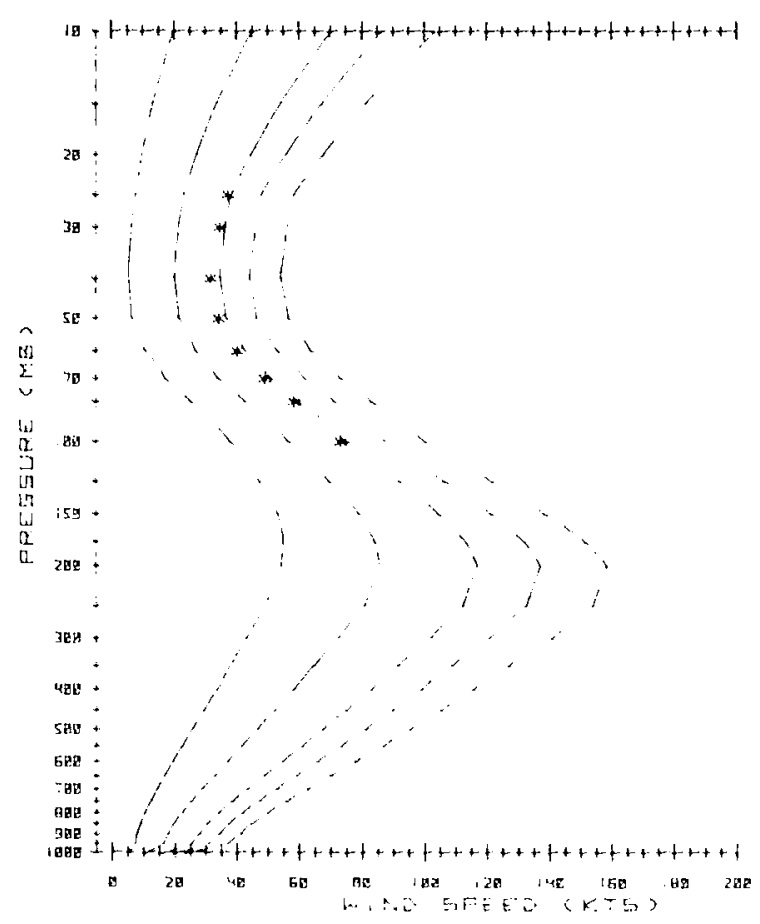

EELIN
$*=-94 \quad 1 \%$ LEVEL

SUMMER

$\underline{3}=-\operatorname{lng} 20$

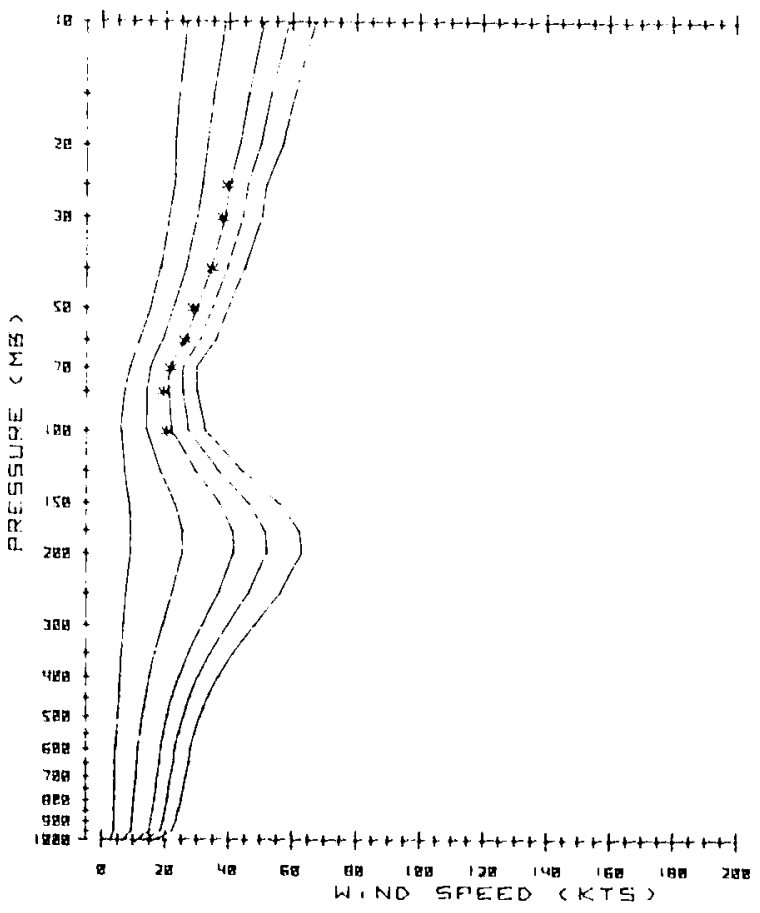

E.TLIN

$\rightarrow=$ GL $i \%$ LEVEL

SpkiNG

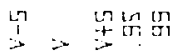

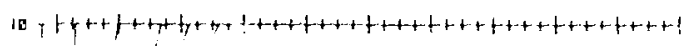

$+1111$

2u. 1 i $1: 1$

$\therefore i+11$

a

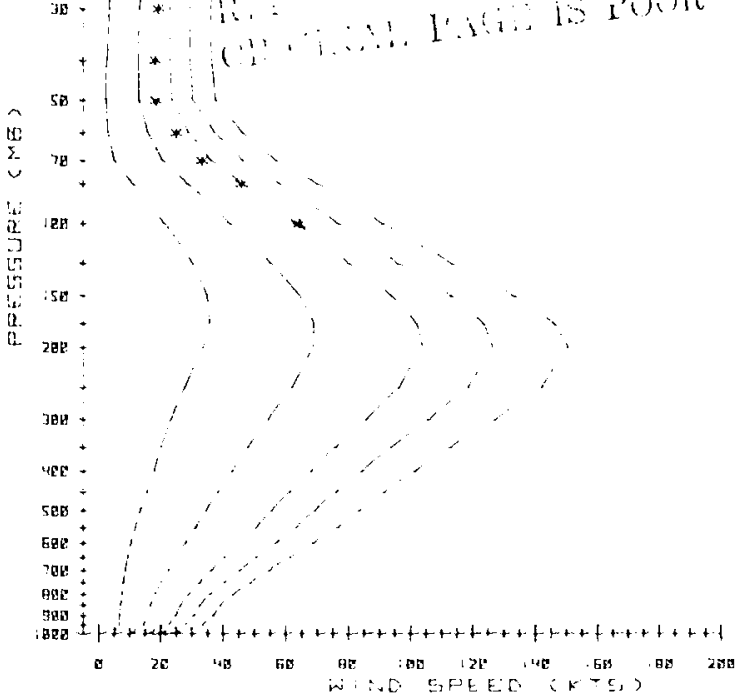

EEL IH
$*=E 4$
1\% LEVEL

FALL

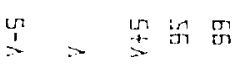

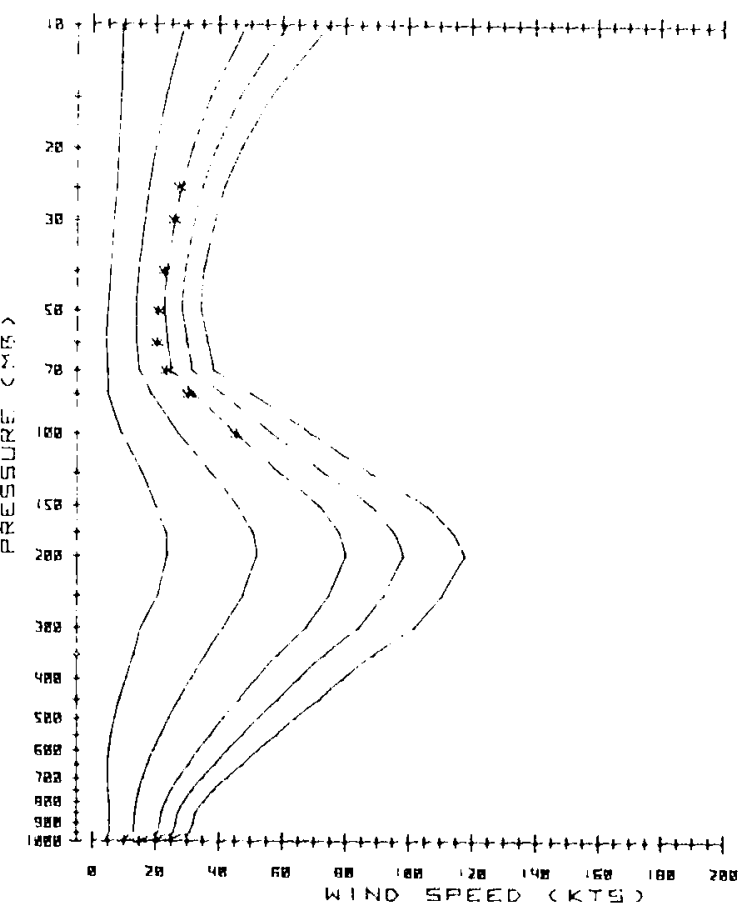



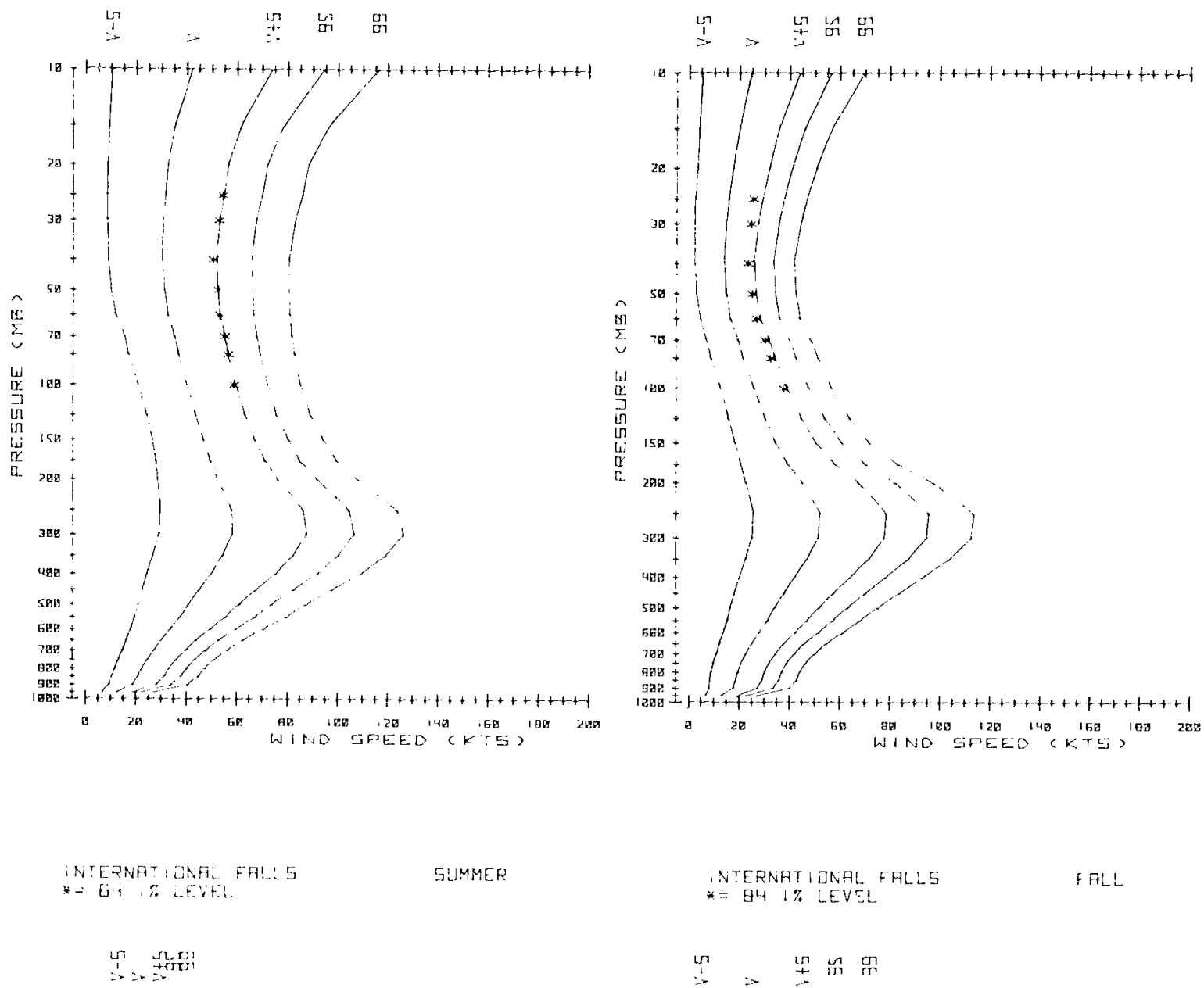

SIMMER
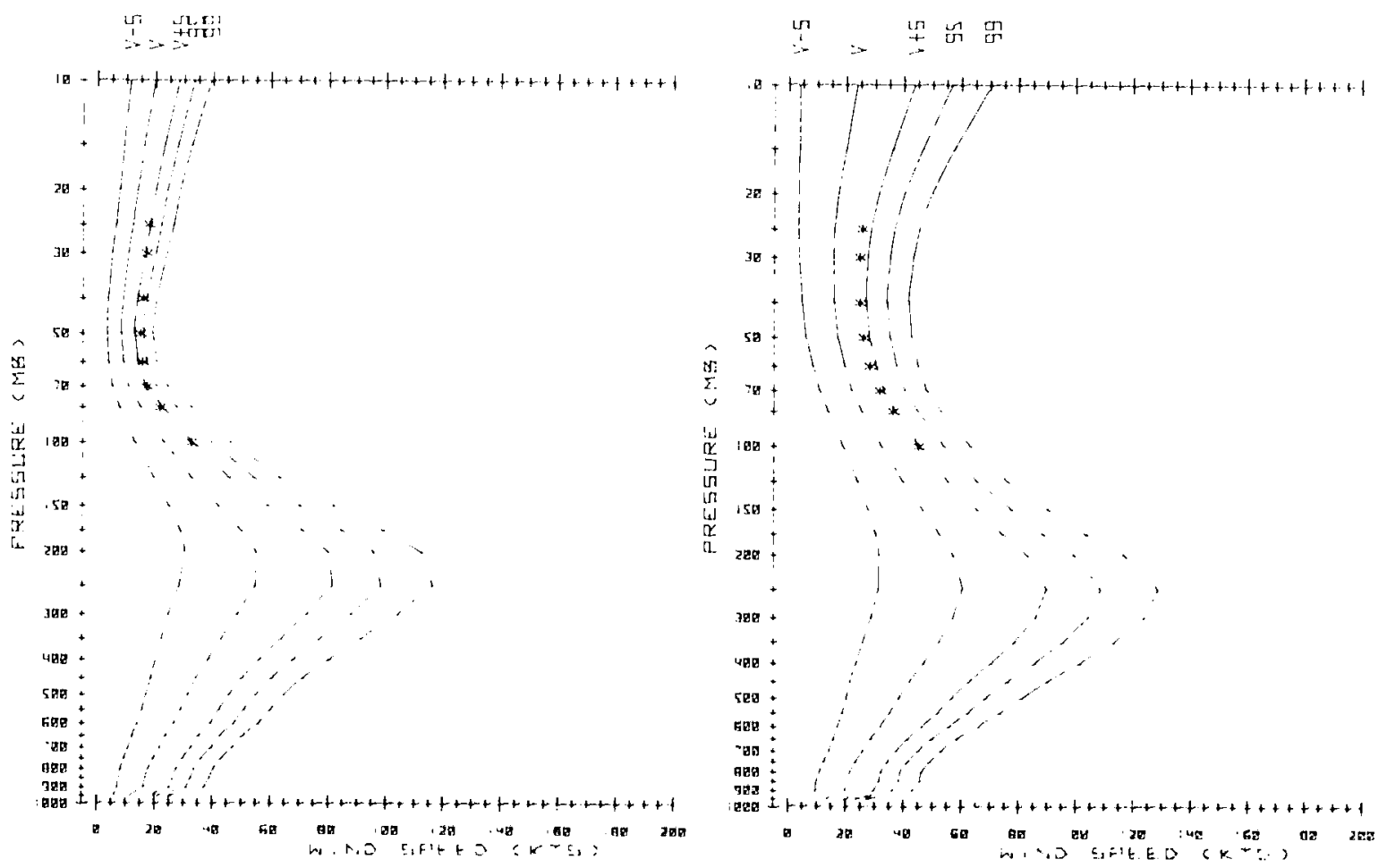
DRKLAND

$*=64.1 \%$ LEVEL

WINTER

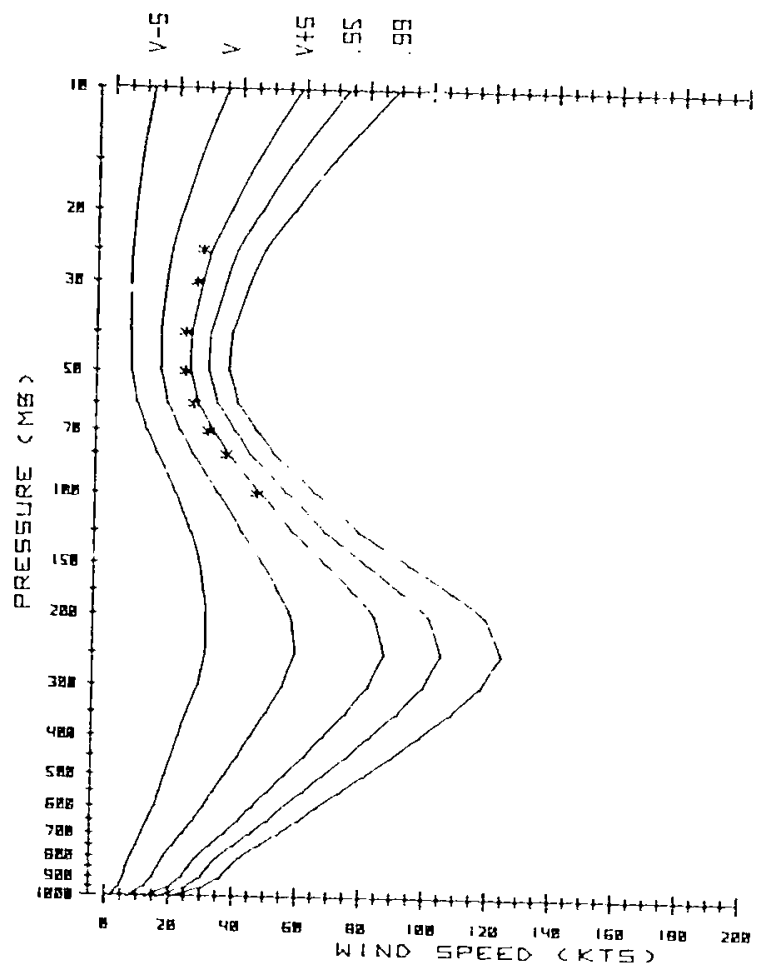

DAKLFND

$*=84.1 \%$ LEVEL

SUMMER

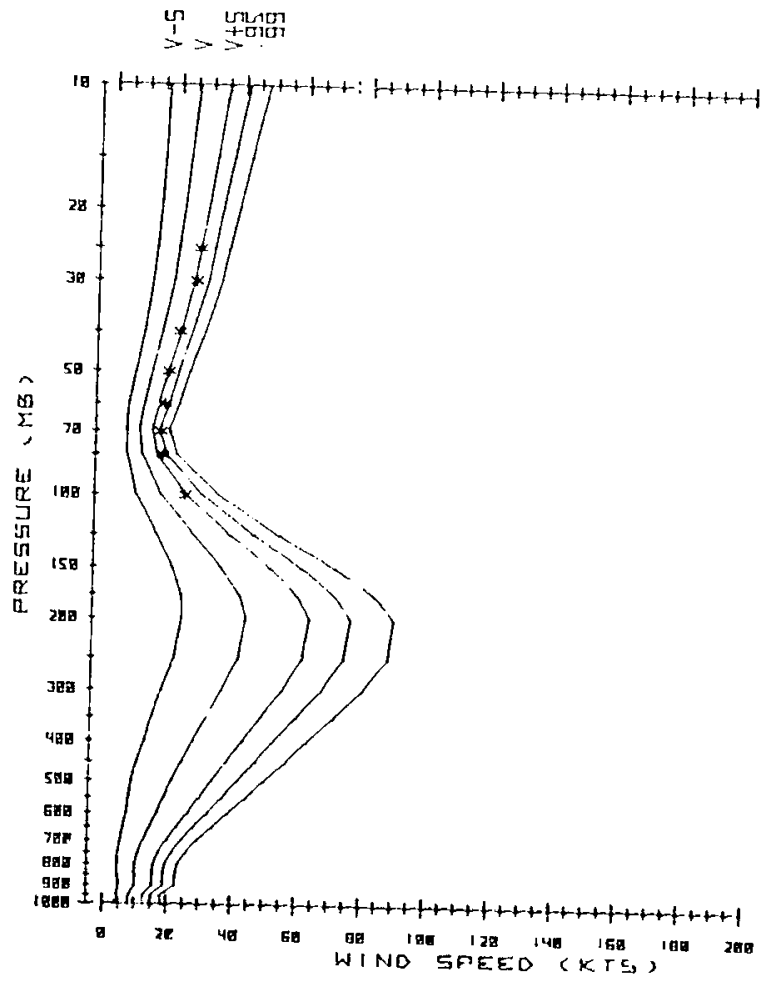

DEKL HND

$*=64.1 \%$ LEVEL

SPRING

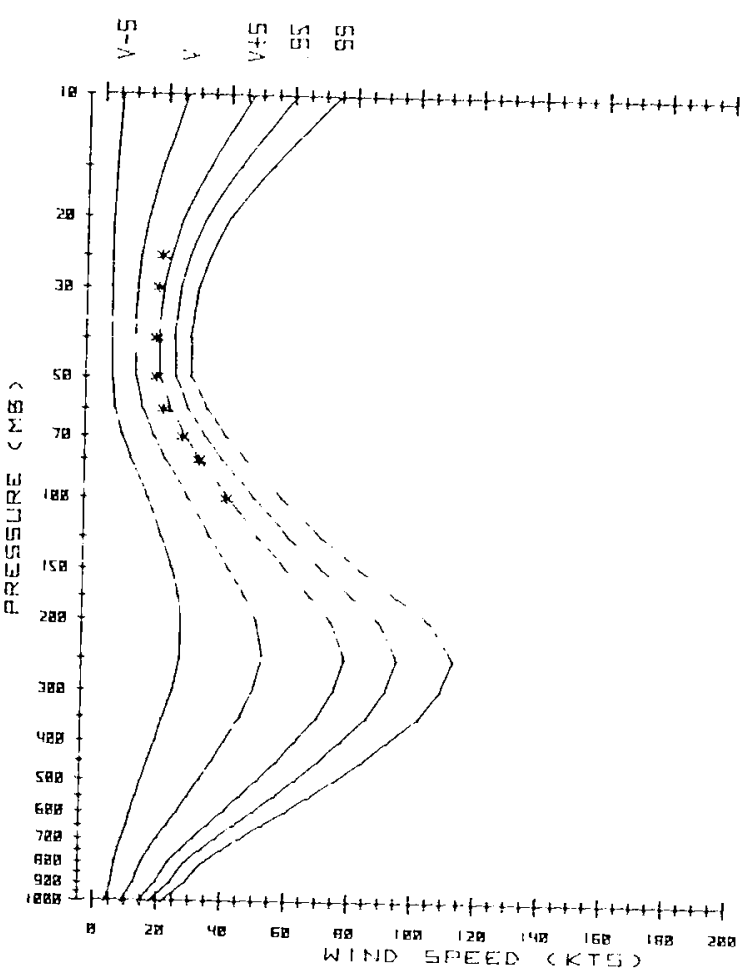

$$
\begin{aligned}
& \text { DAKLANO } \\
& *=E 4 \% \text { LEVEL }
\end{aligned}
$$

FFIL

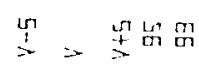

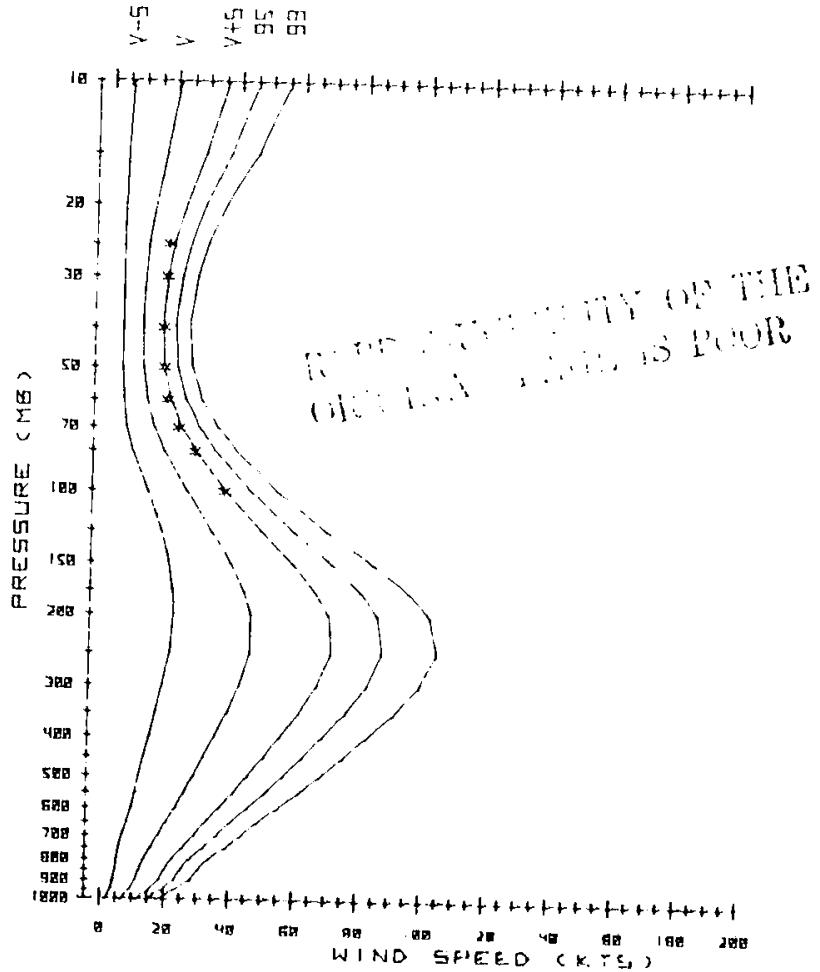

$\hat{x}$

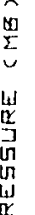



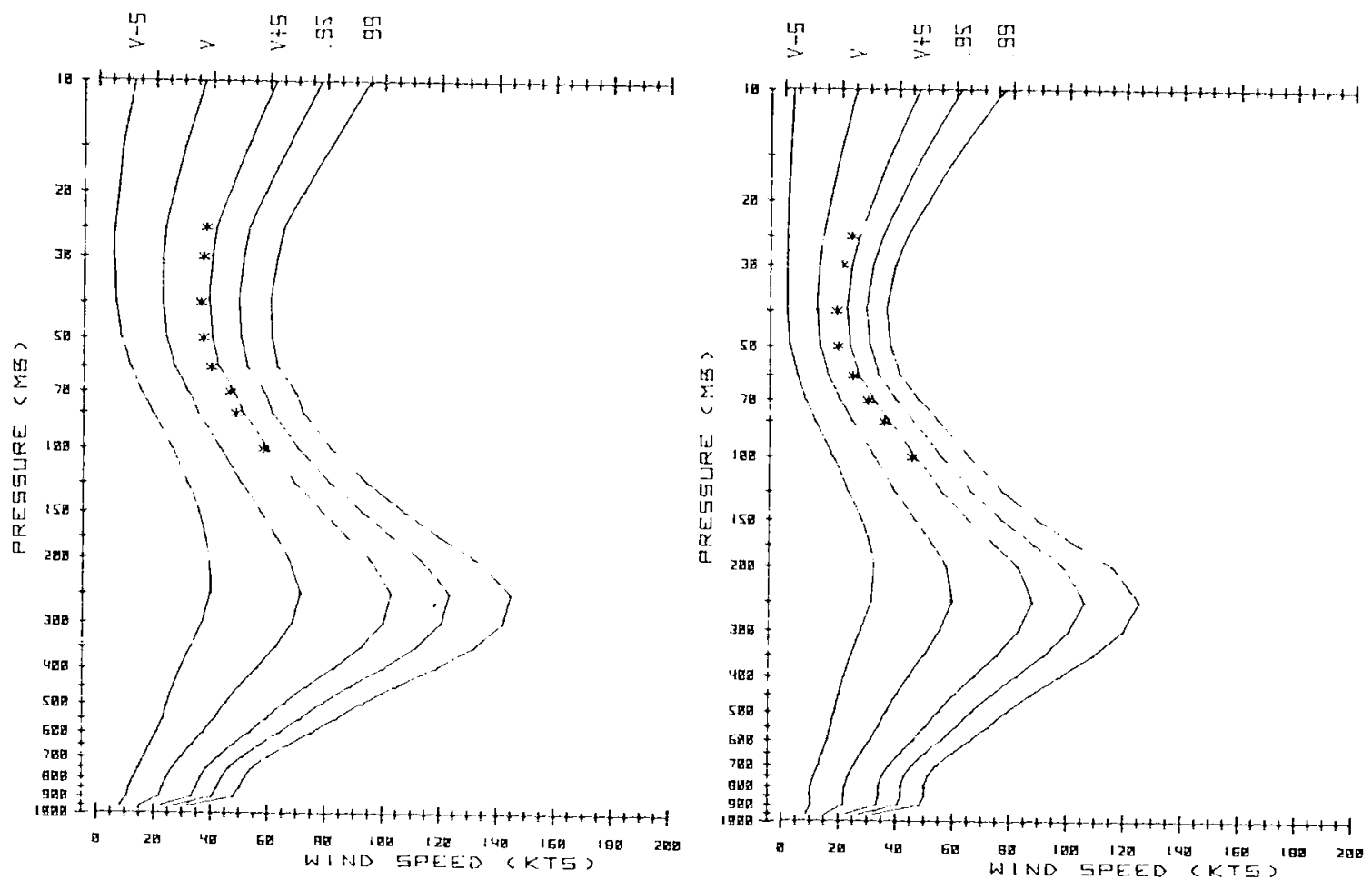

DMAHA

SLMMER

ПMคHA

$*=84 \quad 1 \%$ LEVEL

FALL

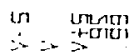

我
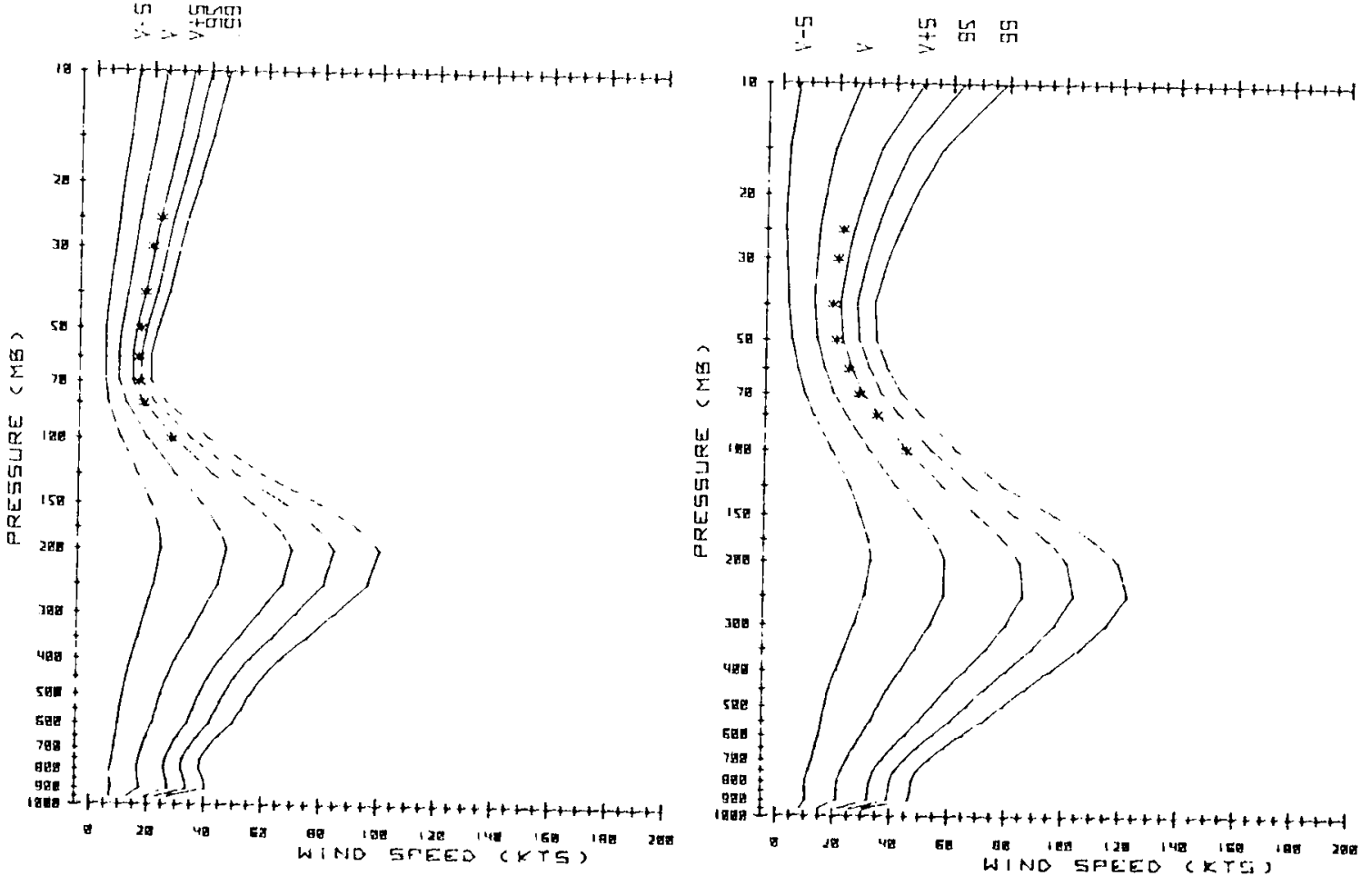
PORTLAND

$*=84.1 \%$ LEVEI

WINTER

I $=\quad$ 岗 昂

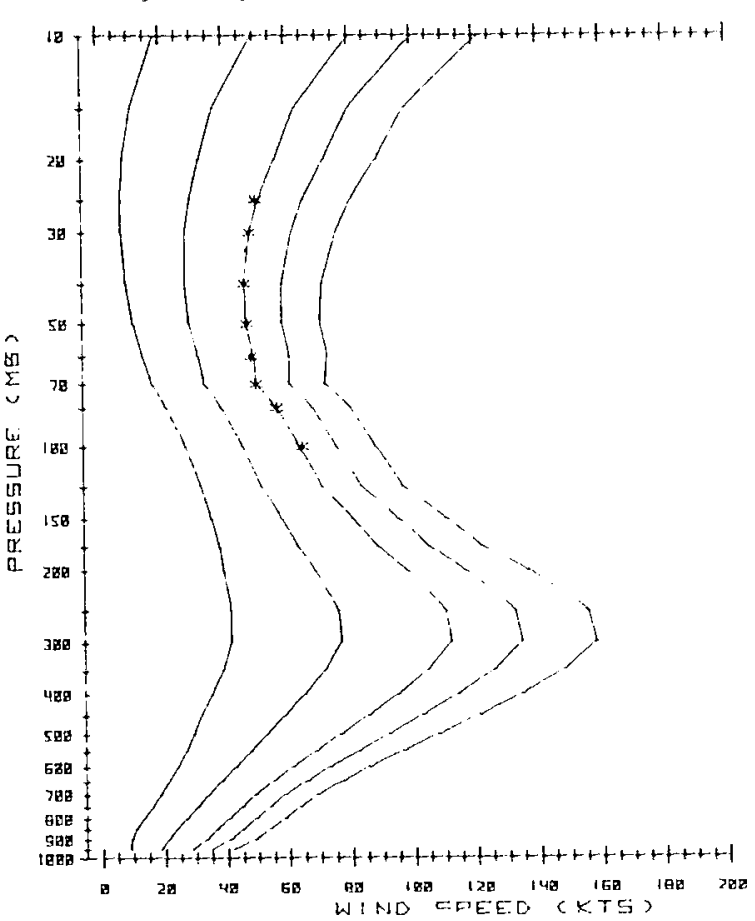

PORTLAND

$*=B 4.1 \%$ LEVEL

SUMMER

S.

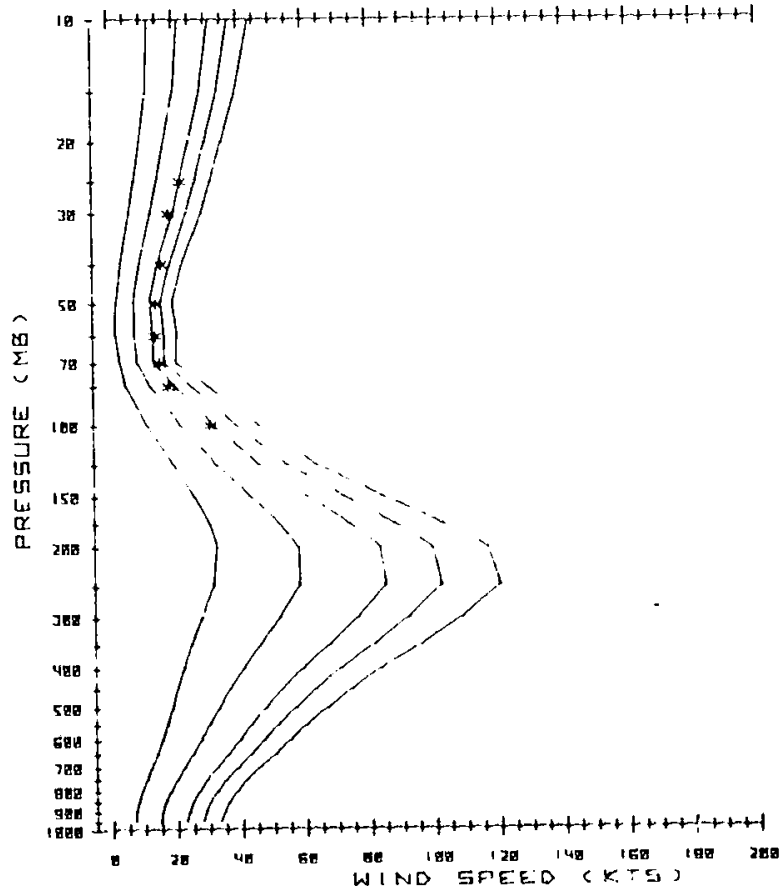

PERTLFAN

$*=E-4: \%$ :TVE:

SFRIN.

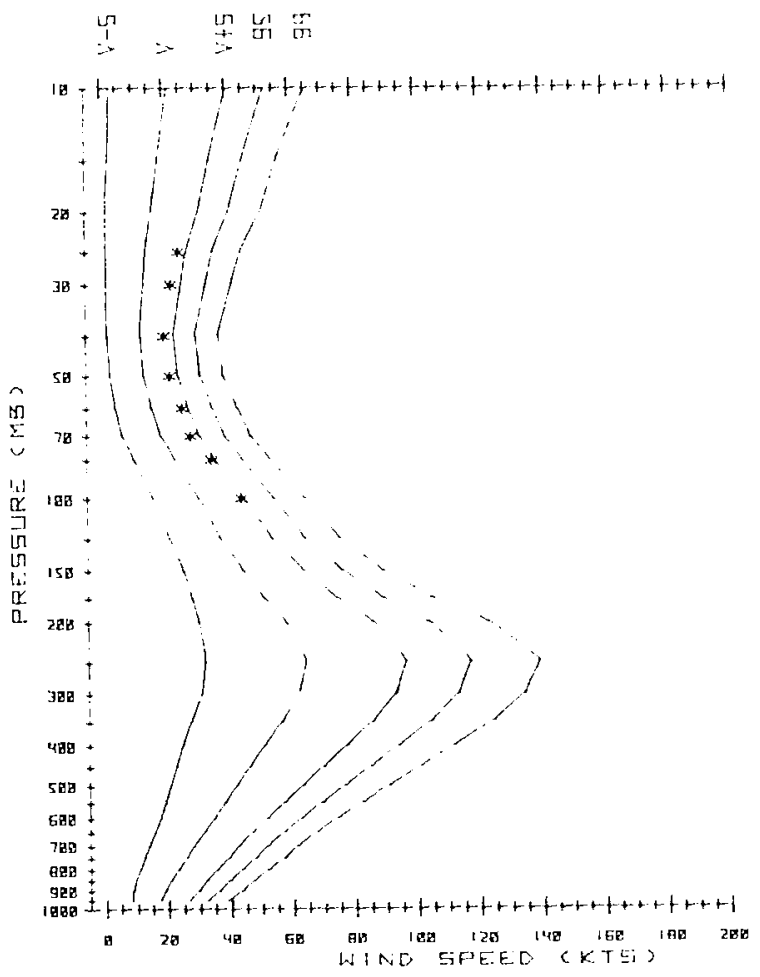

PDRTLAND
$*=E 4 ; \%$ LEVEL

FELL
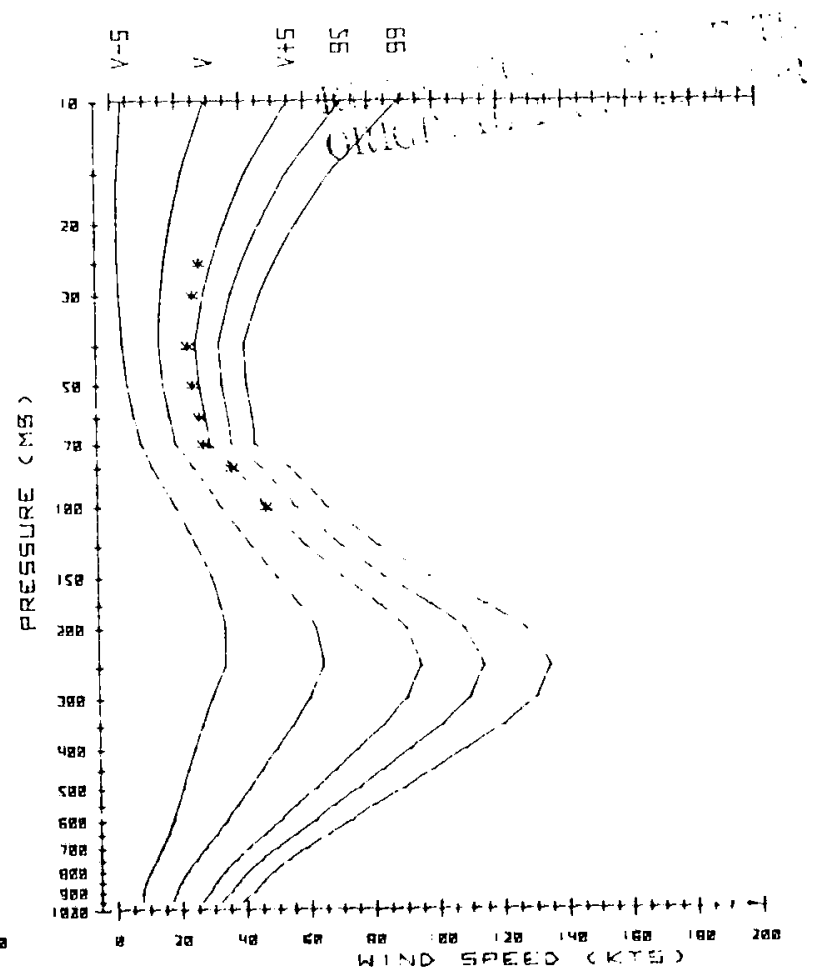

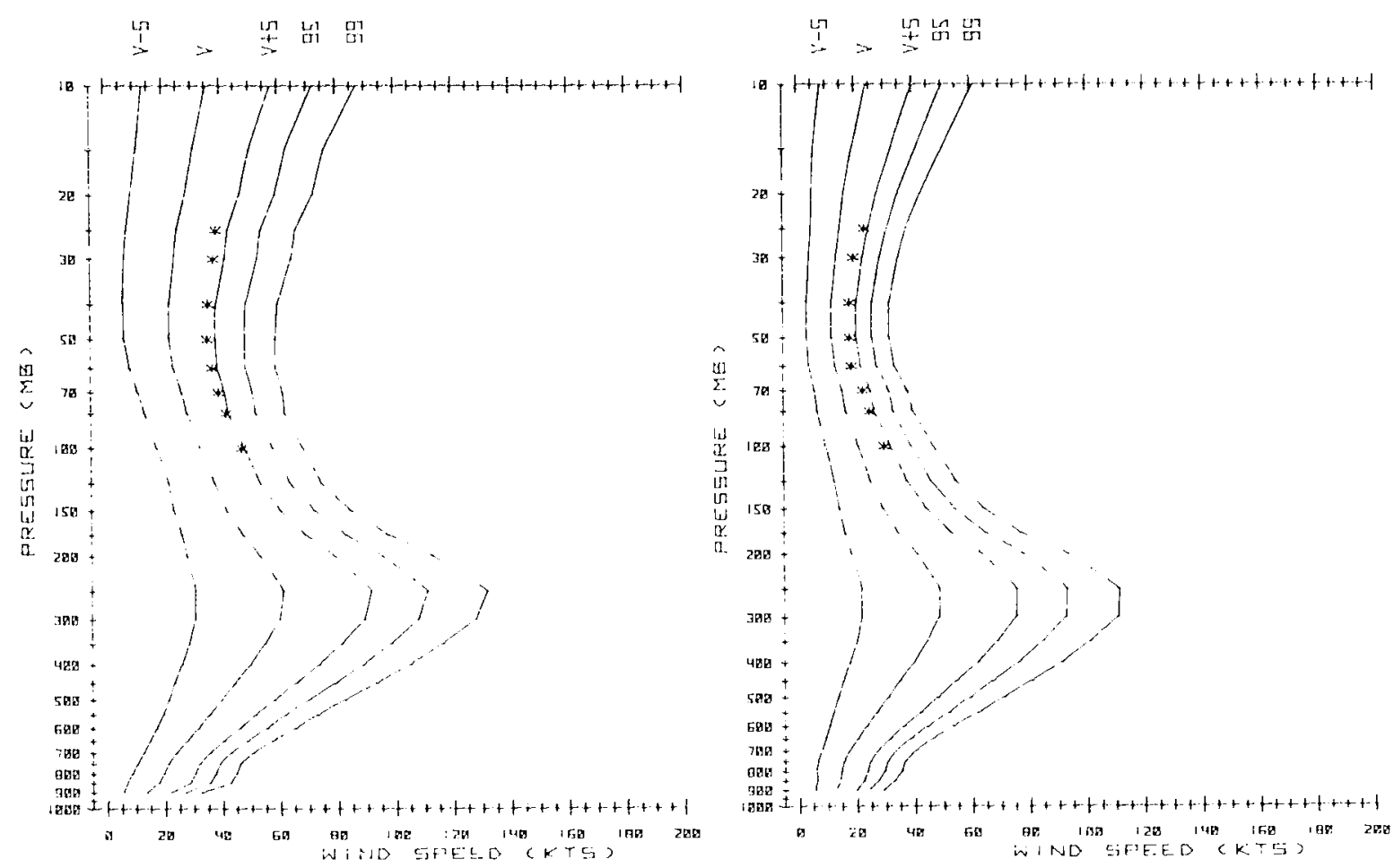

SPCK.ANE

$*=$ Ej $^{4} \%$ LEVE:

SIJMMER

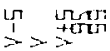

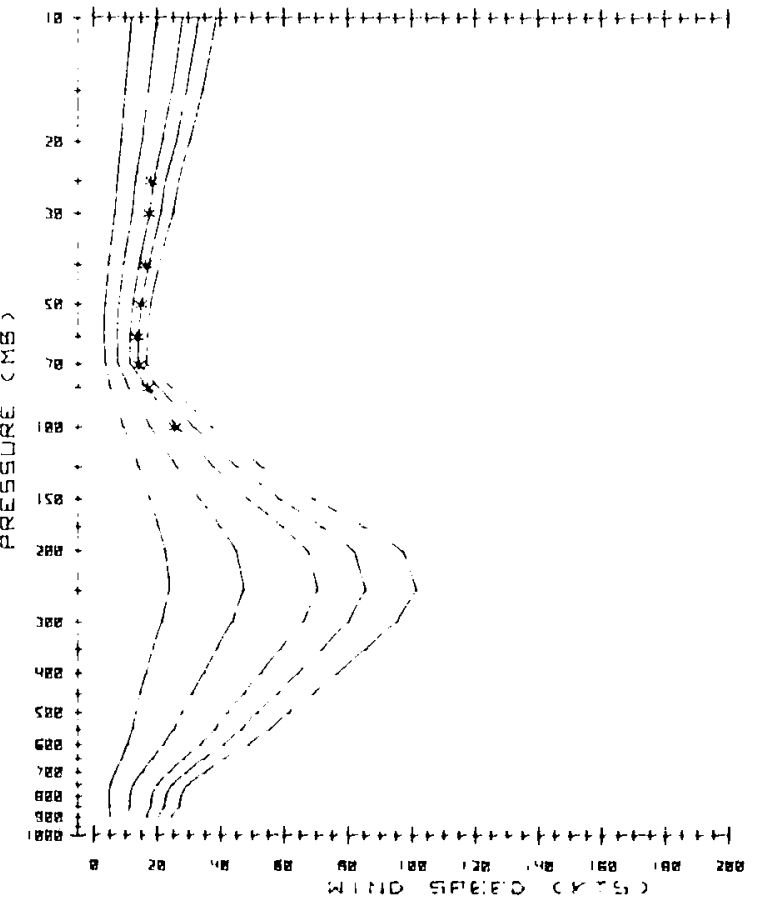

SPDKAHE

* $=$ Gi I\% LEVE:

FALL

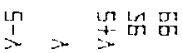

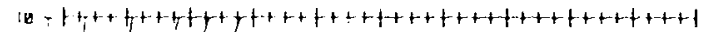

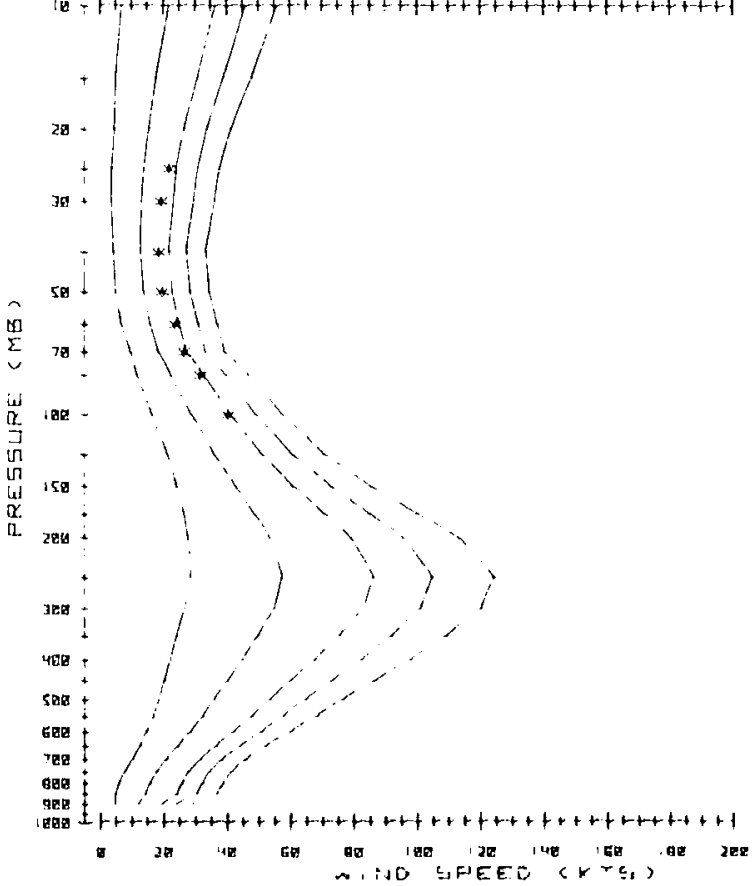


TUC5ON

$*=\theta 4,1 \%$ L.EVEL

WINTER

号 $=$ 崖界

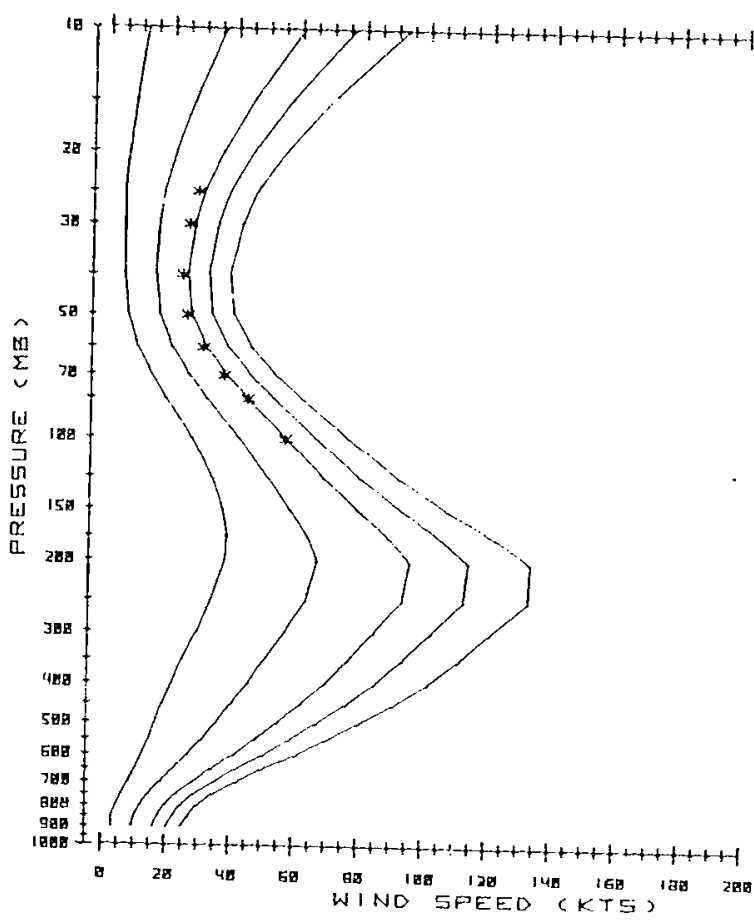

TUCSDN

$*=84.1 \%$ LEVEL

SUMMER

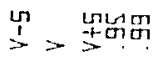

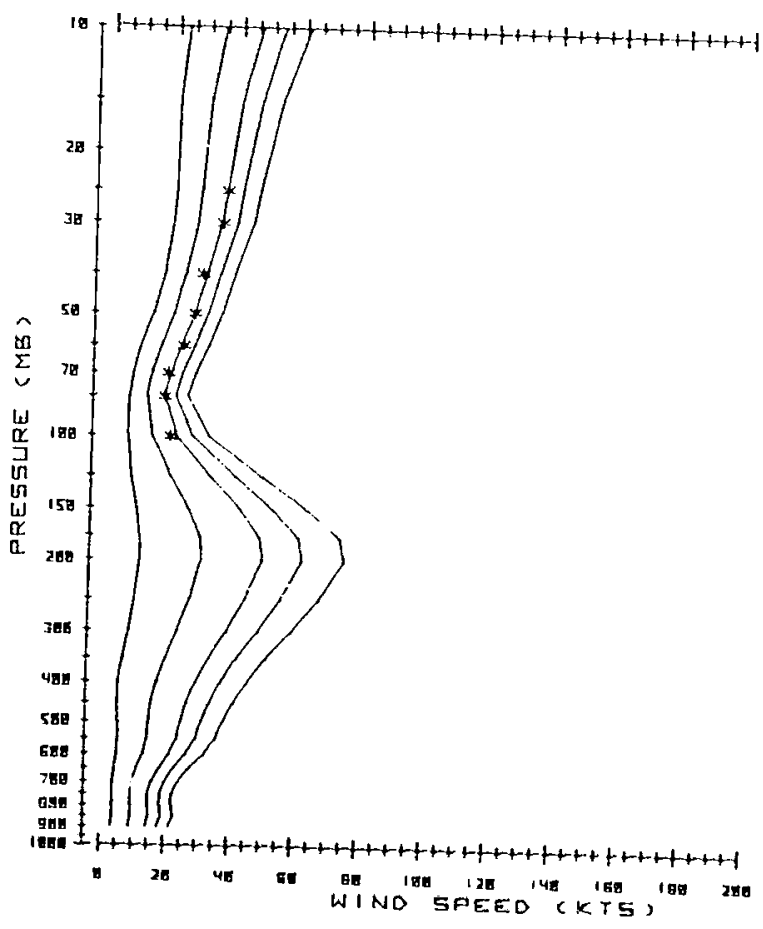

TUKSDN

$*=84.1 \%$ LEVEL

SPRING

$\stackrel{1}{>}>\stackrel{\text { 以 }}{ \pm}$ 告星

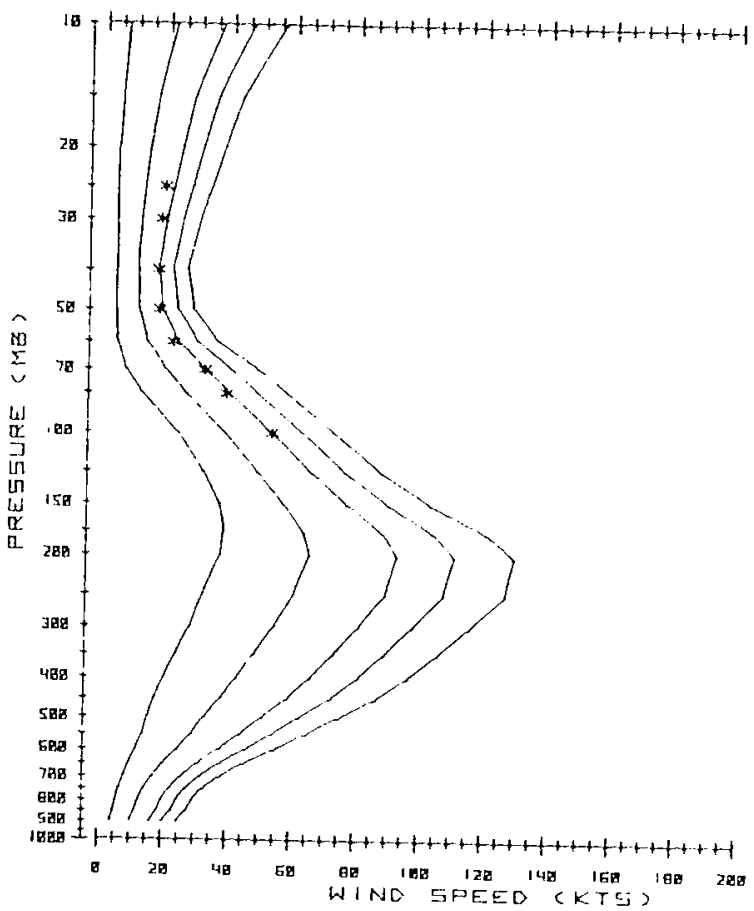

TUCSON

$*=84.1 \%$ LEVEL

FALL

$\stackrel{4}{>}= \pm$ 皆

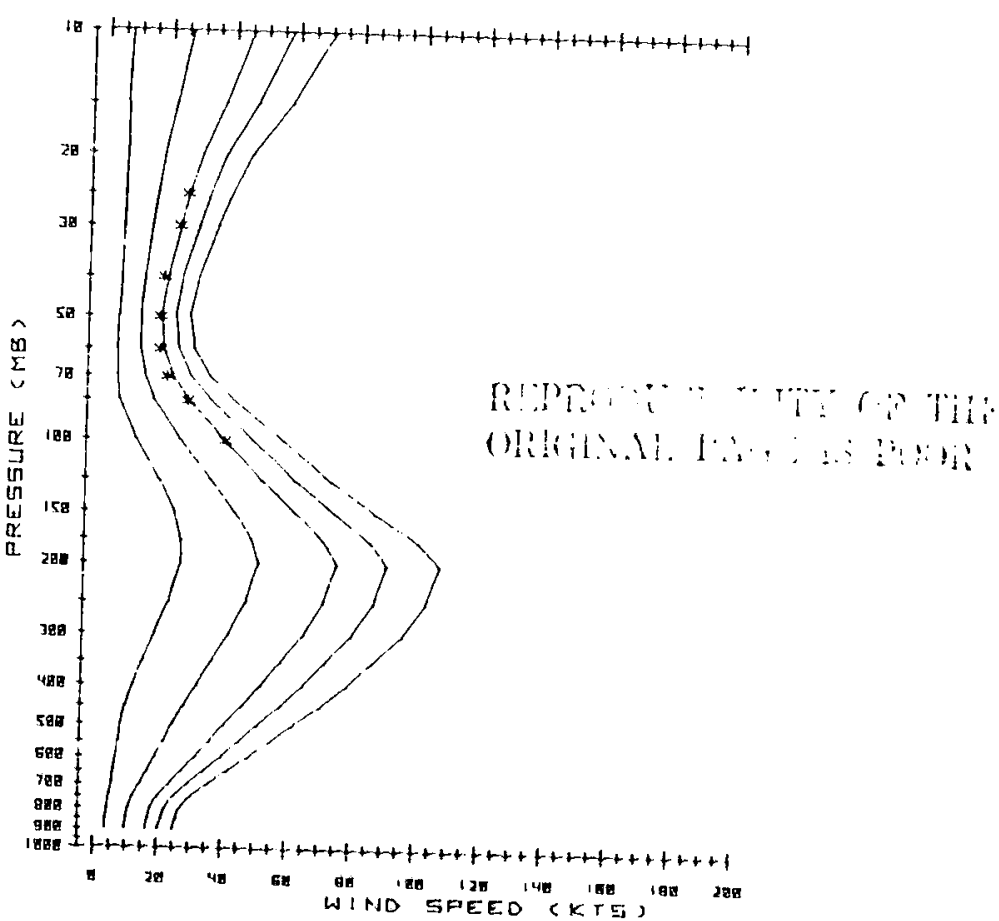




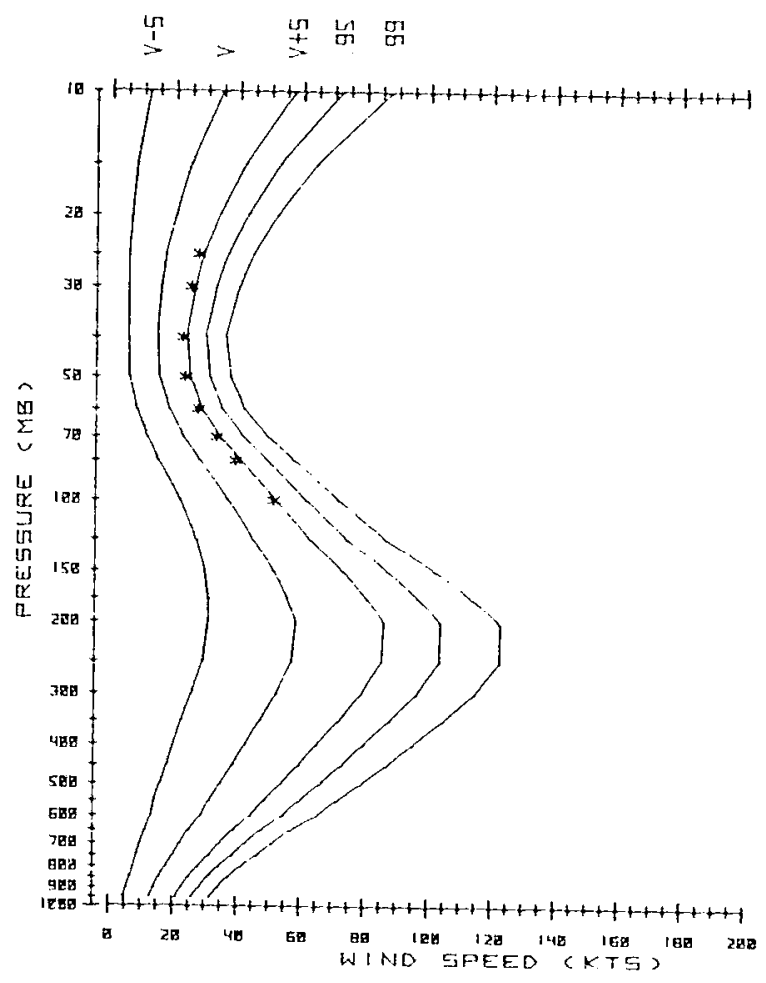

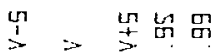

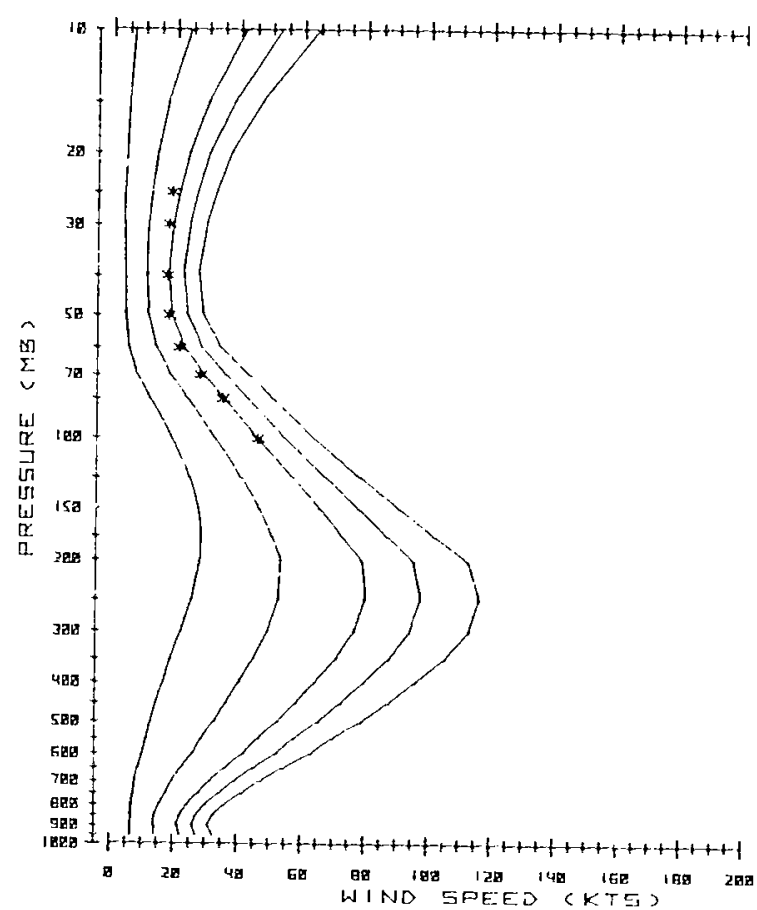

VANDENGERG

SUMMER

VANDENBERE

$*=84$ i\% LEVEL

FALL
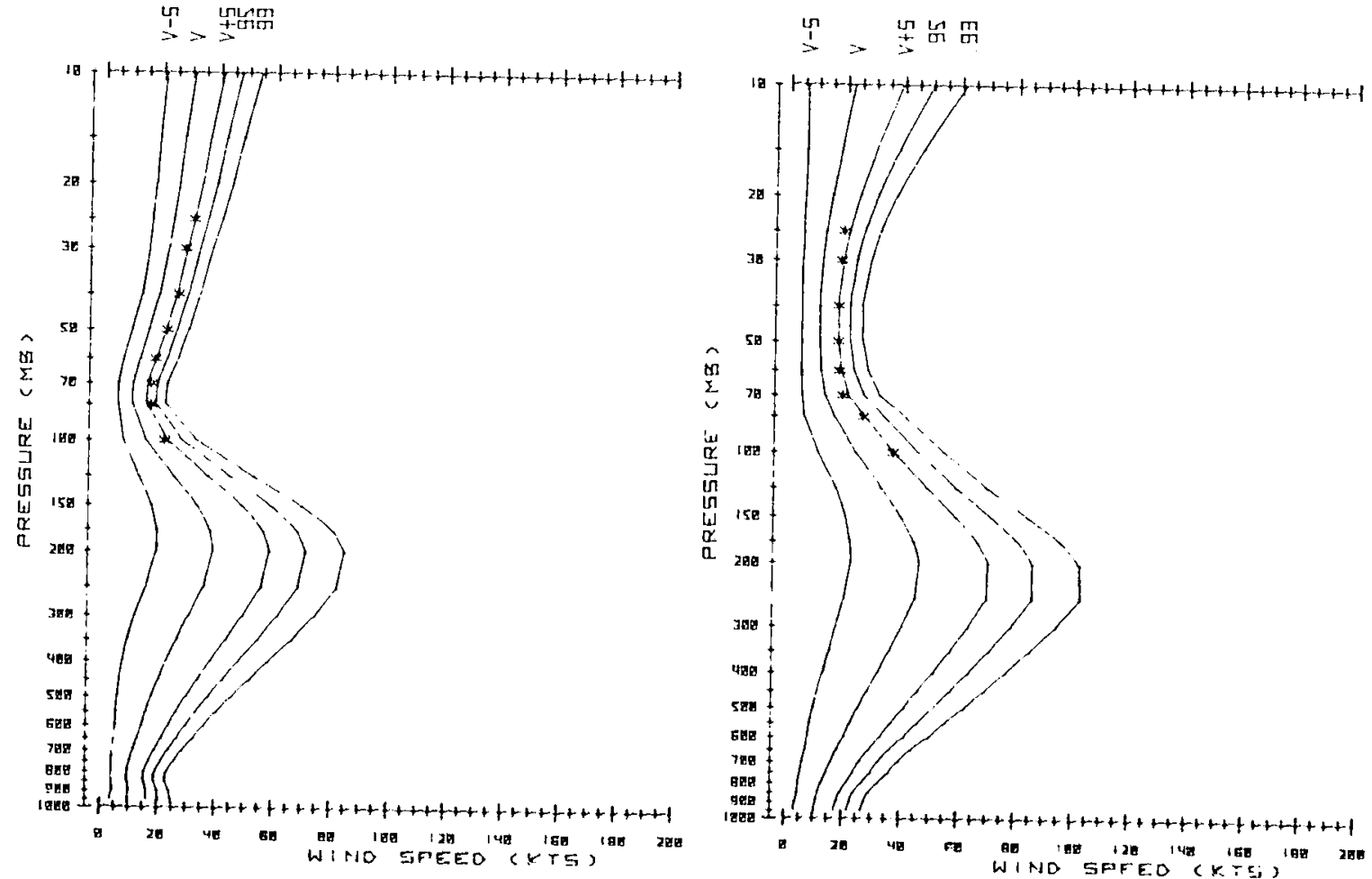
WHSHINGTON

$*=84.1 \%$ L.EVEL

WINTER

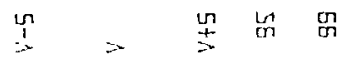

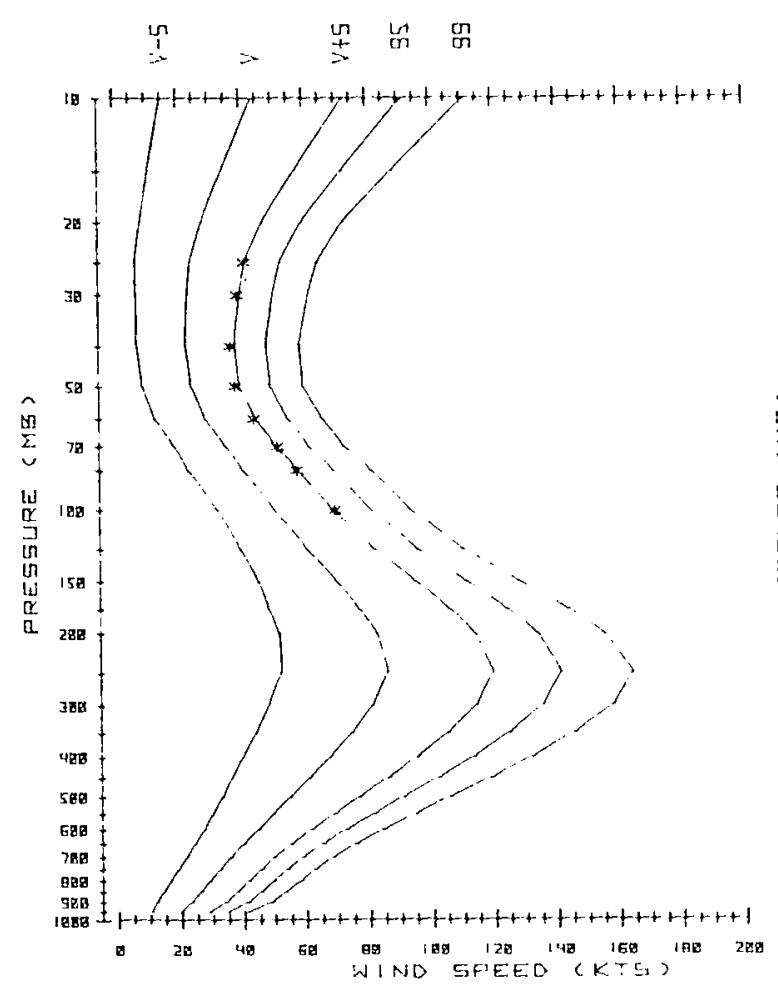

WA5HINGTCN

$*=\theta_{4}$ i $\%$ L.EVEL

SPRINE

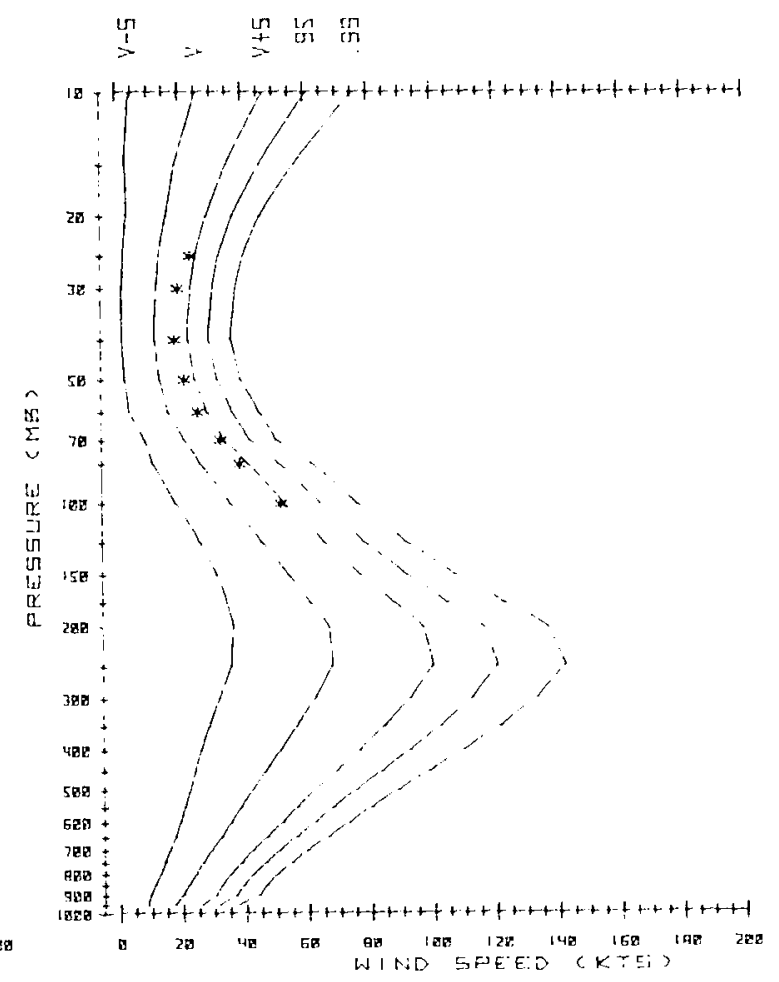

WASH I NGTLIN

$*=84.1 \%$ LEVEL

SUMMER

WFSHINGTON
$*=-4 \quad 1 \%$ LEVEL

FALL

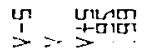

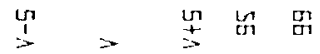
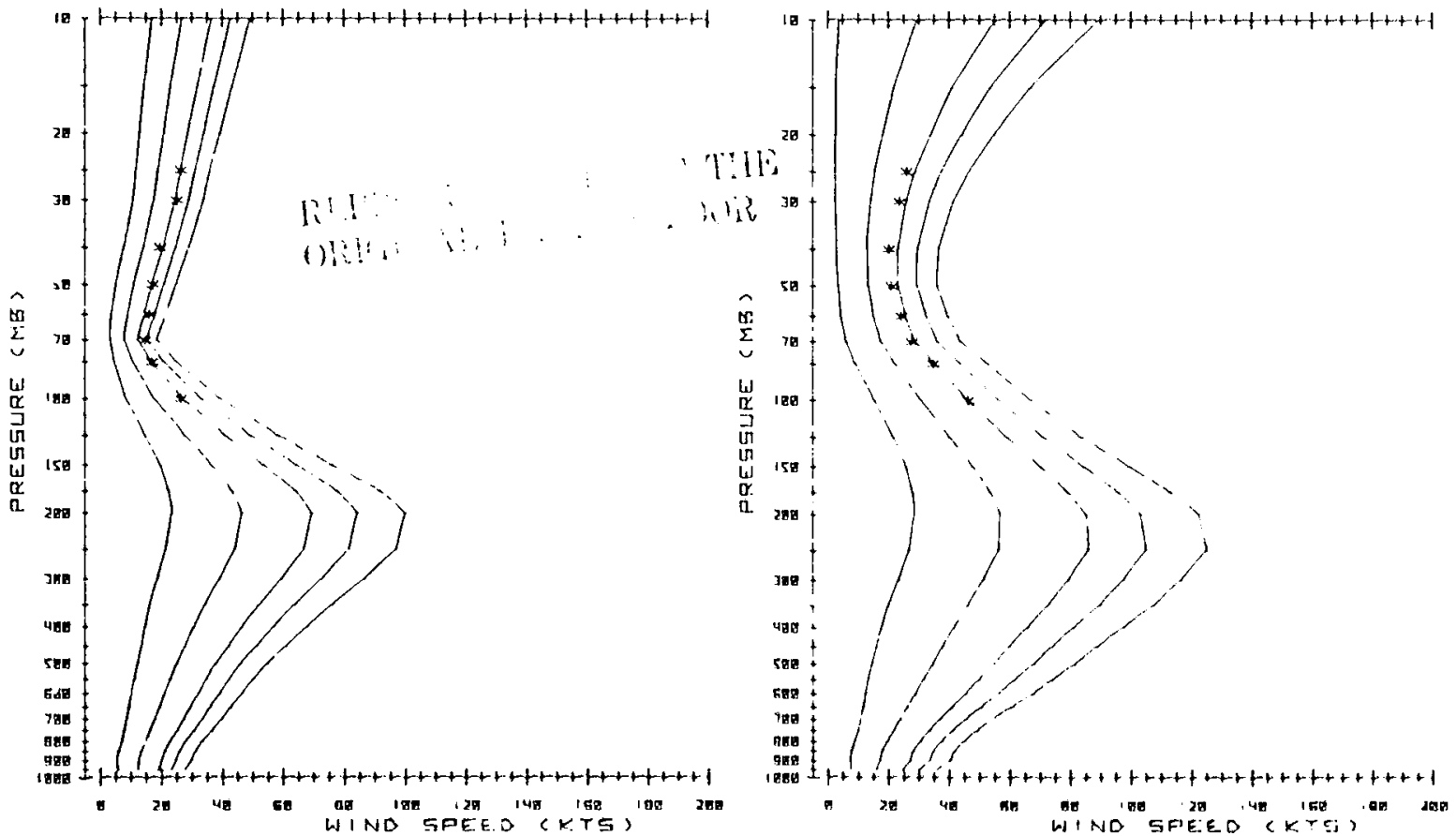

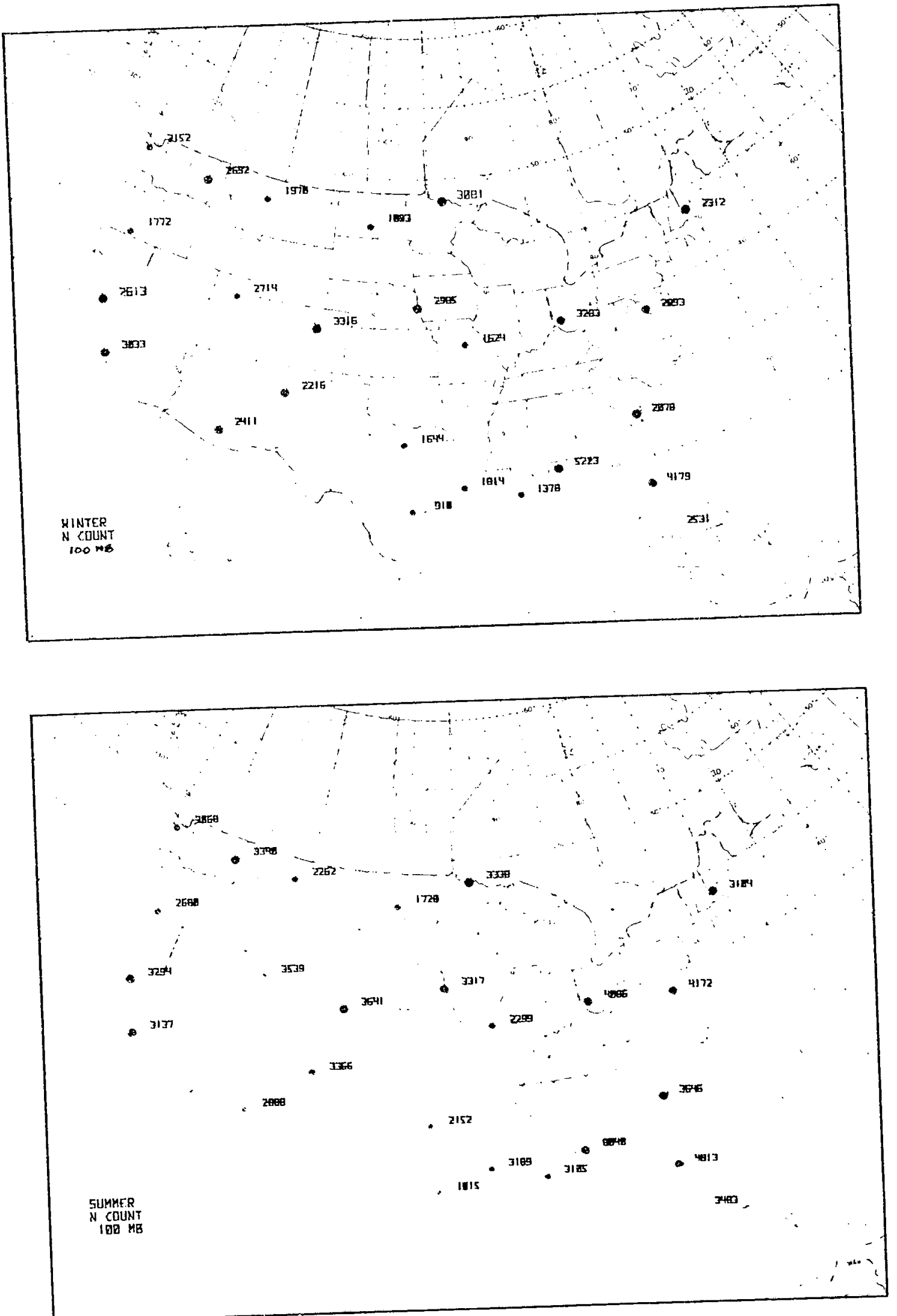

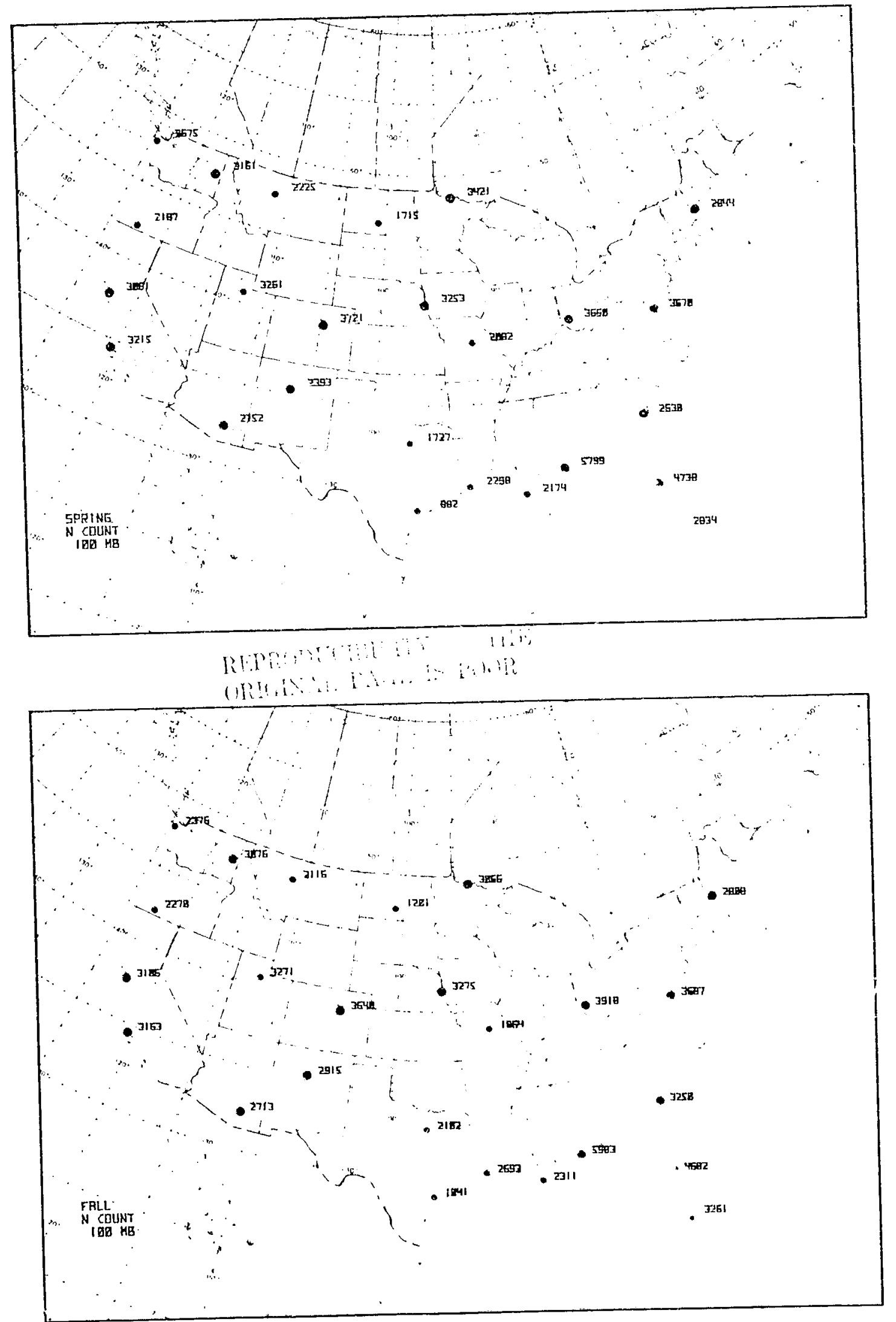

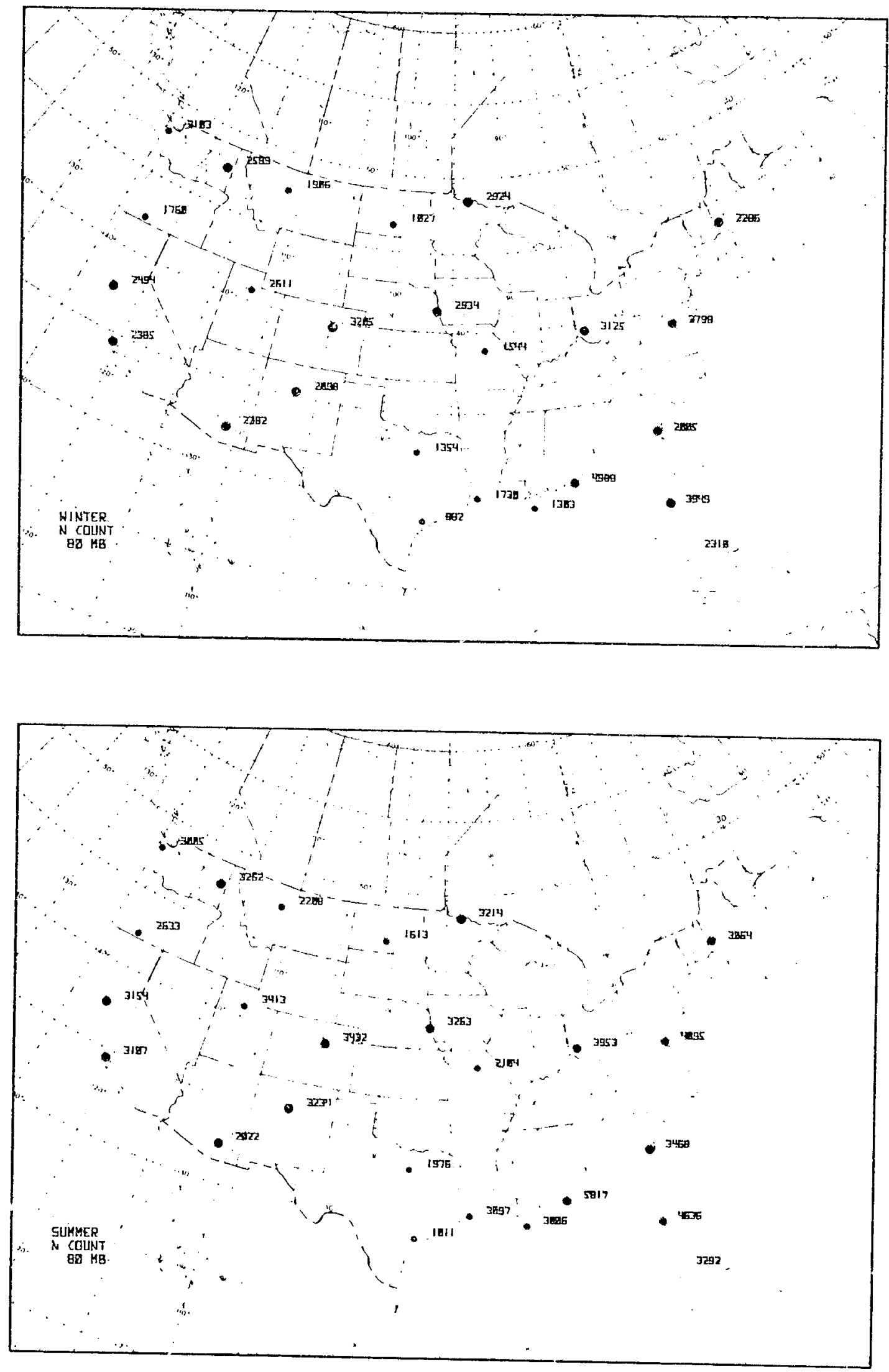


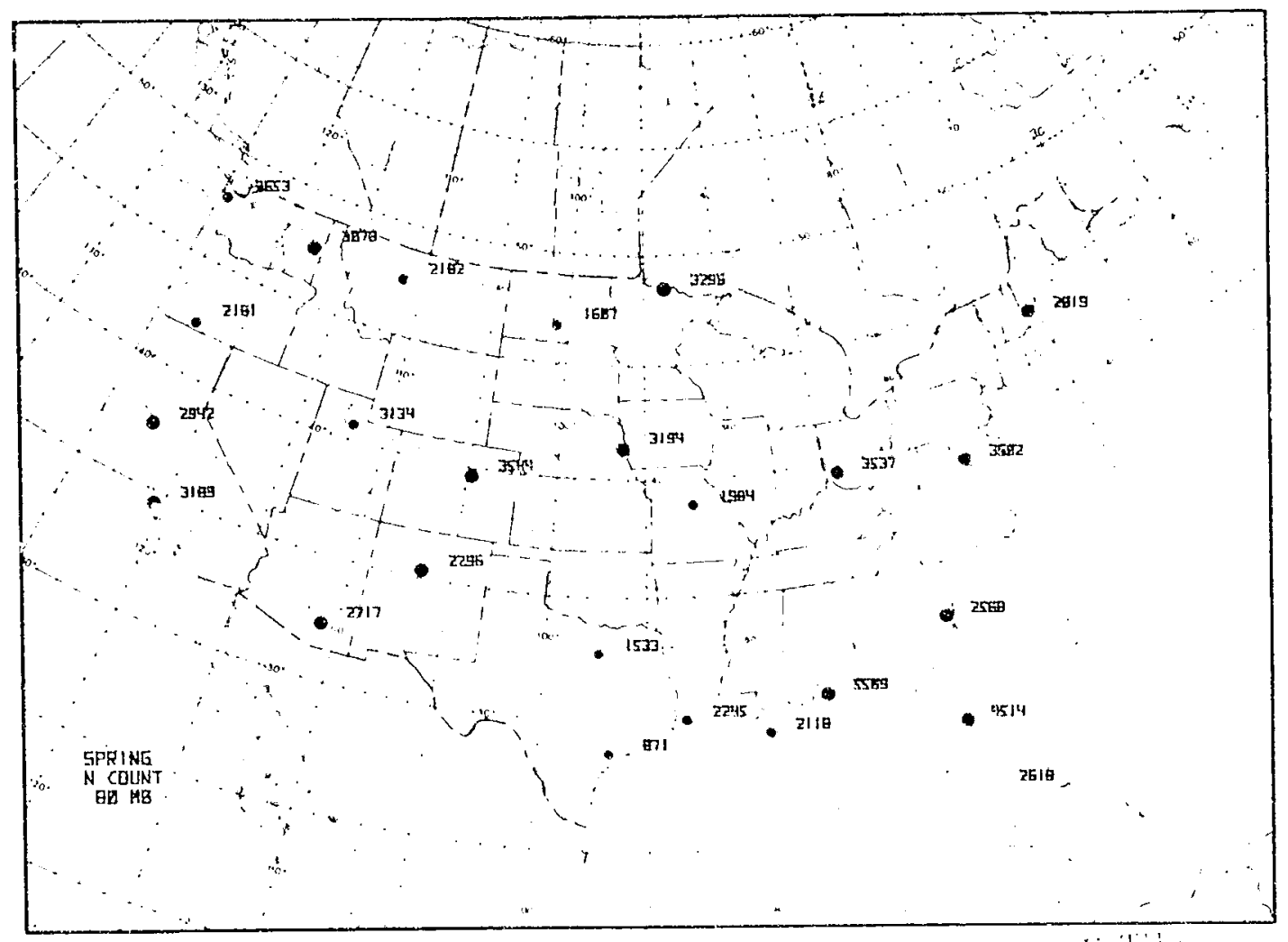

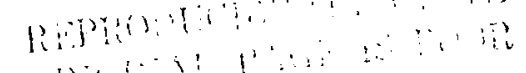

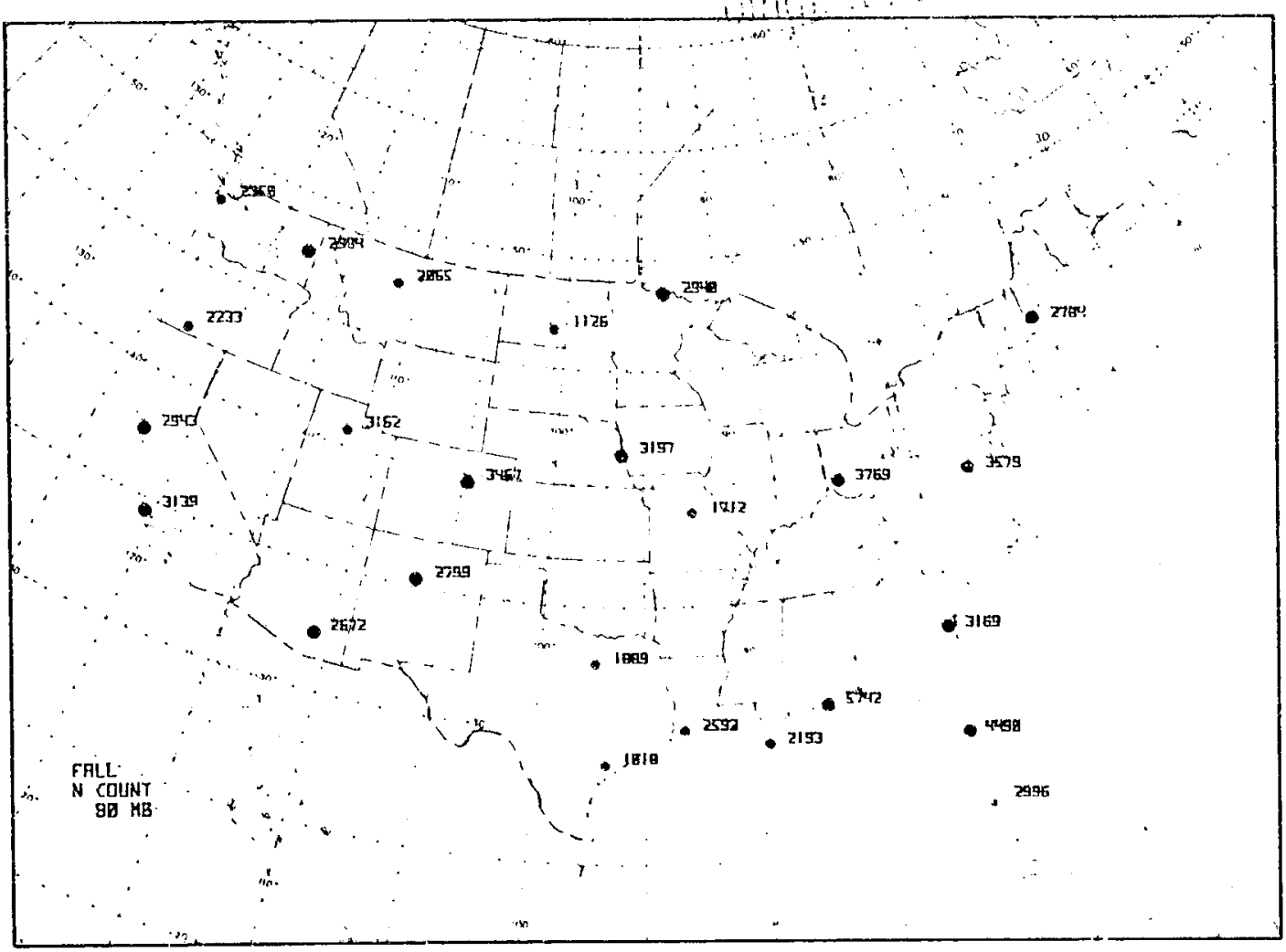



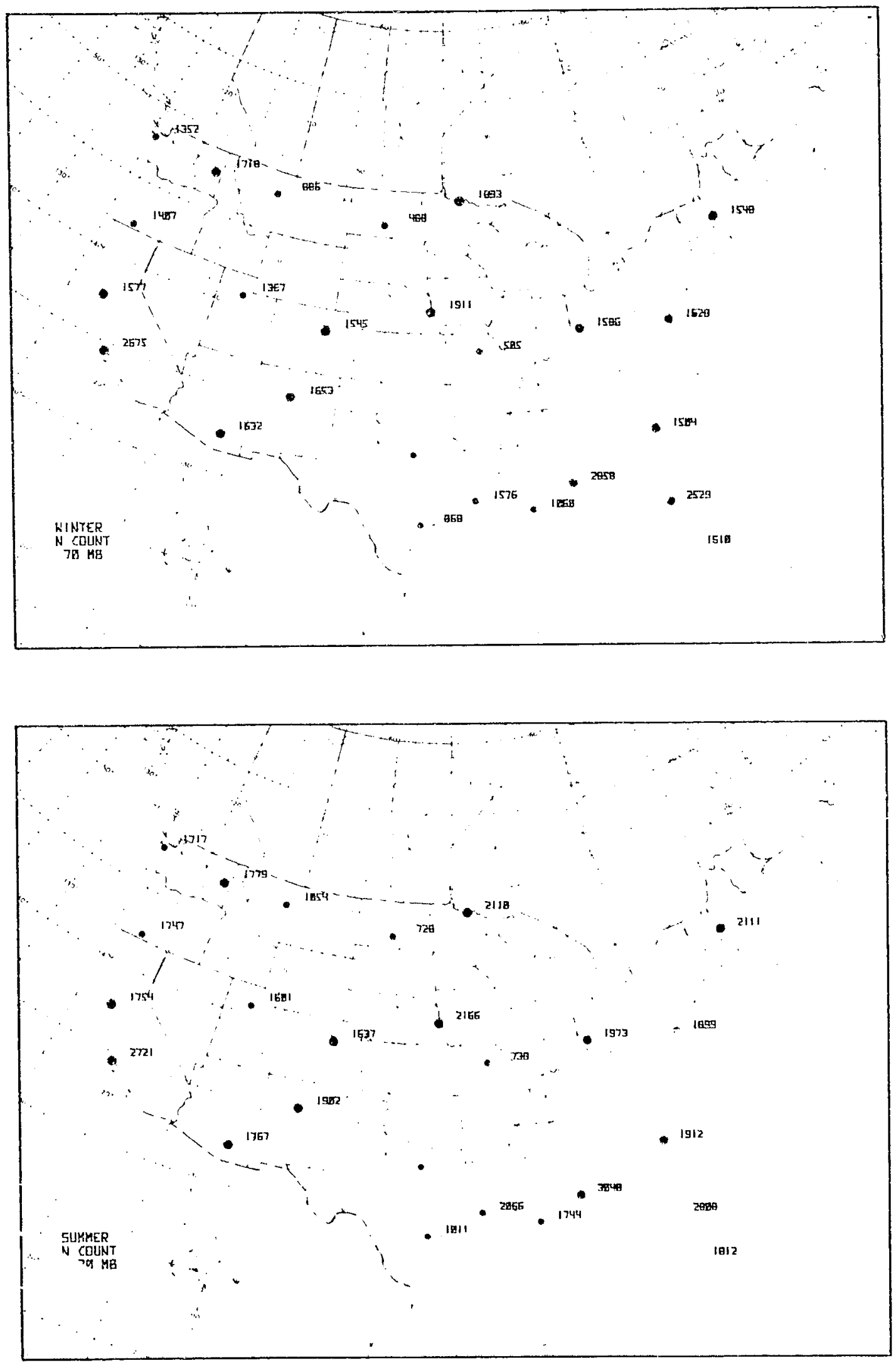

36 

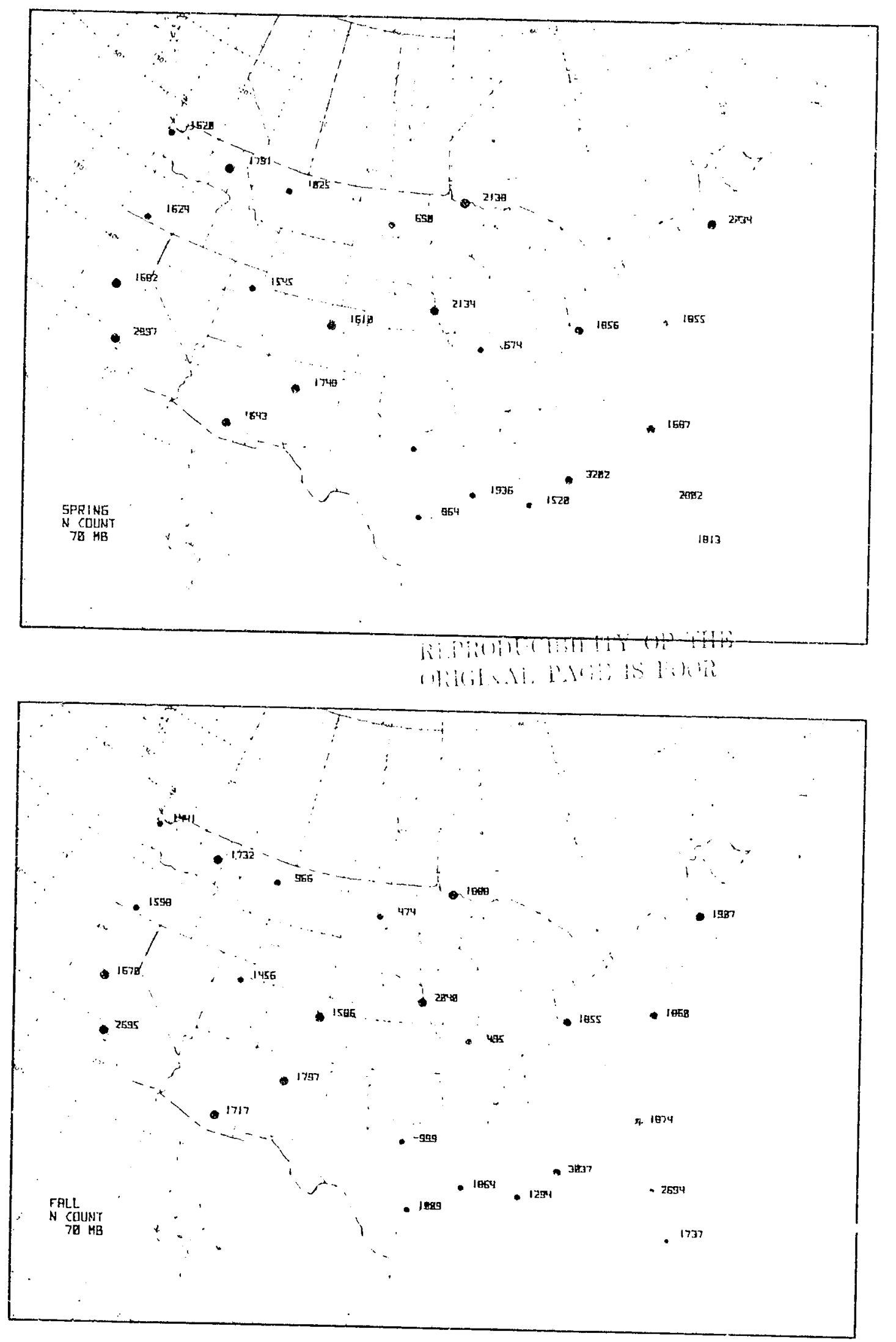

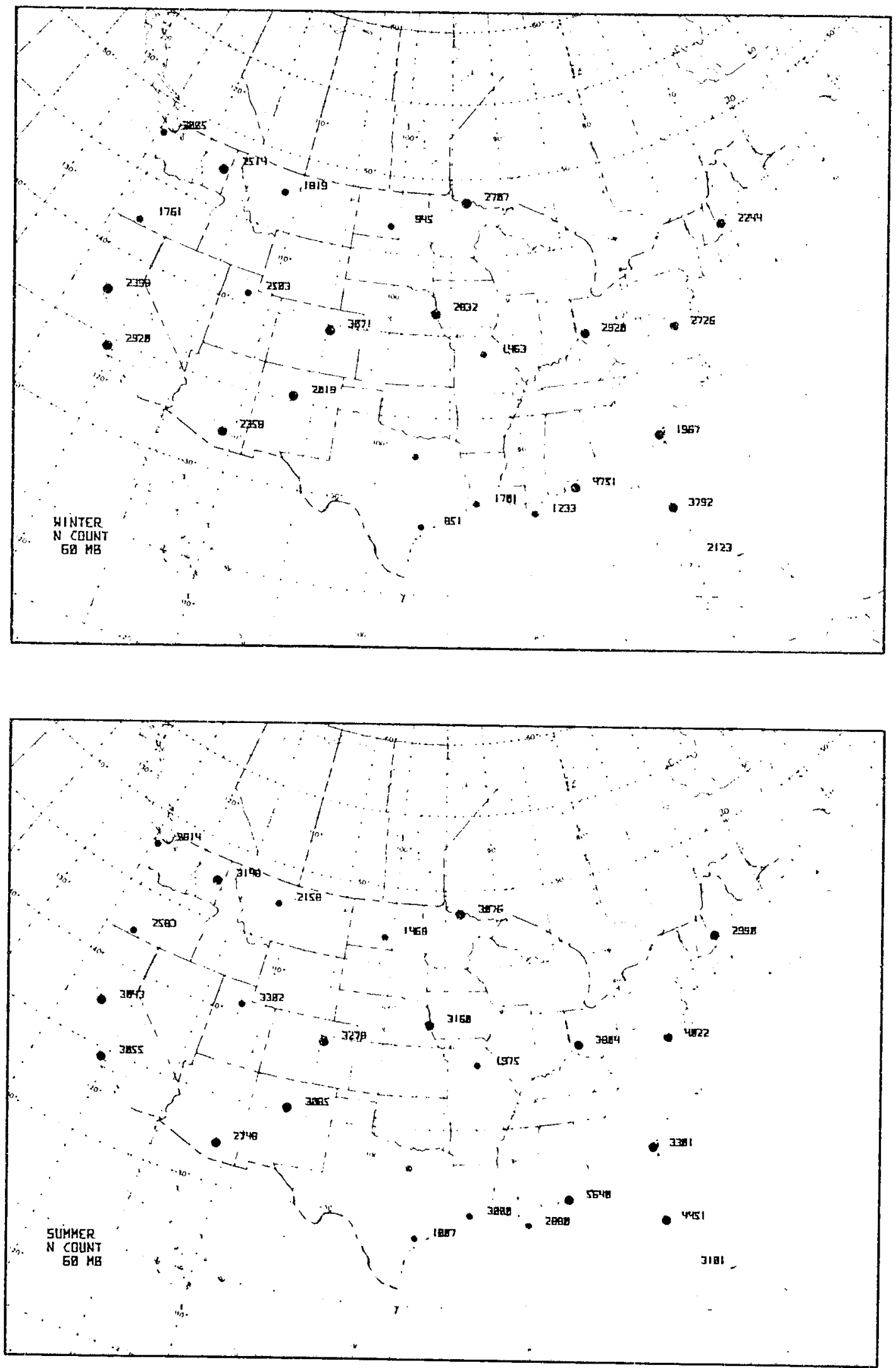

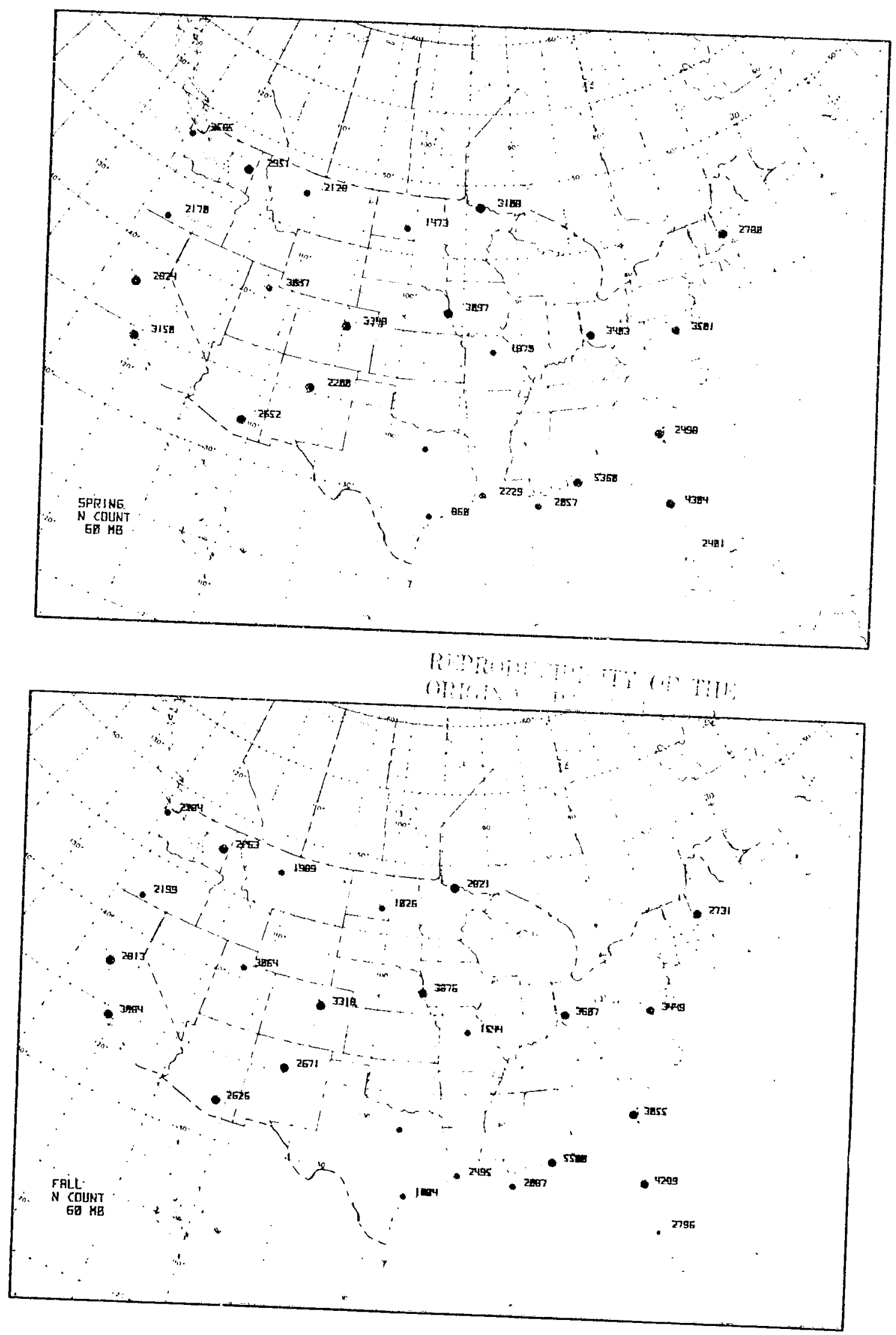

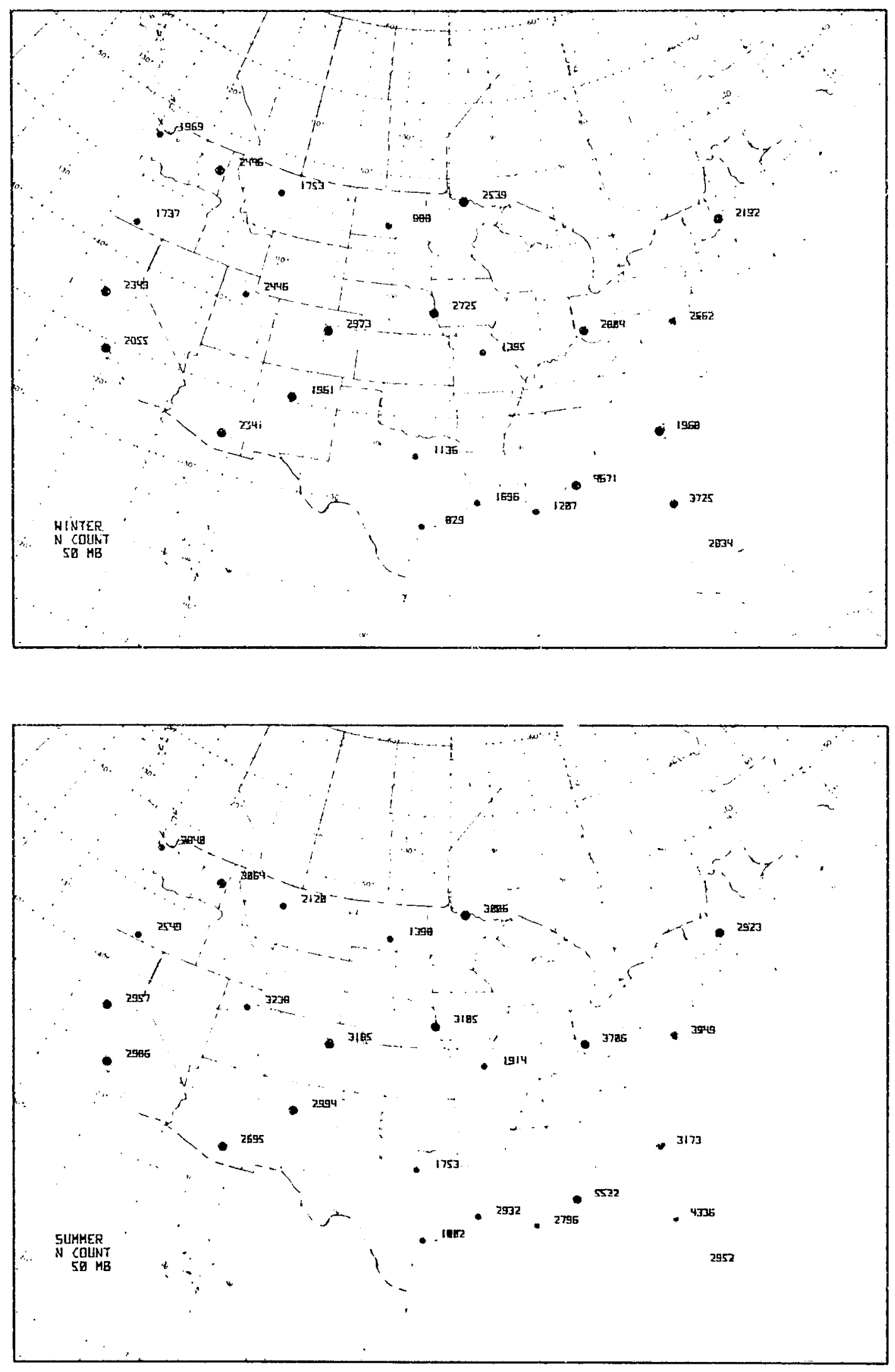

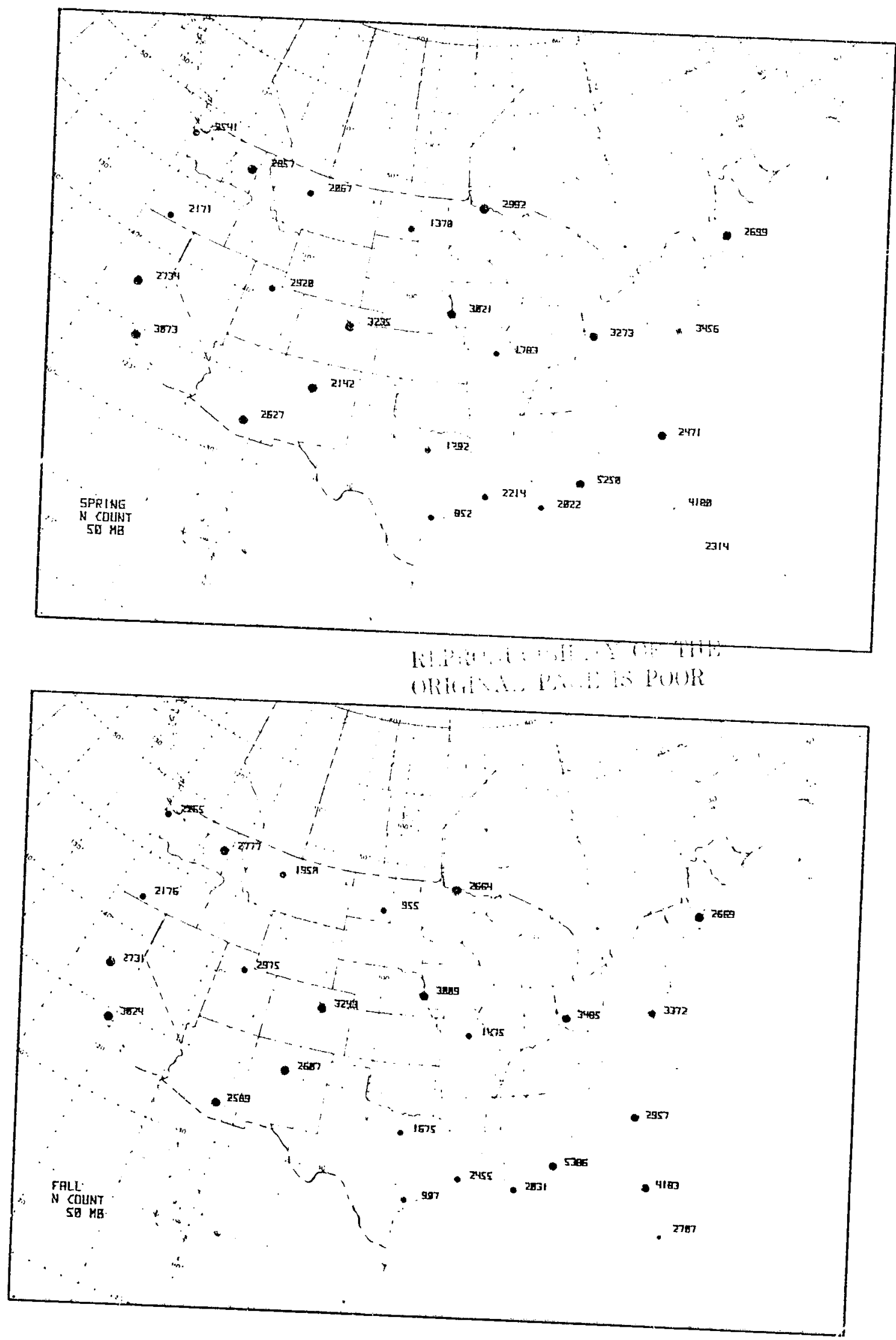

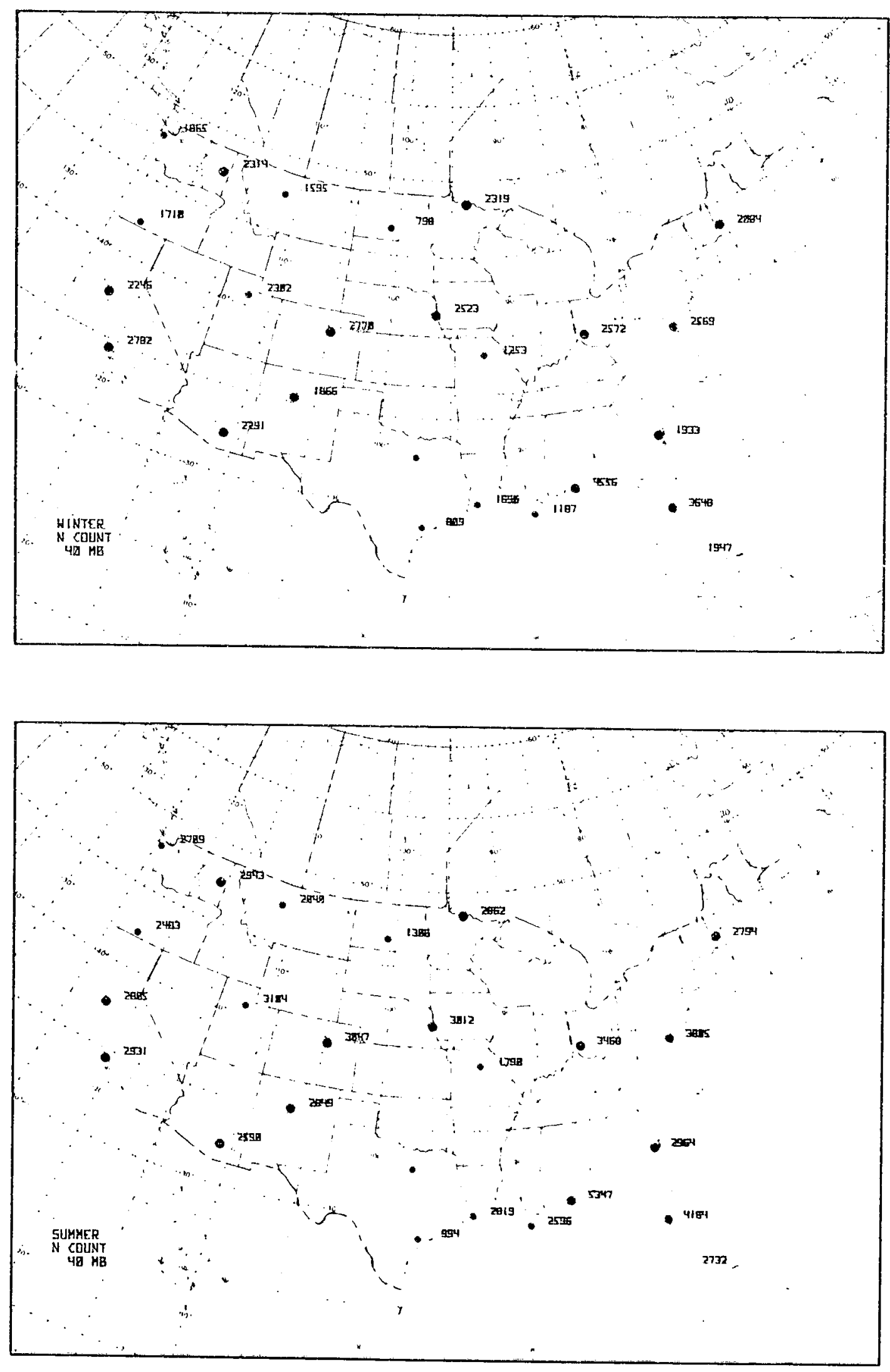

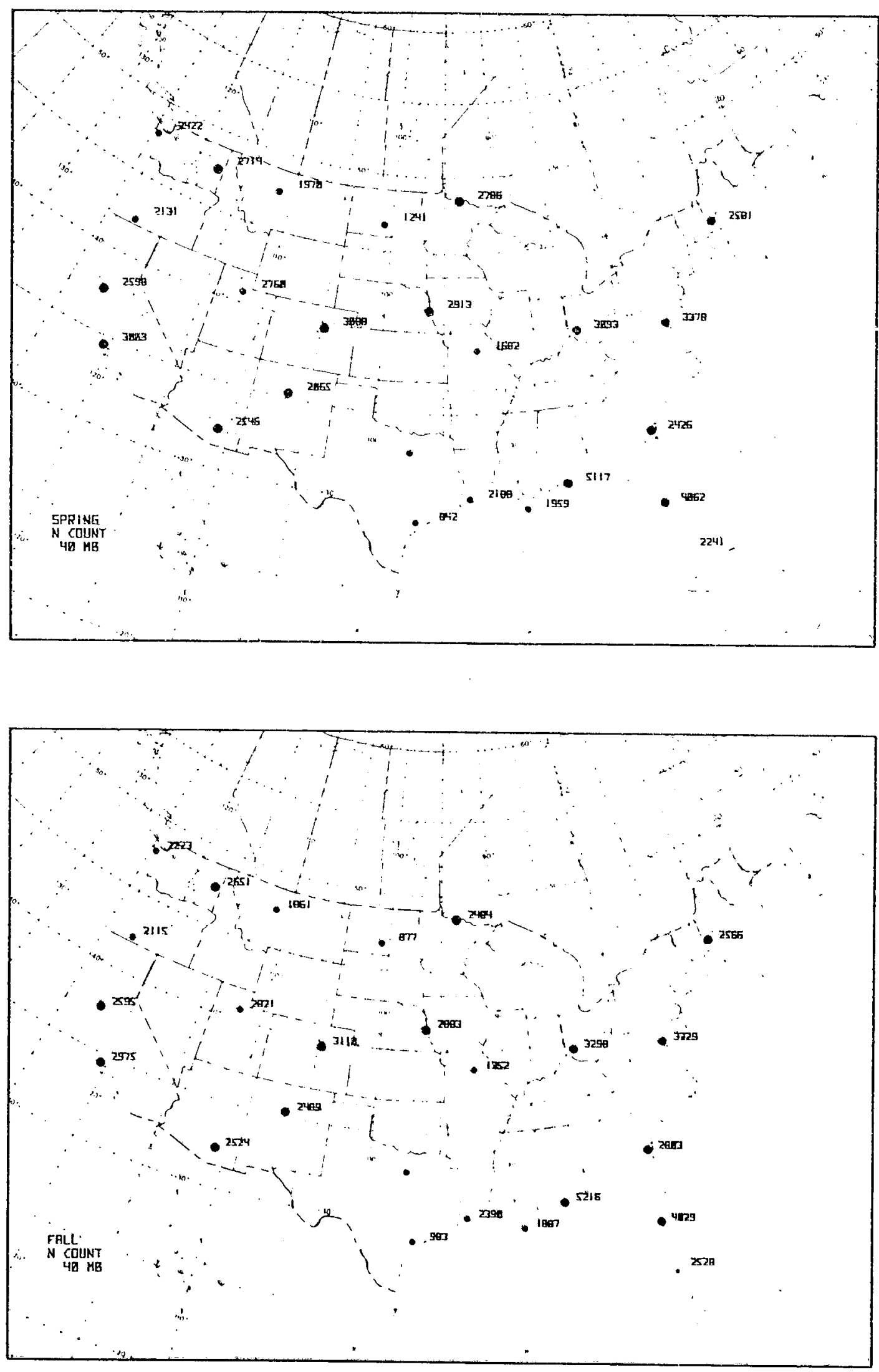

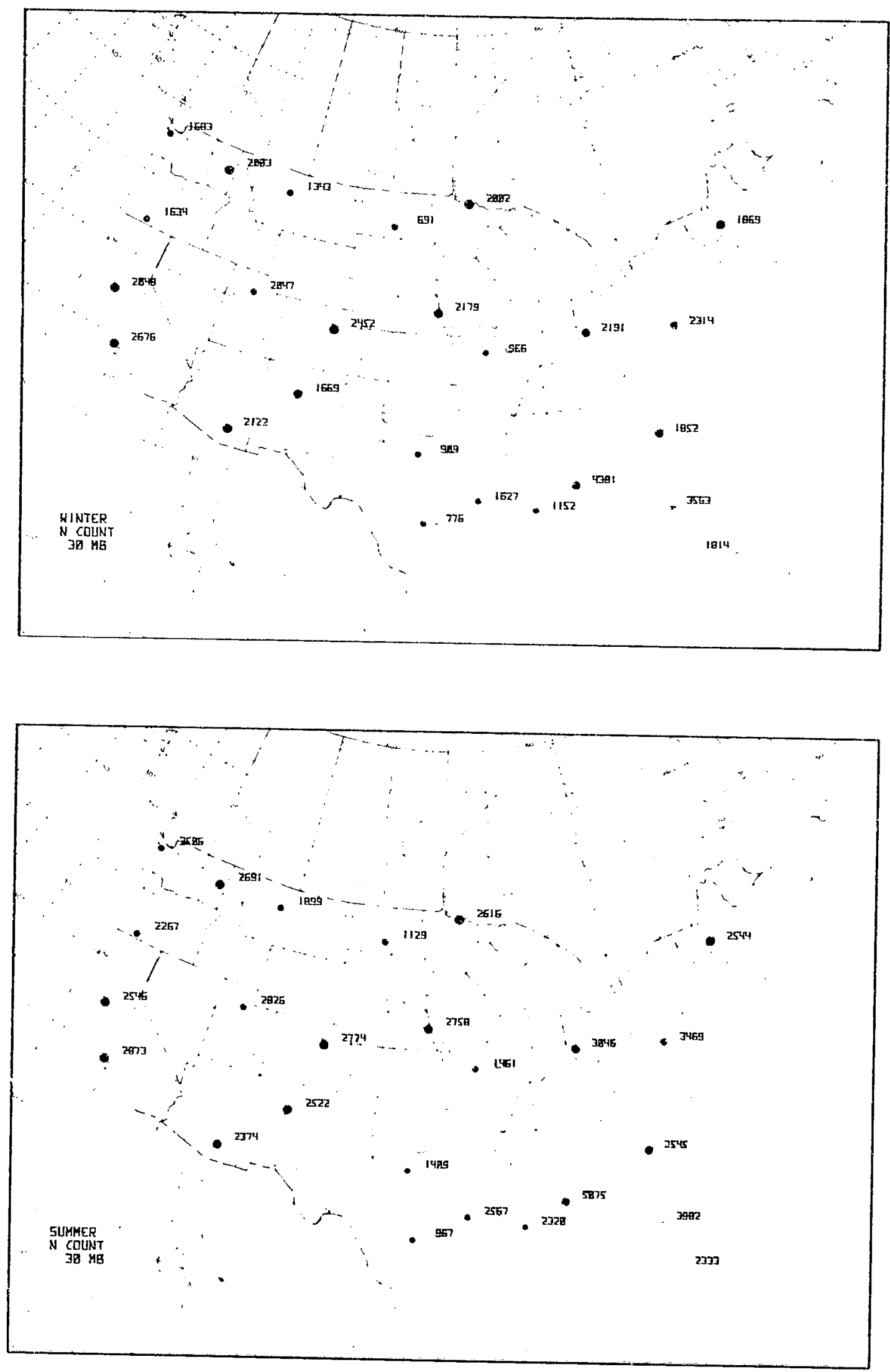

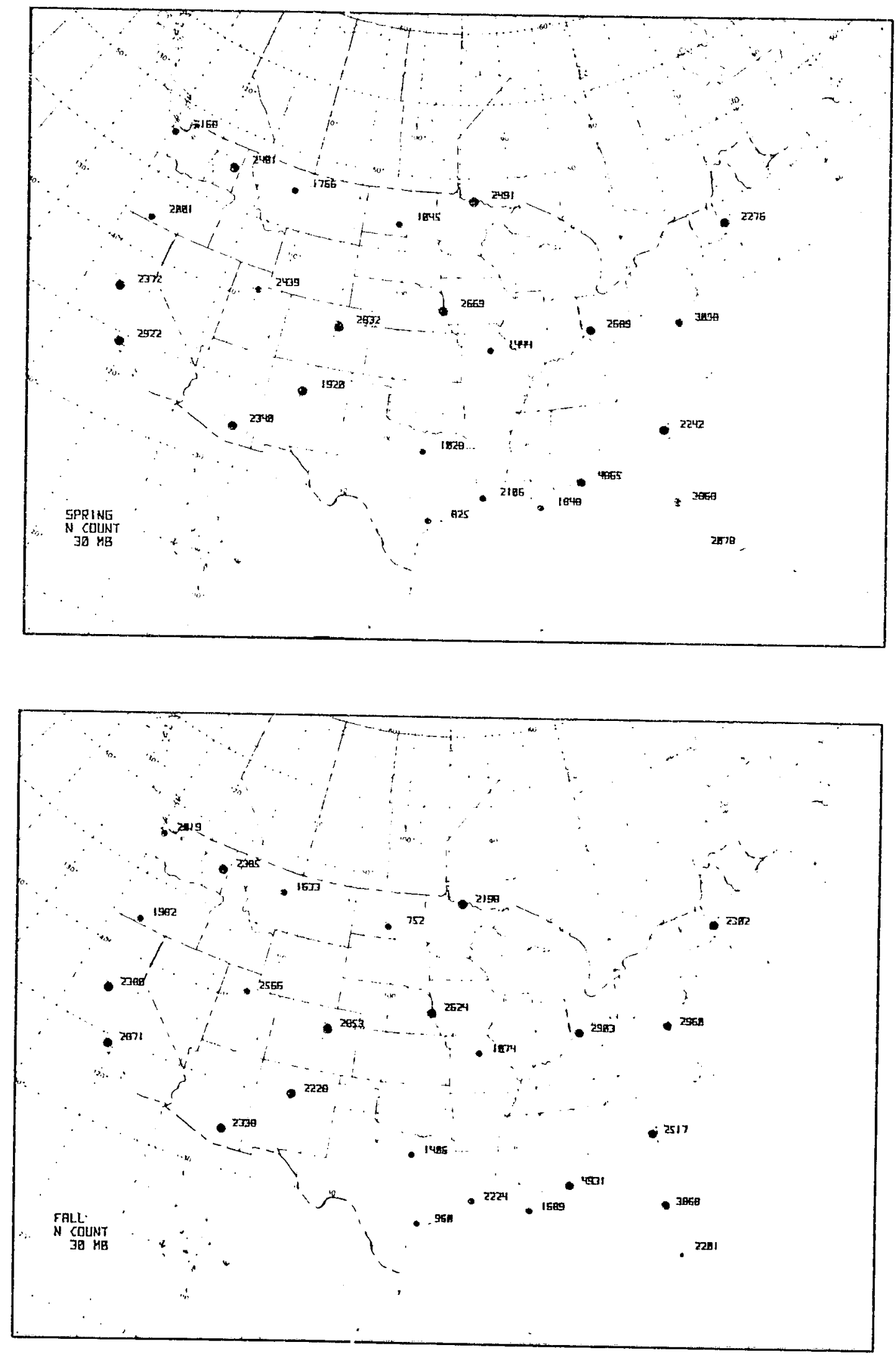

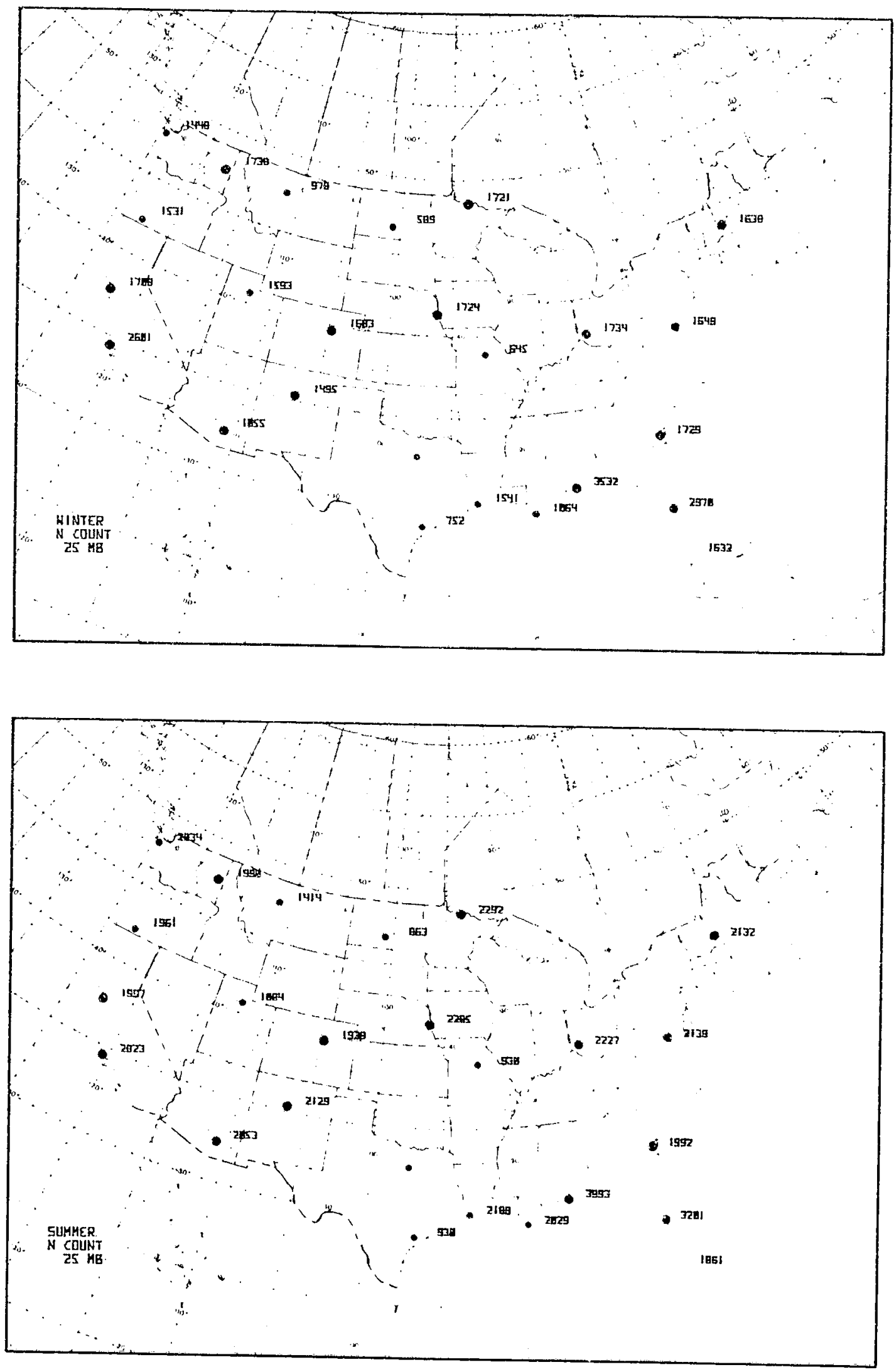

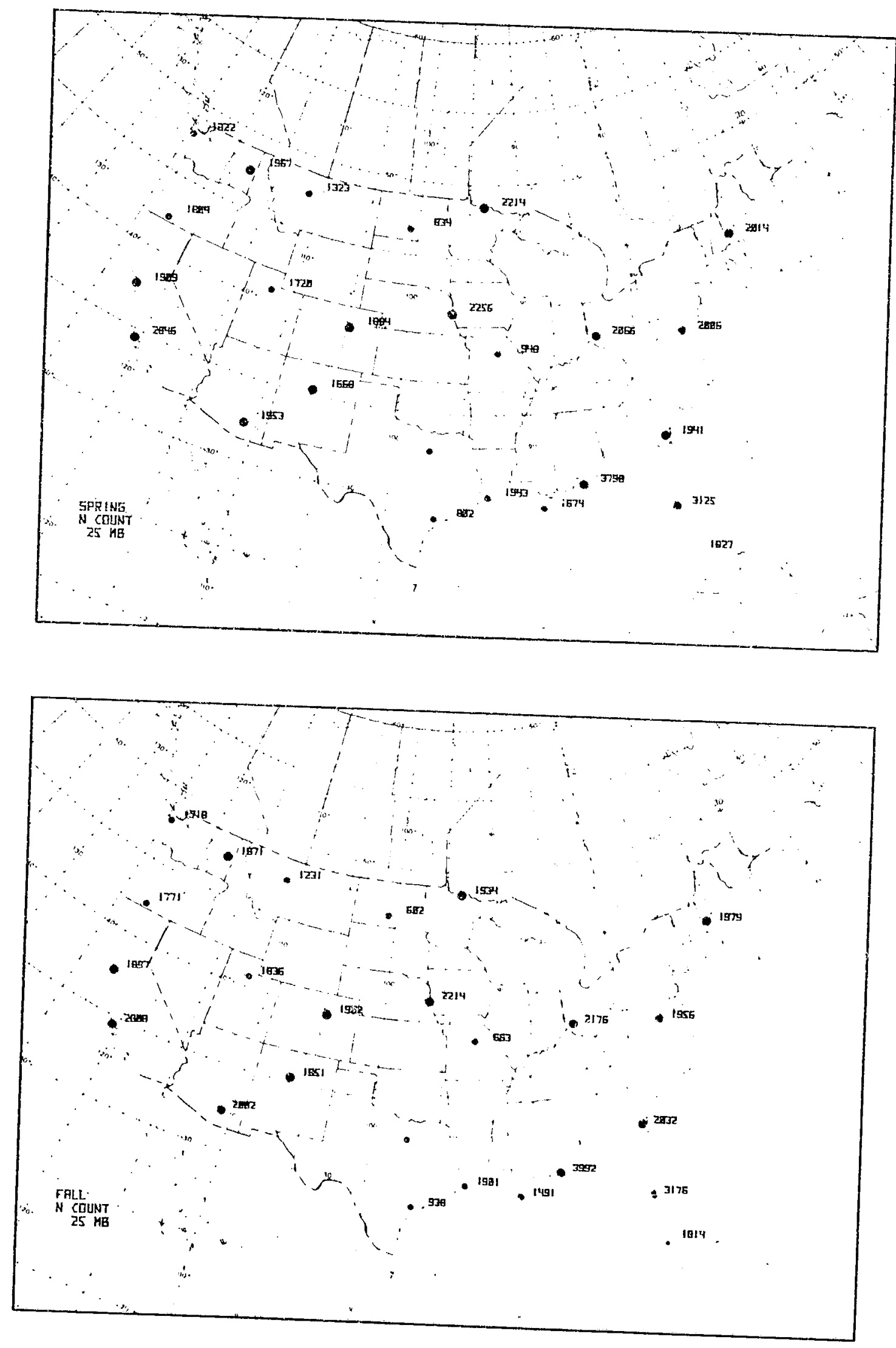

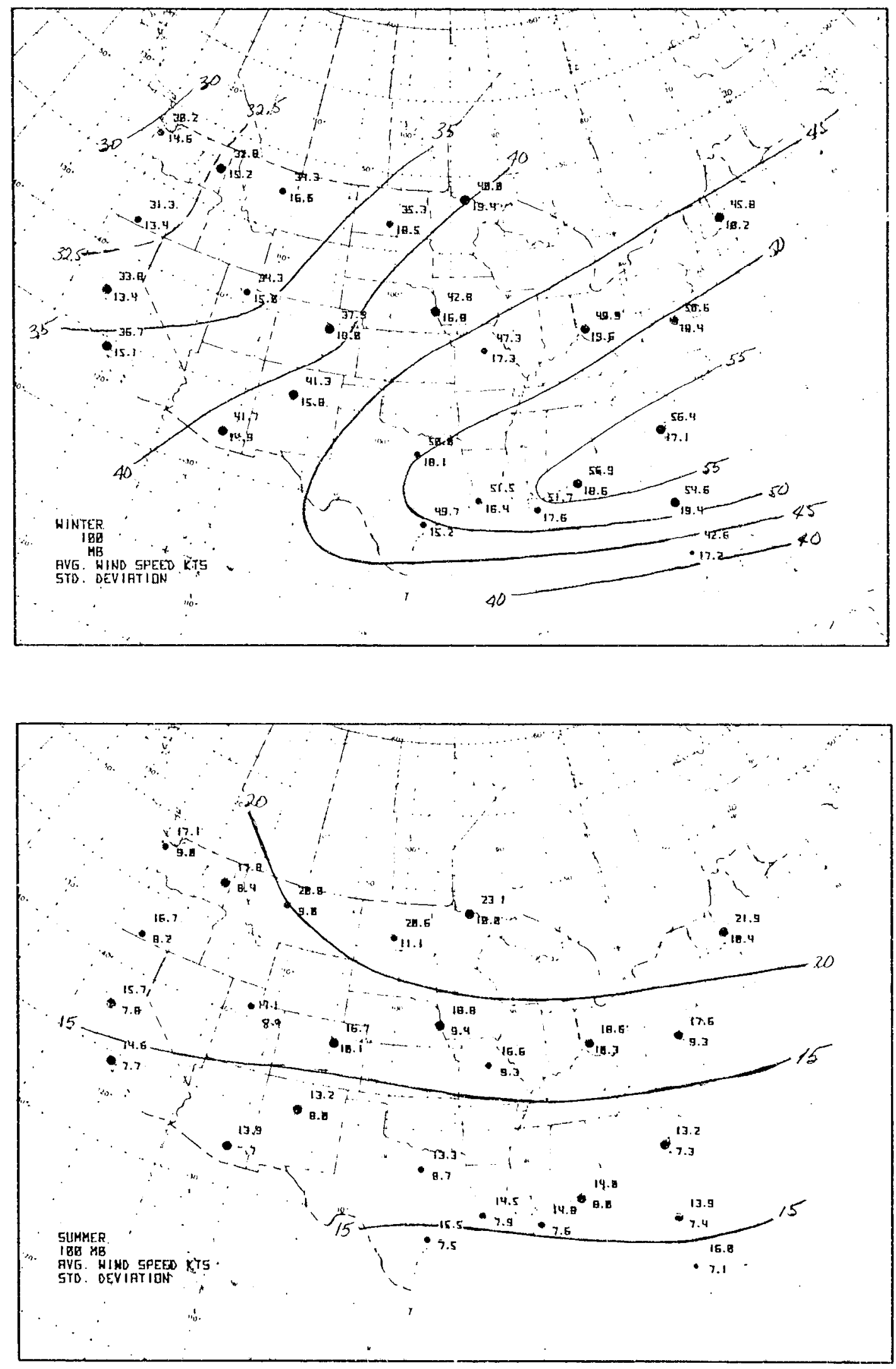

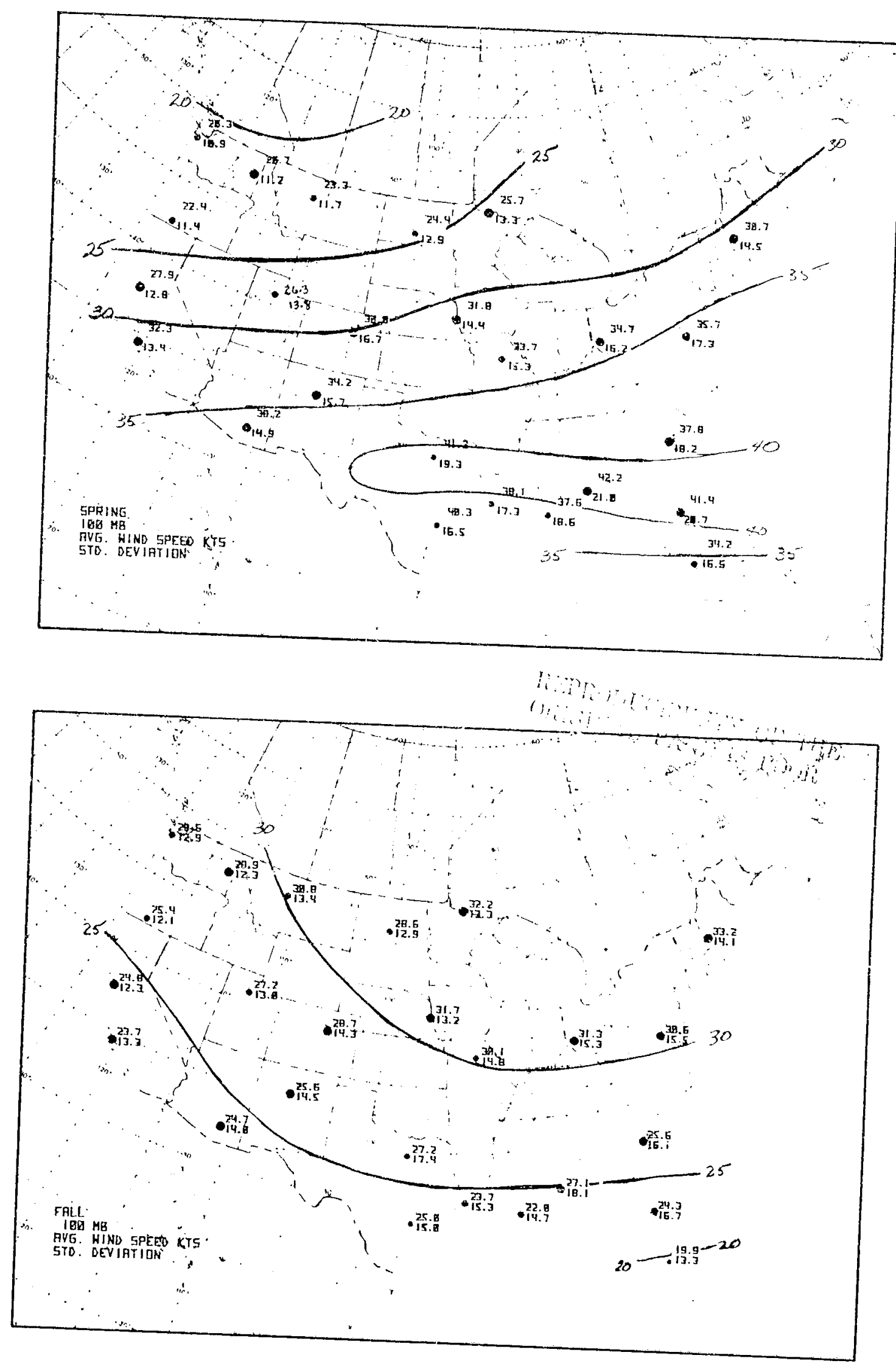

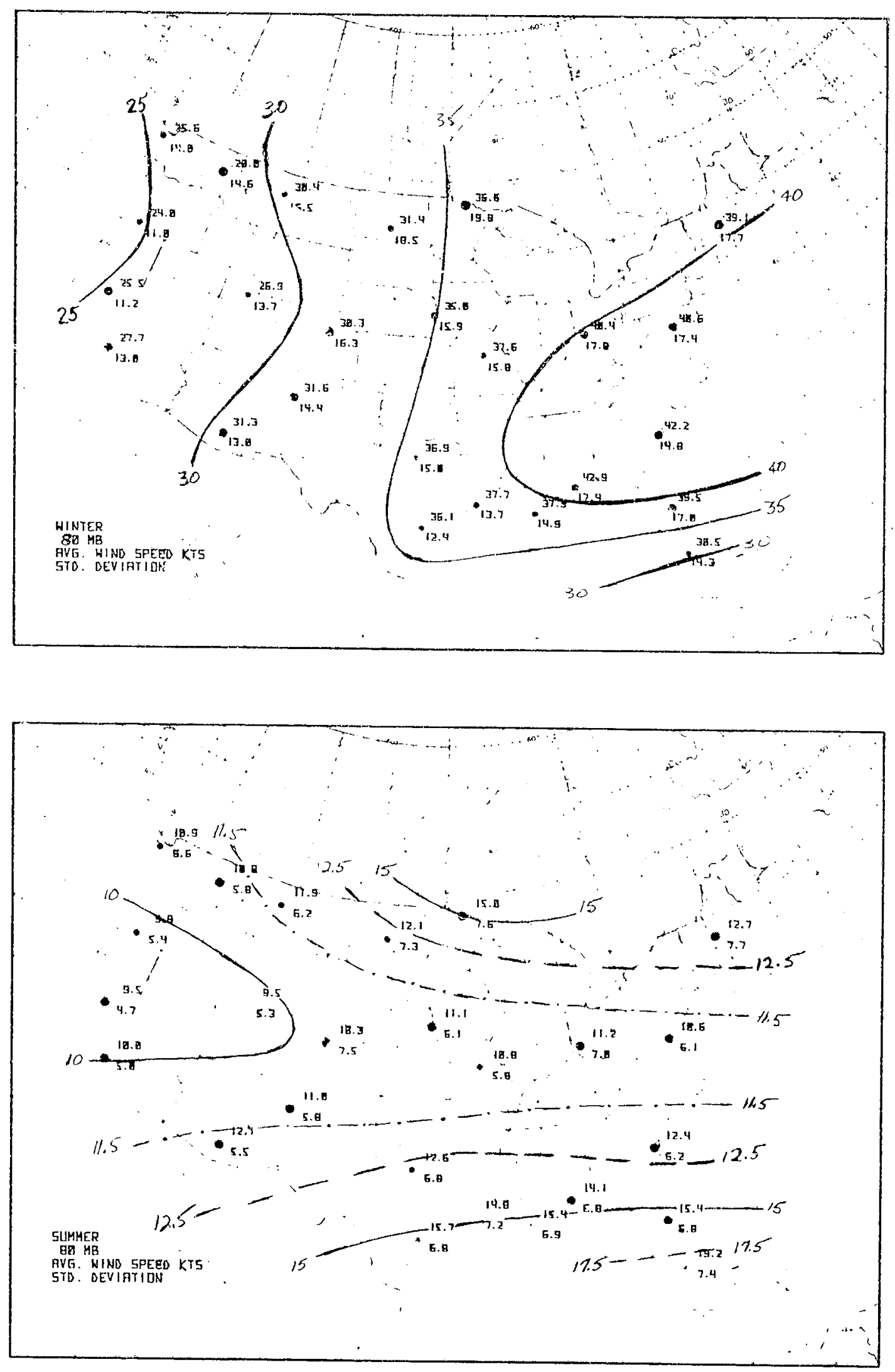

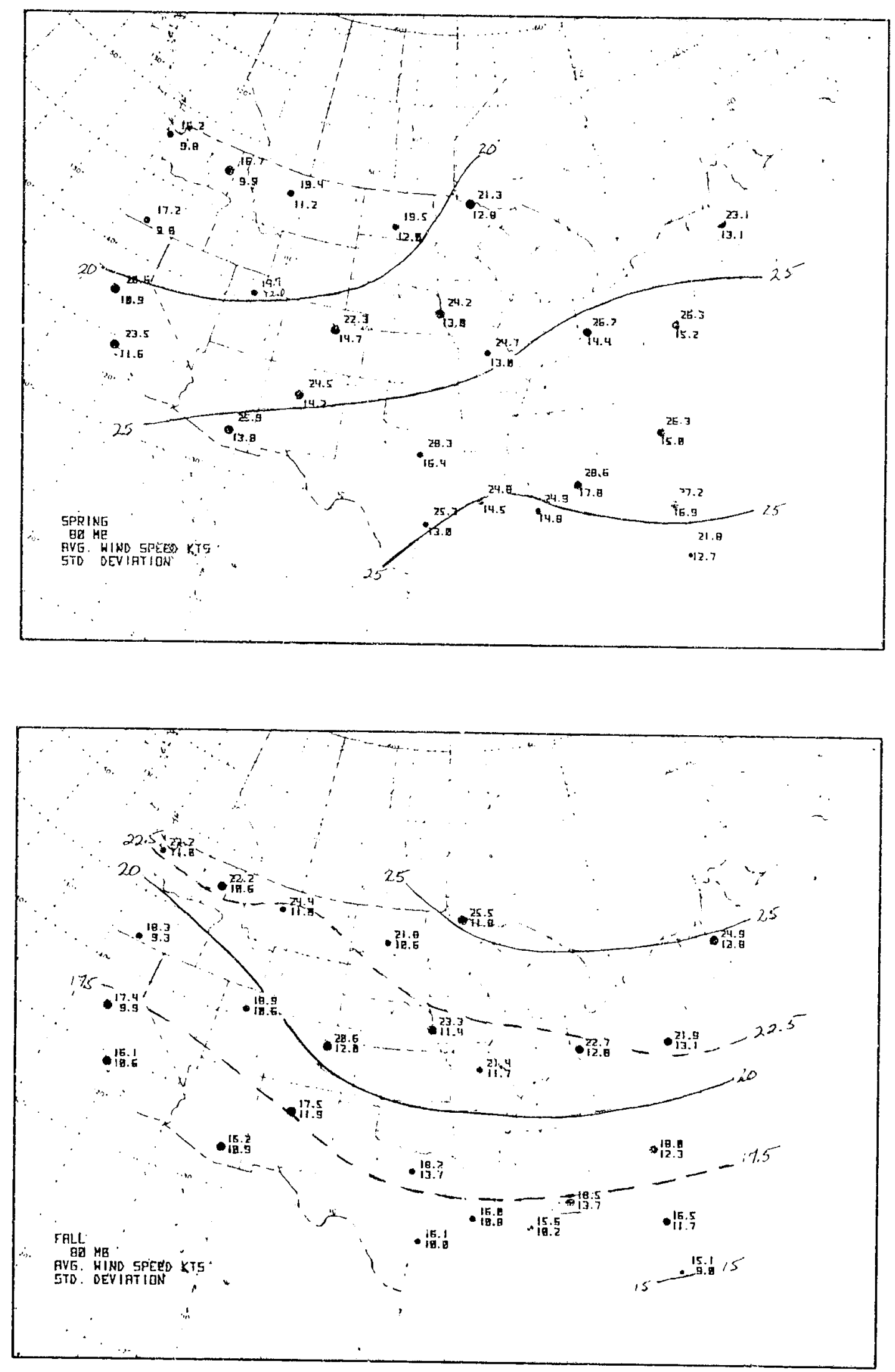

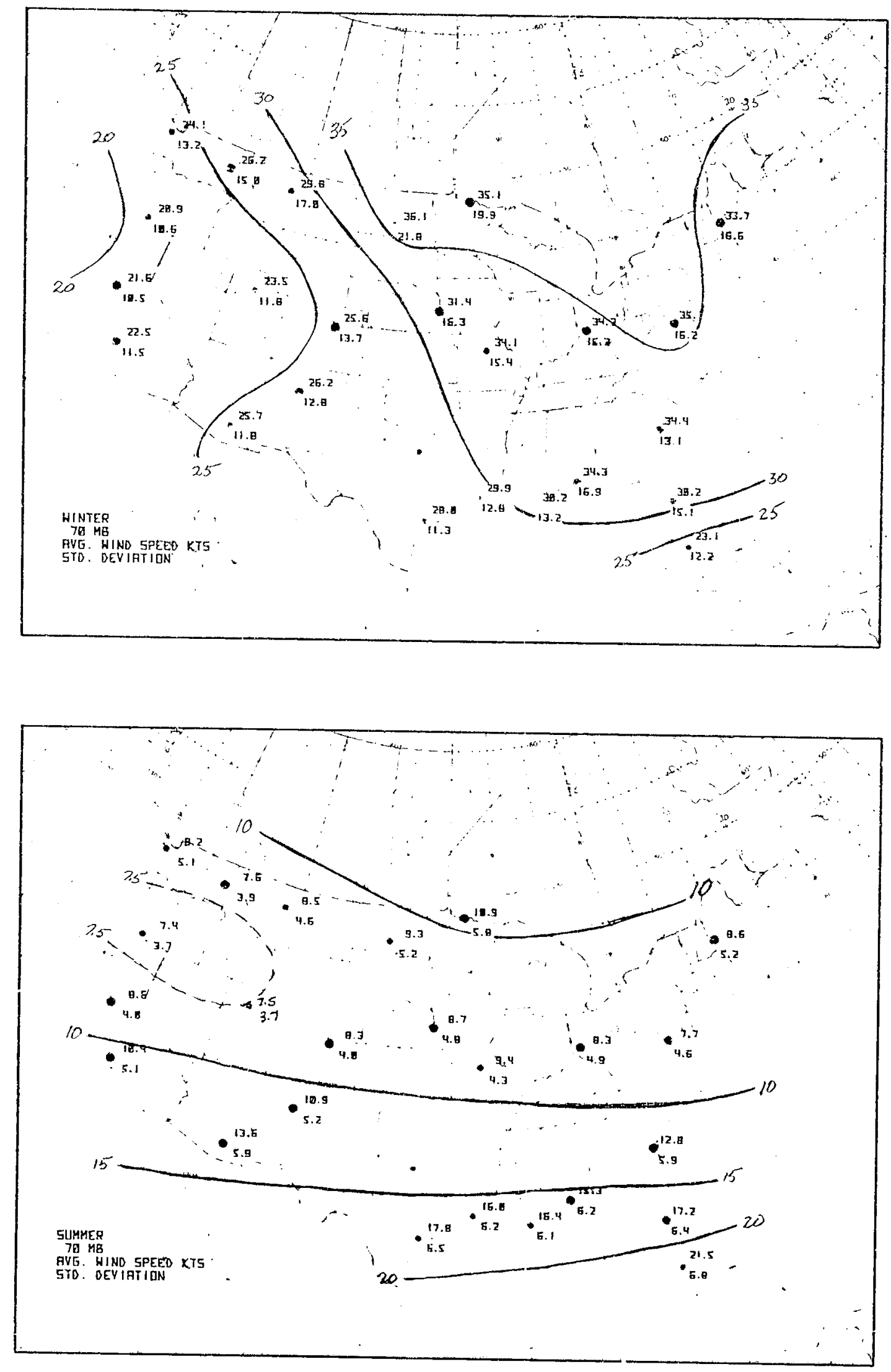

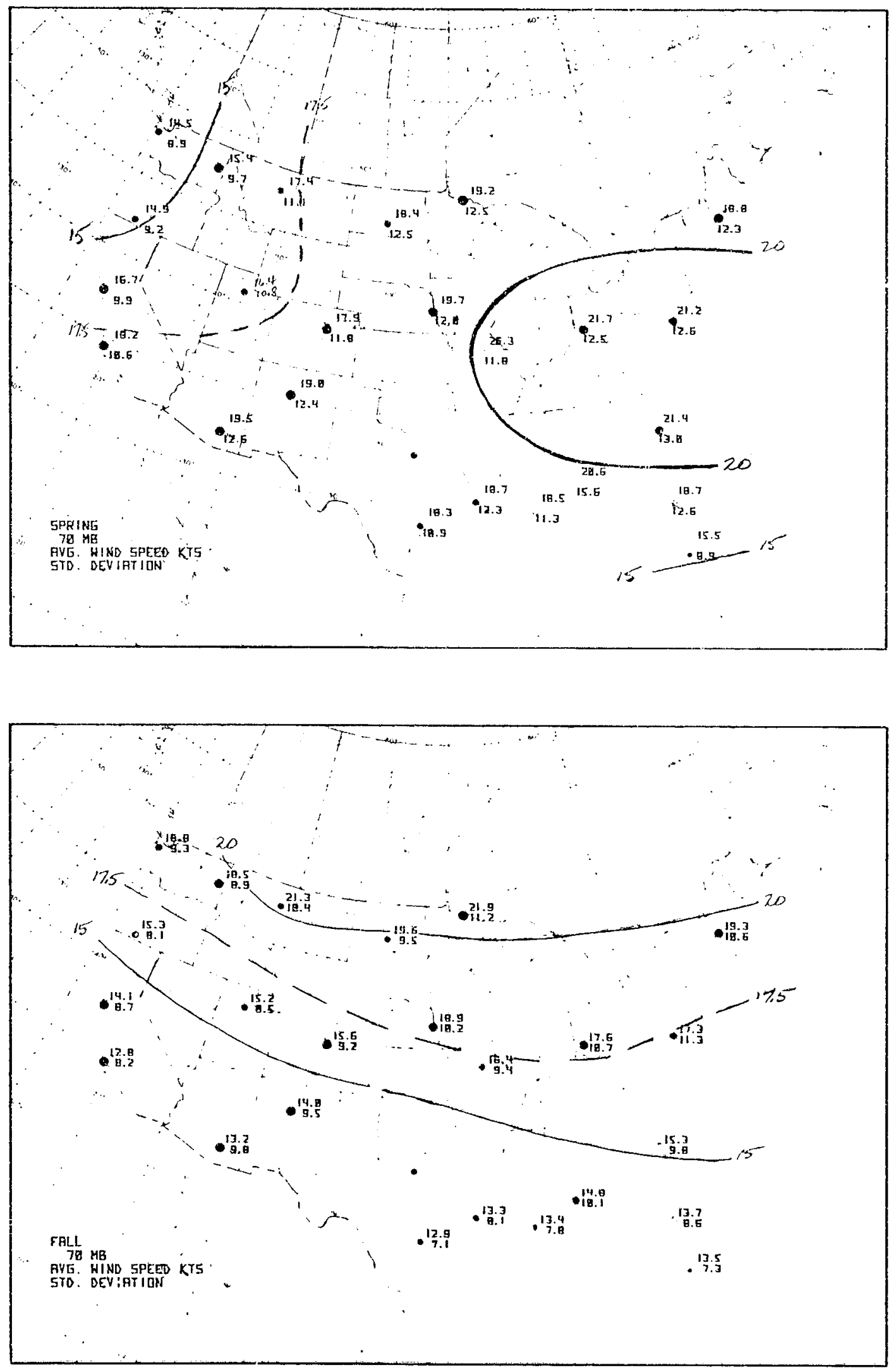

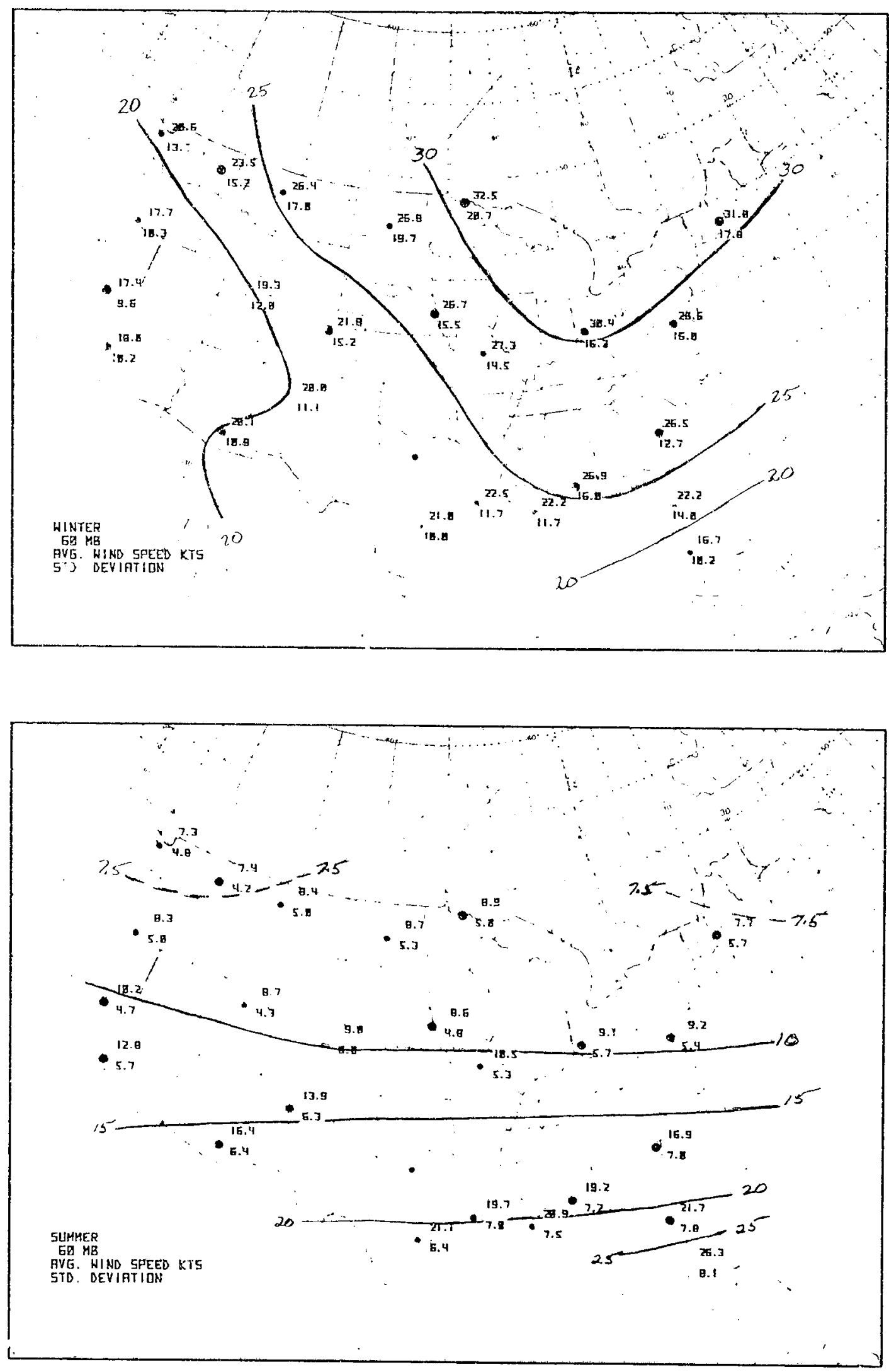

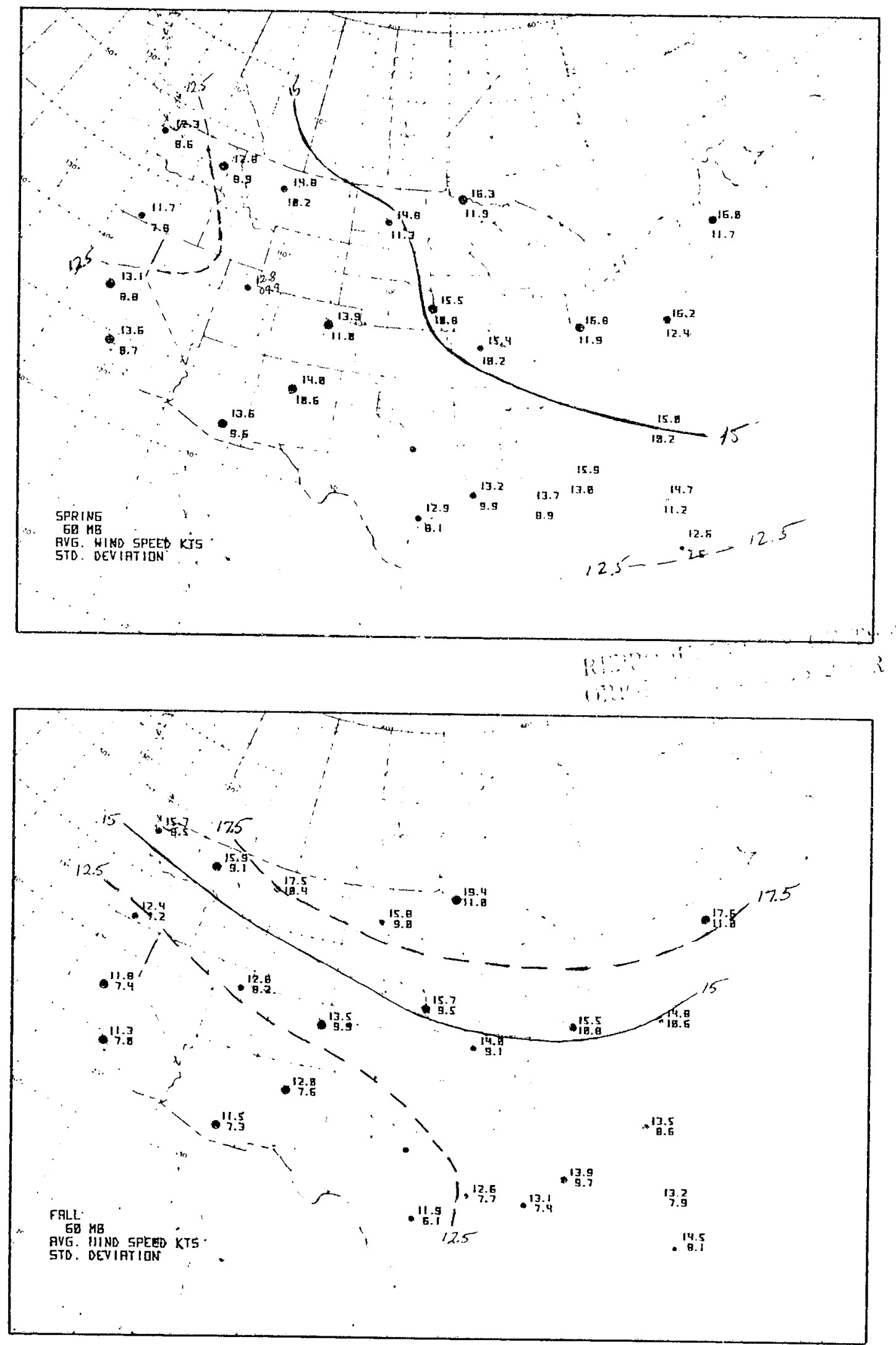

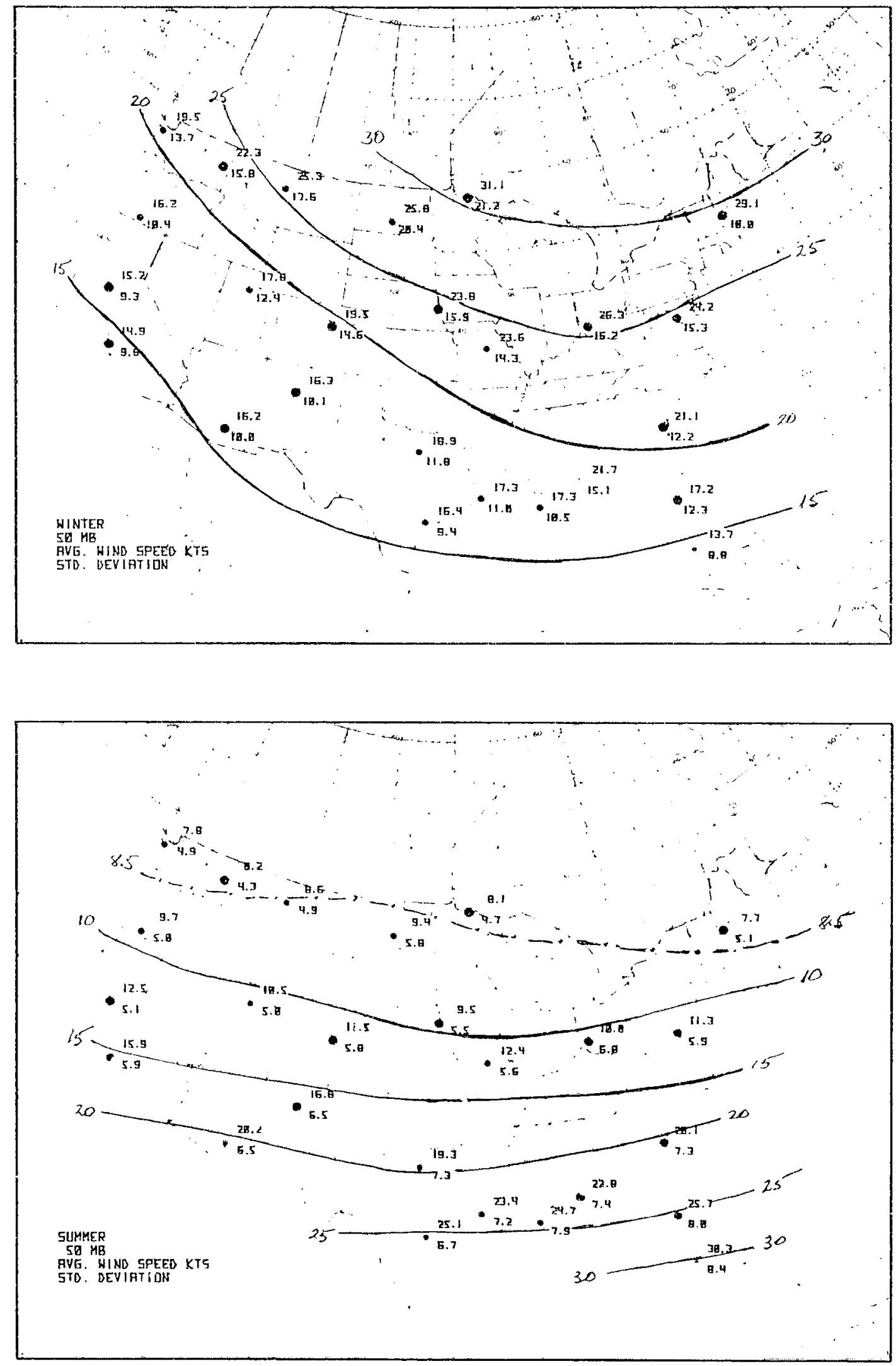

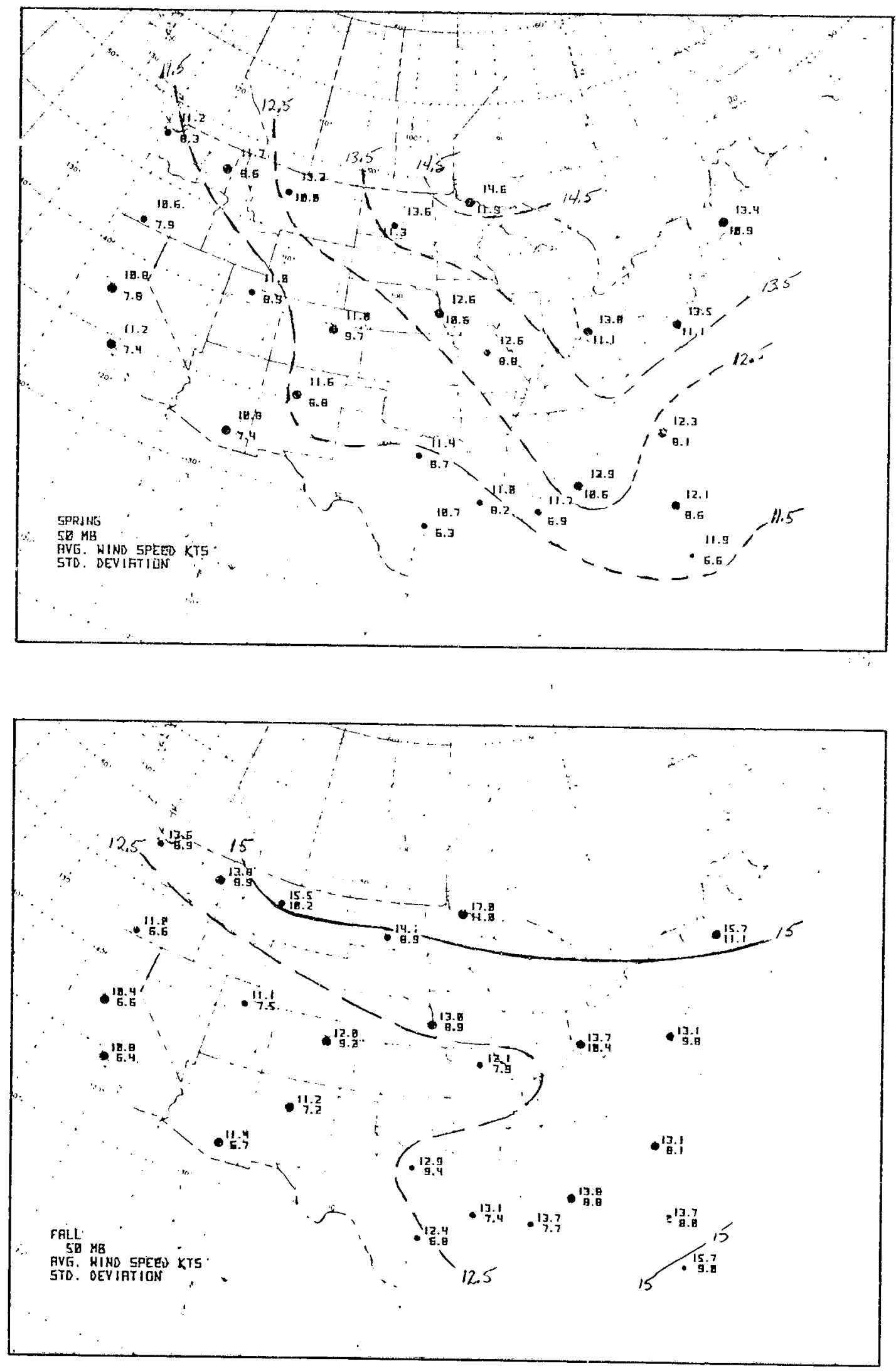

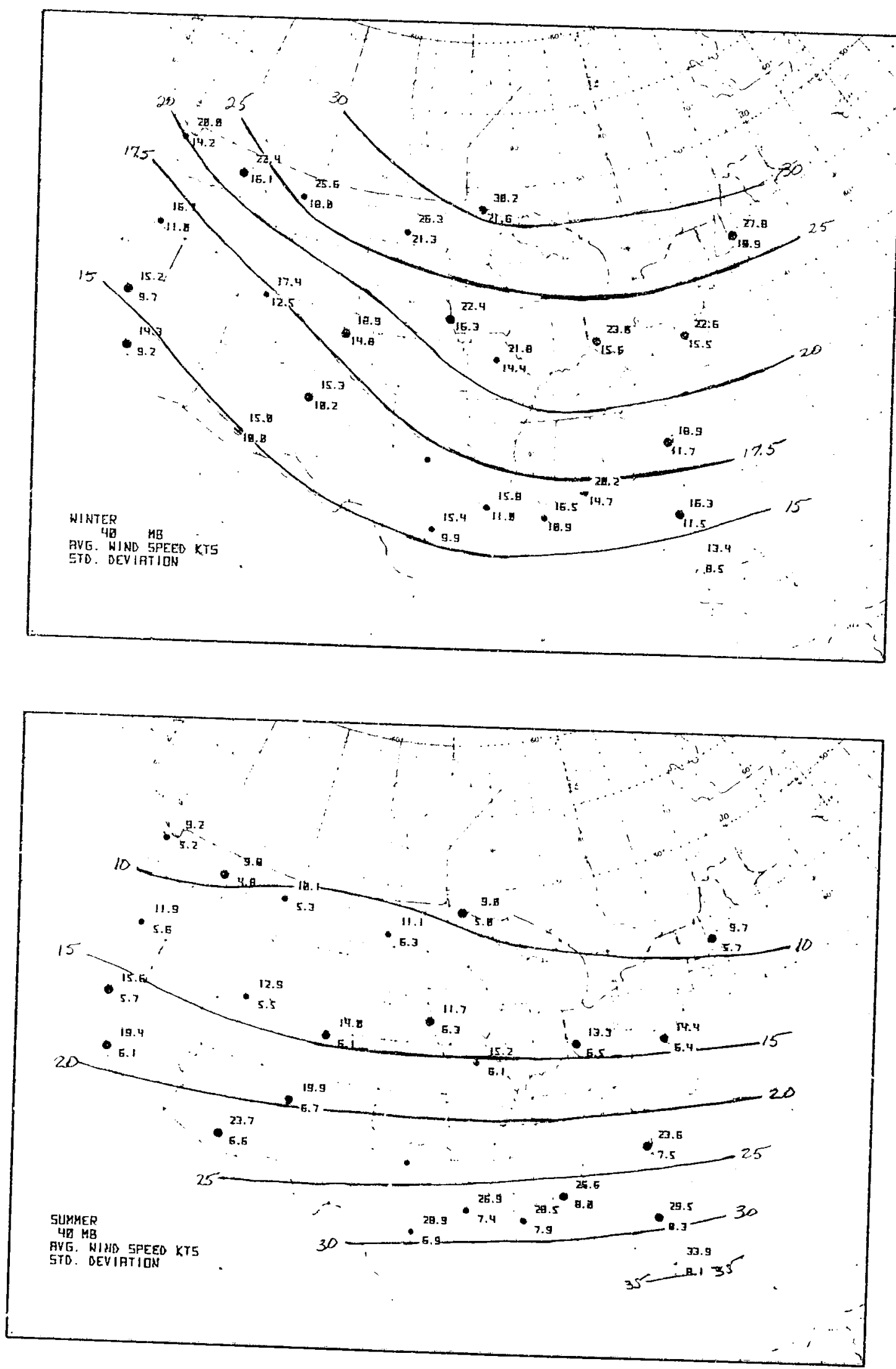

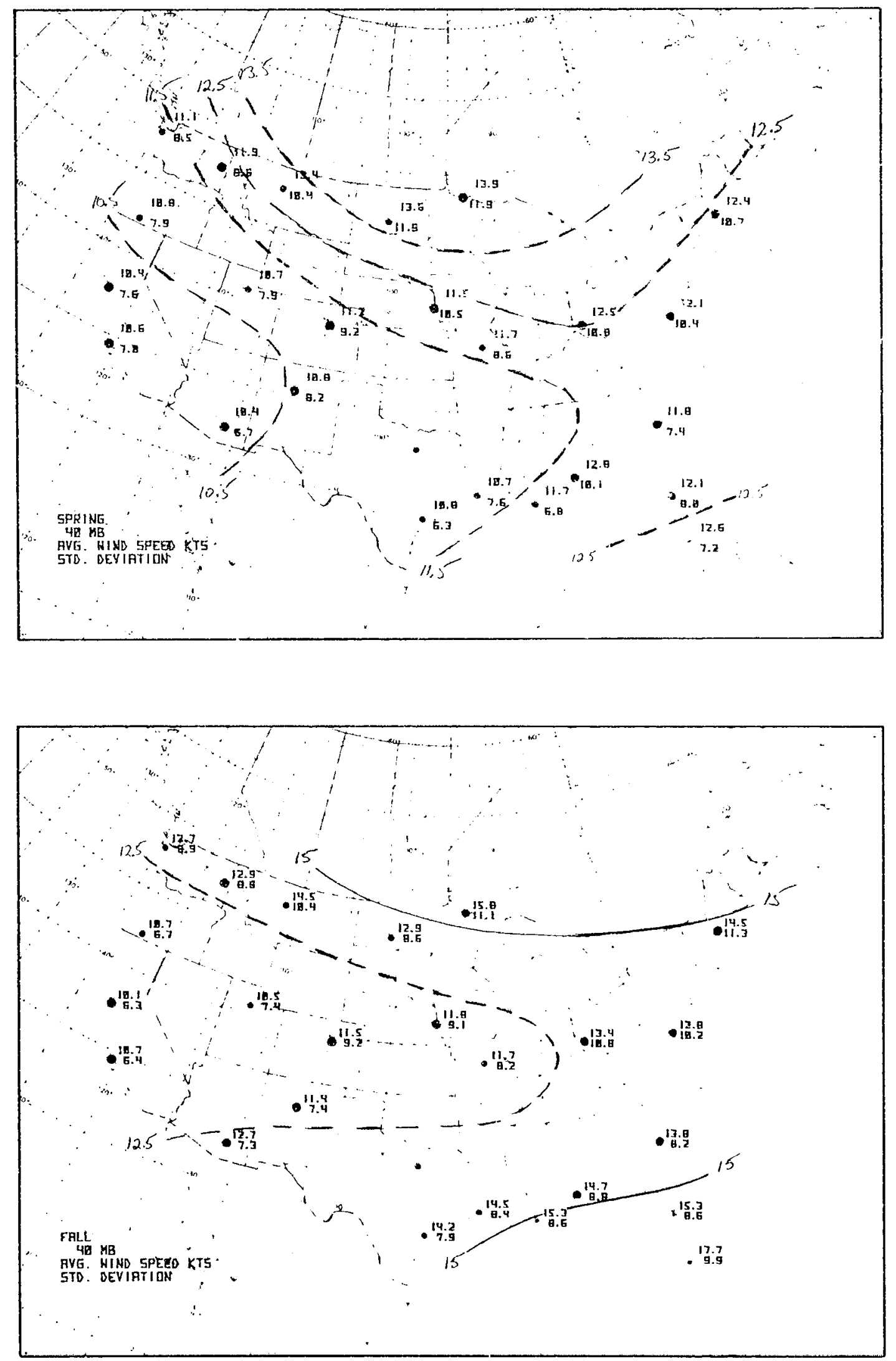

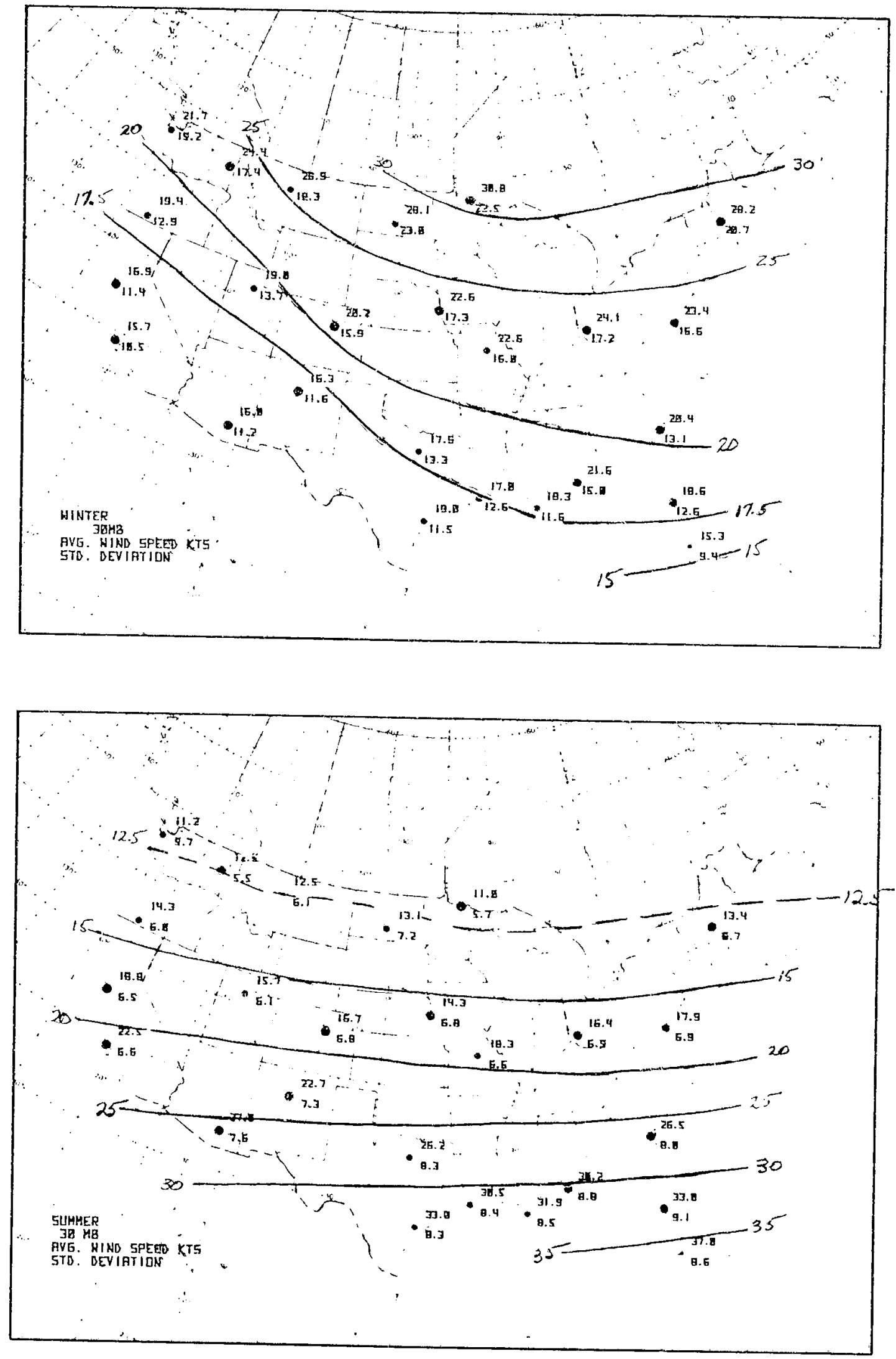

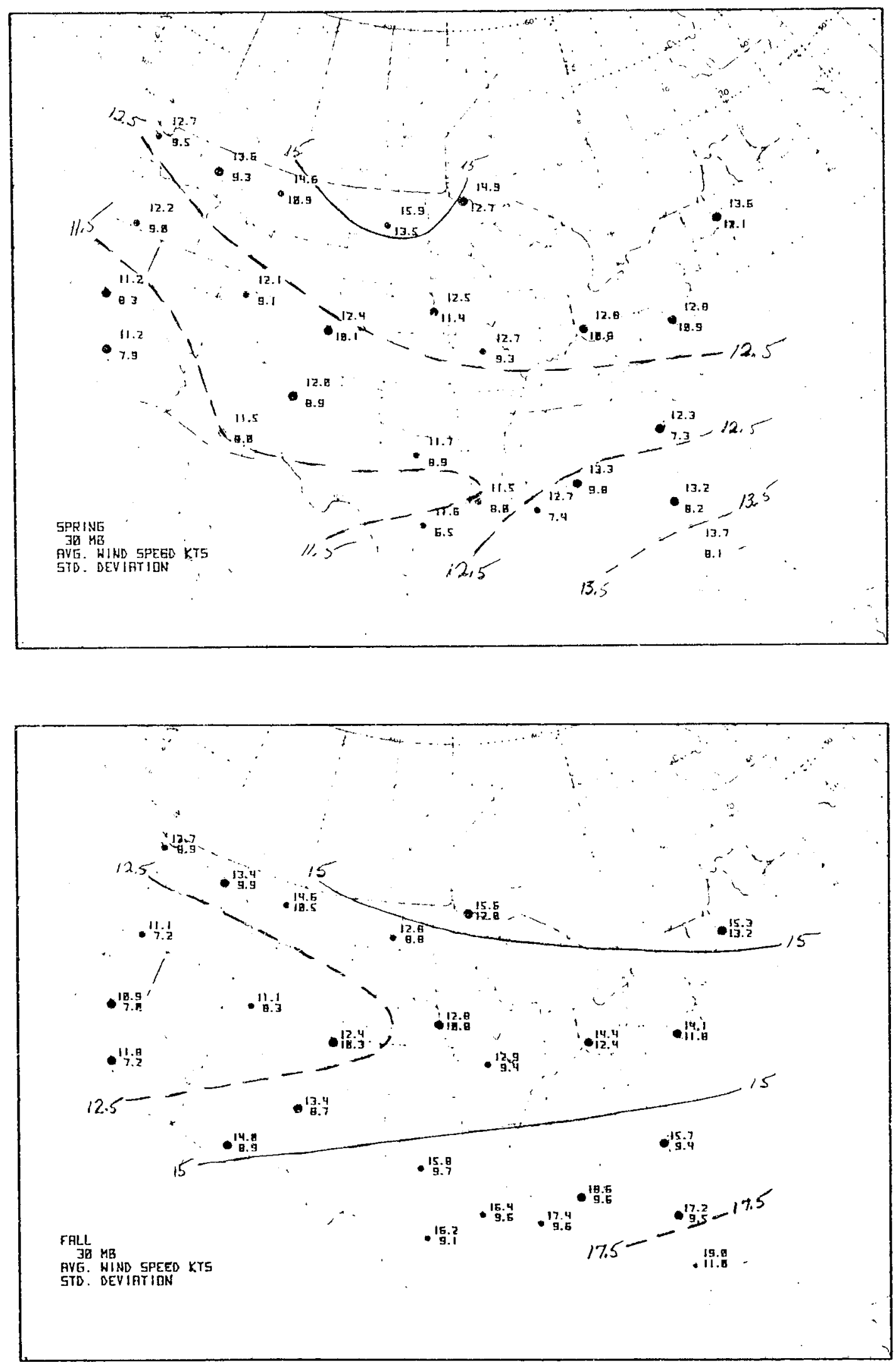

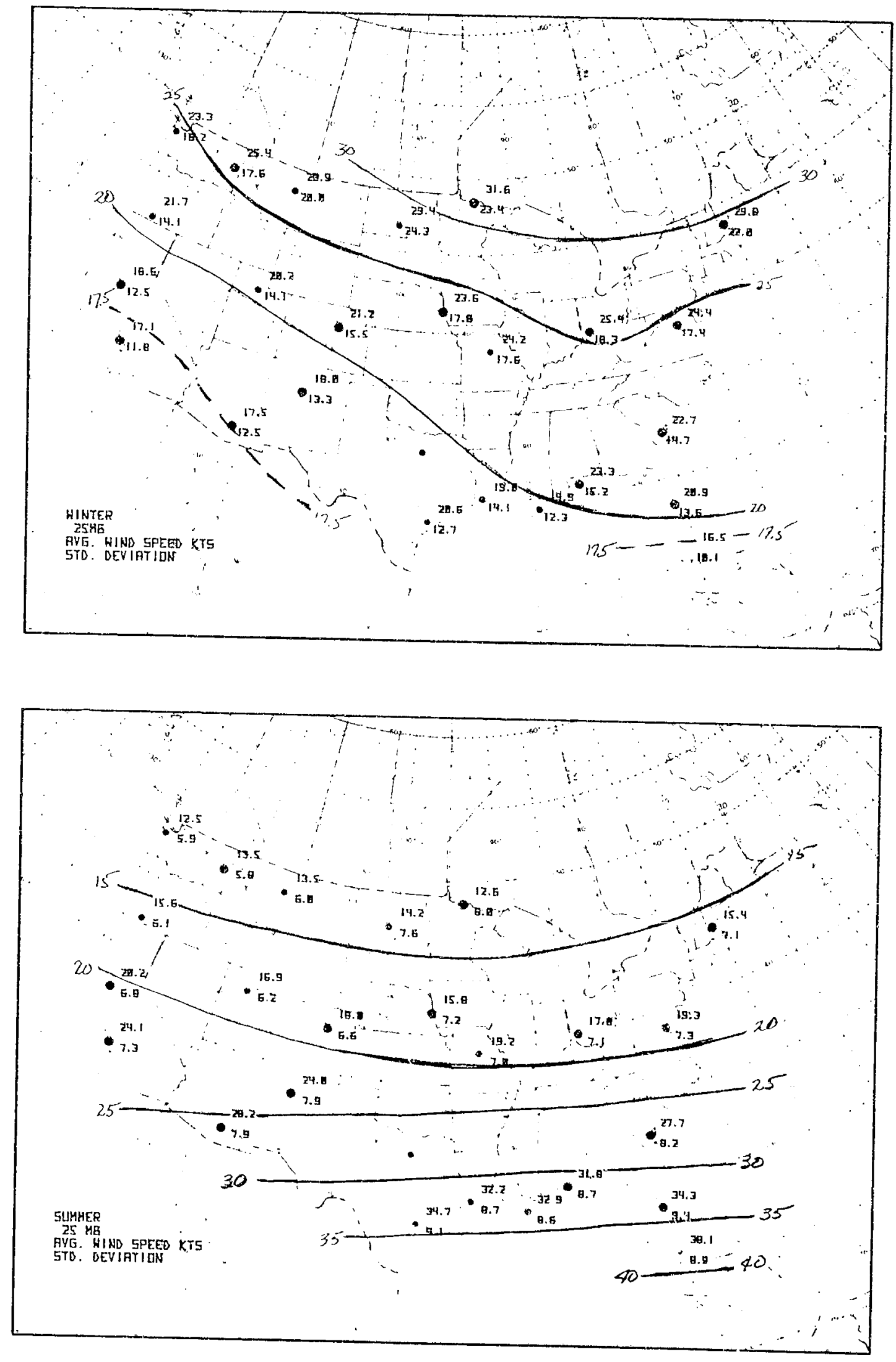

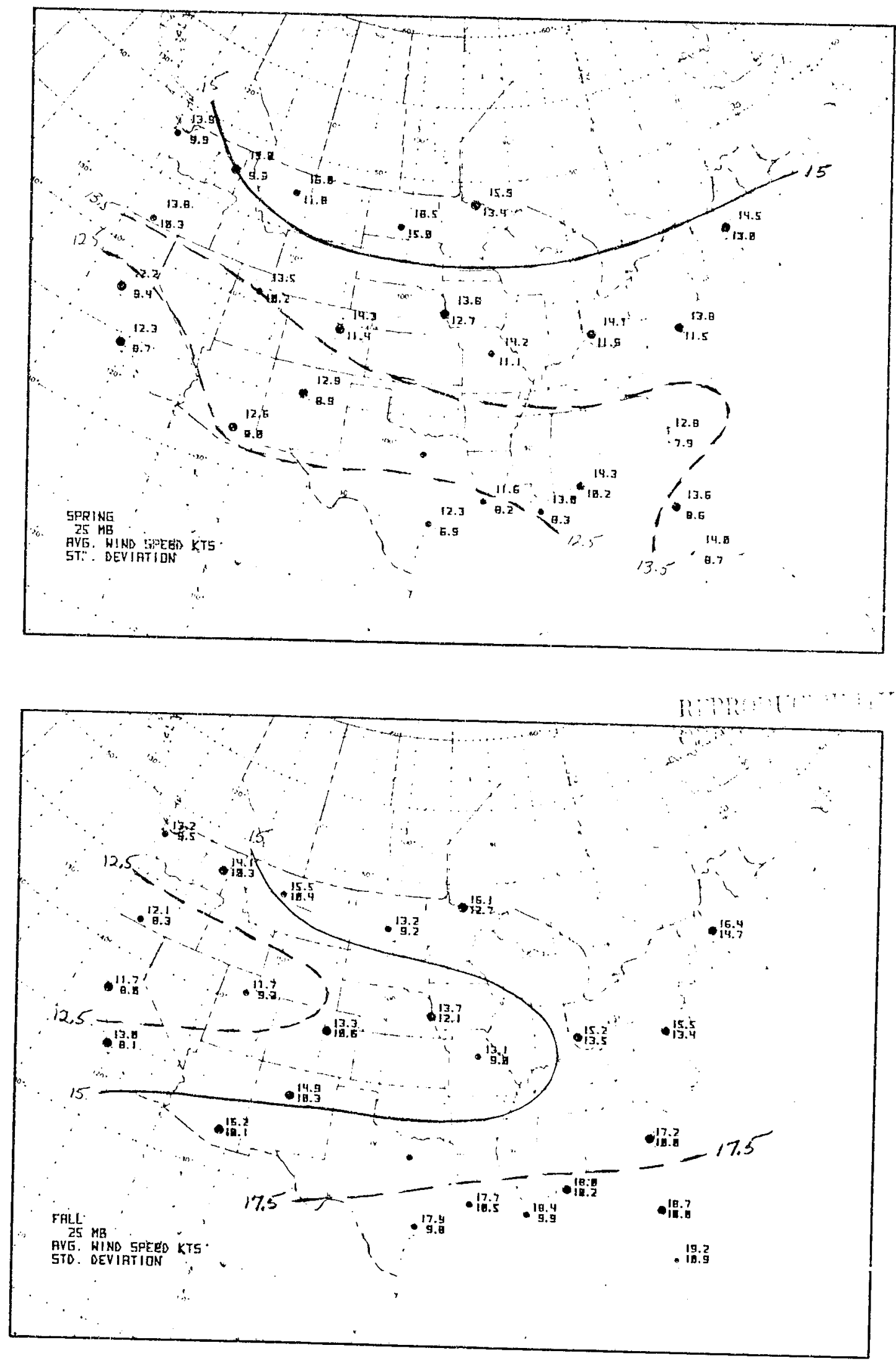

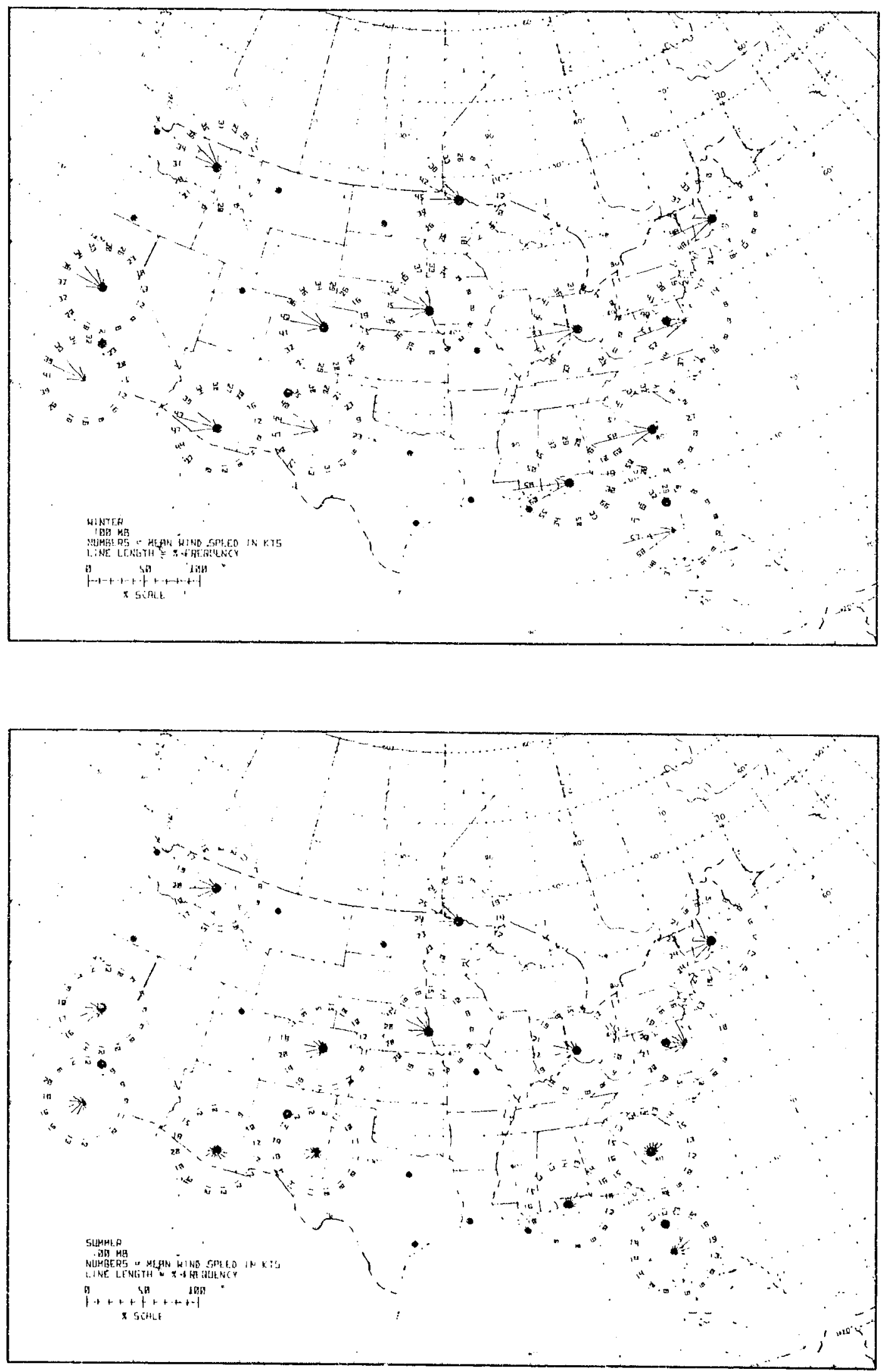

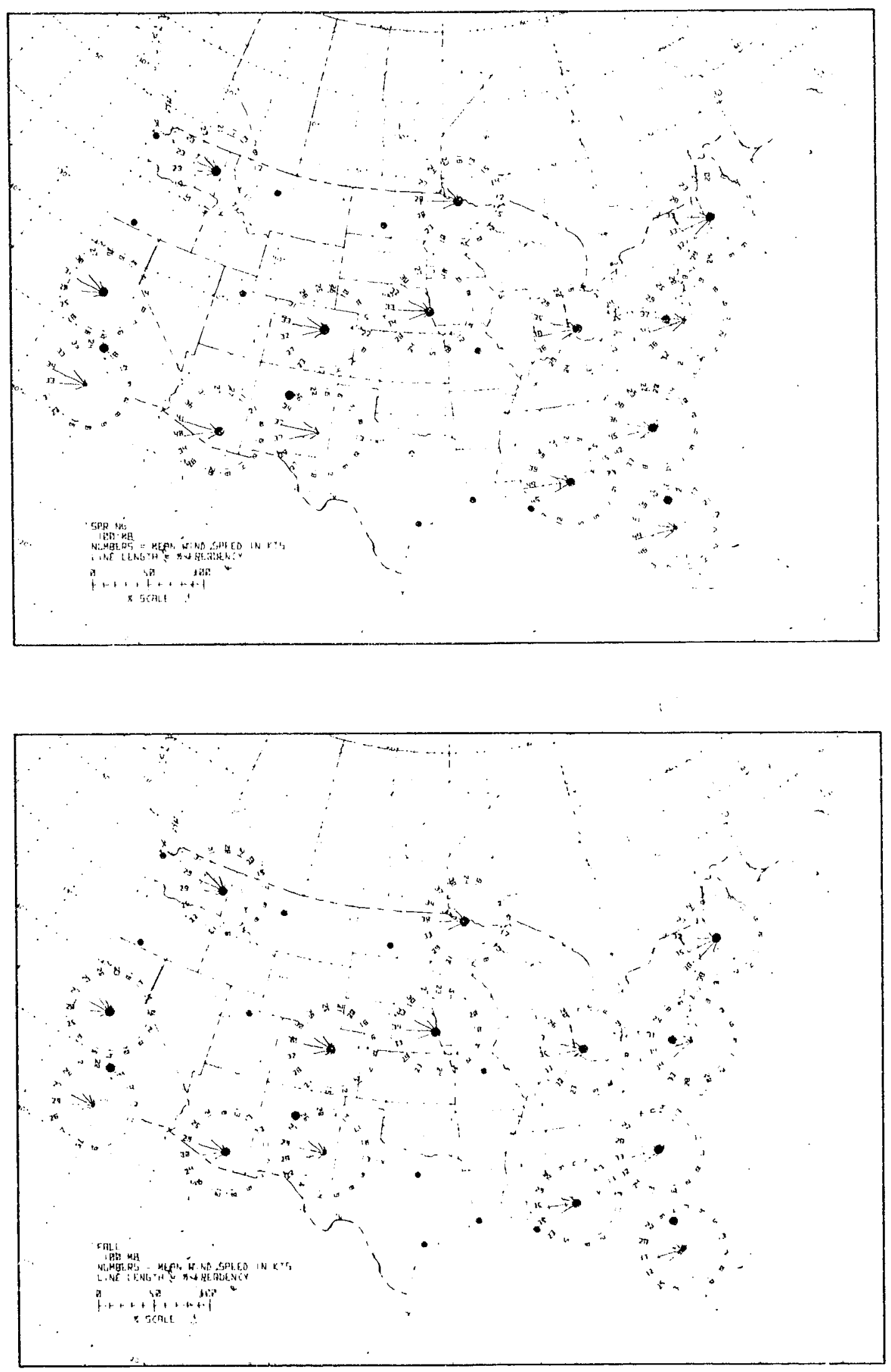

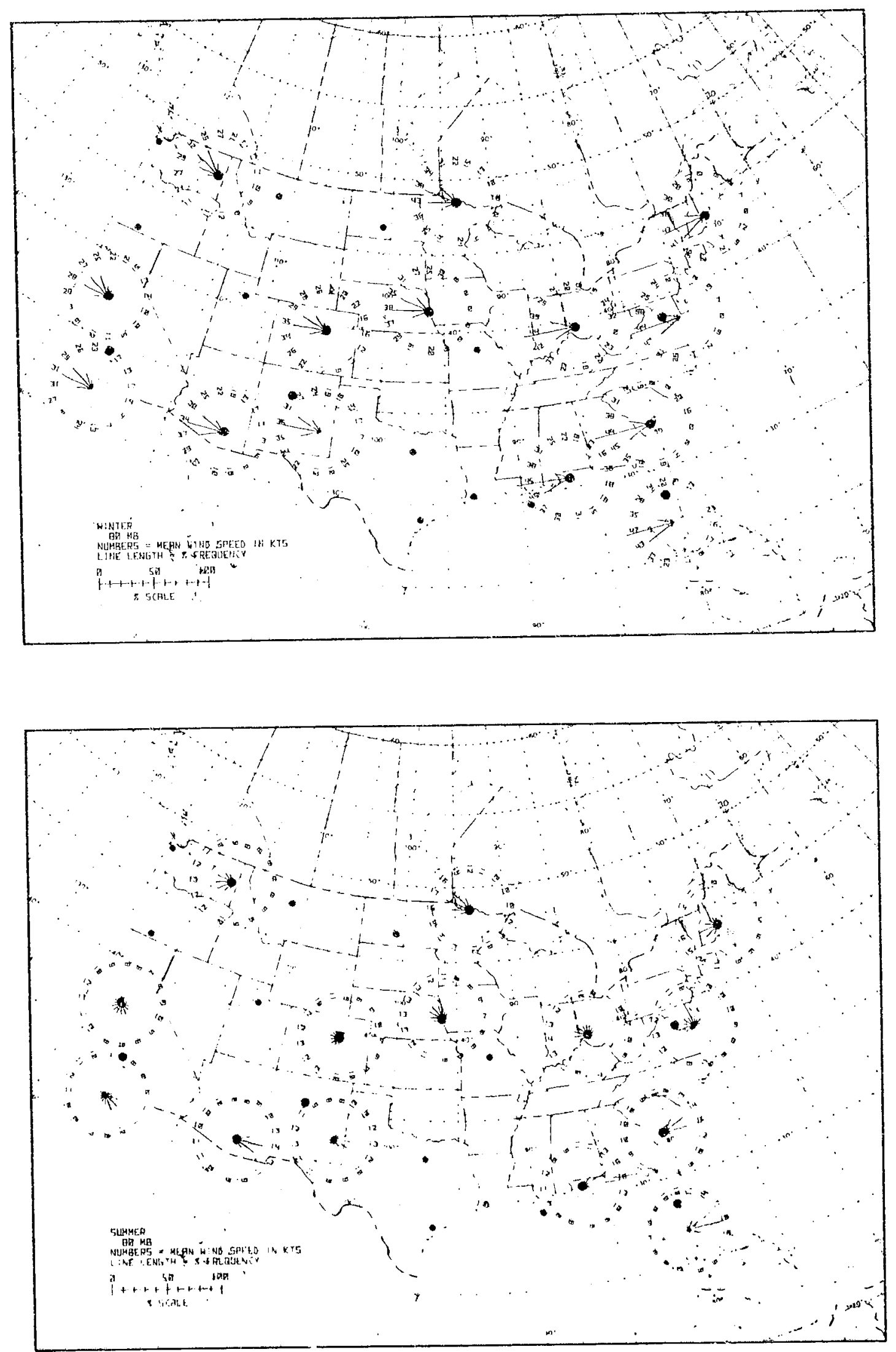

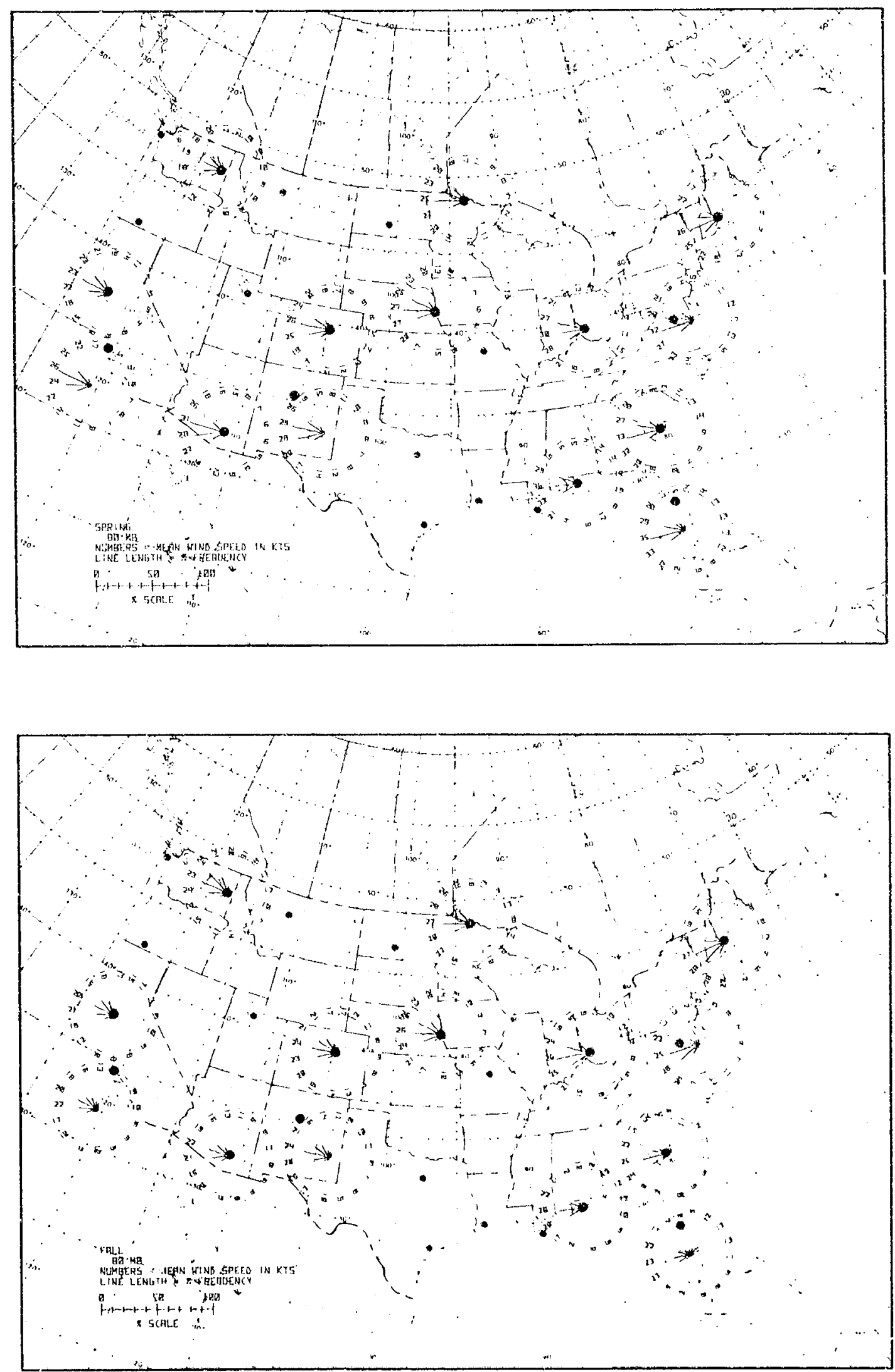

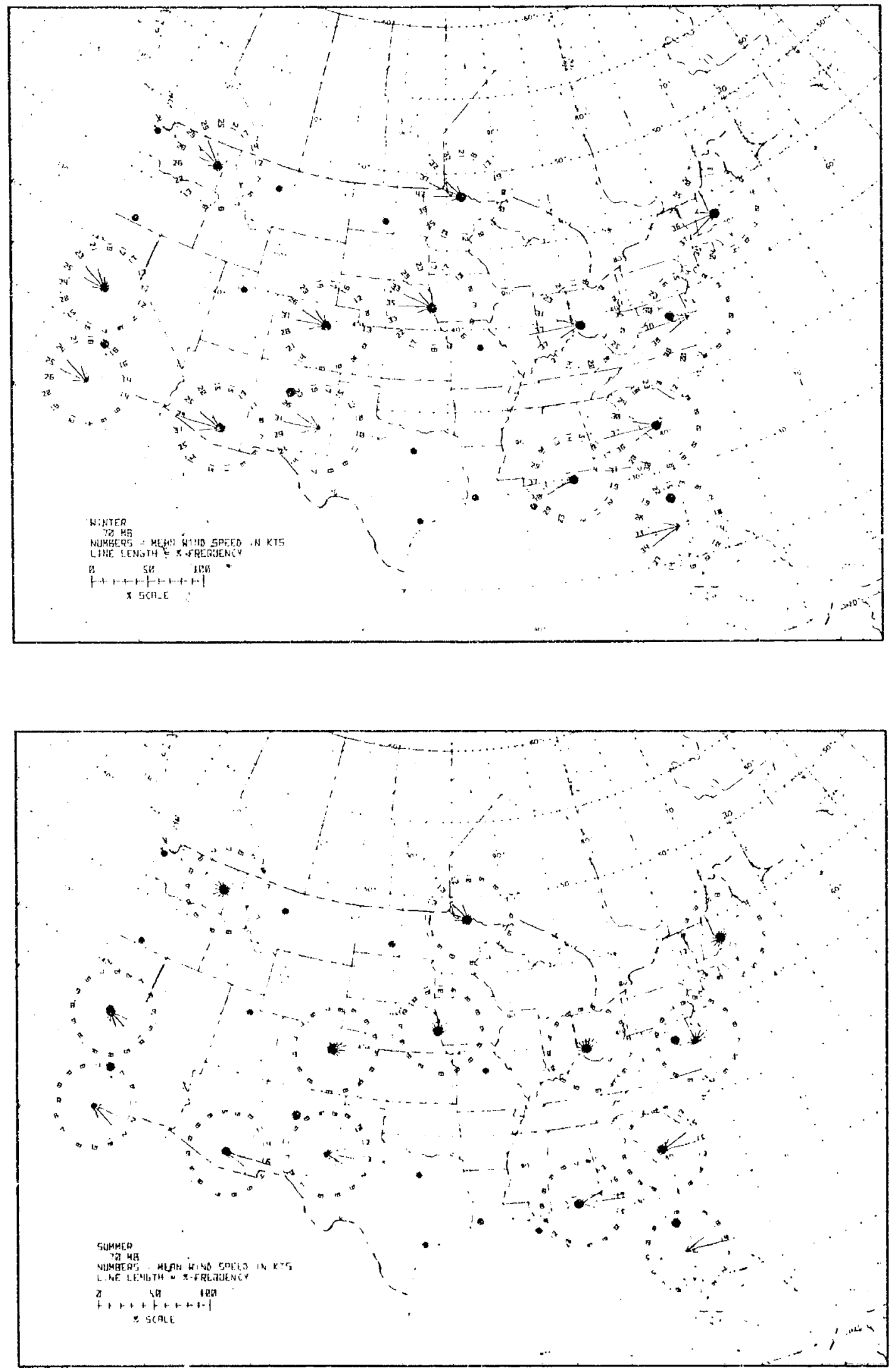

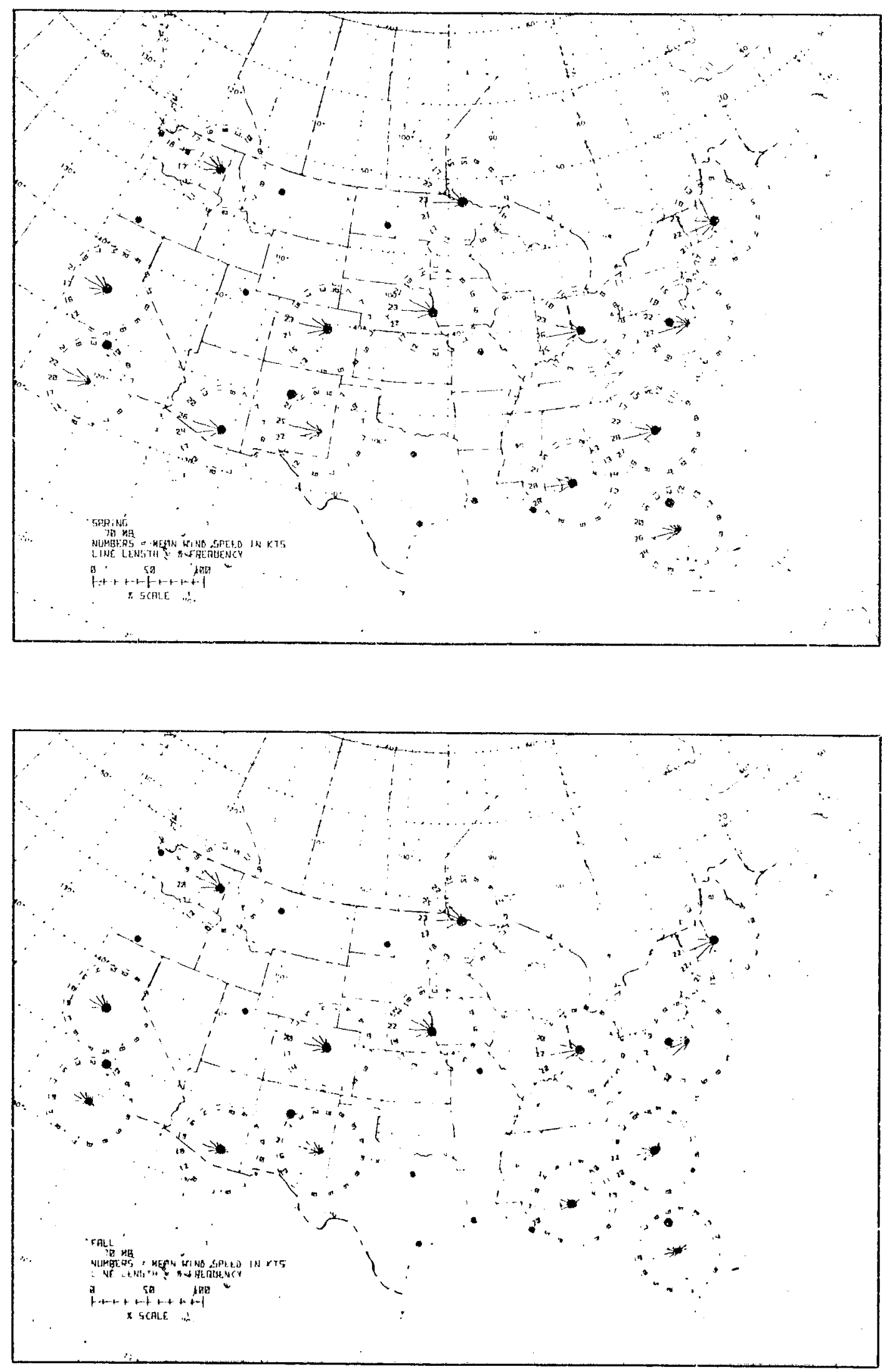

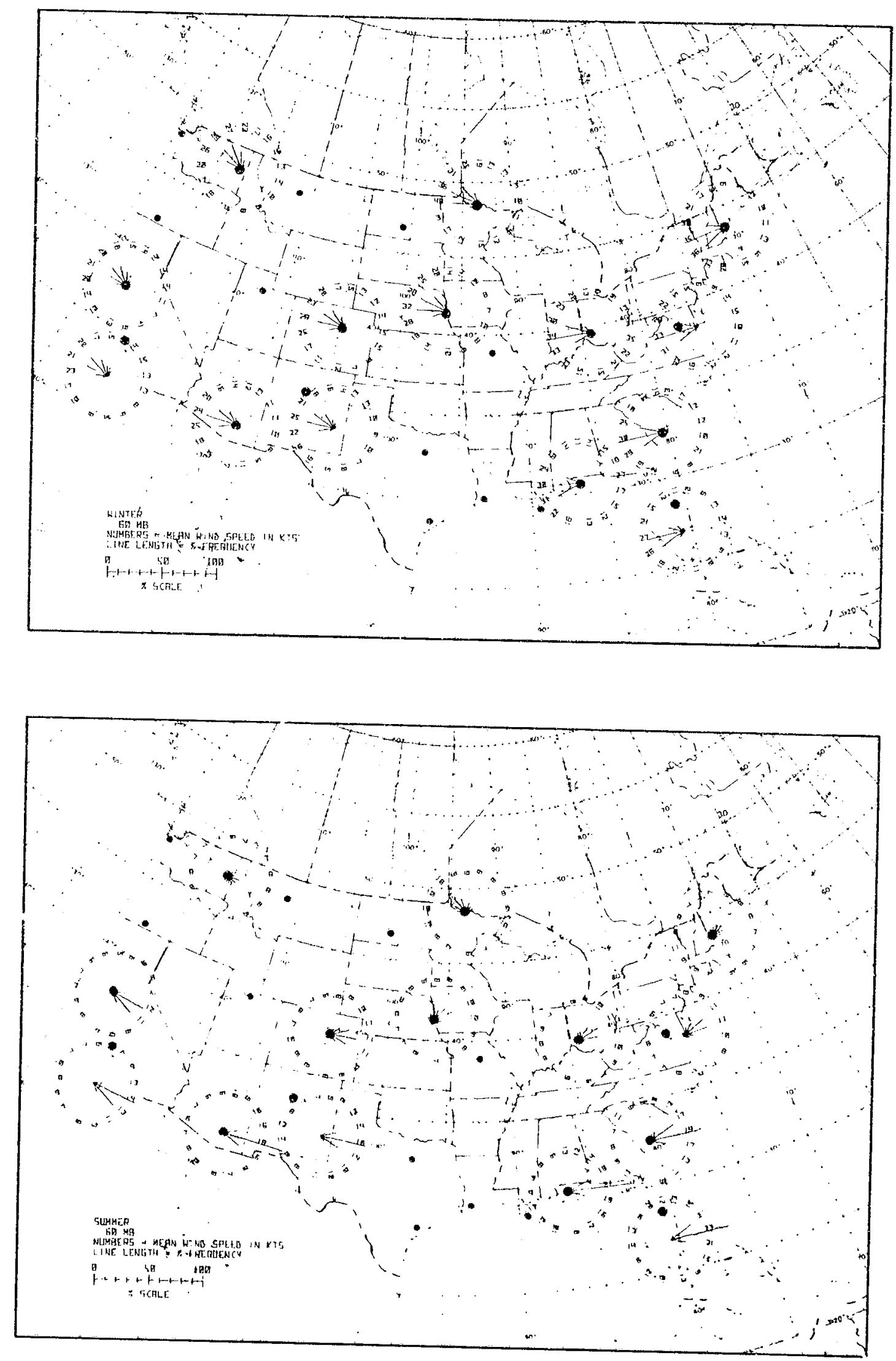

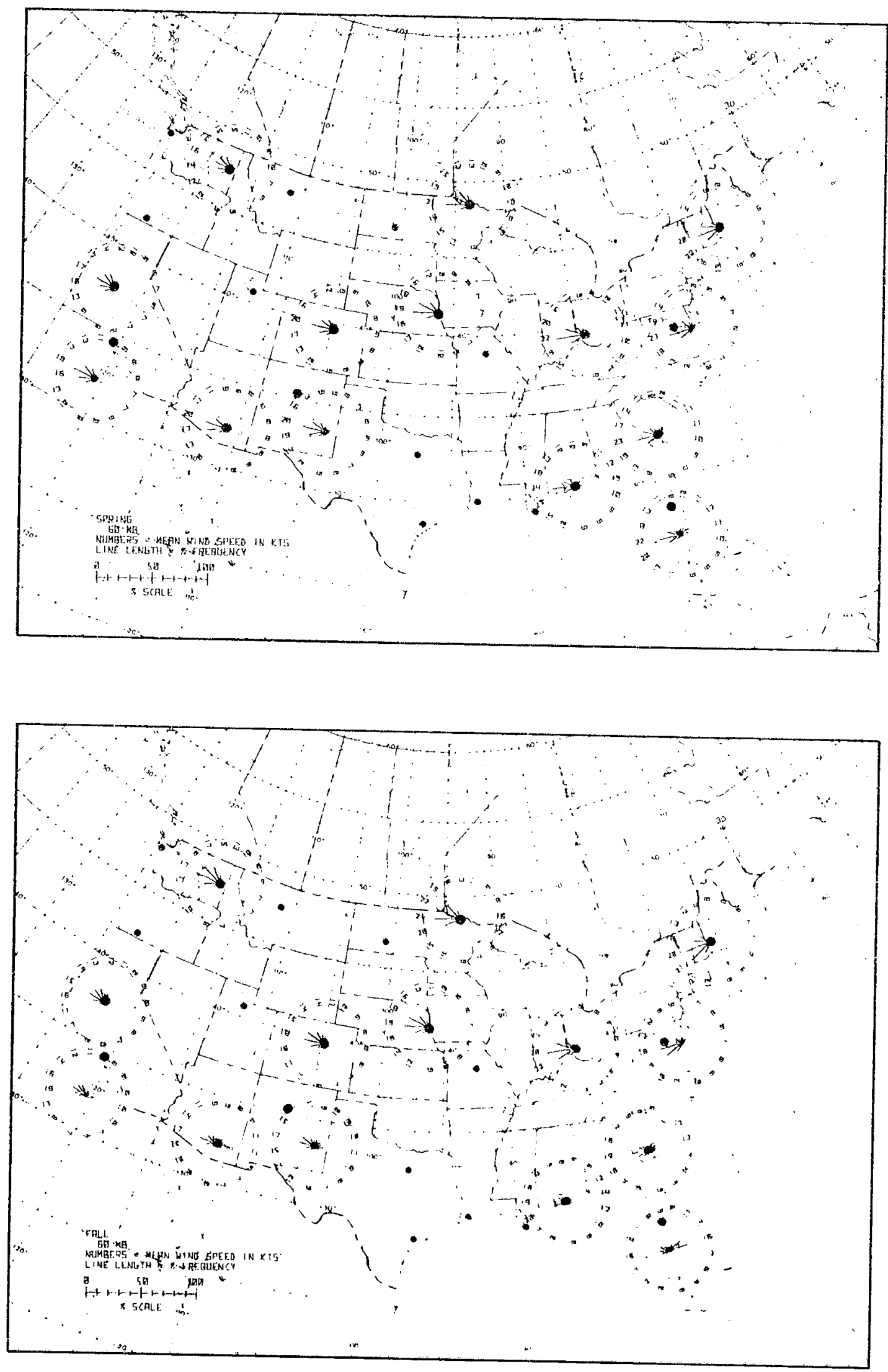

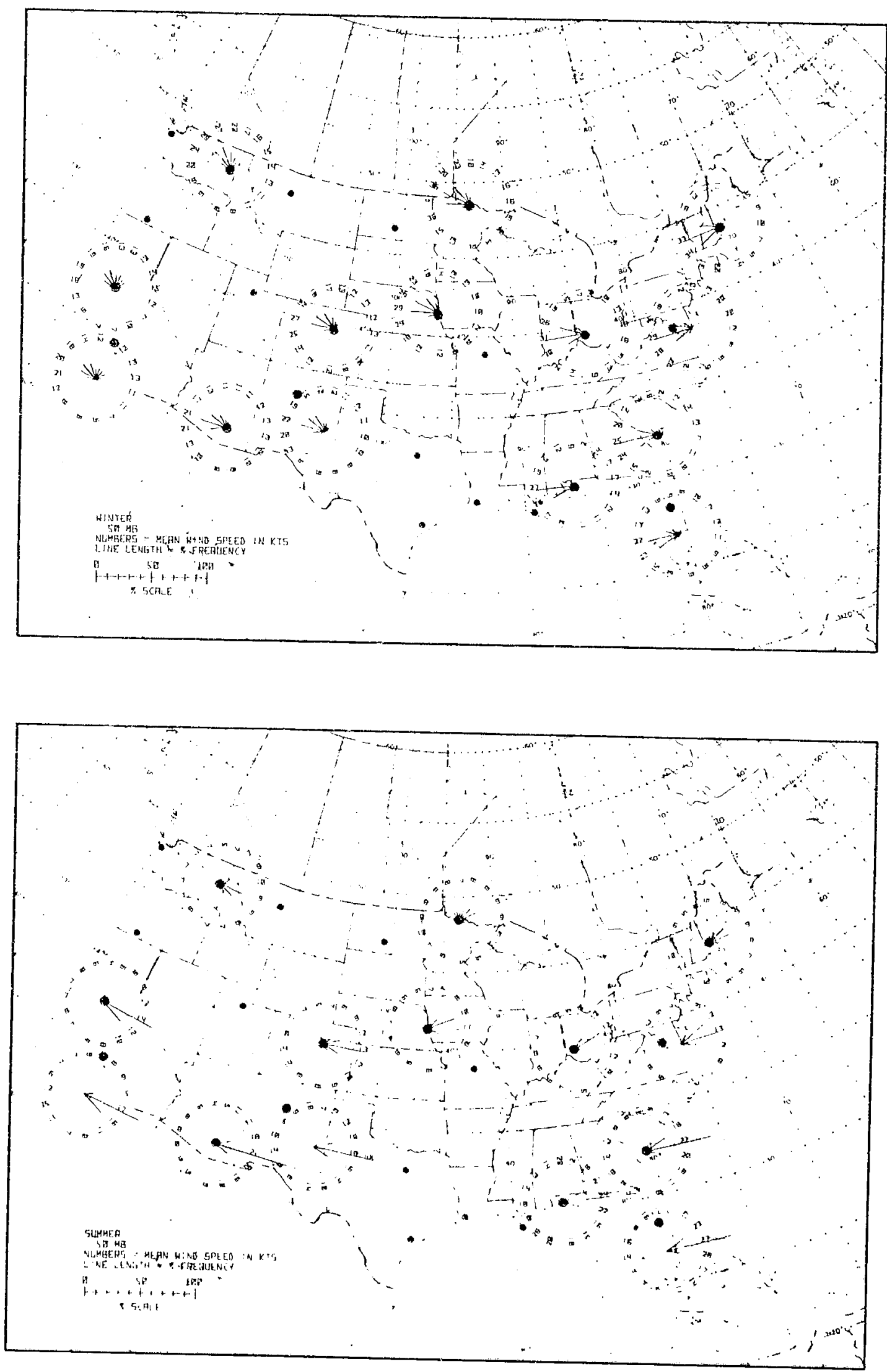

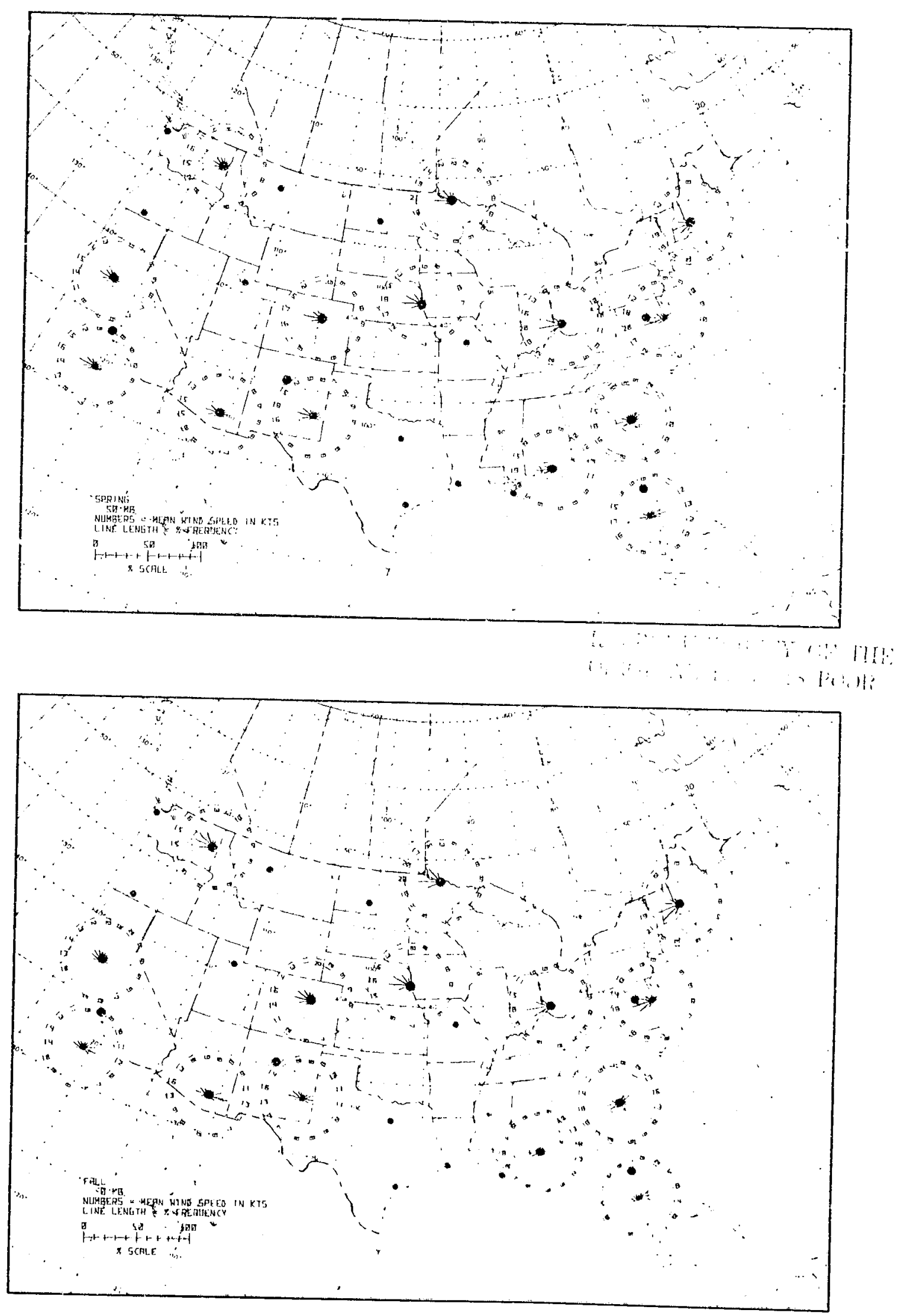

73 

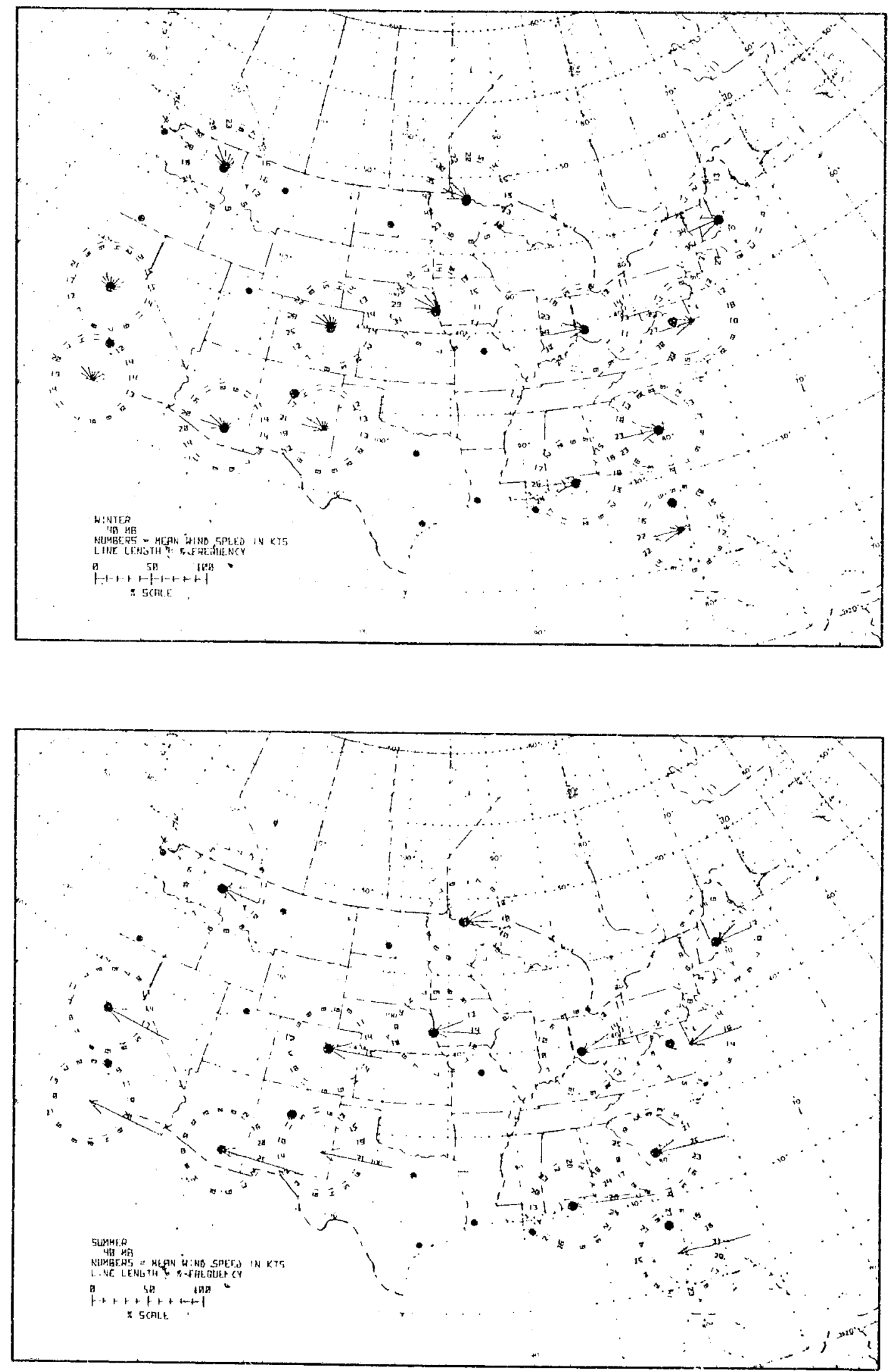

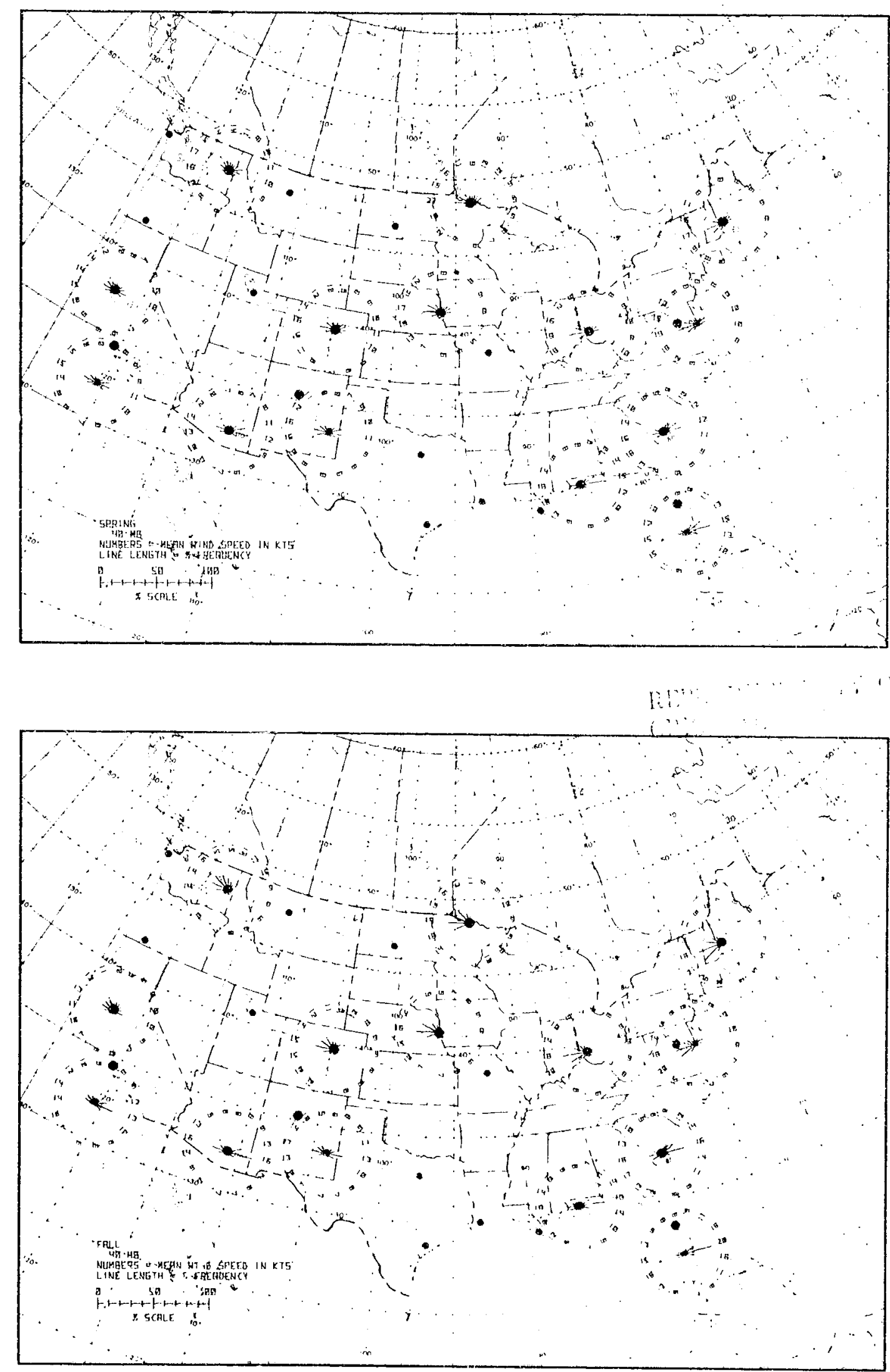

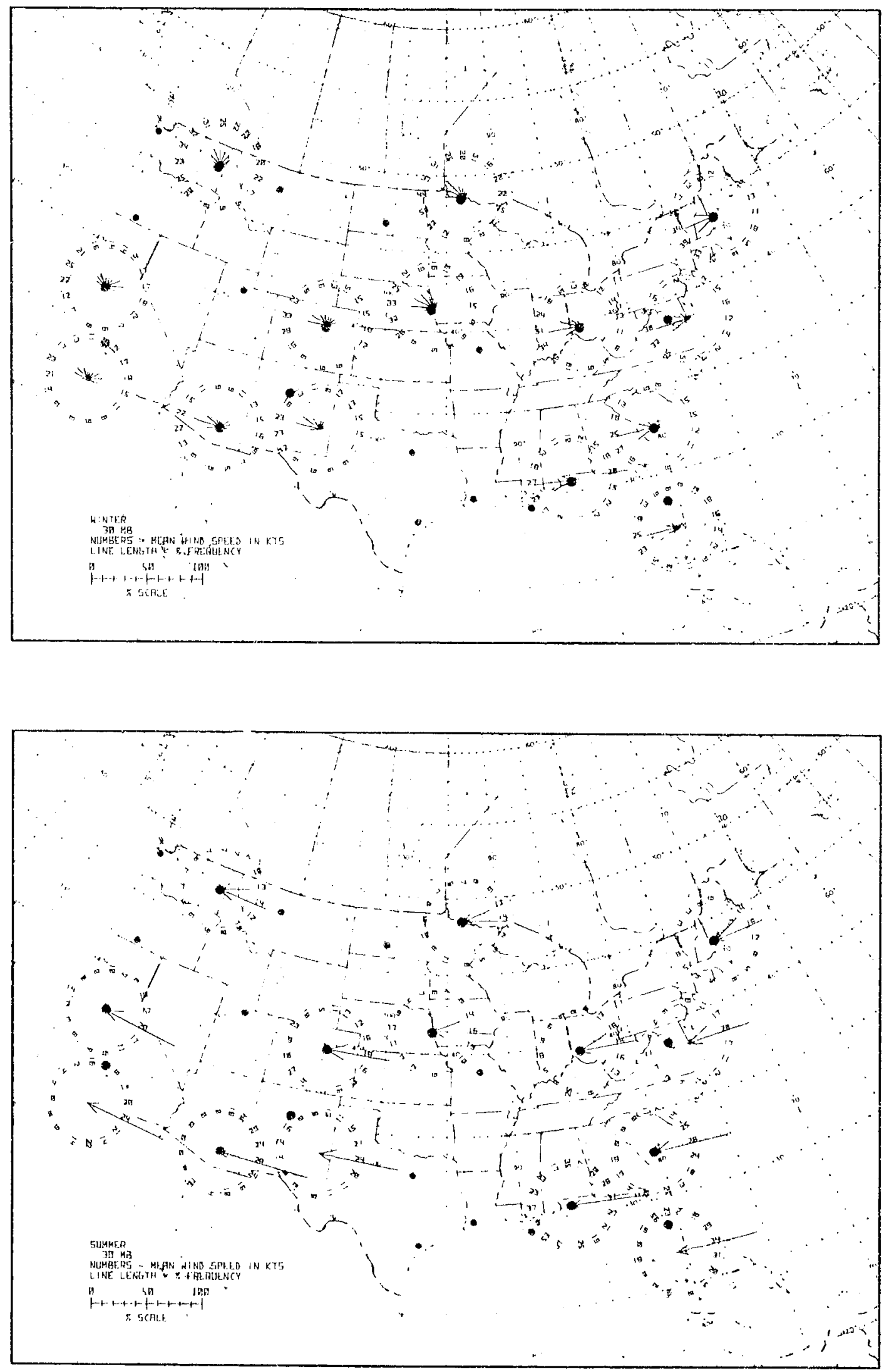


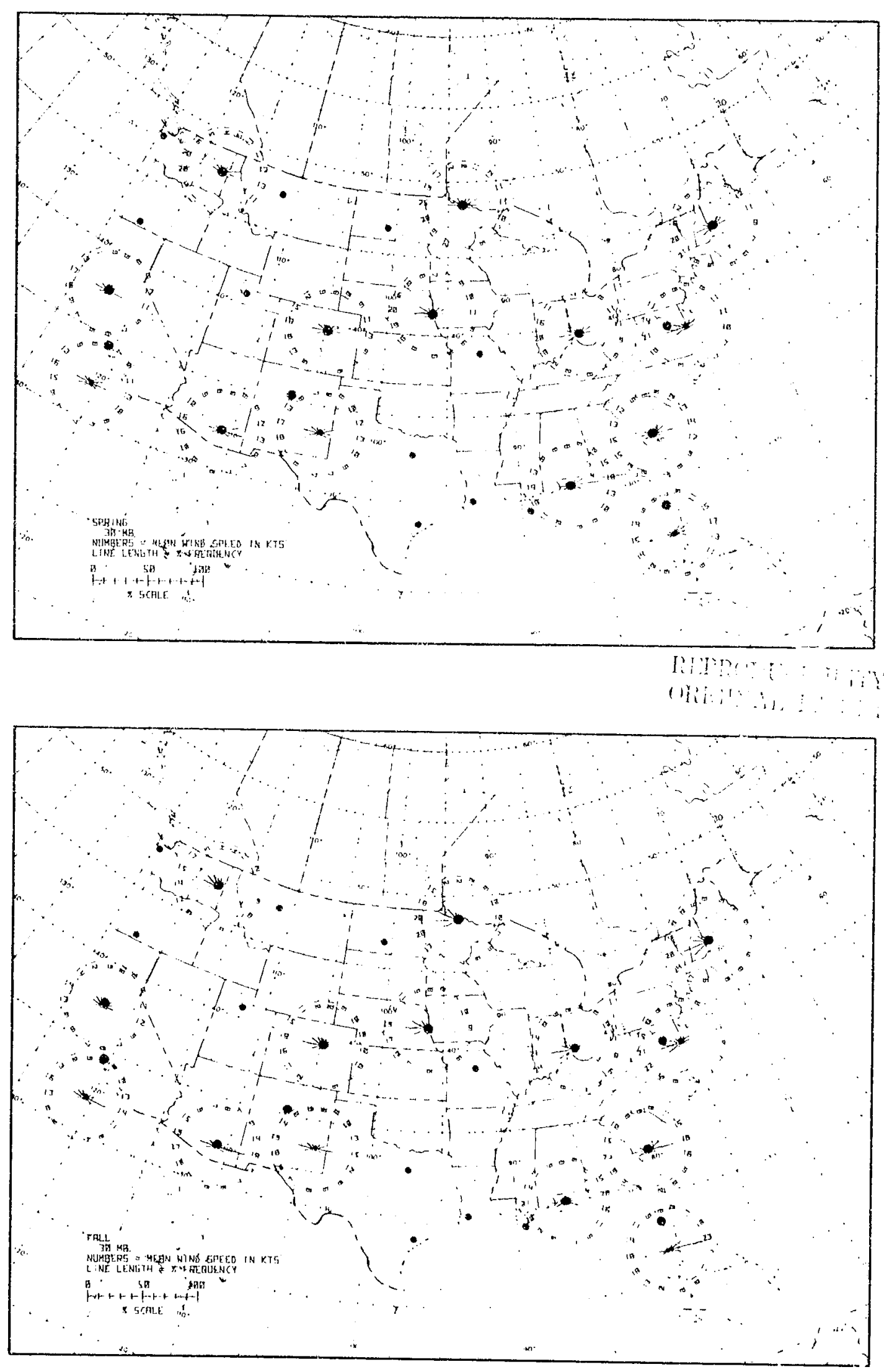



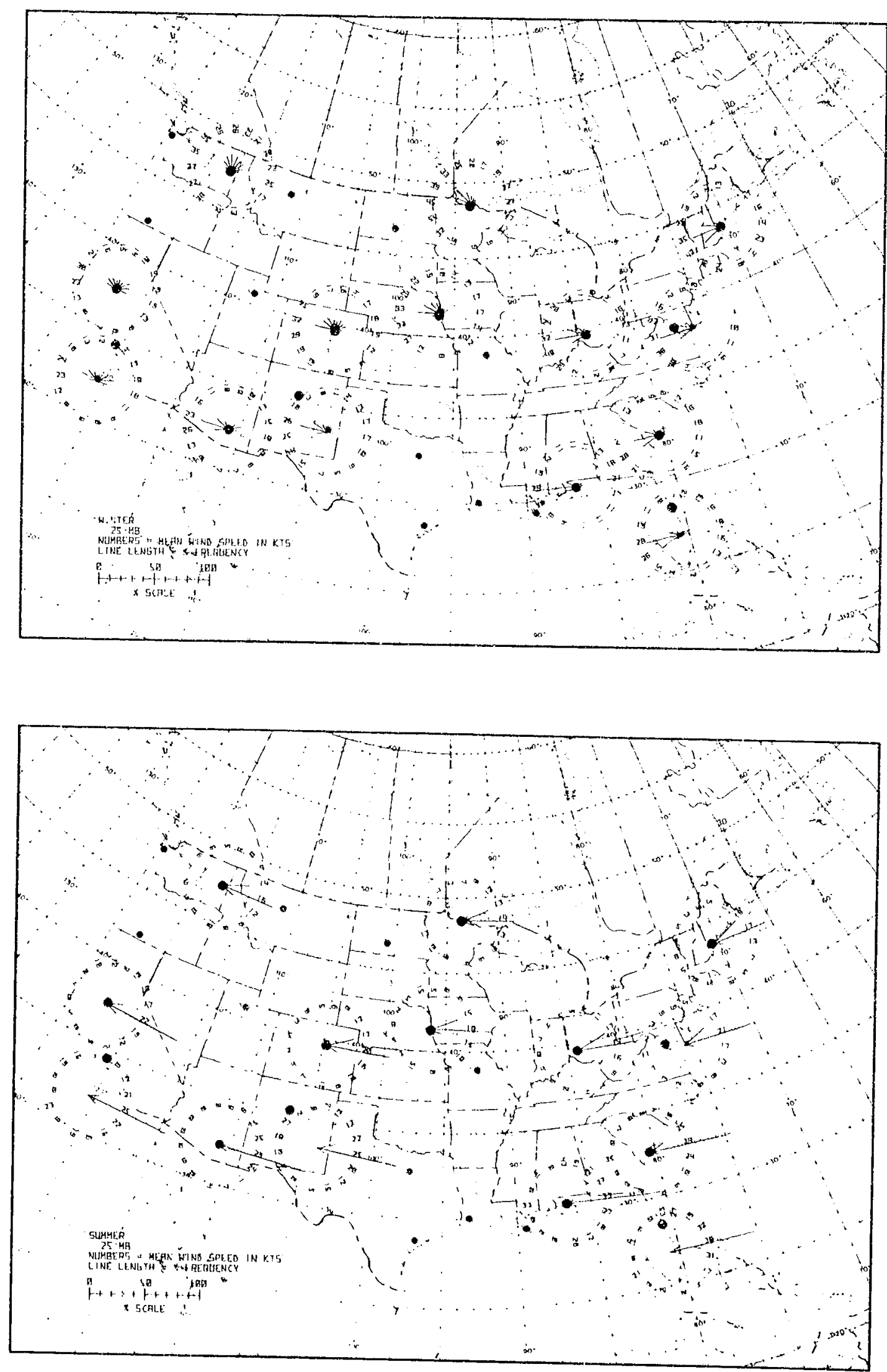

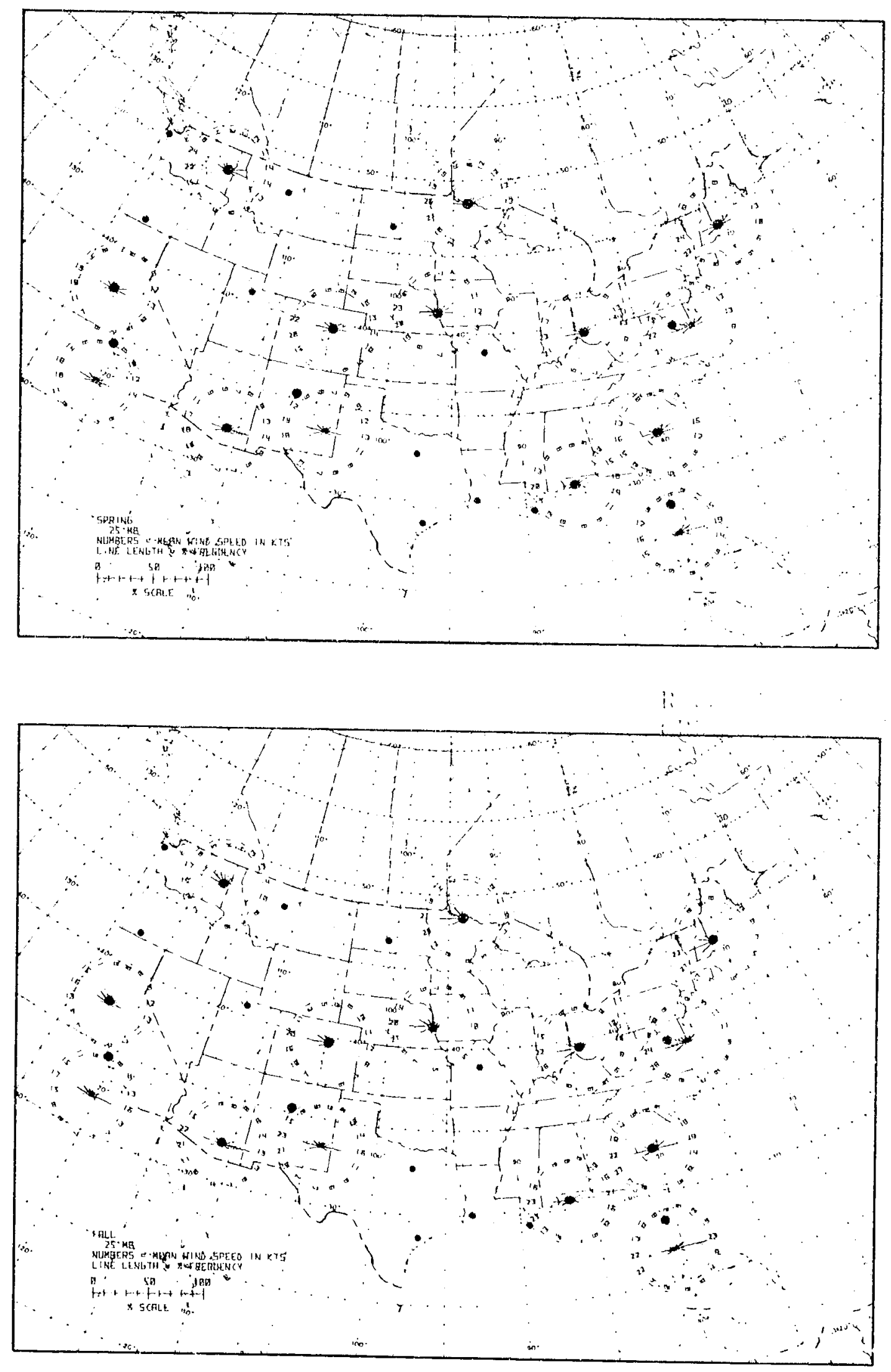

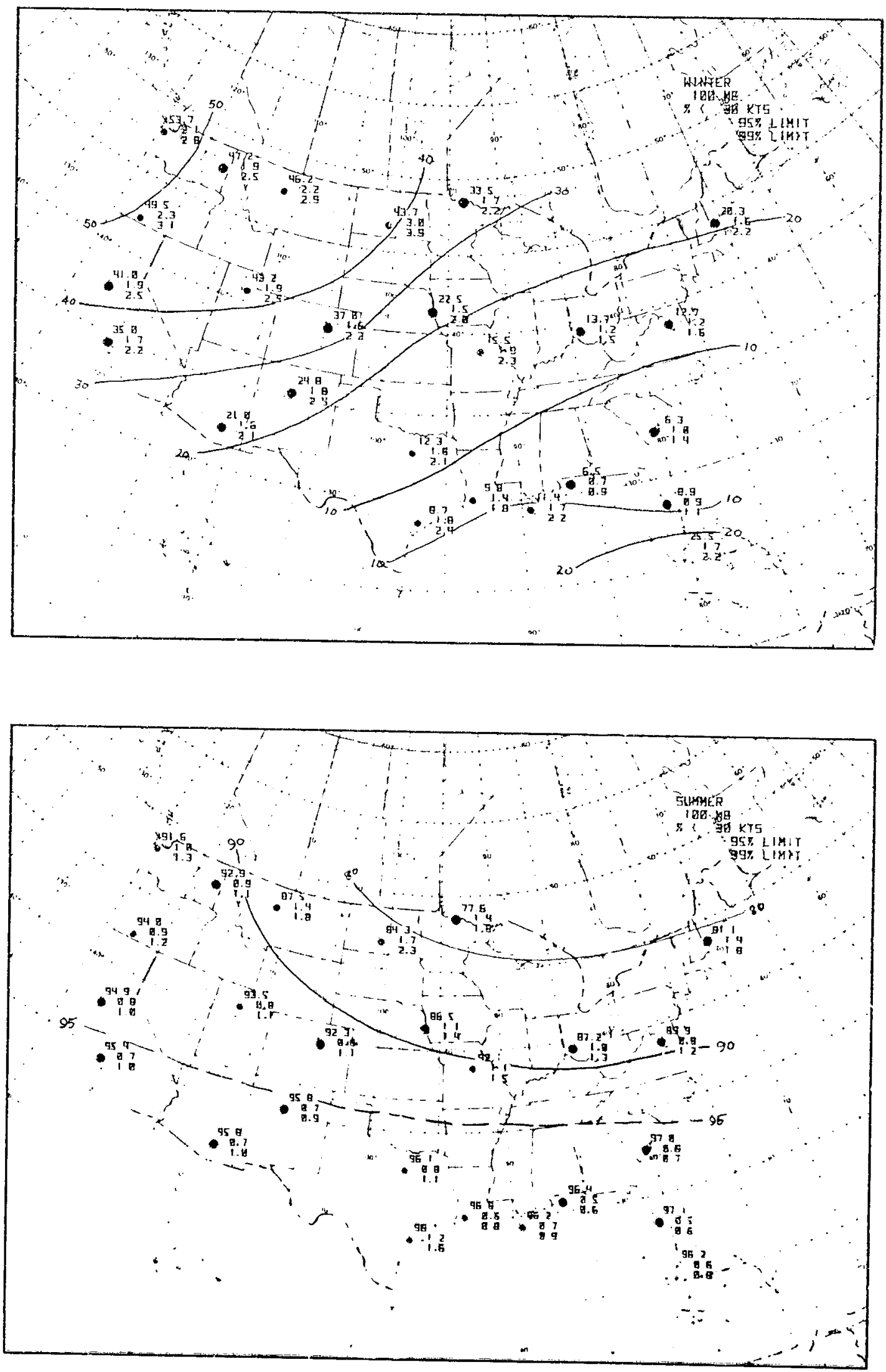

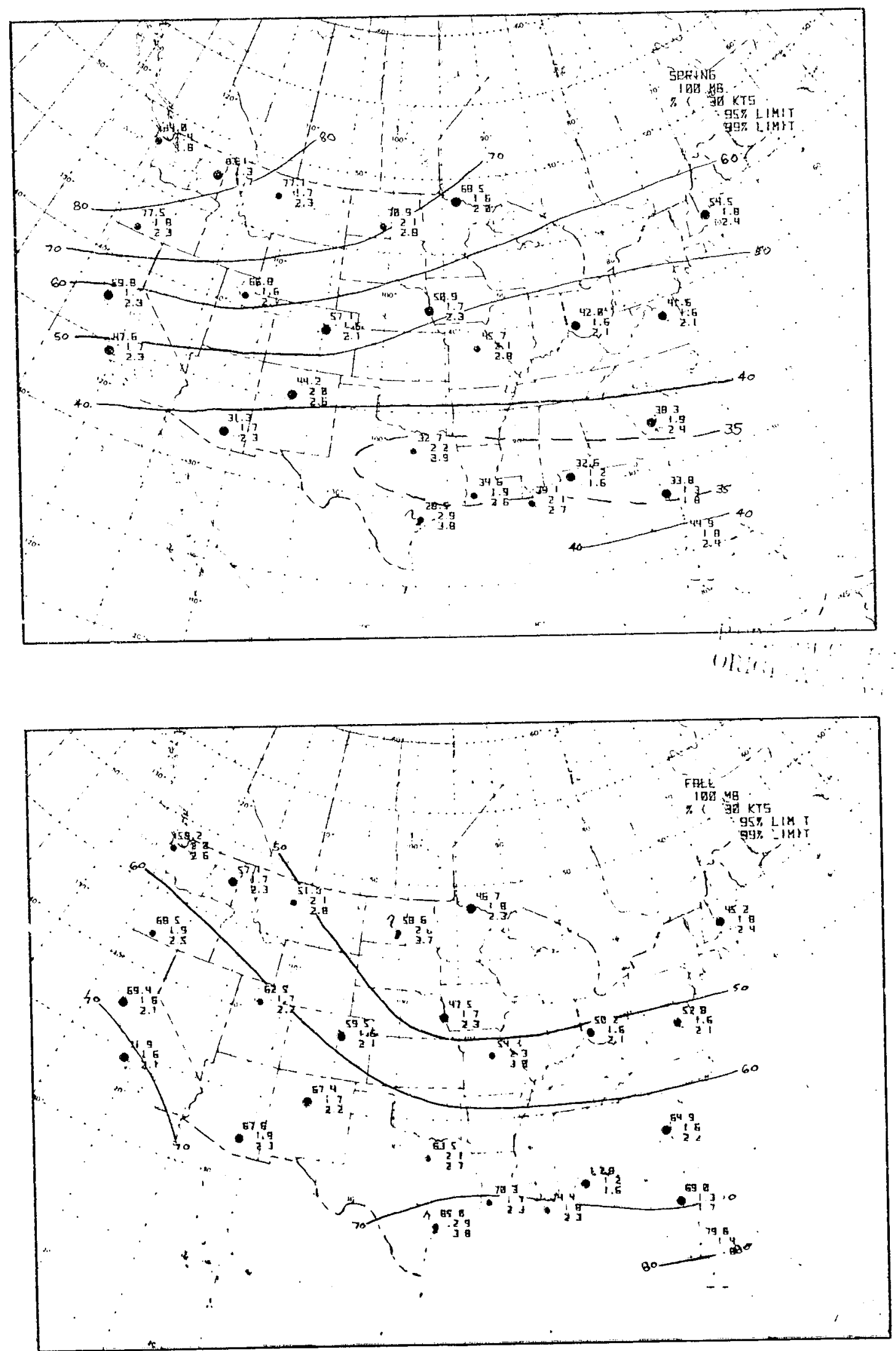

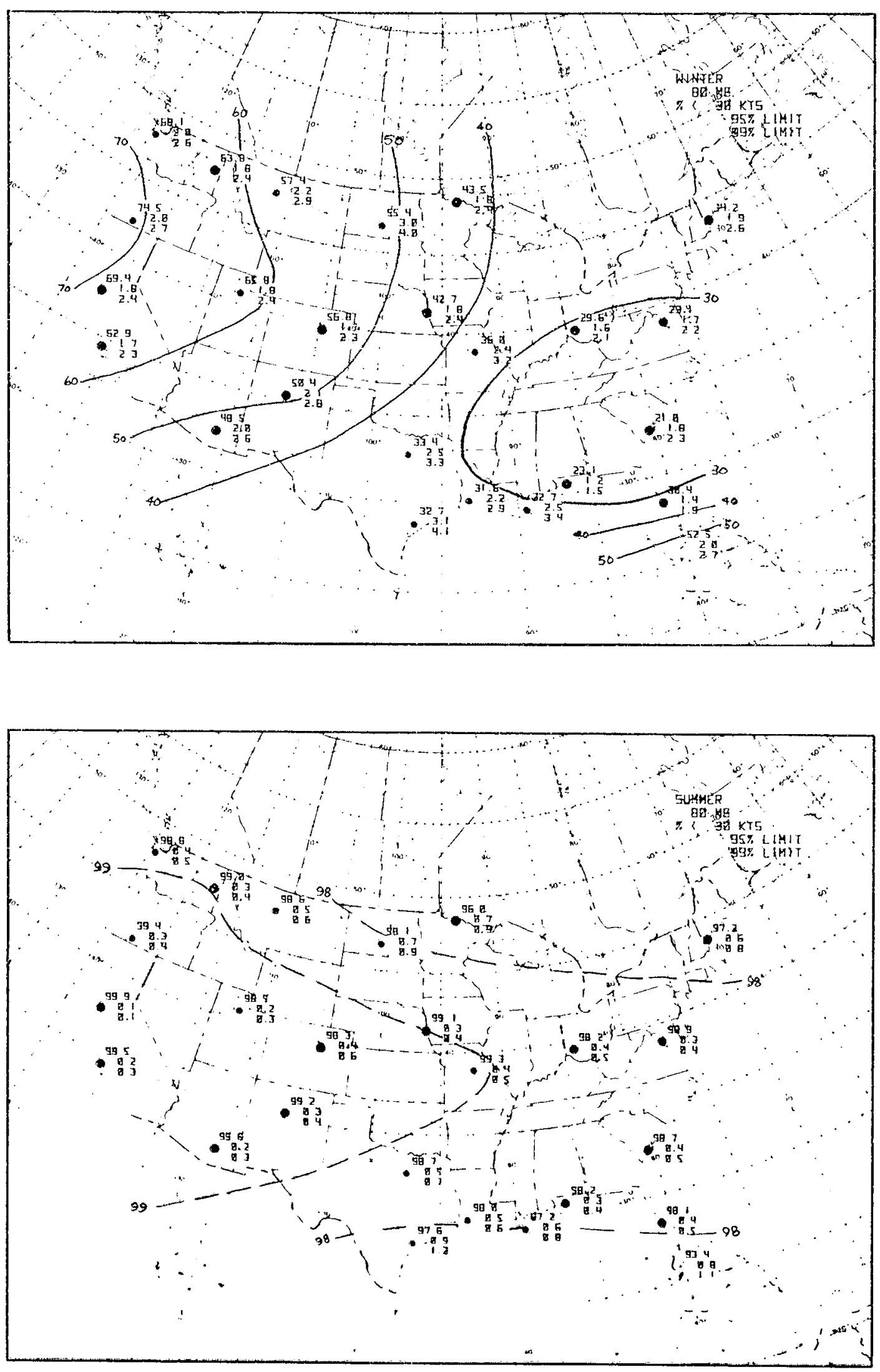


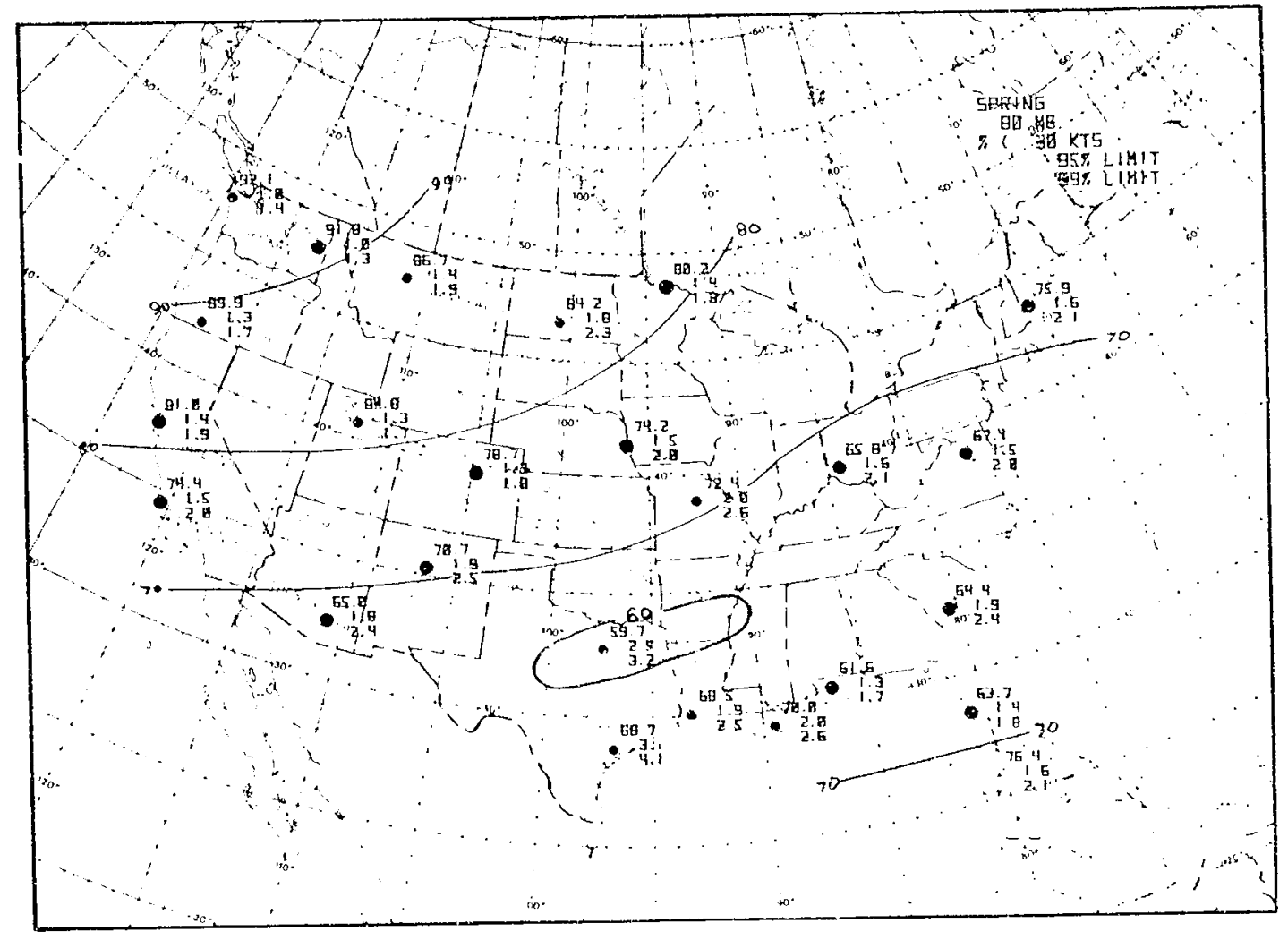

L $1 \%$

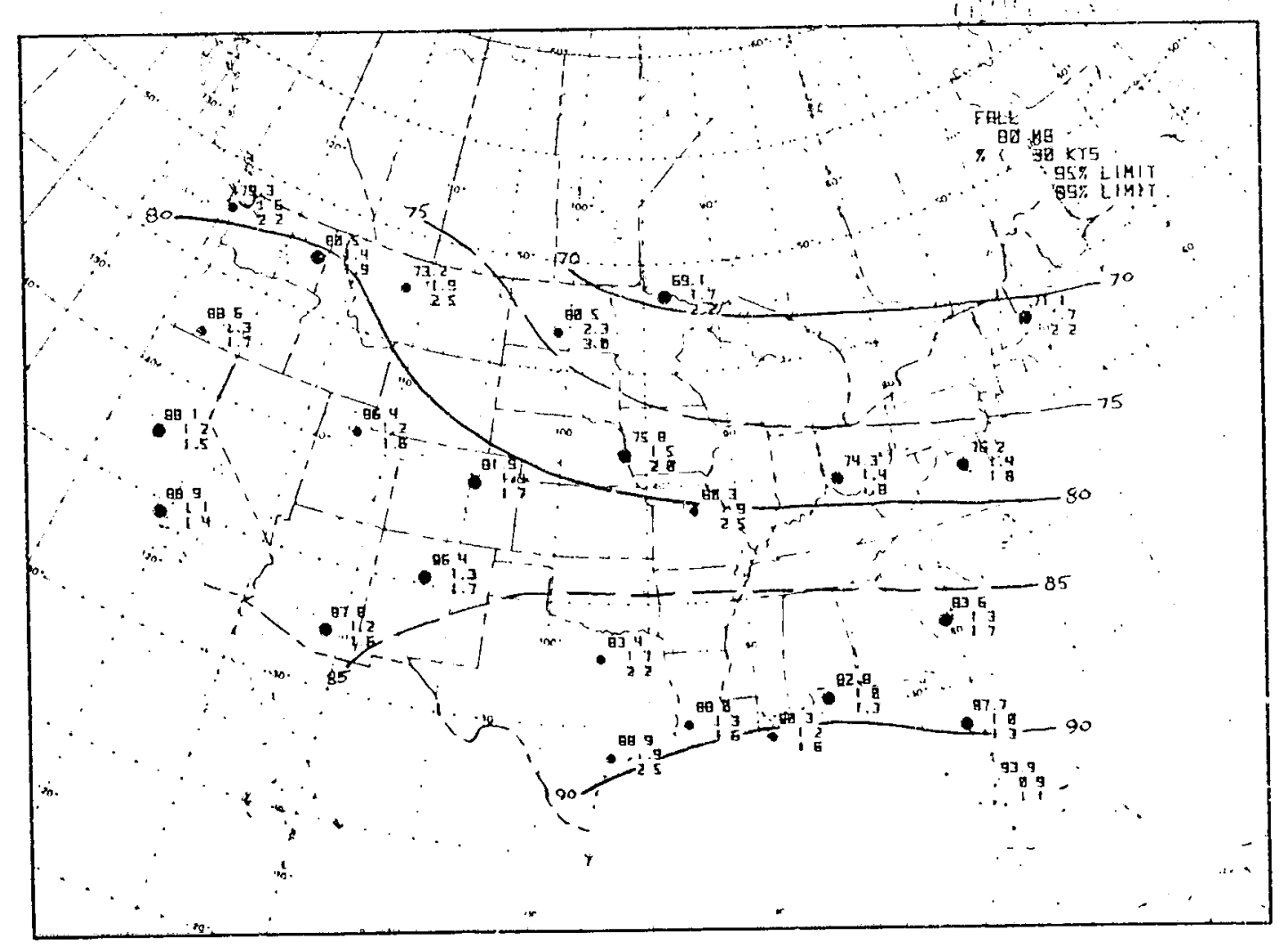



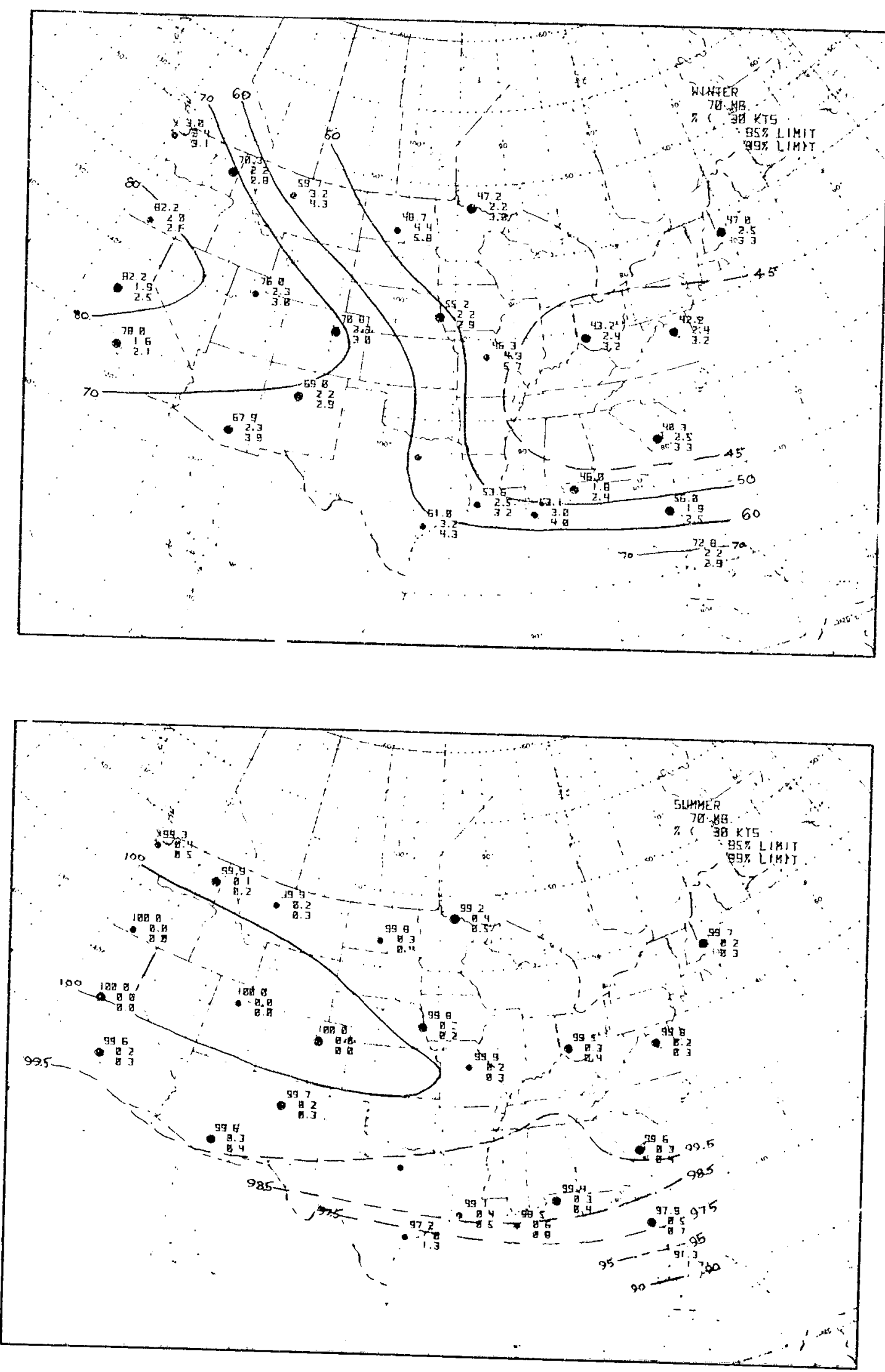


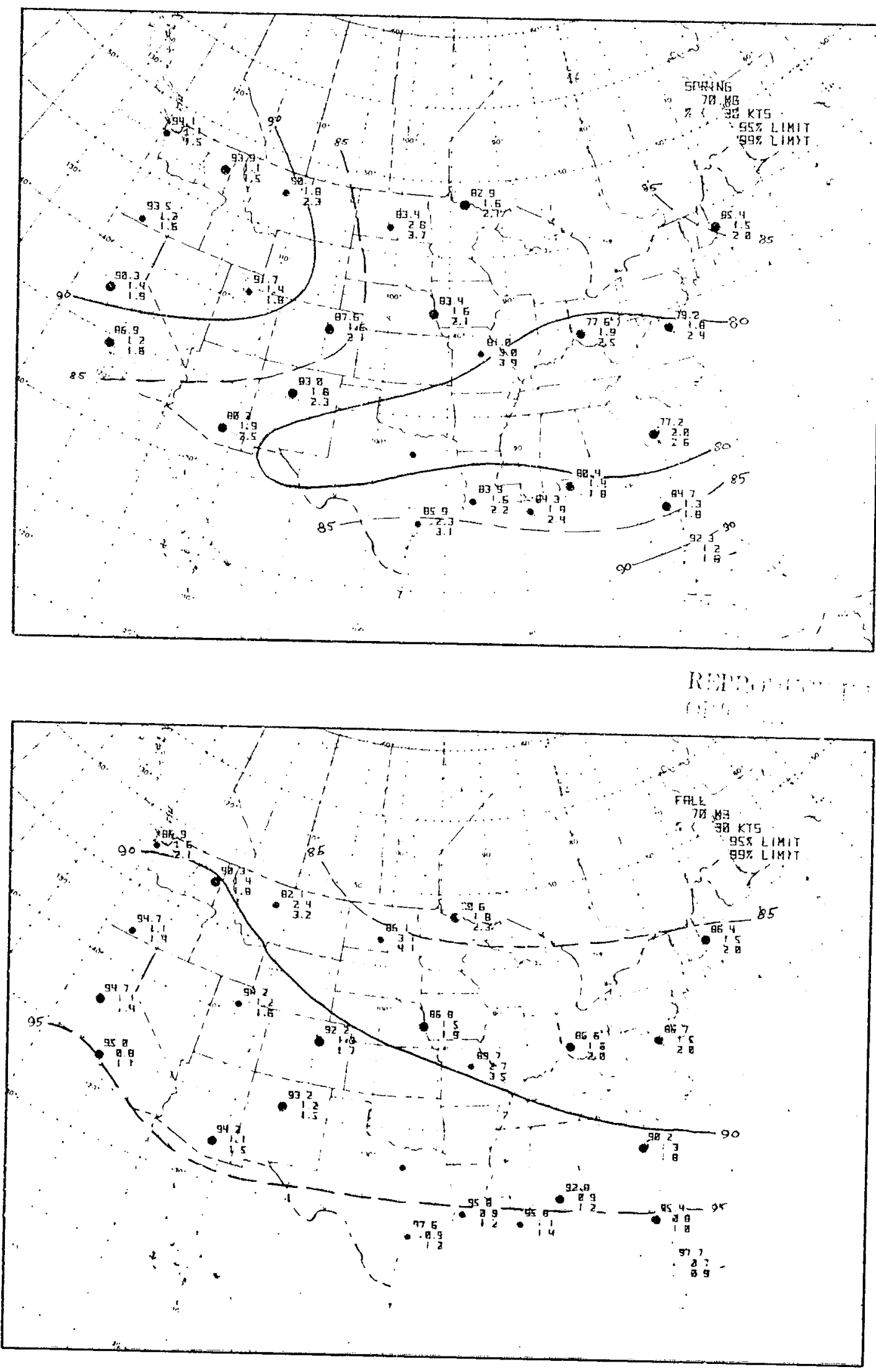



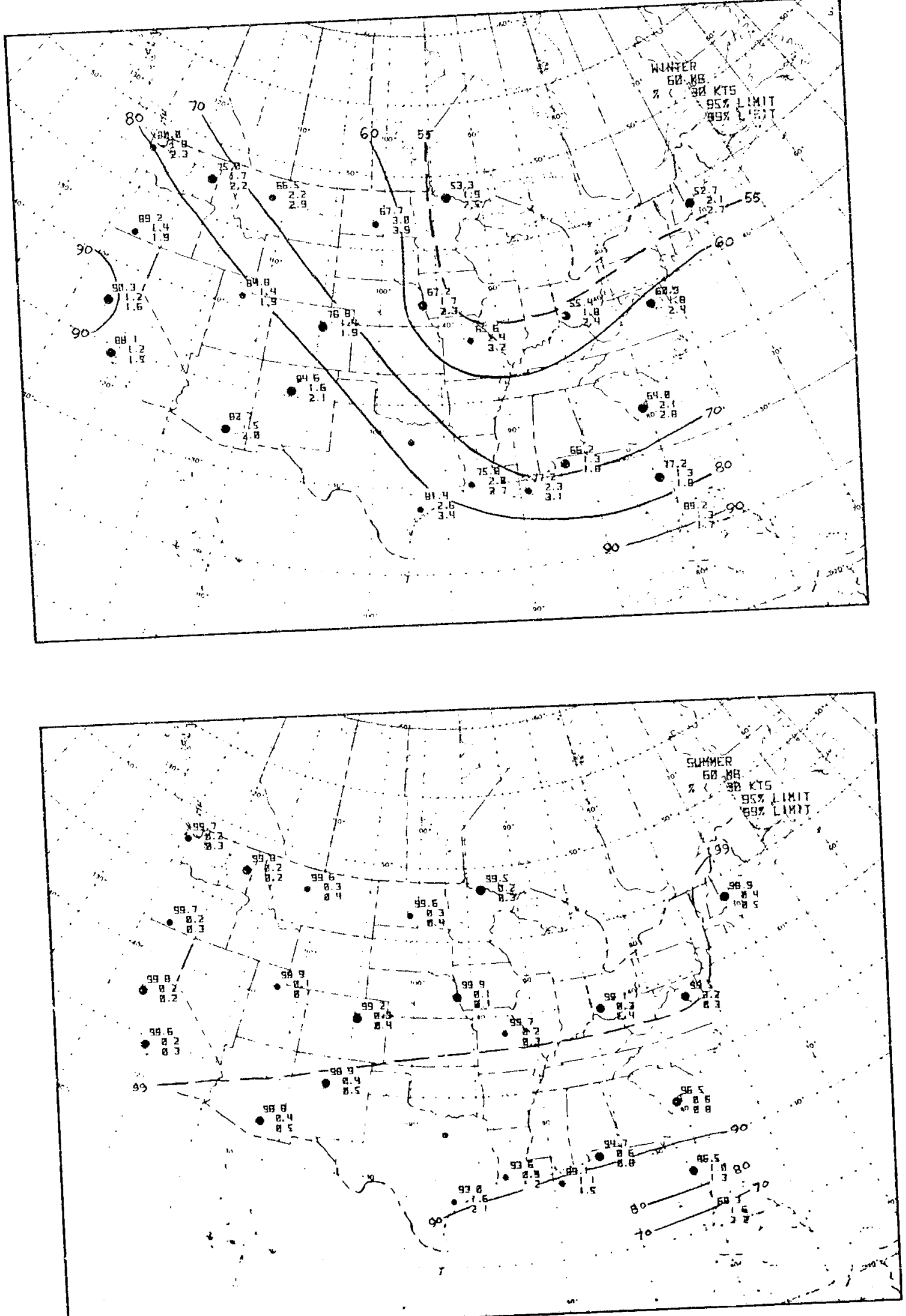

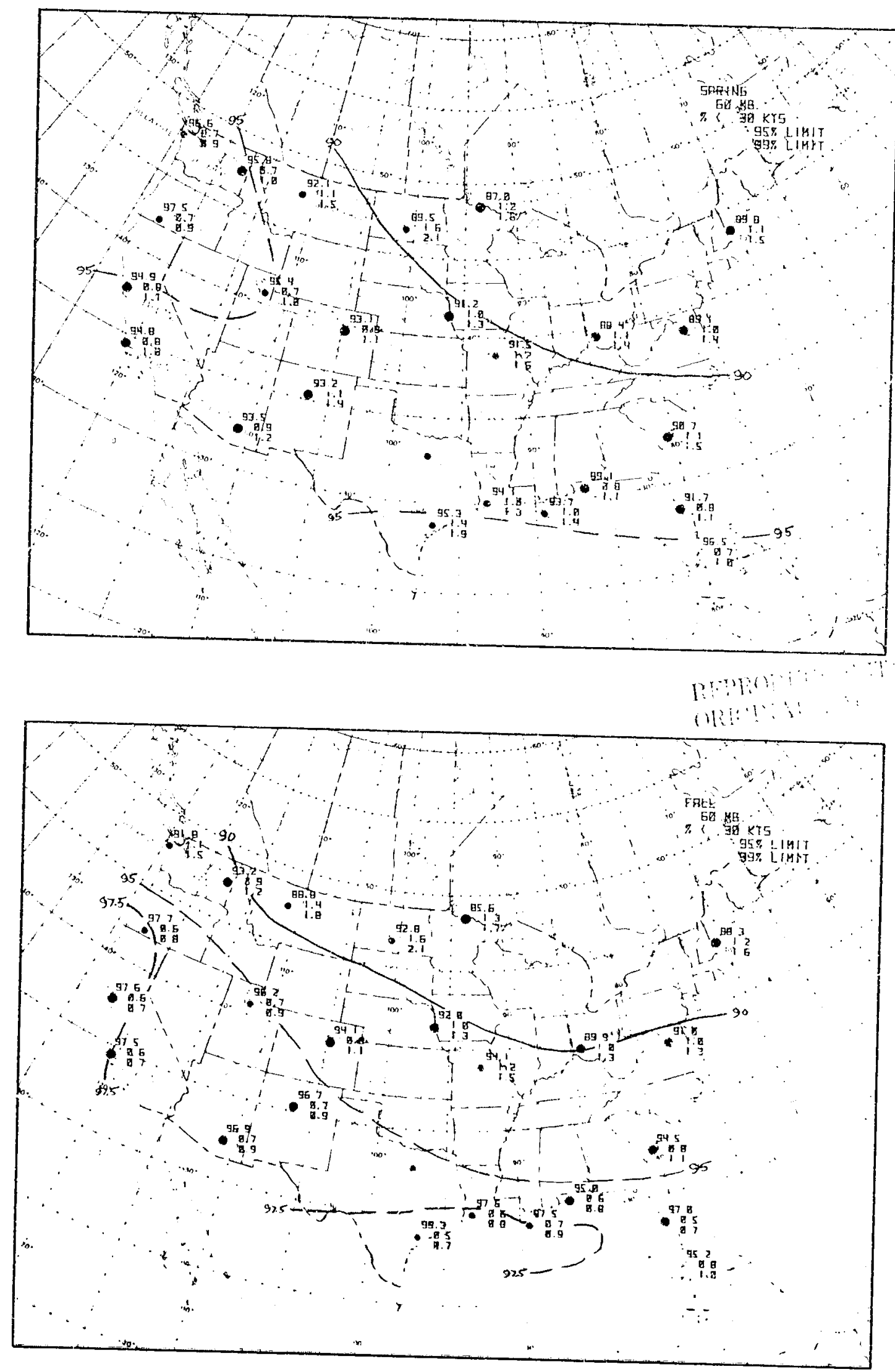

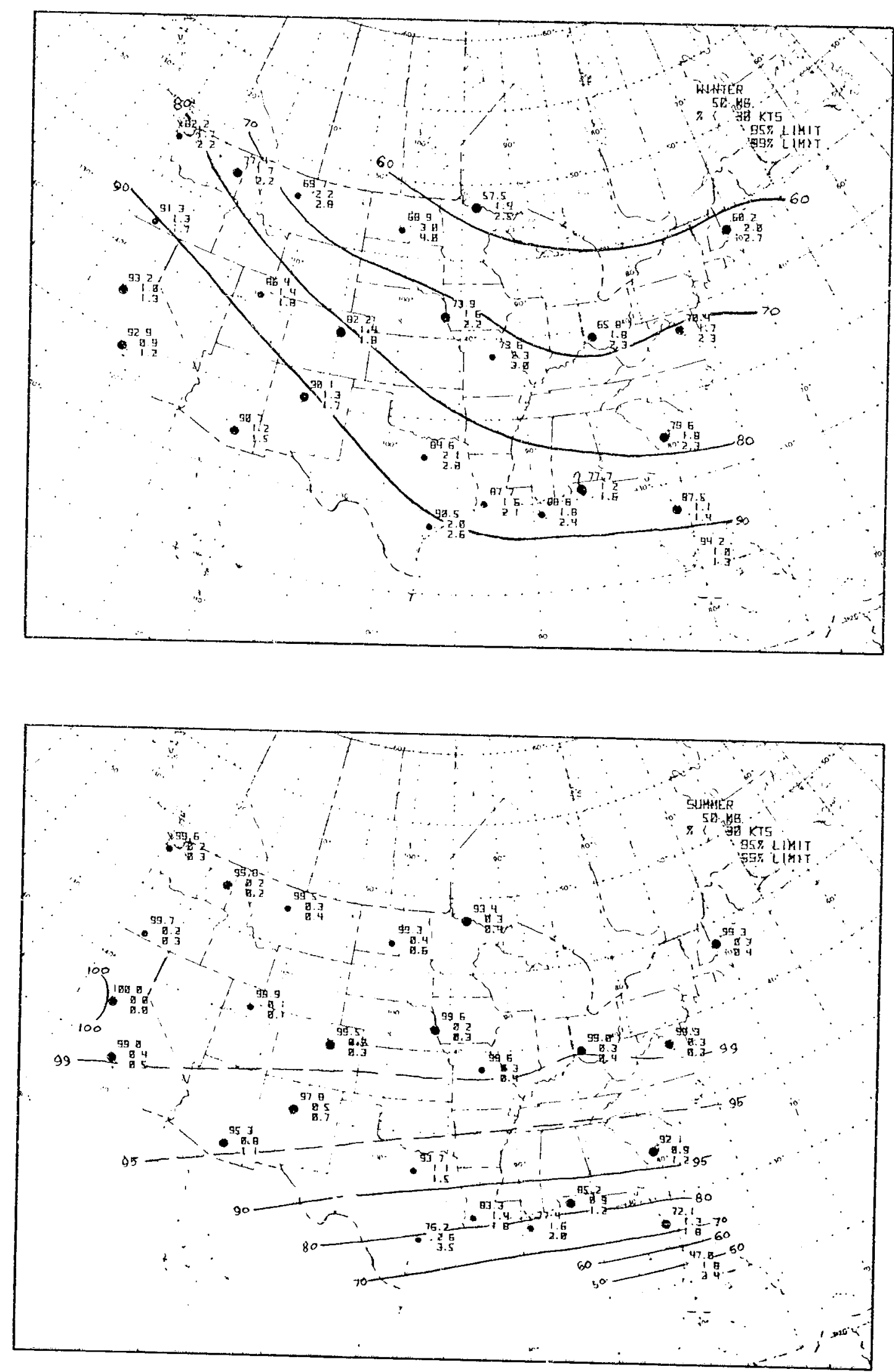

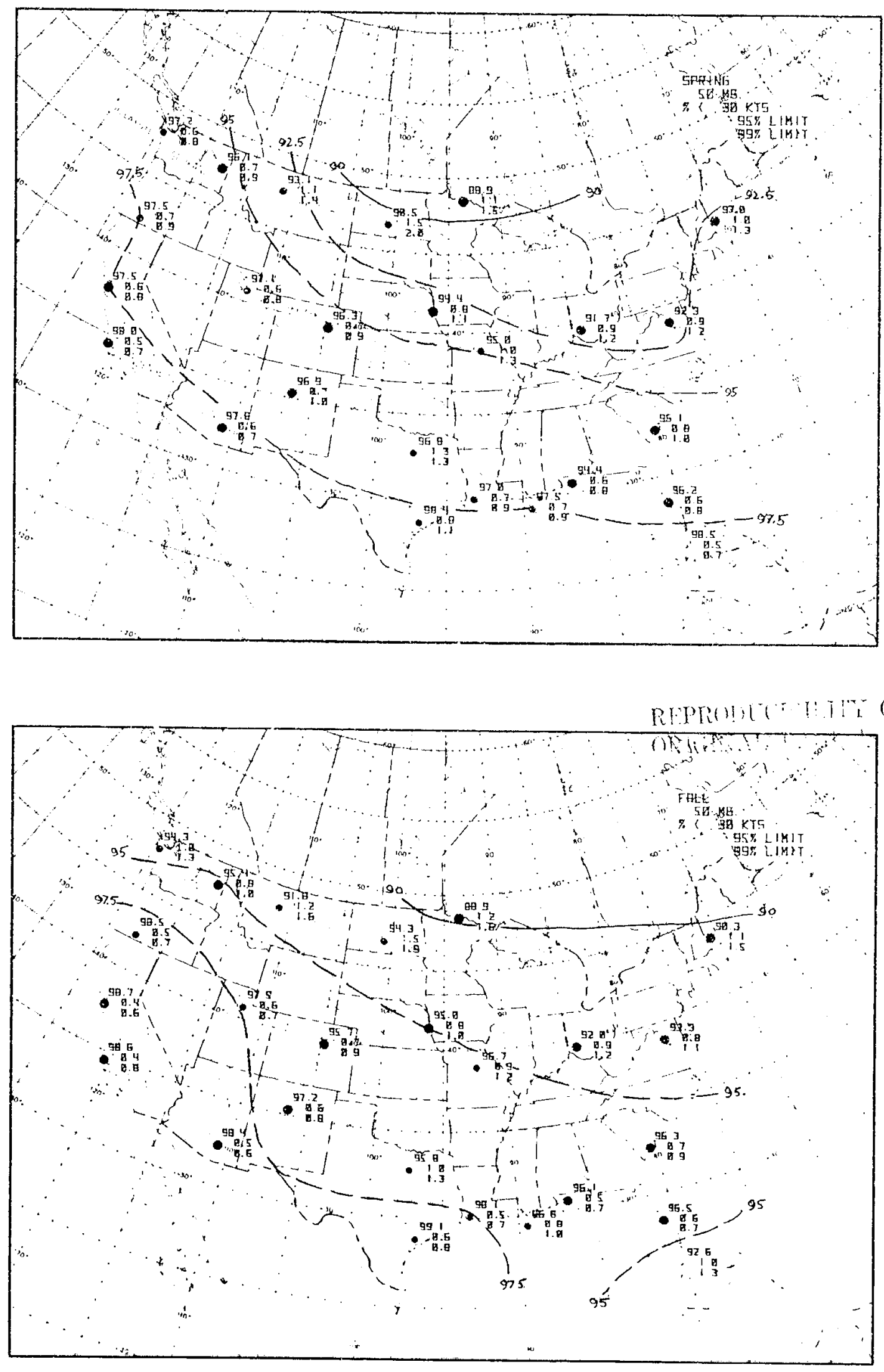

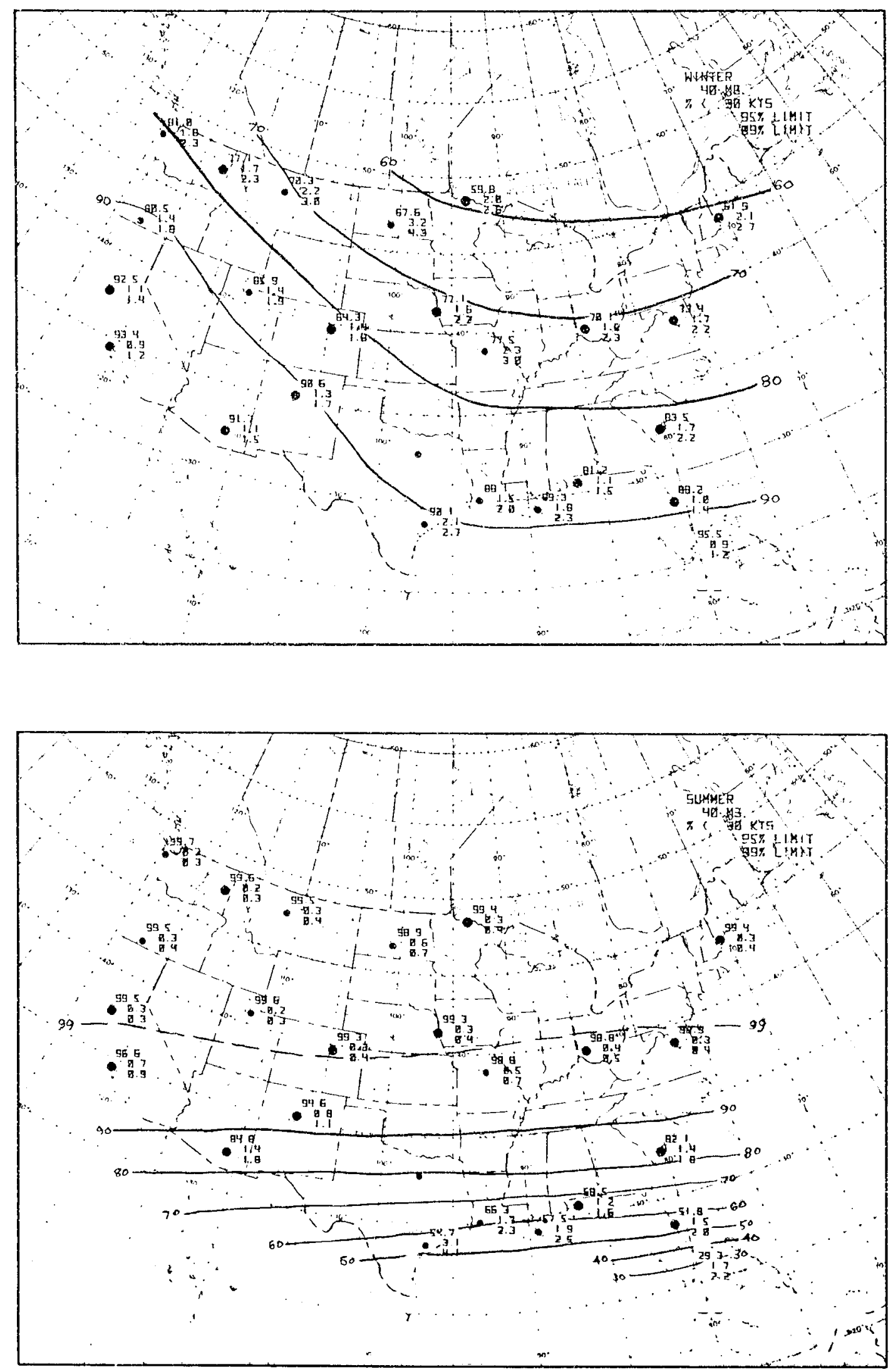


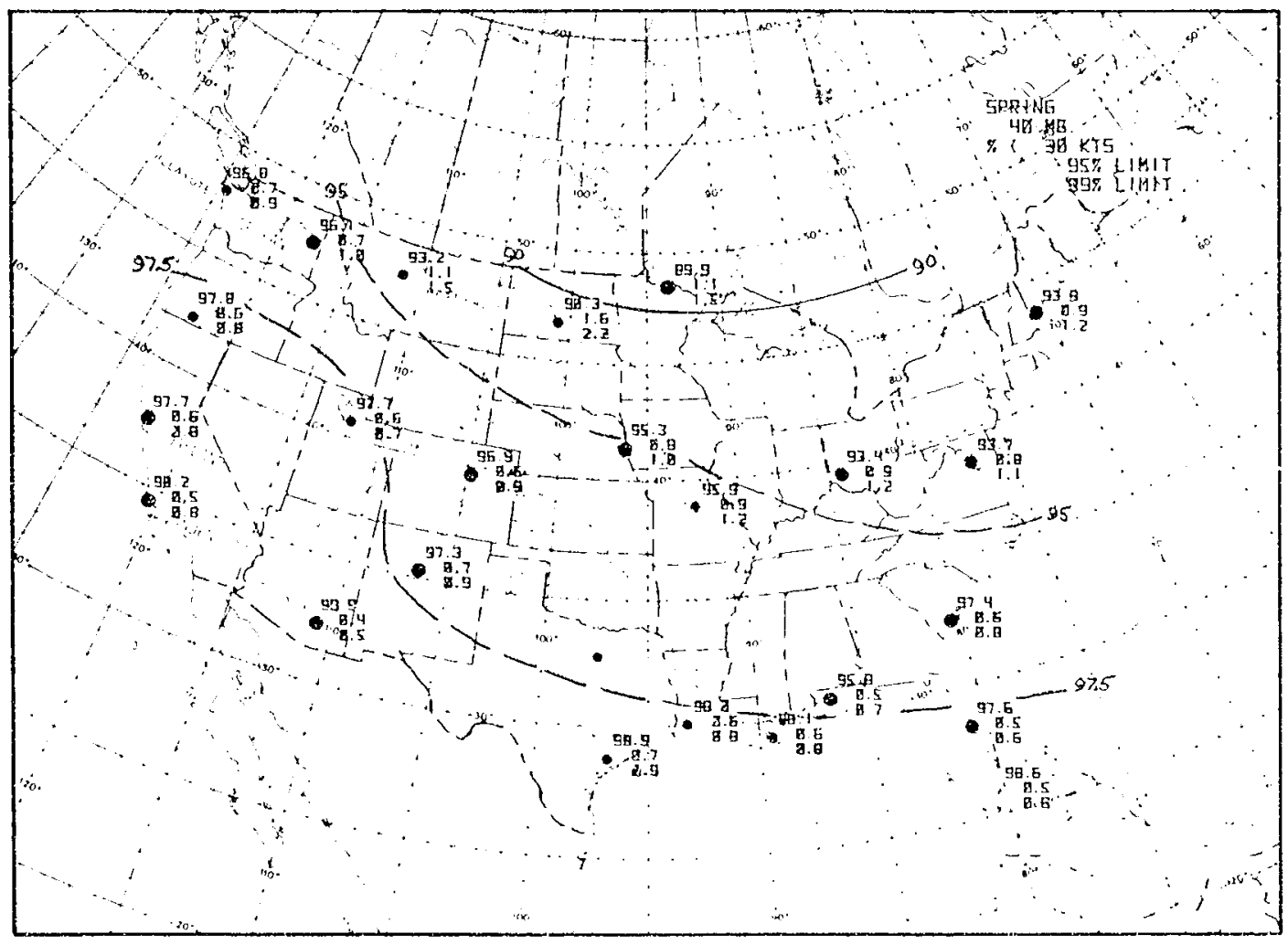

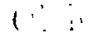

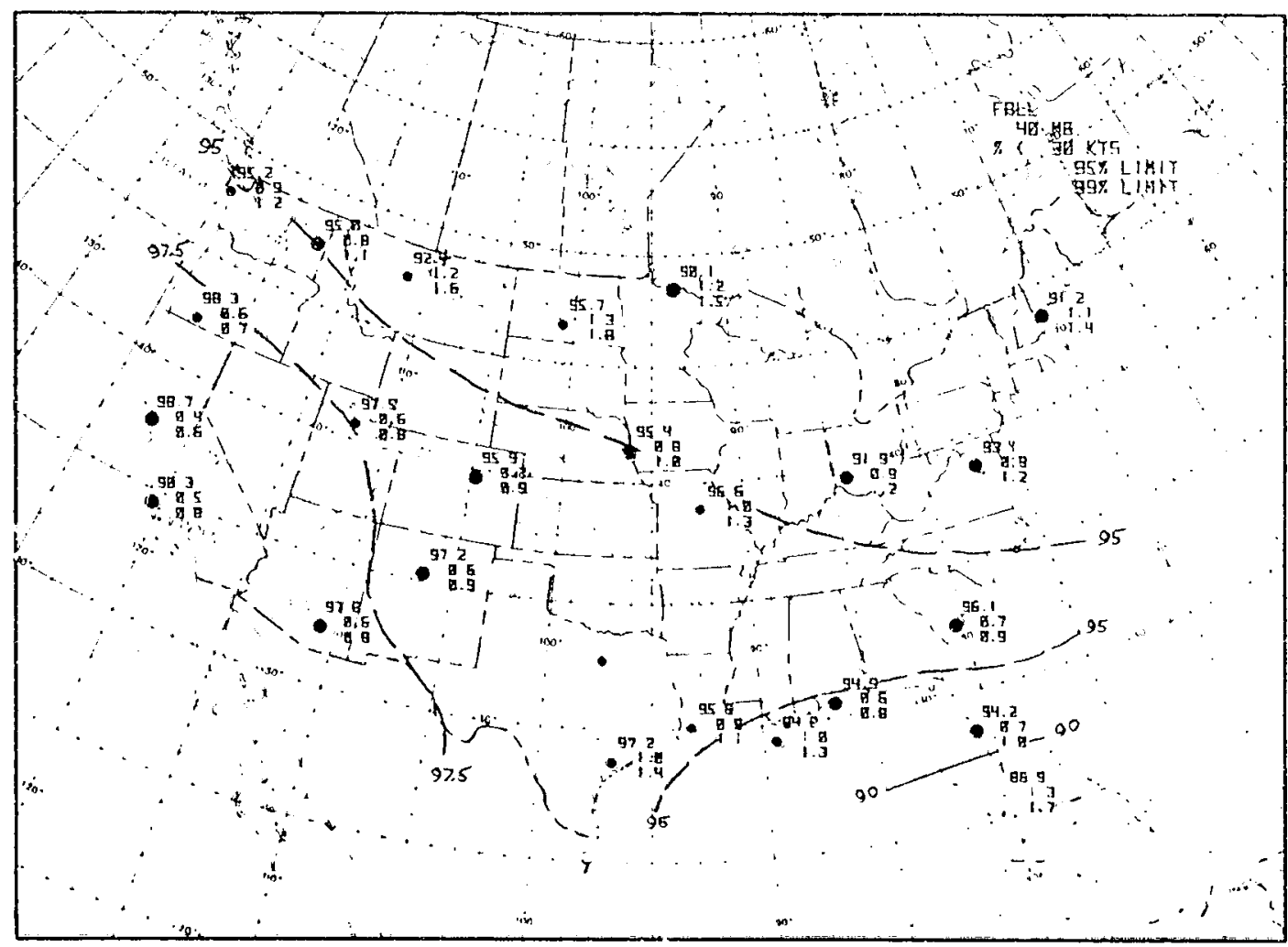



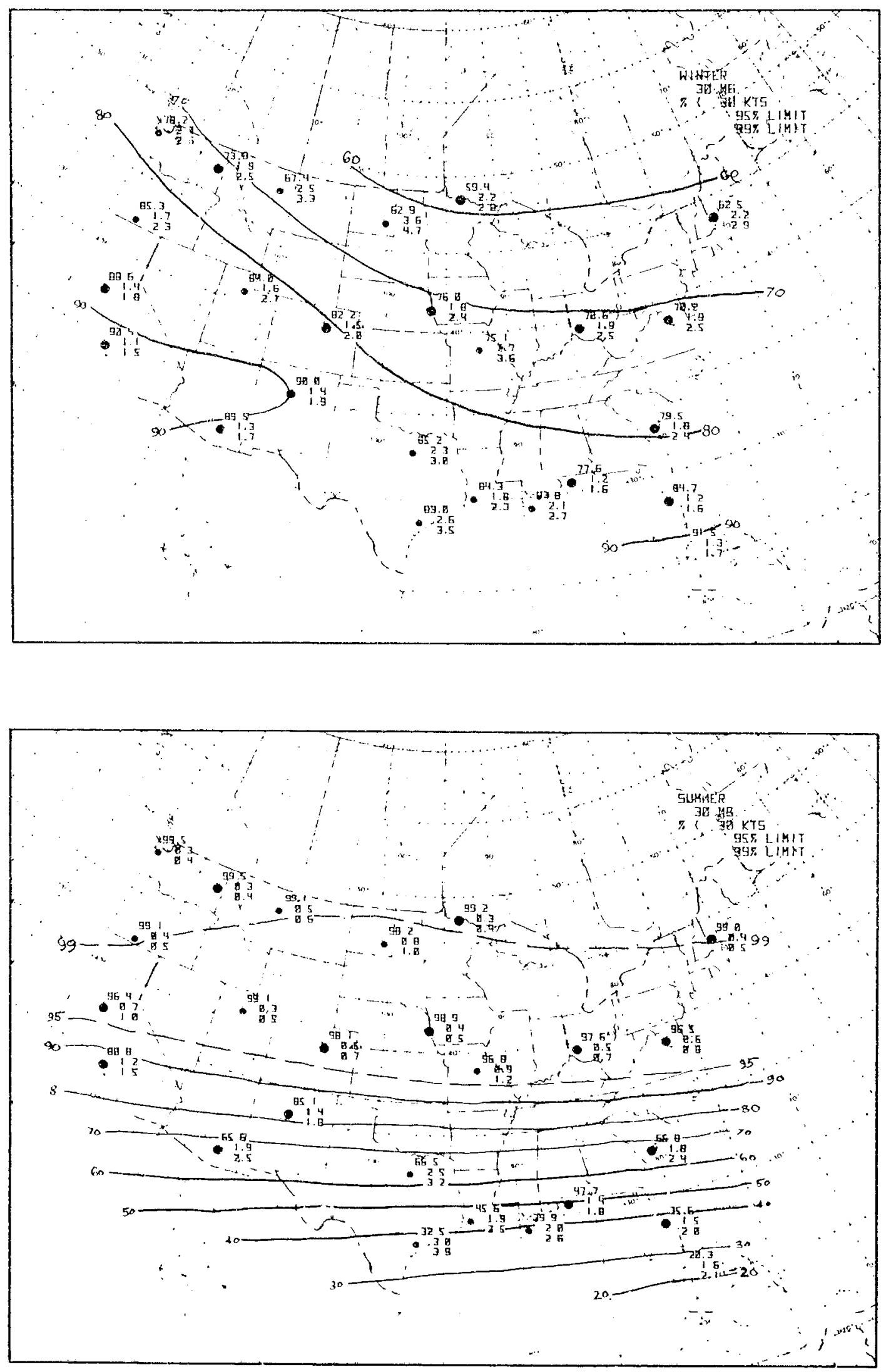


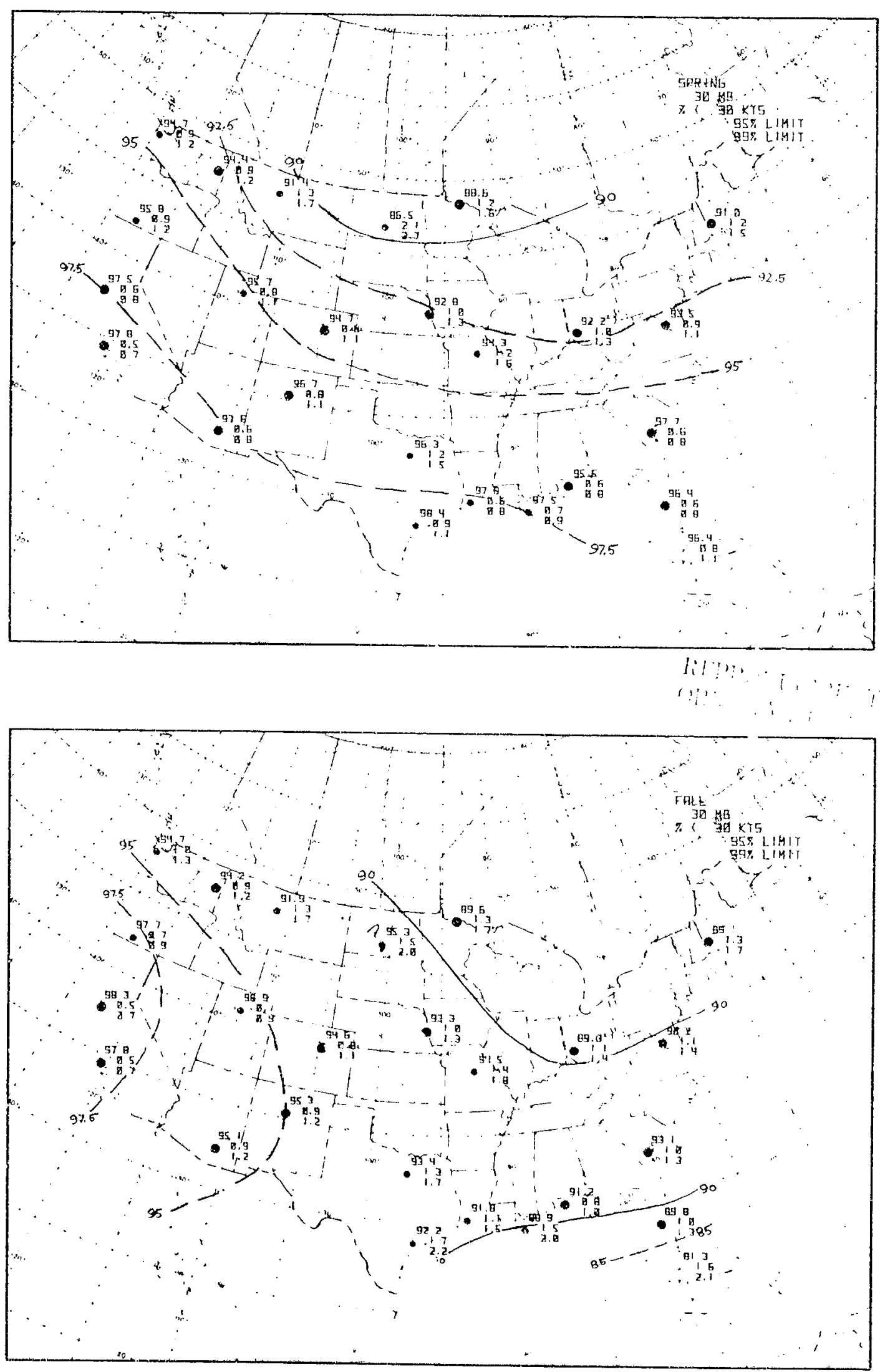



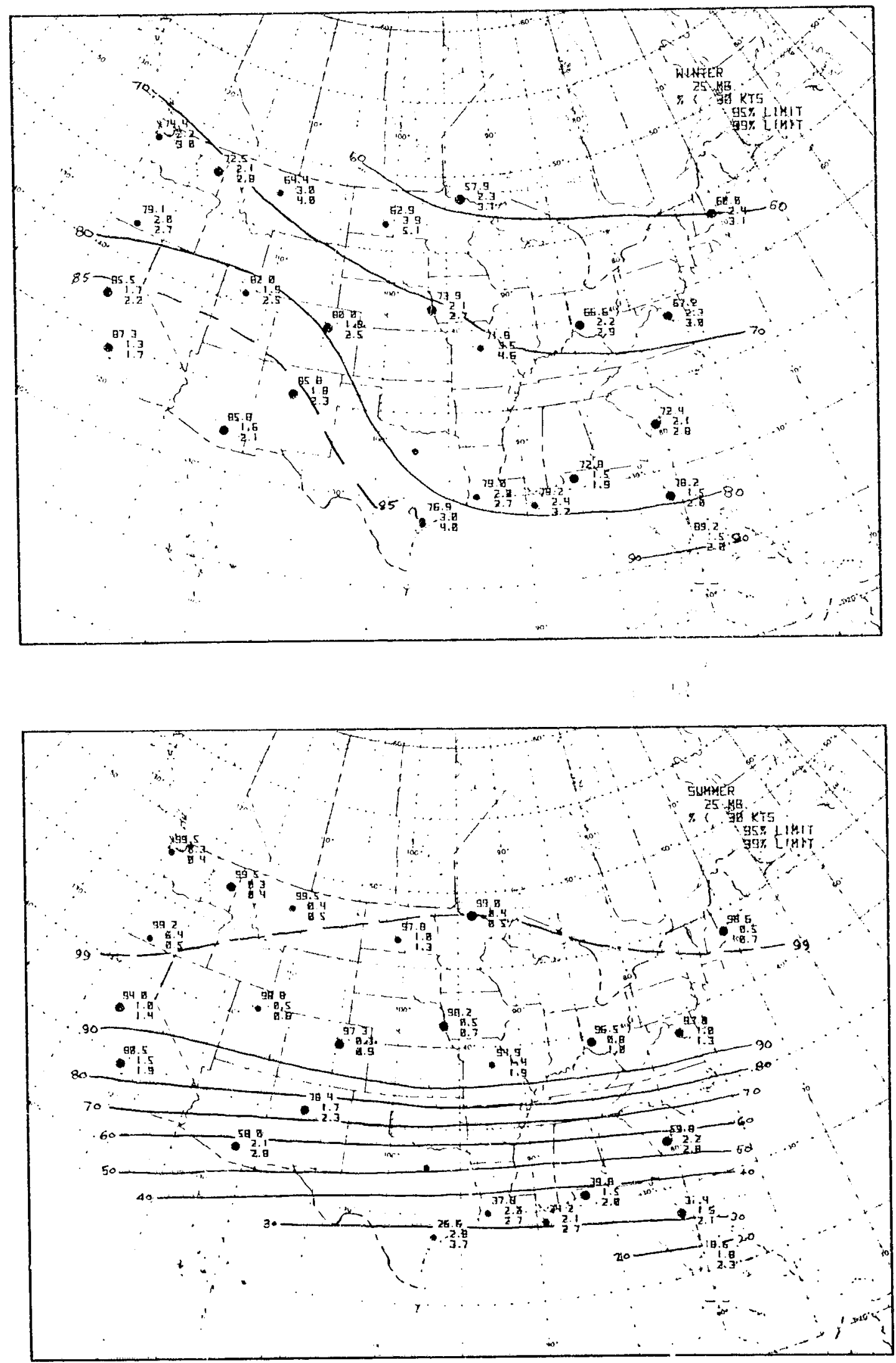

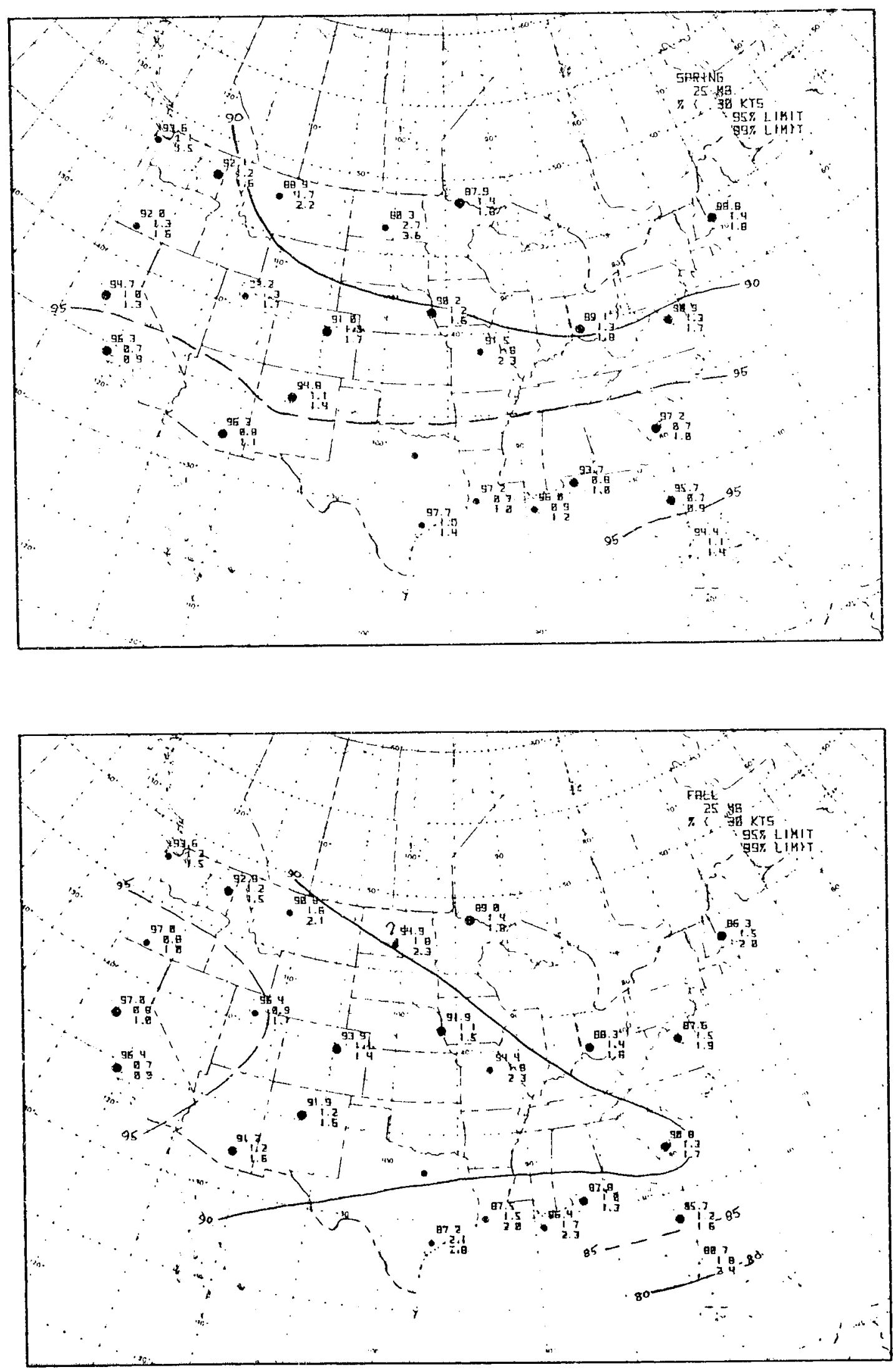

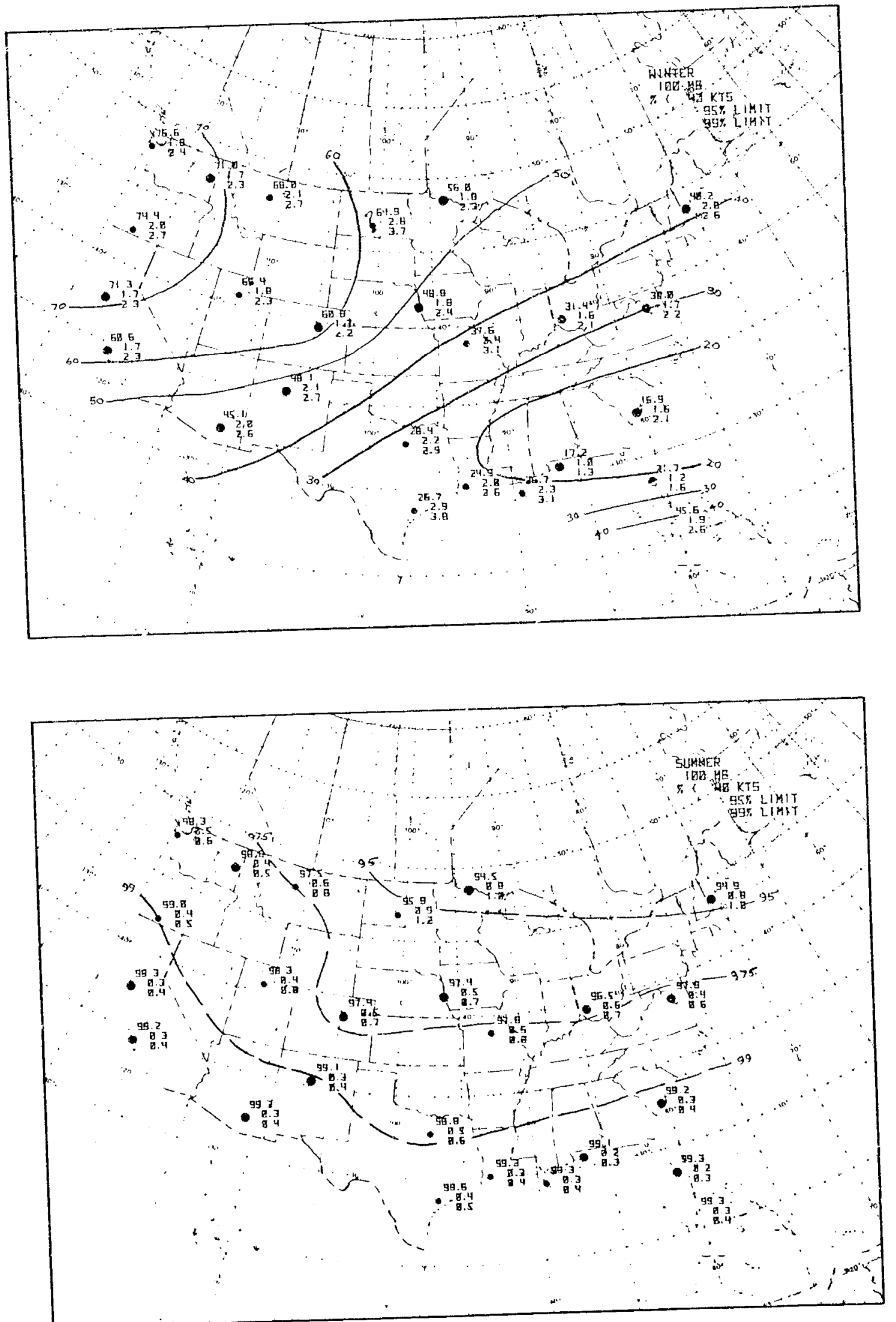

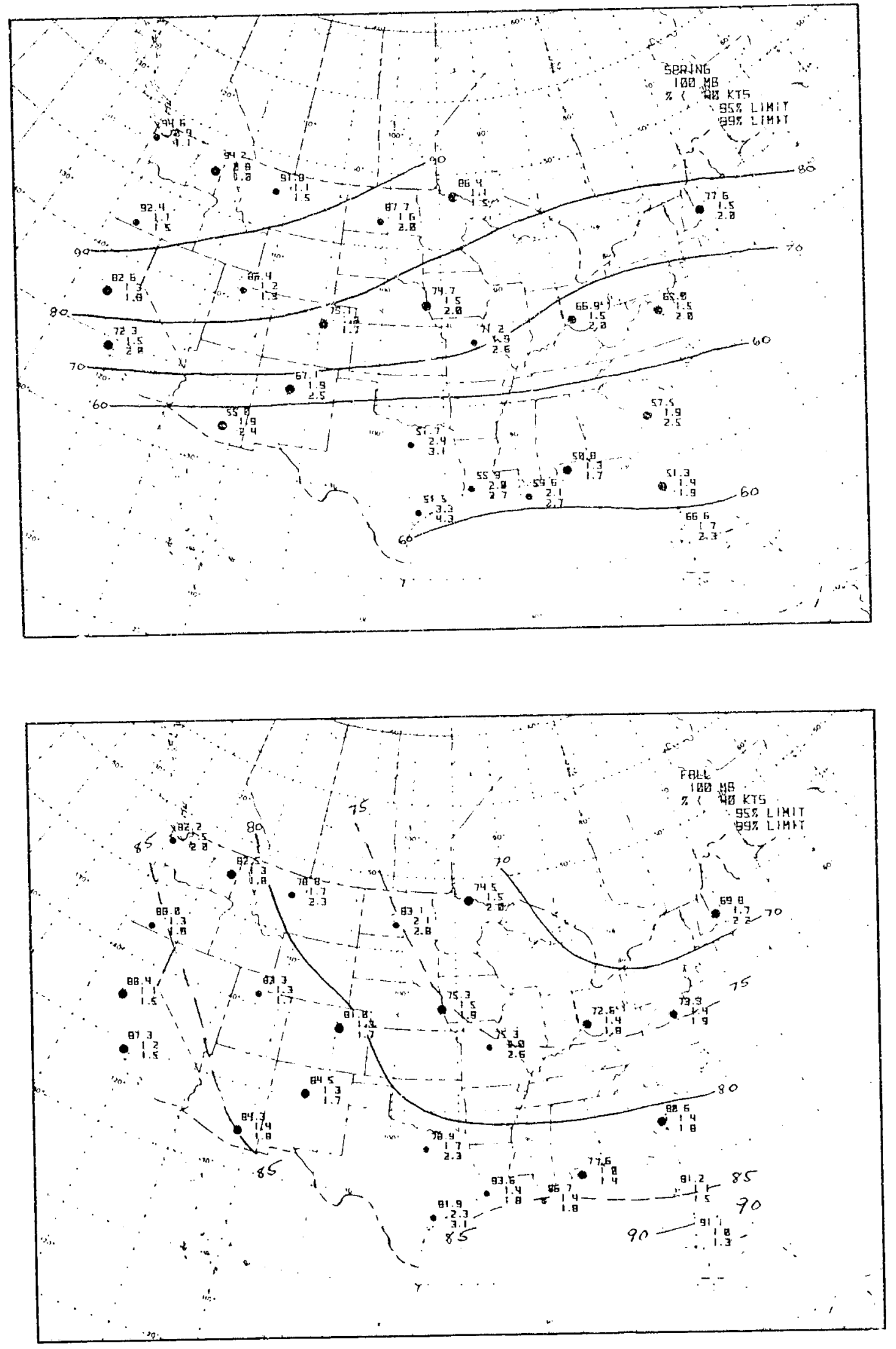

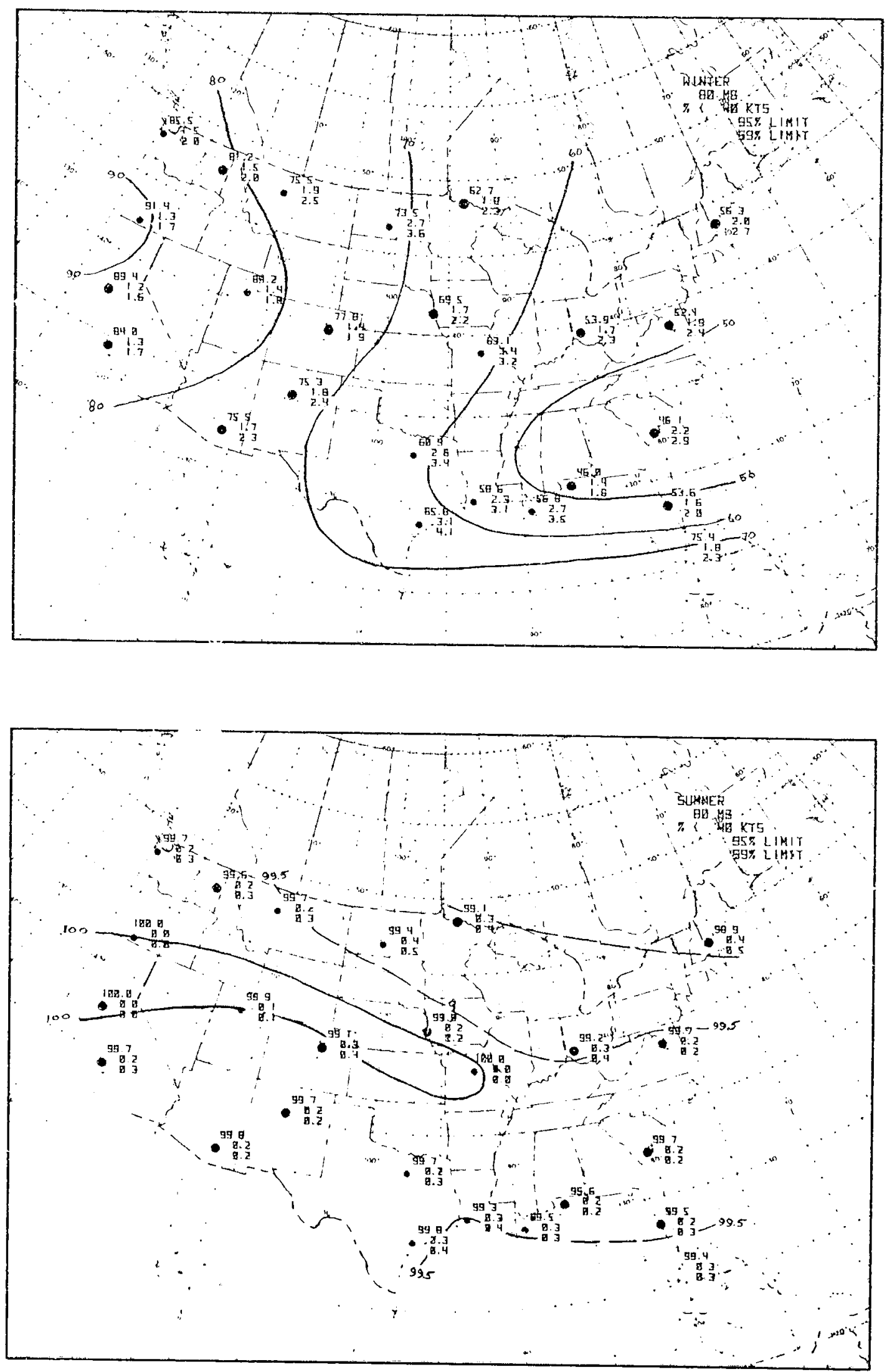

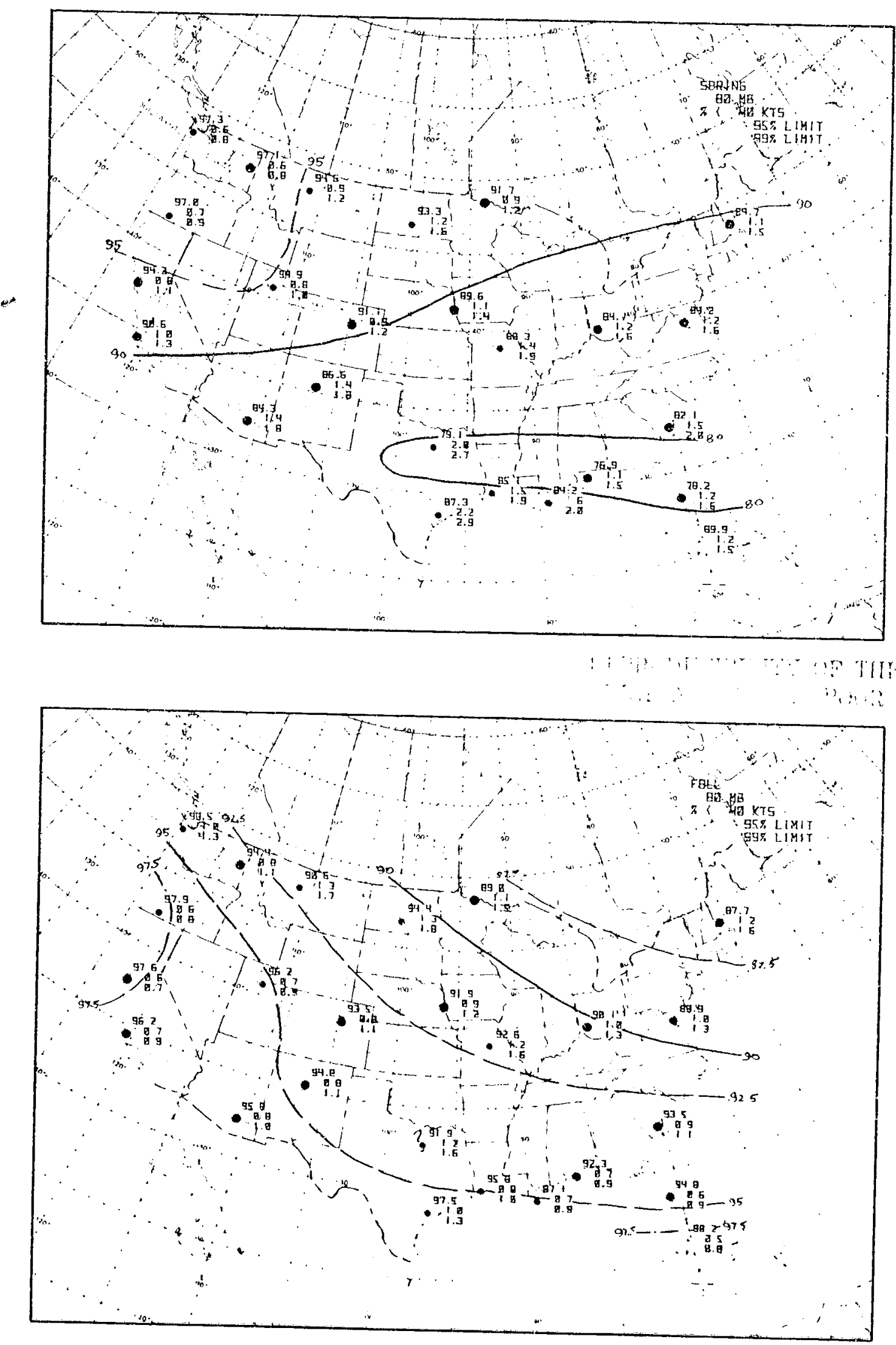

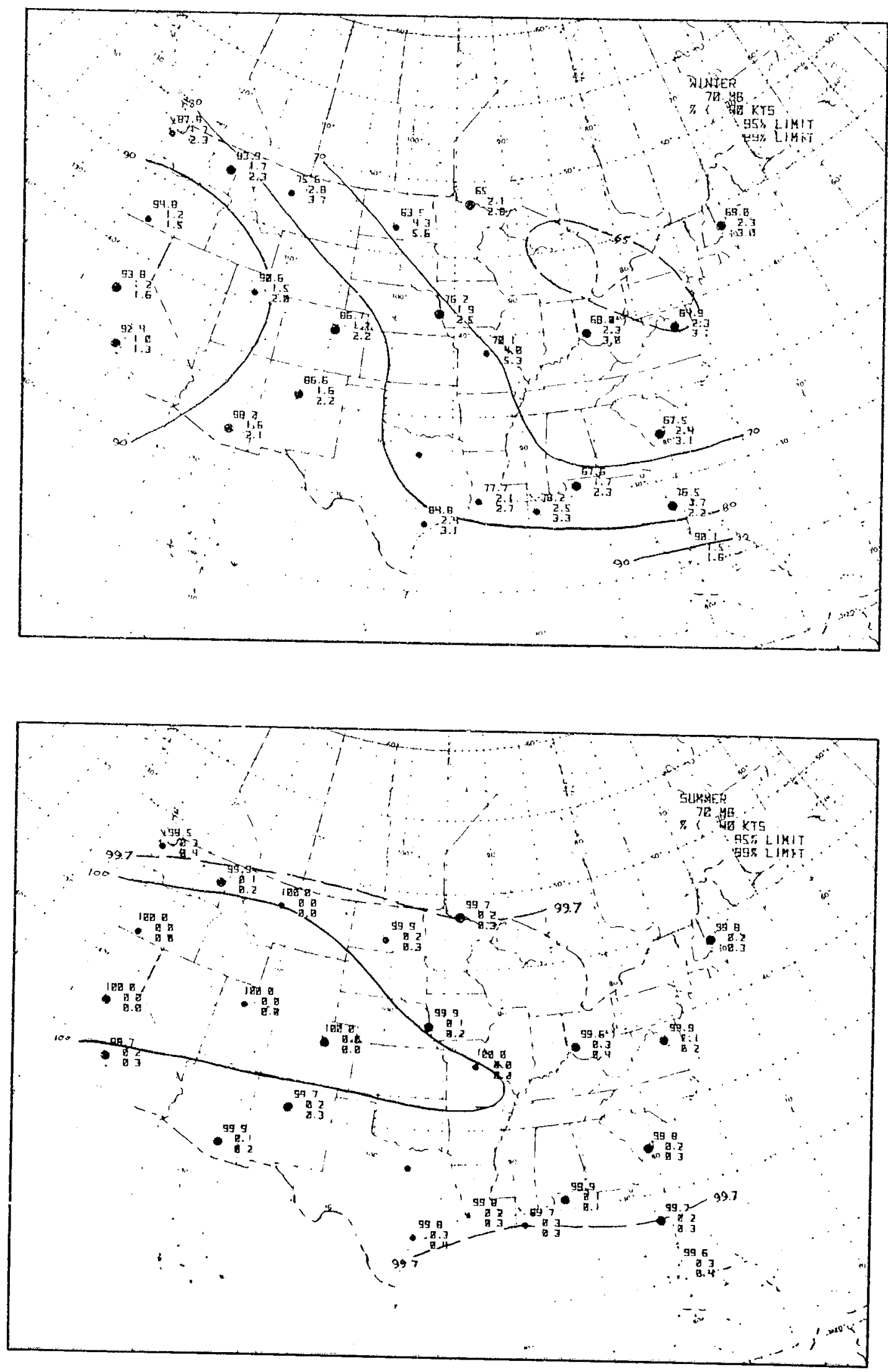

100 

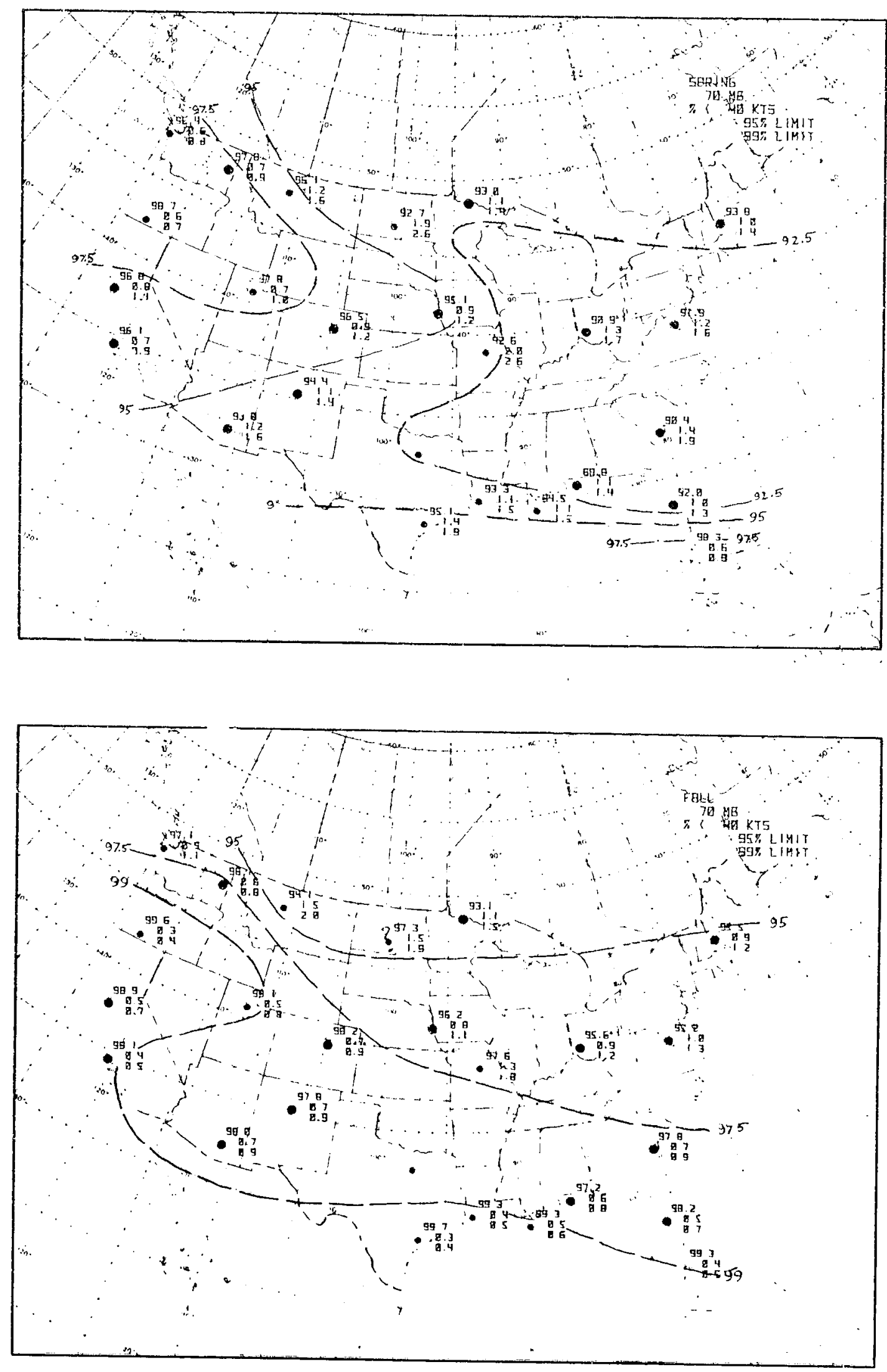

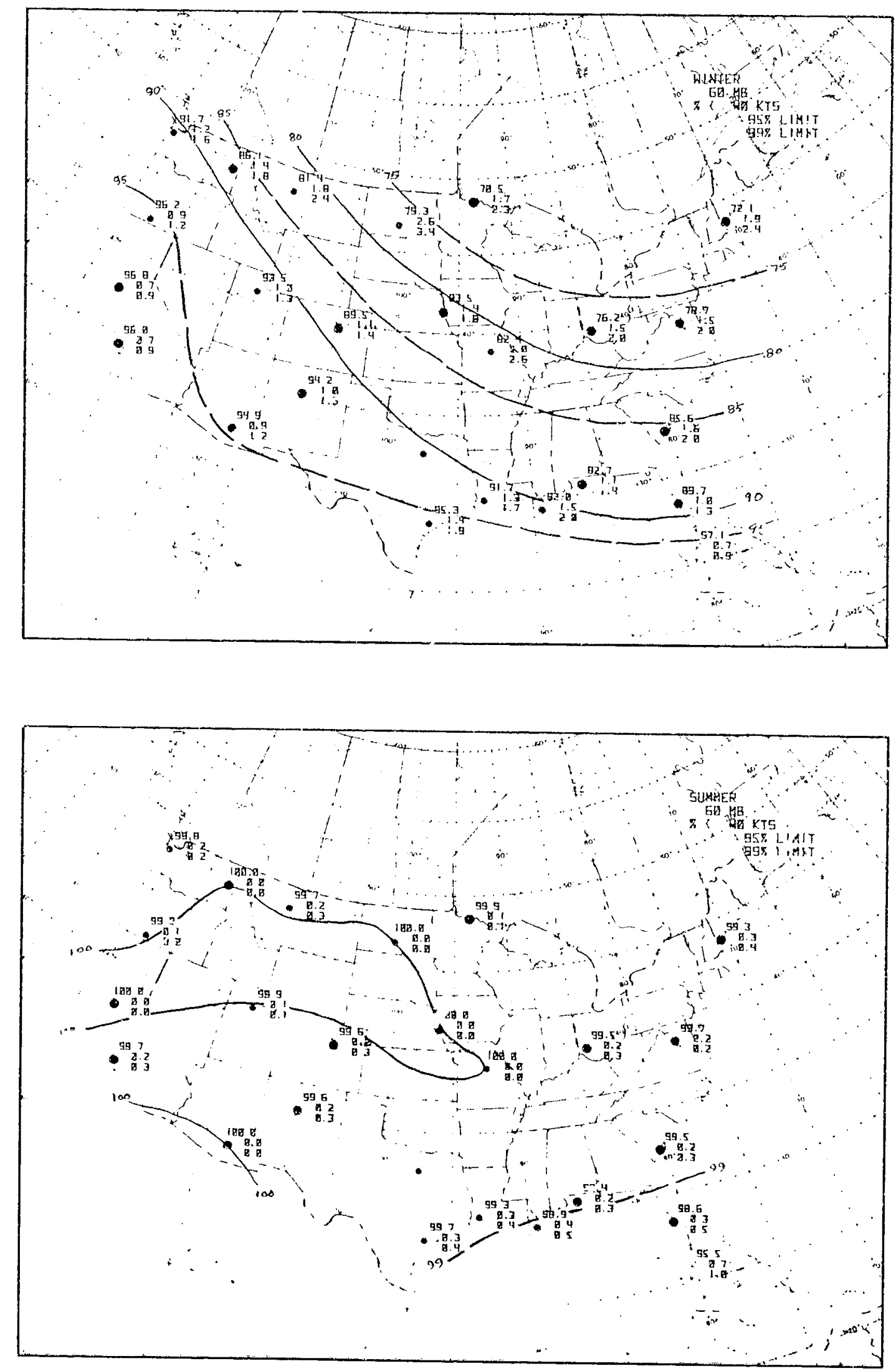

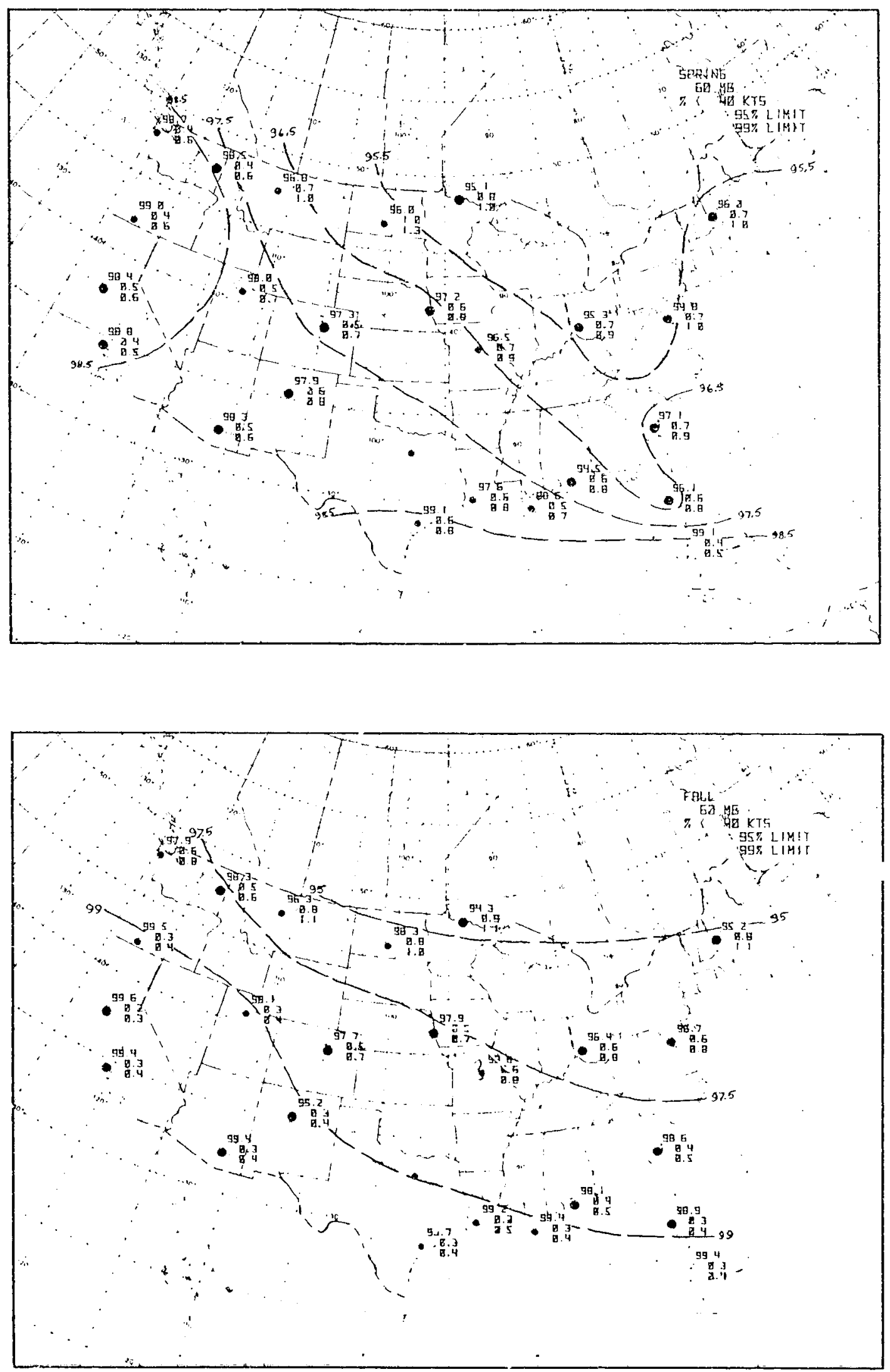

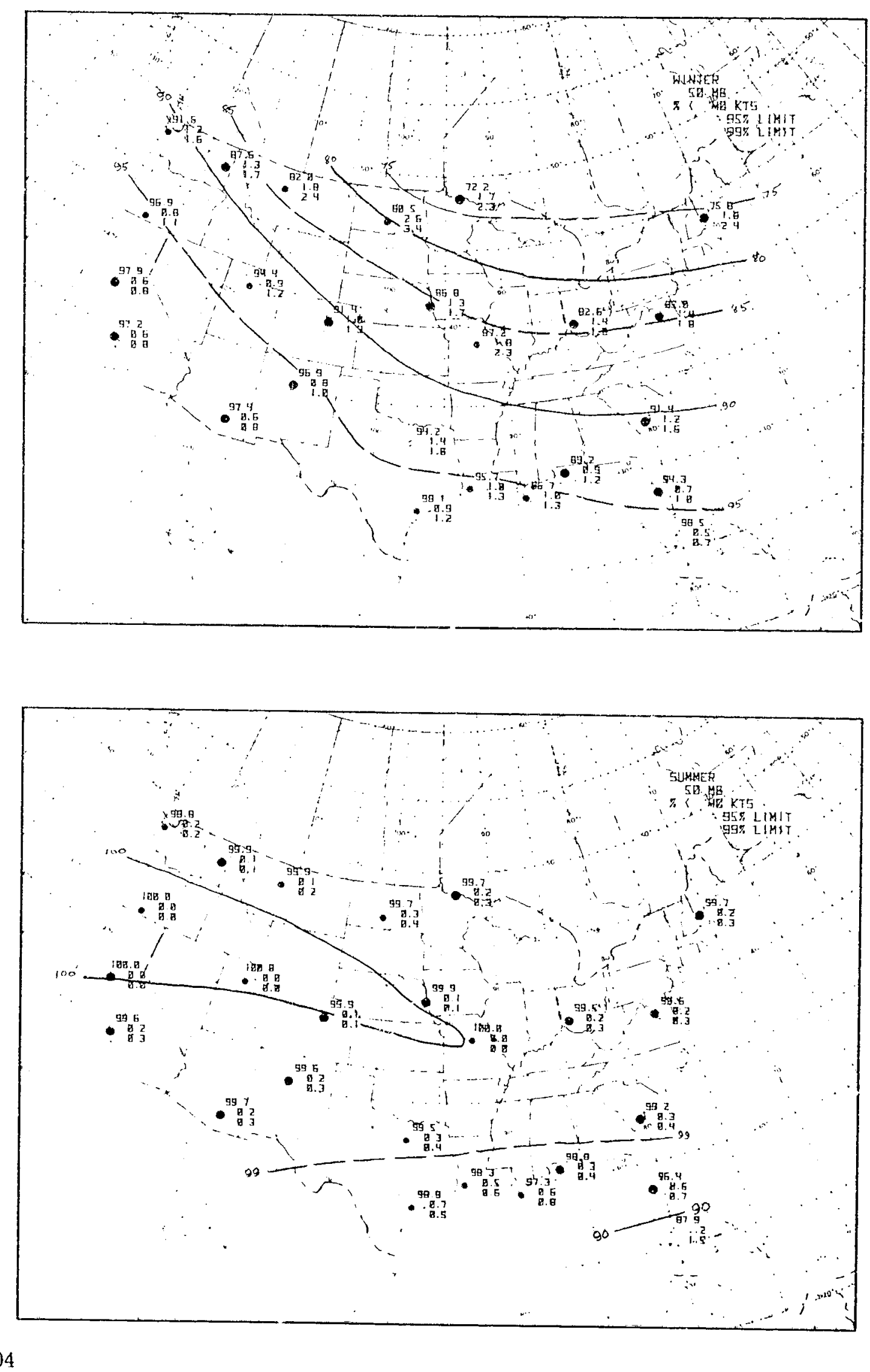

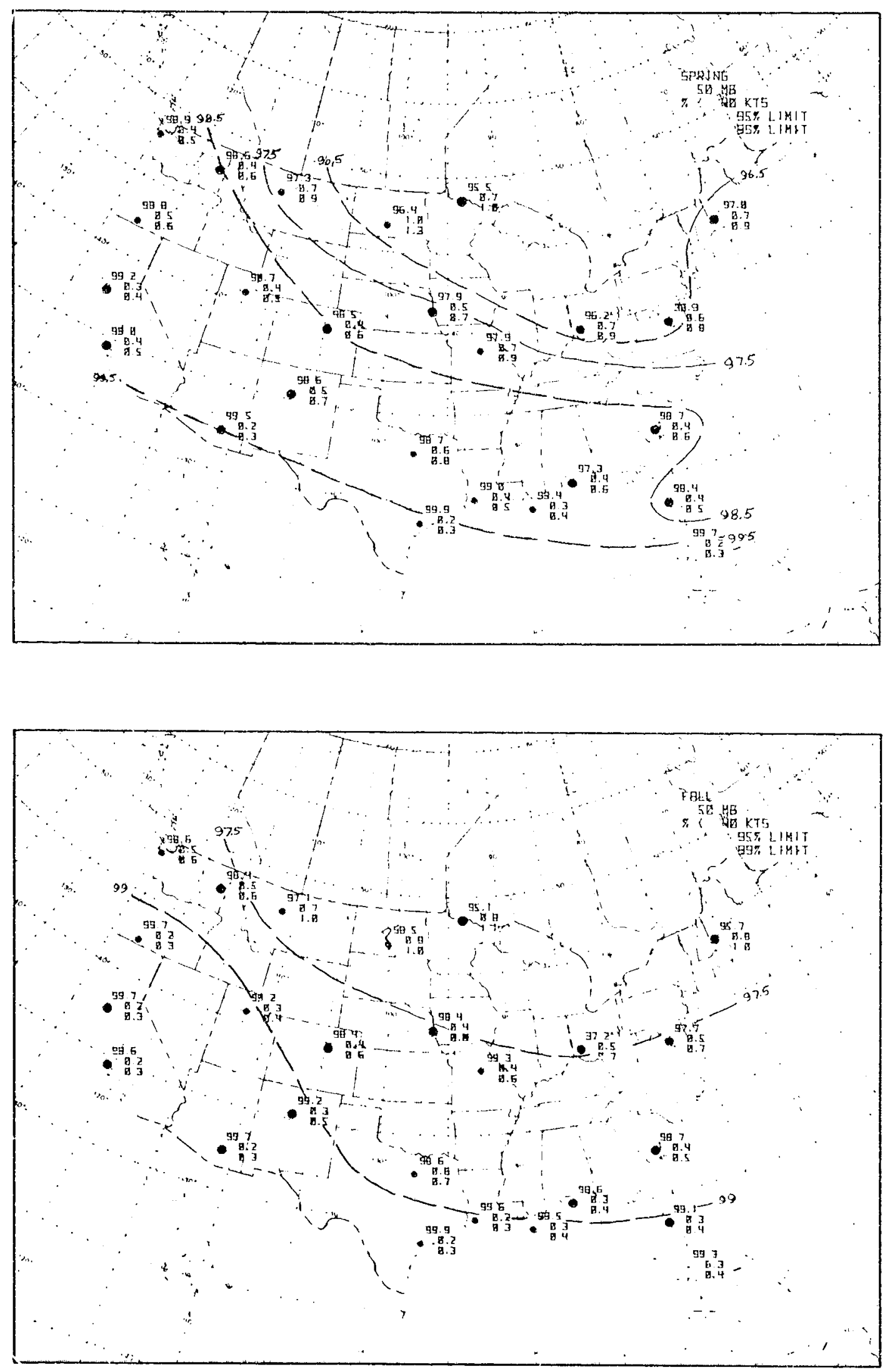

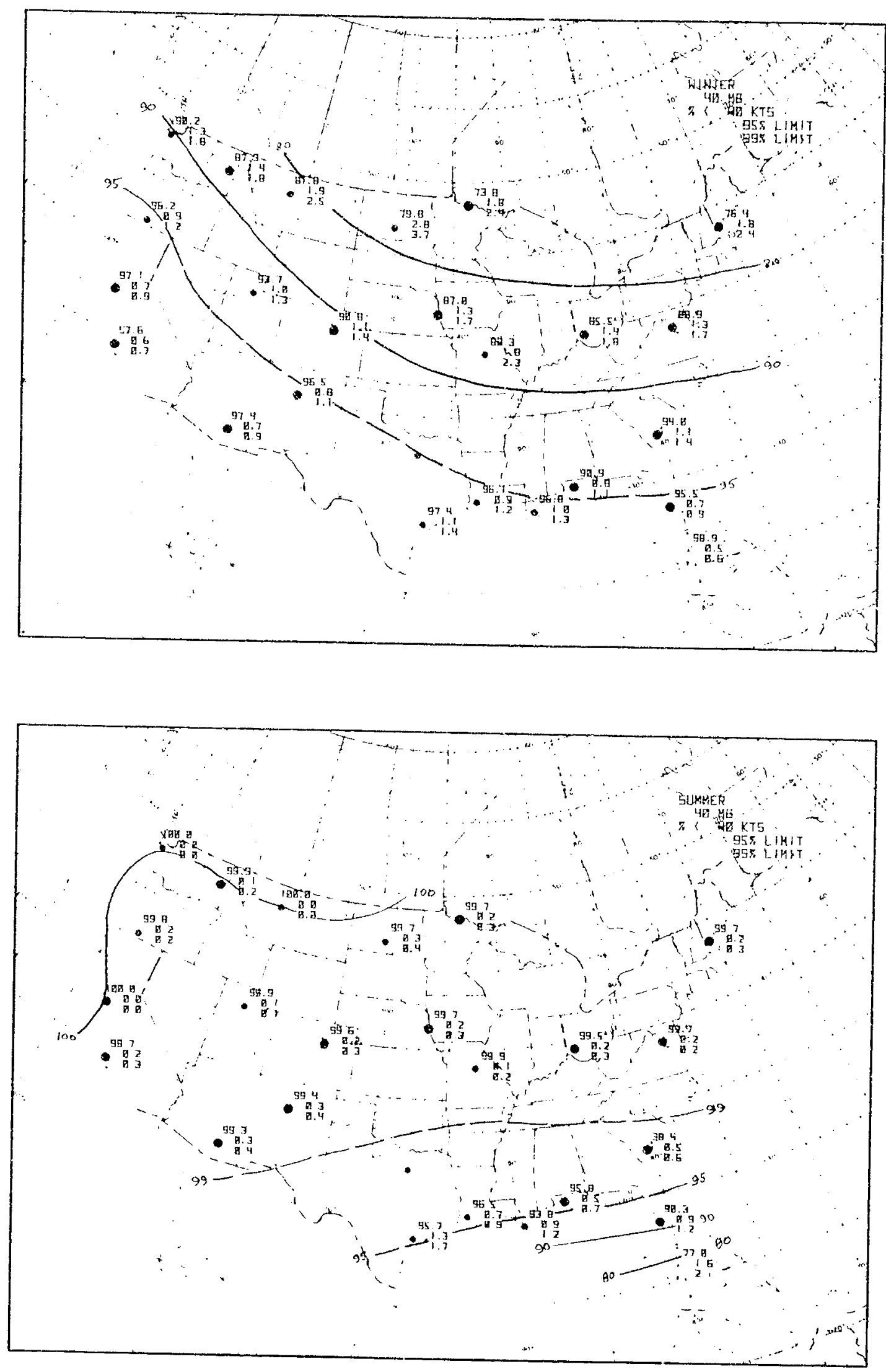

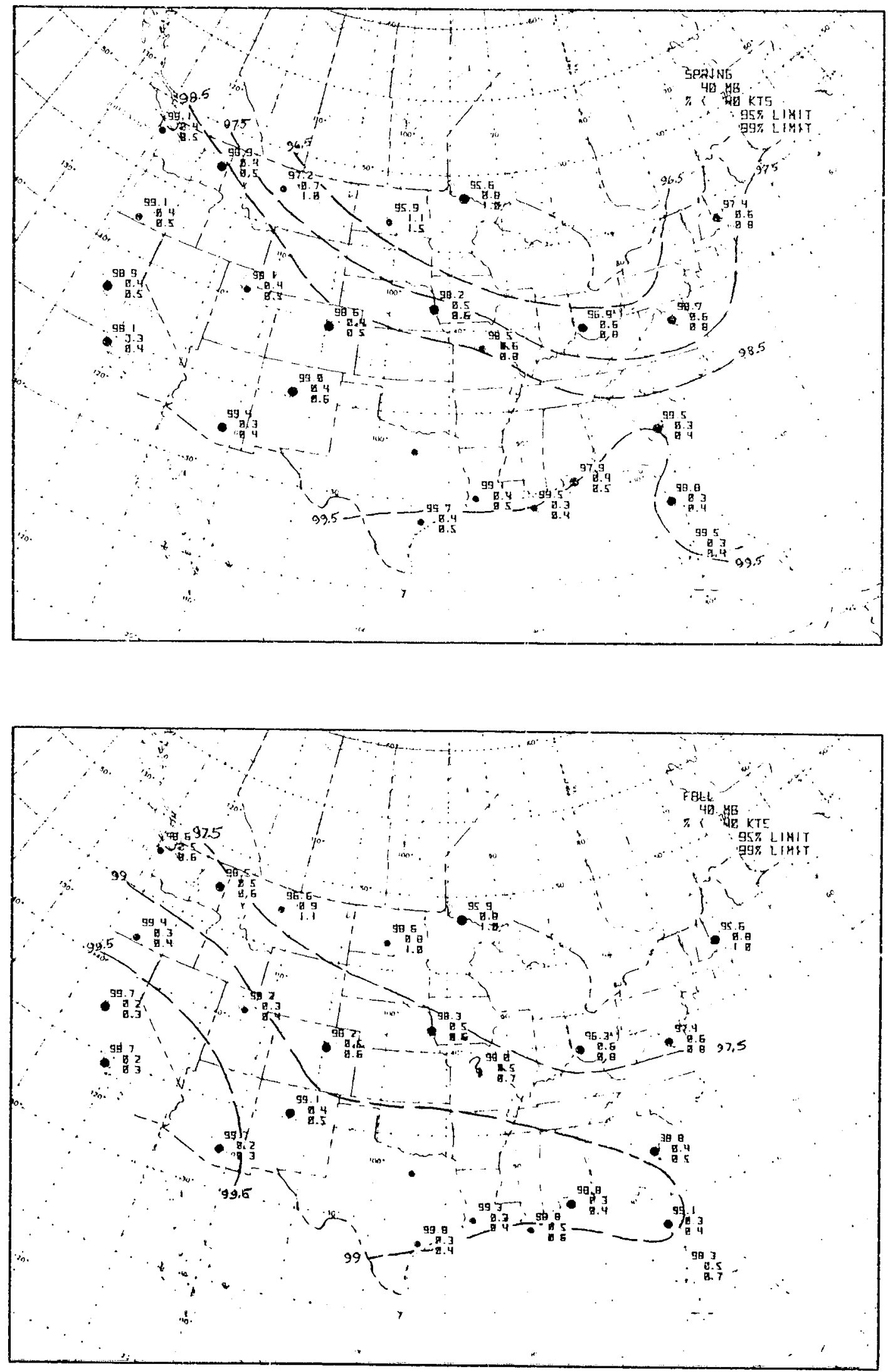

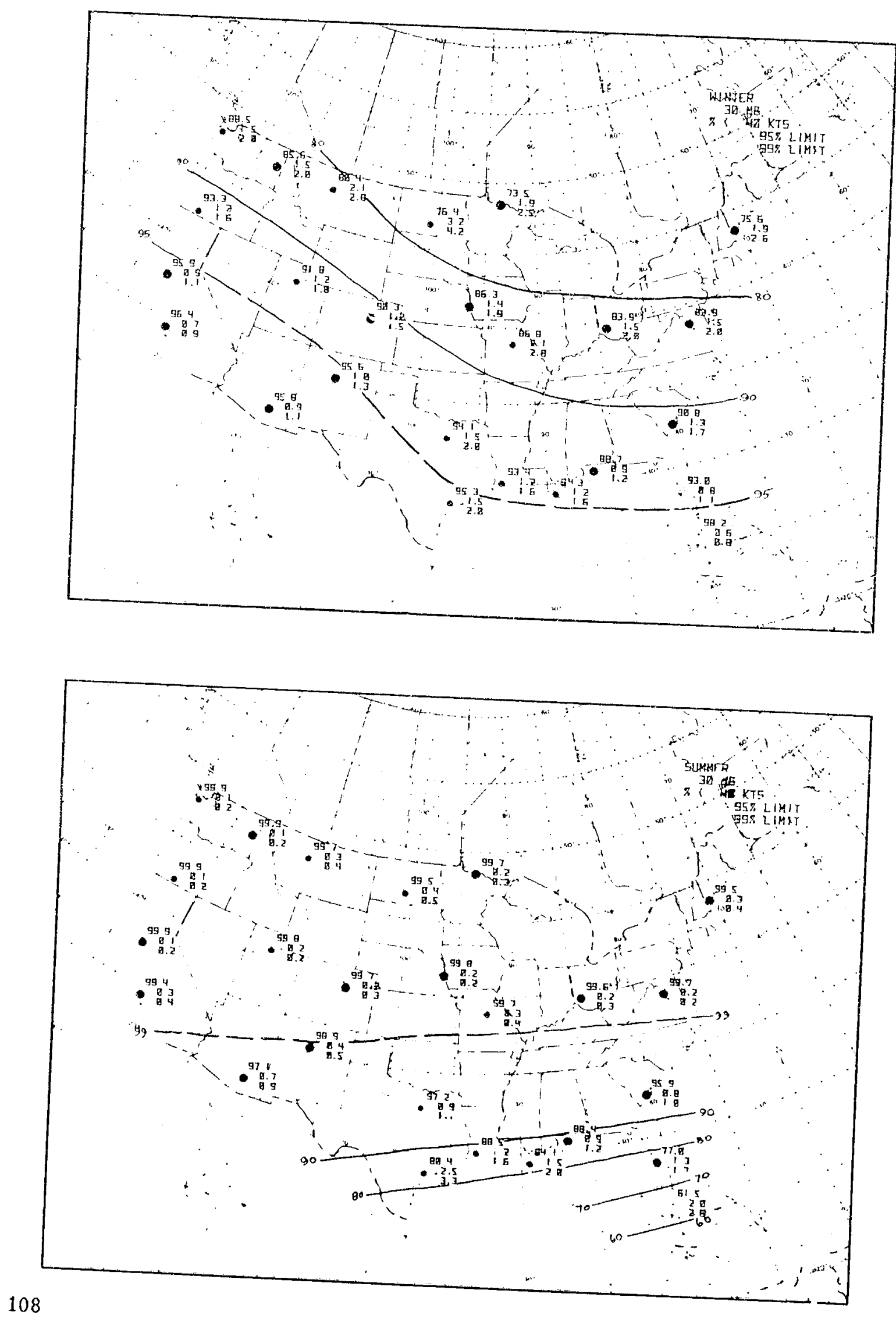


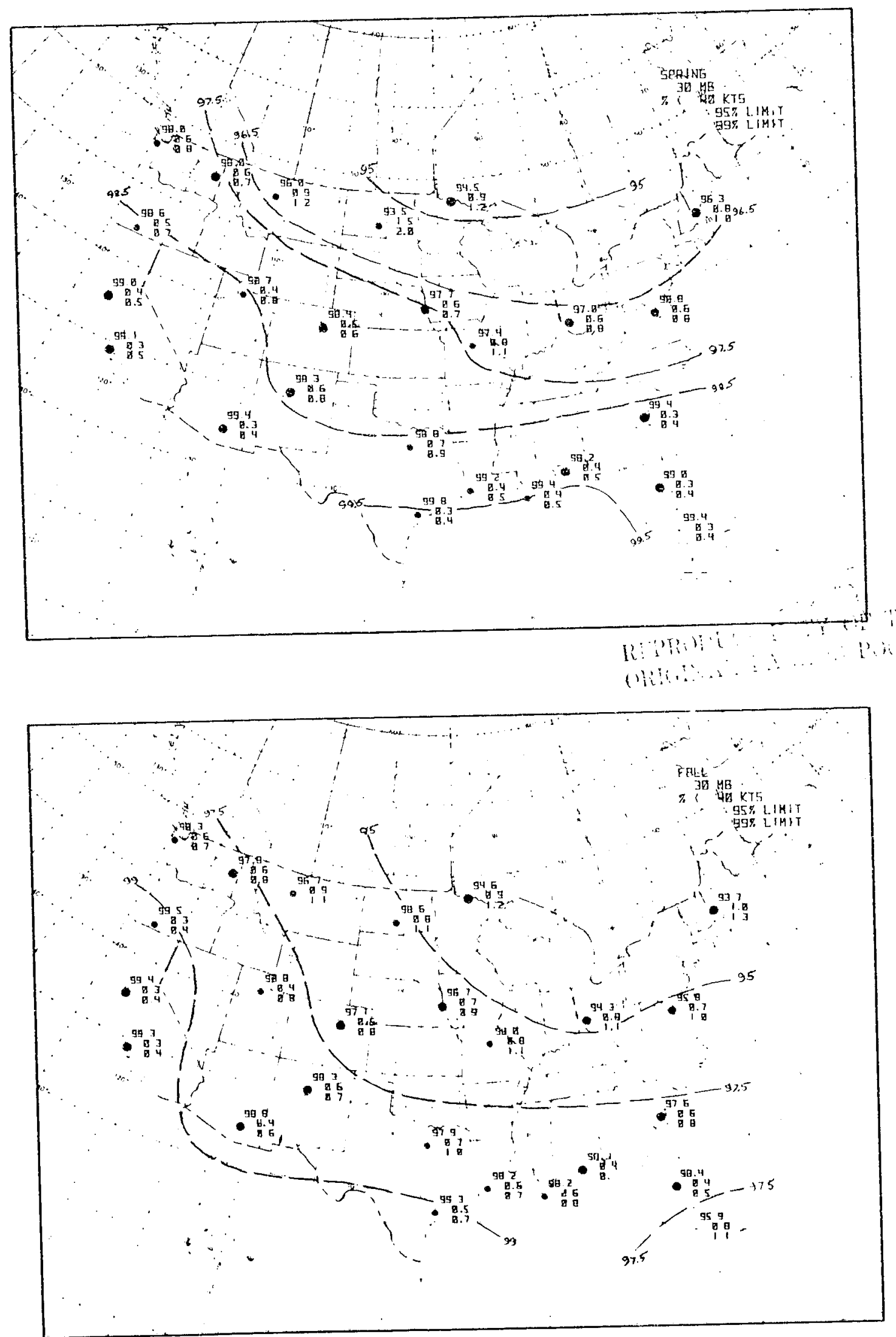



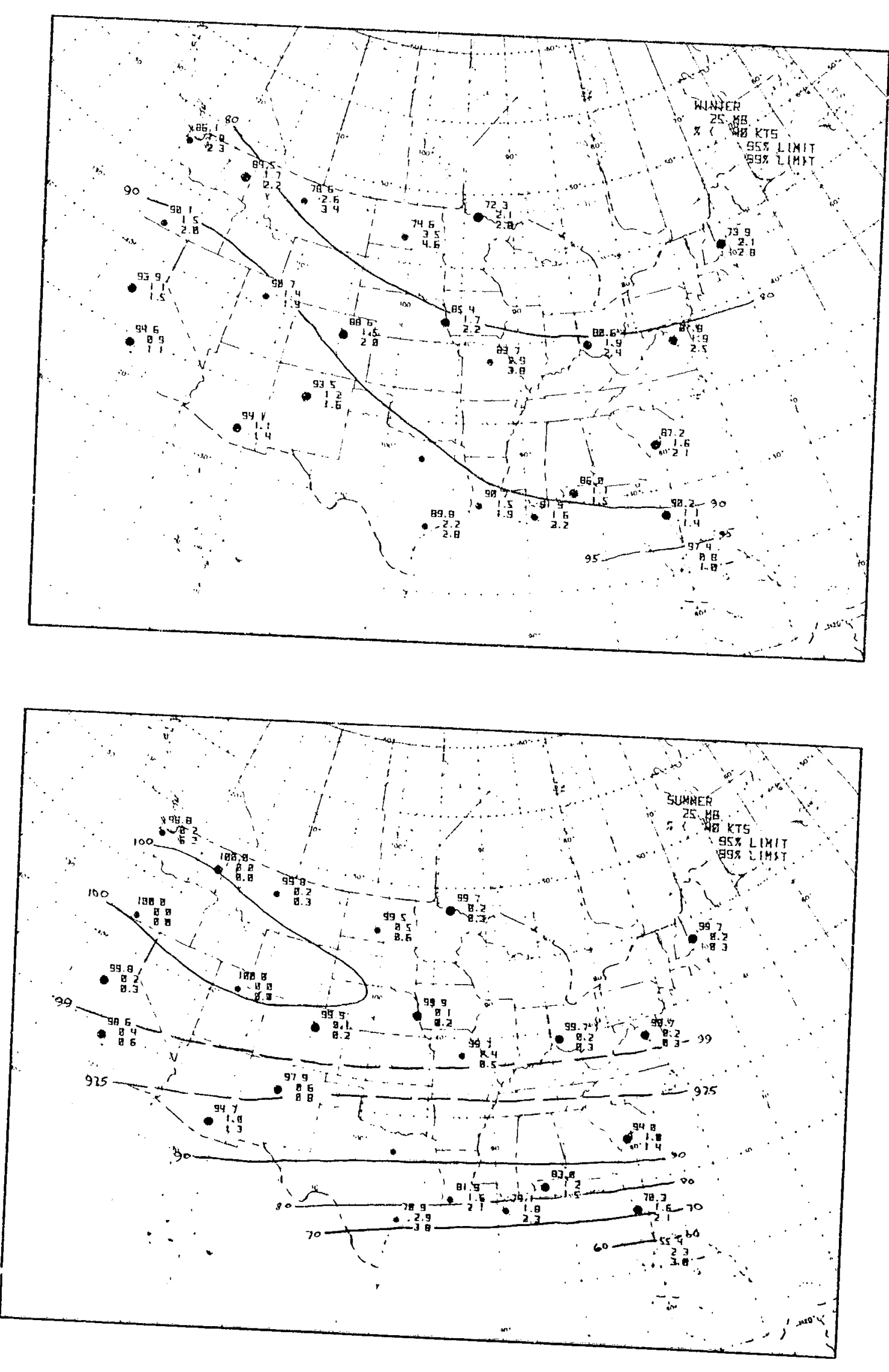

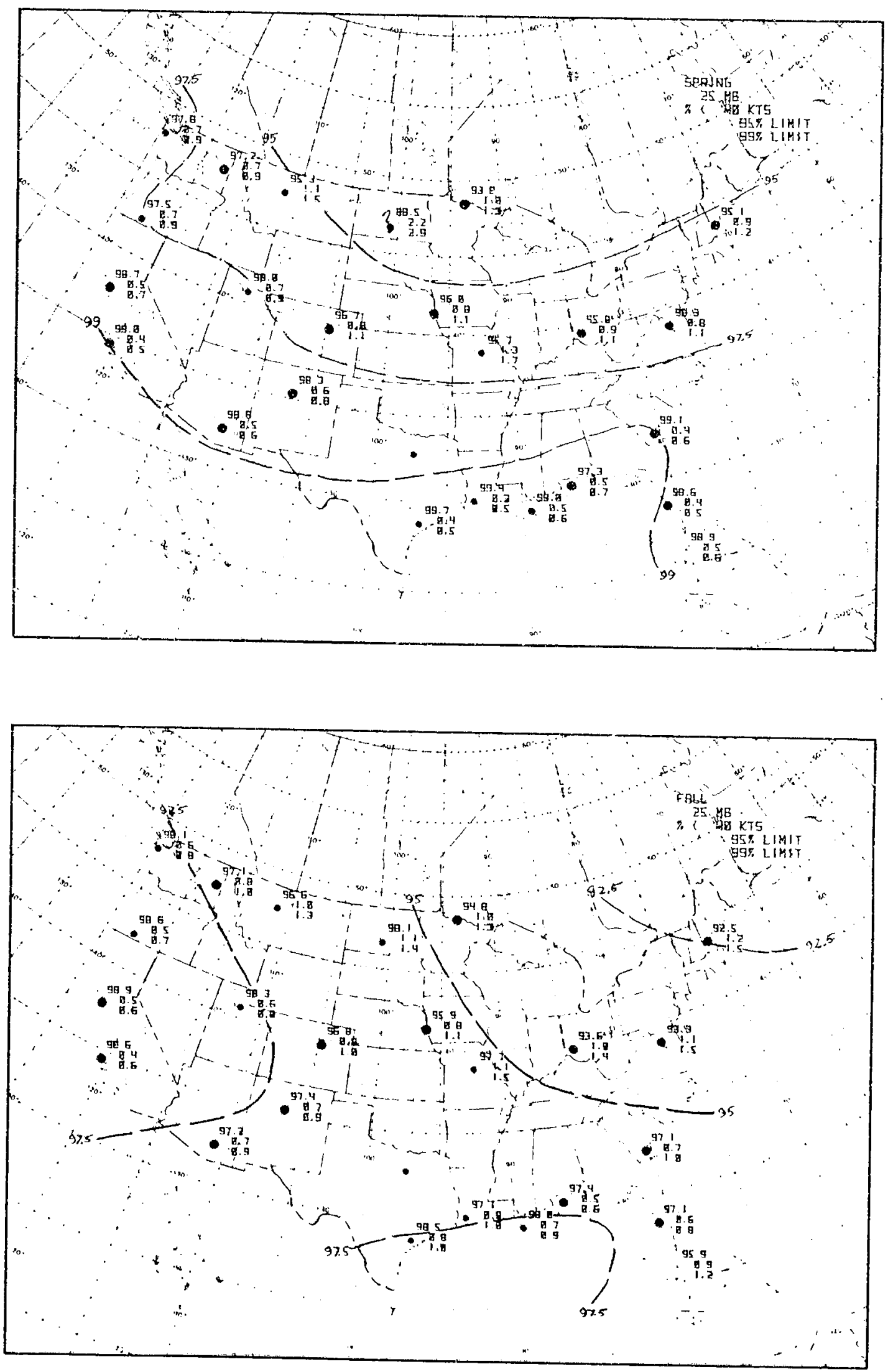

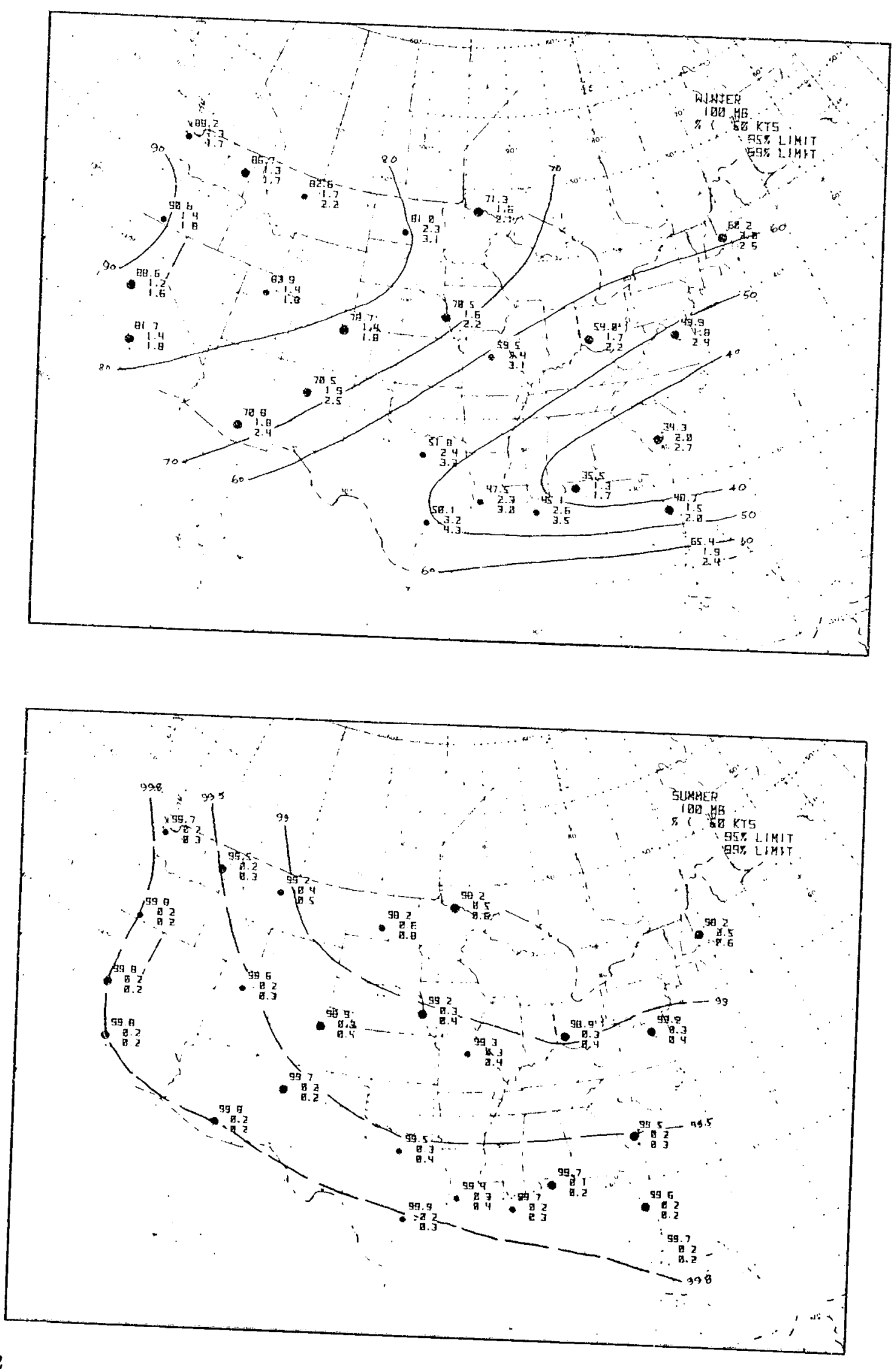

\section{2}



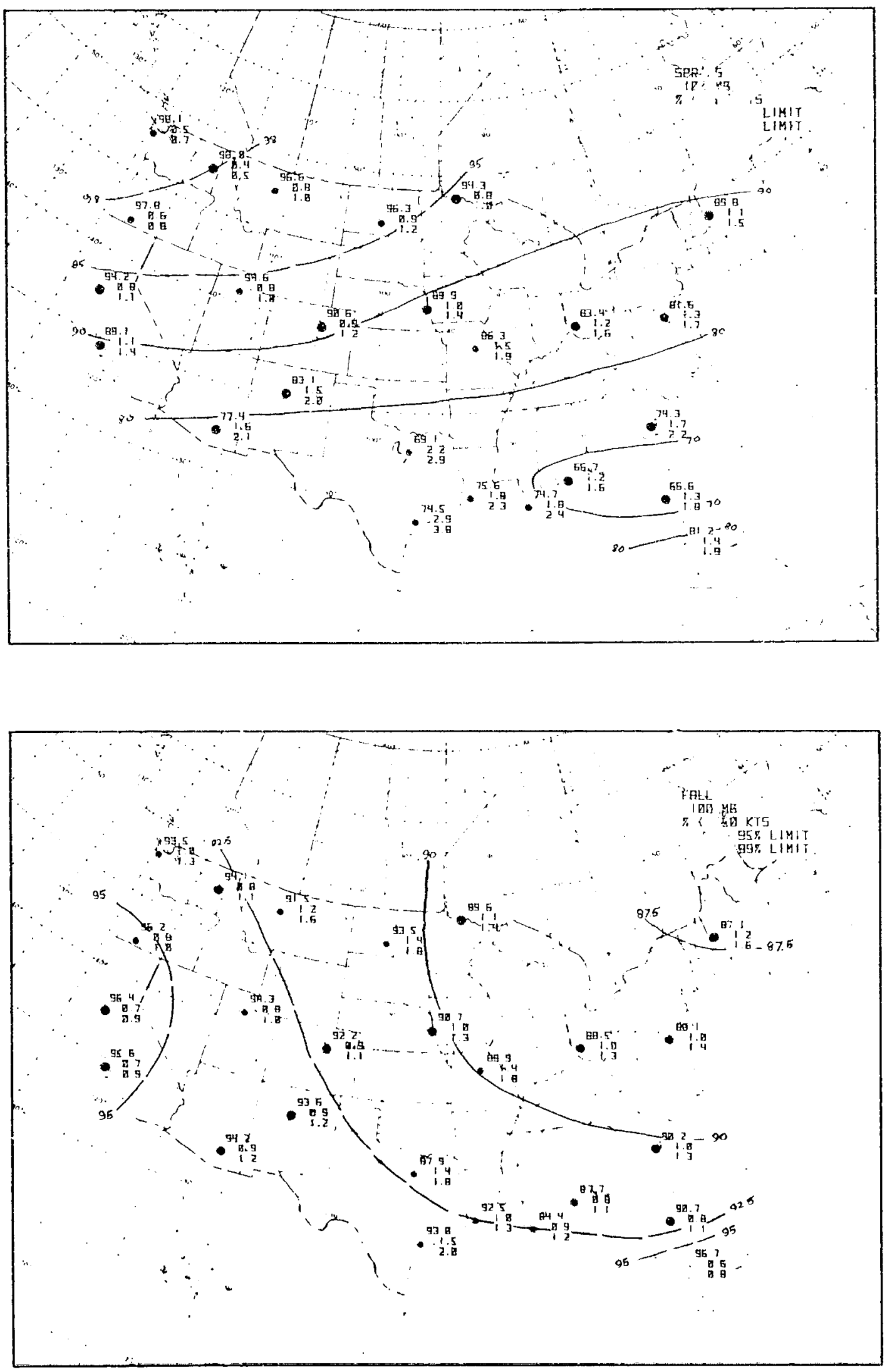

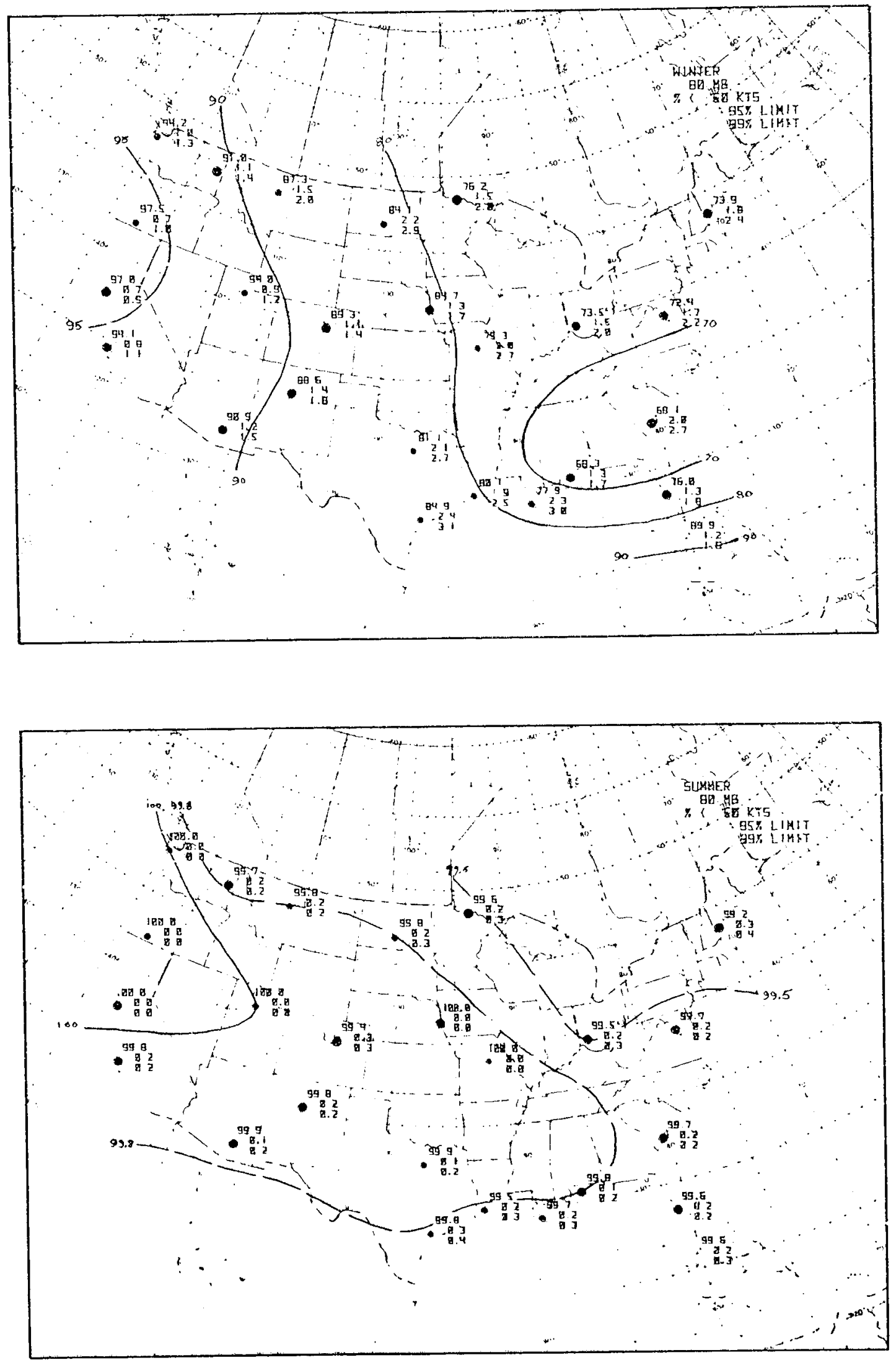

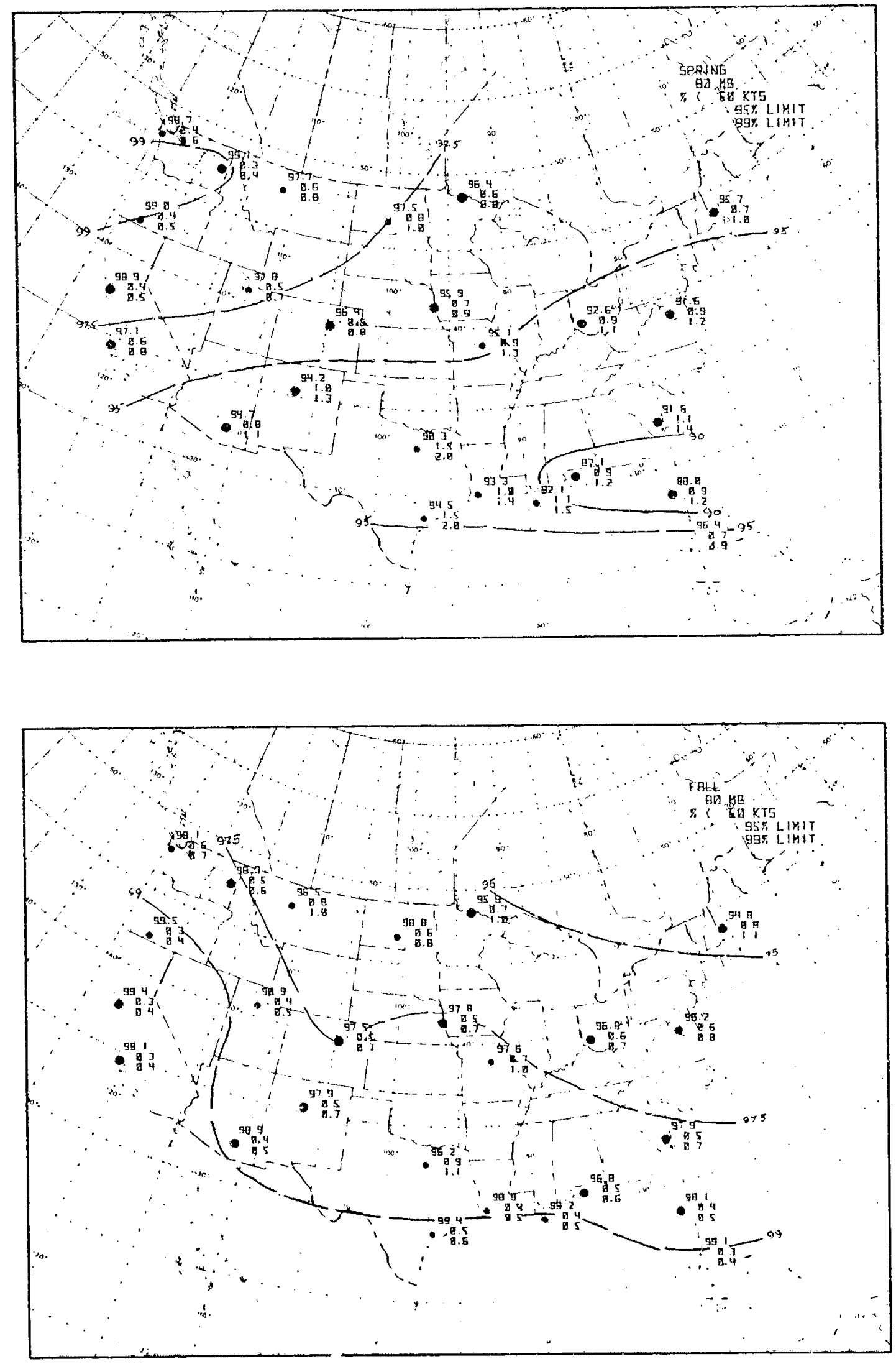

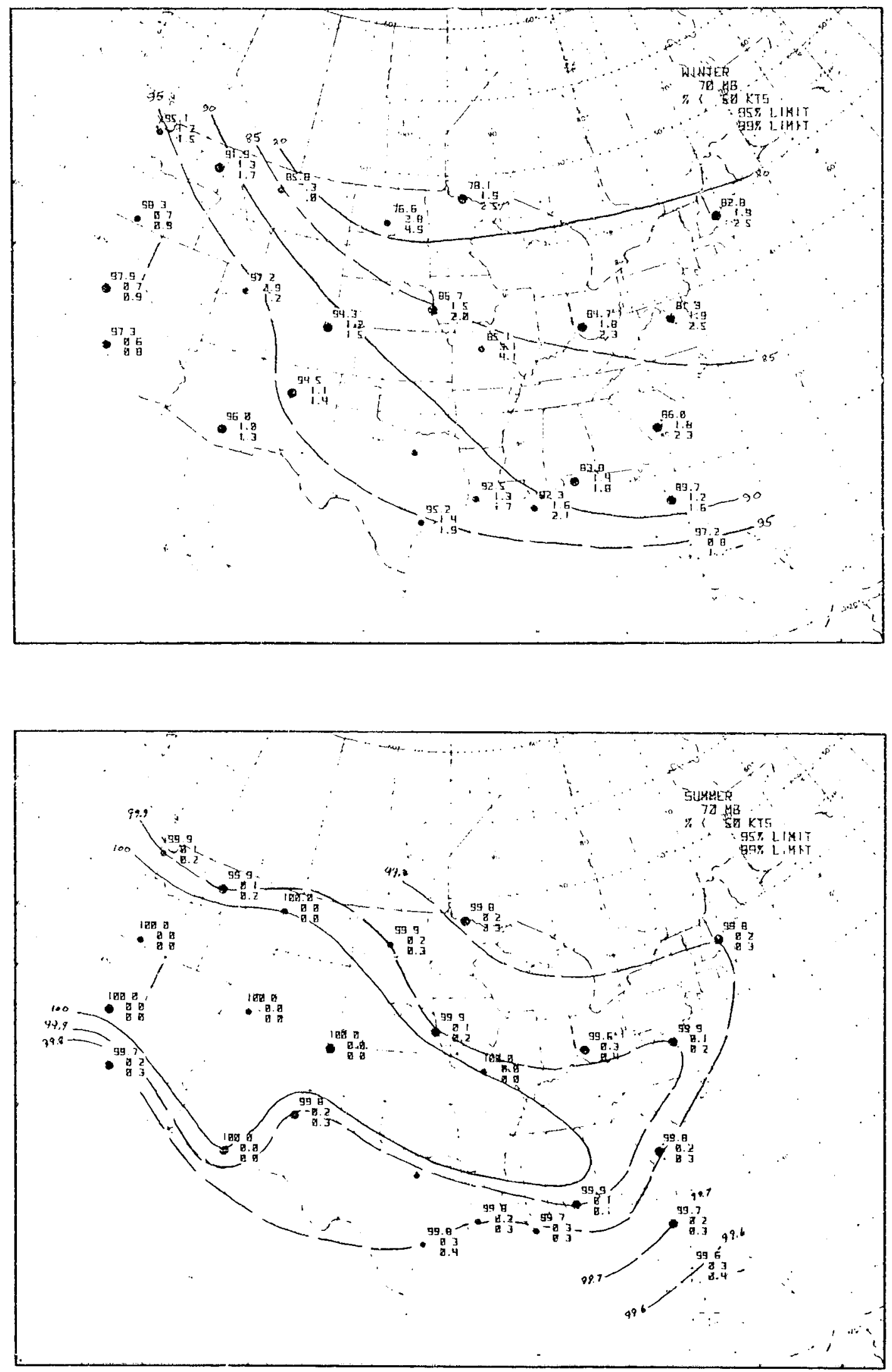


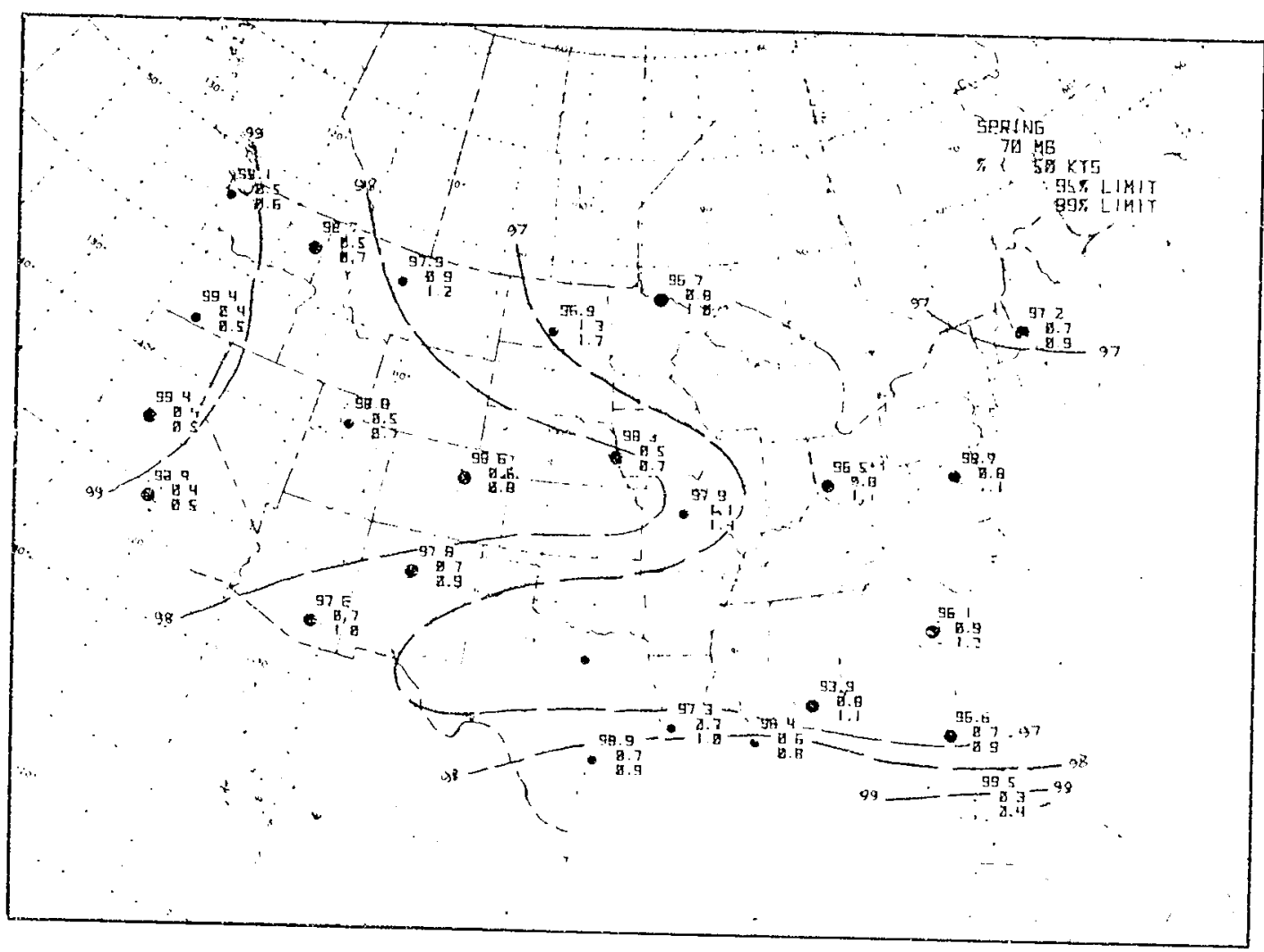

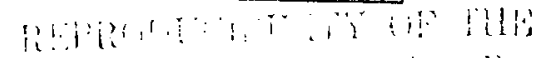

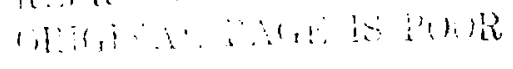

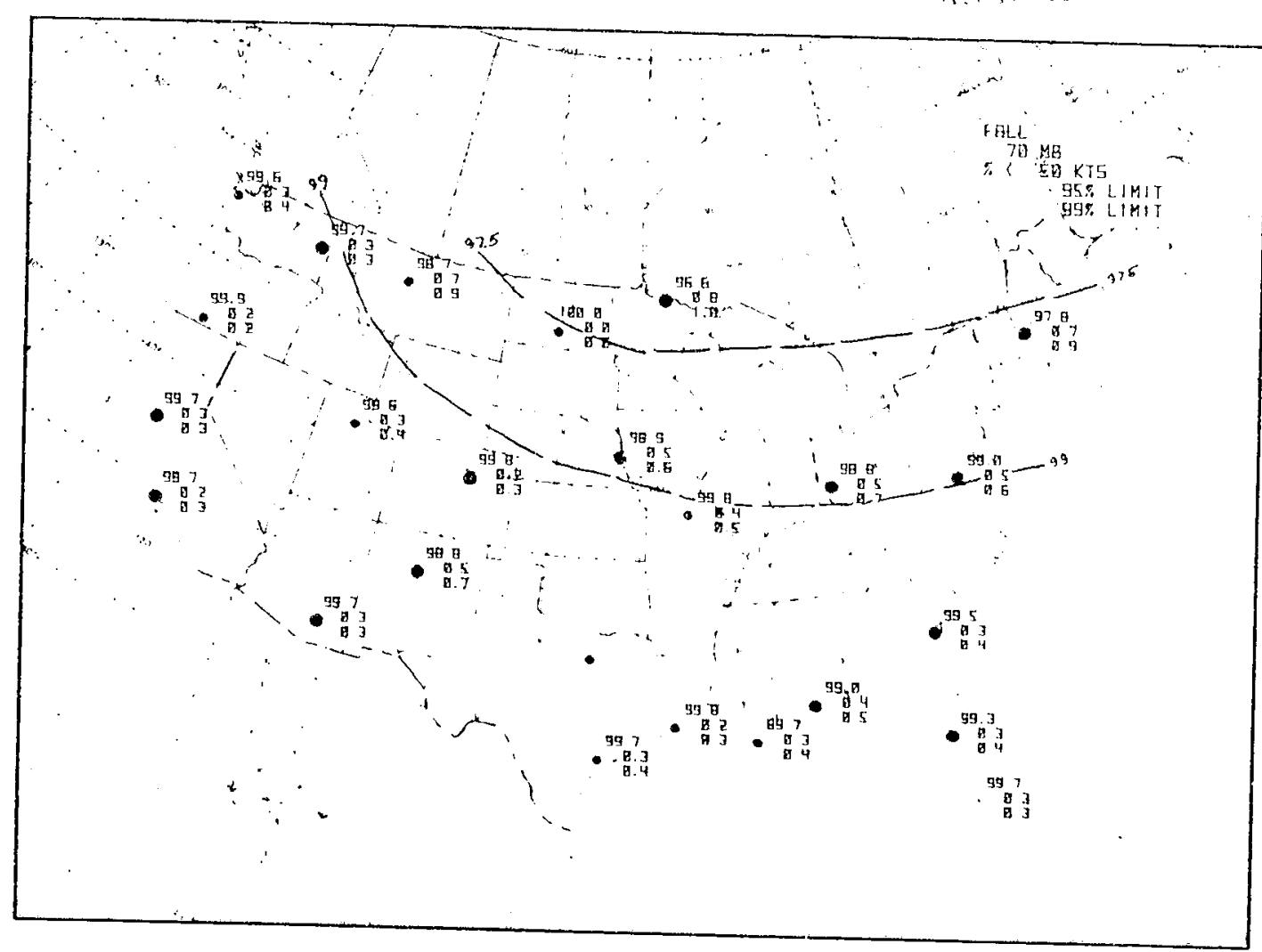



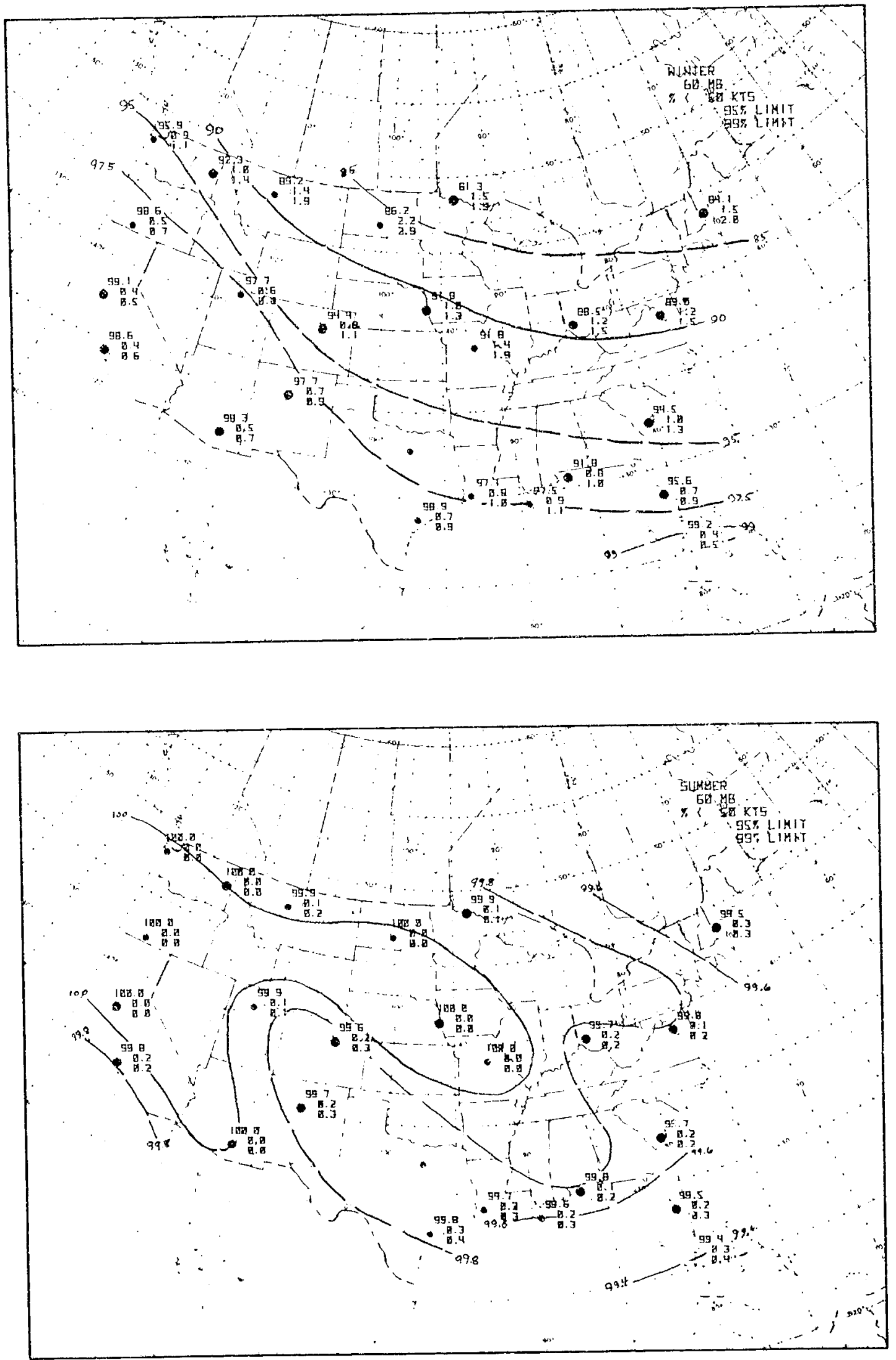

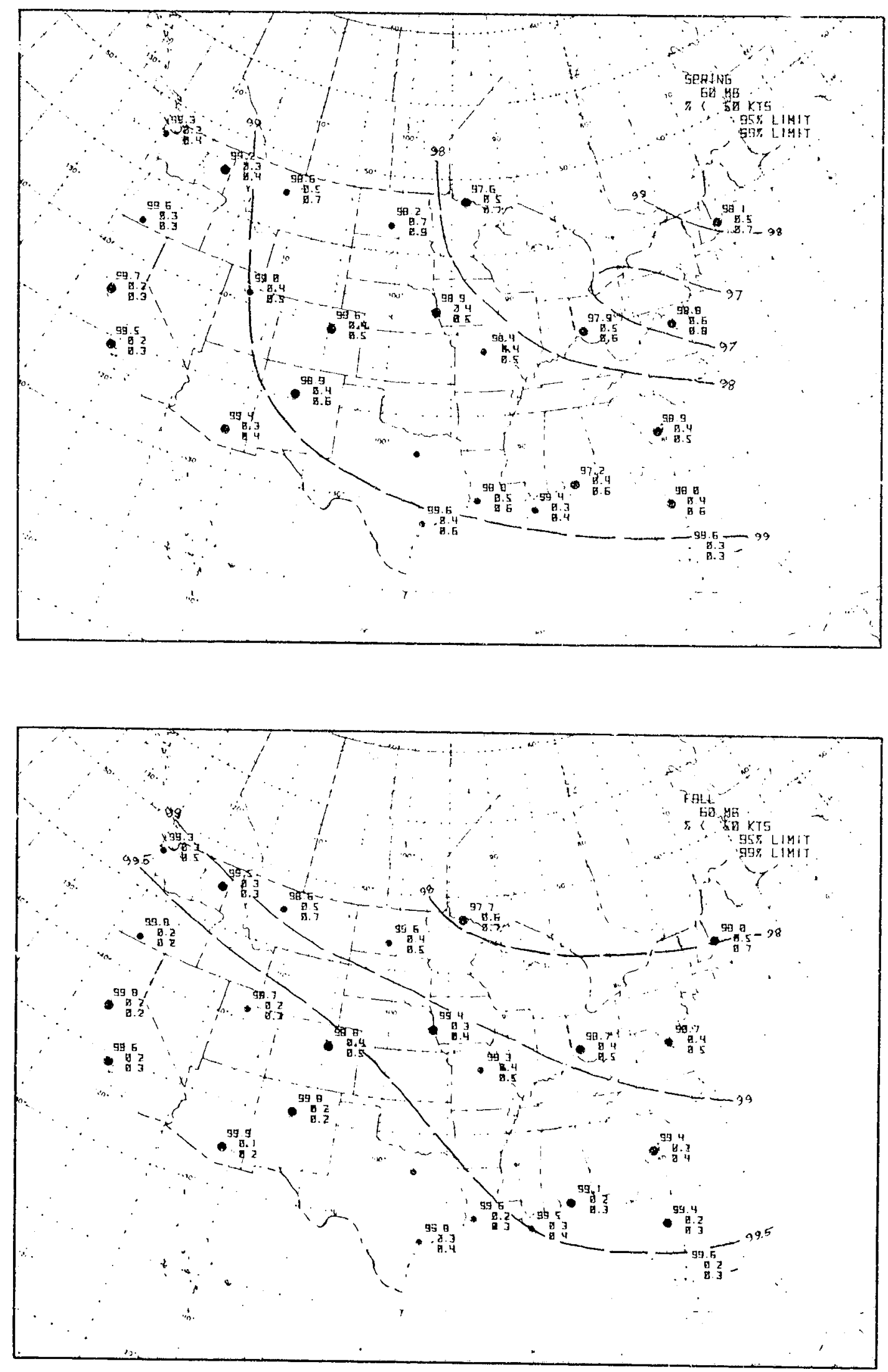

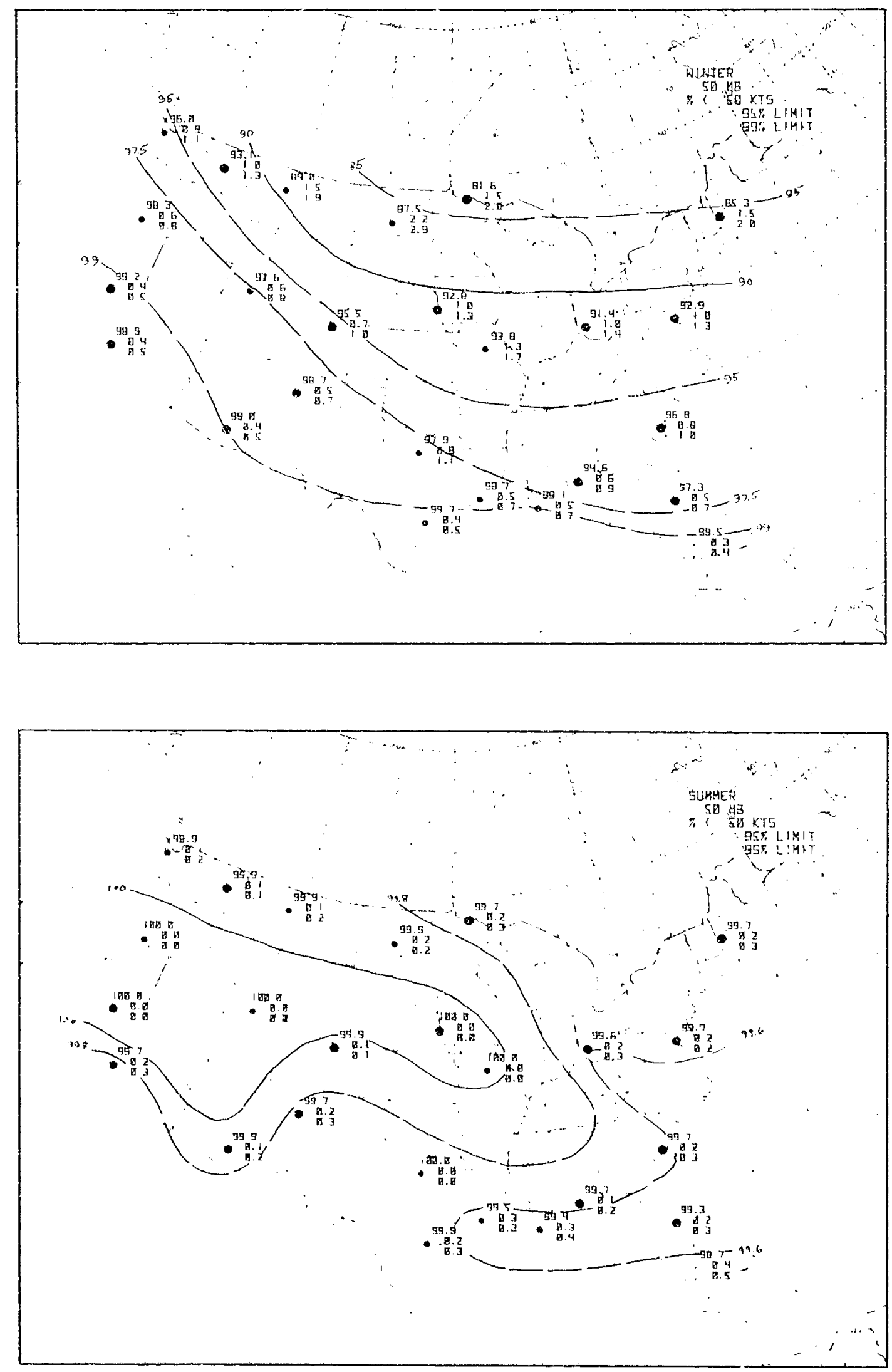

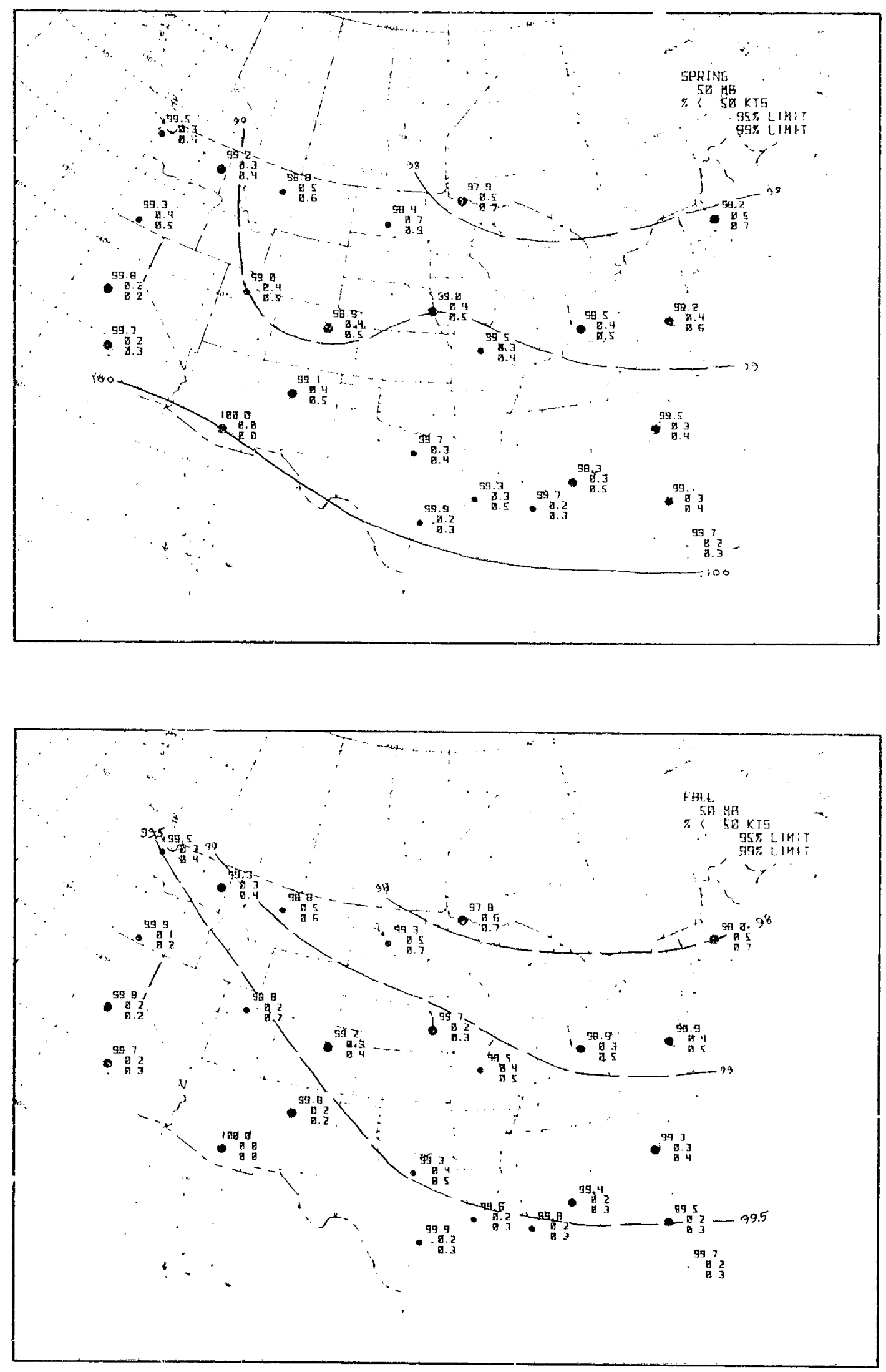

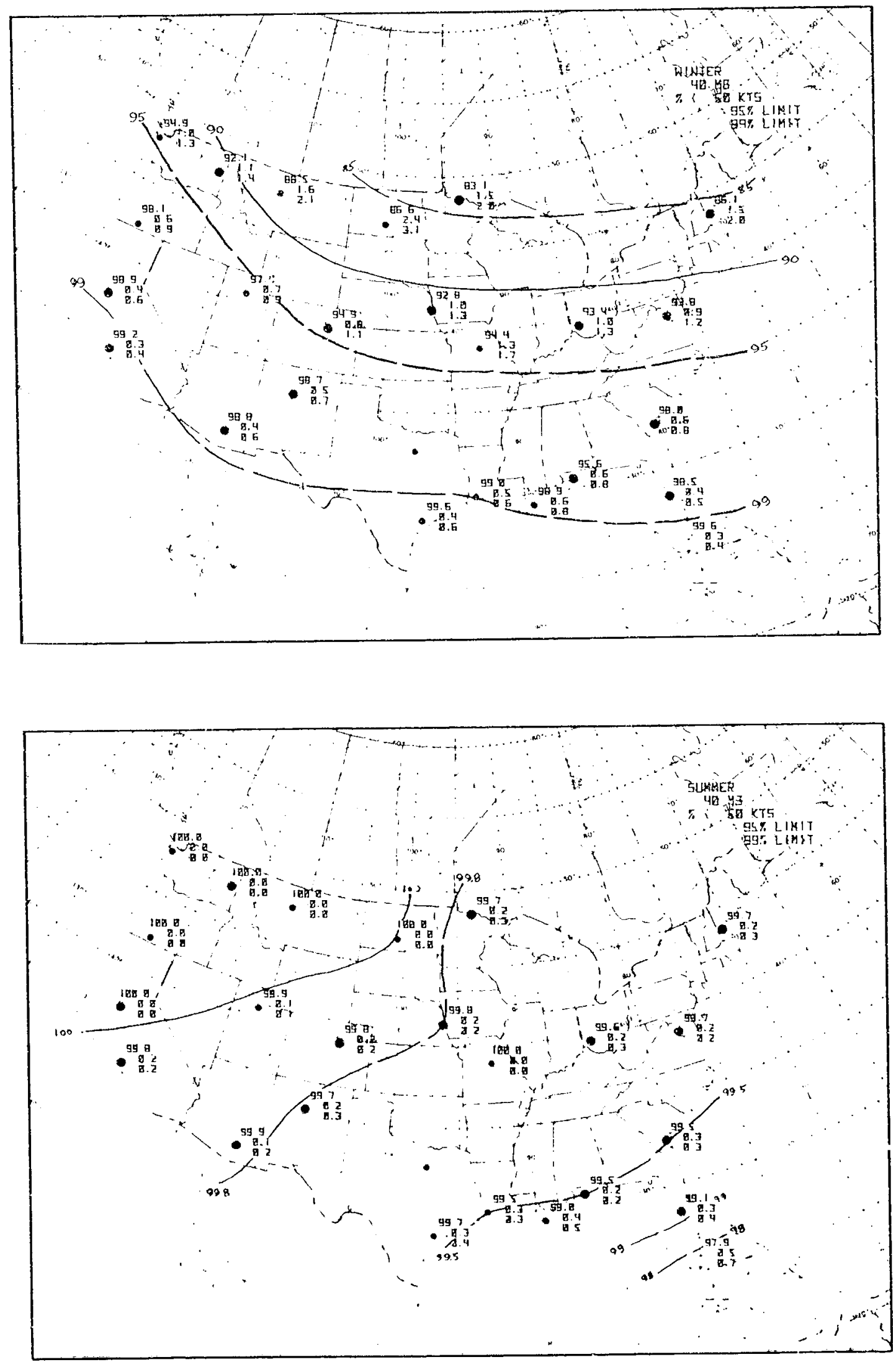


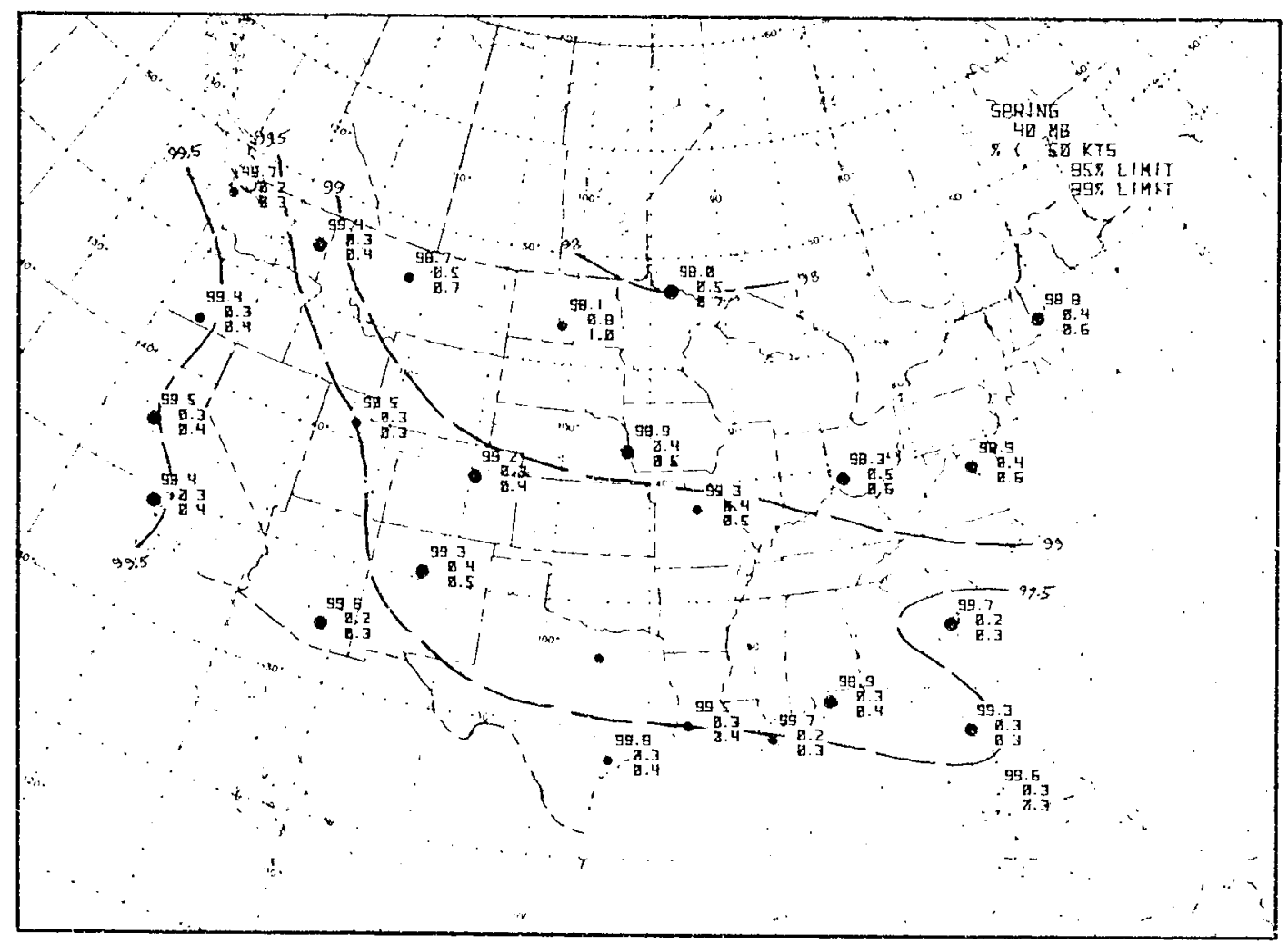

1

T:

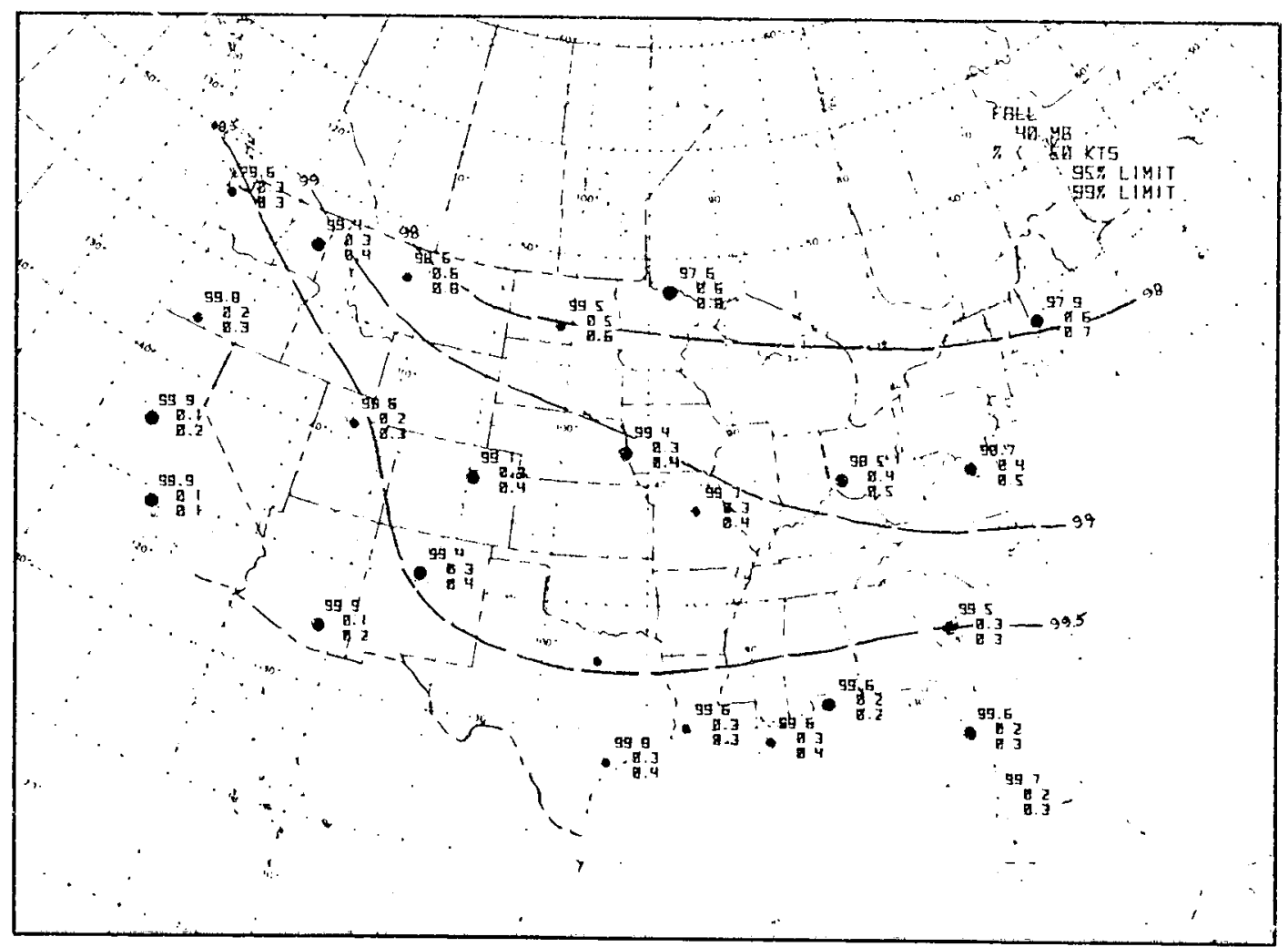



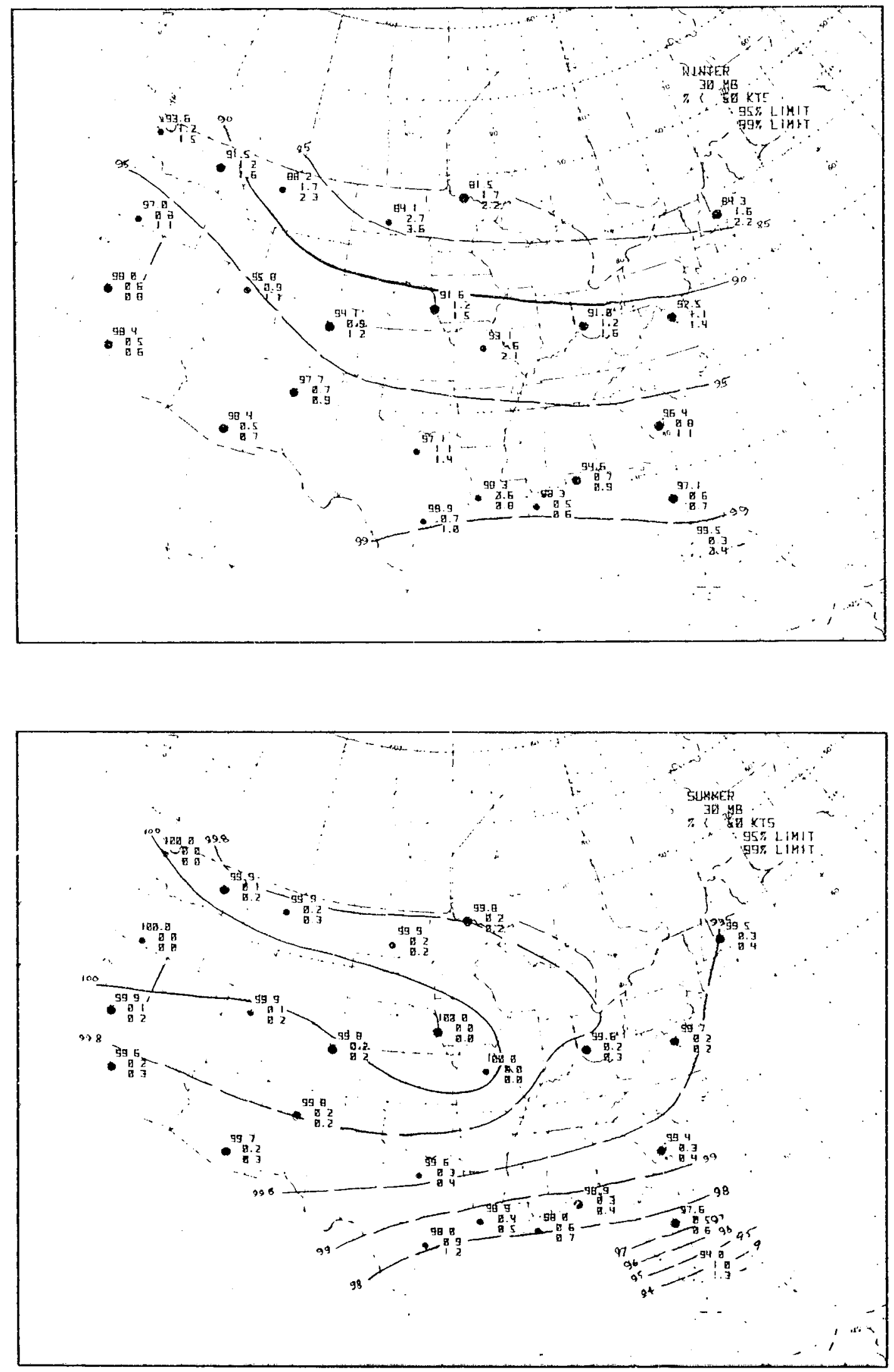

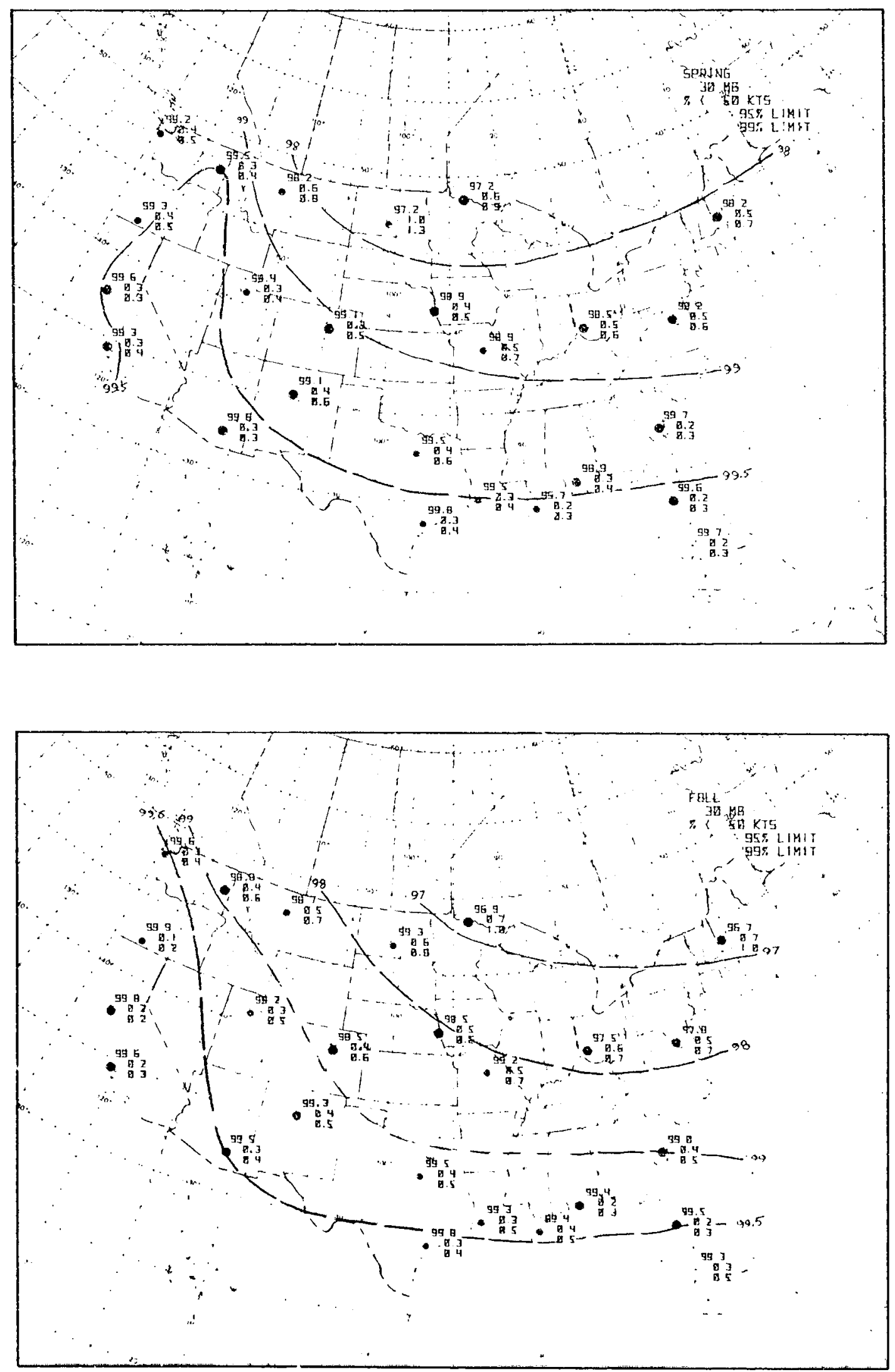

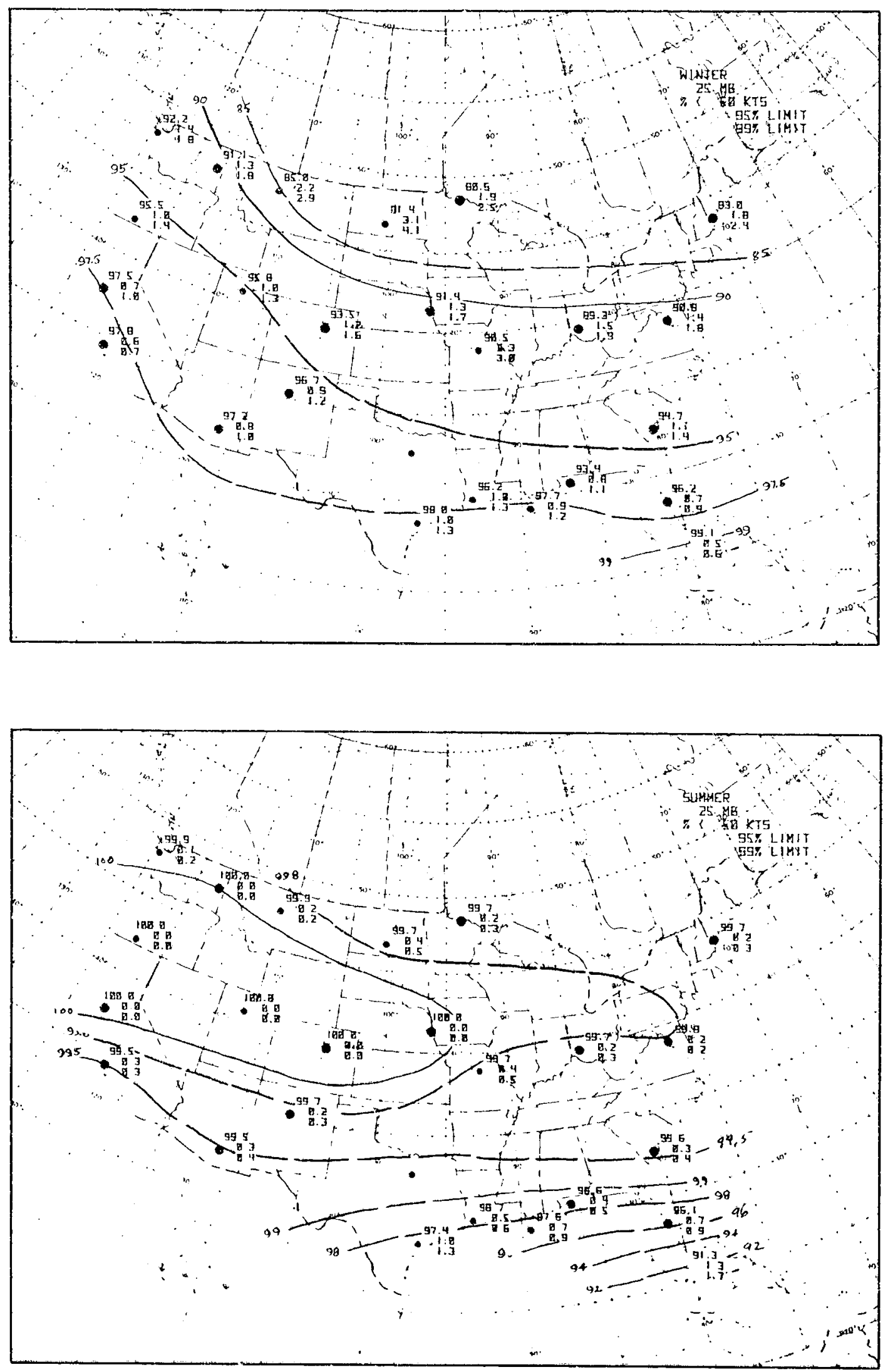


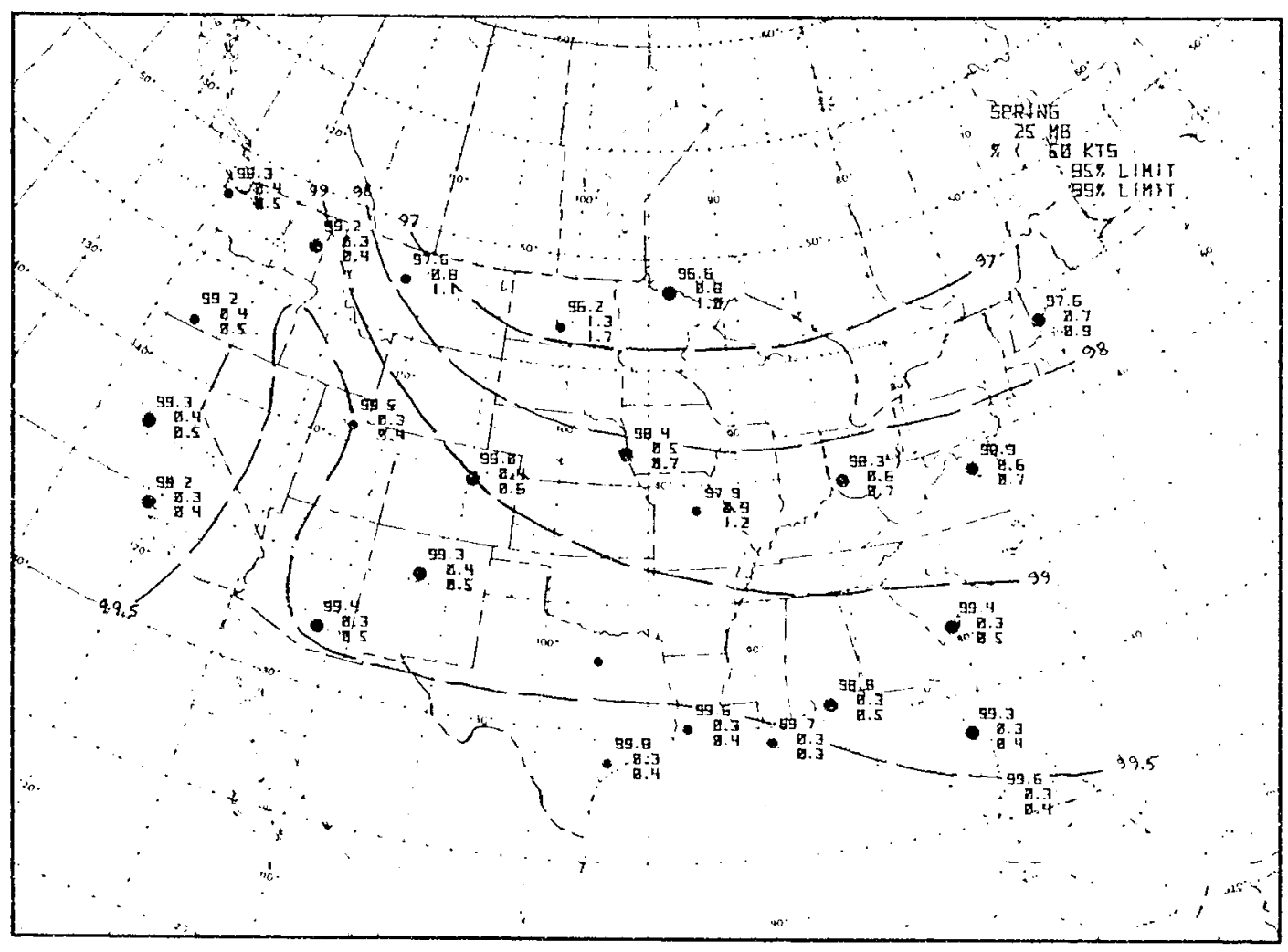

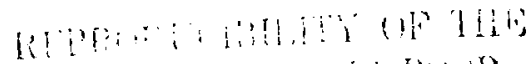

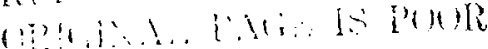

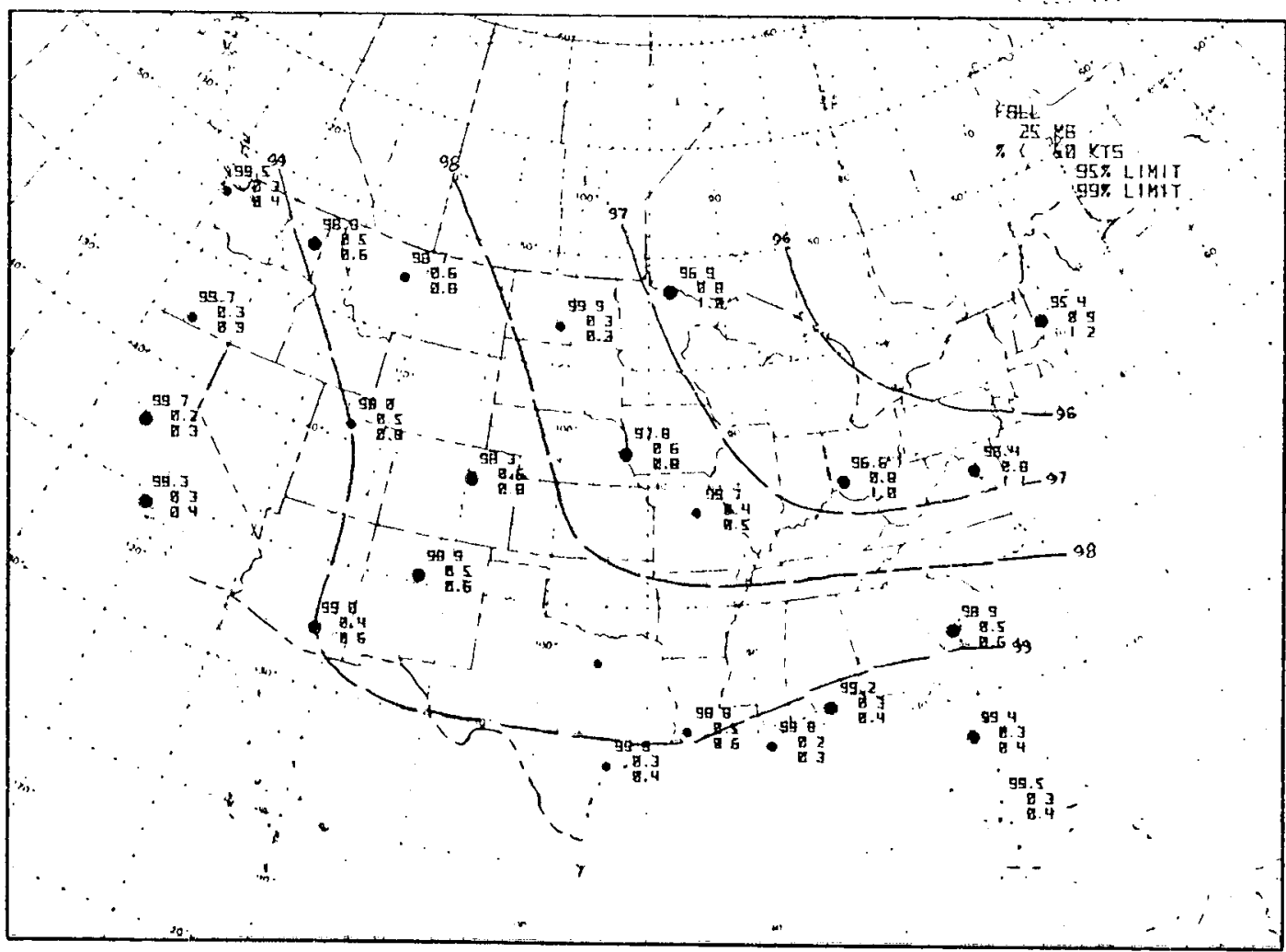



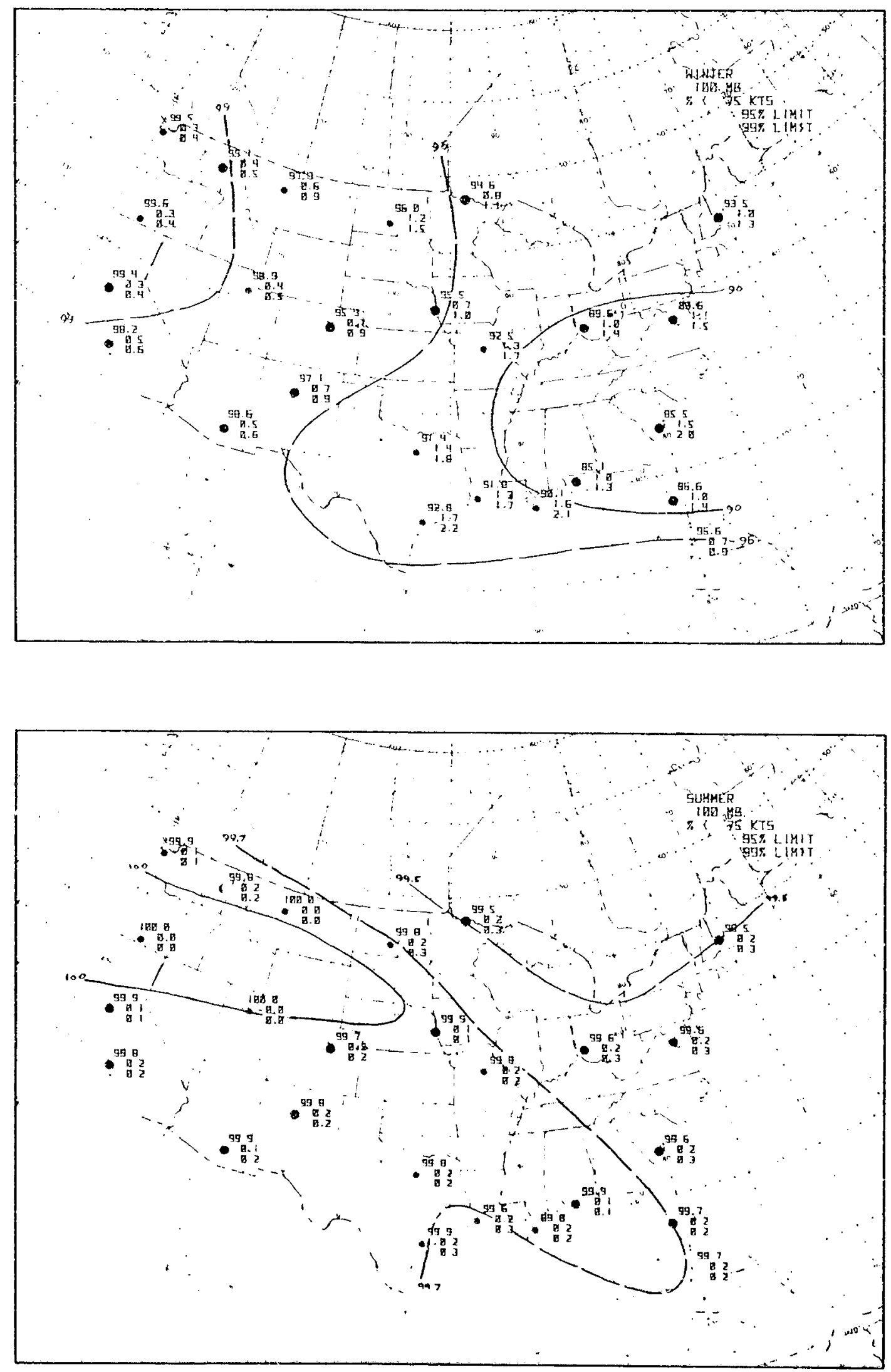

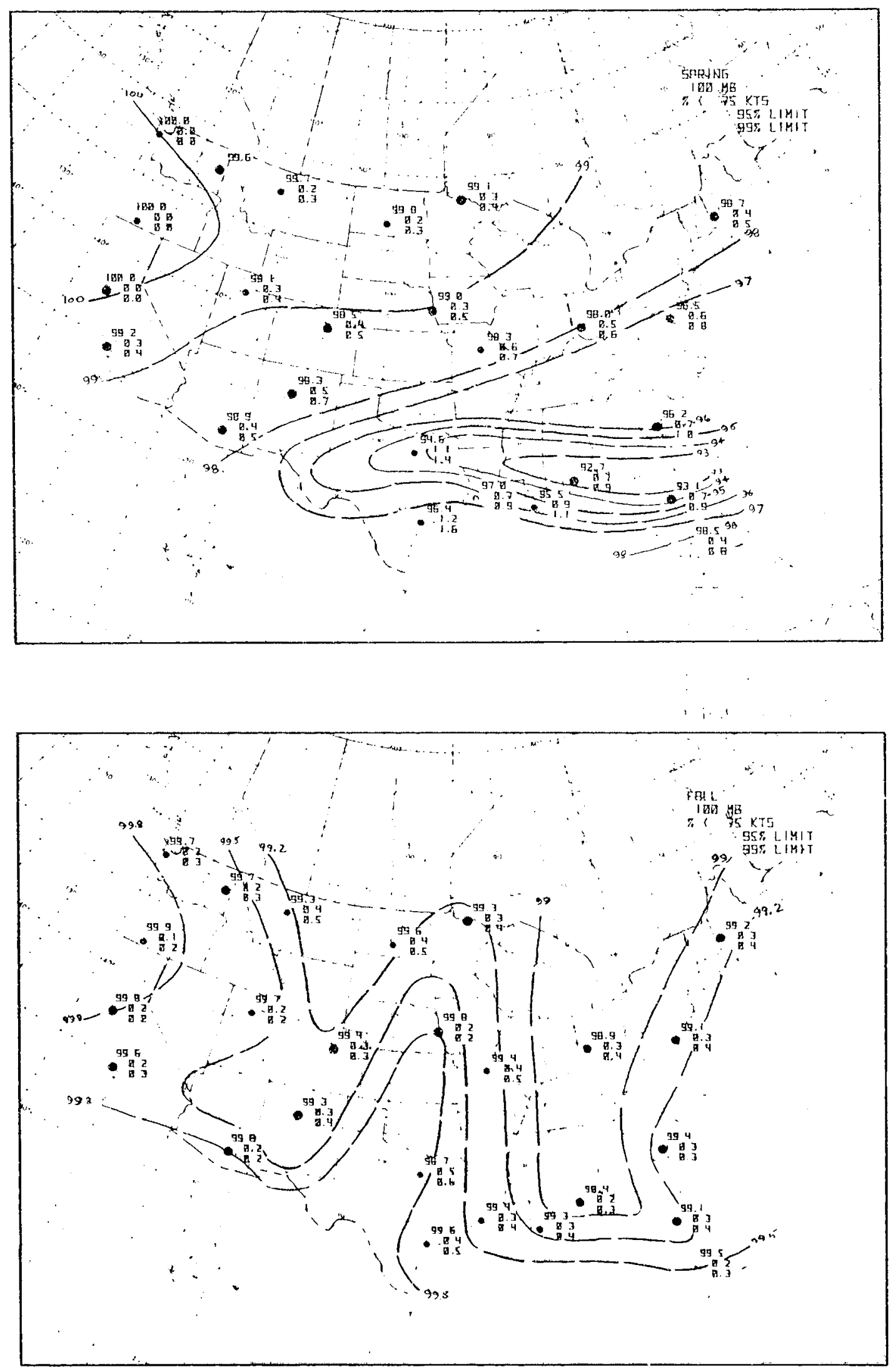

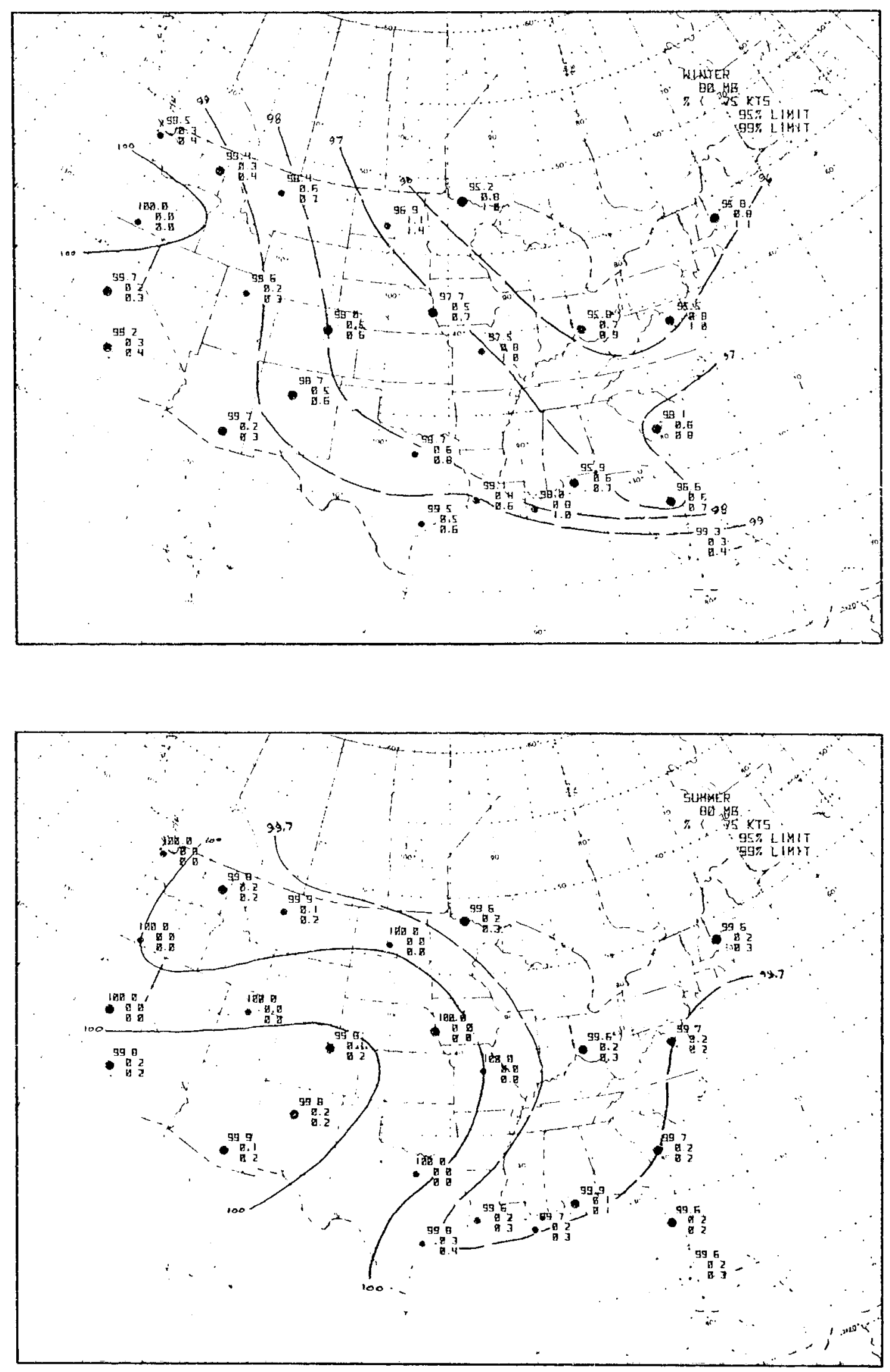

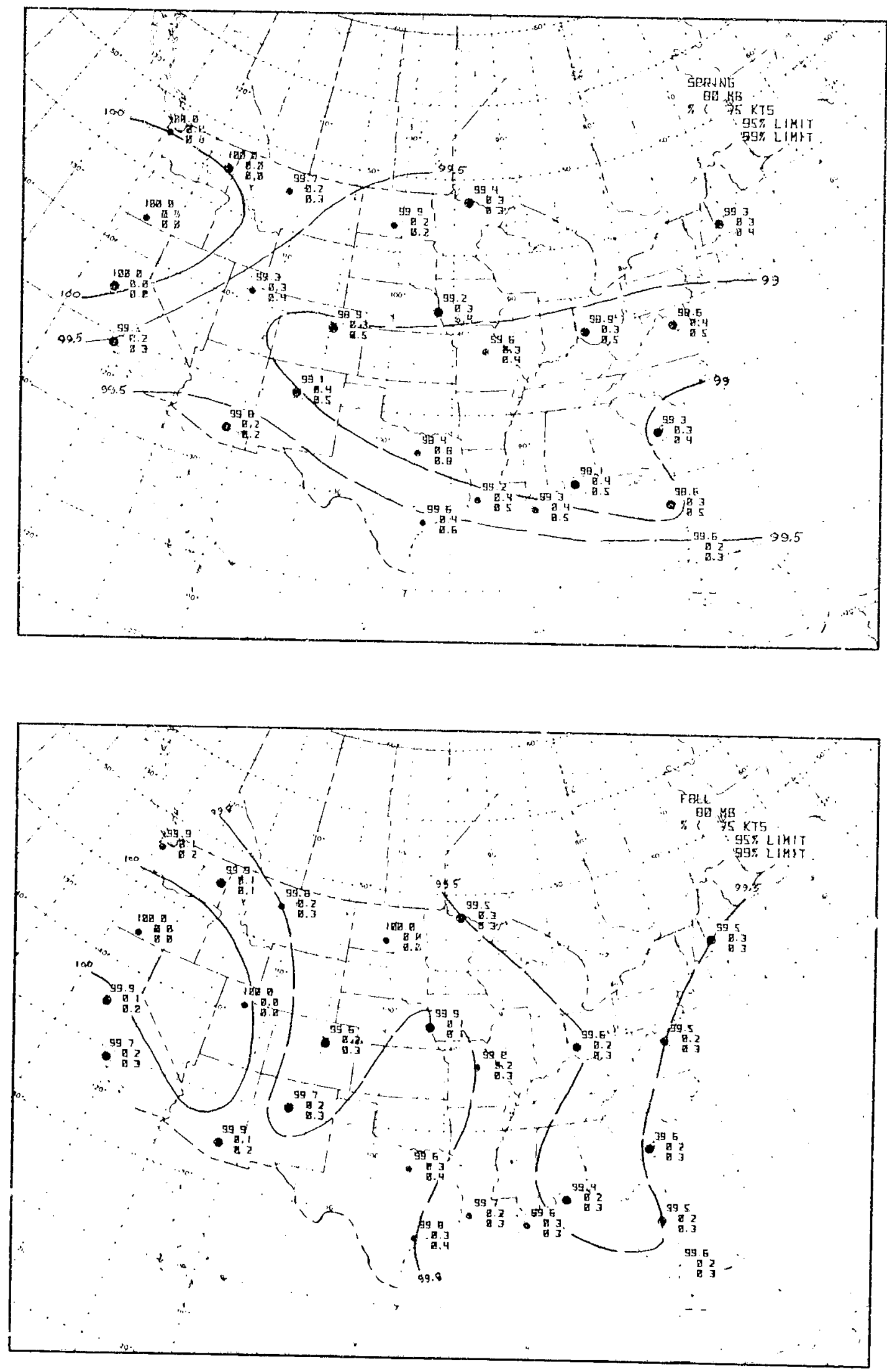

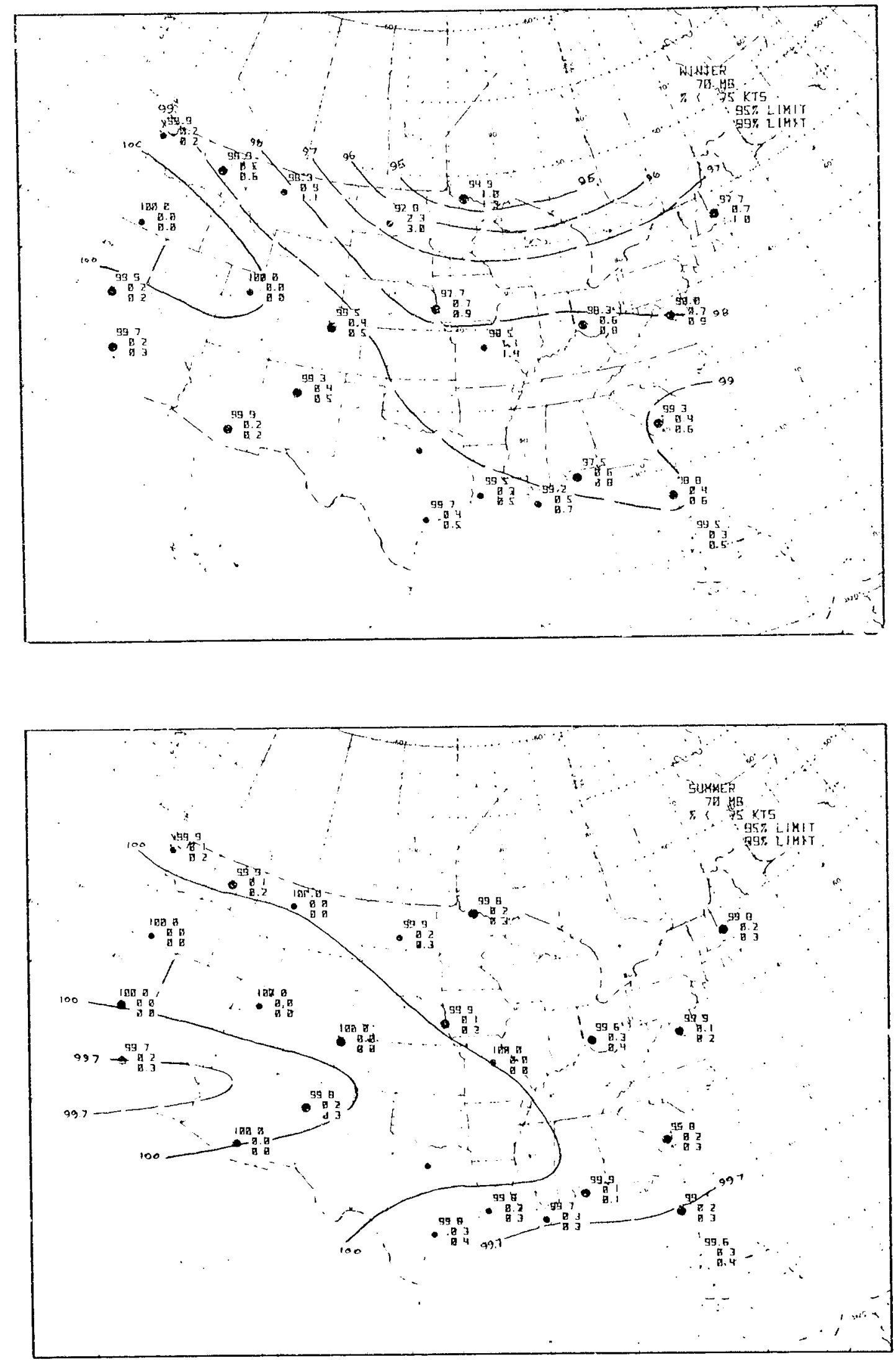


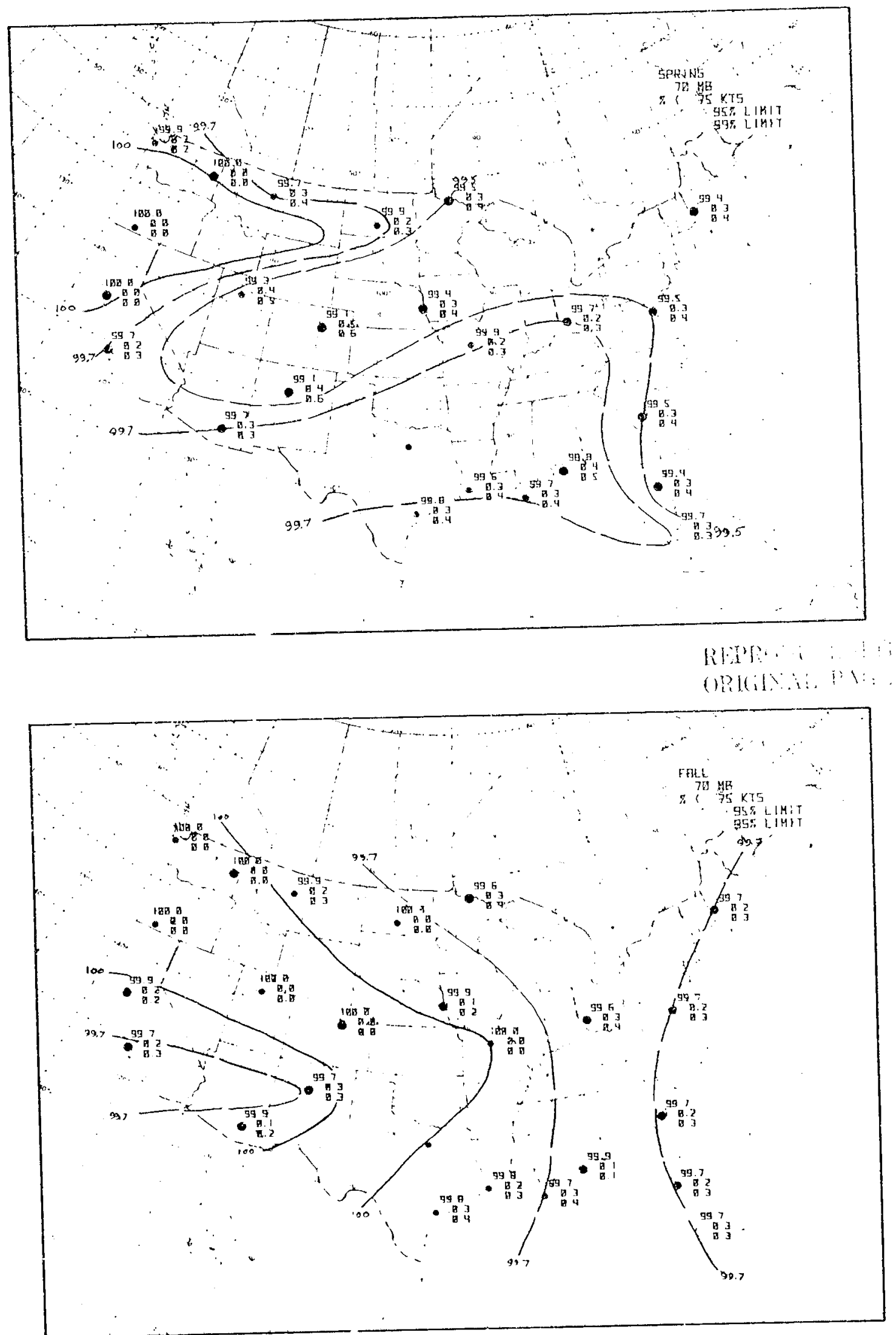



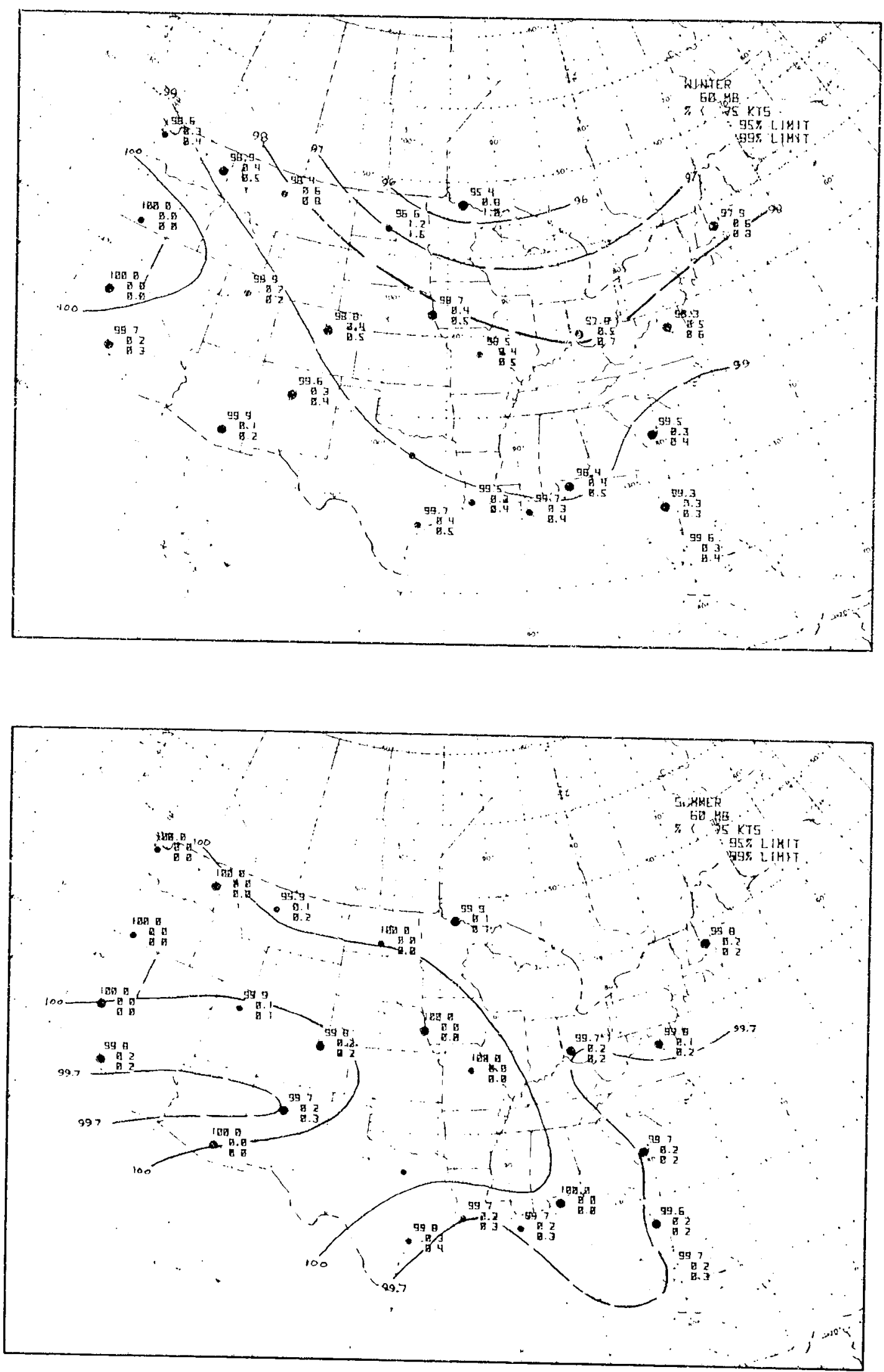

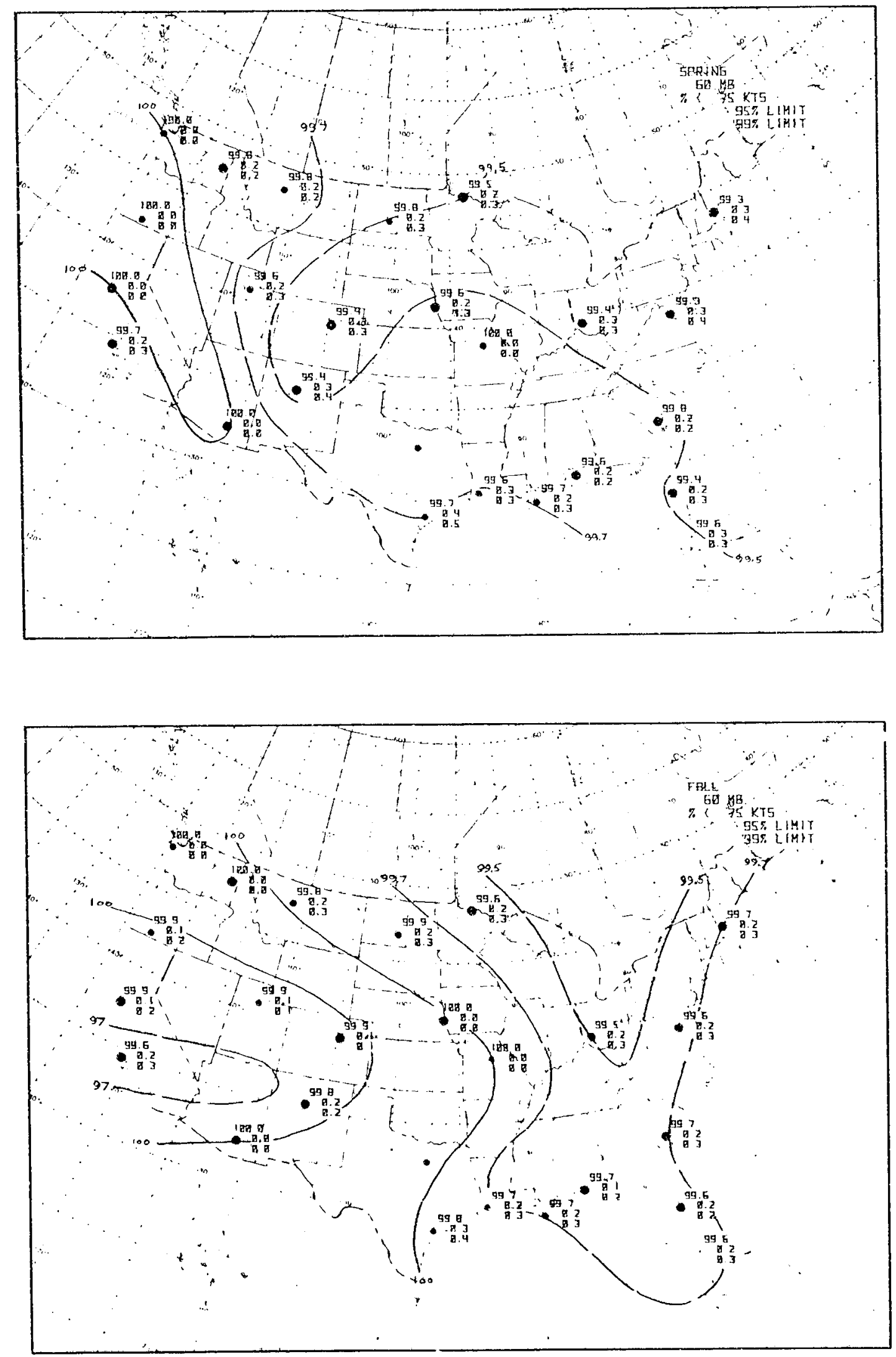

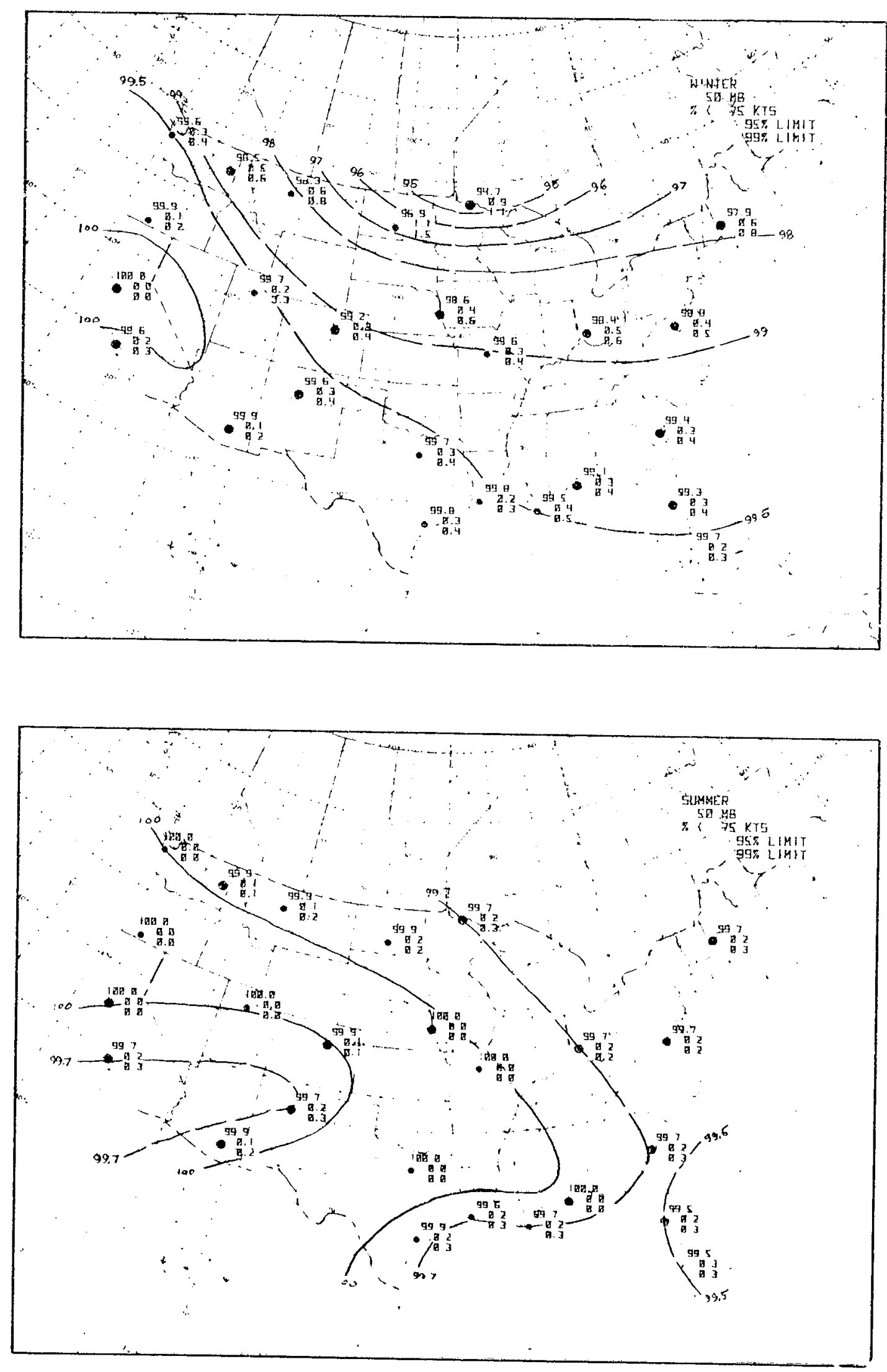

136 

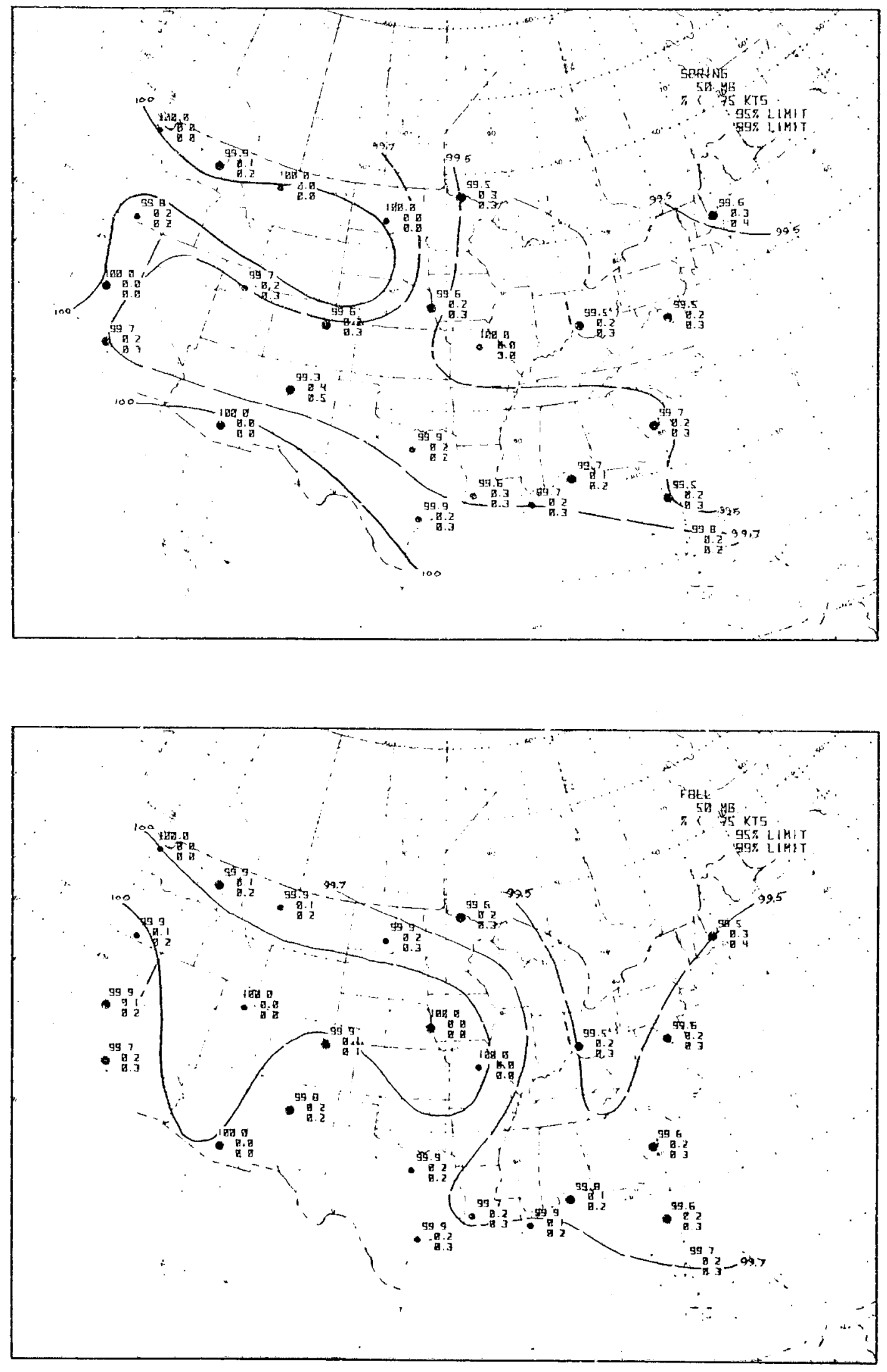

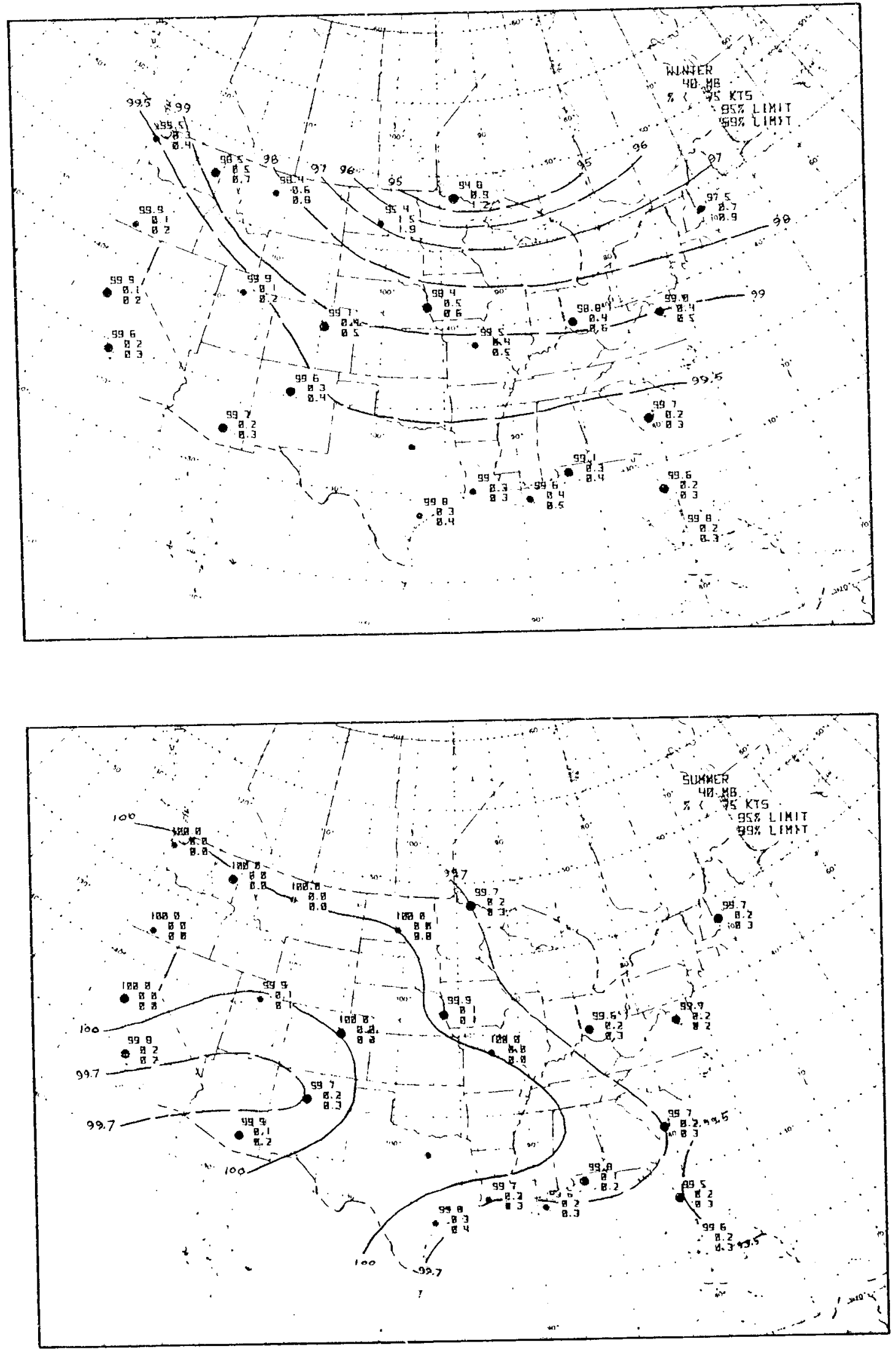

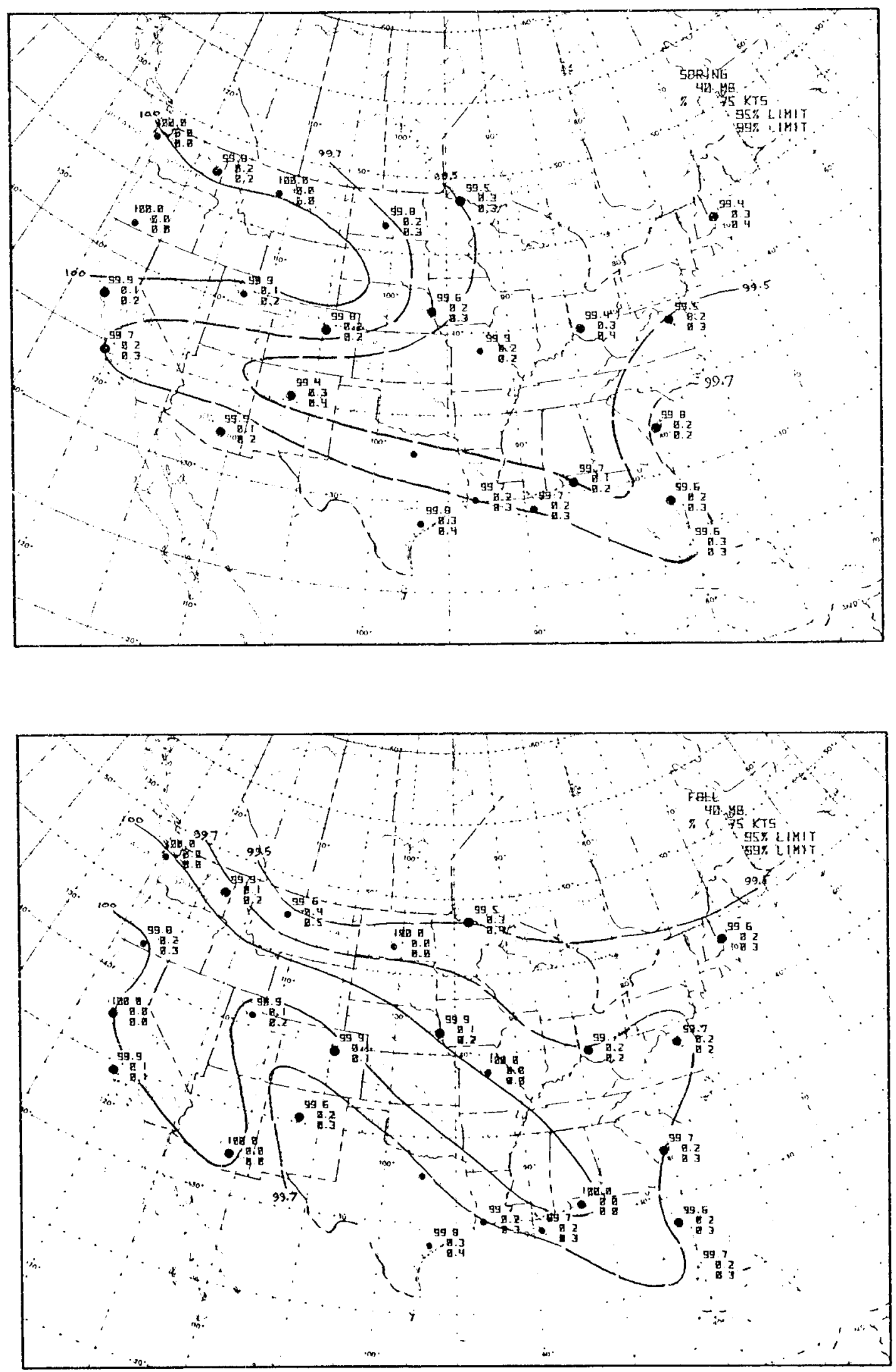

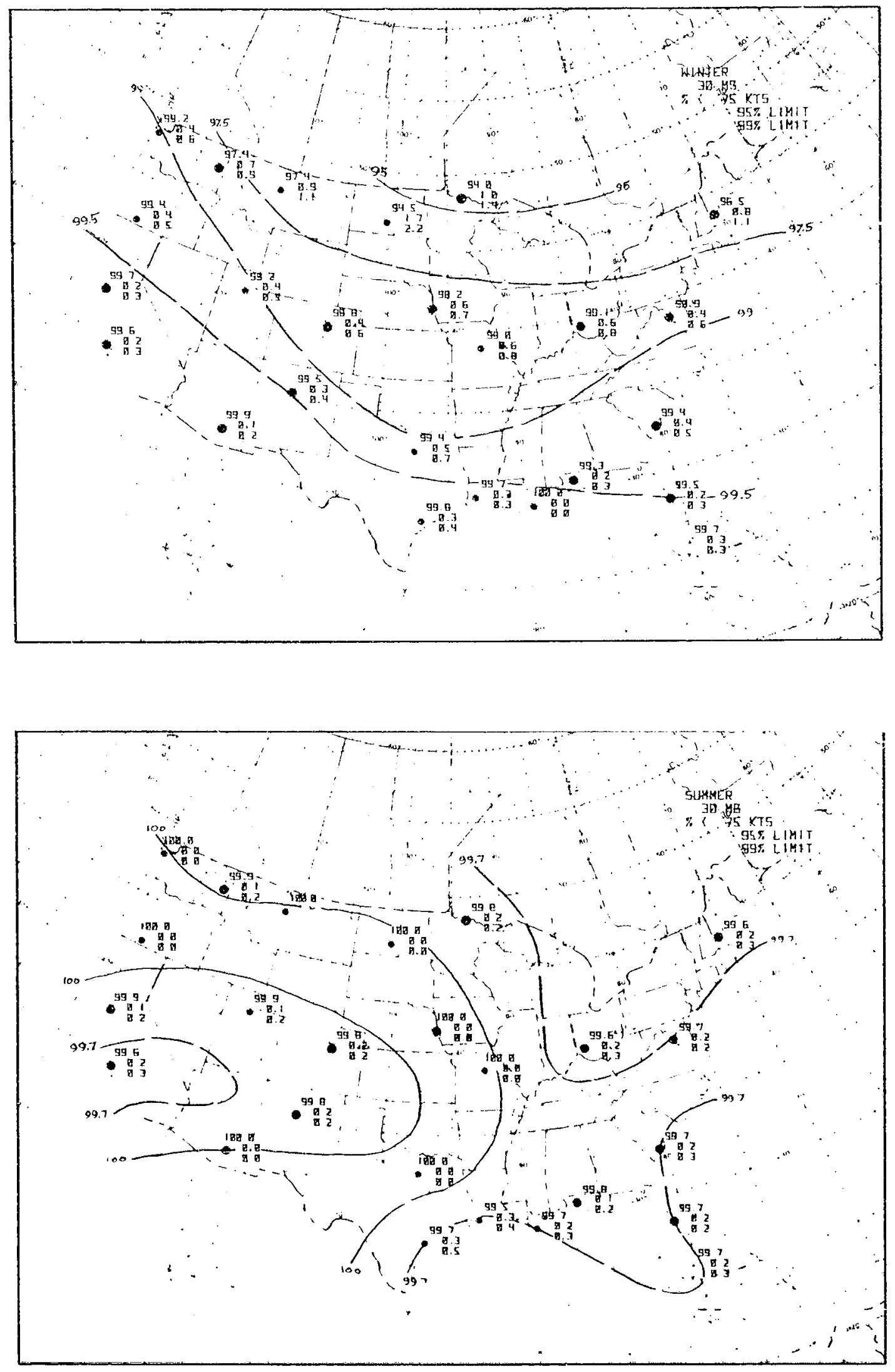


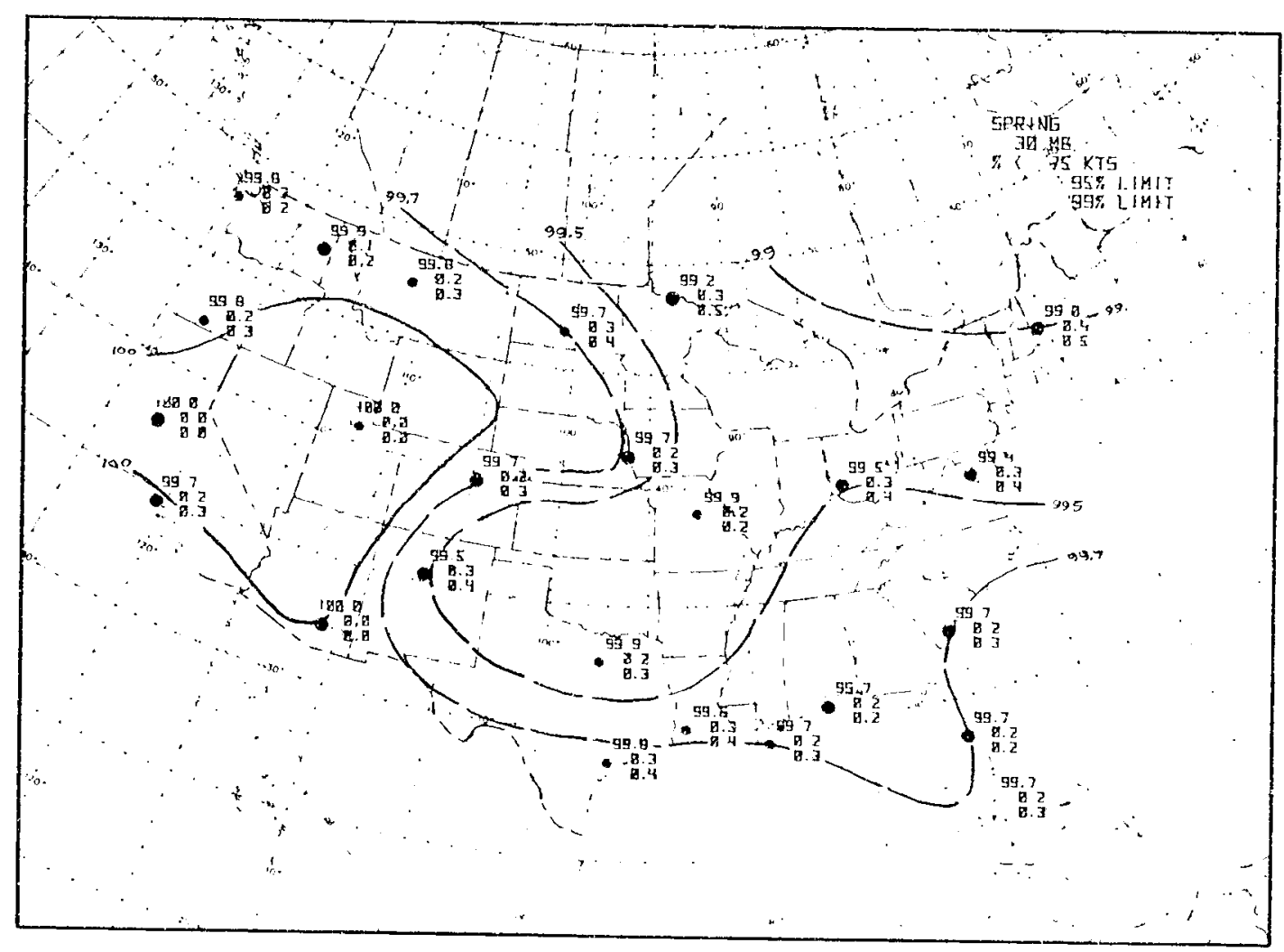

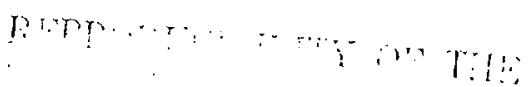

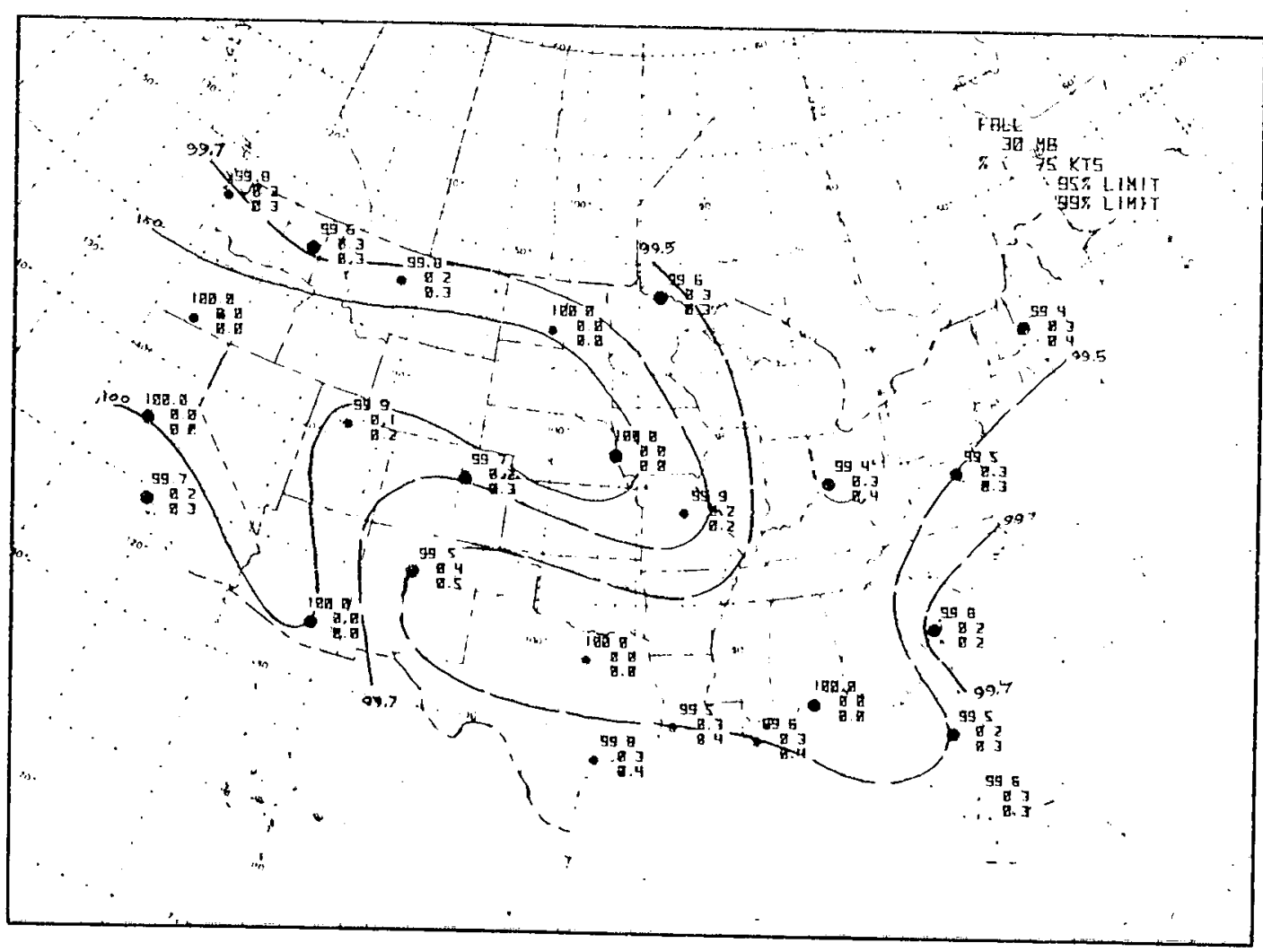



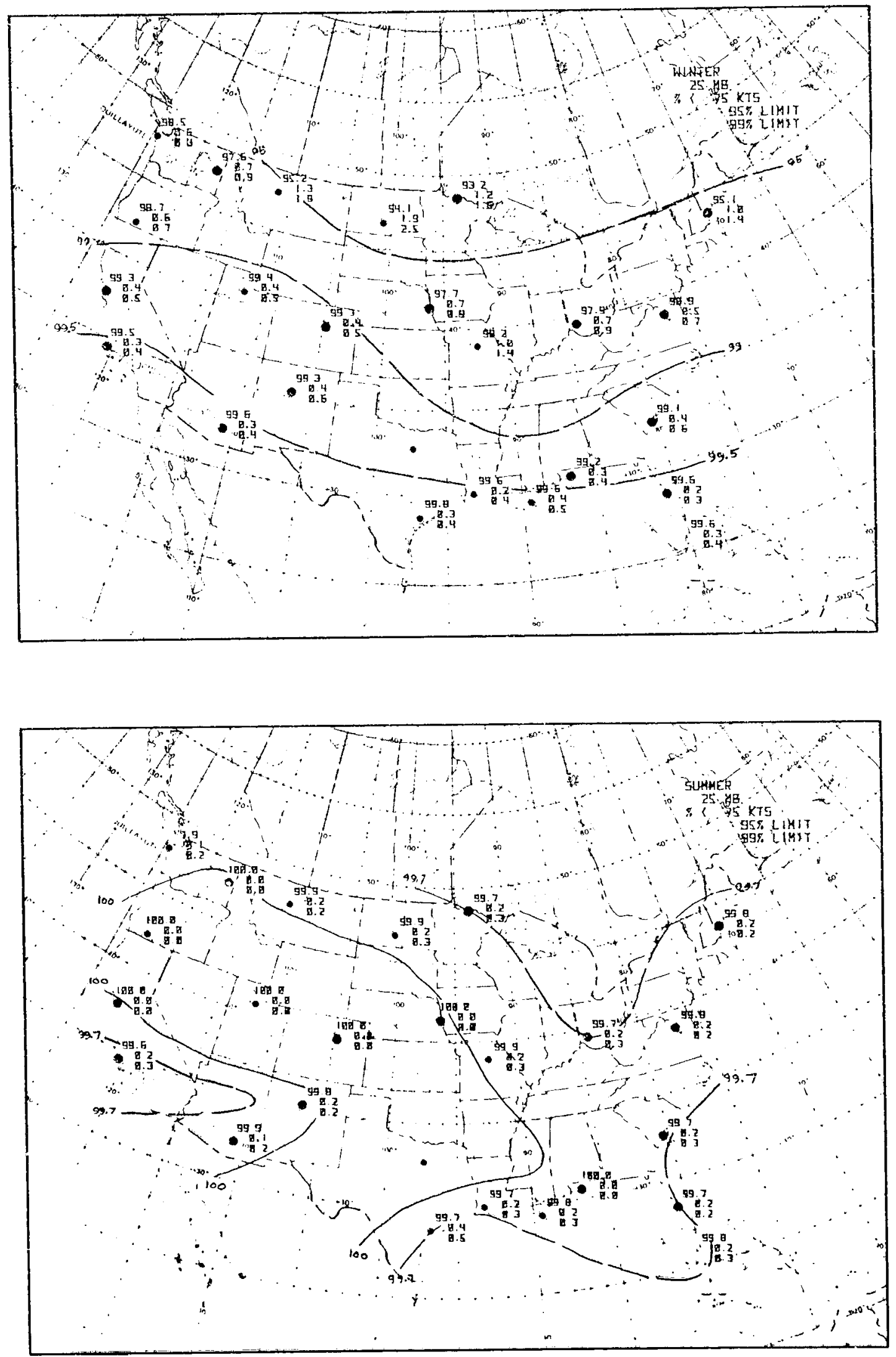

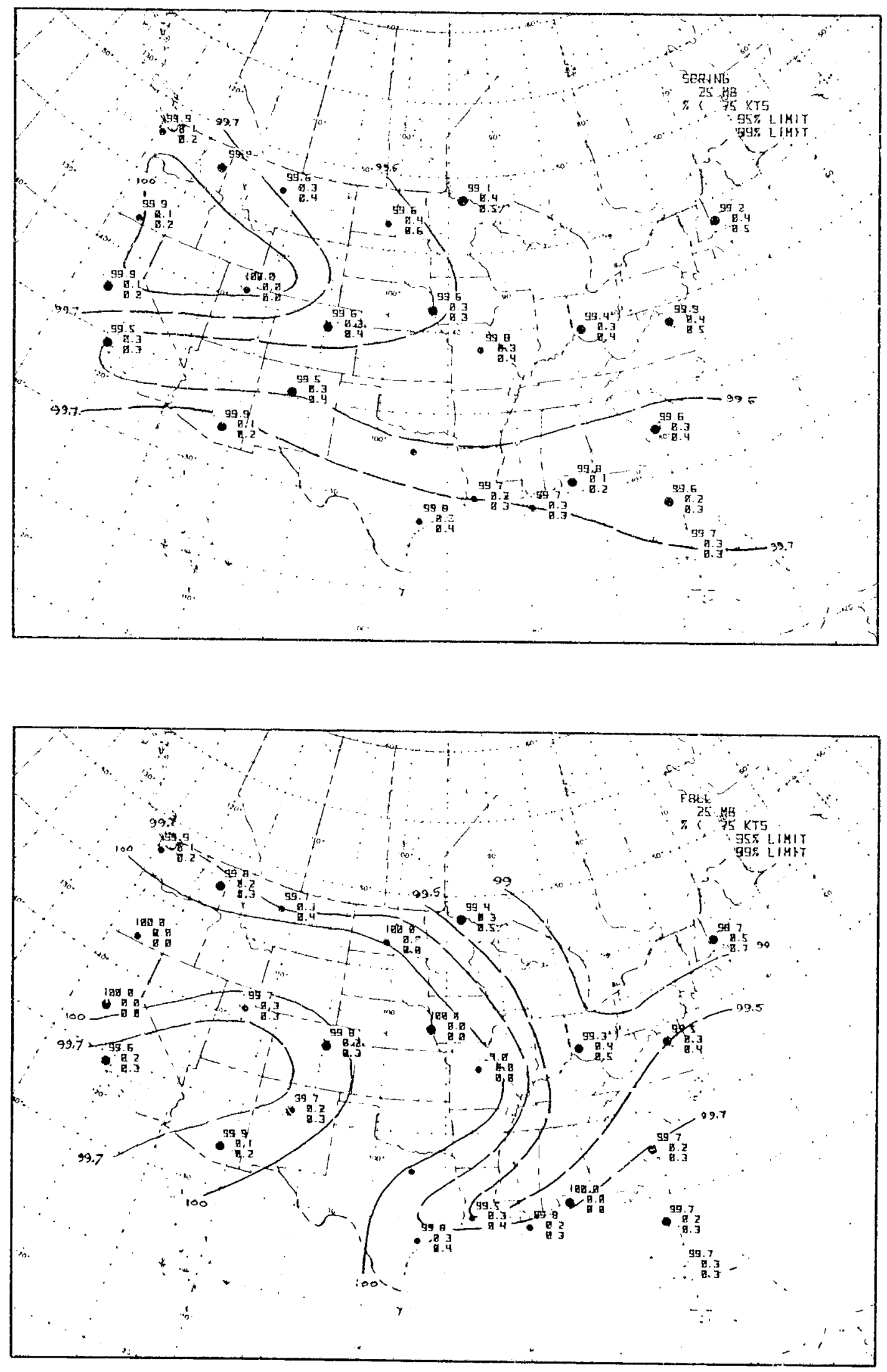
SECTION B

EUROPEAN 


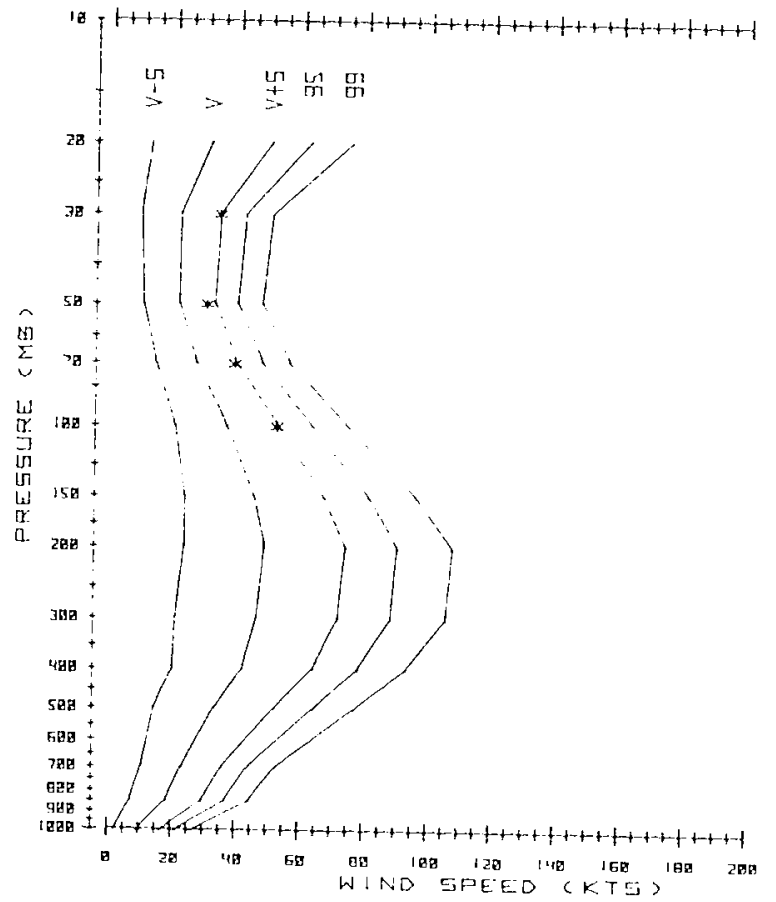

FILGER

*=

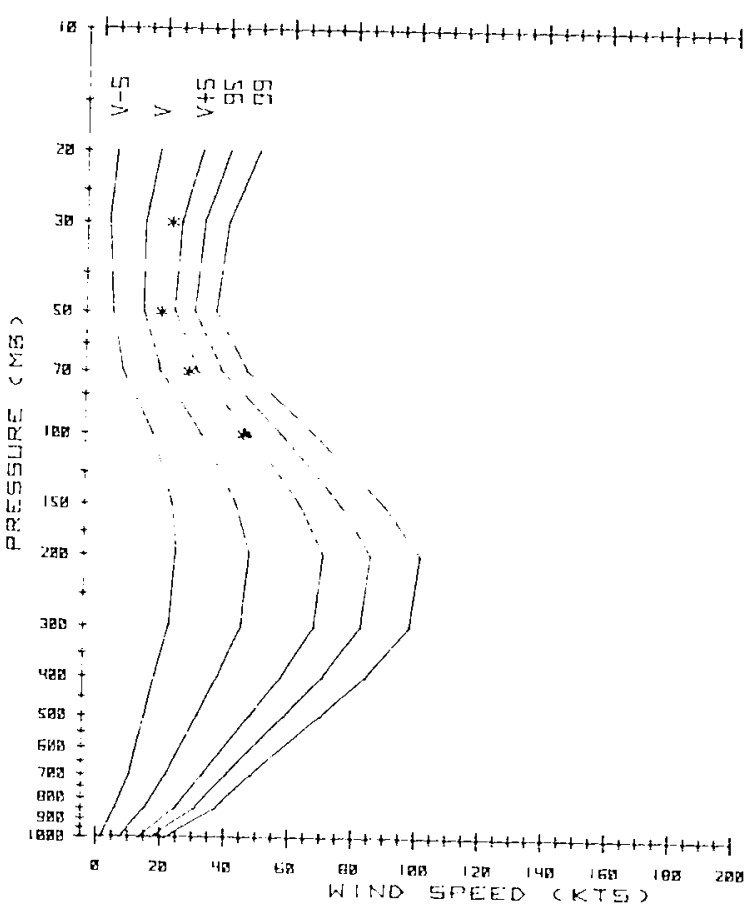

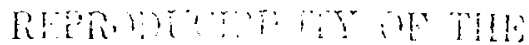

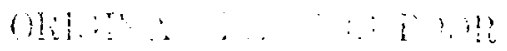

FILGER

*: B4 $1 \%$ LEVEL

FFIL
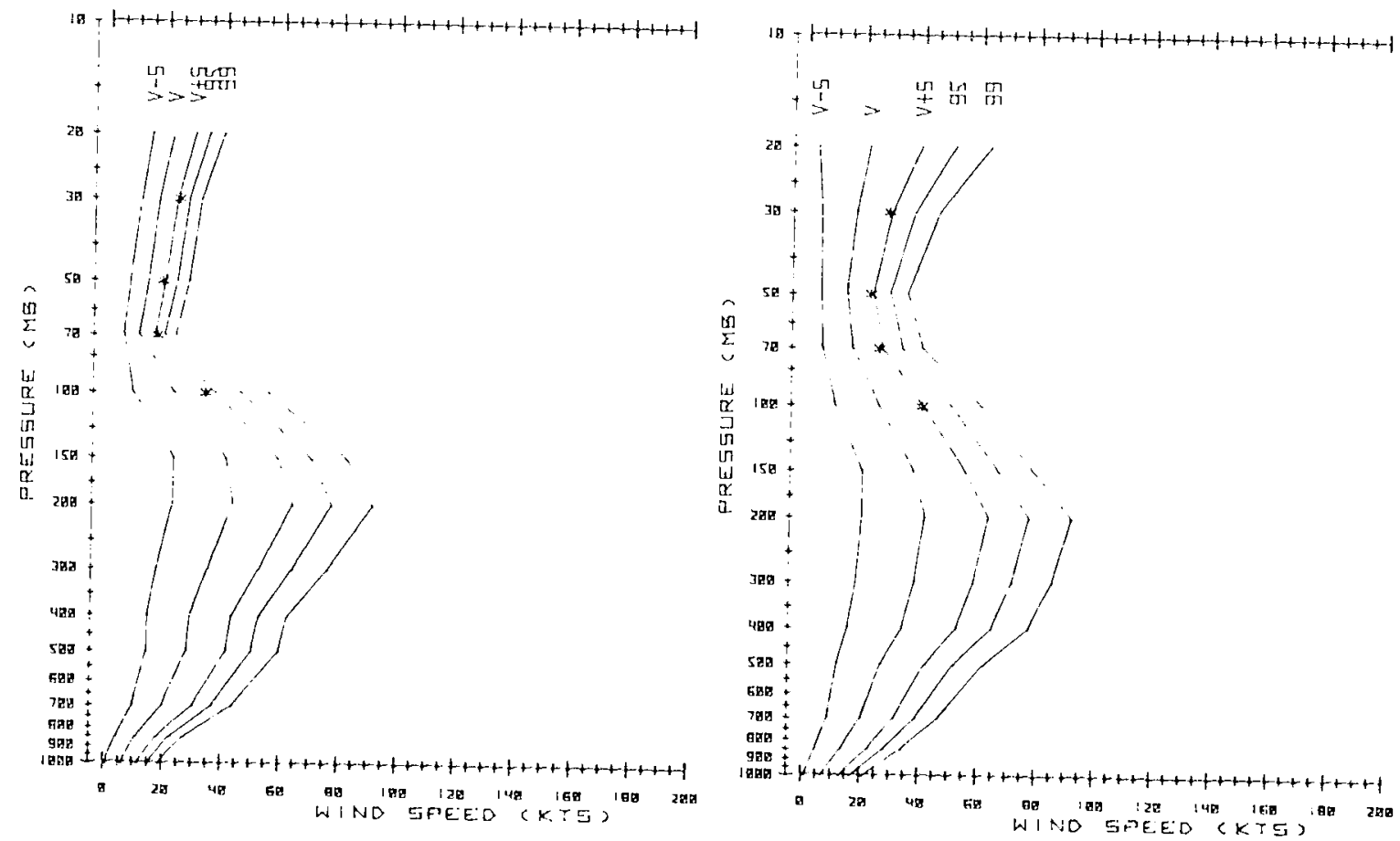
$10-t+t+t+1+t+t+1+t+t+t+t+t+t+t+t+t+t+t+t+t+t+t+1$

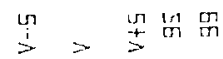

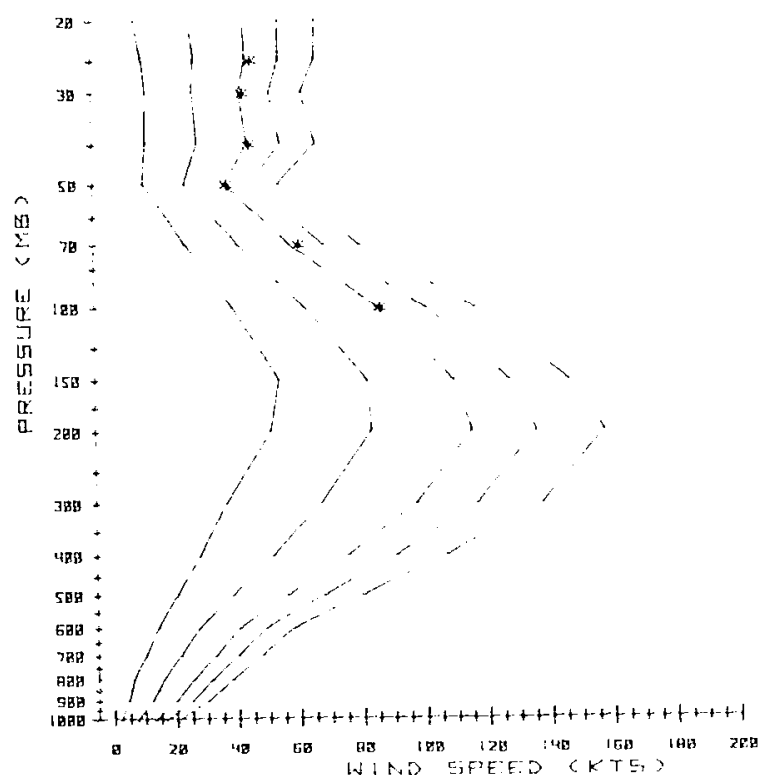

BET OAGAN

$K=E^{4} 1 \%$ LEVEL.

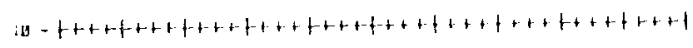

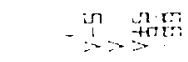

$2 x-\ldots$

- 1 - 1

$30-1, x+1$

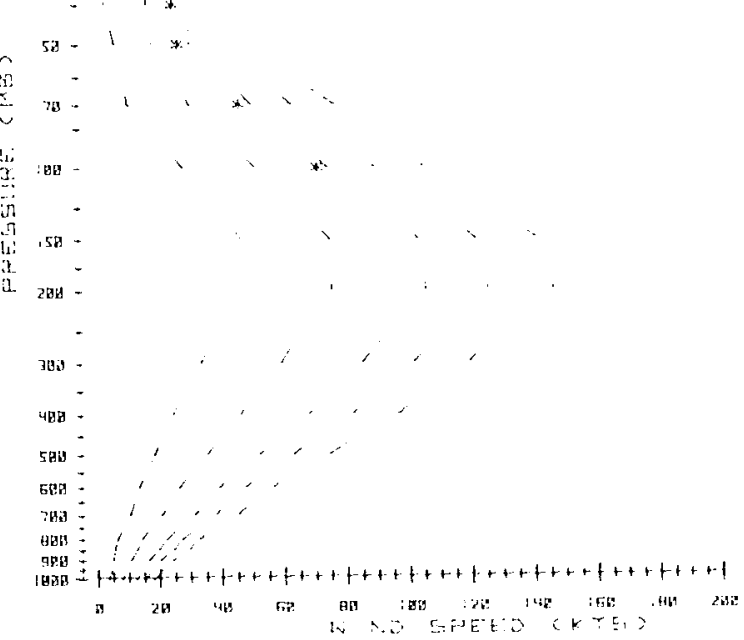

BET OAGAN

* $=$ GU $1 \%$ LEVEL

FALL
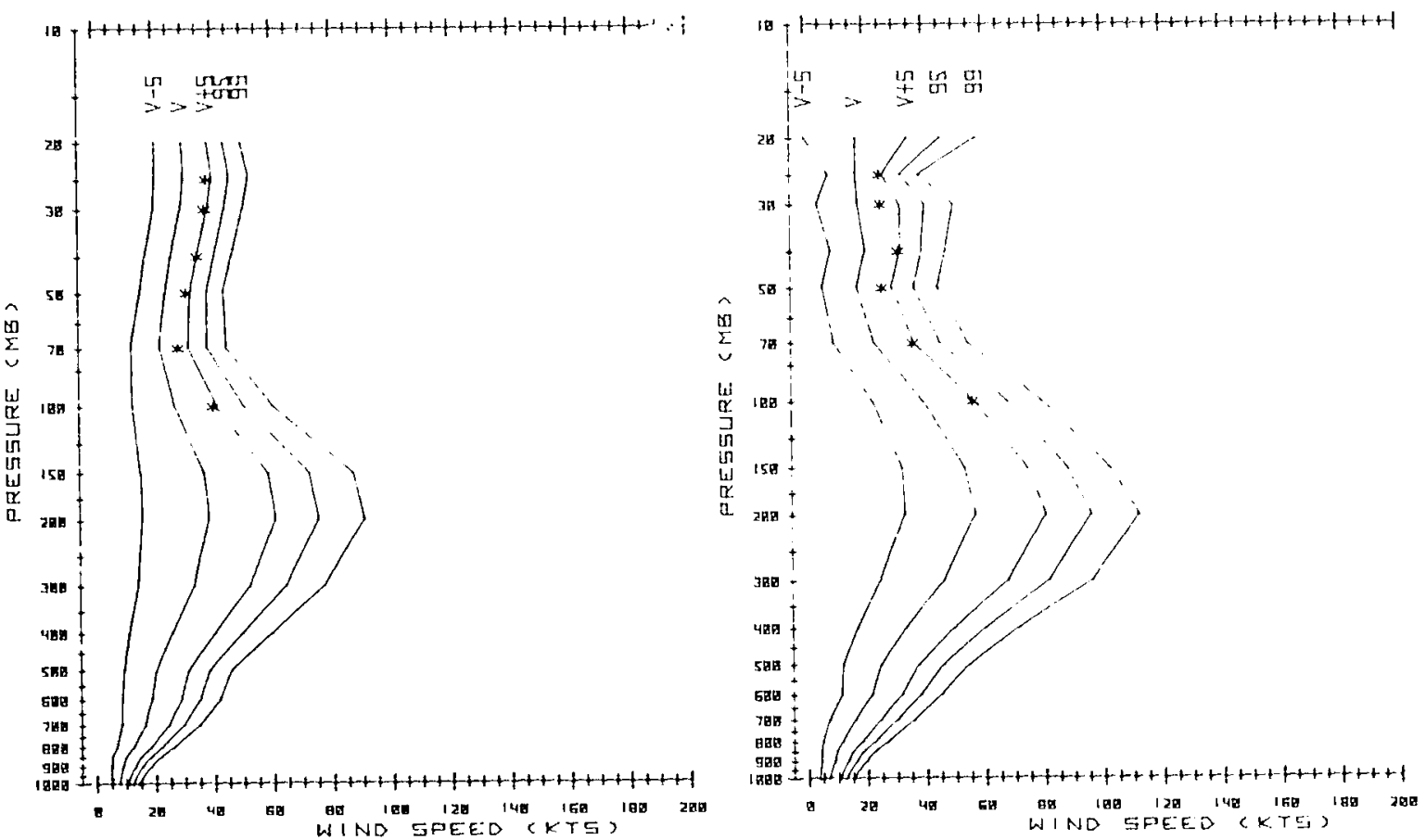

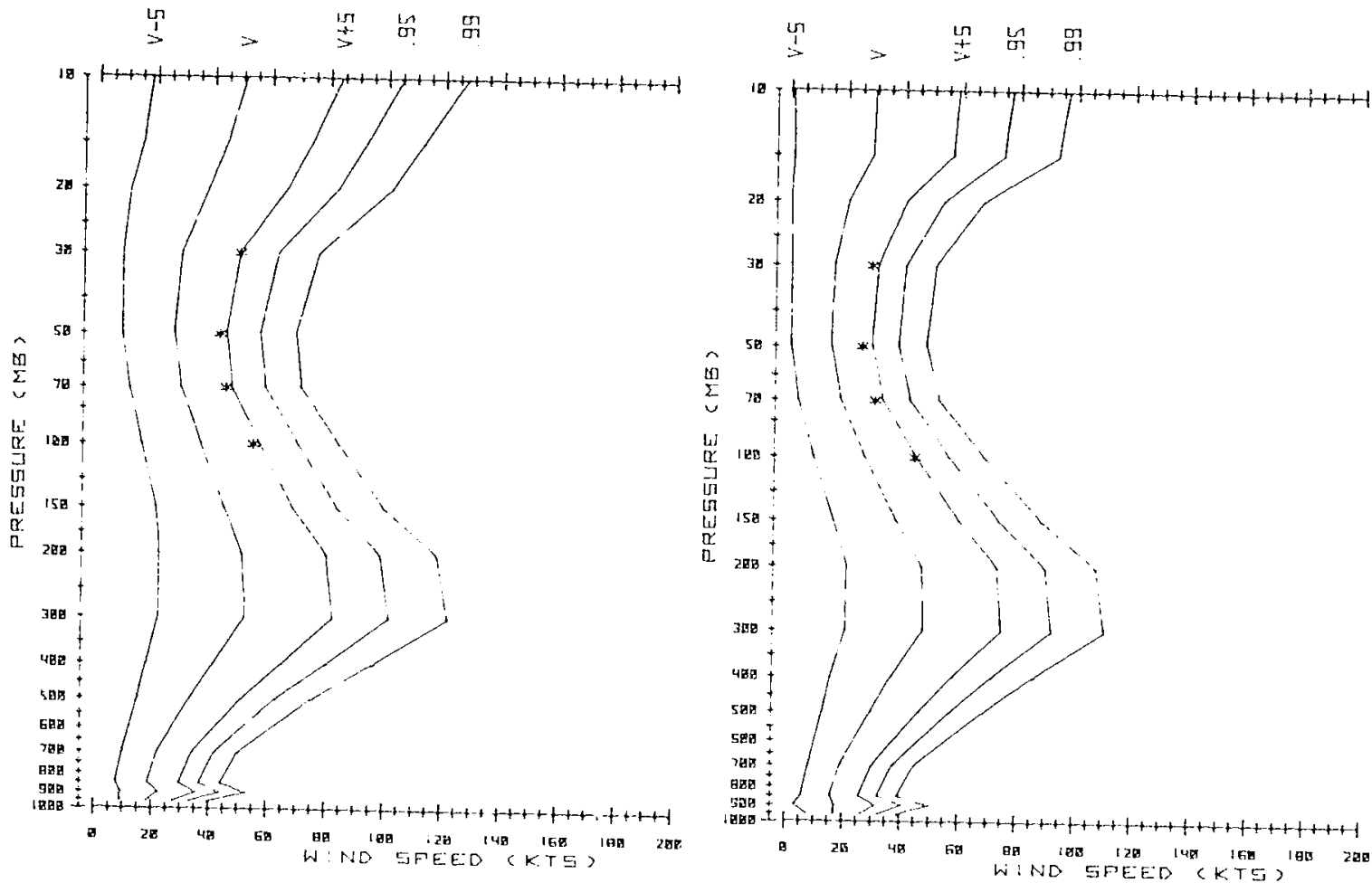

BRINDIEI

* $=94.1 \%$ LEVEL

SUMMER

ERIND।5I

$*=641 \%$ LEVEL

FALL

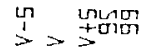
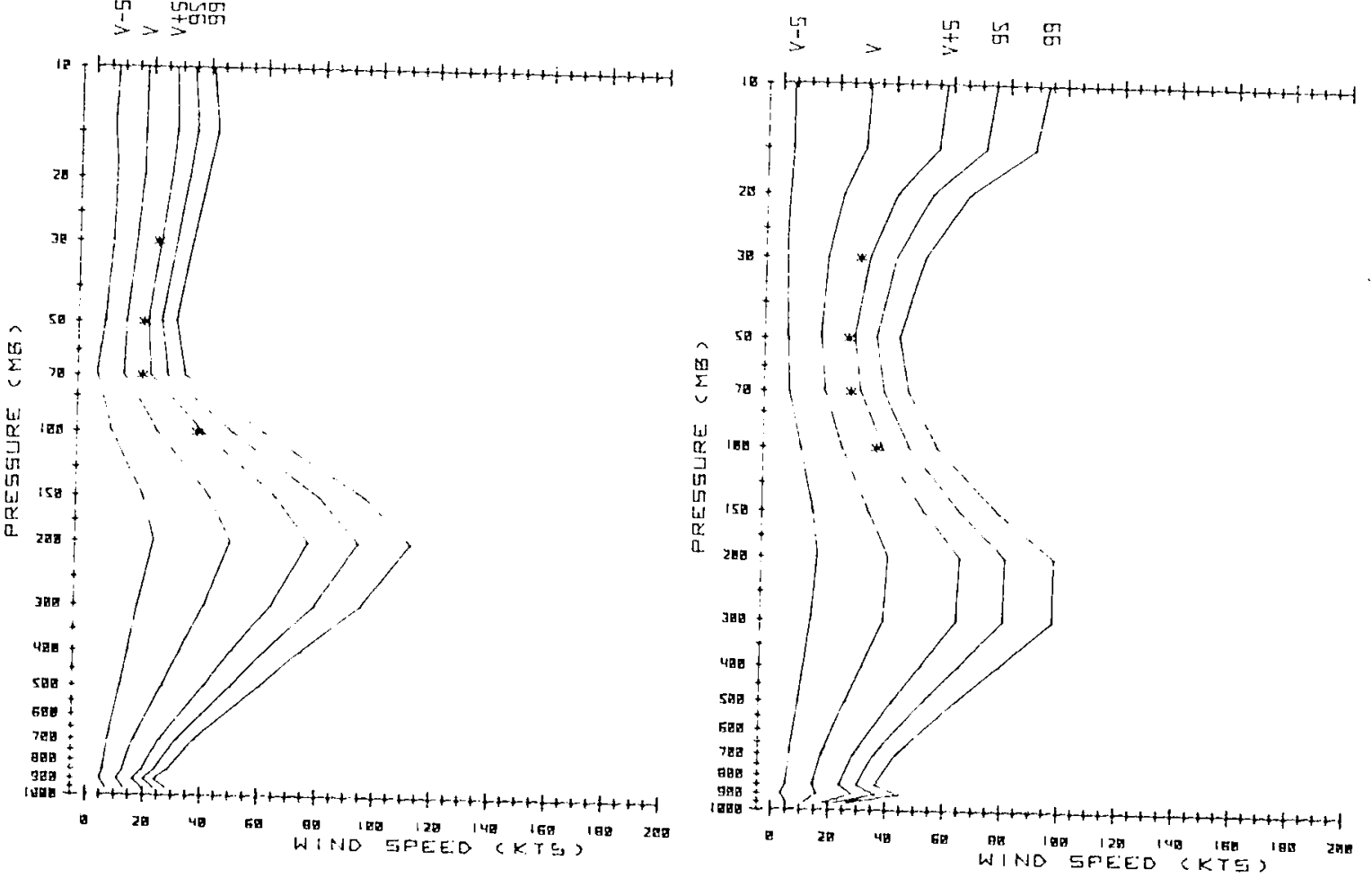
ESSEN

$*=$ Q4 . 1\% LEVEL

号 $>$ 号皆昂

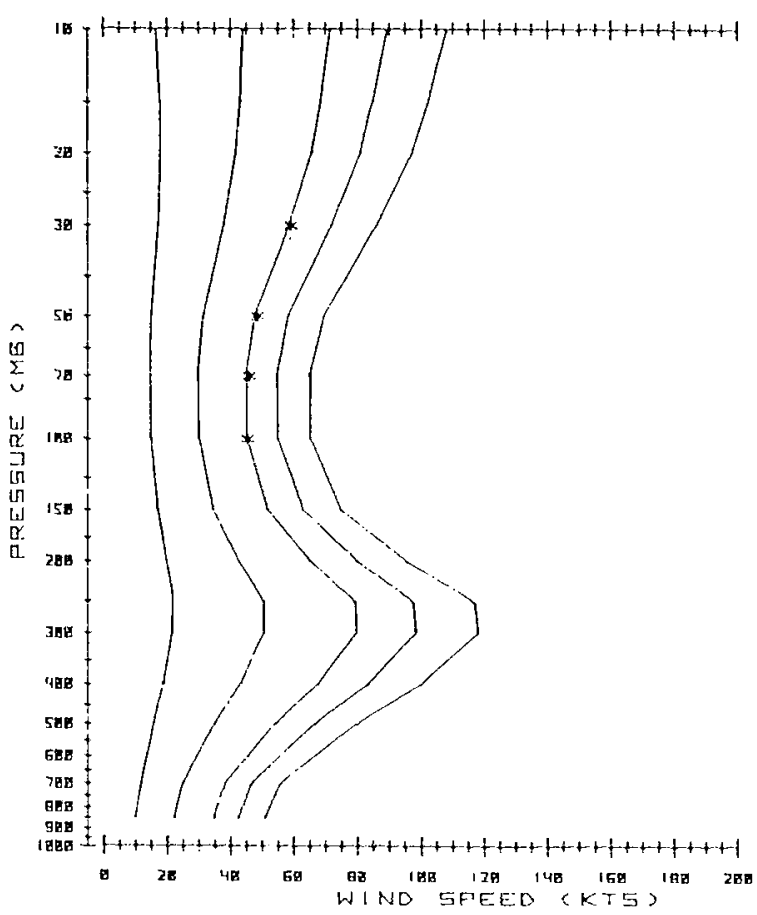

E.5.5:

$*=B-1 \%$ : $=$ EV :

SLIMNER

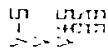

10 $-t+t+1+t+t+t+t+t+t+t+t+t+t+t+1+t+t+t+t+t+t$

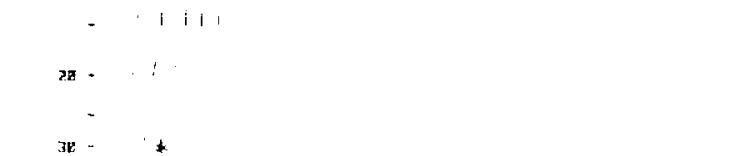

ESGEN

* $=$ BU $1 \%$ L.EVEL

5PRING

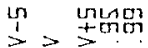

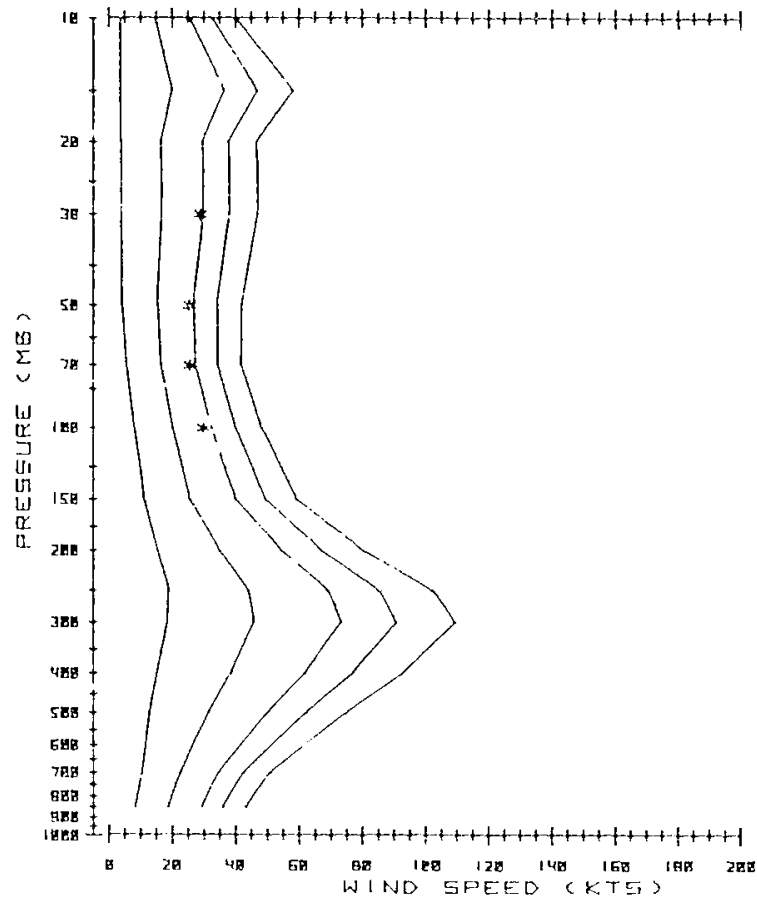

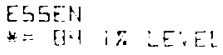

FA:L

证

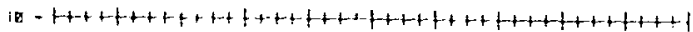

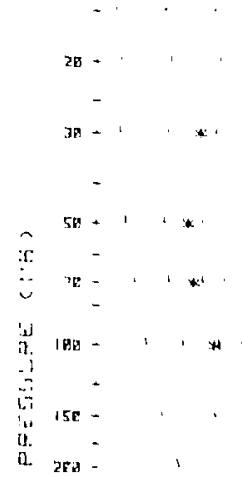

10

4ด: -

SER:

क्ष: $\vdots 1: 1$,

9Re

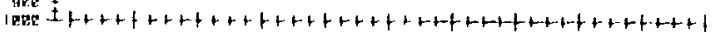

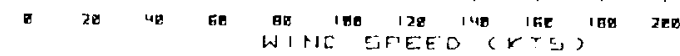

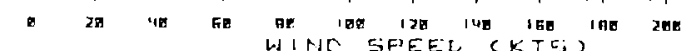




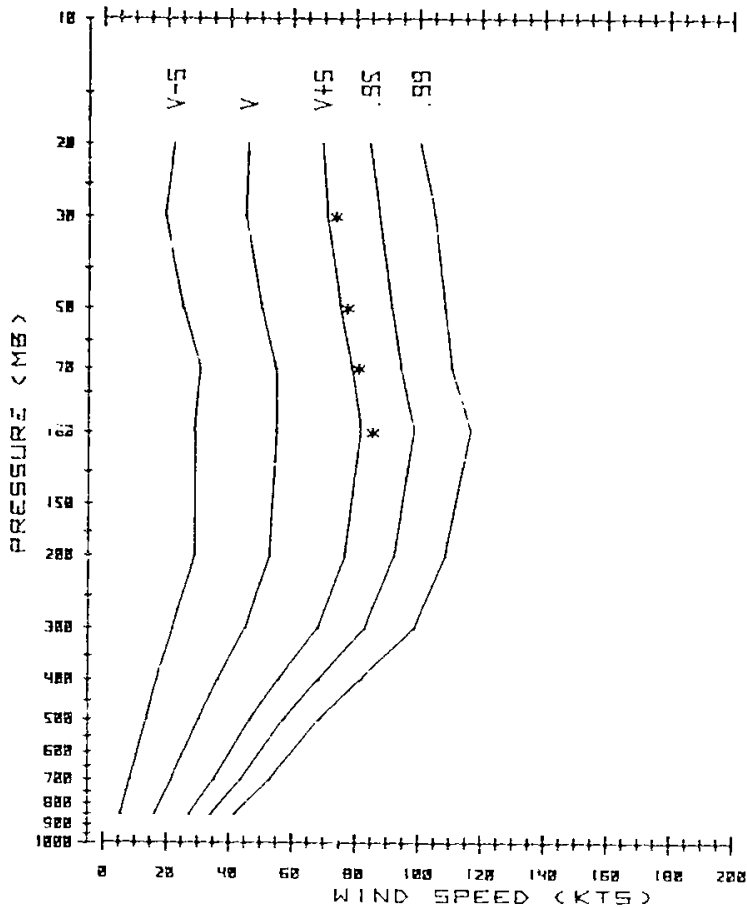

$|Z M| R$

$*=84.1 \%$ LEVEL

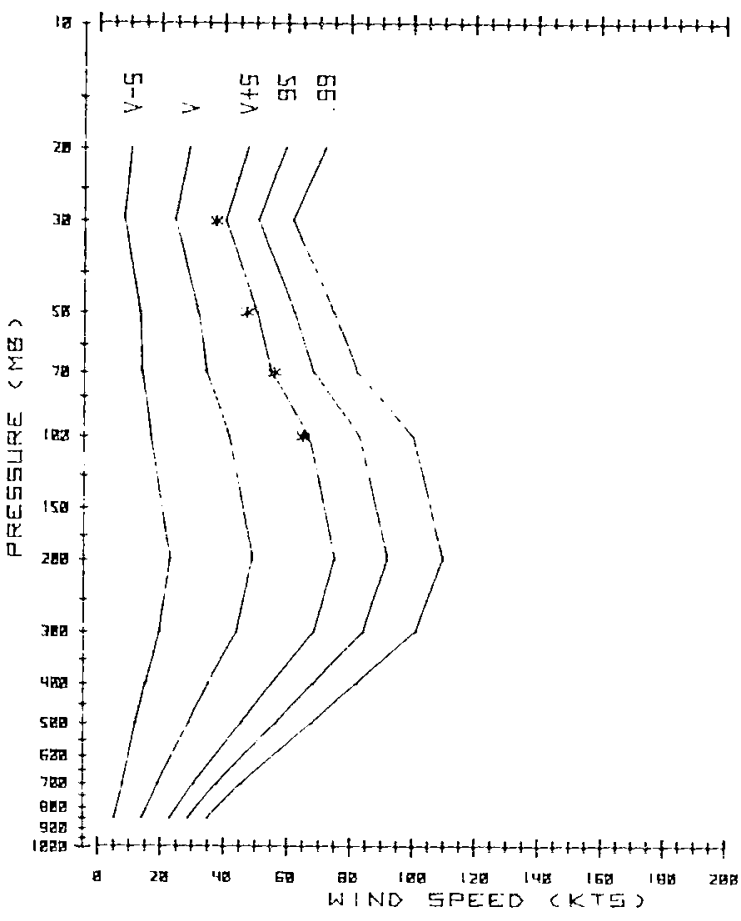

IZMIR

$*=B^{4} .1 \%$ LEVEL

FALL
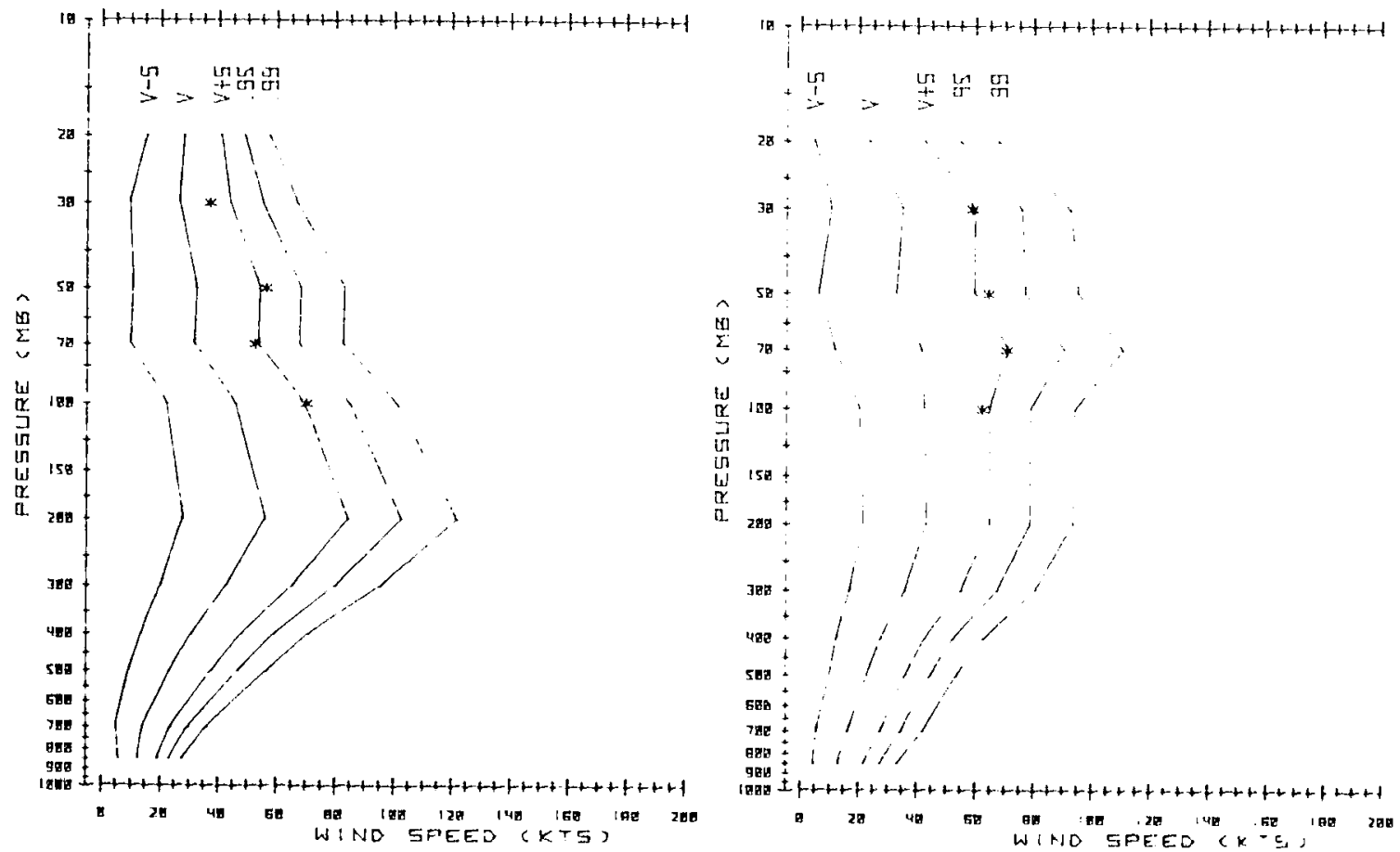

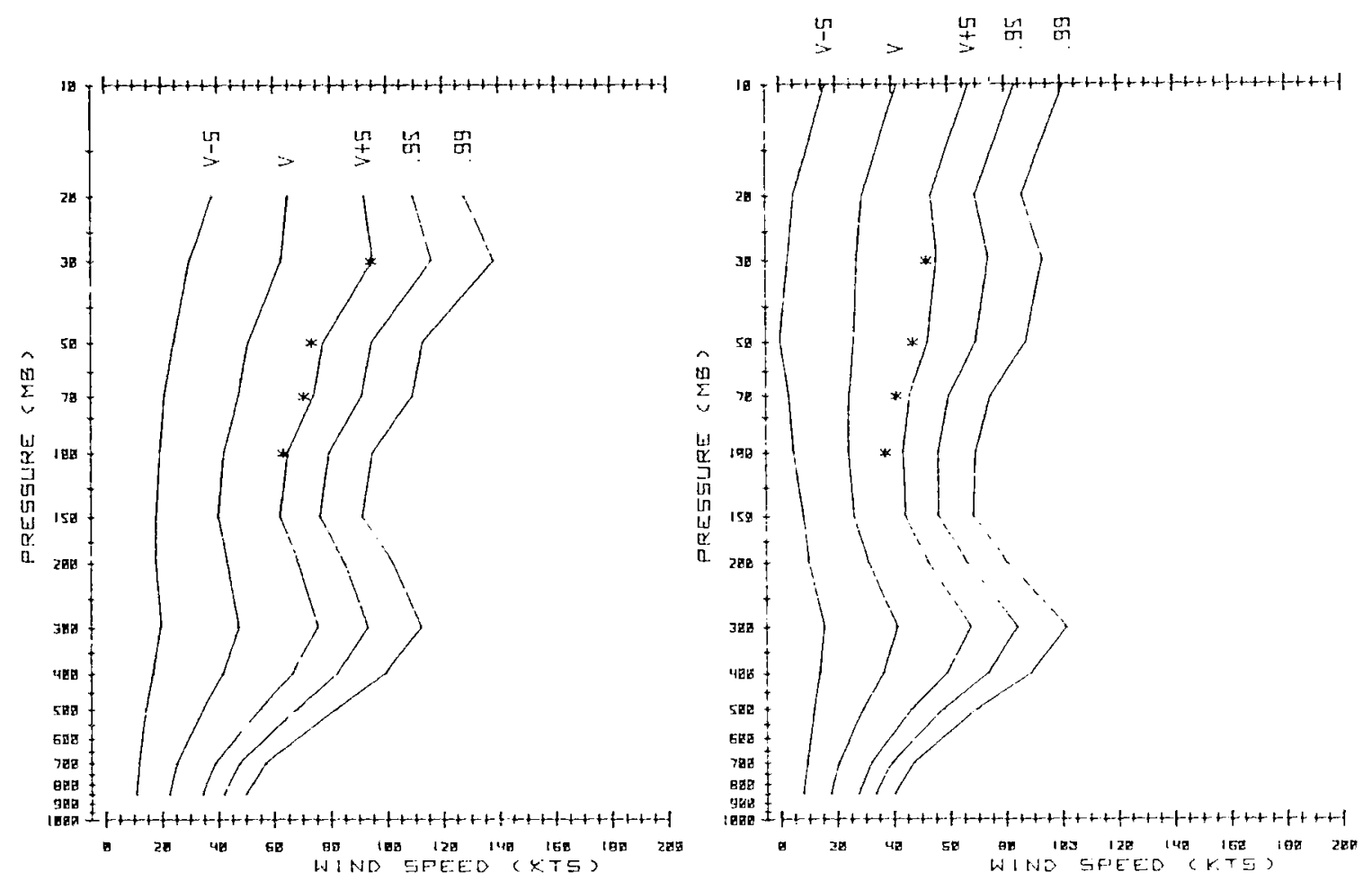

$$
\begin{aligned}
& \text { UDK IDINEN } \\
& *=84 i \% \text { LEVEL }
\end{aligned}
$$

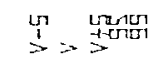

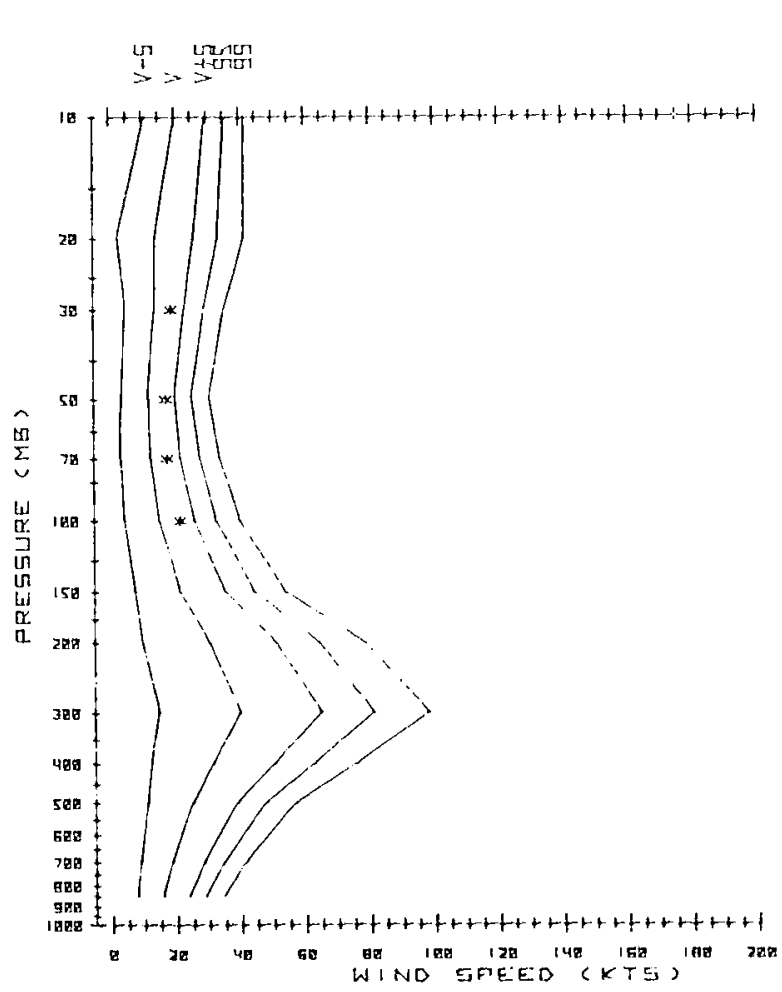

SIMMMER

SIM
-JOKIDINEN

$*=$ GU. 17 LEVEL

FALL

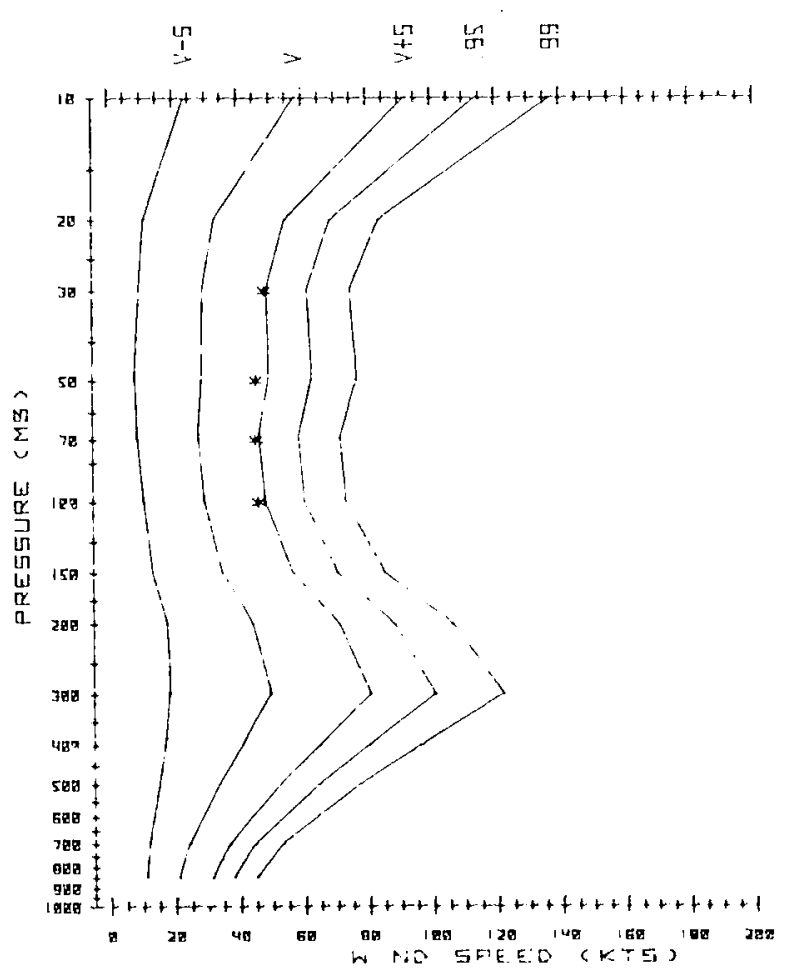




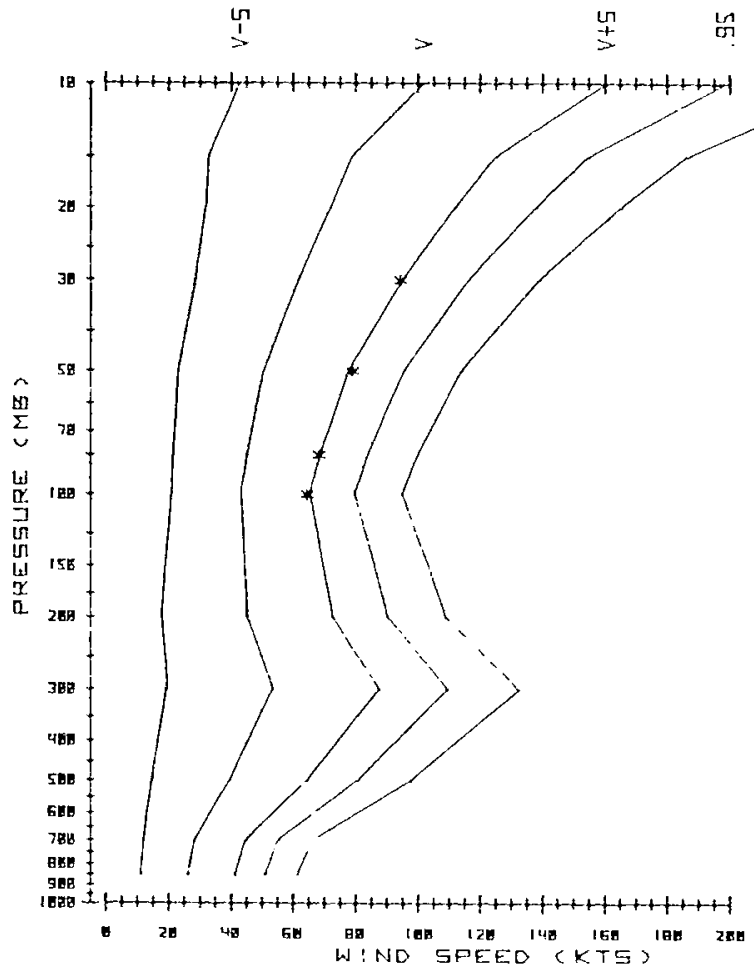

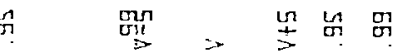

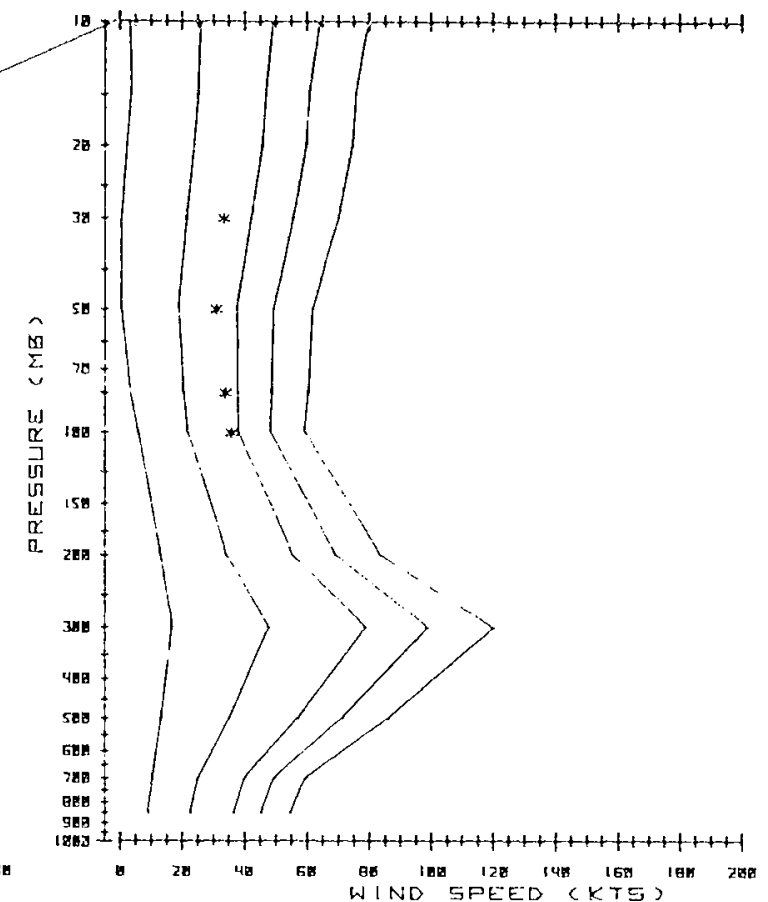

KEFLAV IK

$*=B 4,1 \%$ LEVEL

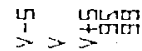

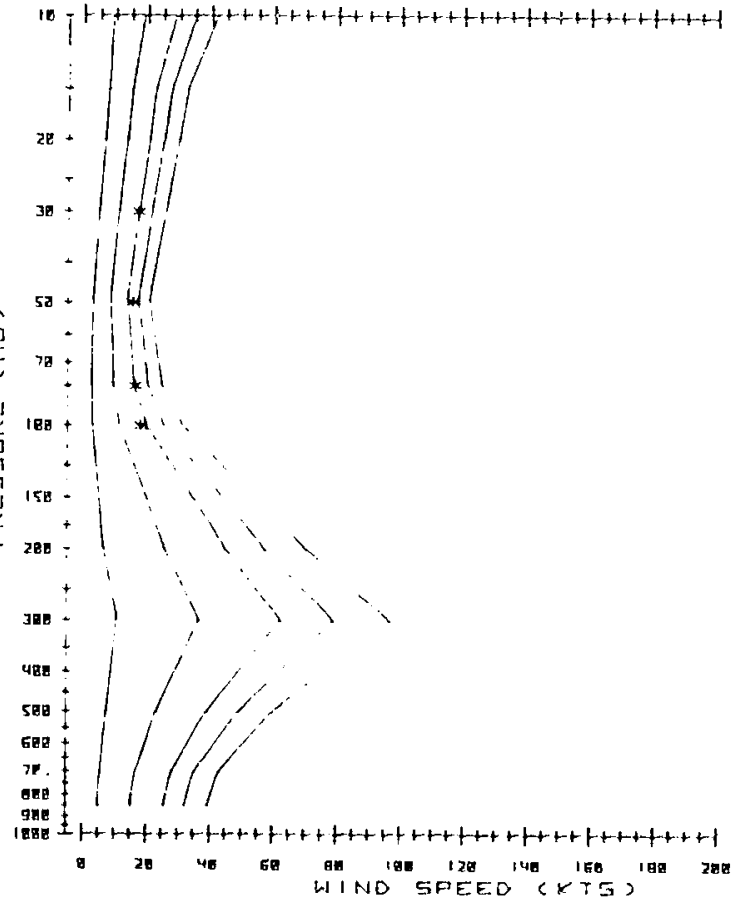

SUMMER
KEFLAVIK
$*=$ GU I\% LEVEL

FRLL

$\stackrel{1}{>}> \pm$ 告昂

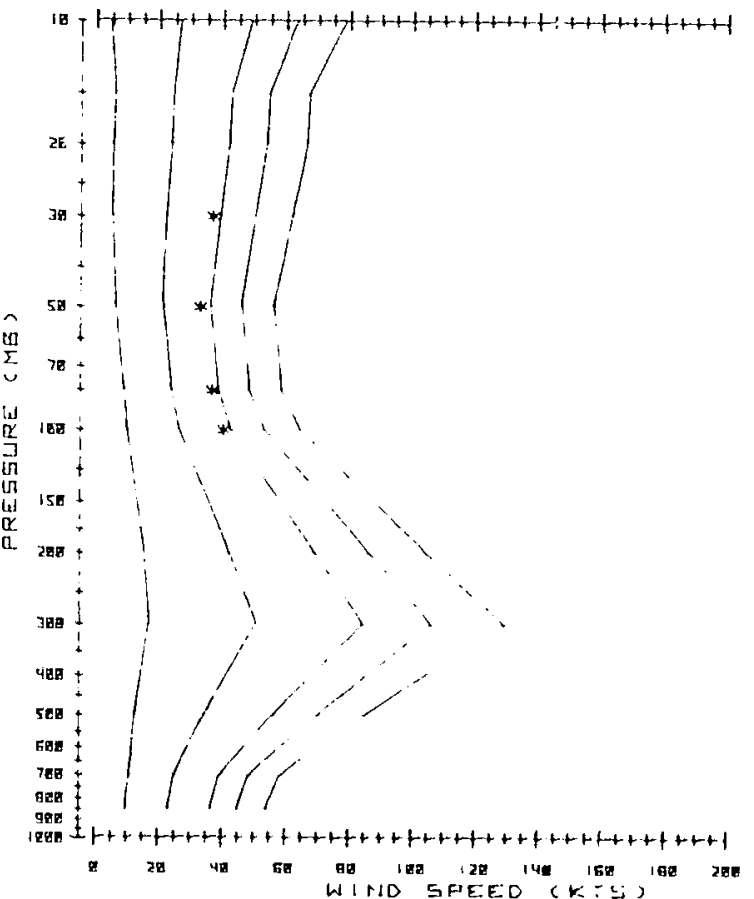




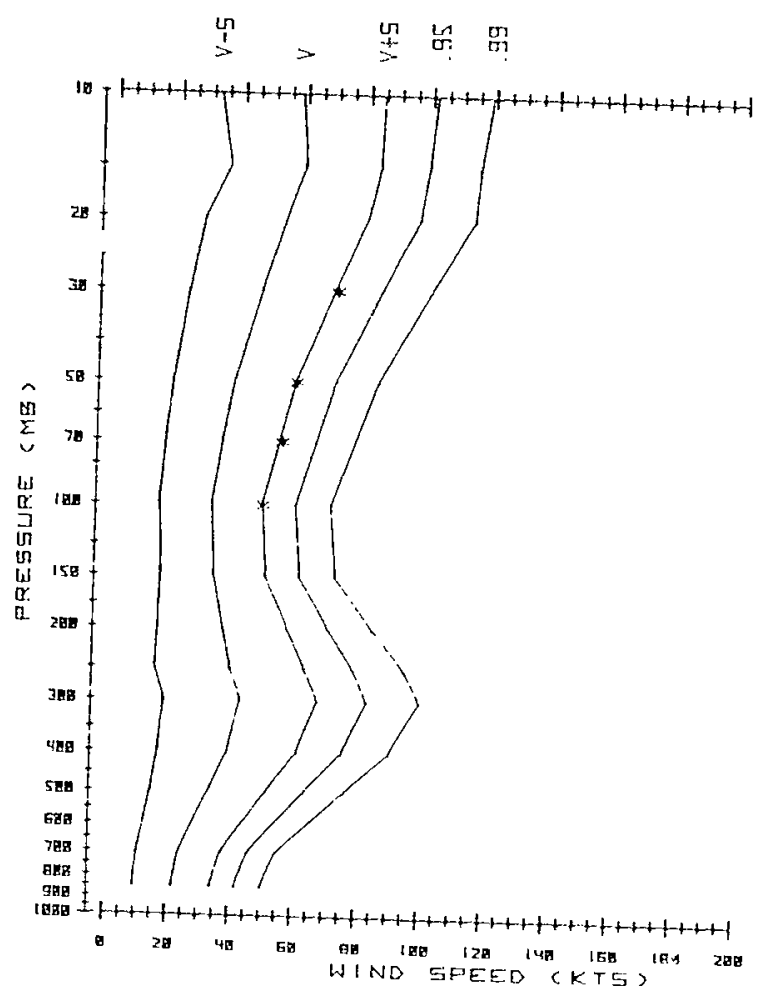

KOBENHAVN * $=$ GU. 1\% LEVEL

SUMMER $\stackrel{4}{1}=\stackrel{4}{401}$

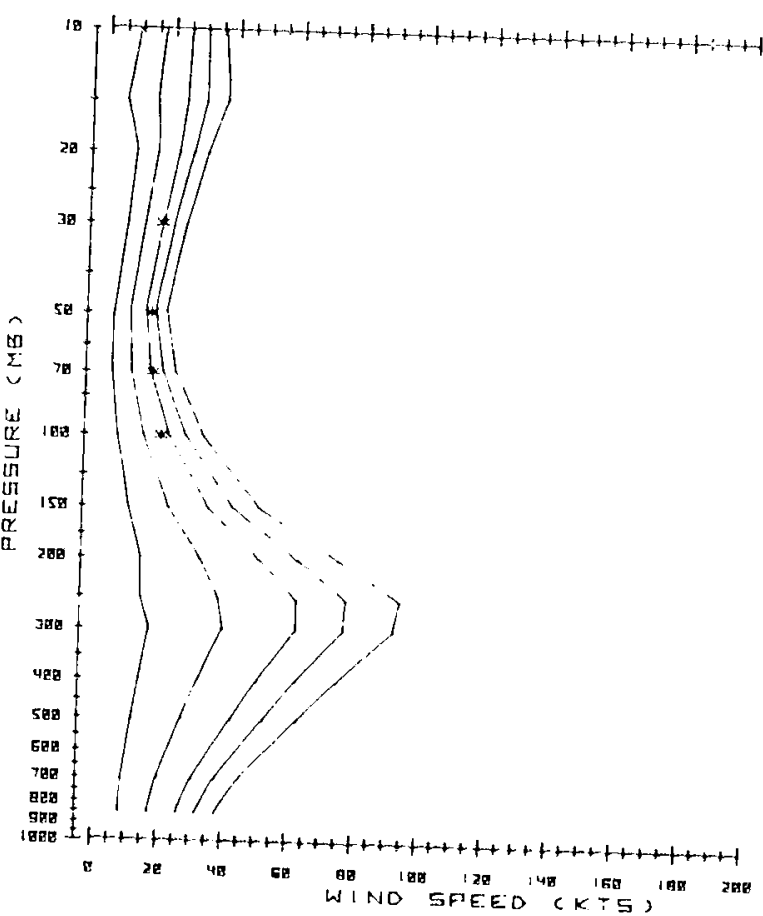

$\begin{aligned} & 1 \\ & 3\end{aligned}=$ แ

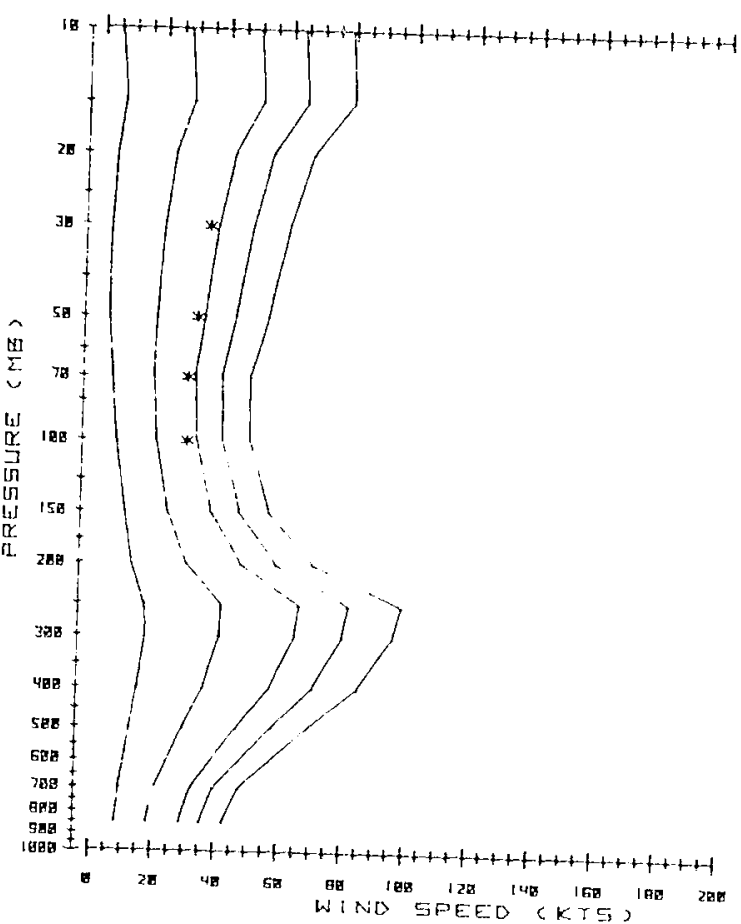

KIBENHAVN

$*=B_{4} \%$ LEVEL

FALL

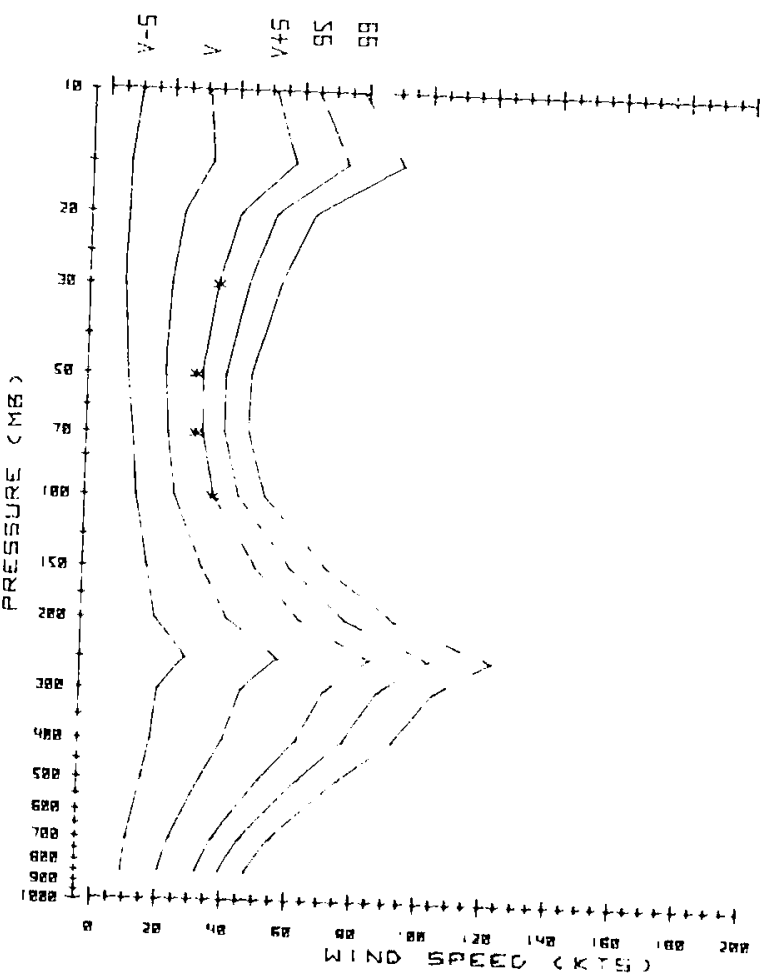




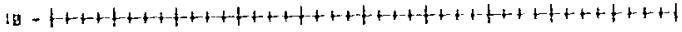

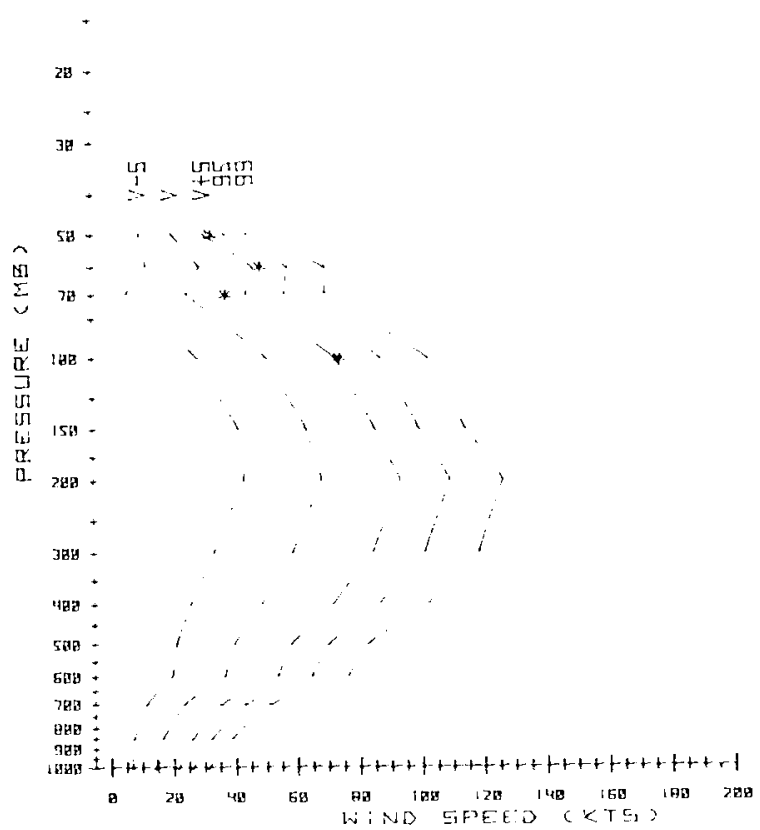

MATRLH
$*=94.1 \%$ LEVEL

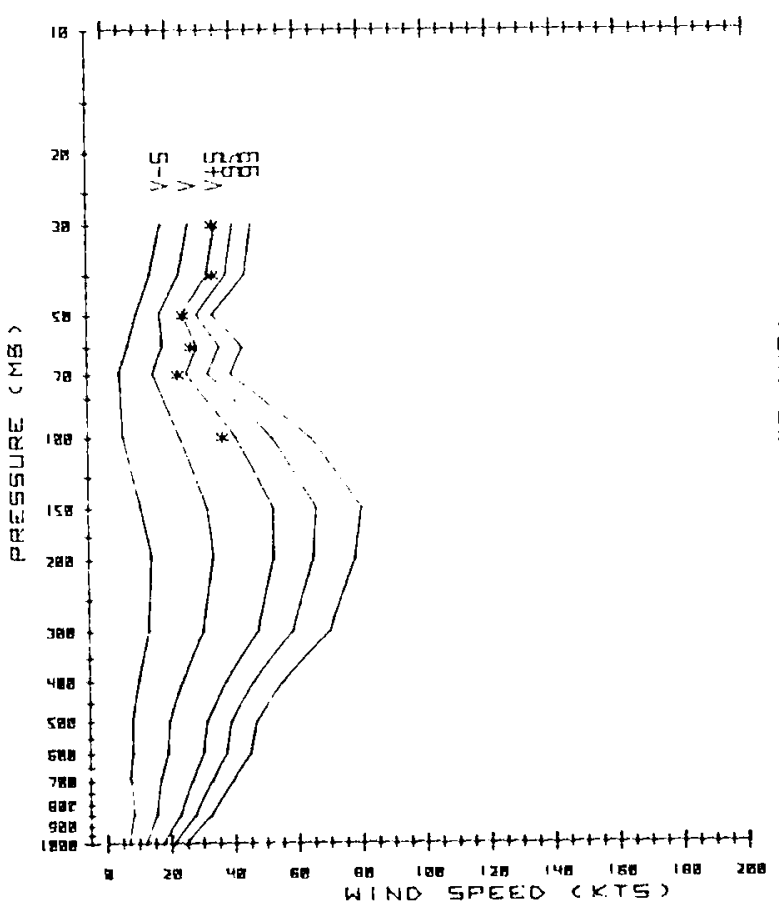

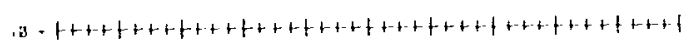

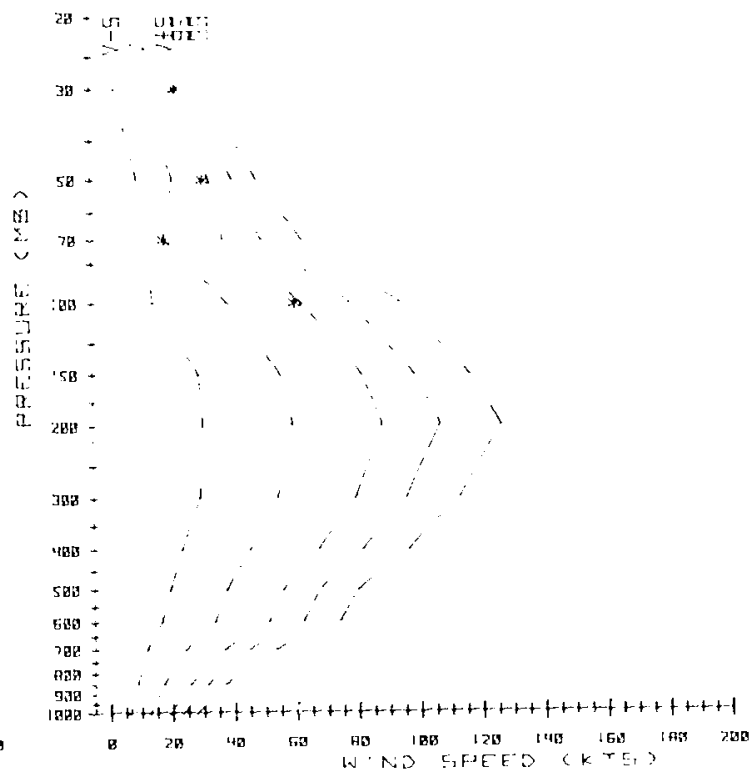

MATRUH

* $=84$ i LEVEL

FRLL

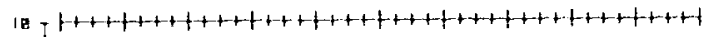

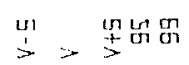
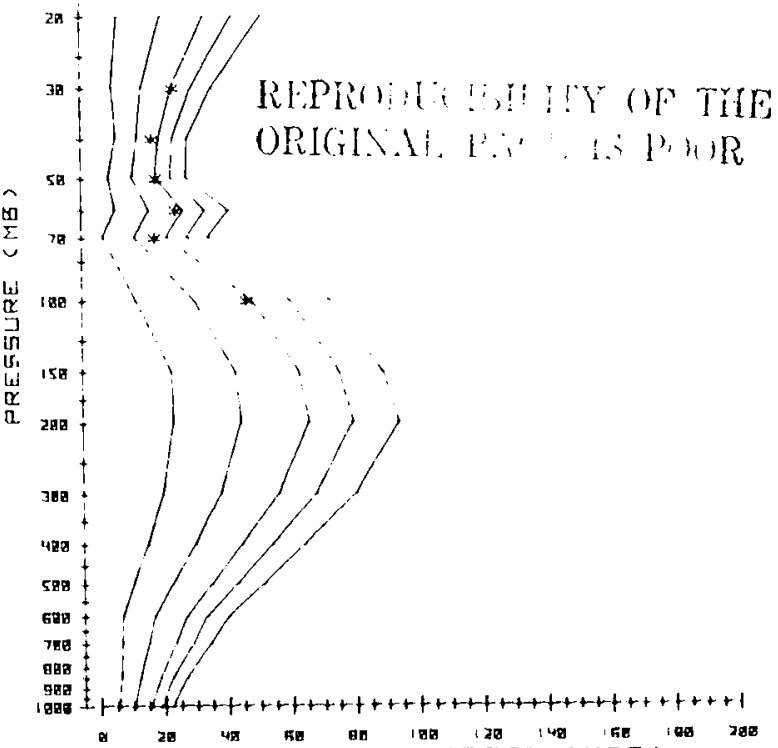

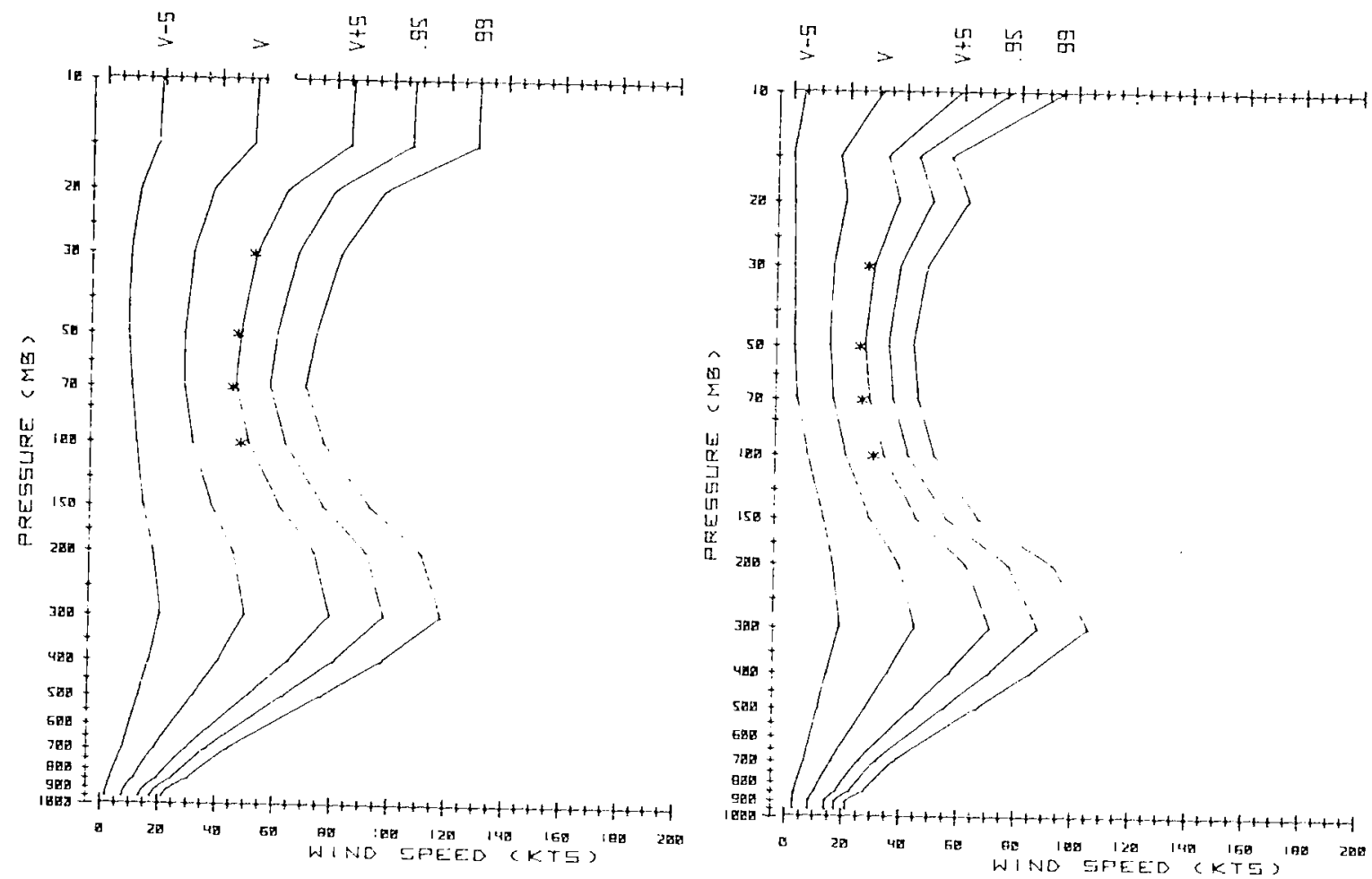

$M I L F N D$
$*=\theta^{4} .1 \%$ LEVEL

SUMMER

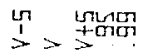

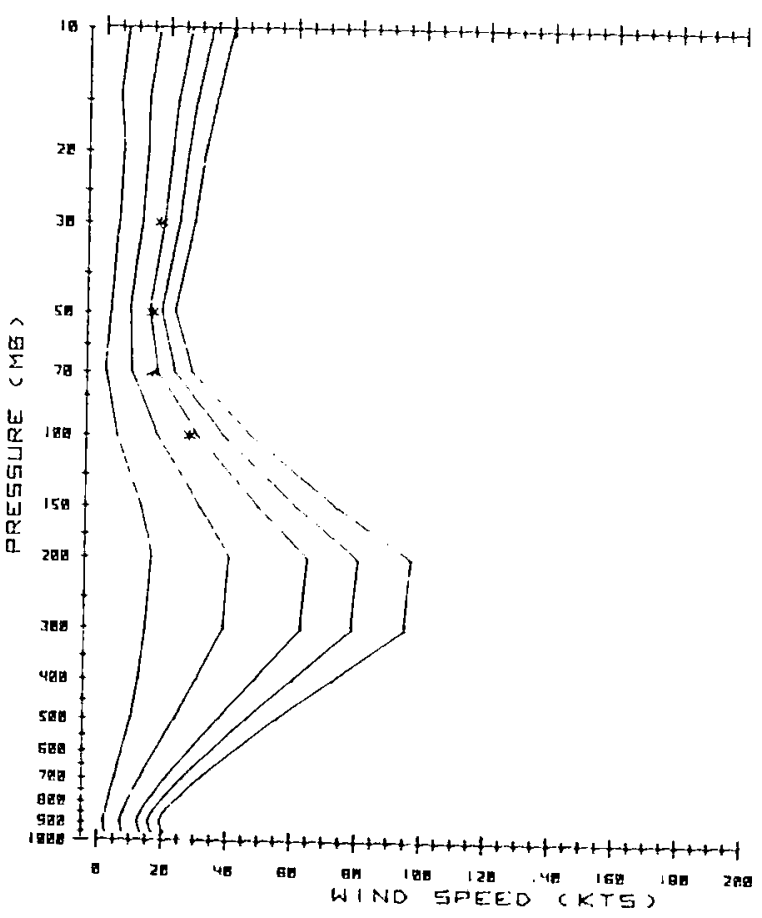

MiLANE

$*=$ GU I\% LEVEL

FALL

$\stackrel{1}{>}>$ 足出 品

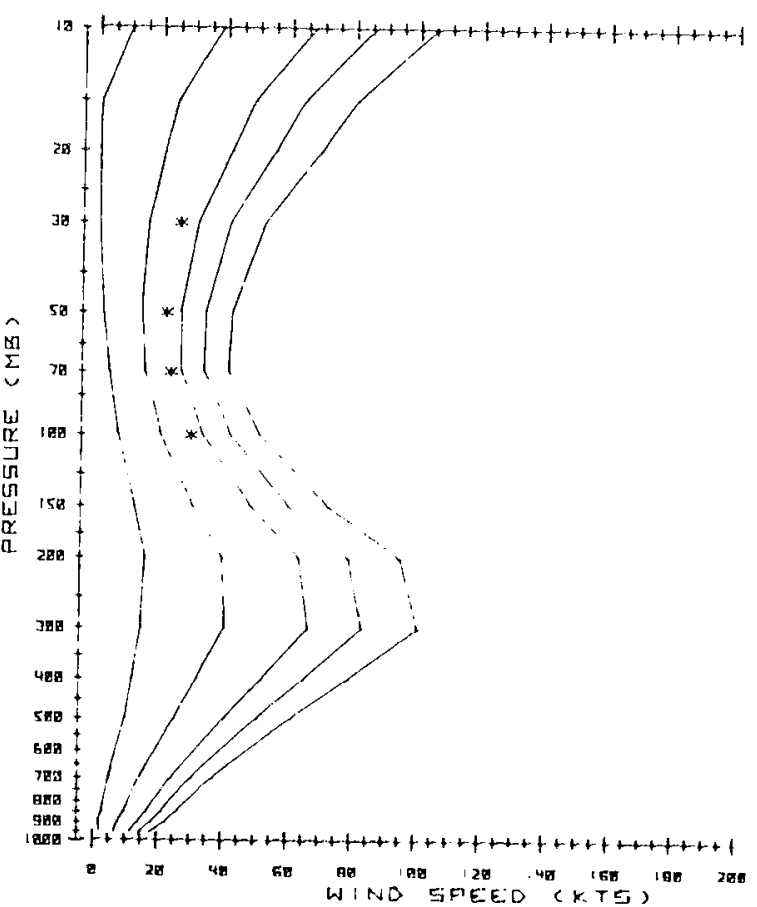



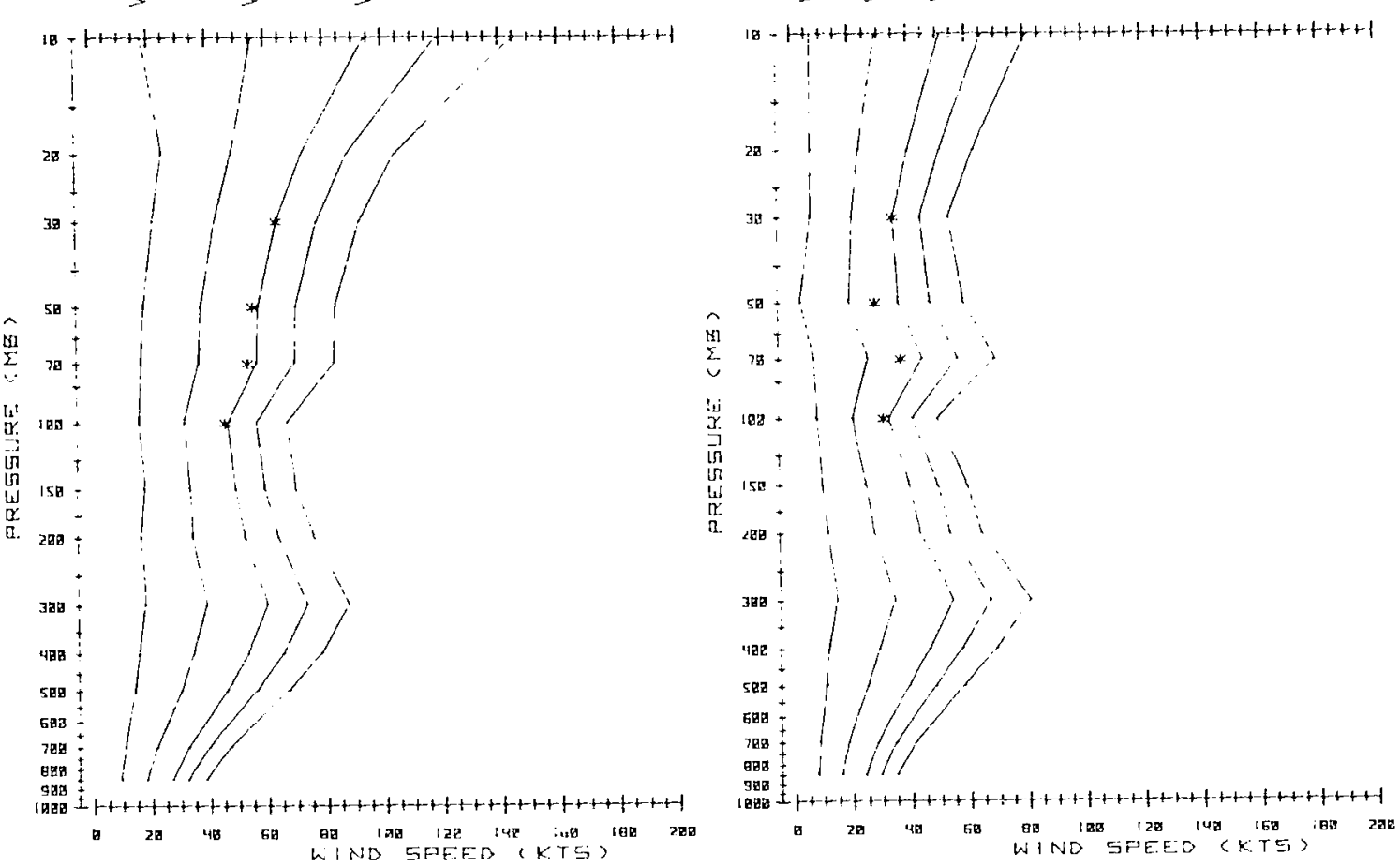

$\underset{*=84}{\text { DDE.55月 } 1 \% \text { LEVEL }}$

SUMMER

$\stackrel{4}{>}>\stackrel{\min }{>} \stackrel{4}{>}$

DDE55月
$*=04$
04 LEVEL

FRLL

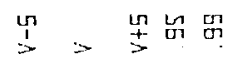
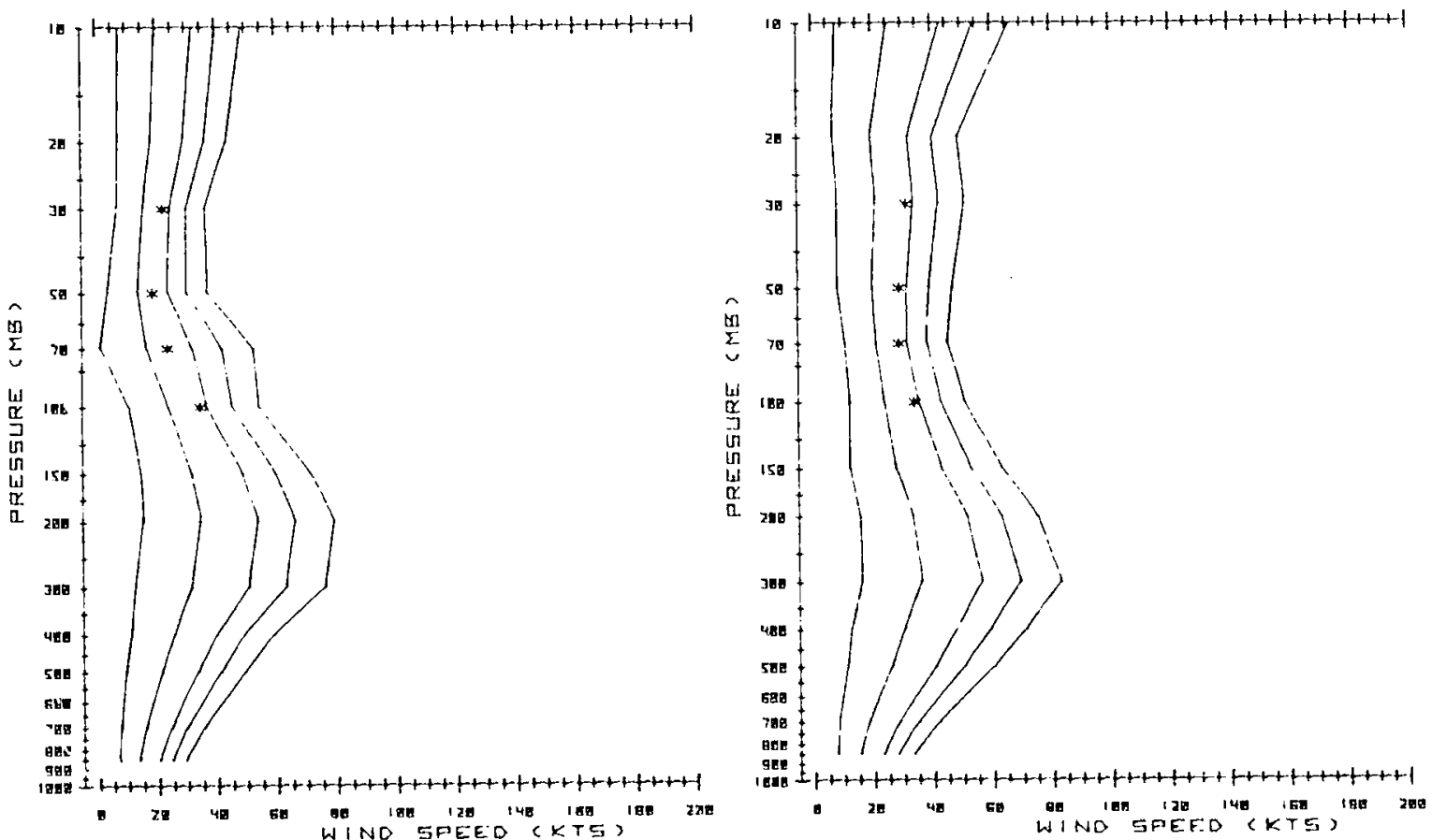
THORSHAVN

* $=$ BU $^{1} 1 \%$ LEVEL

WINTER

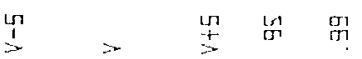

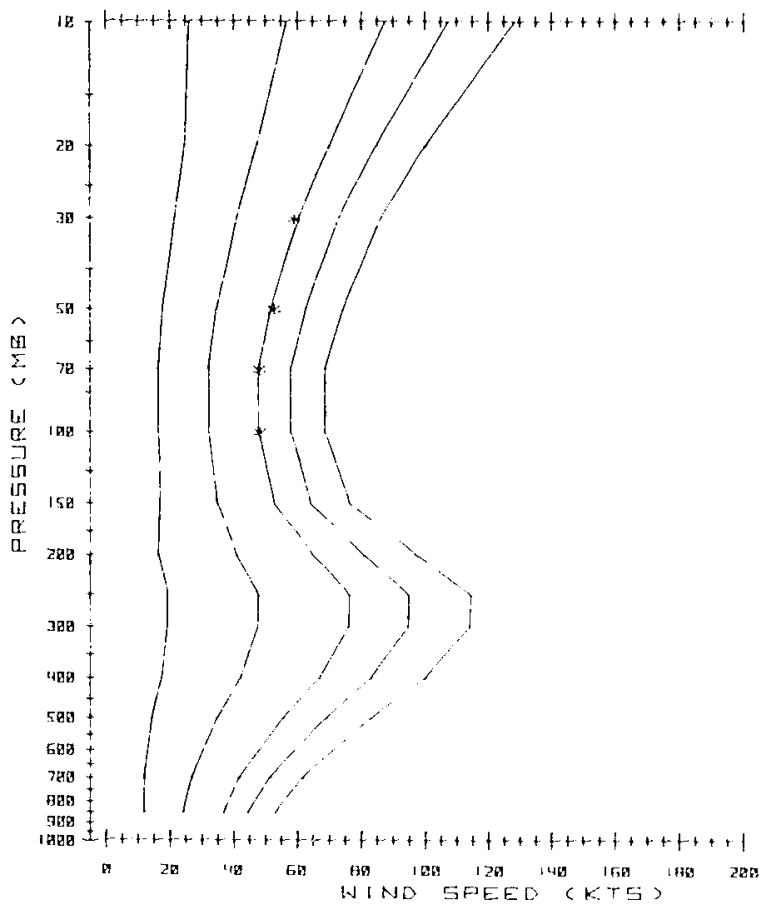

THIRSHAVN

$*=841 \%$ LEVEL

SLIMMER

ㄴ.

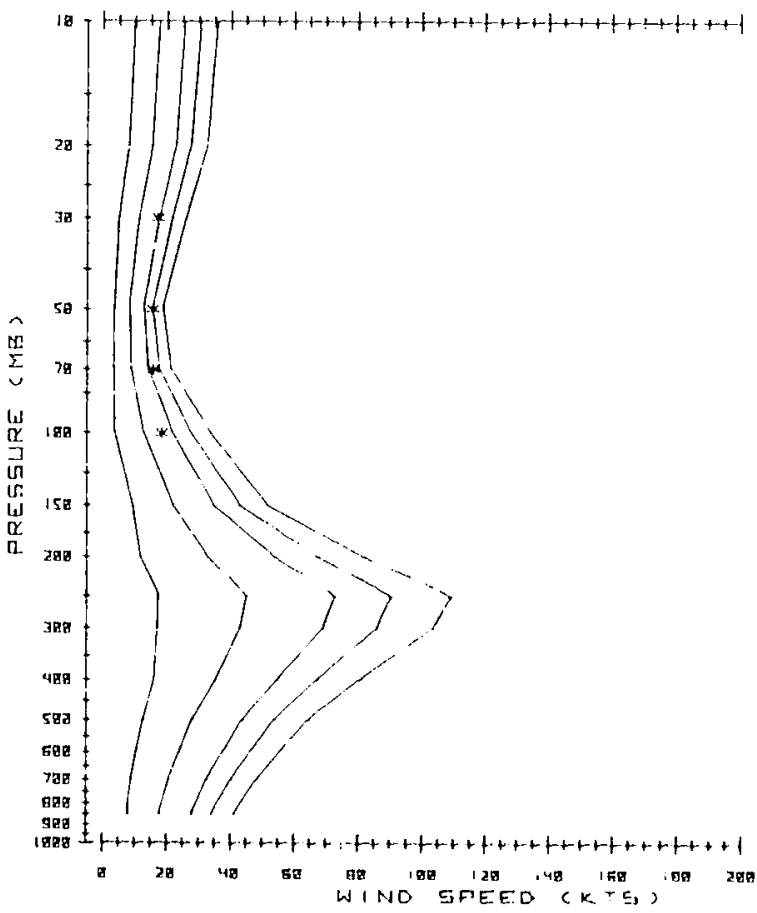

THLRSHABVN

$*=A 4 \quad$ I\% LEVEL

LPR A ME

บ

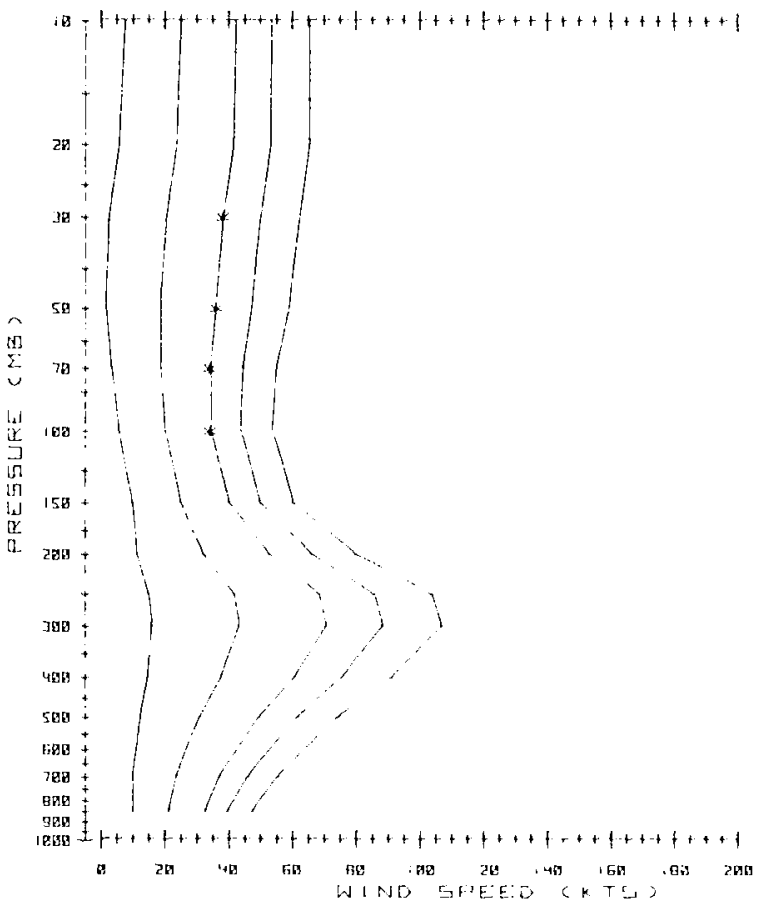

THIRSSHAVN

$*=04 \%$ LEVEL

FALL

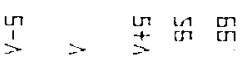

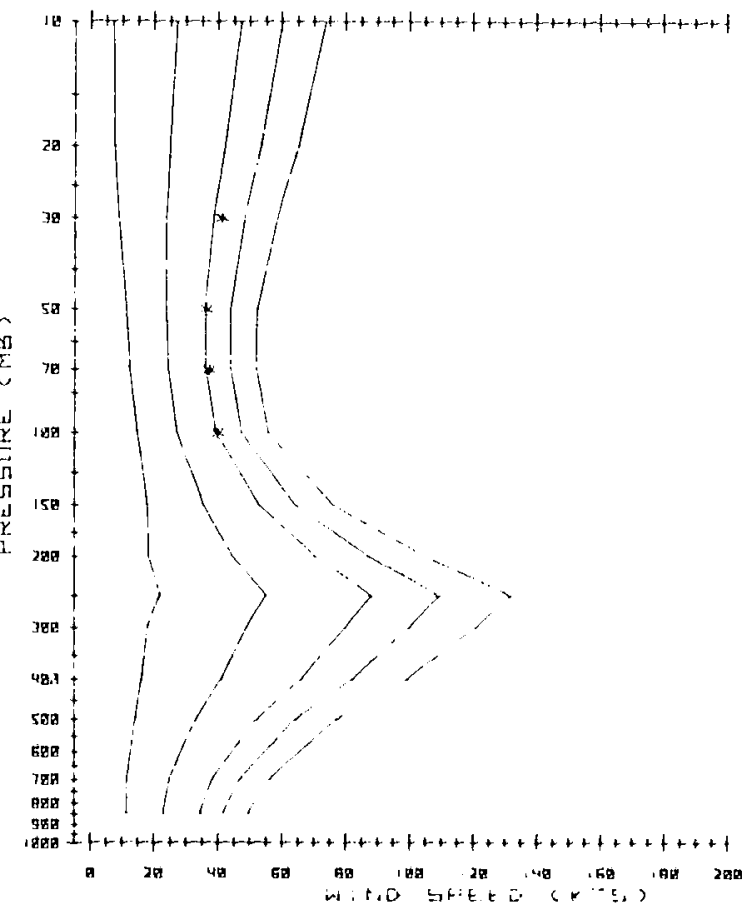


TRIPDL I

$*=$ Bप. $\%$ LEVEL

WINTER

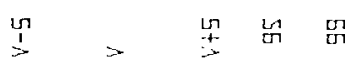

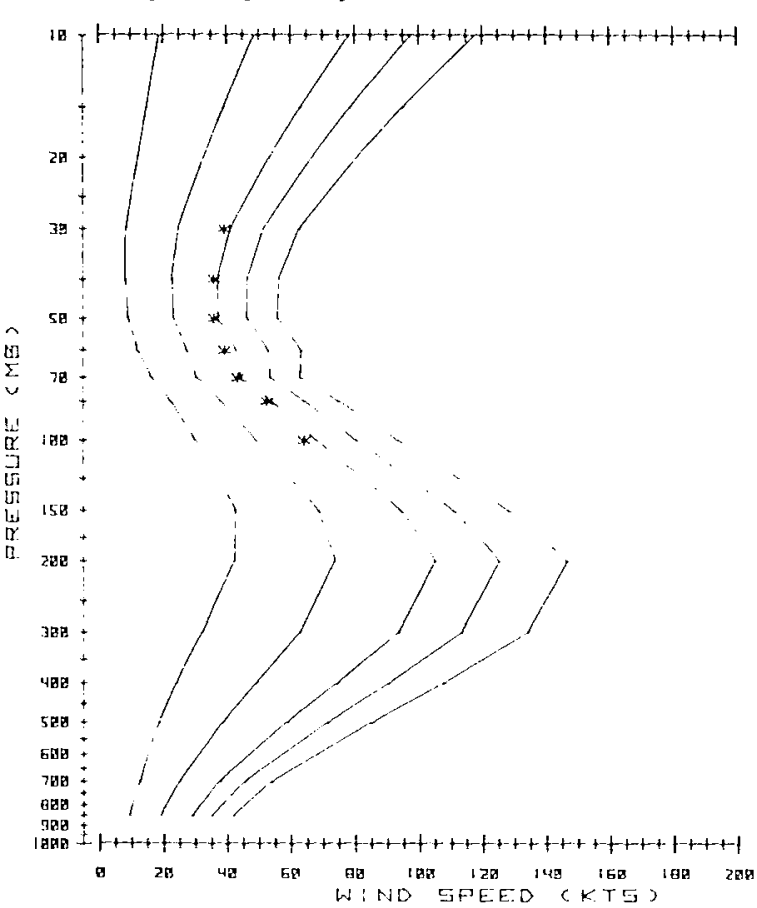

TR:PEL :

*- BU I\% LEVE!

SUMMER

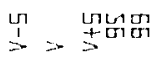

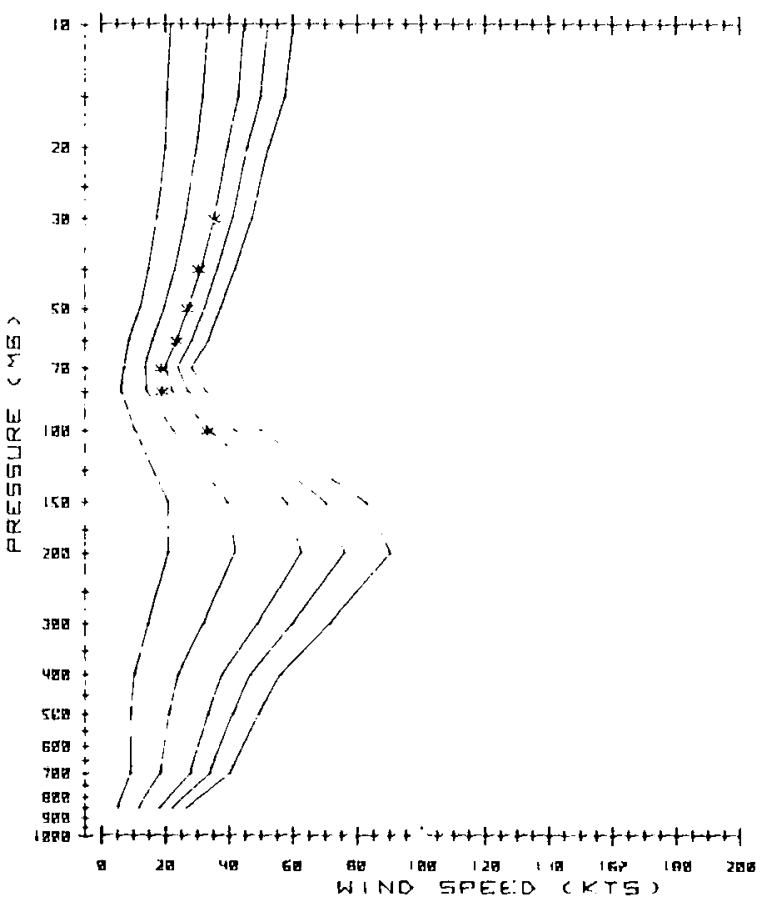

TRIPDL!

* $=$ पU \% LEVEL

SPRINE

$\frac{1}{3}-\frac{7}{2}$
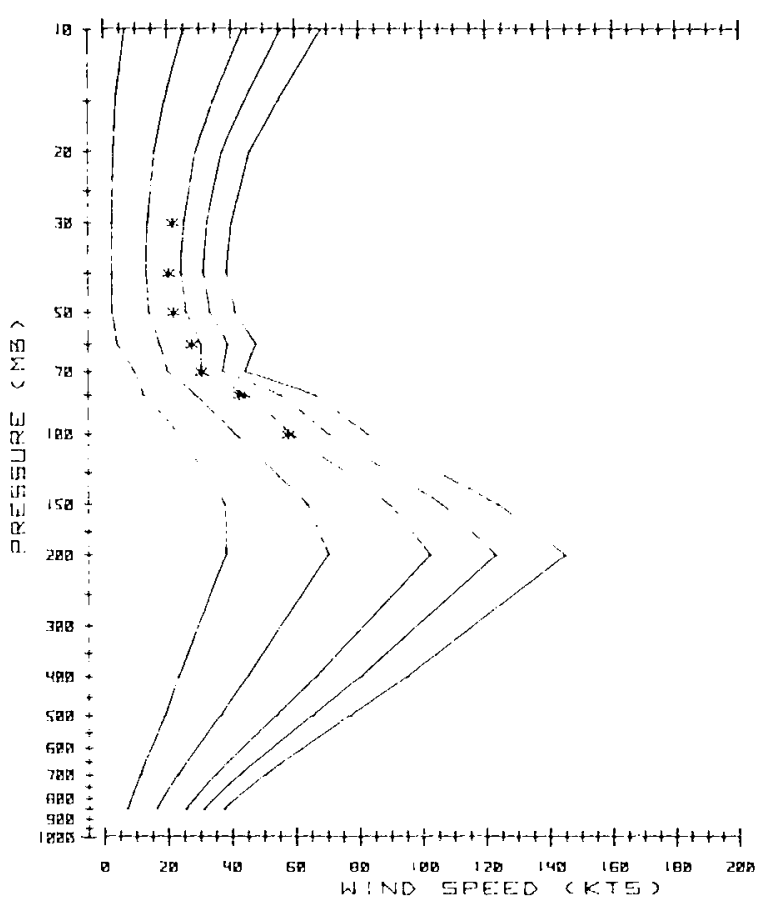

TR i PDL I

$*=84 \%$ LEVEL

FALL

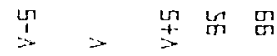

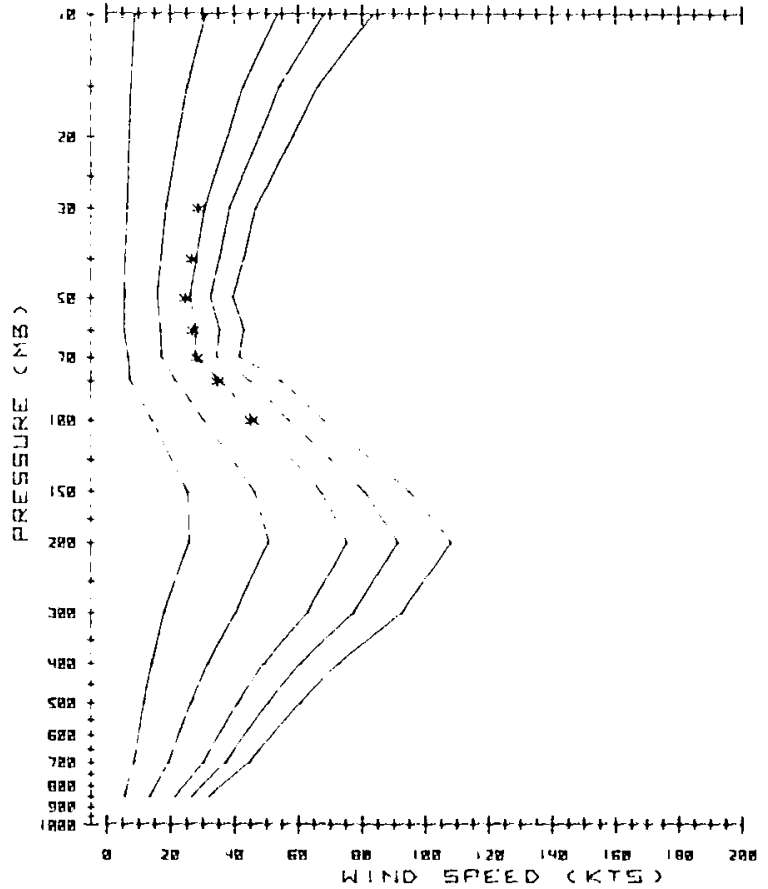




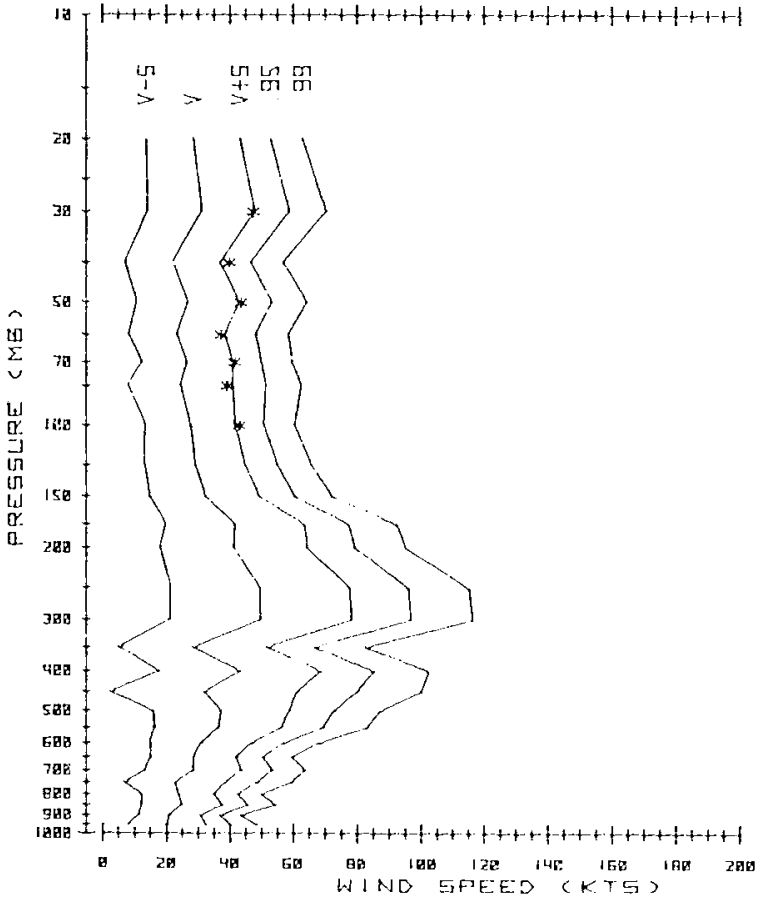

VA!ENTIA * = GU 1\% LEVEL

SLMMER

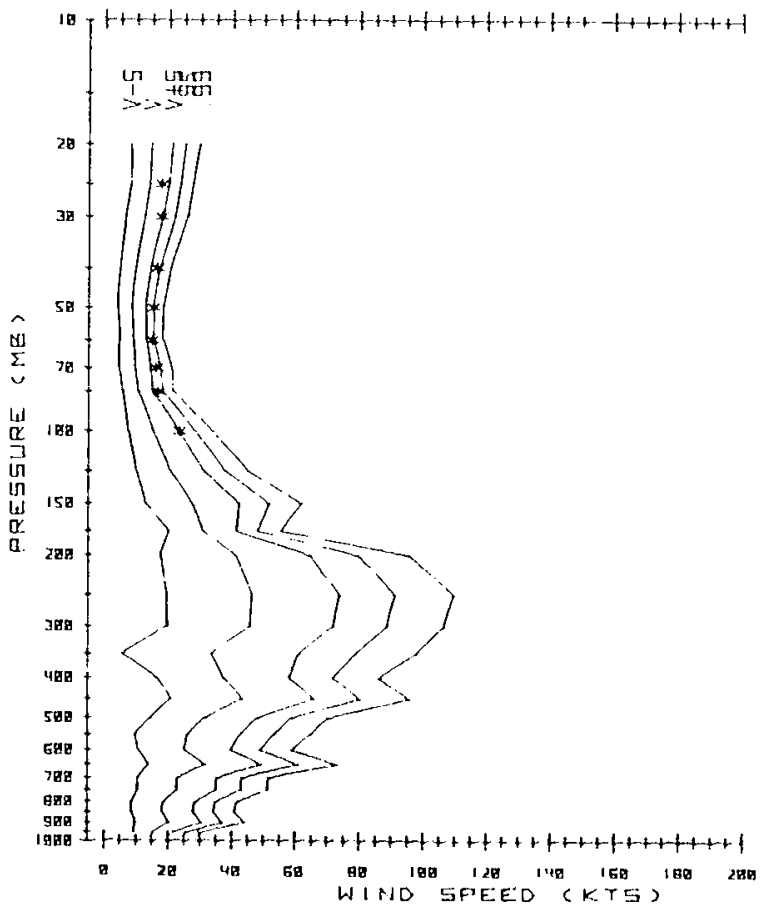

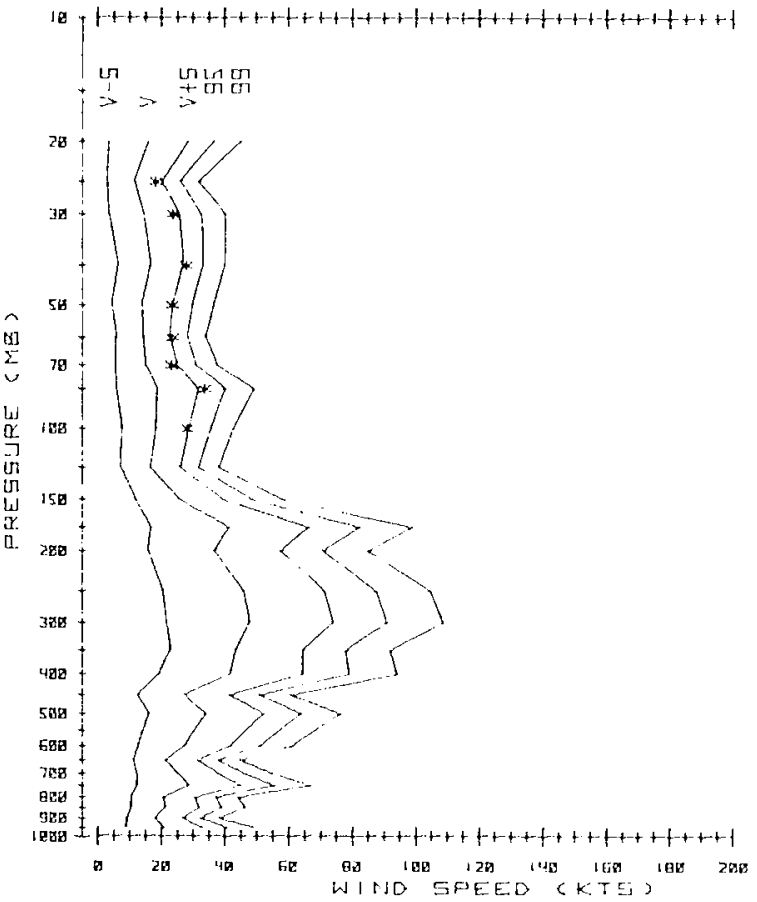

VALENTIA $*=B^{4}: \%$ LEVEL

FHLL

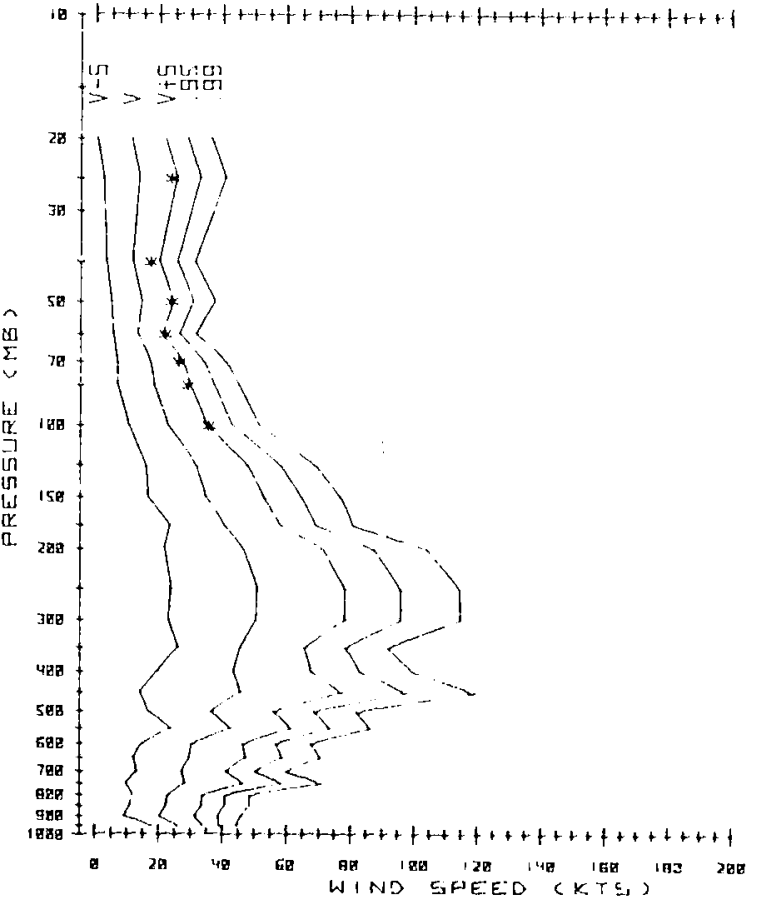



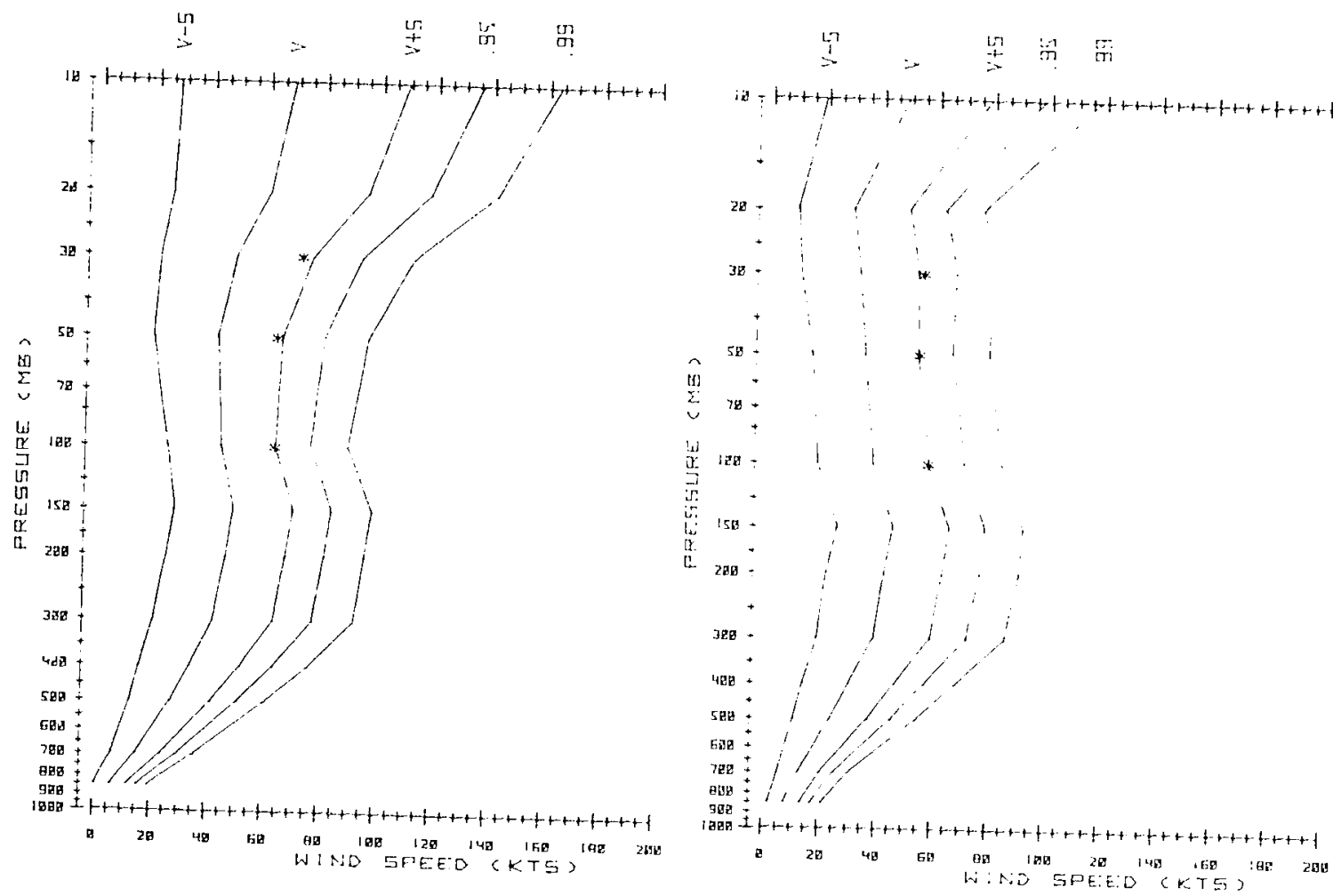

YEREVAN

$\forall=B 4.1 \%$ LEVEI

SIJMMER

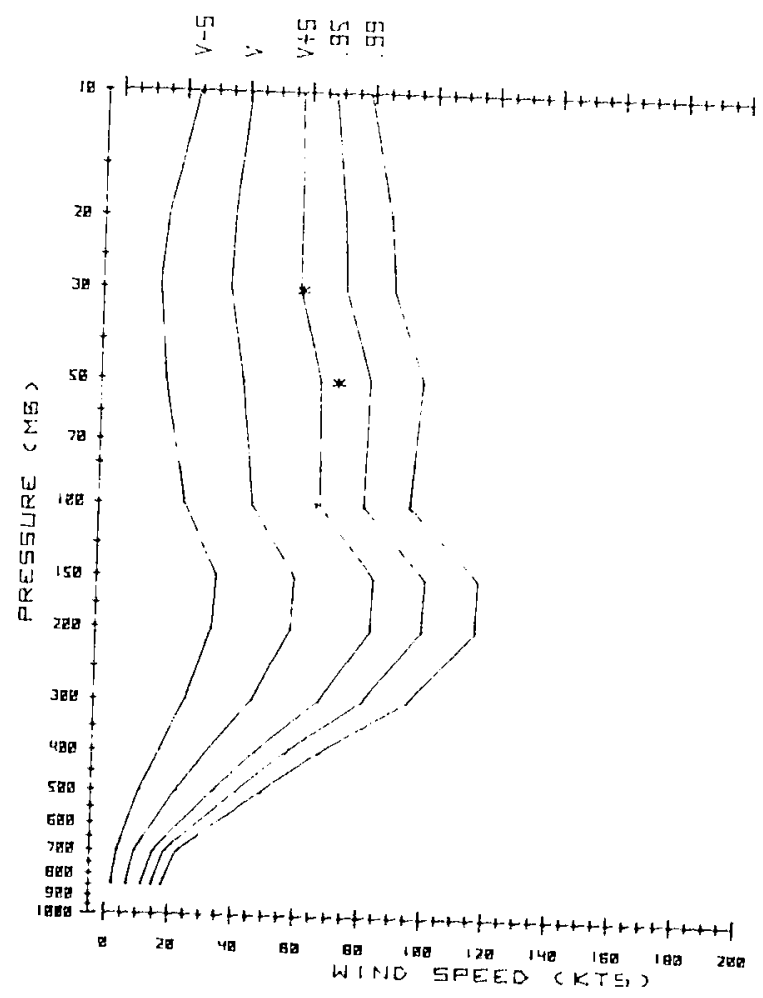

YENE:HN

$*=E 4$ i\% I.E. E

Fri! L

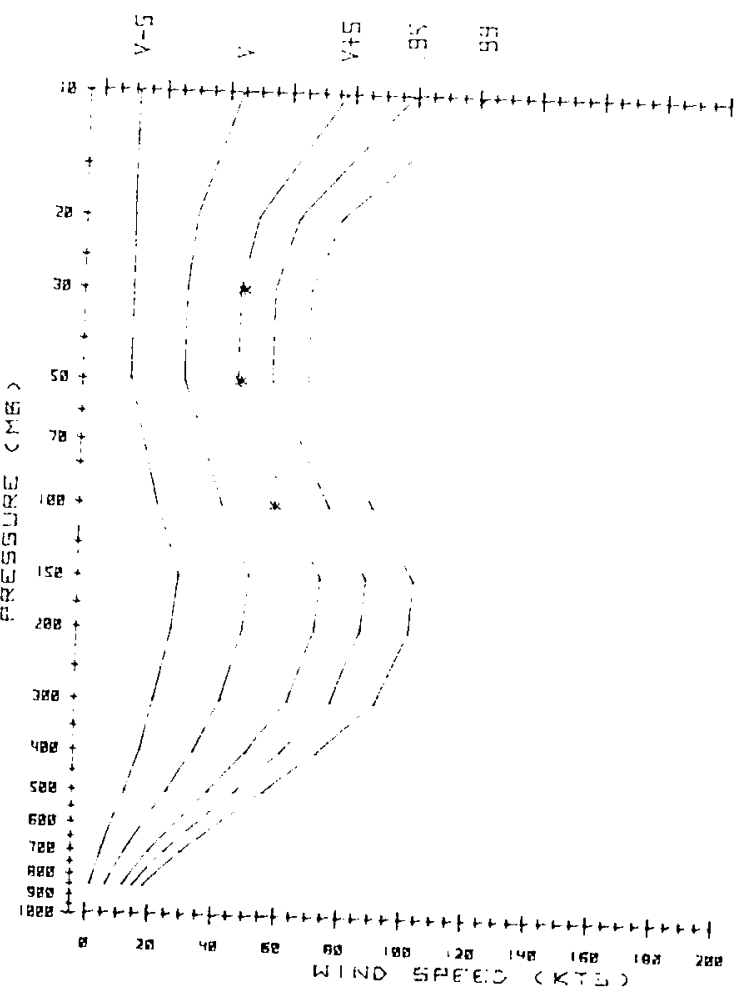



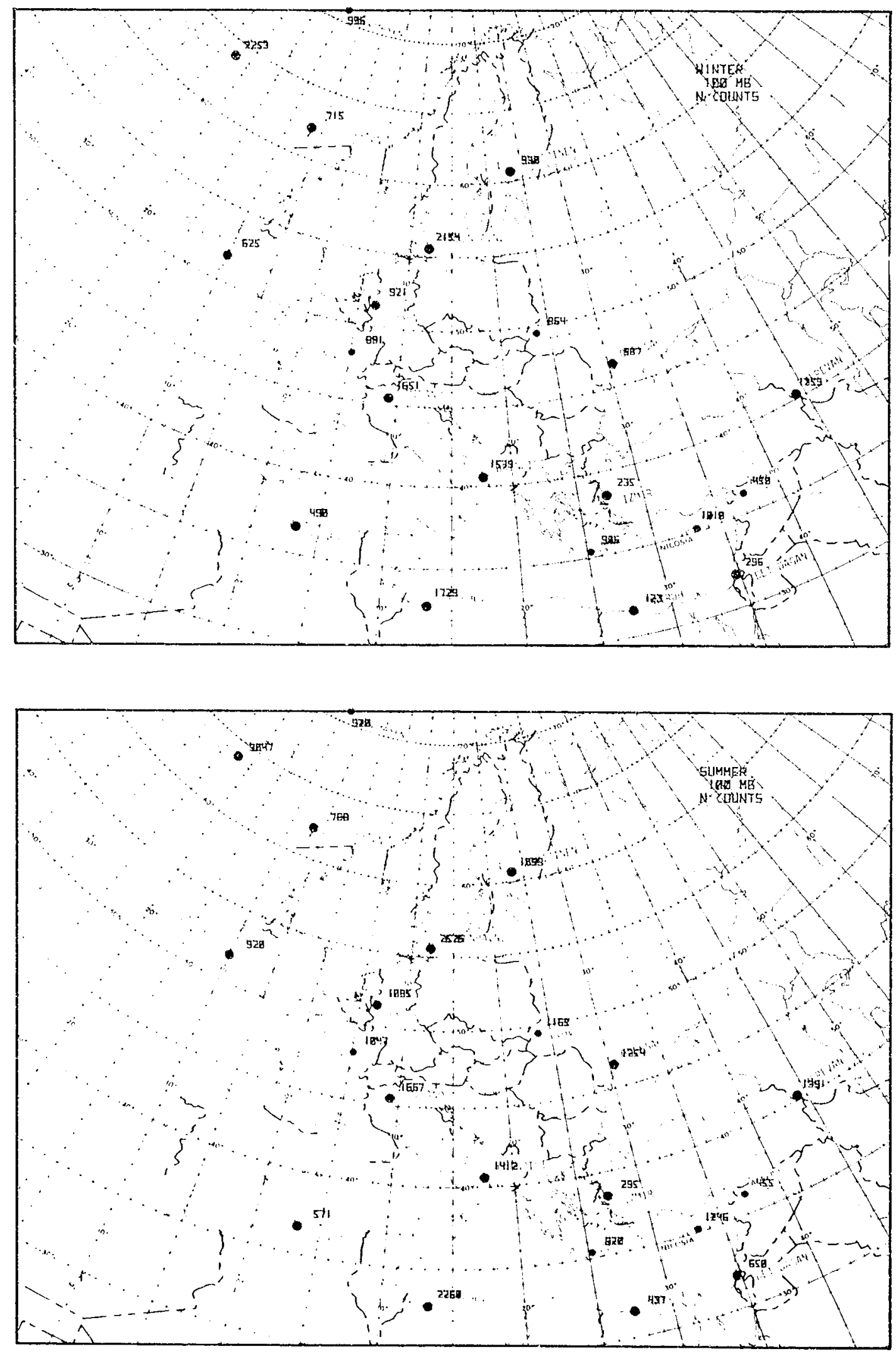


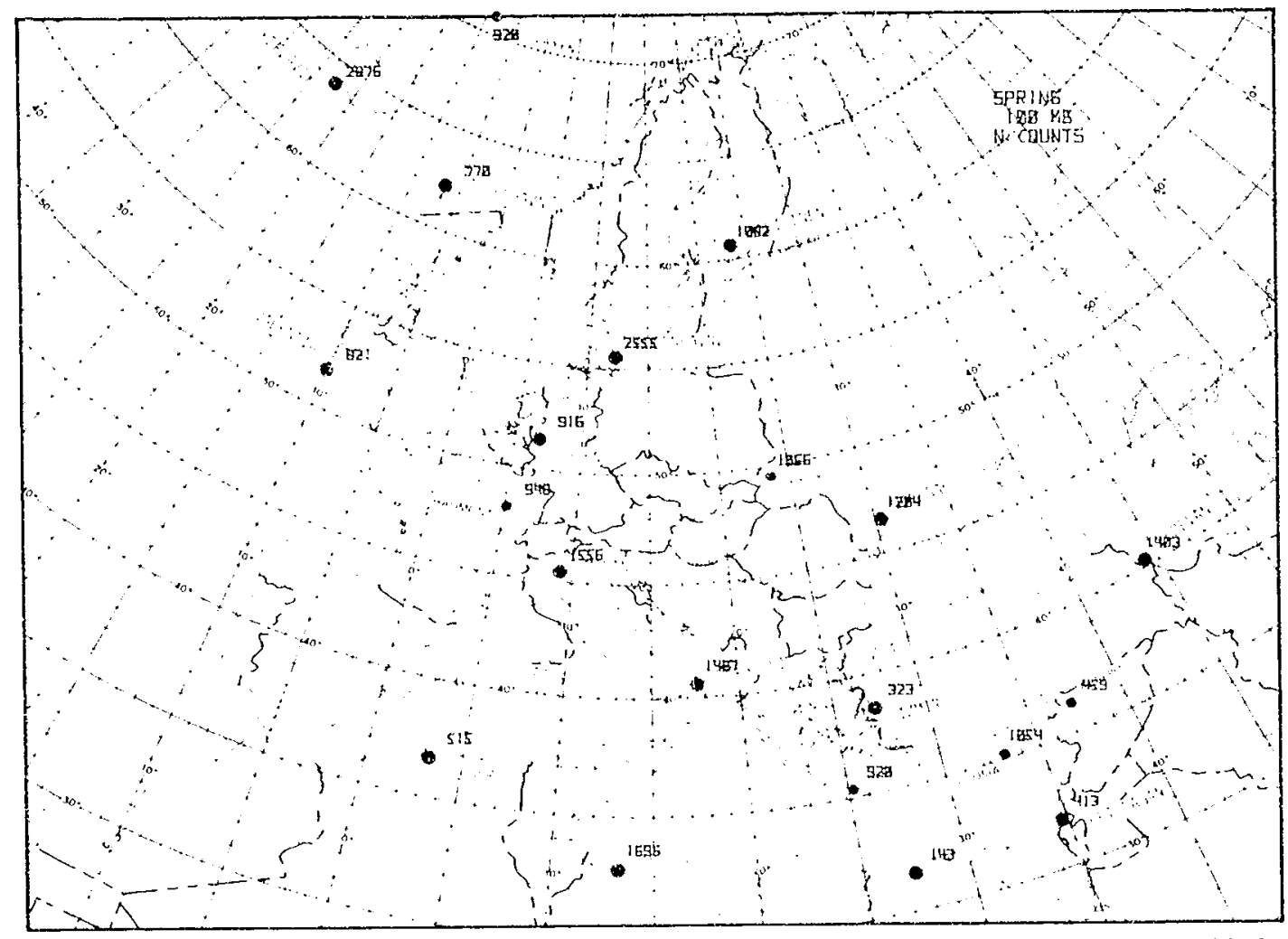

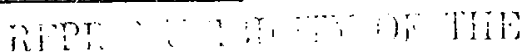

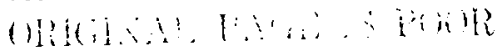

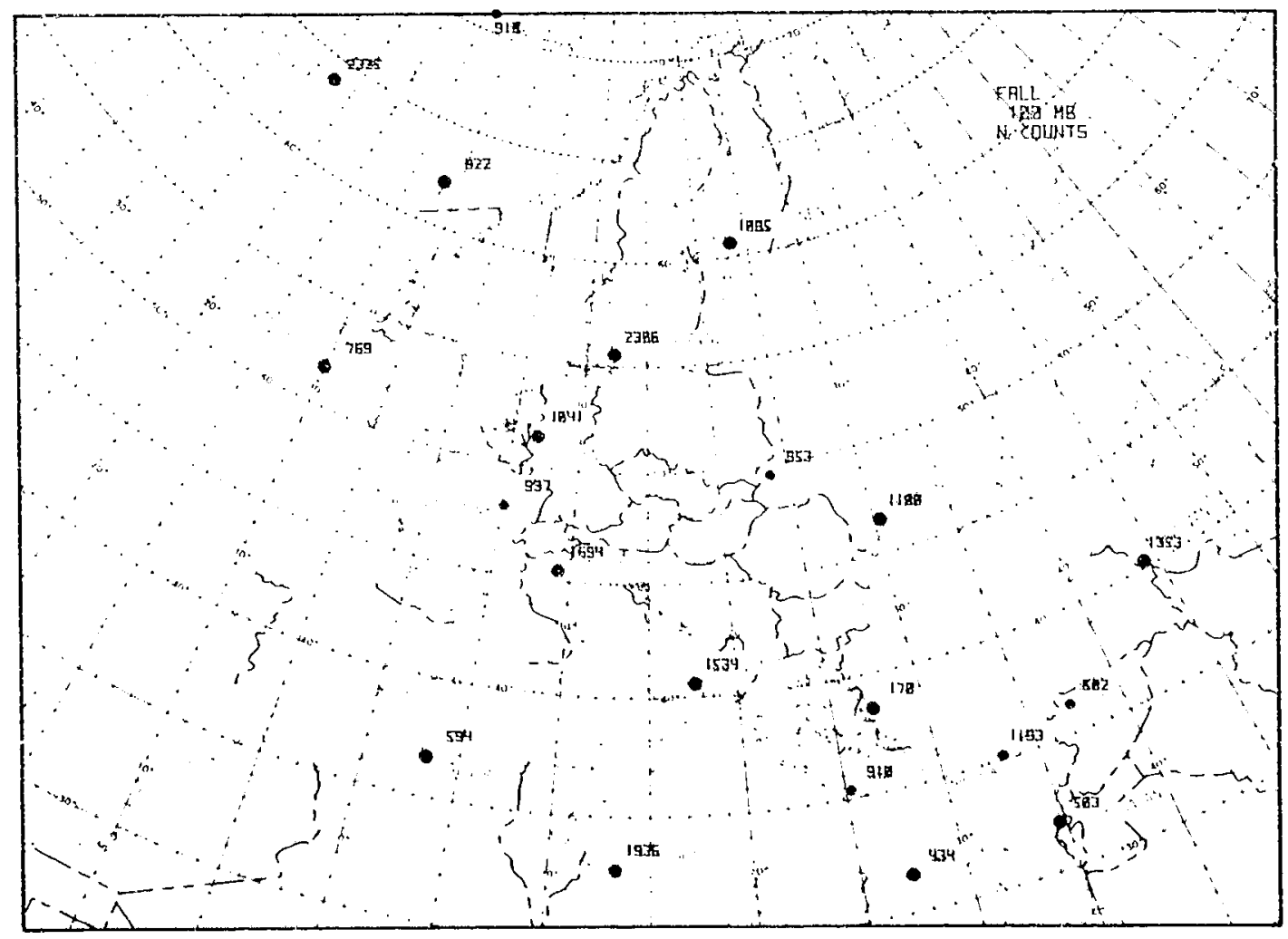



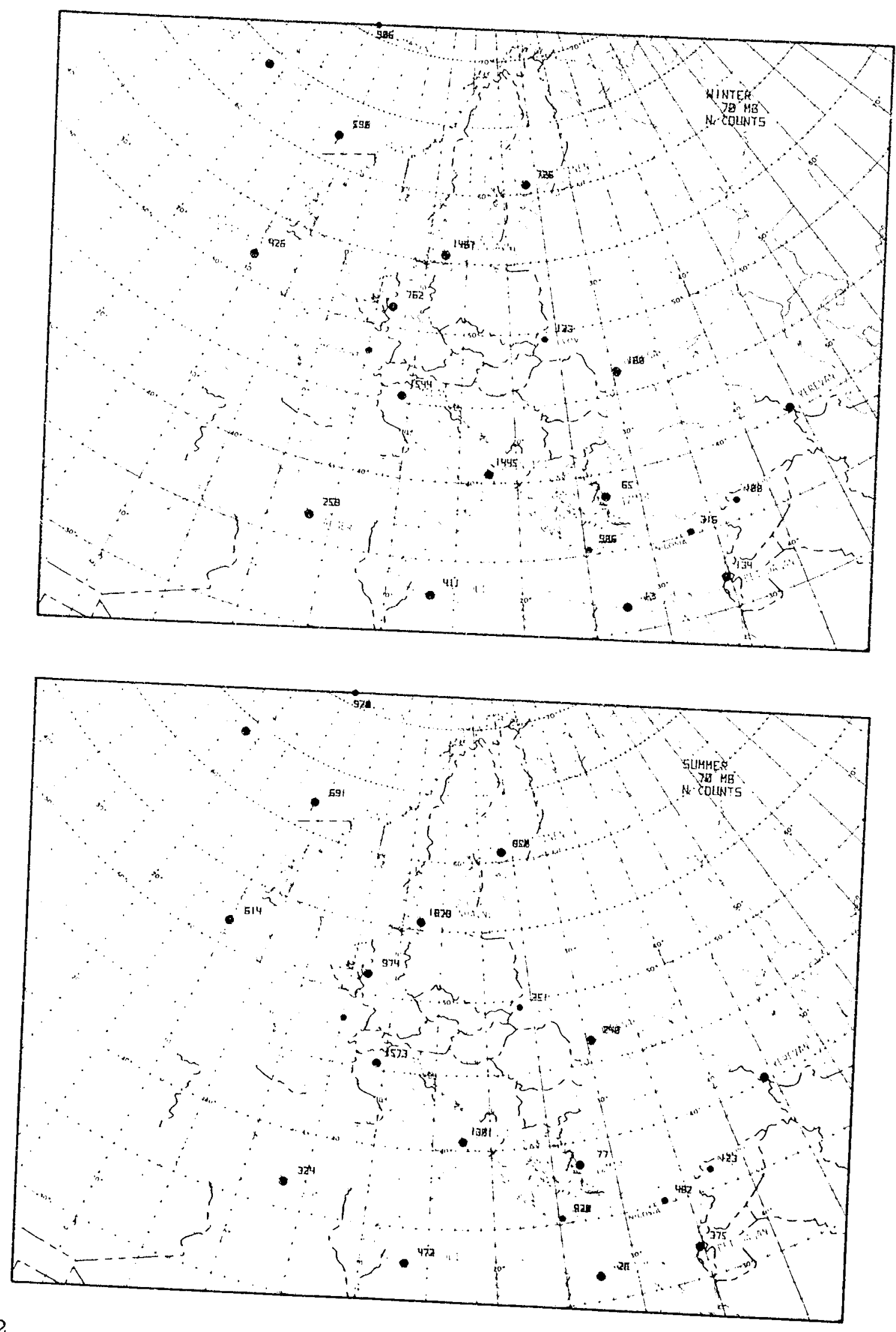

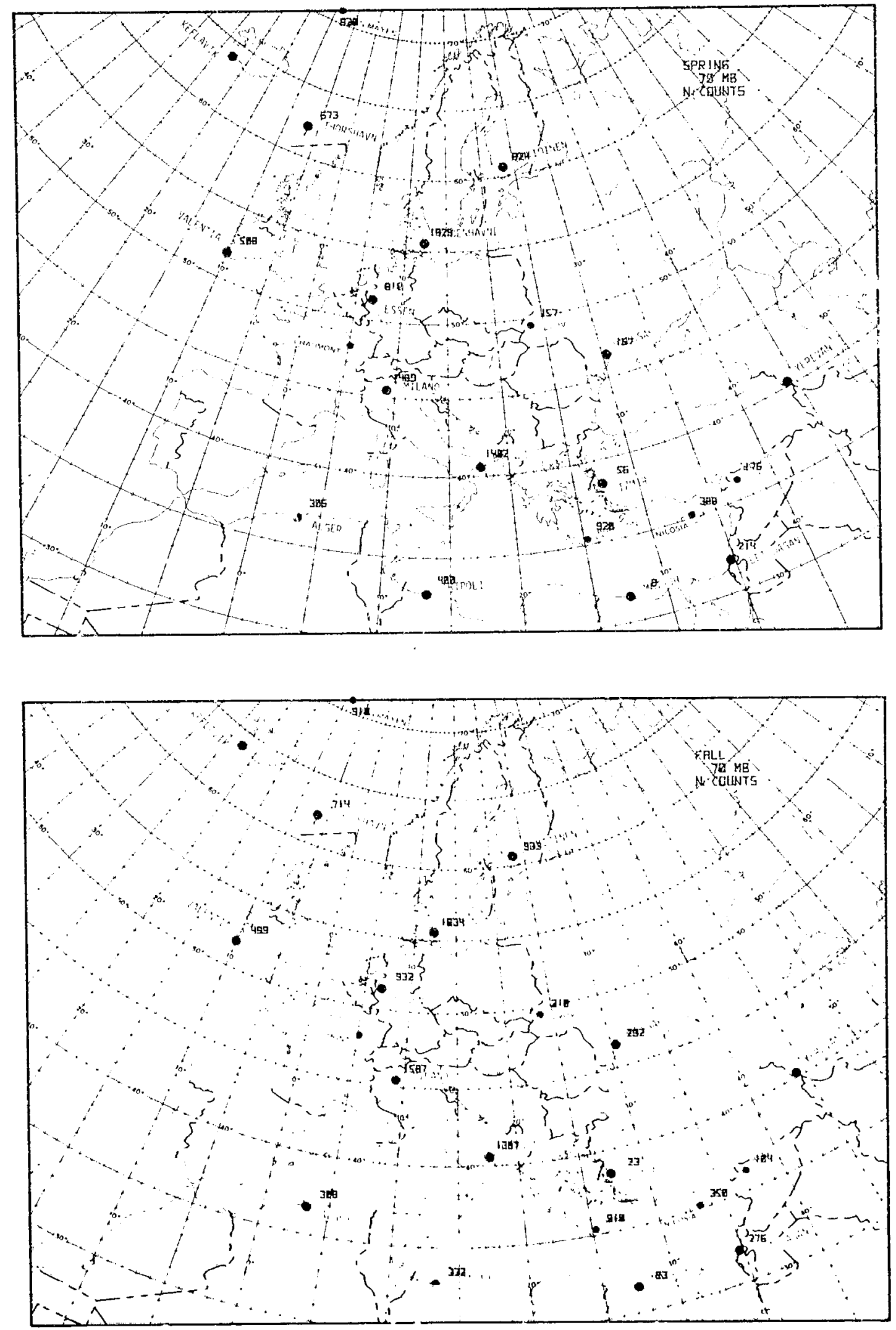

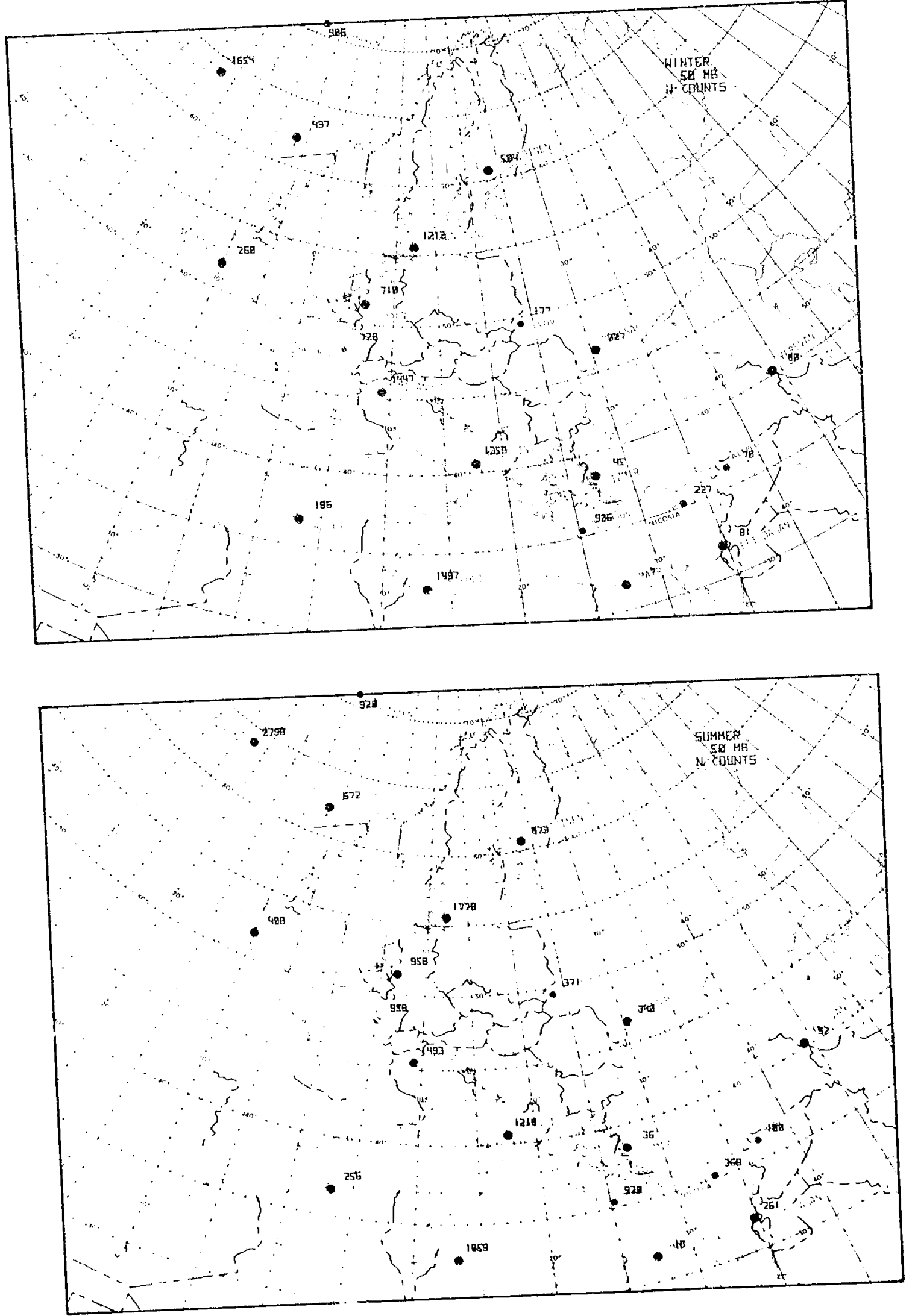


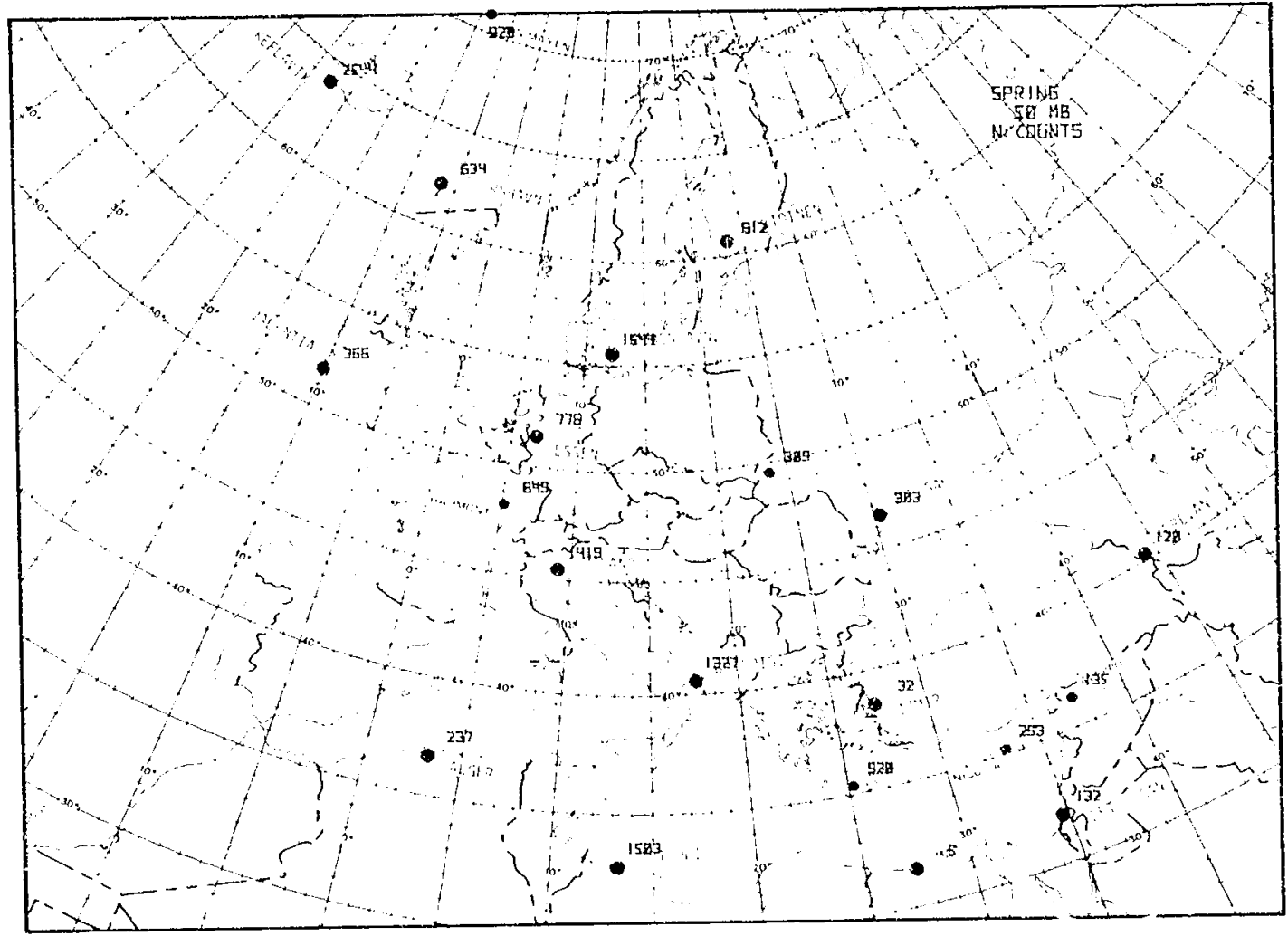

R.

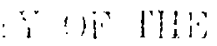

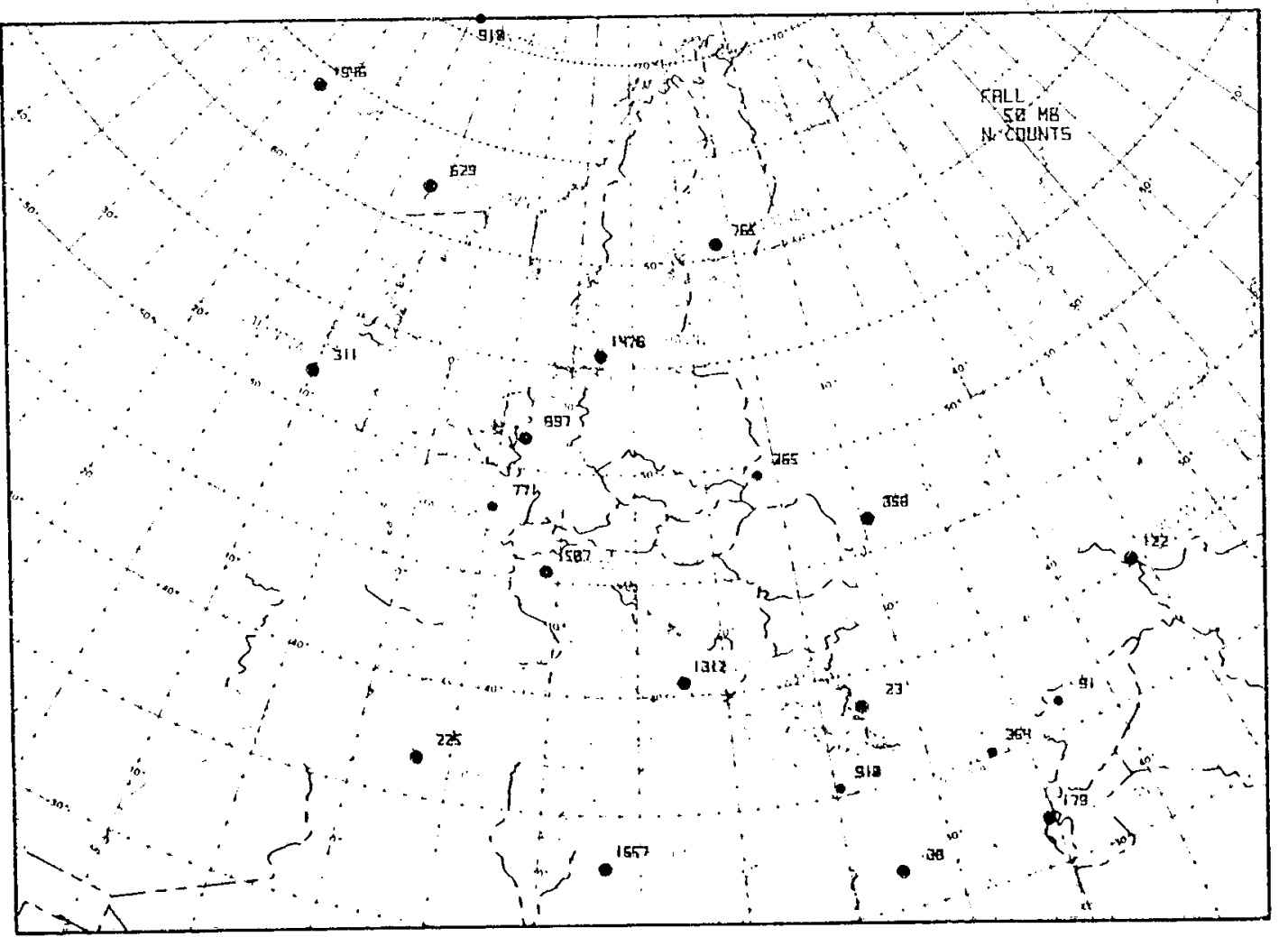



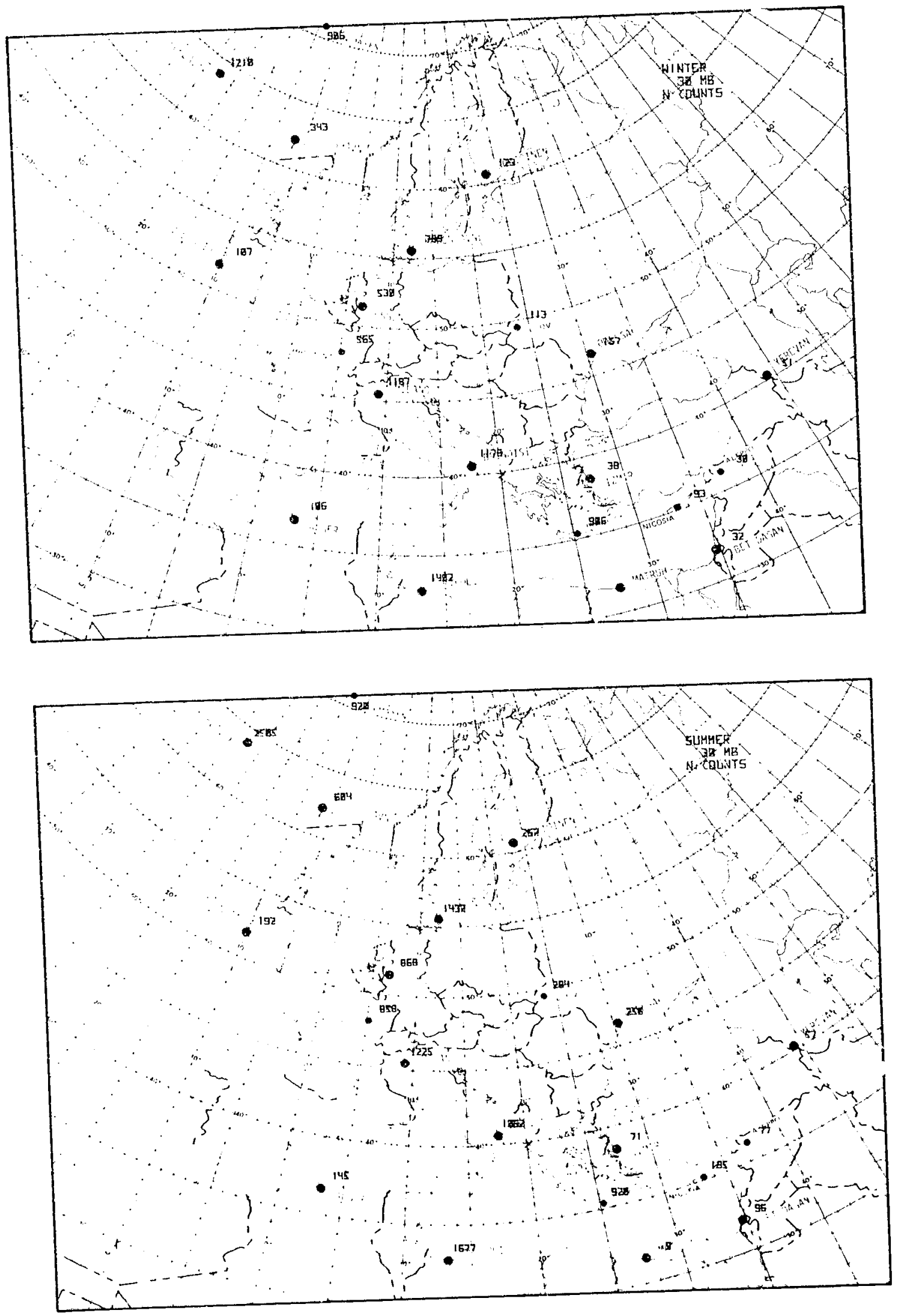


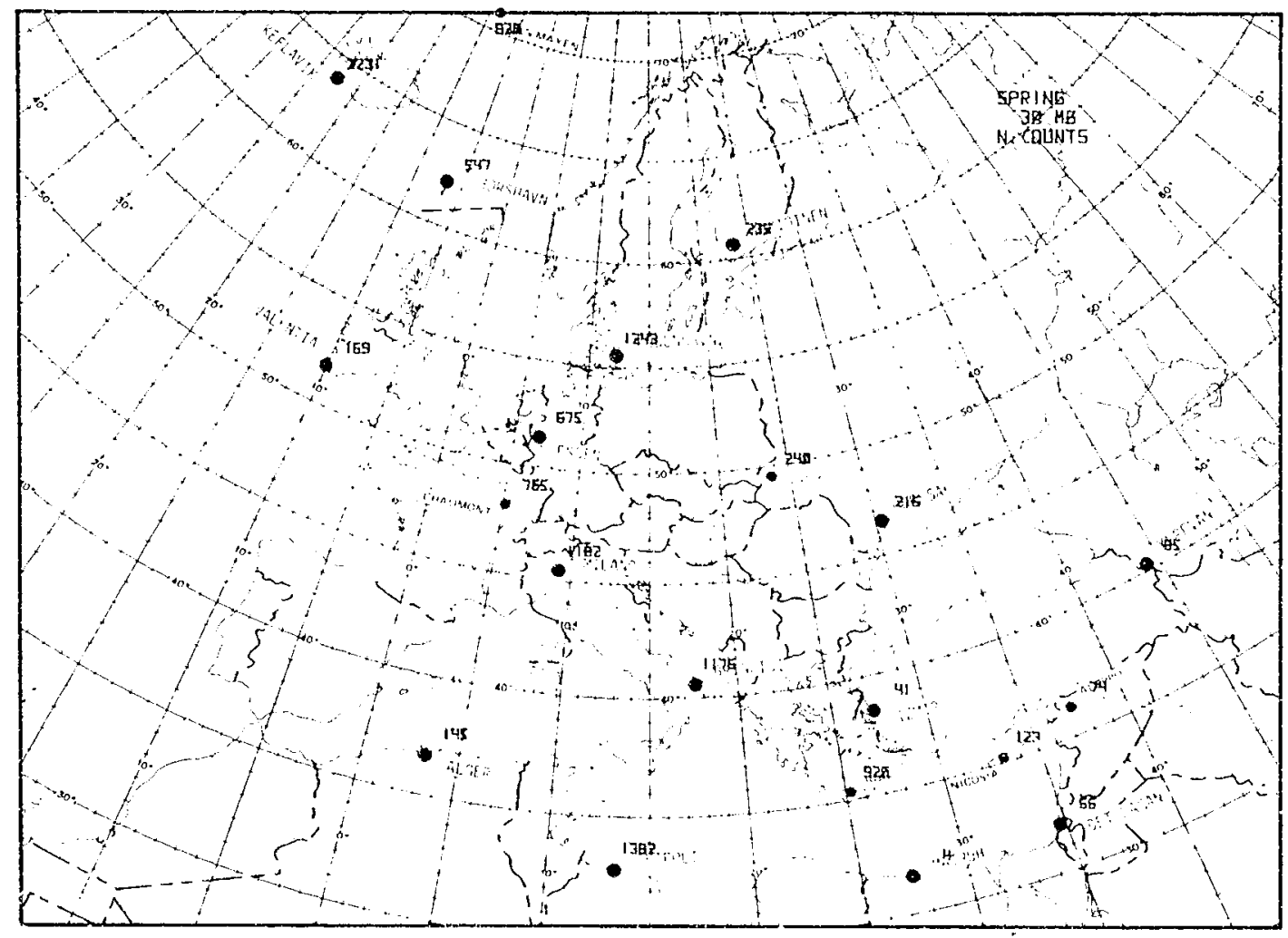

L: :

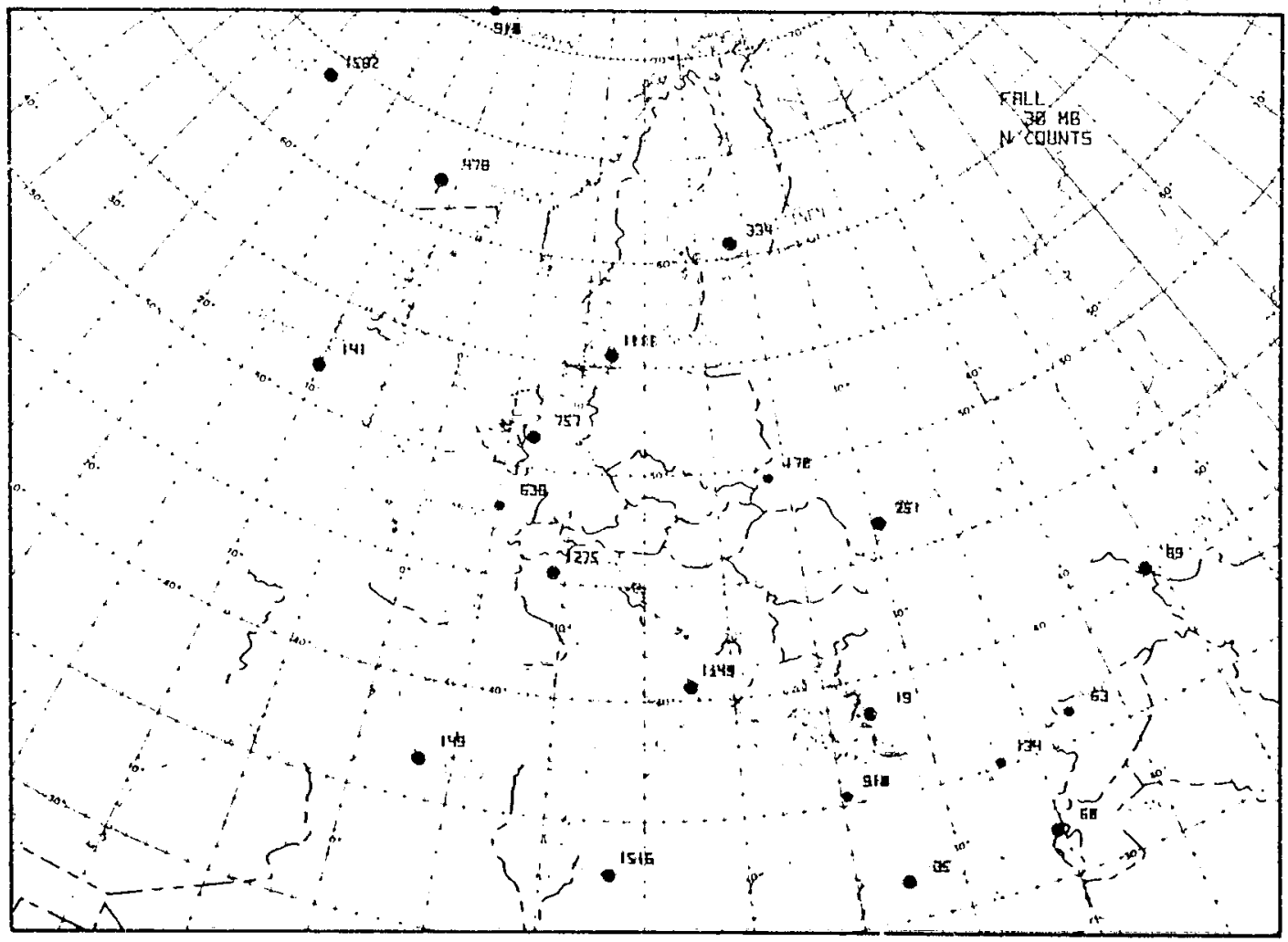



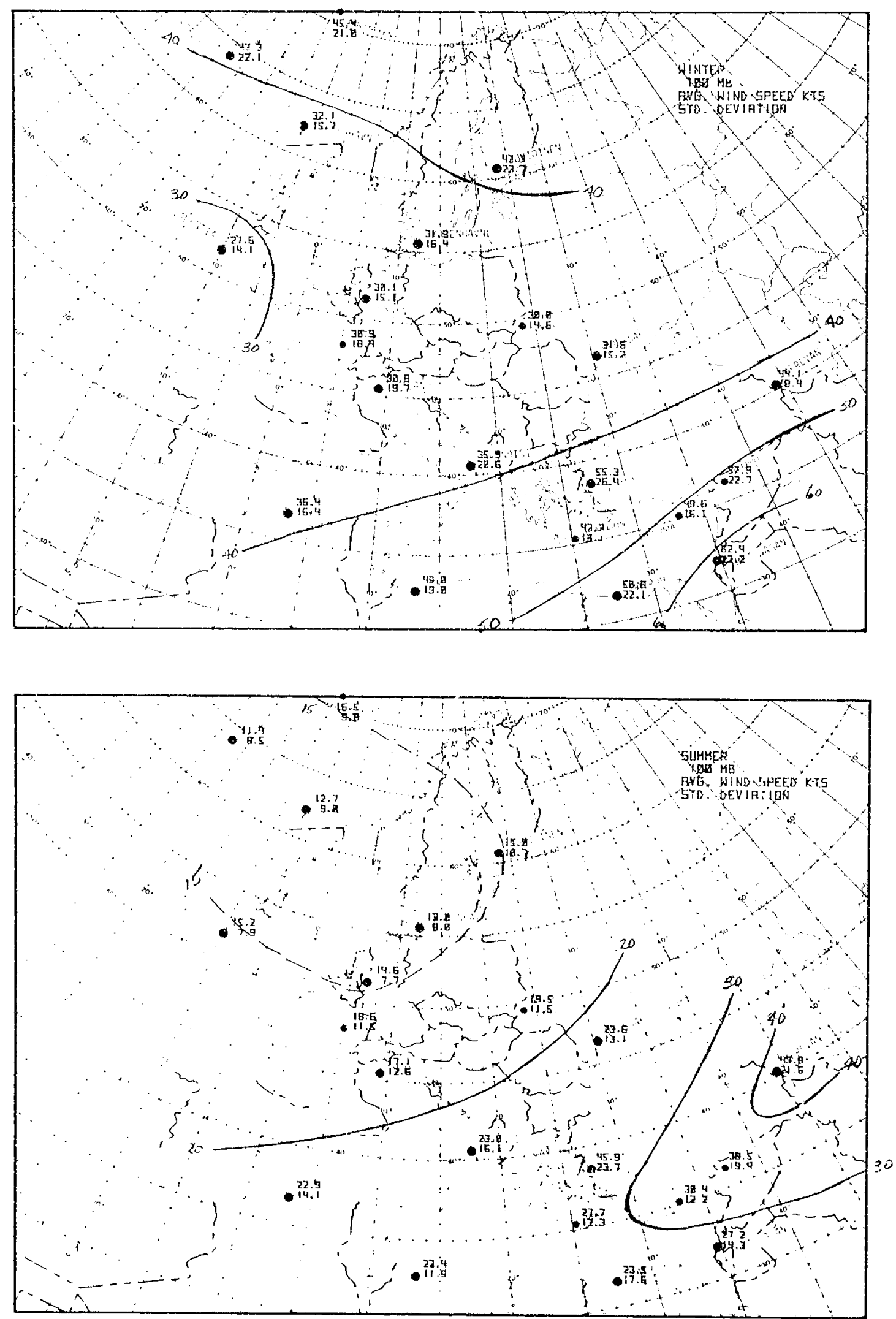

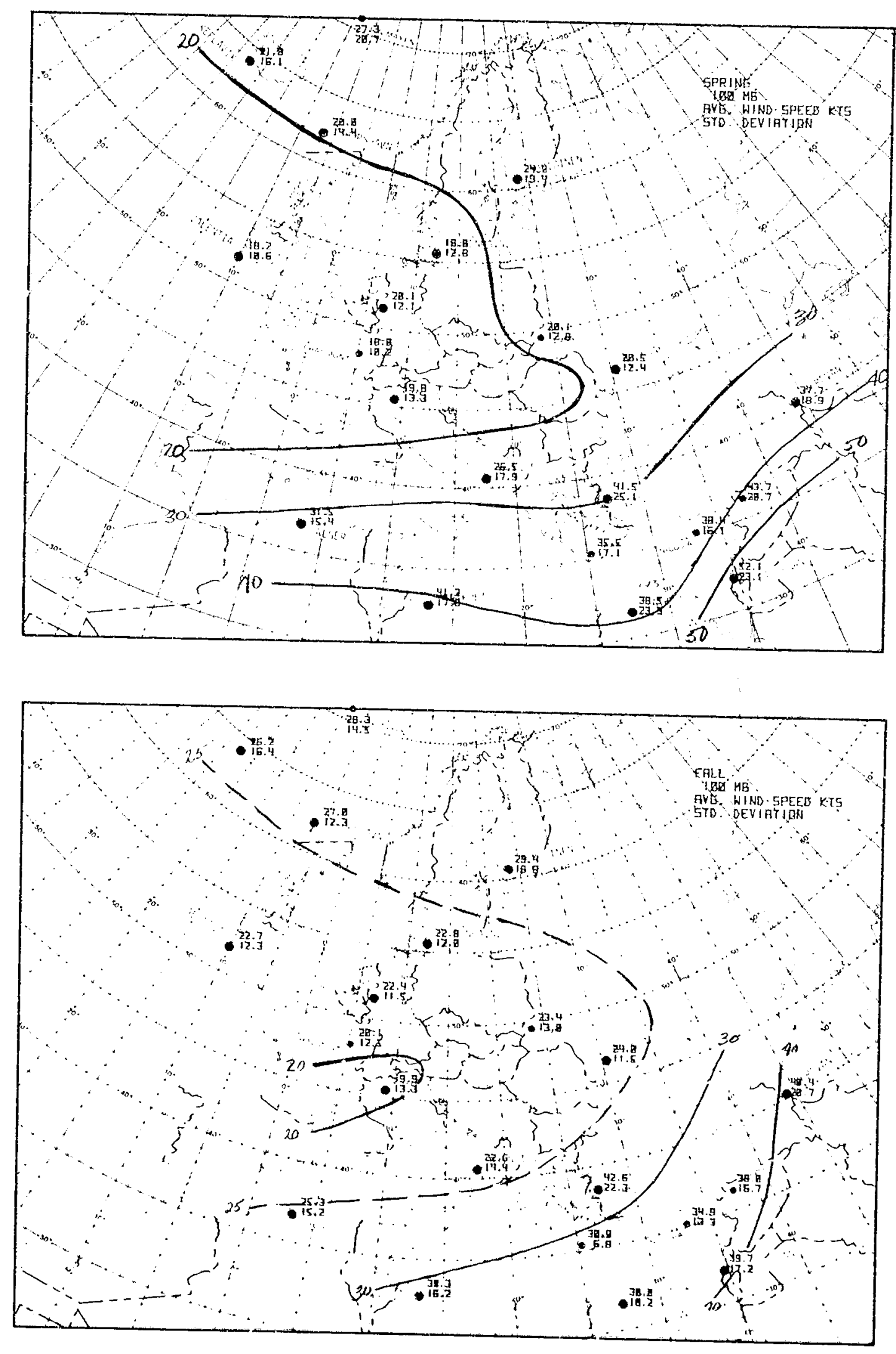

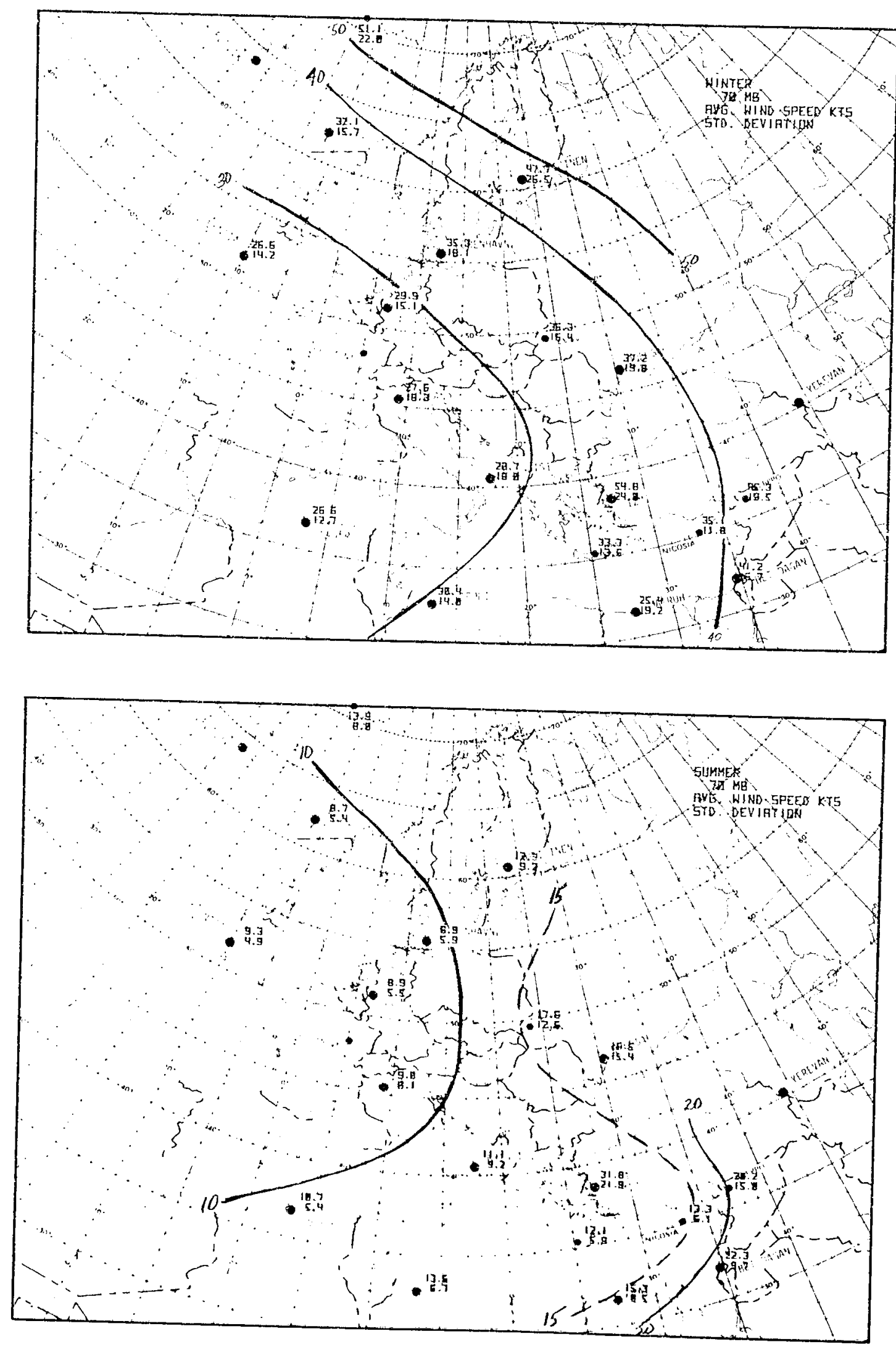

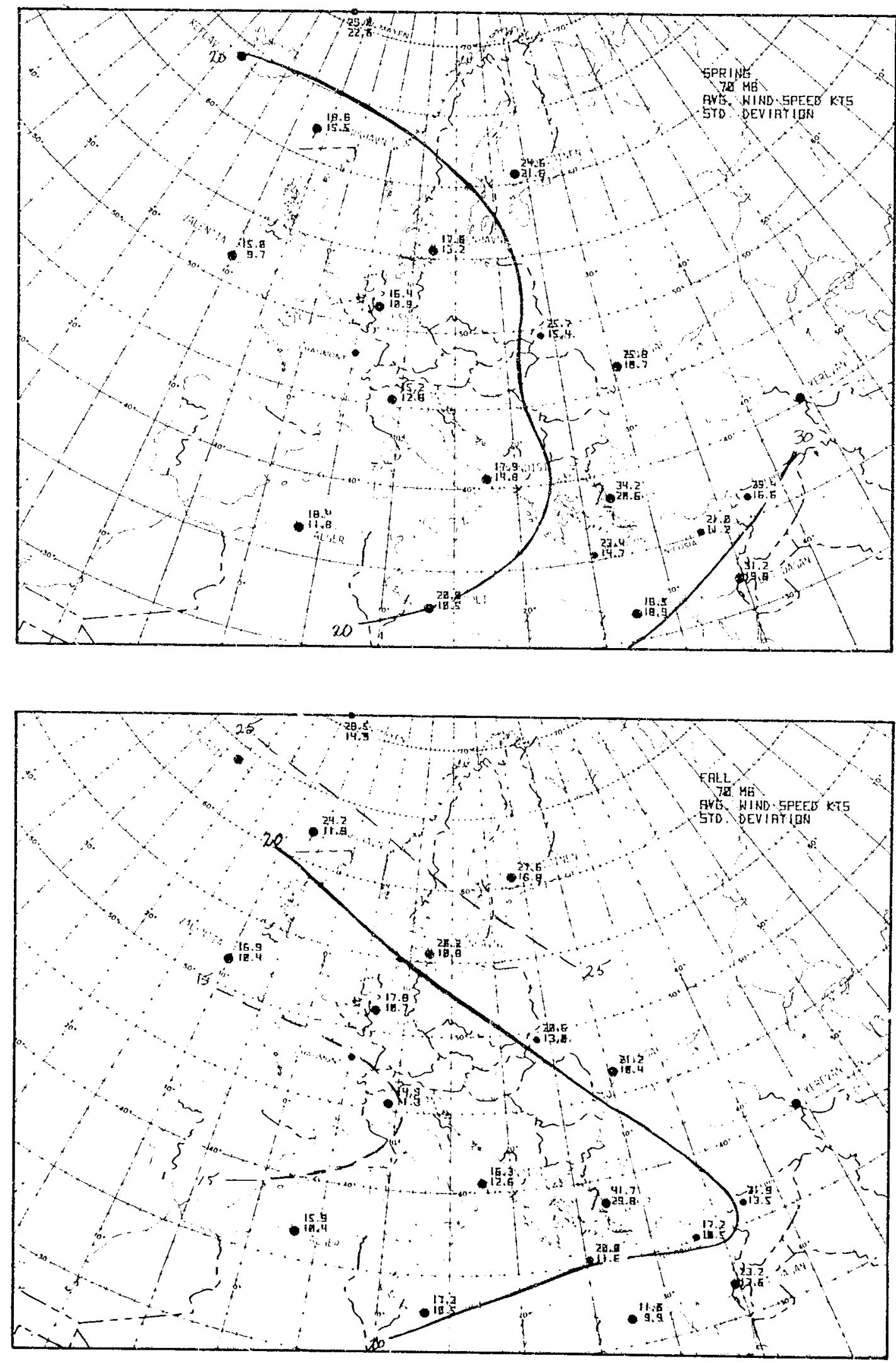

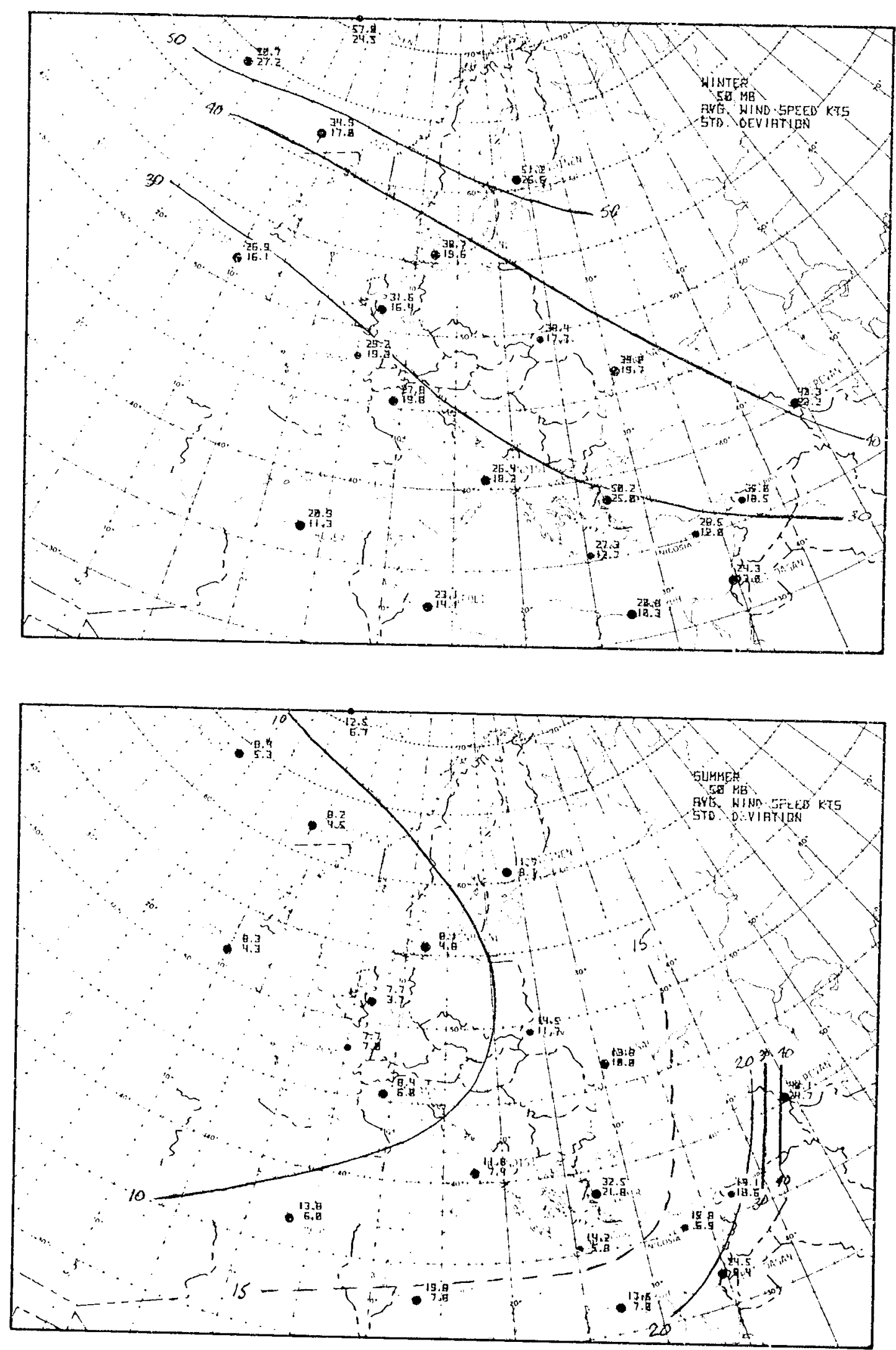


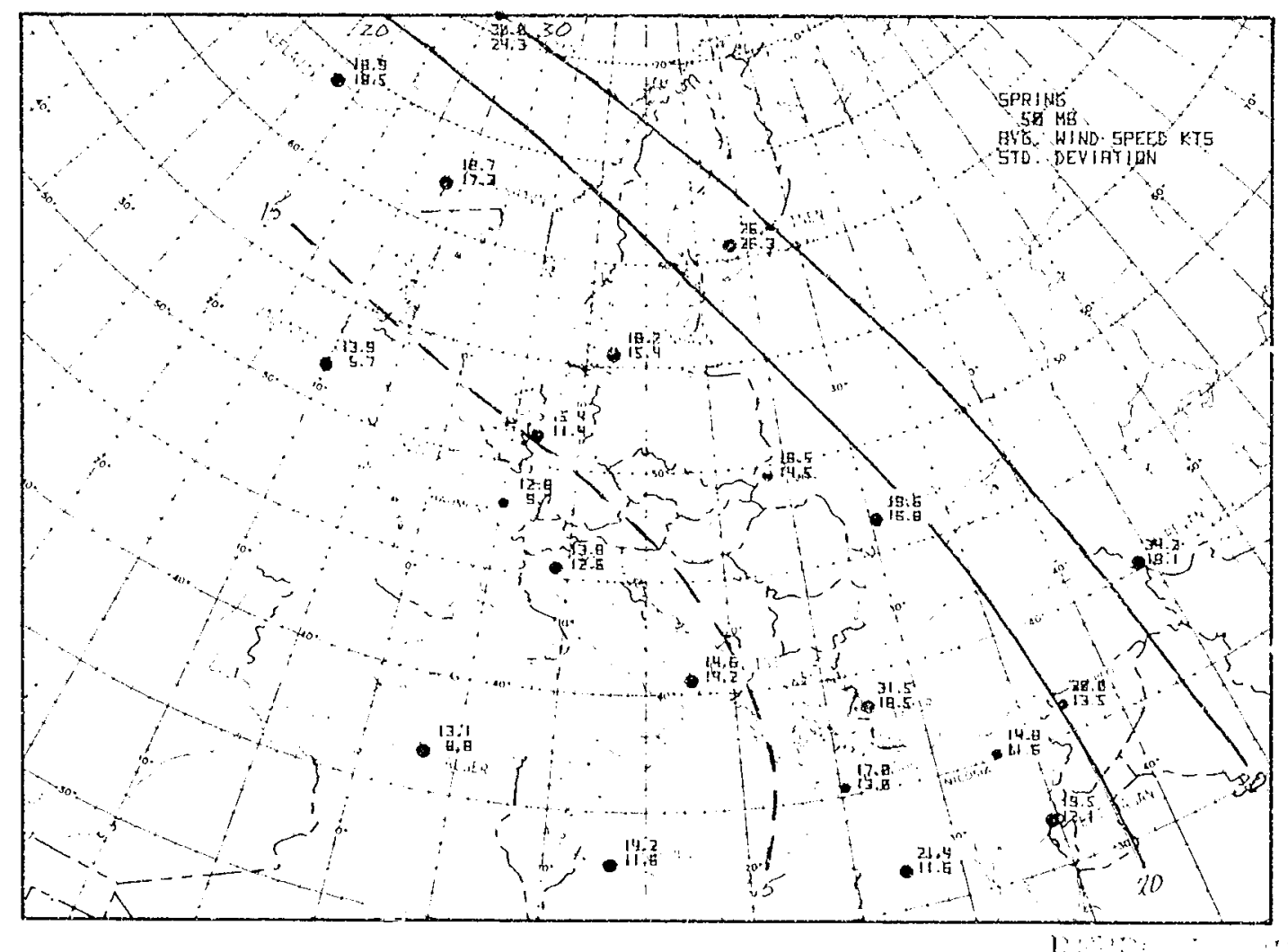

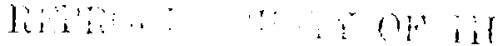

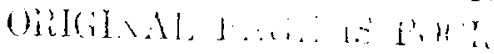

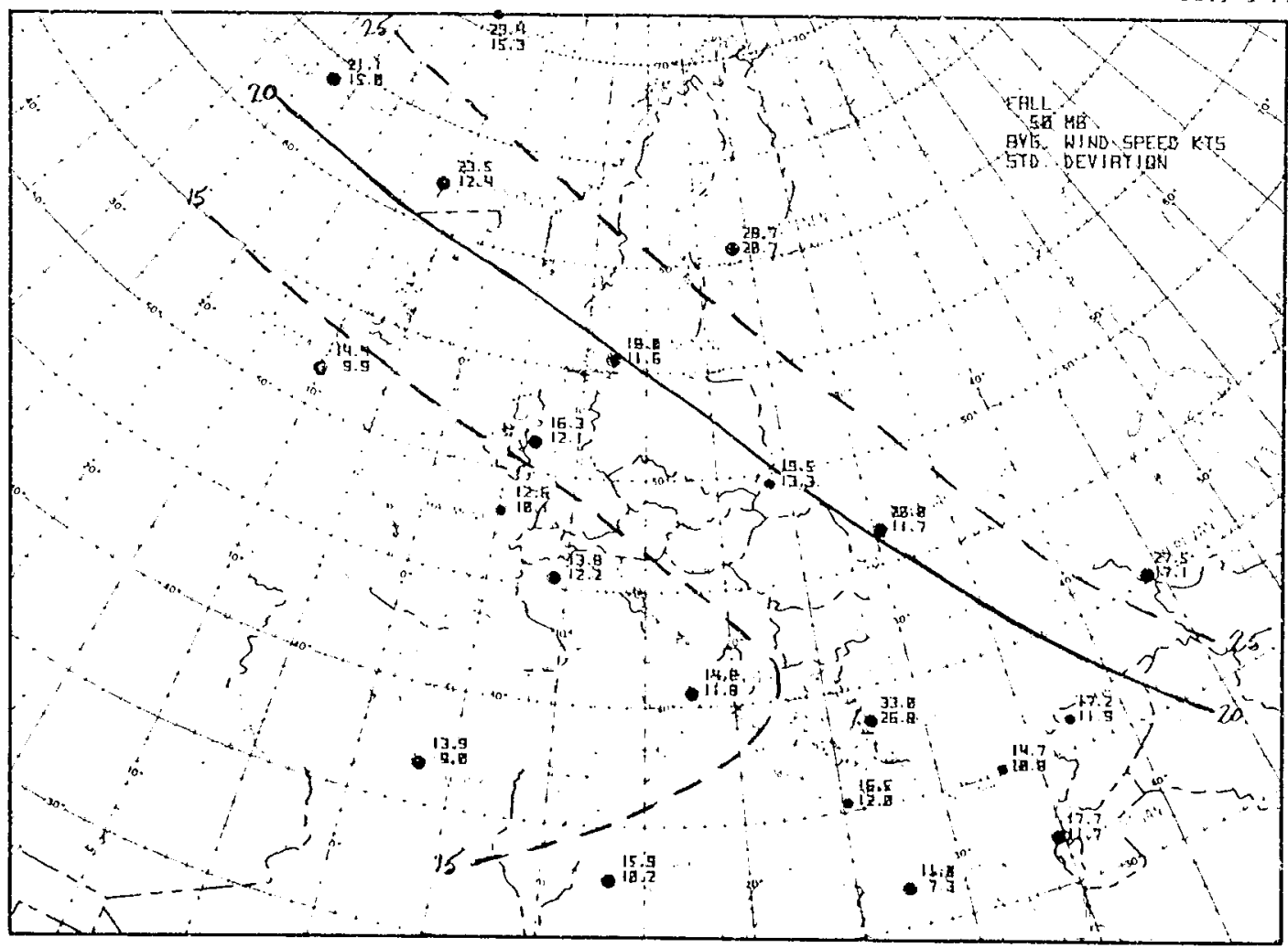



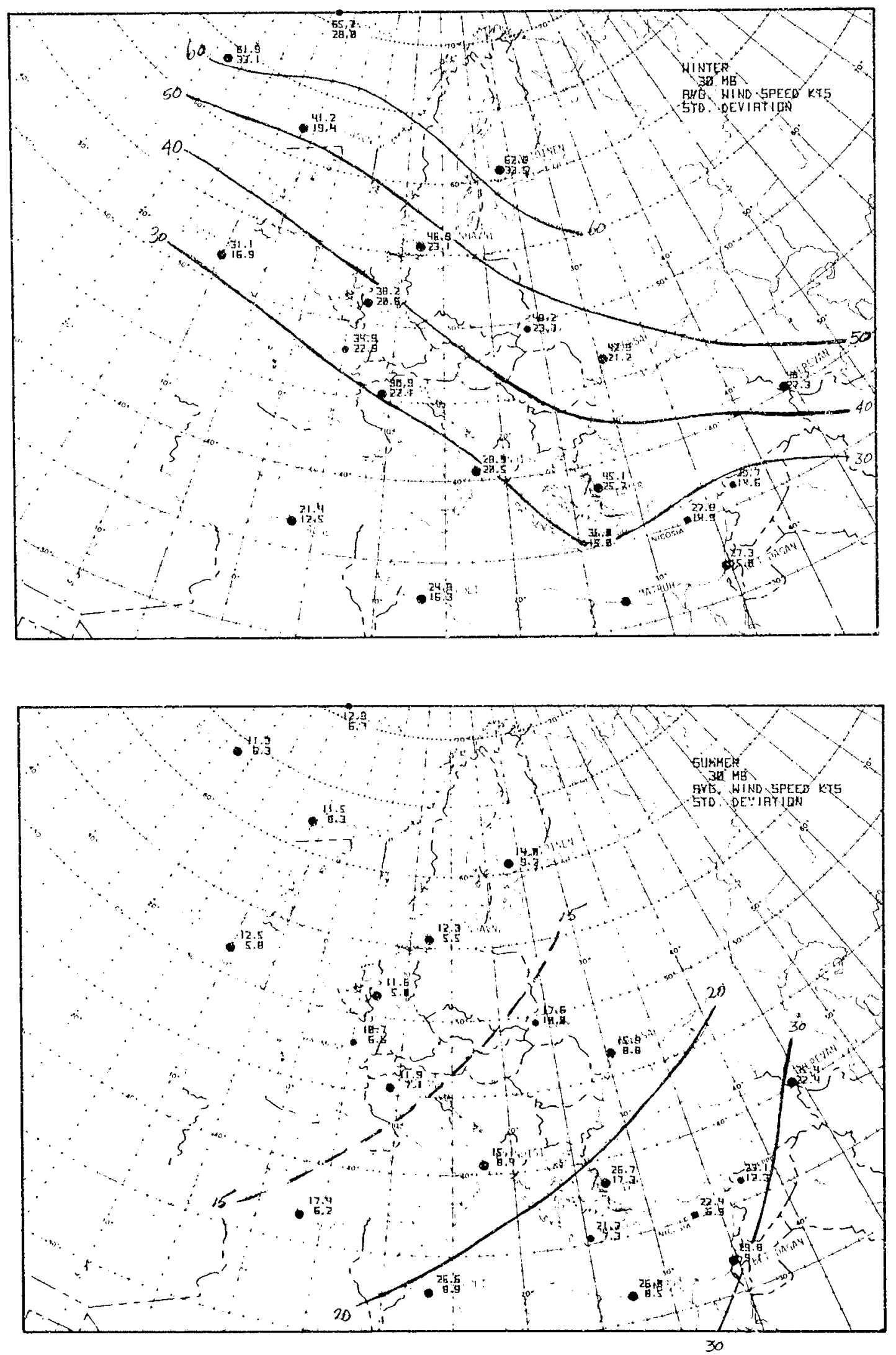

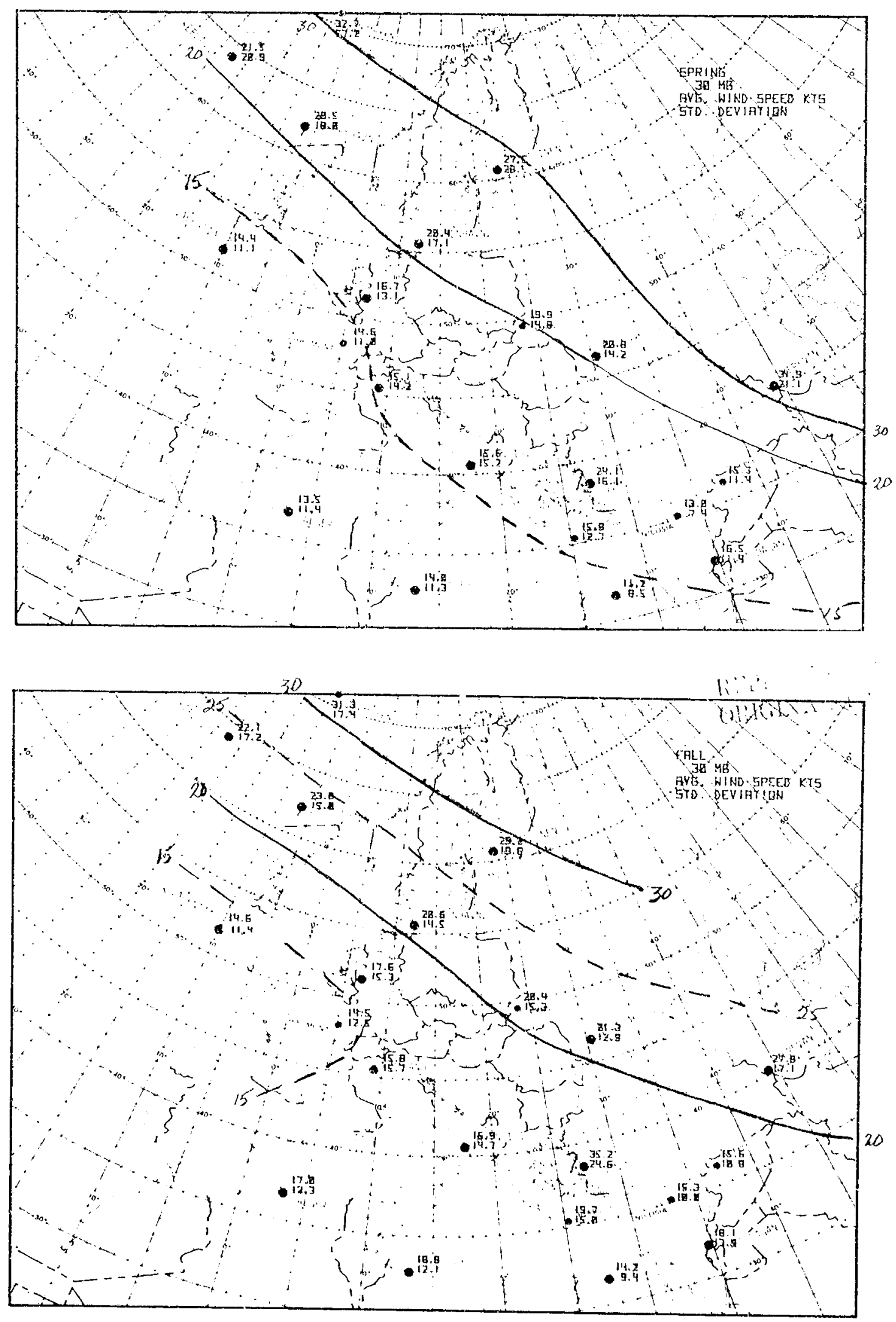

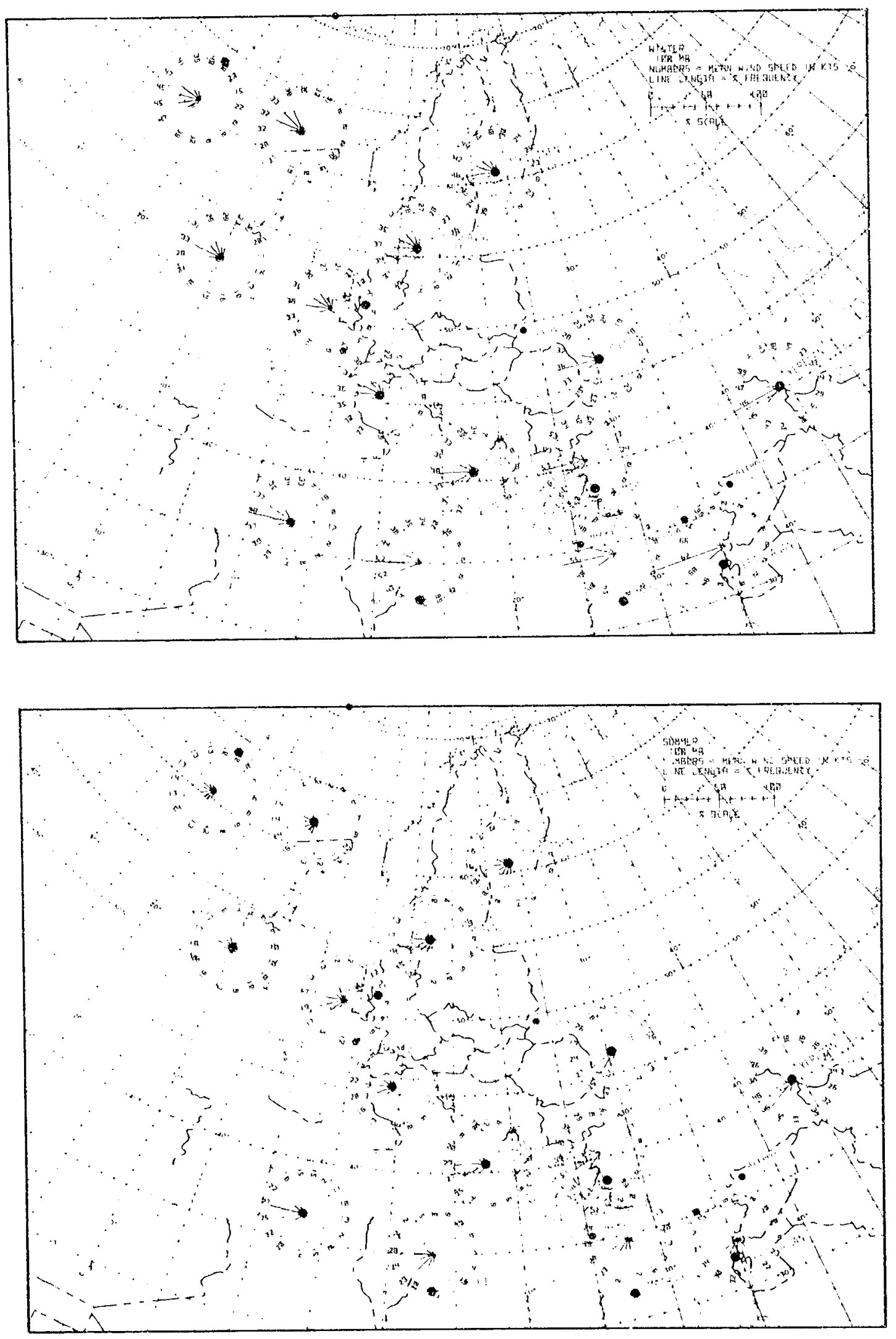

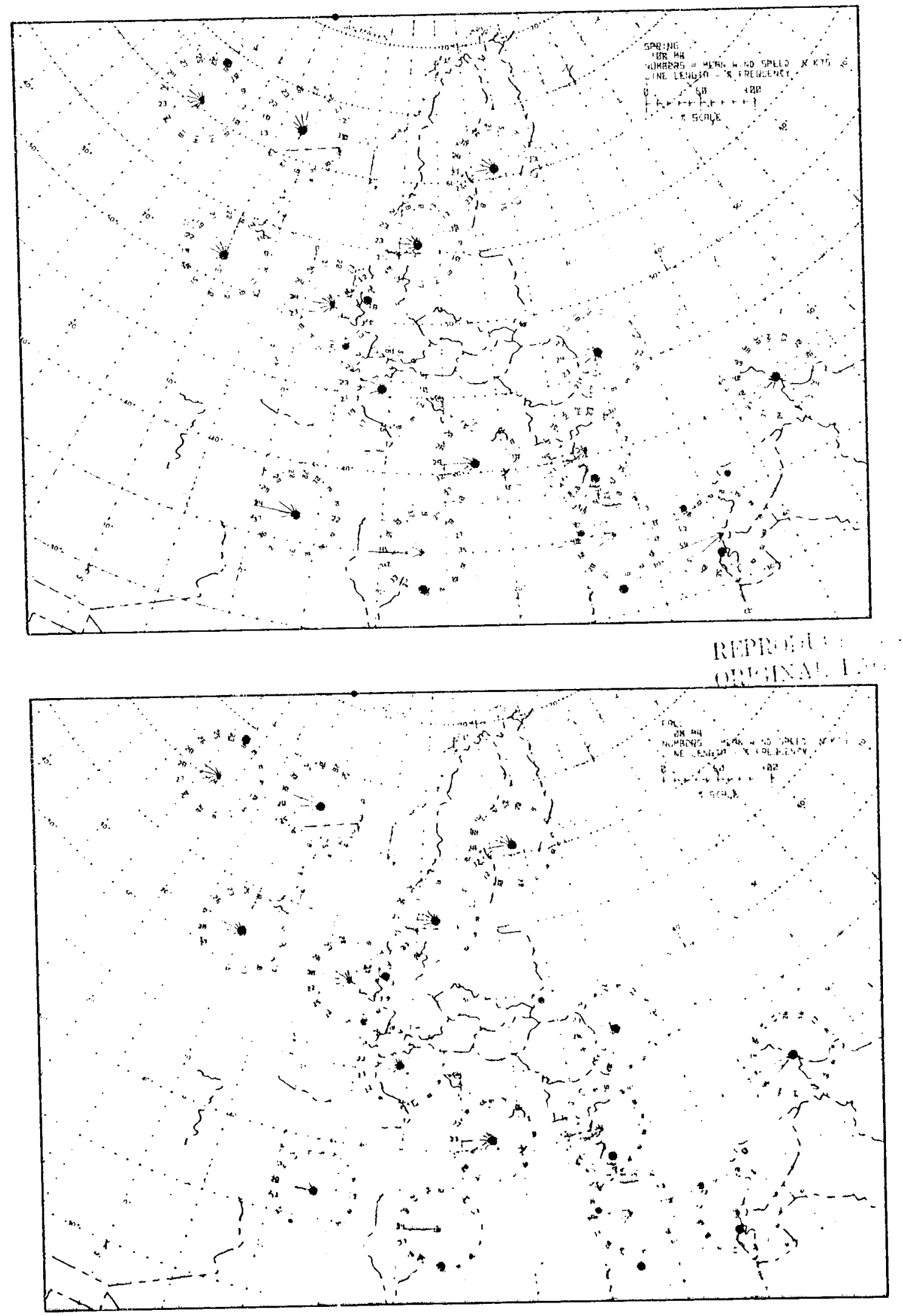

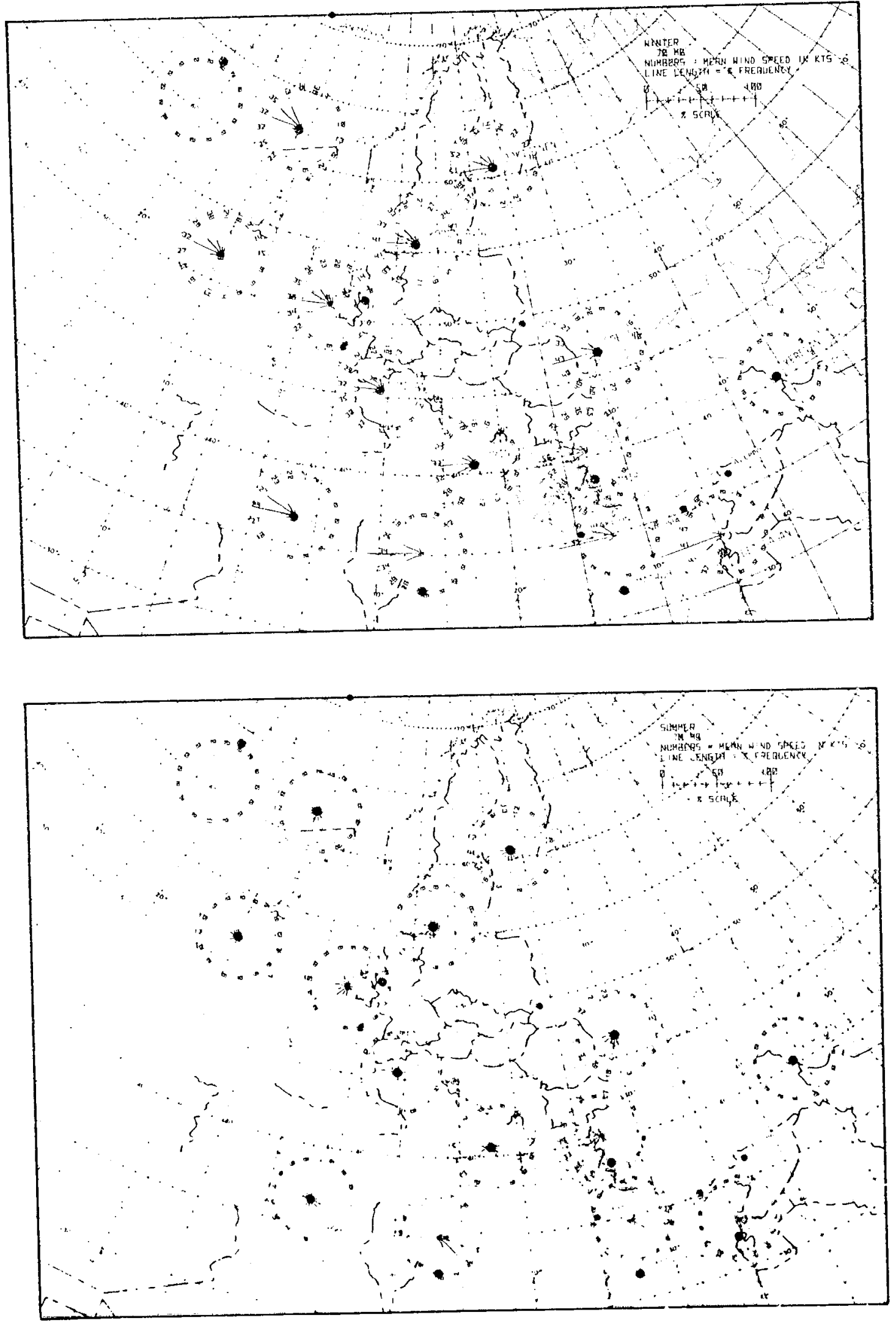

178 

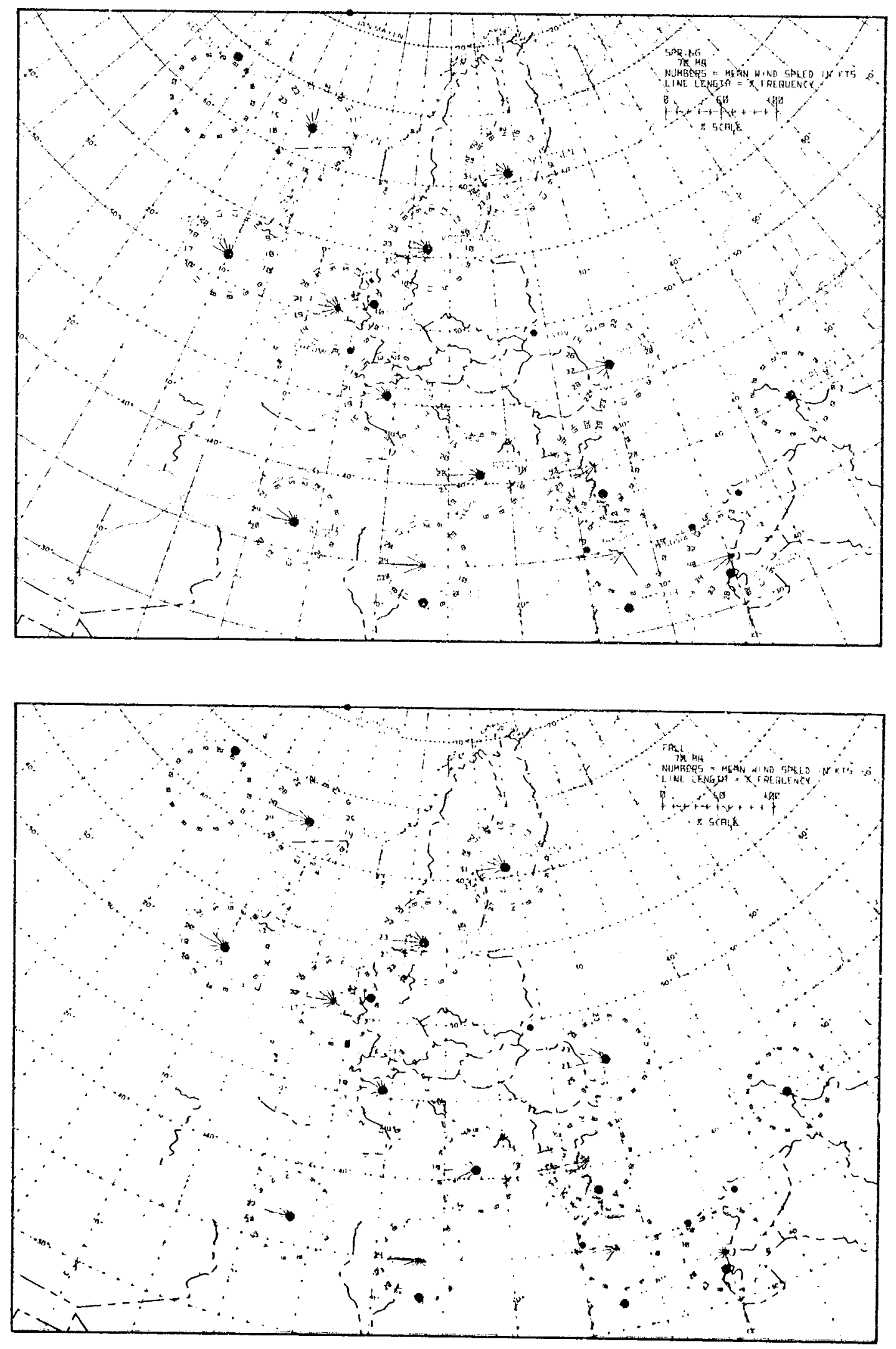

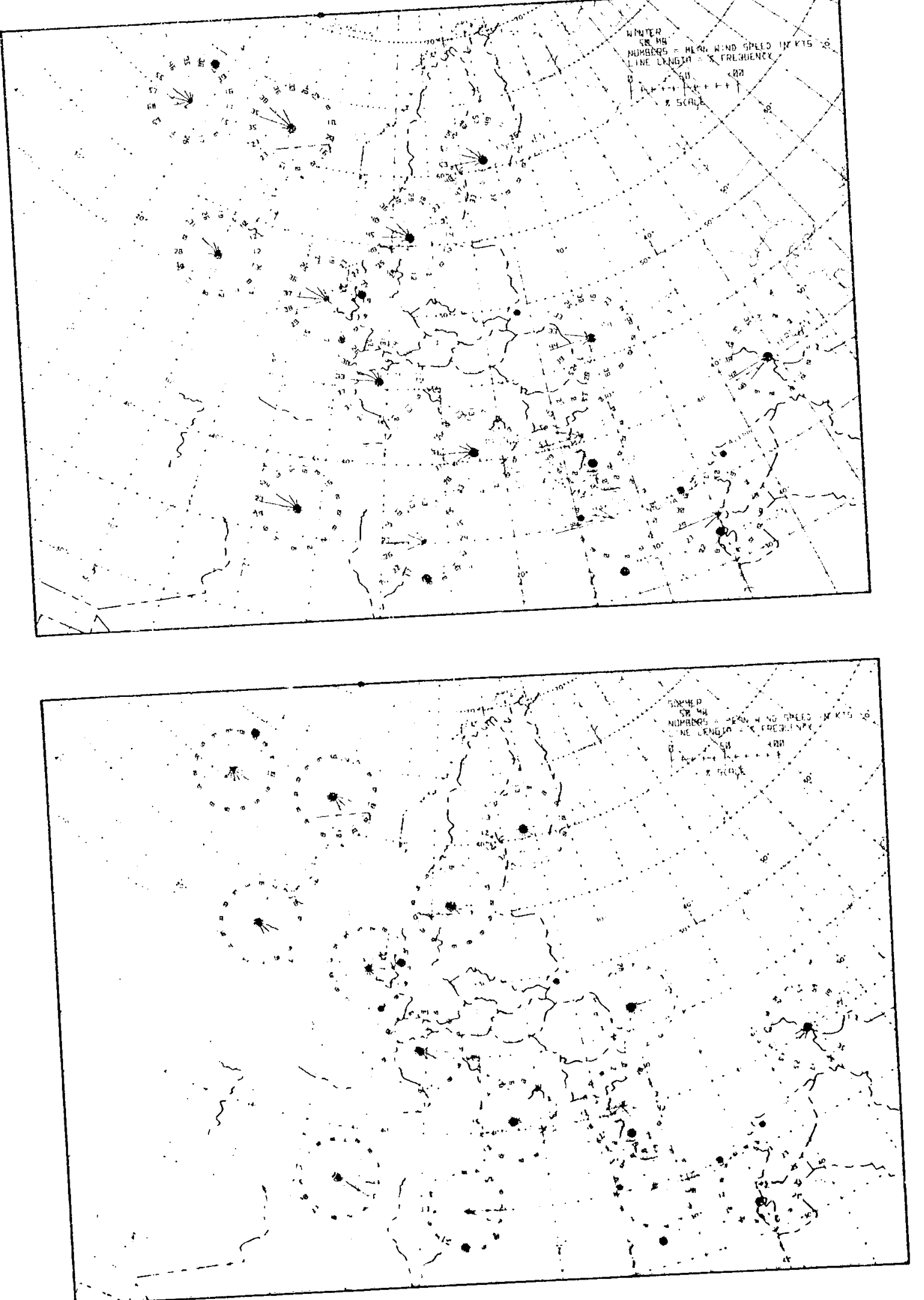

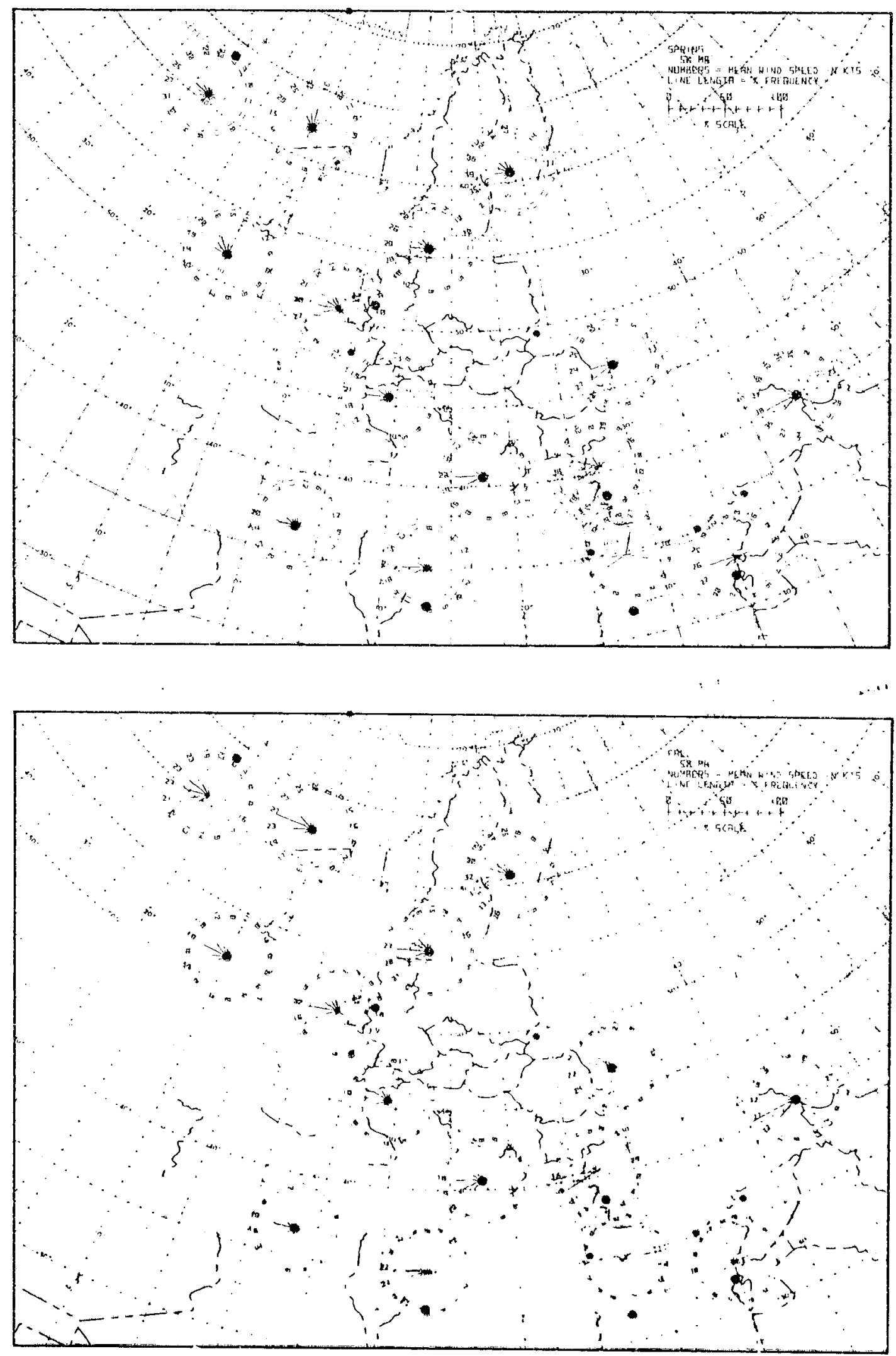

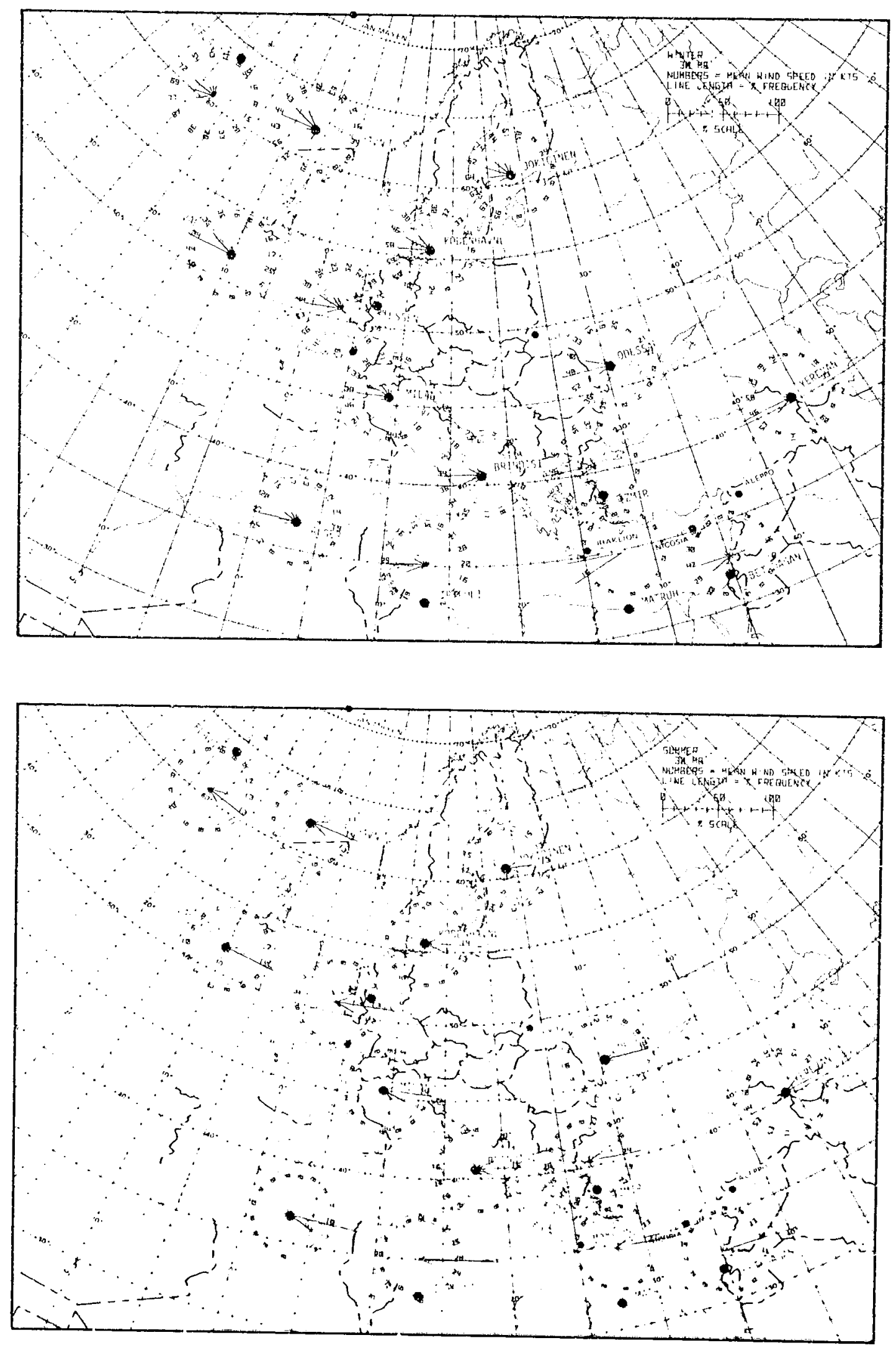

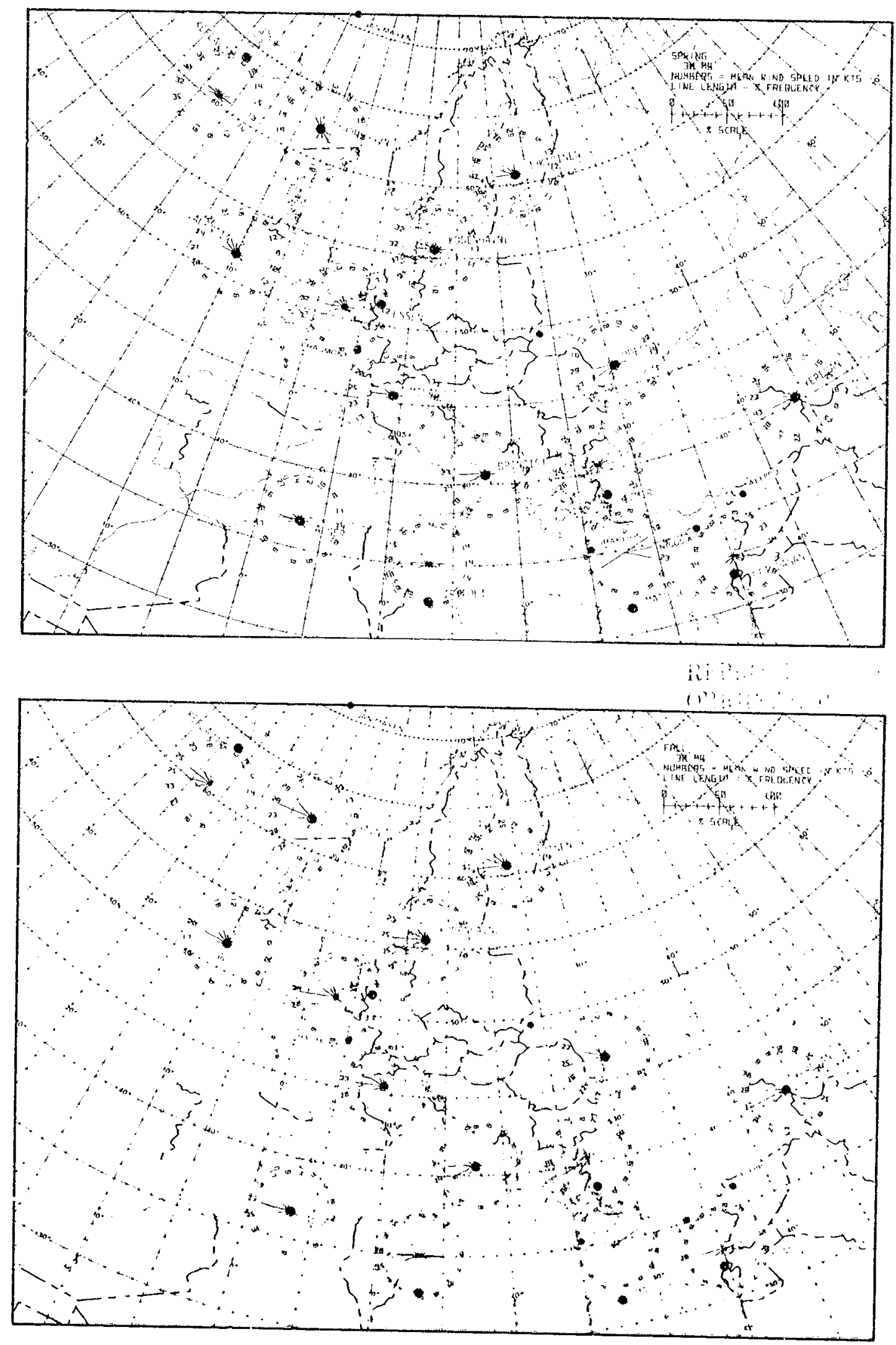

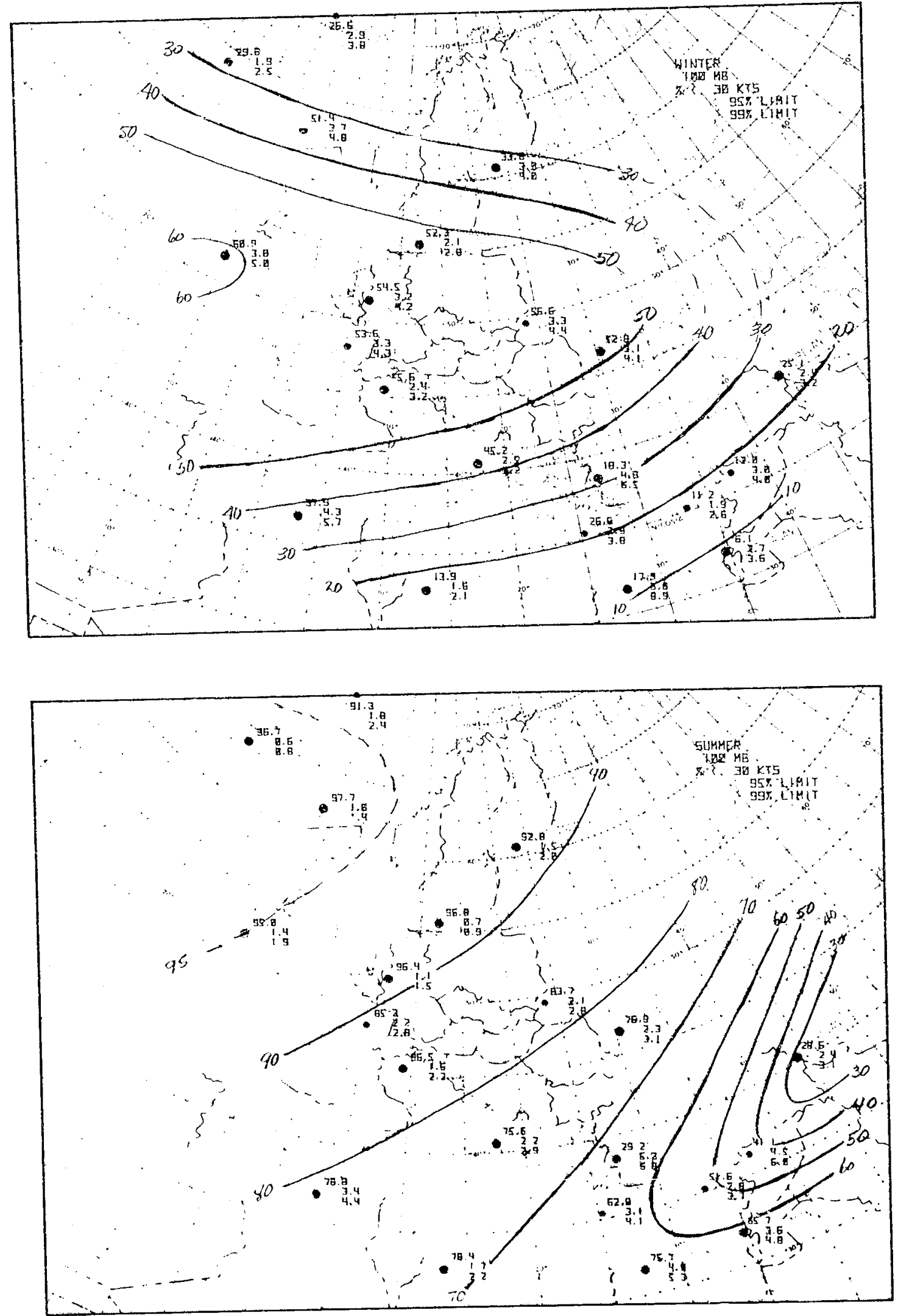

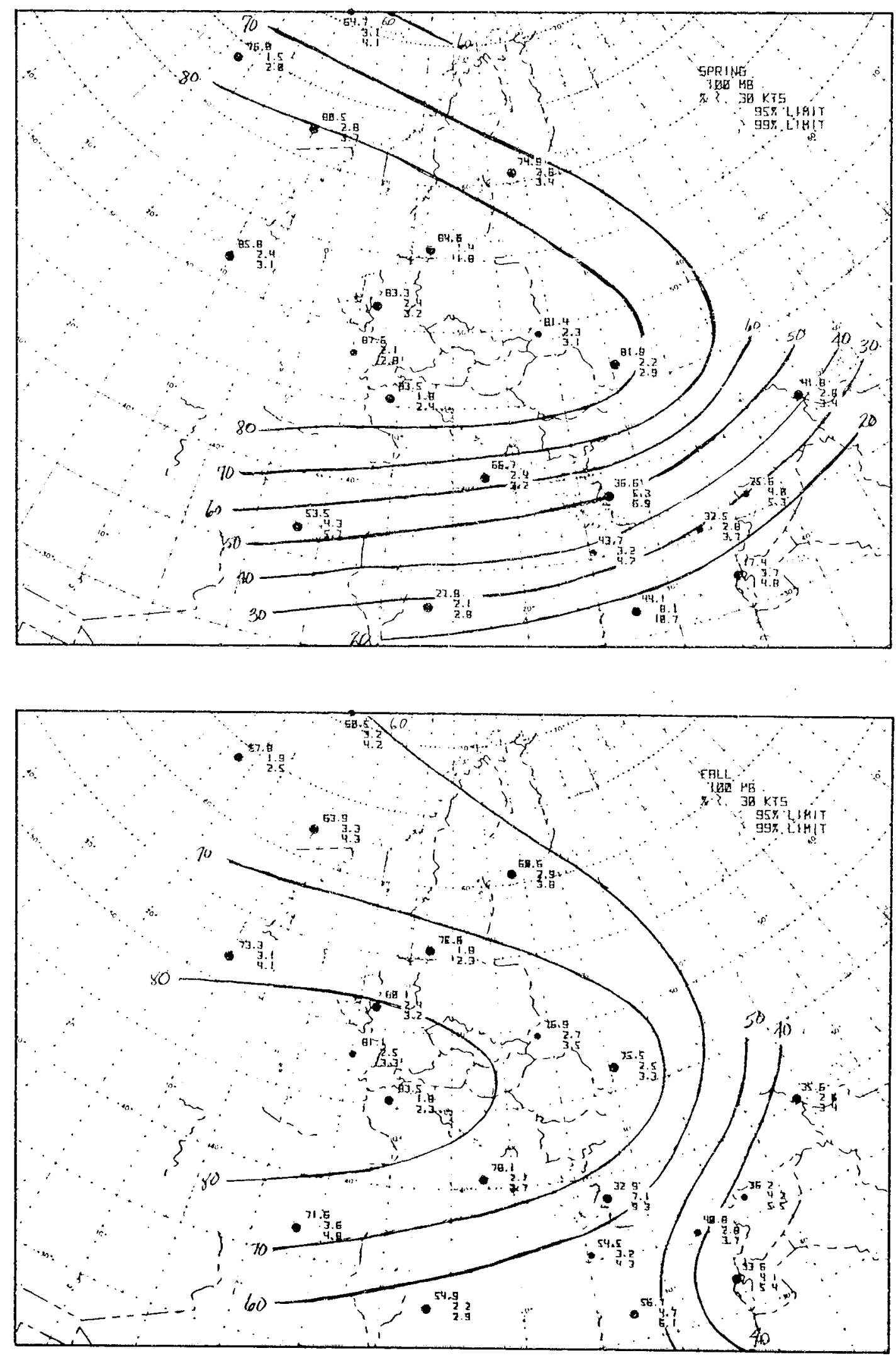

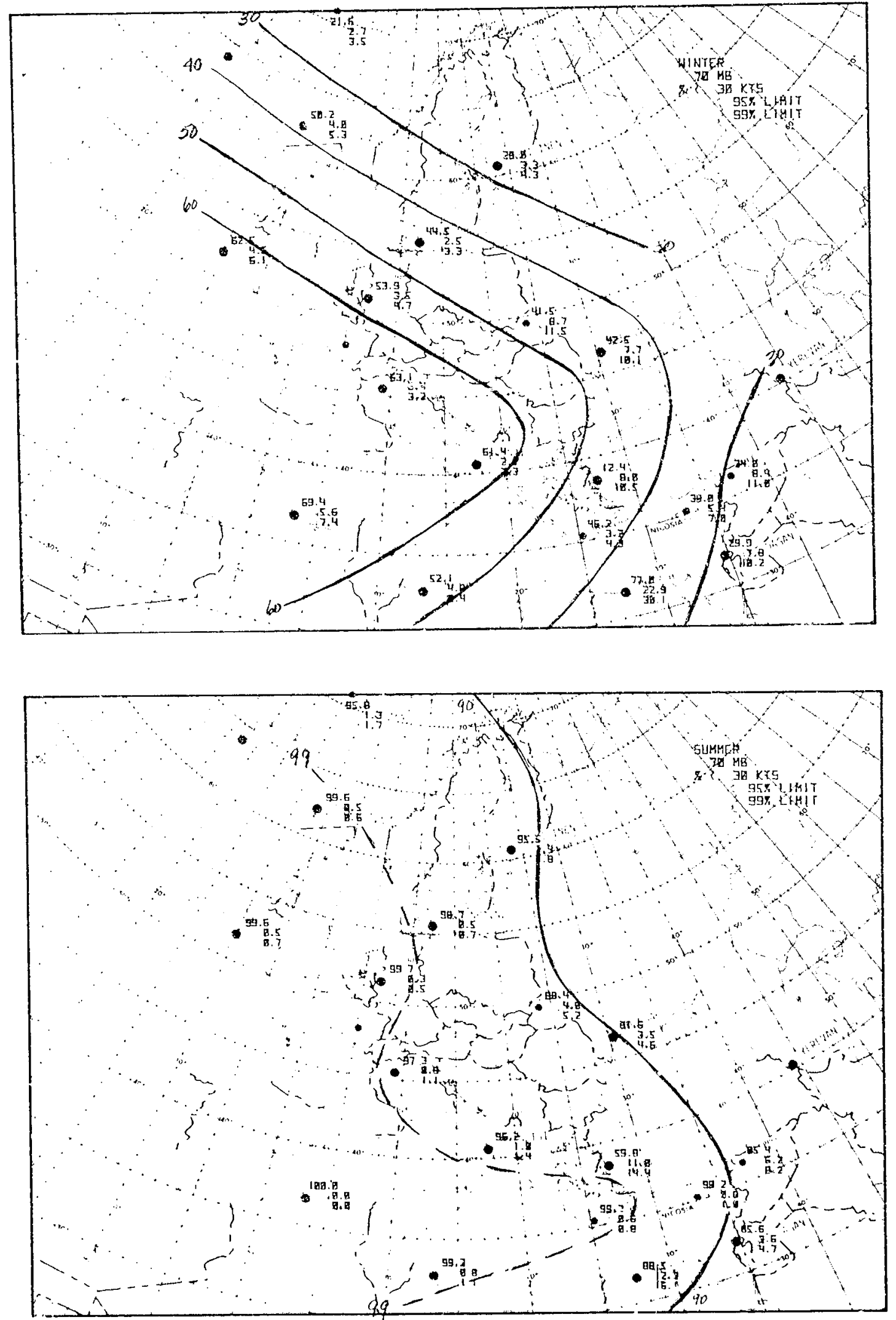


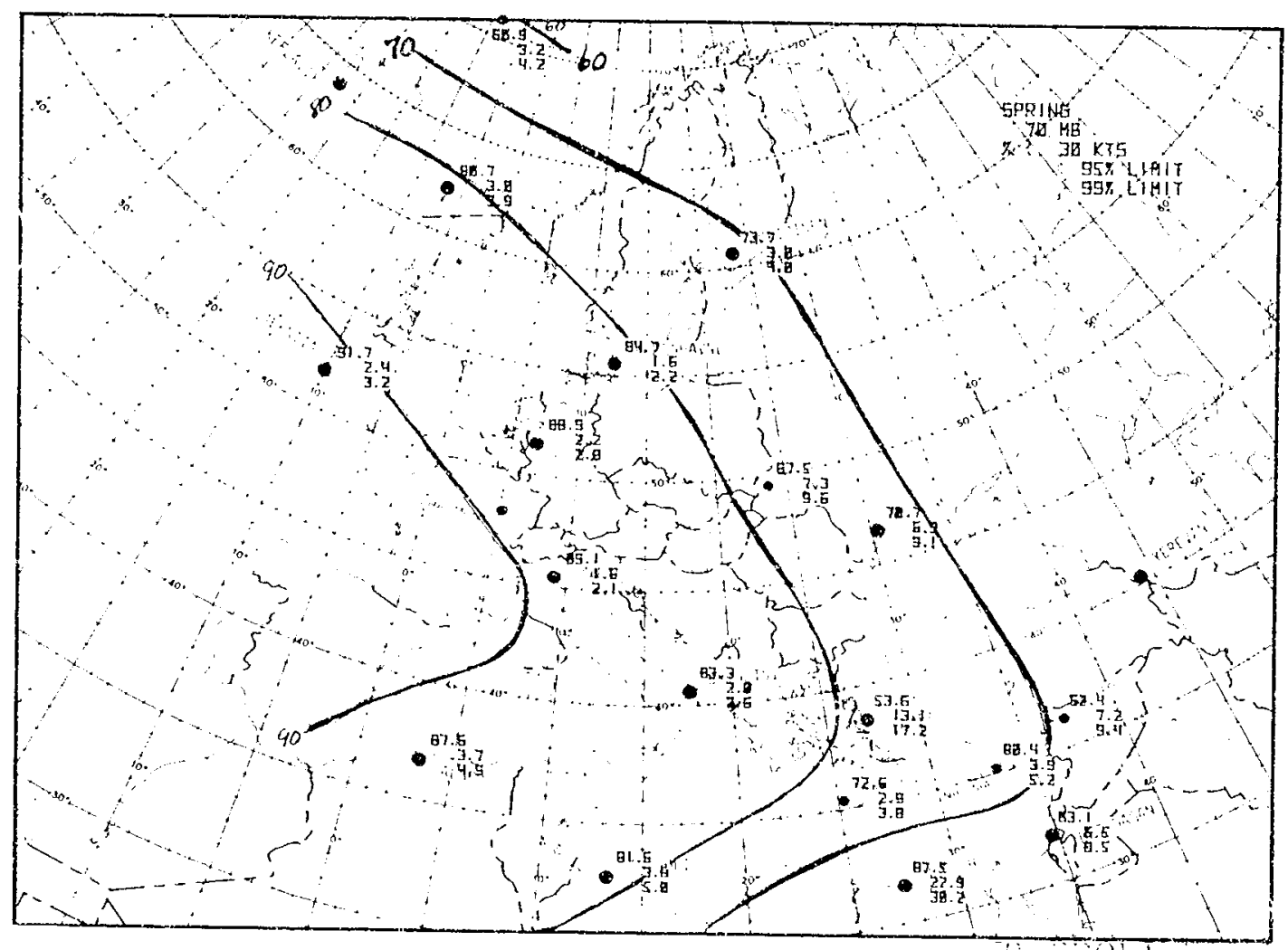

(1) $: \ldots \ldots$

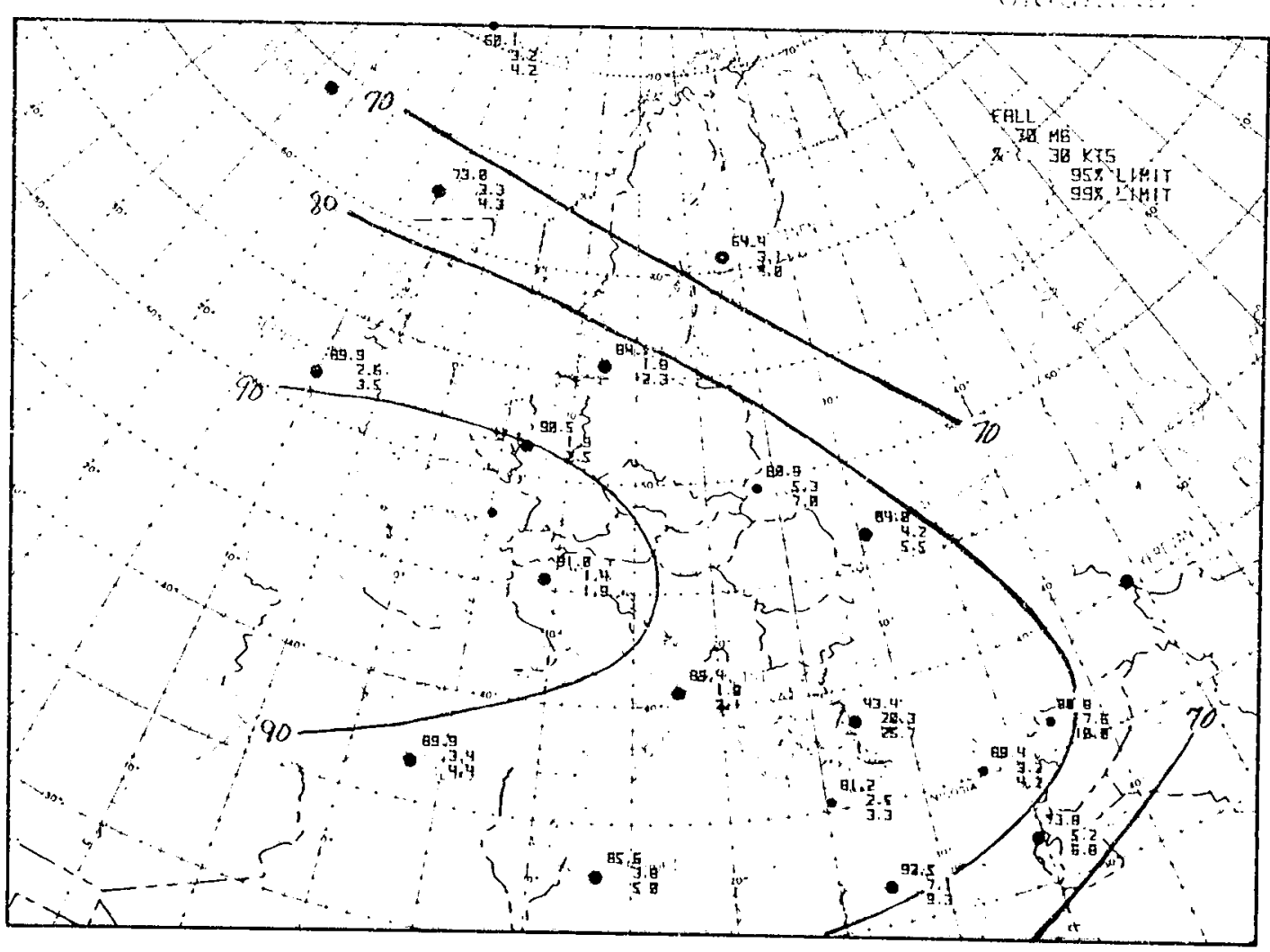



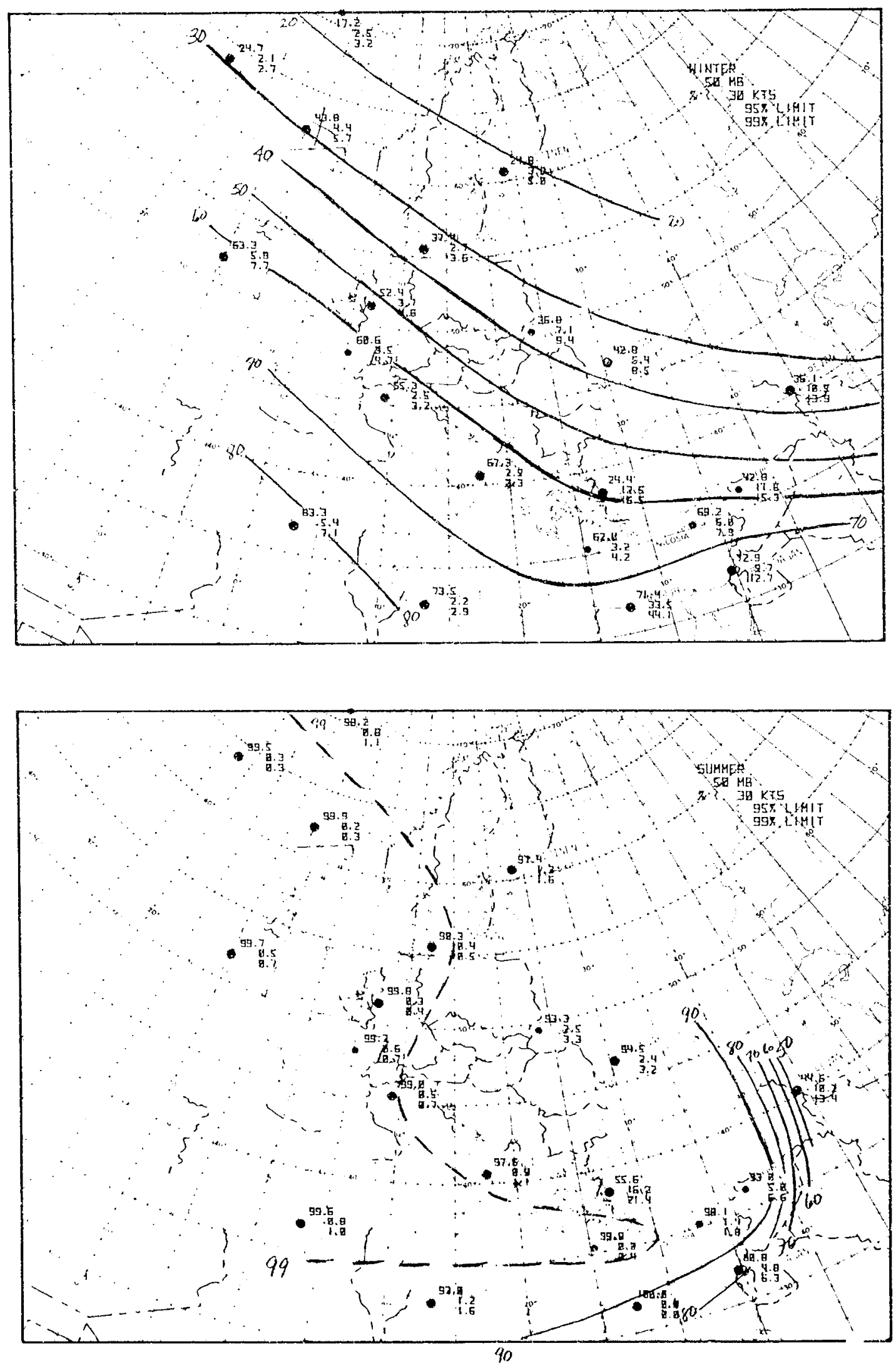


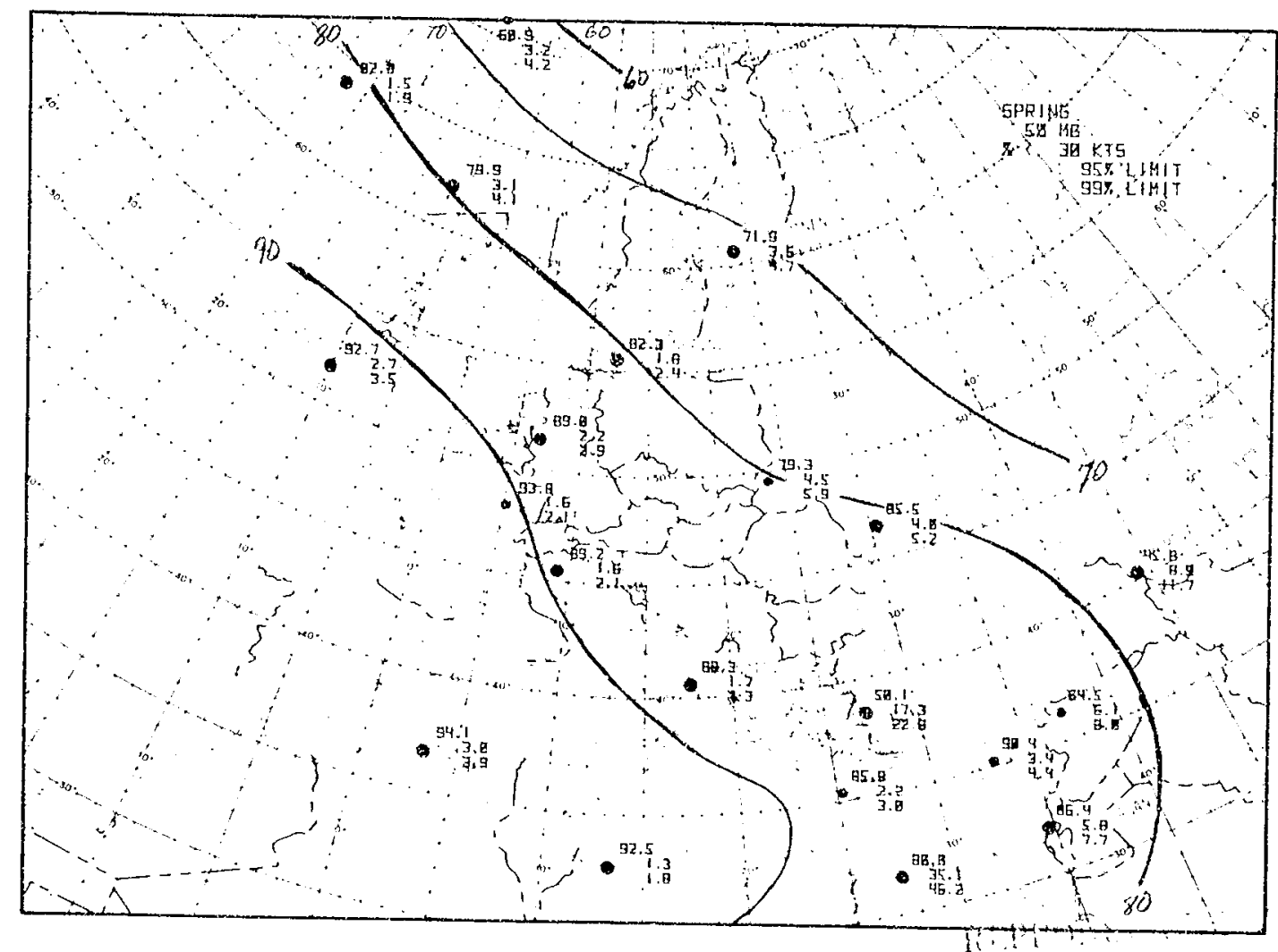

?19.9.

(ilin: II i

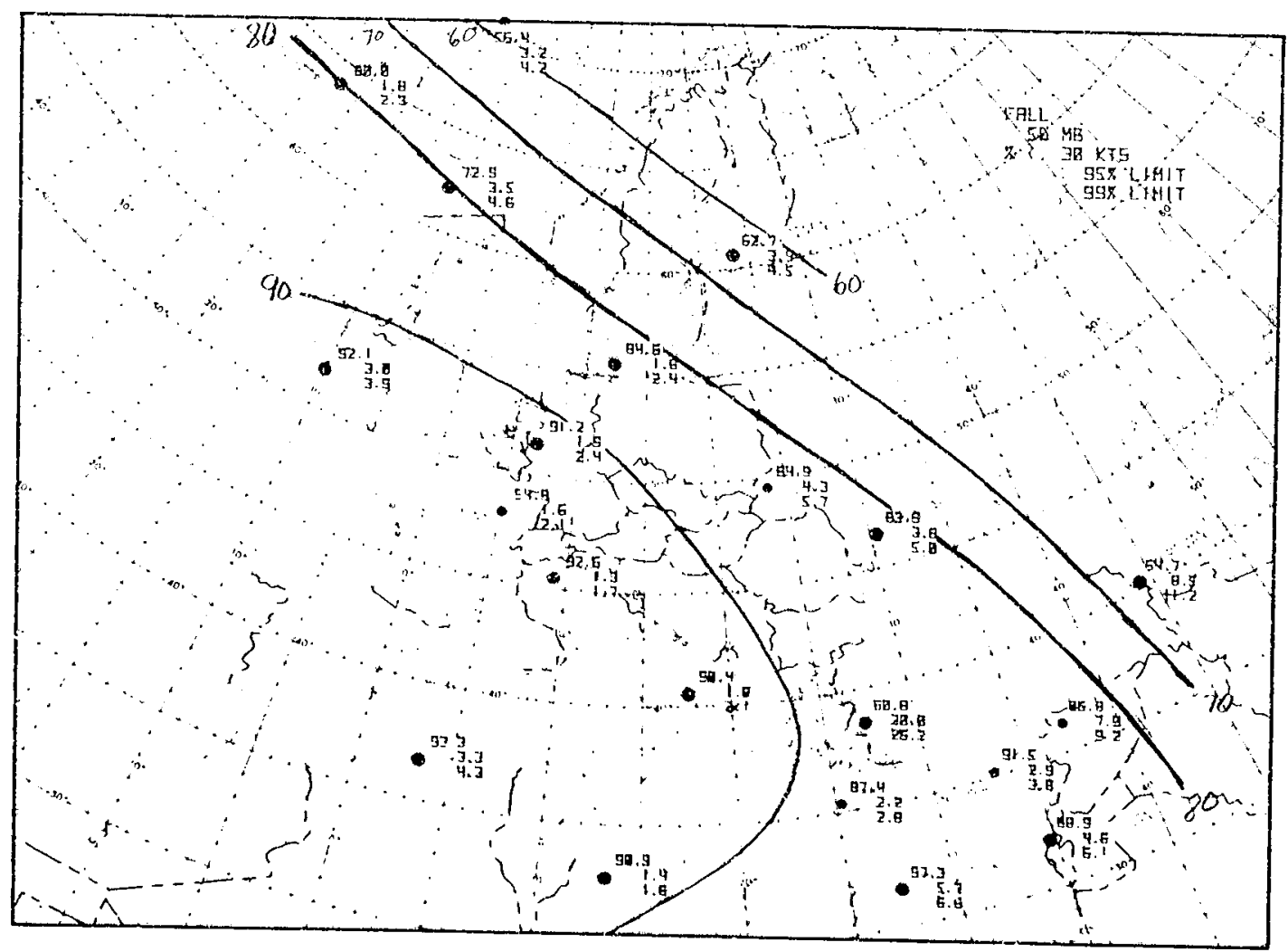



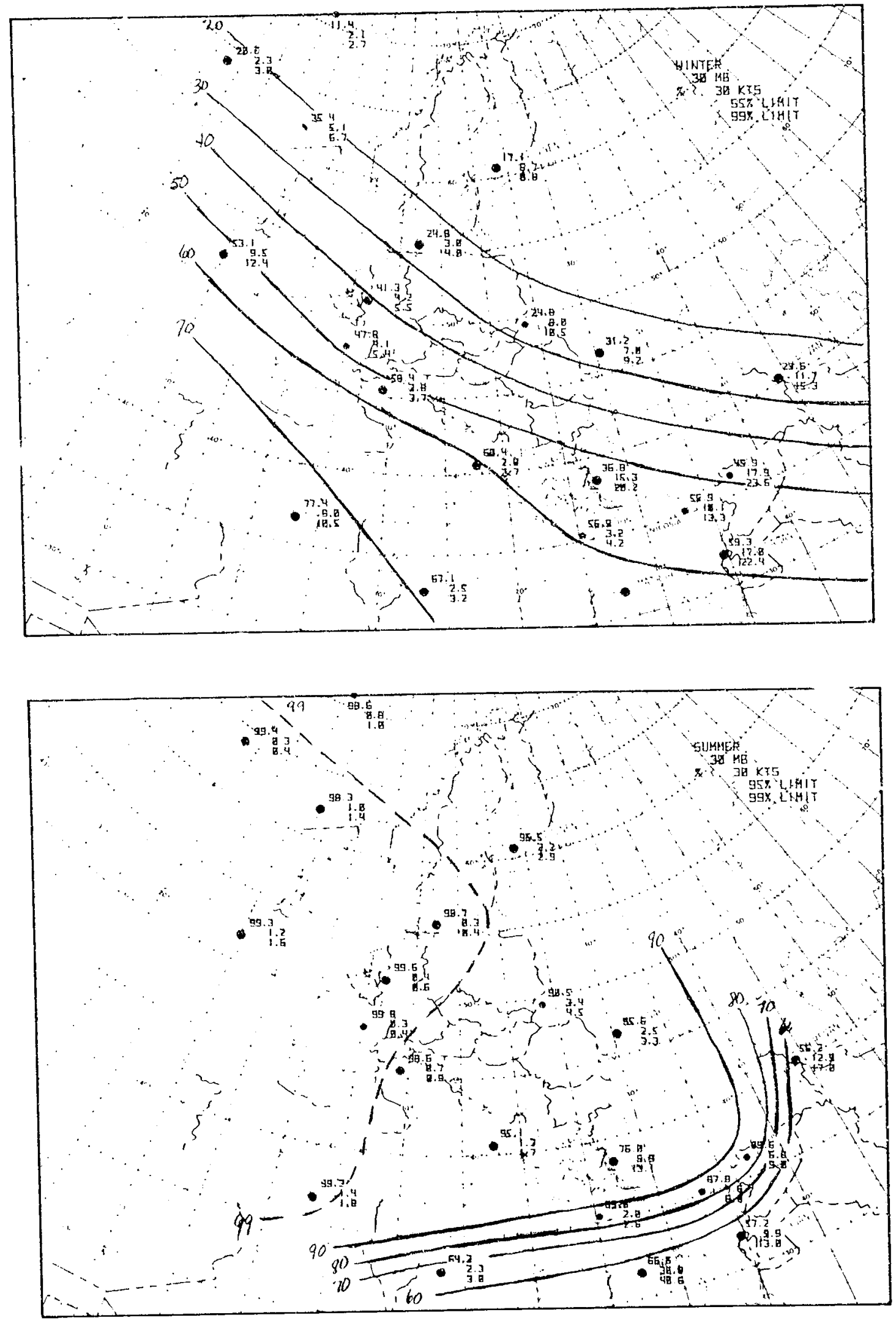

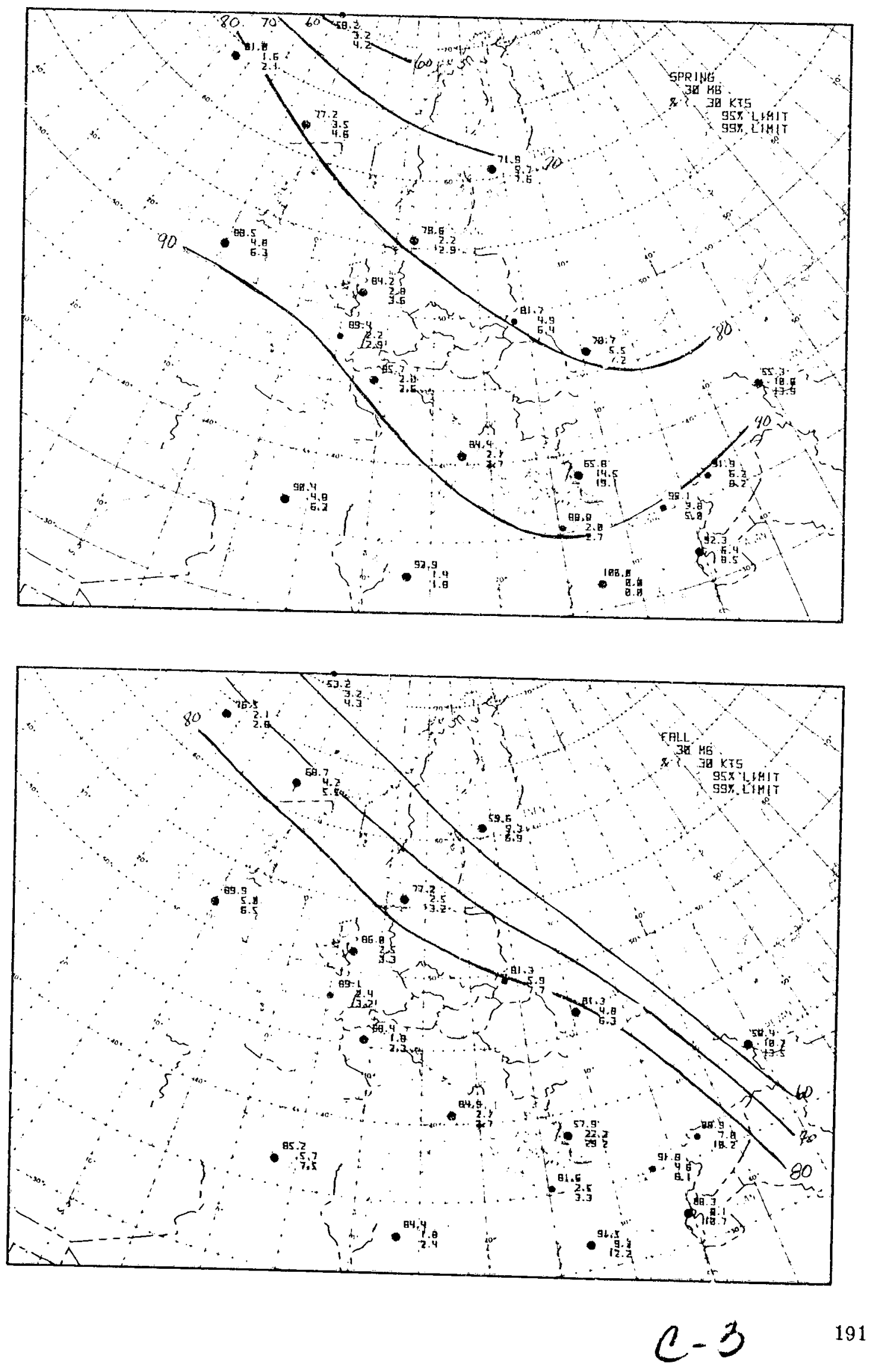

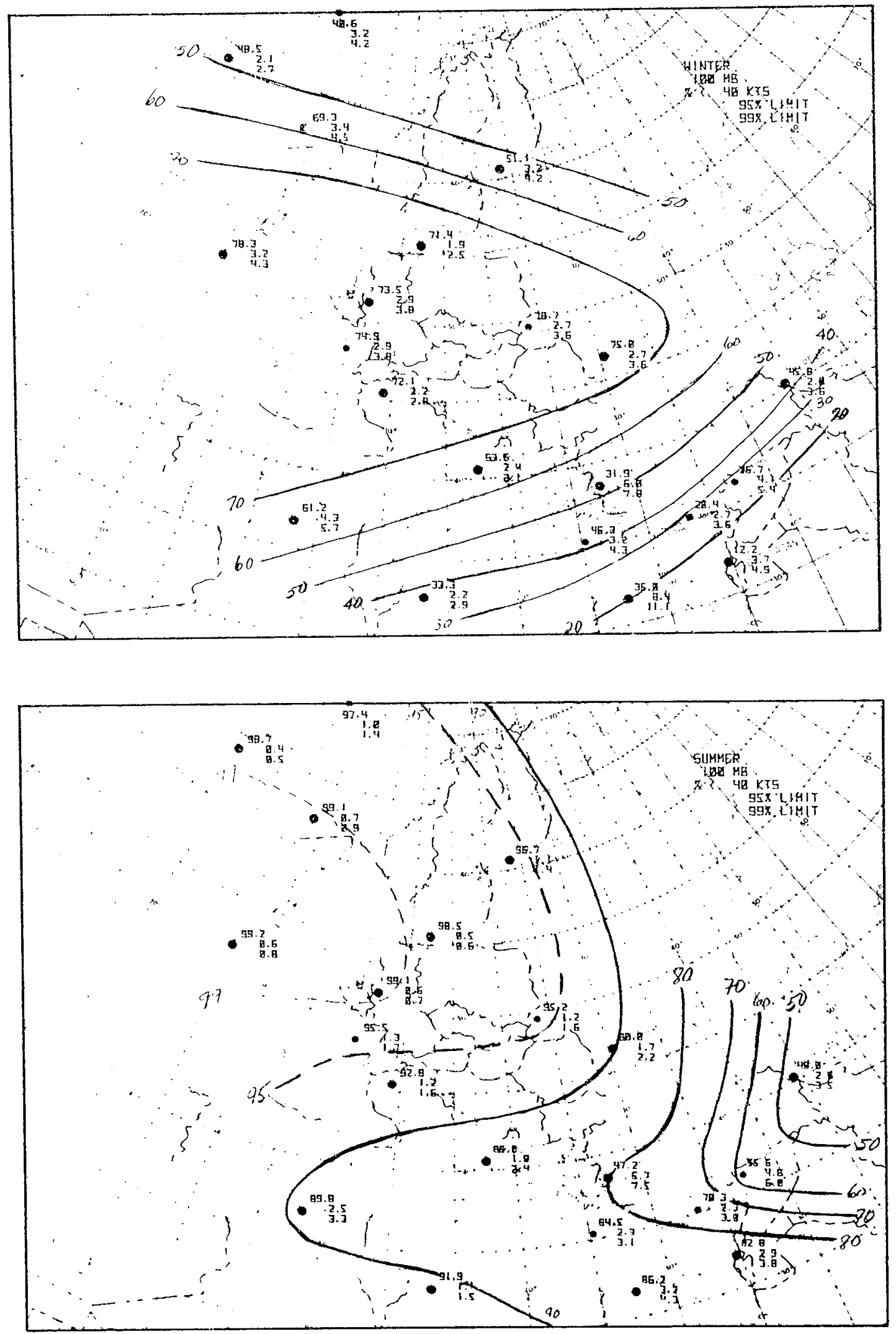

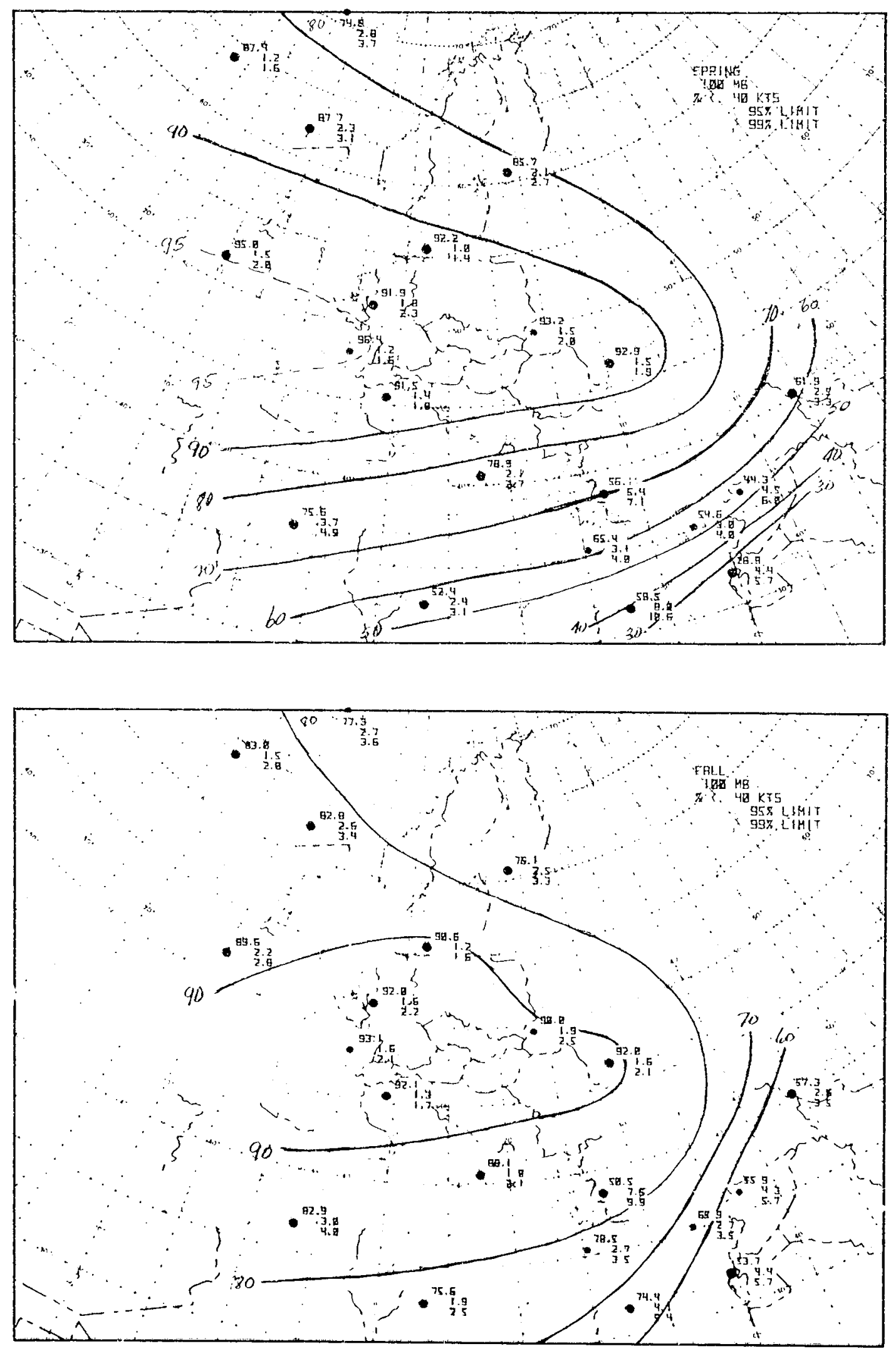

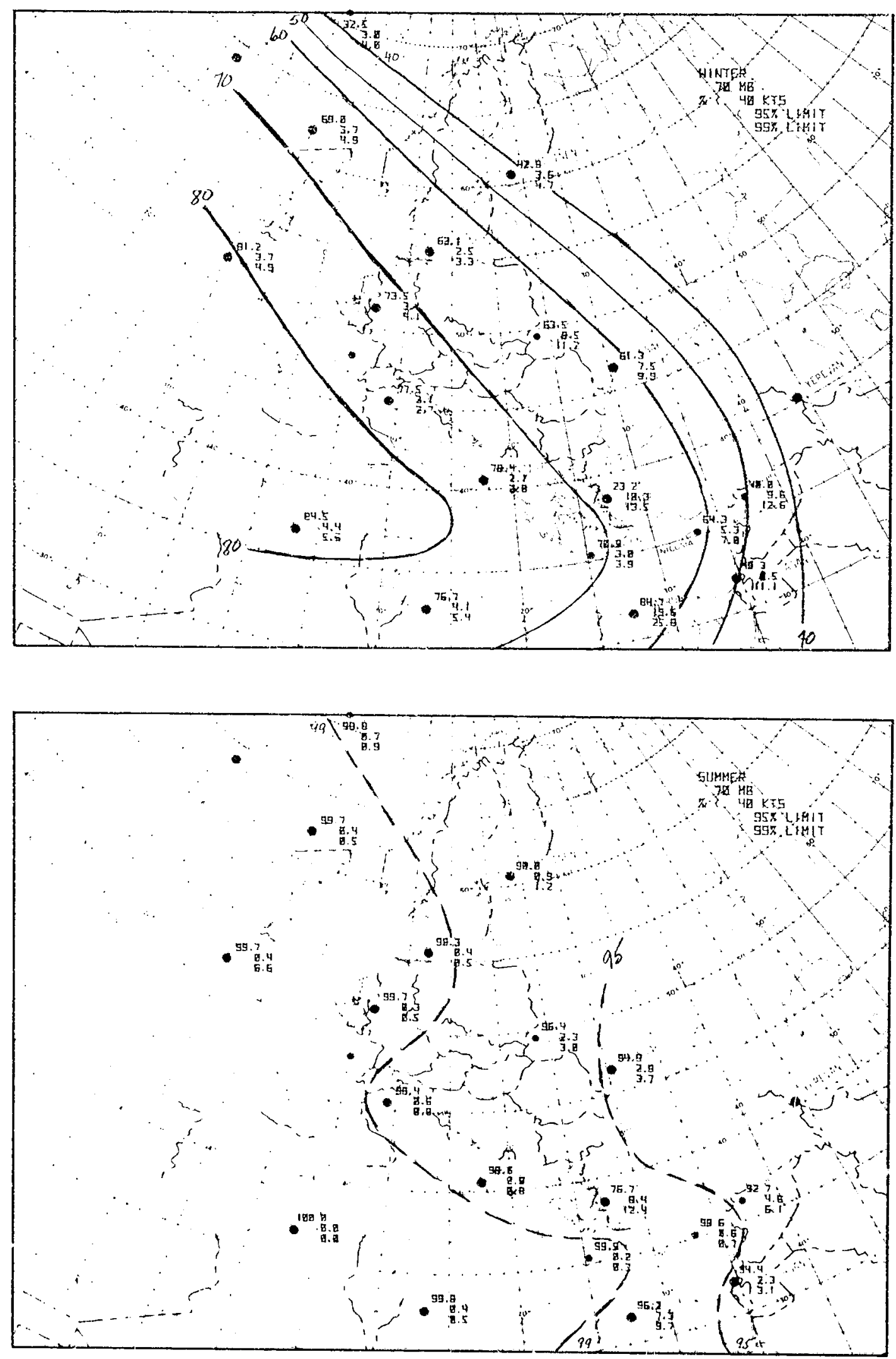


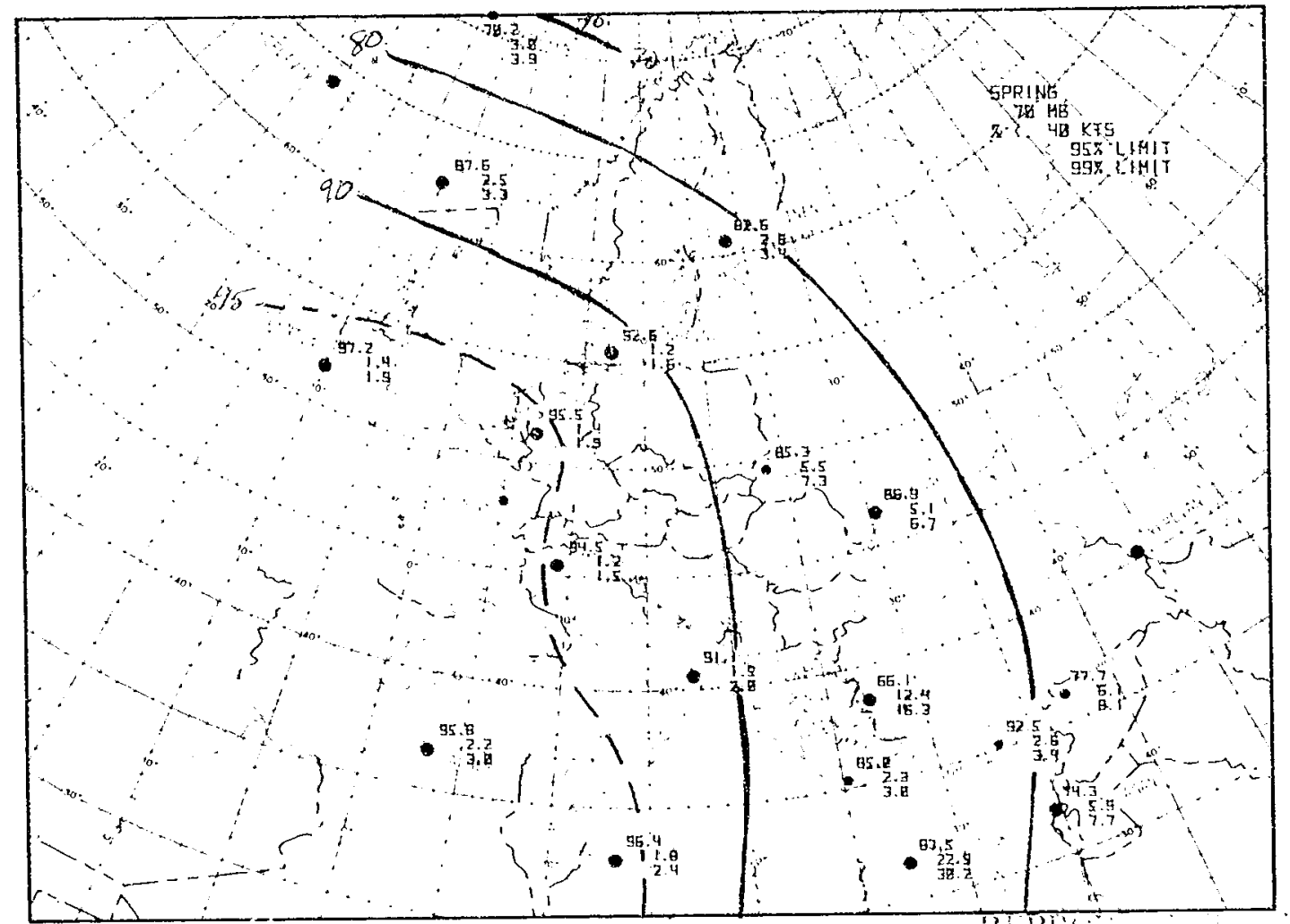

MII!!:
(1)!?!?

\% T!!

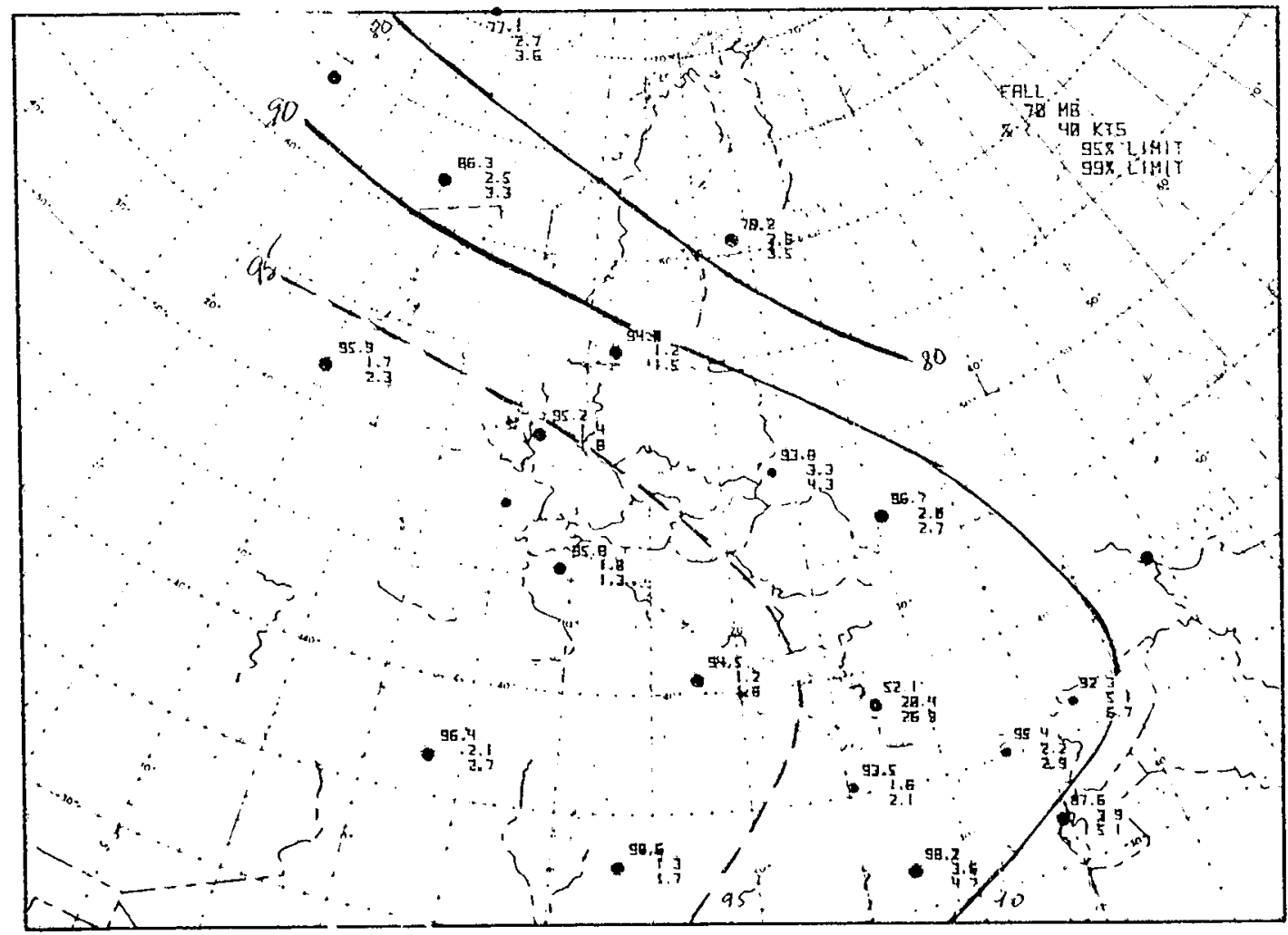



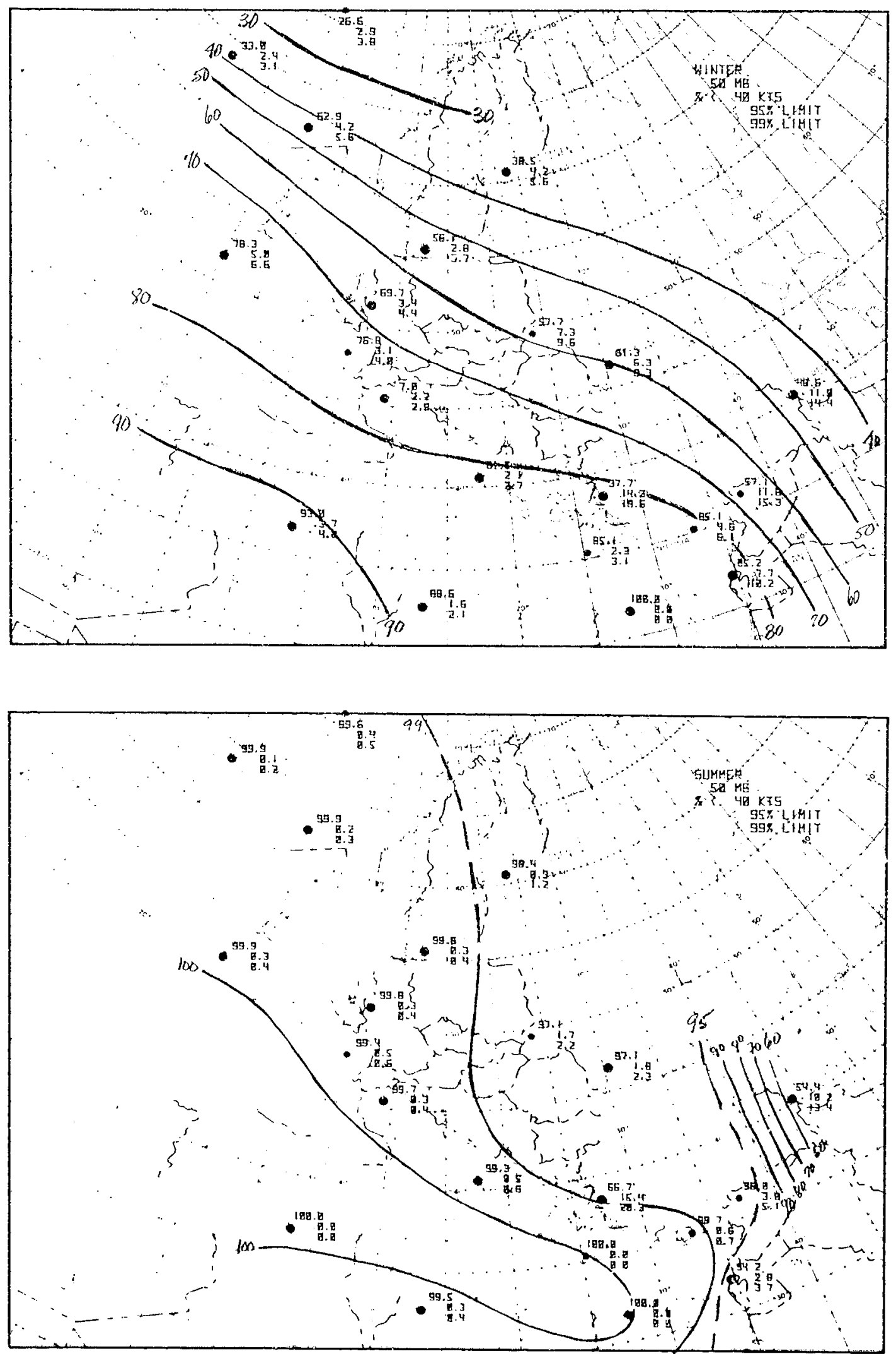

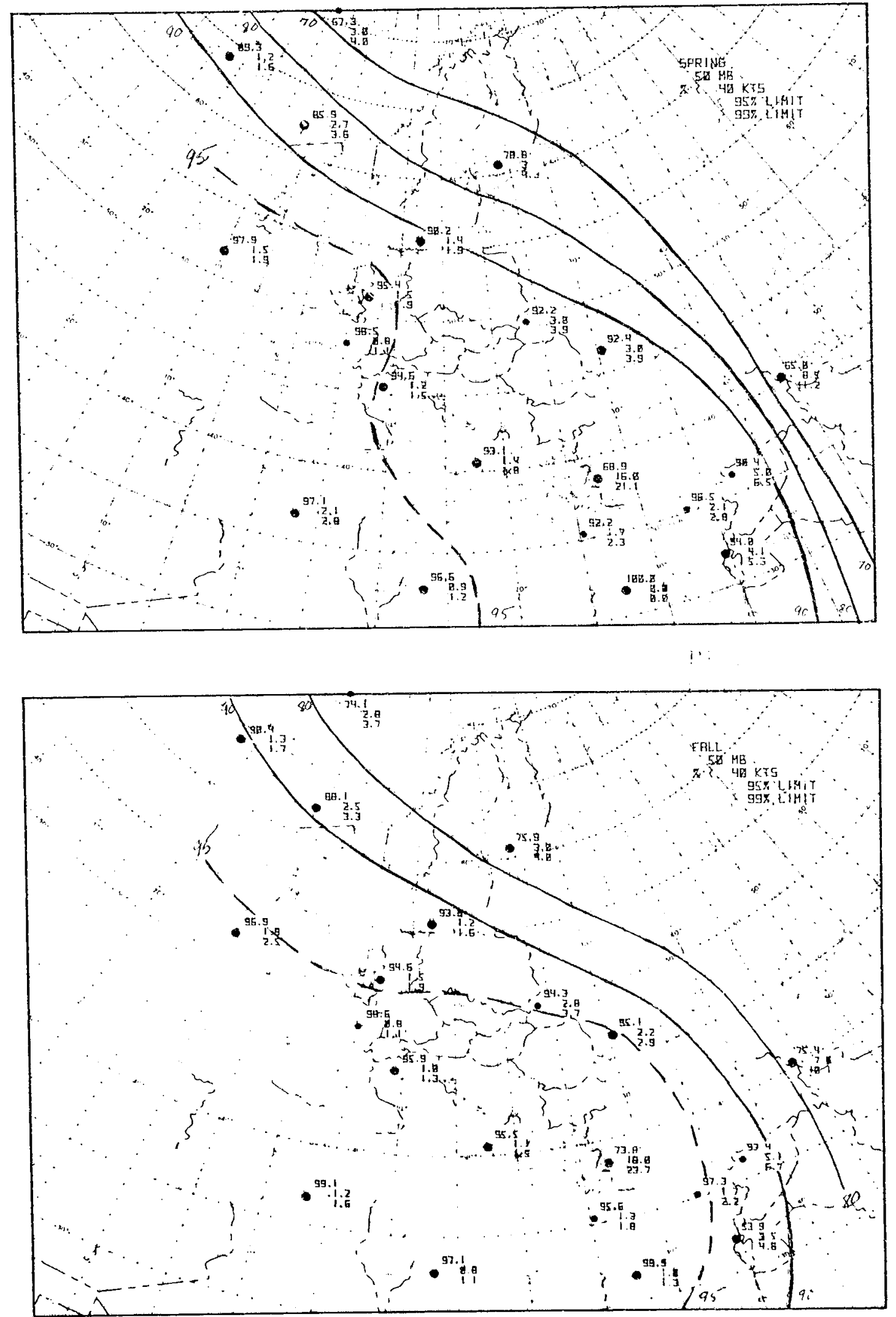

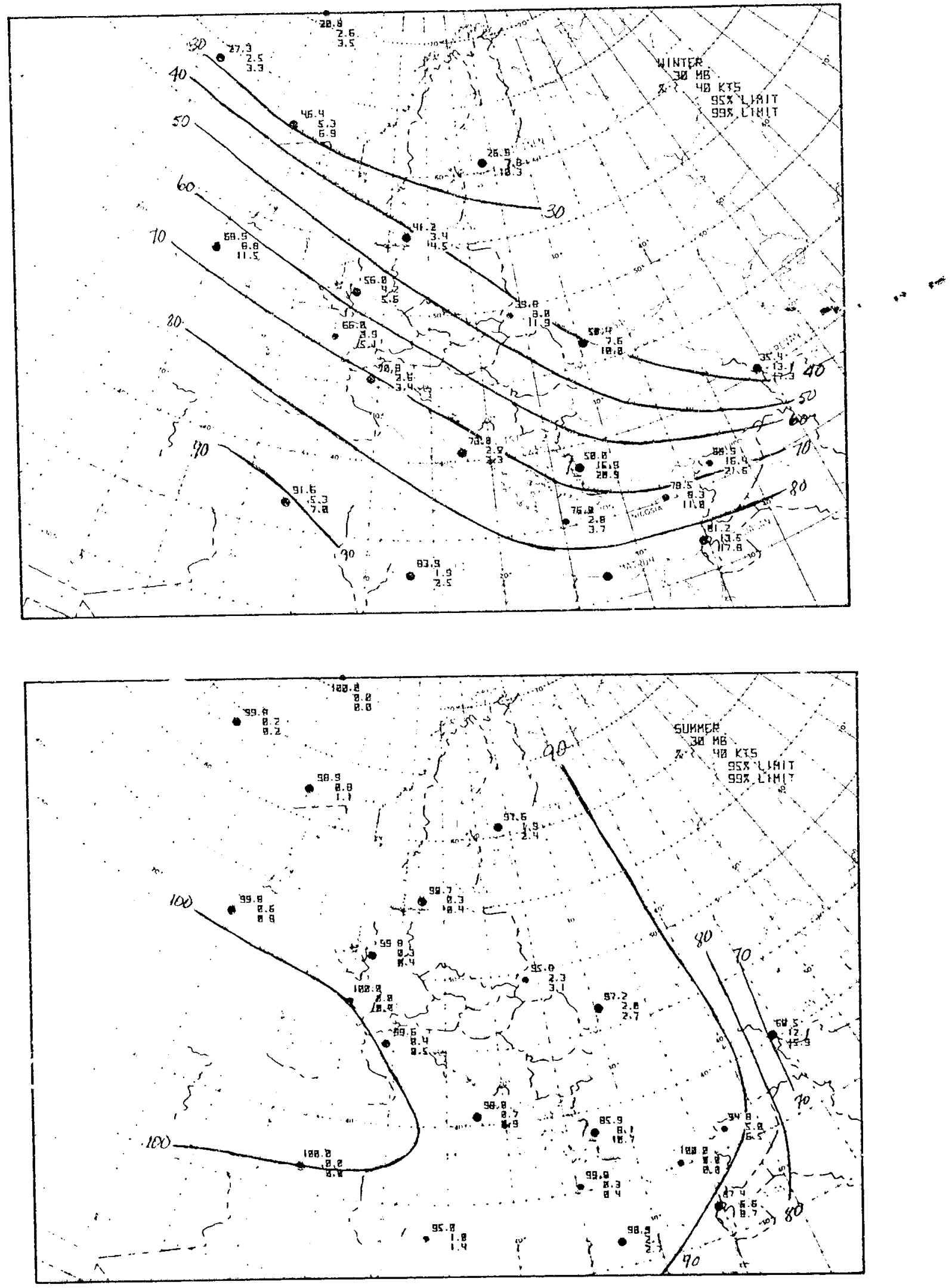

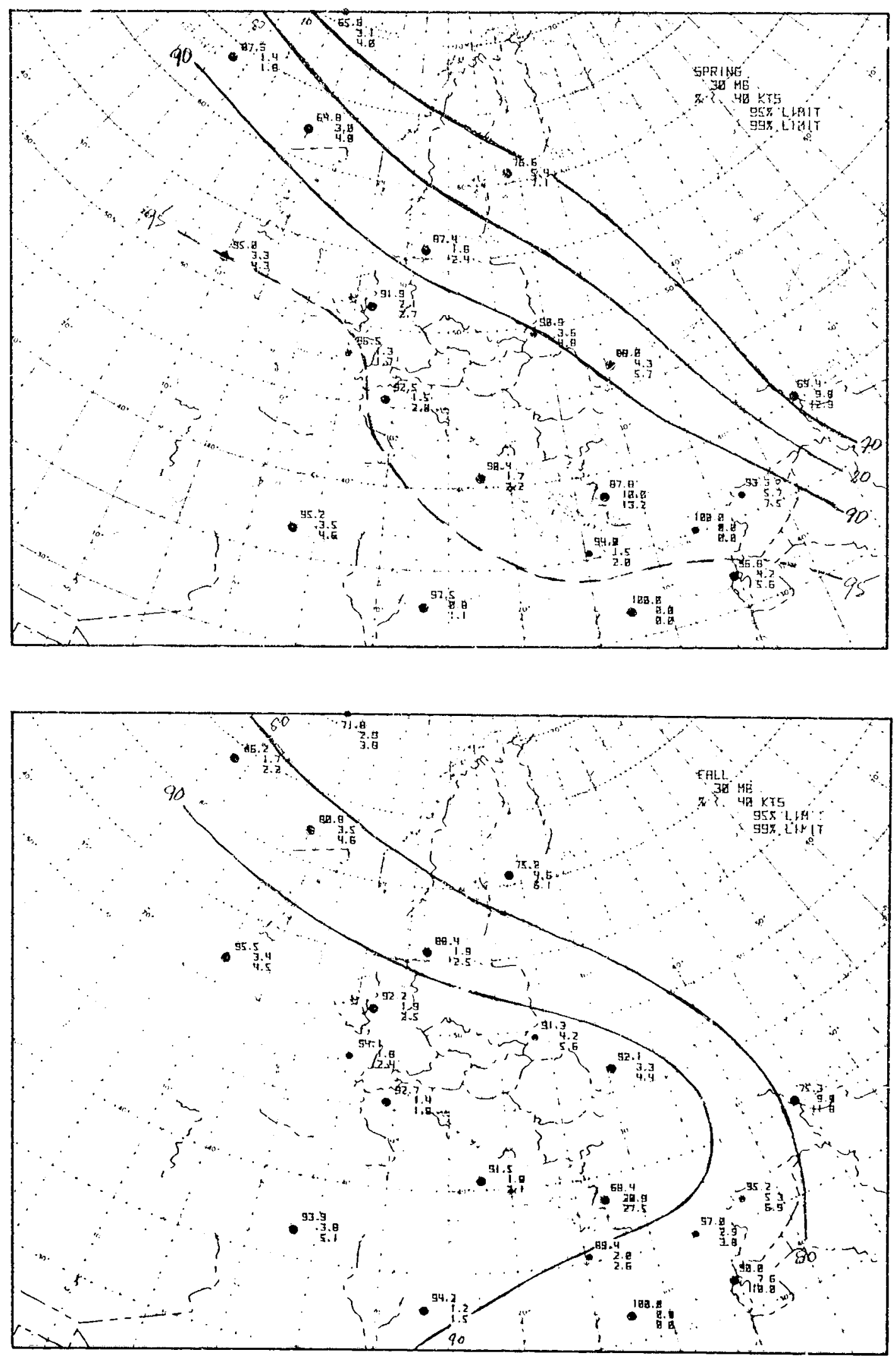

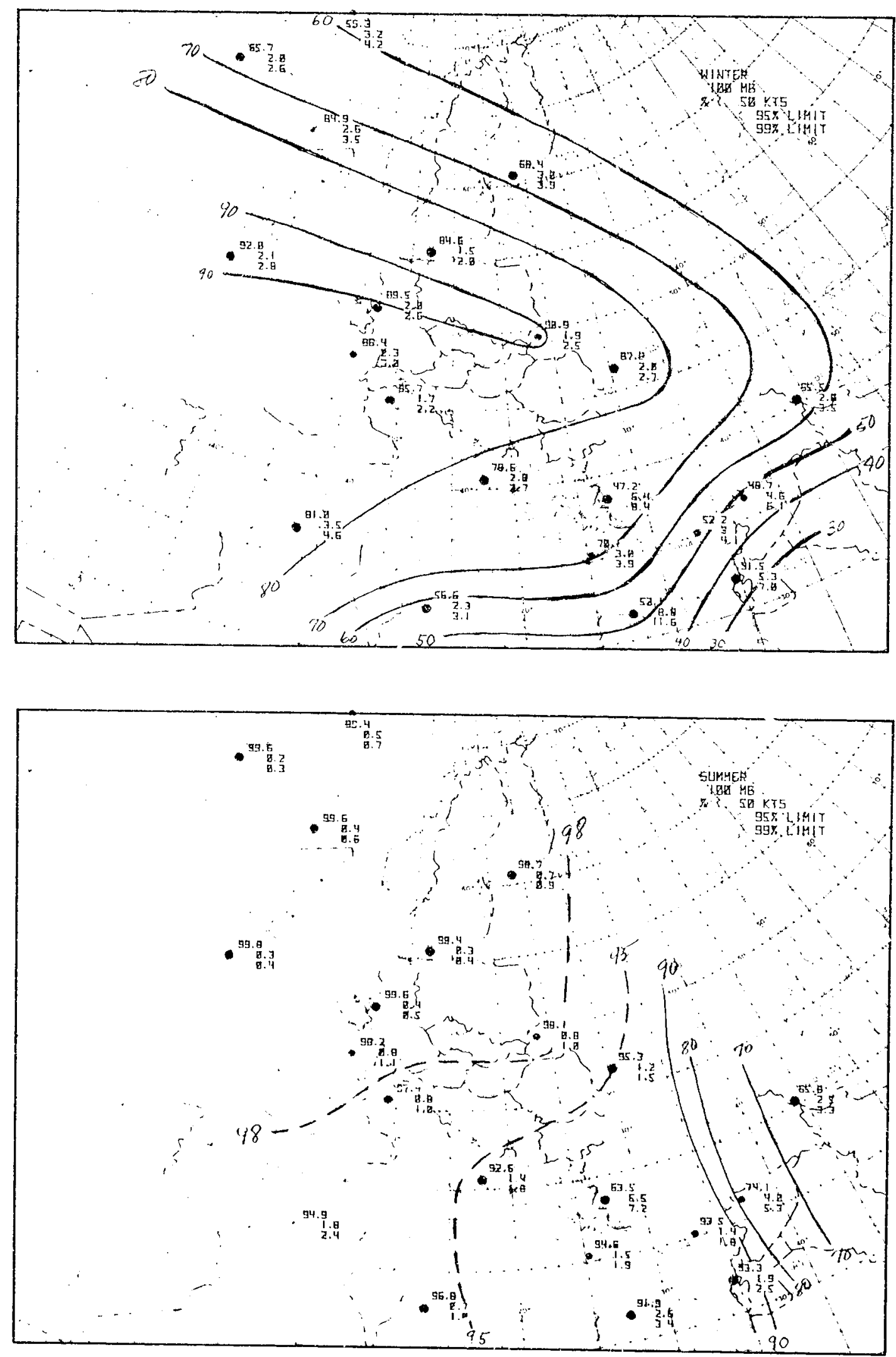


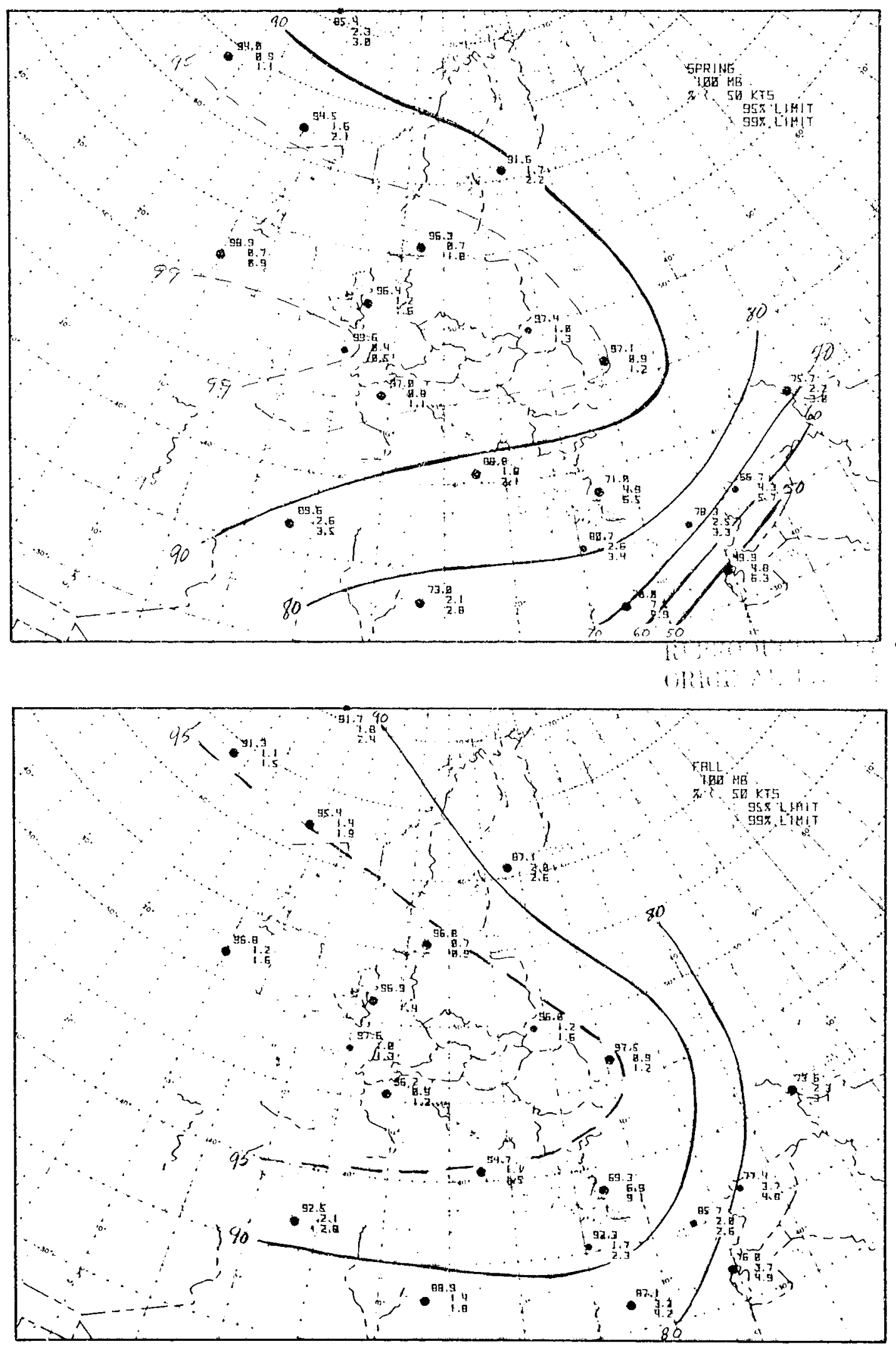



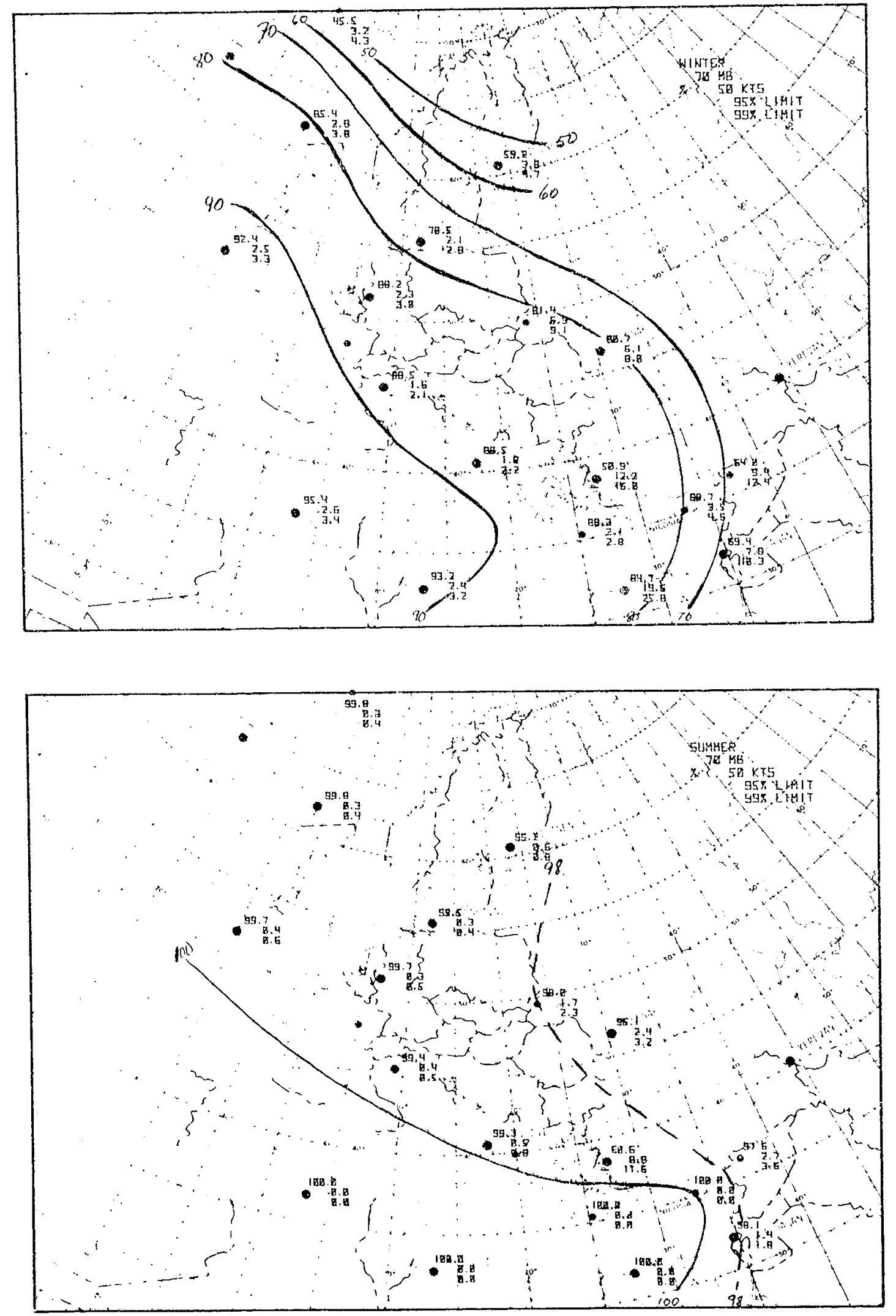

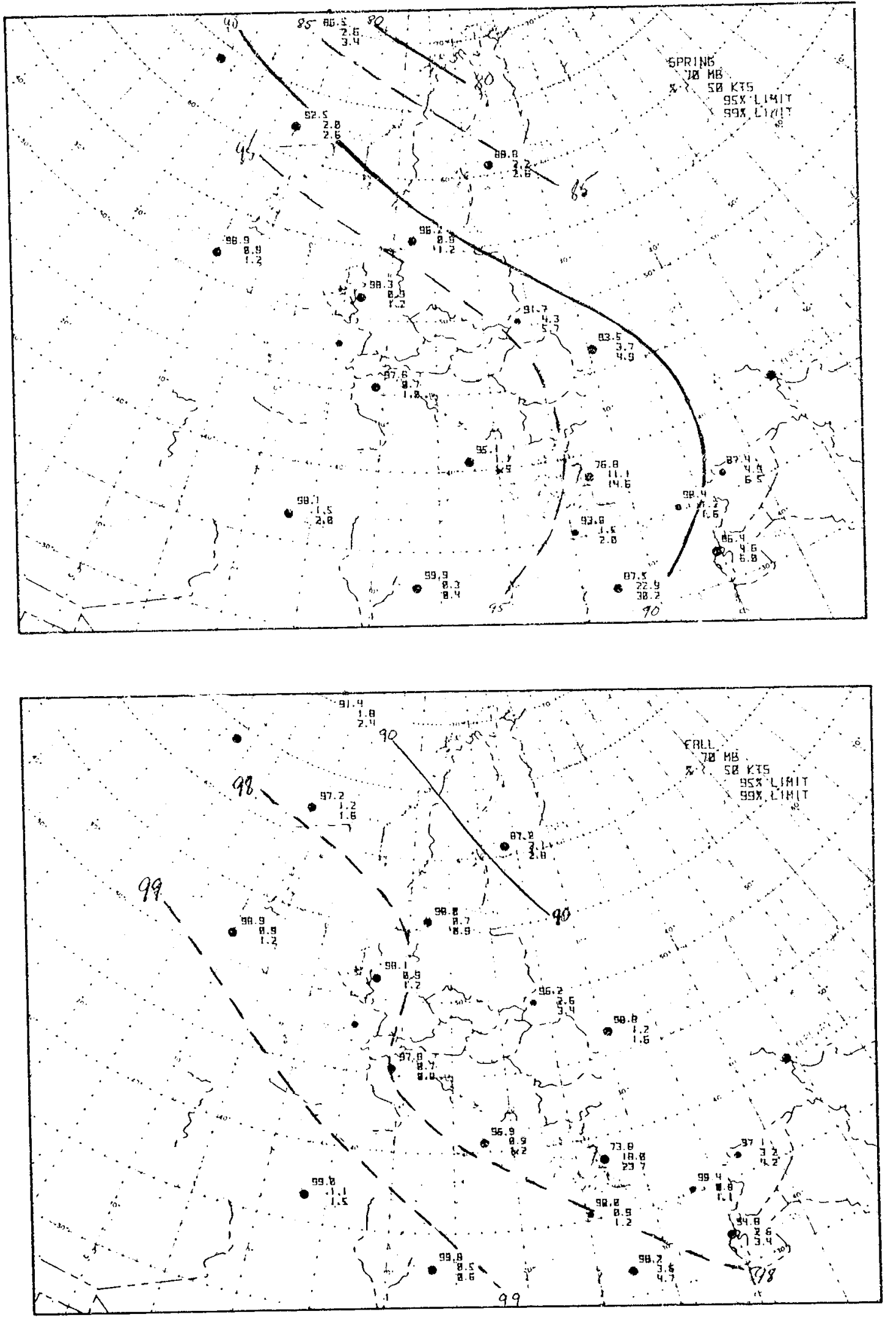

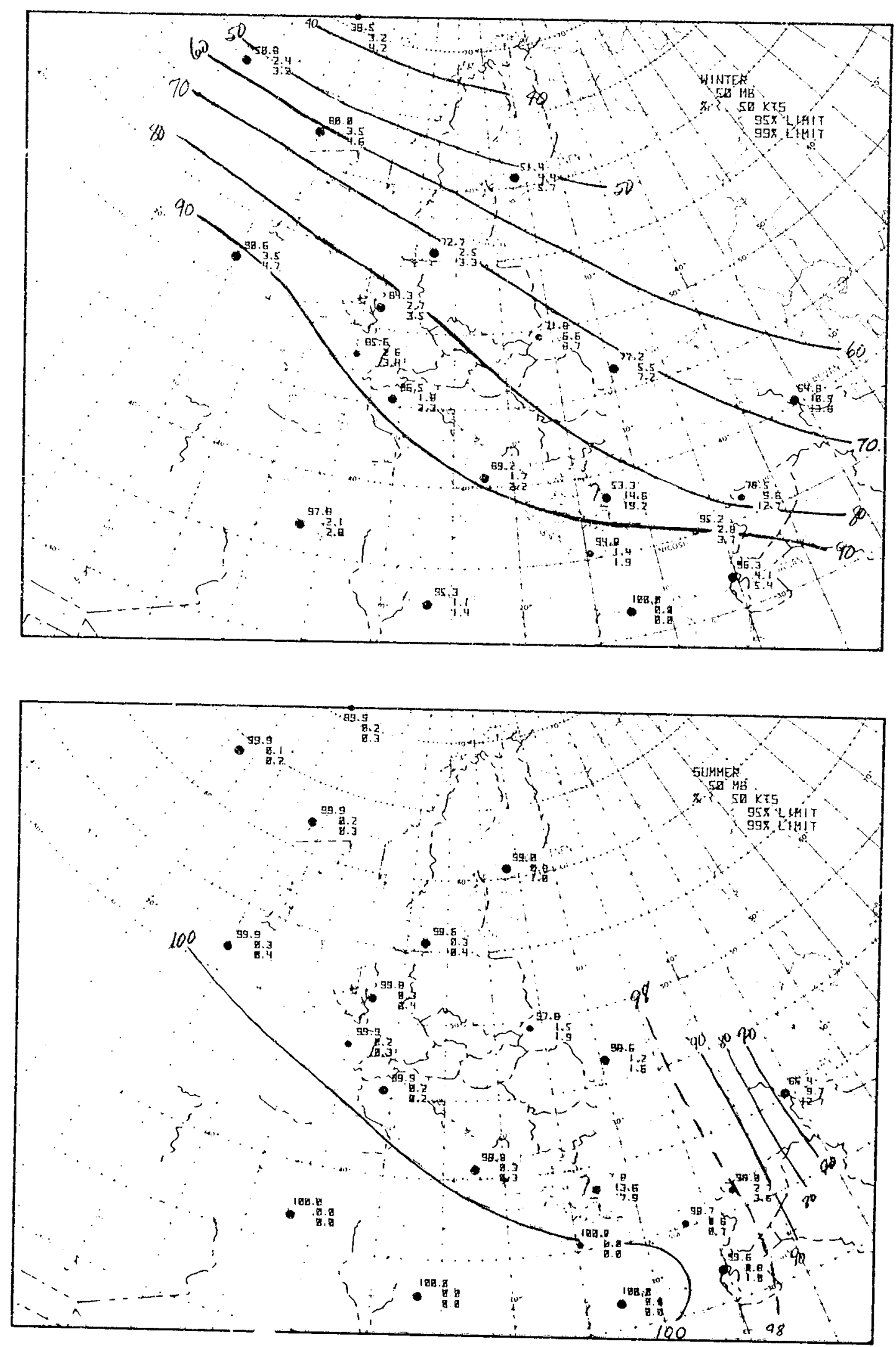

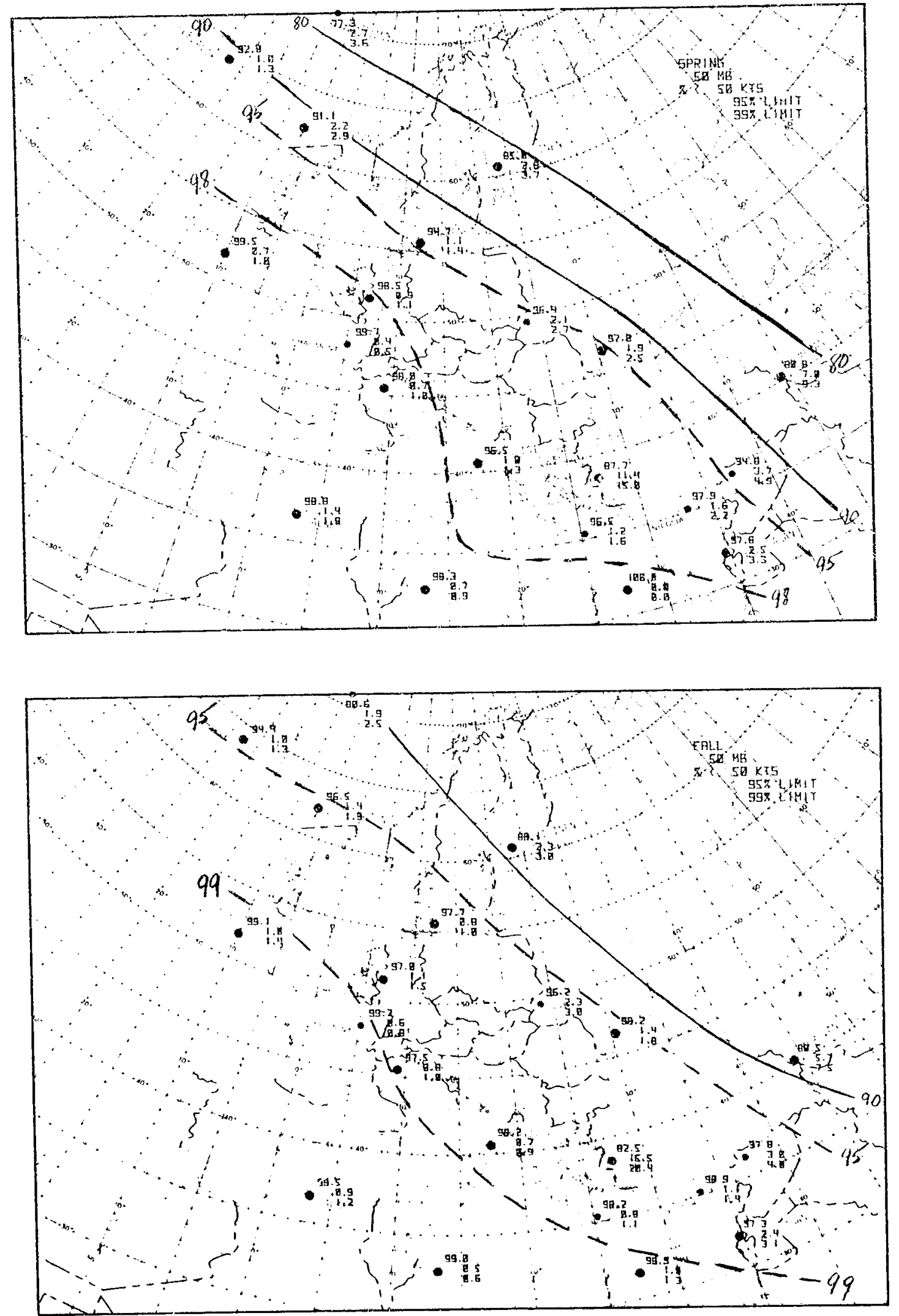

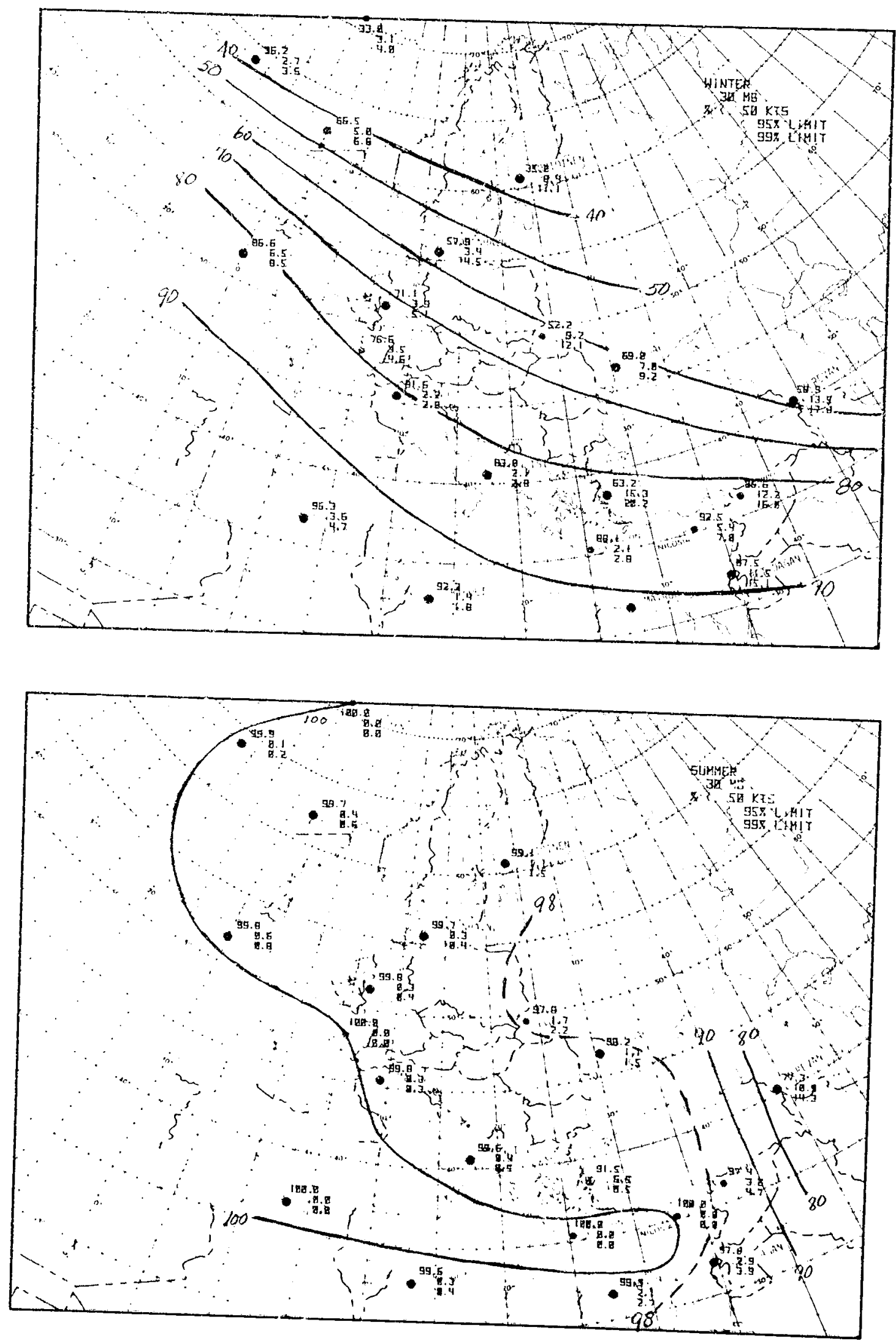


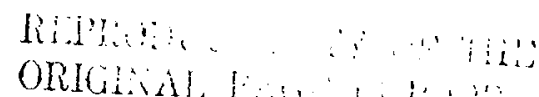
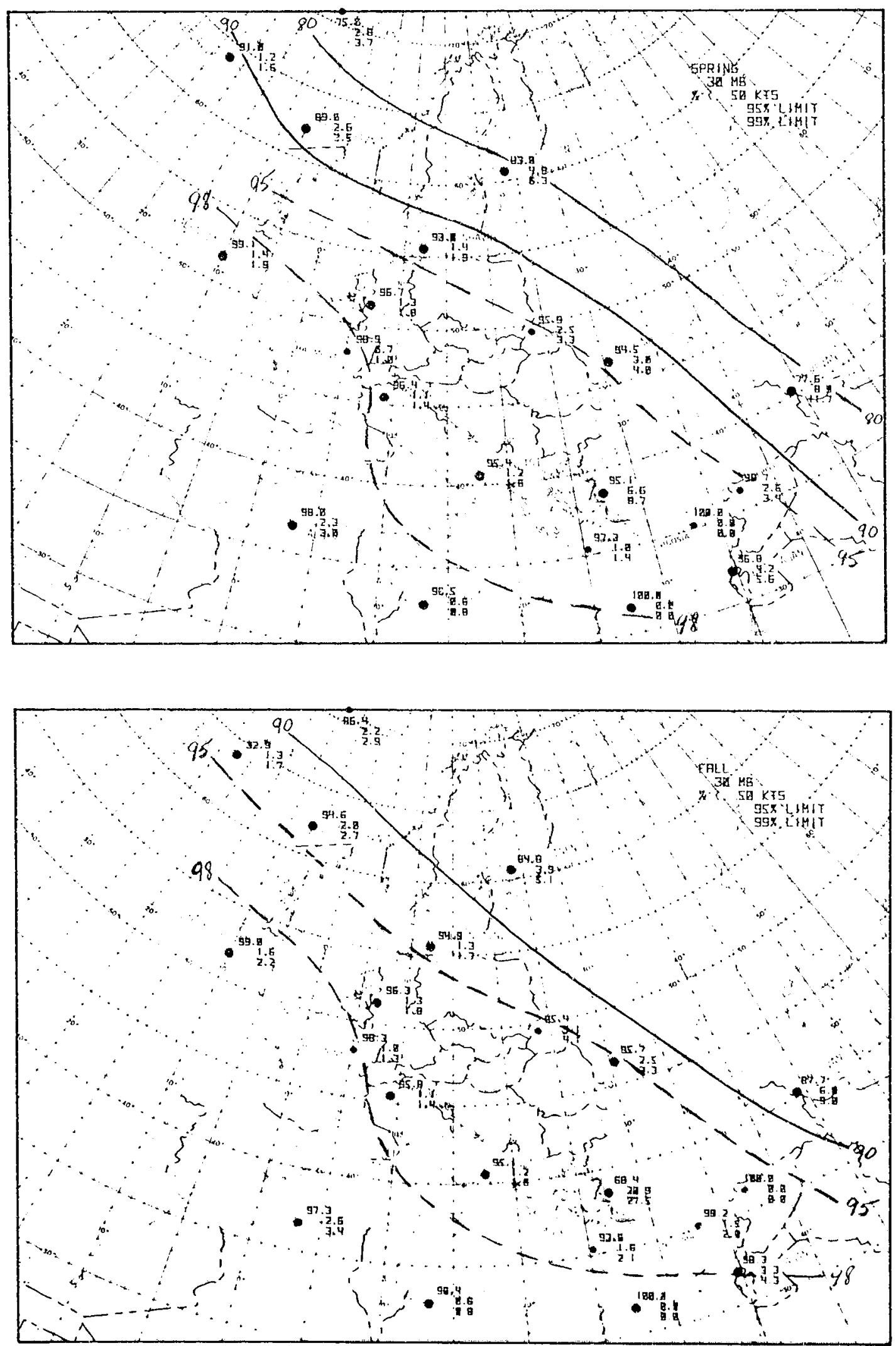

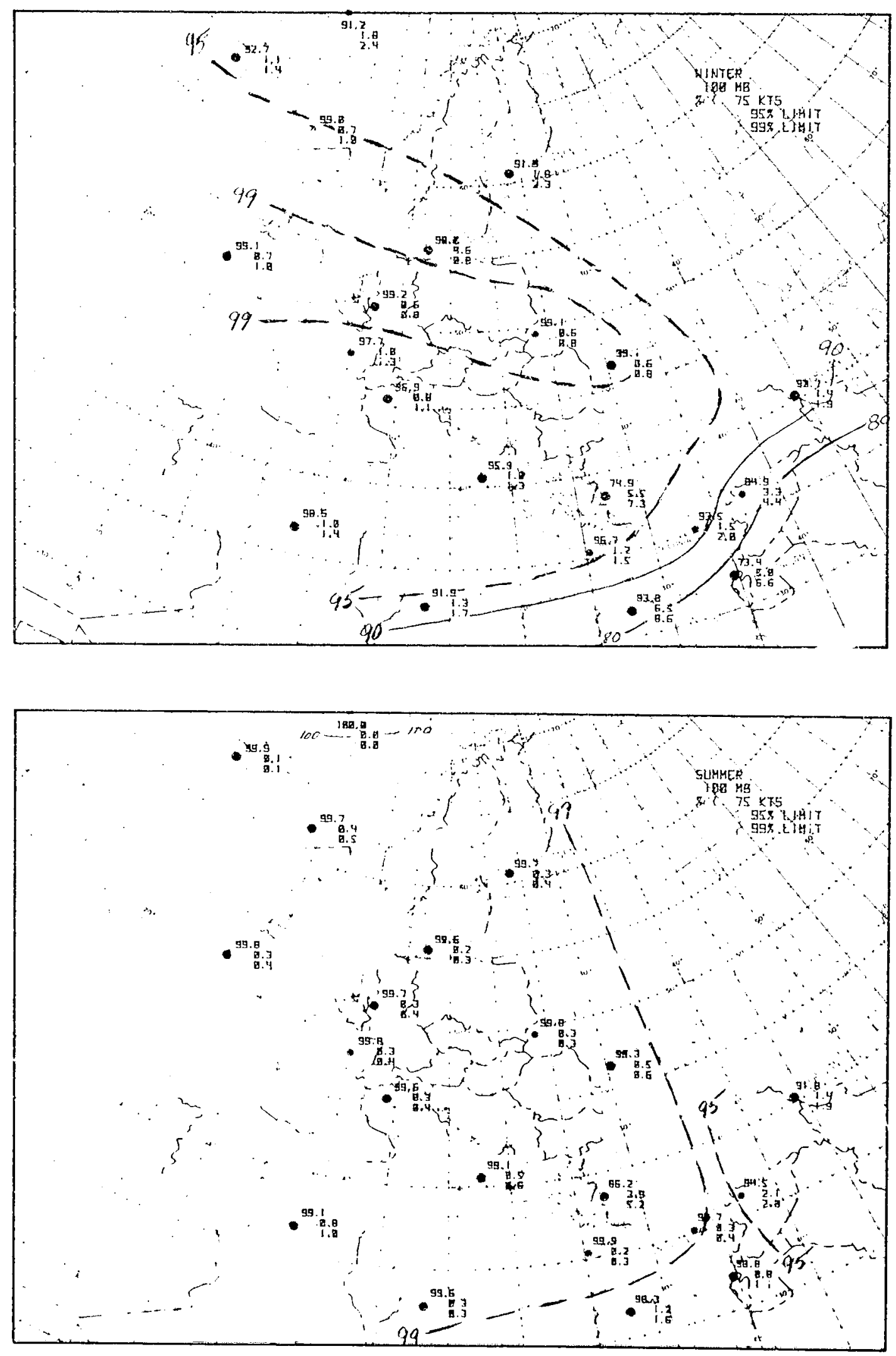

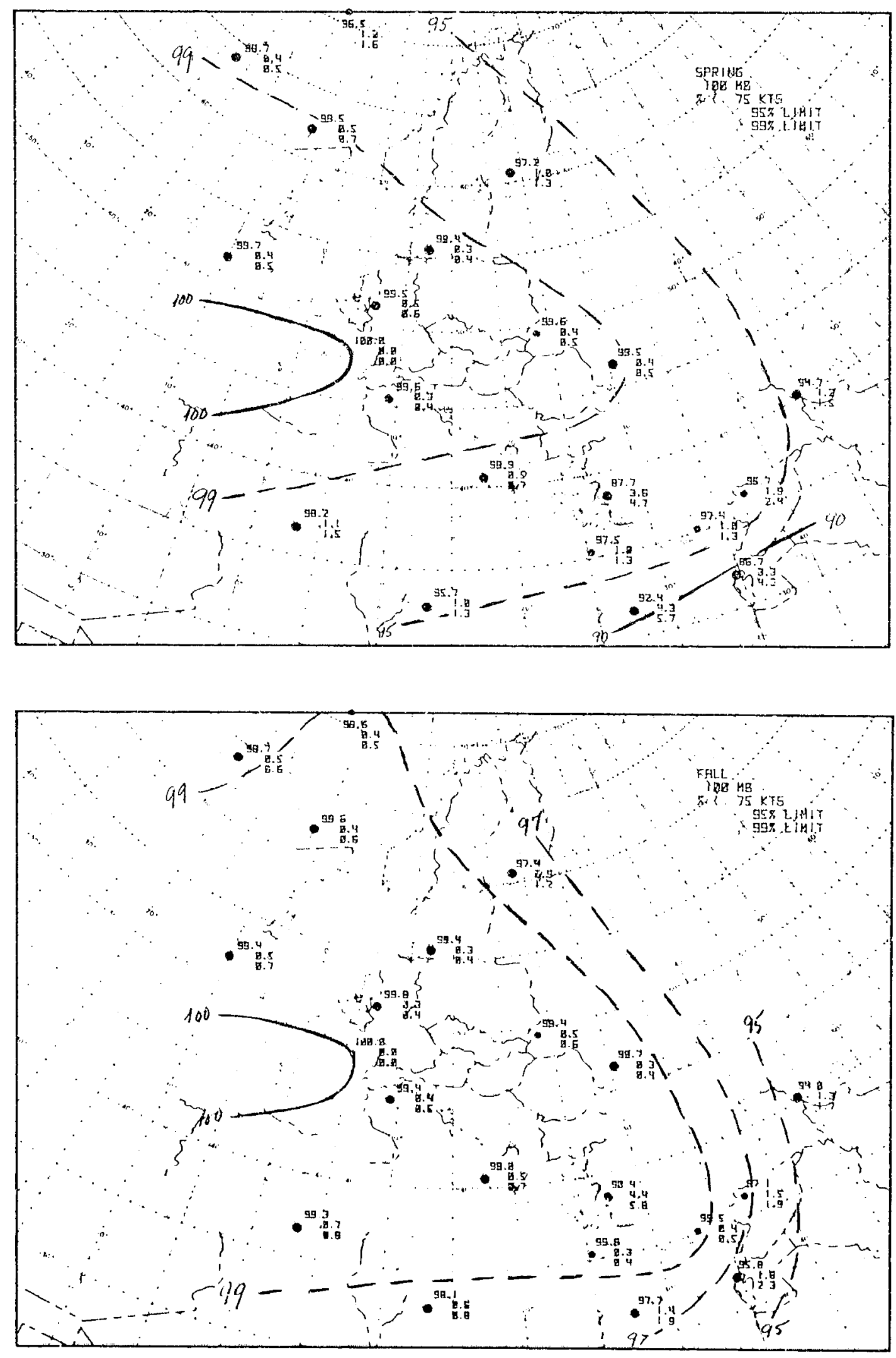

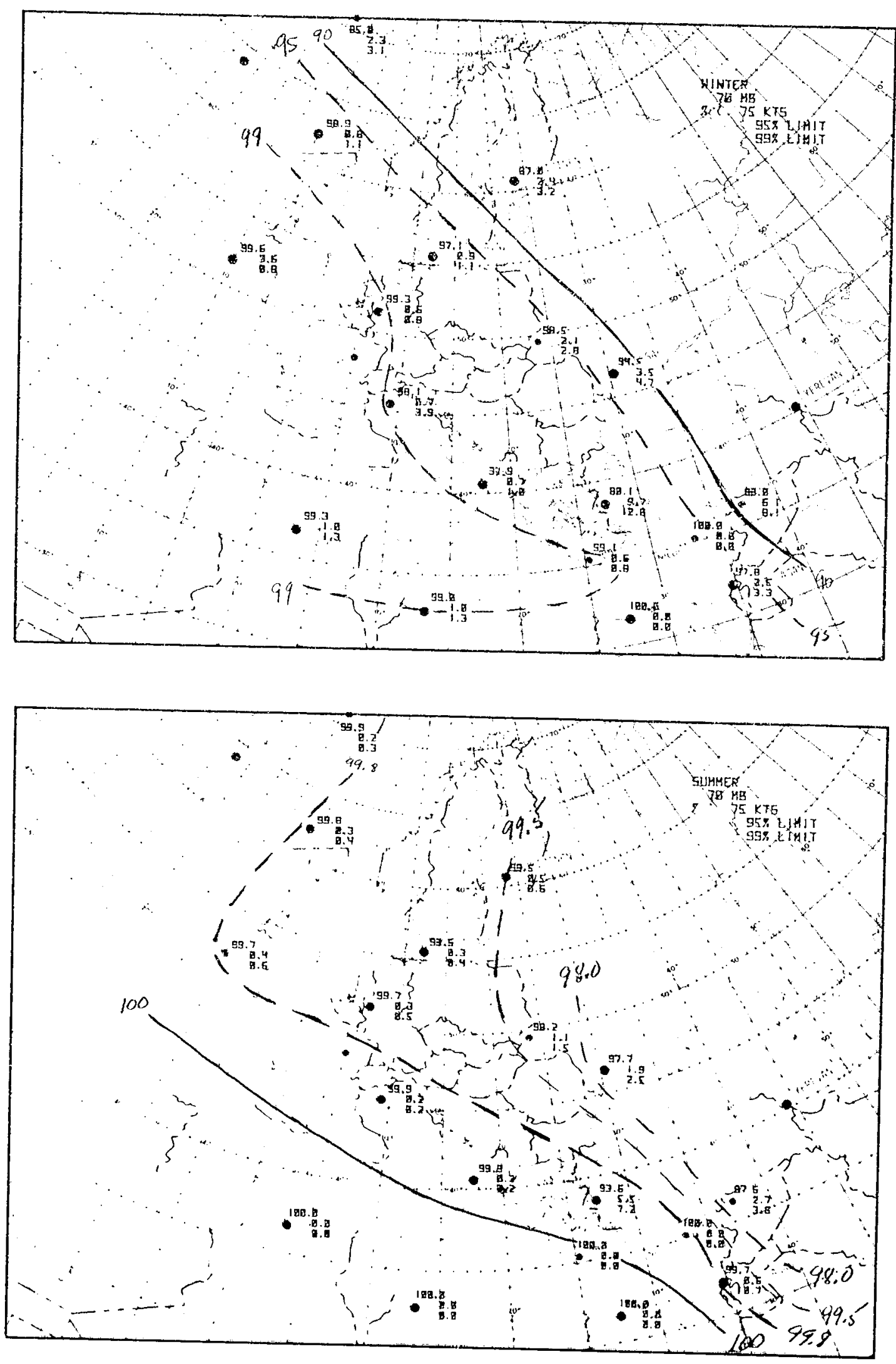

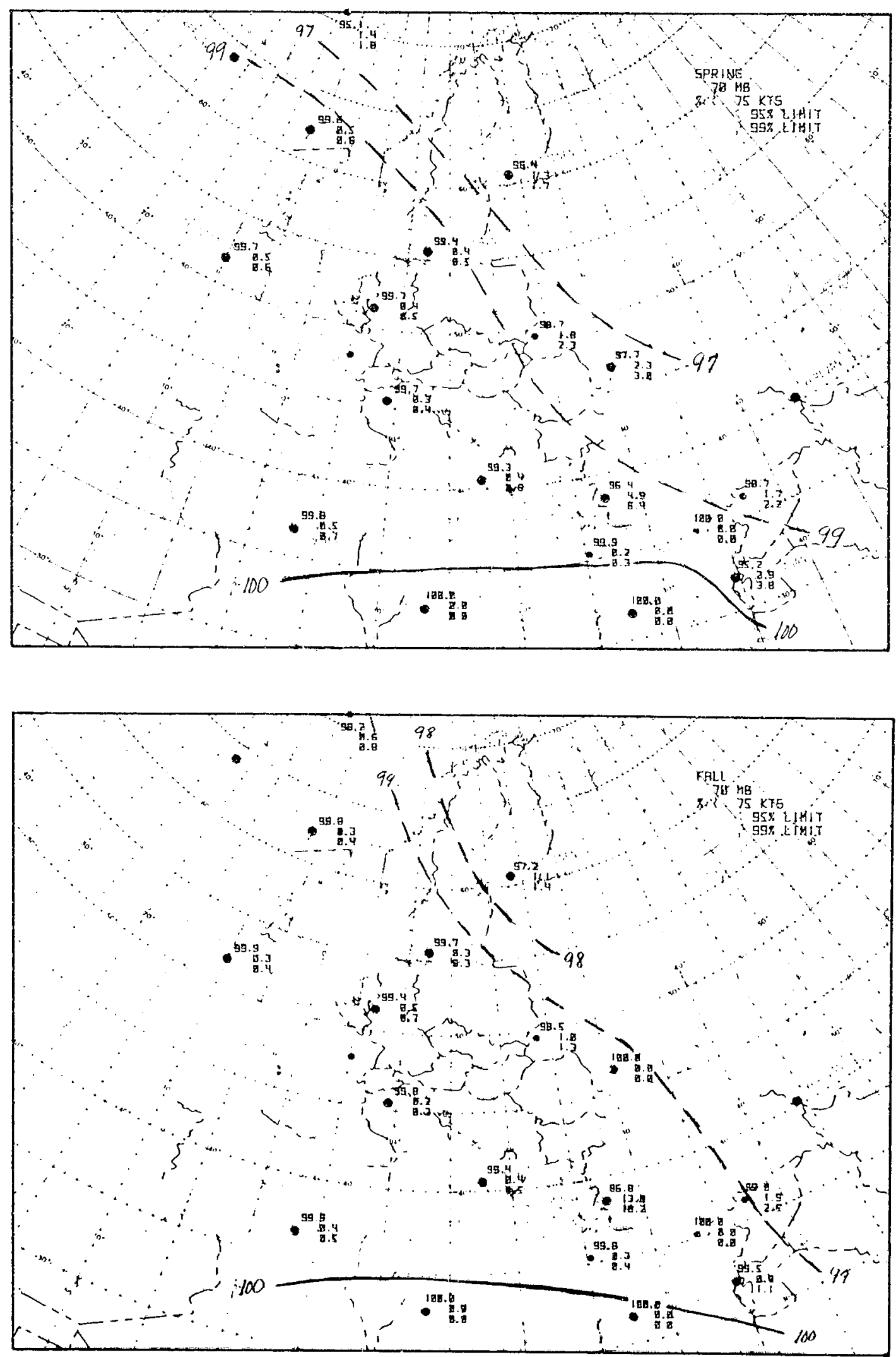

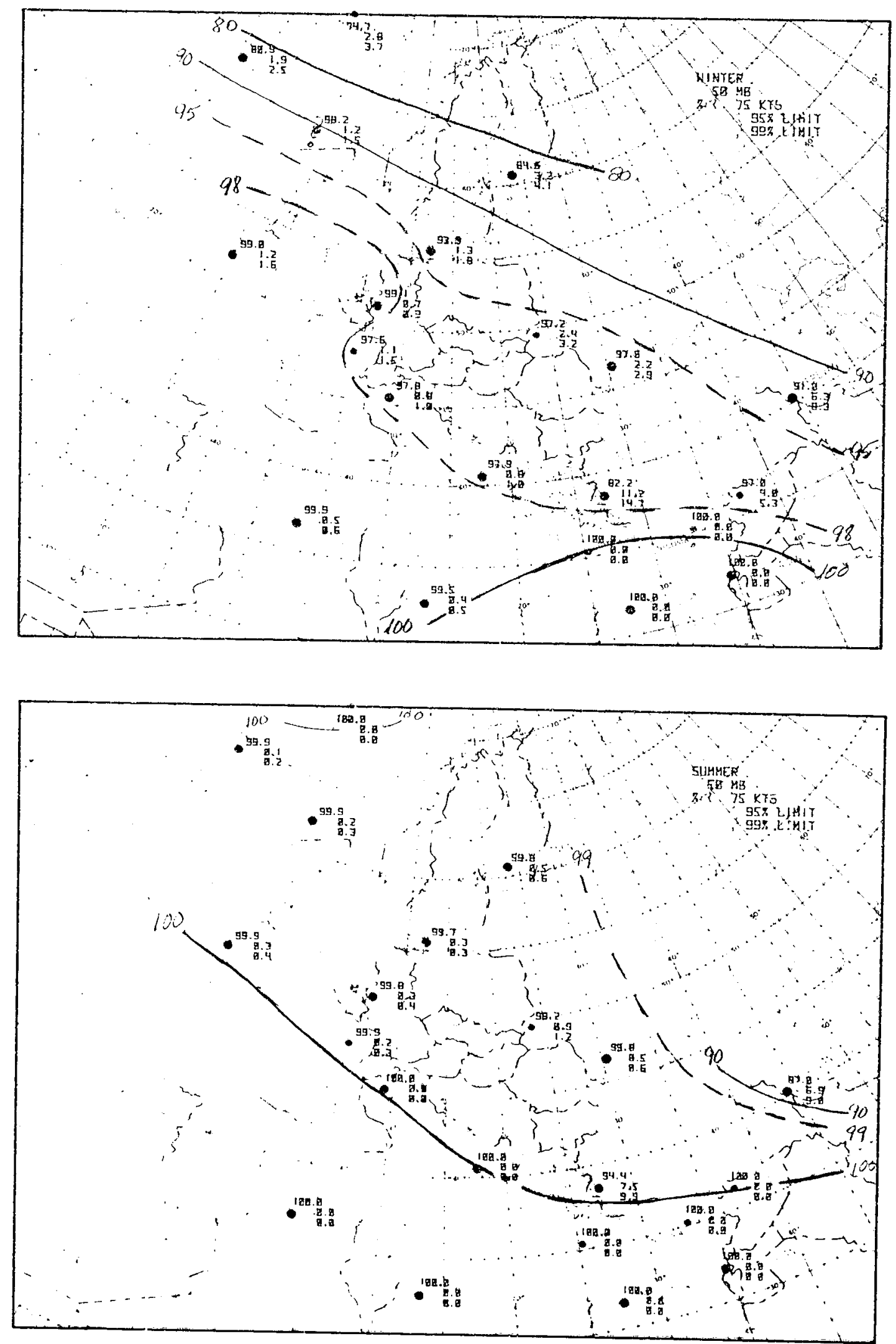
REHUA ORIGLAl HAR IS l; ;
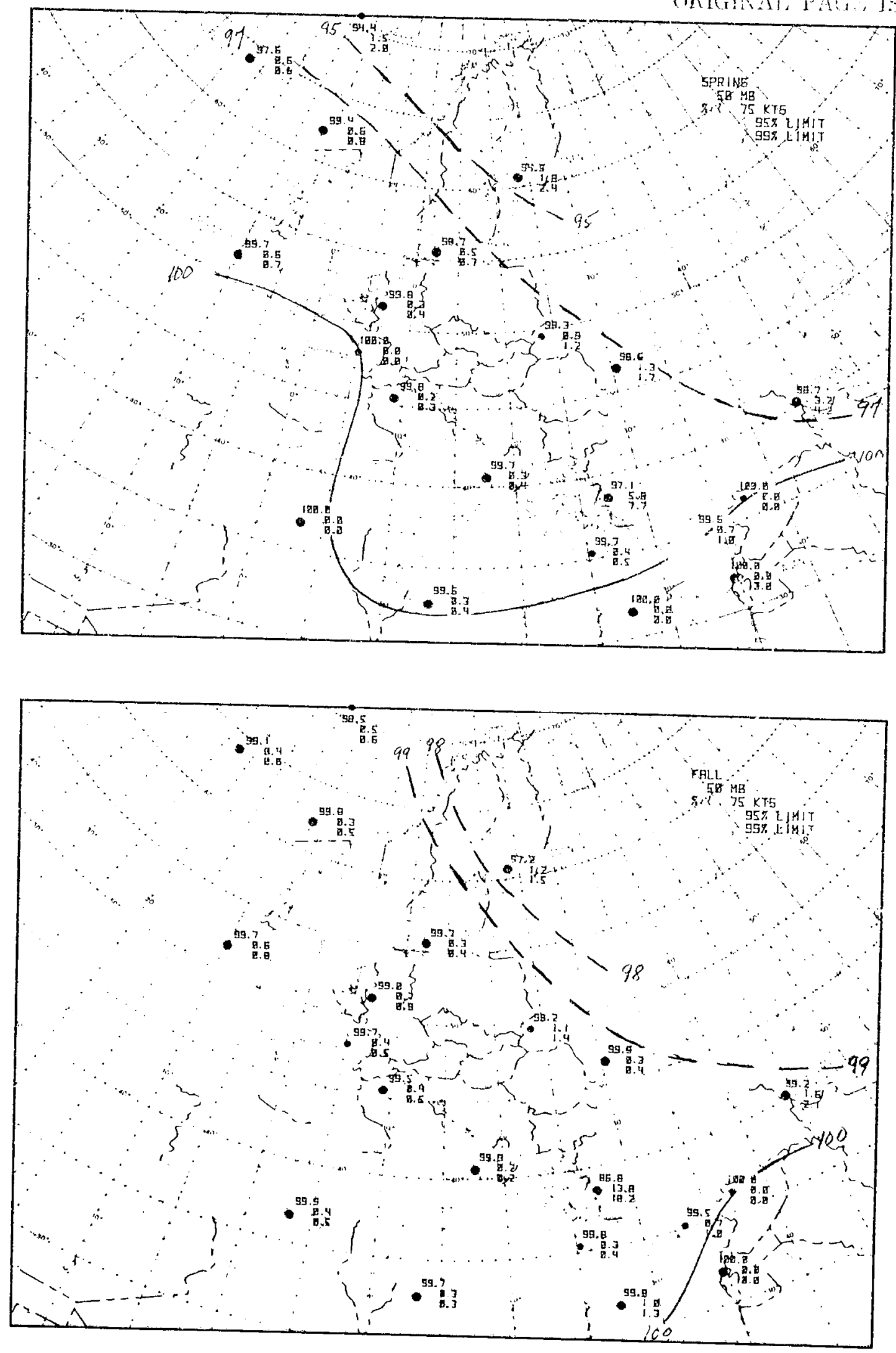

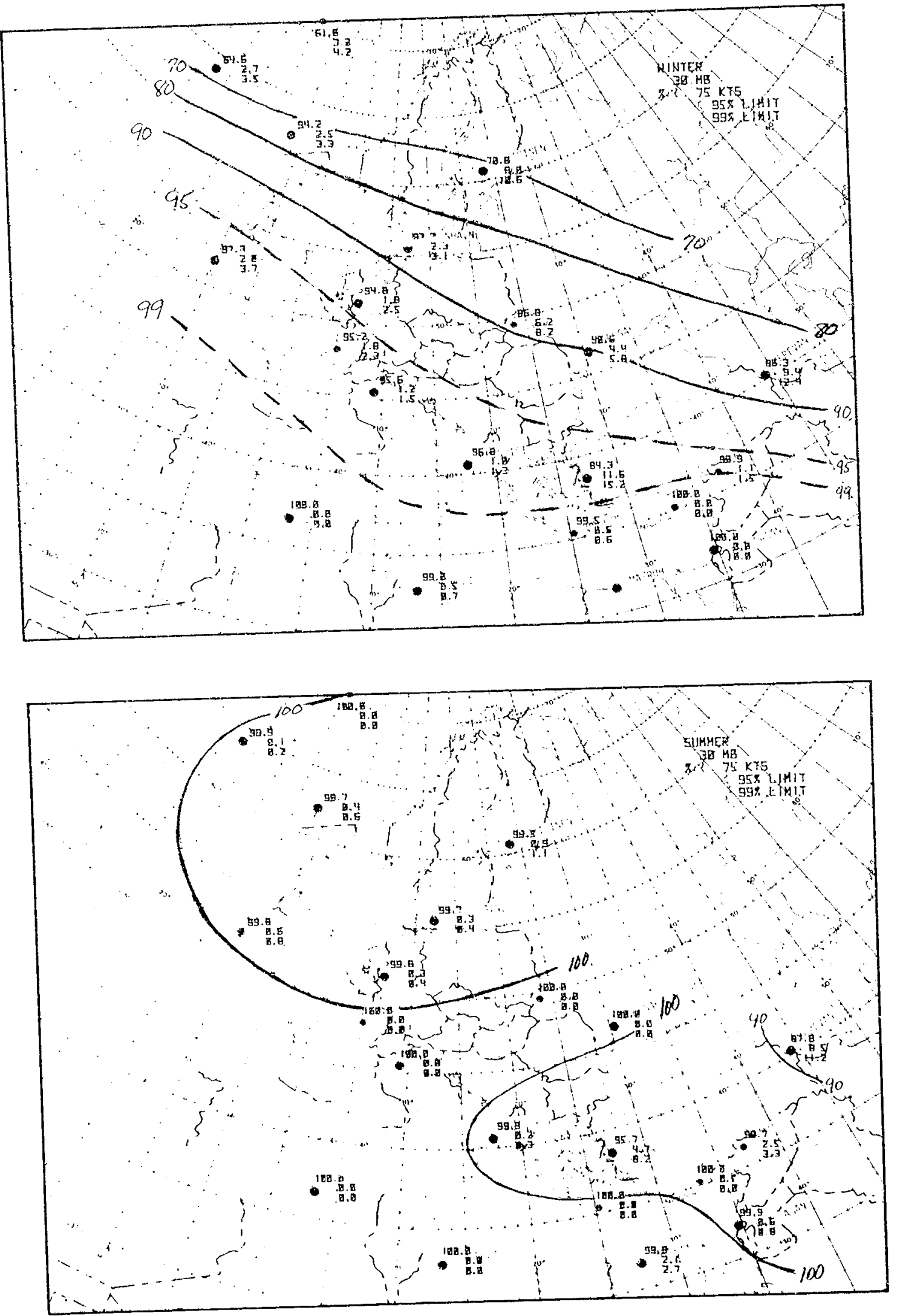

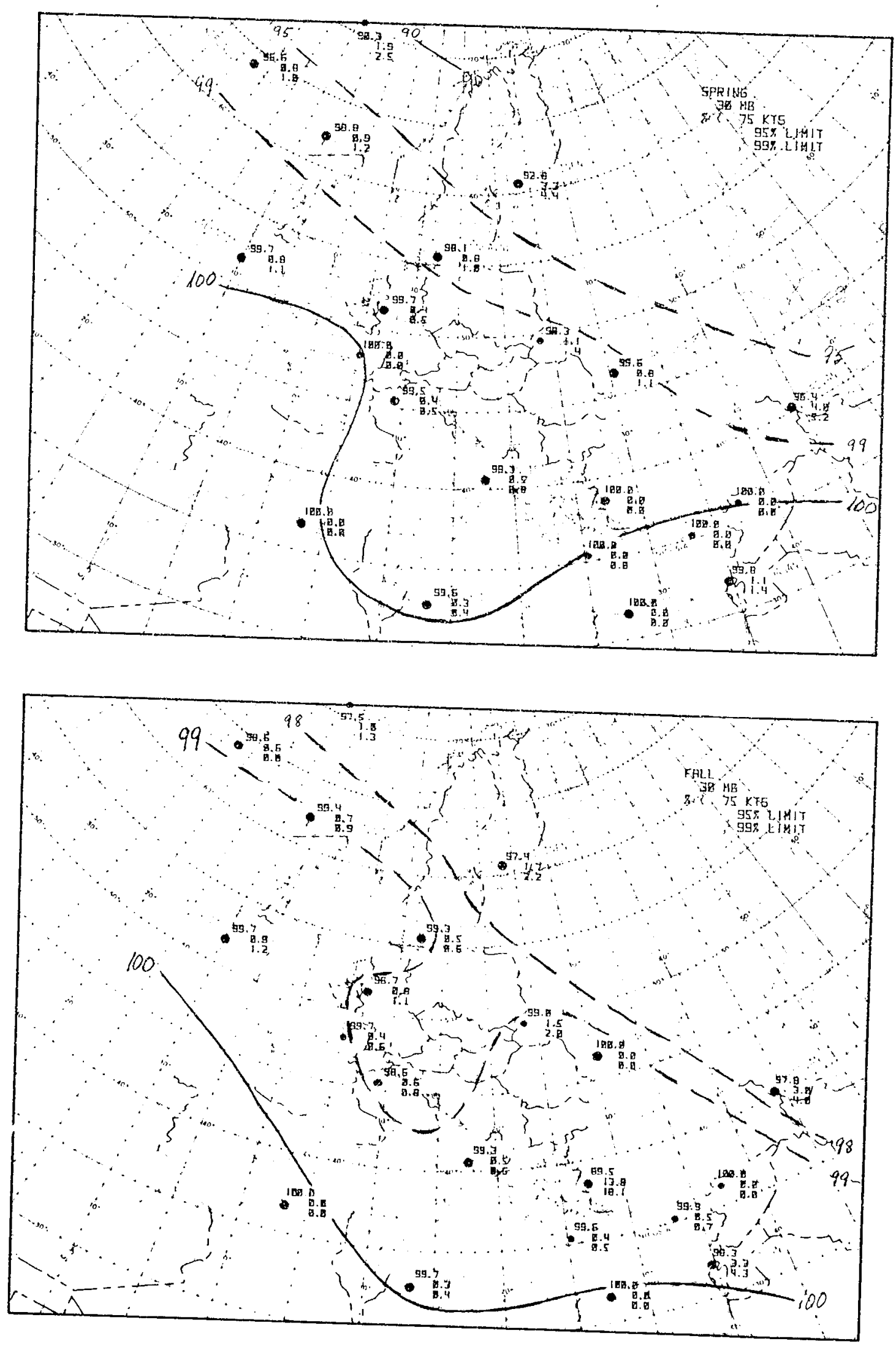
SECTION C

PACIFIC

$\operatorname{mox}$, 

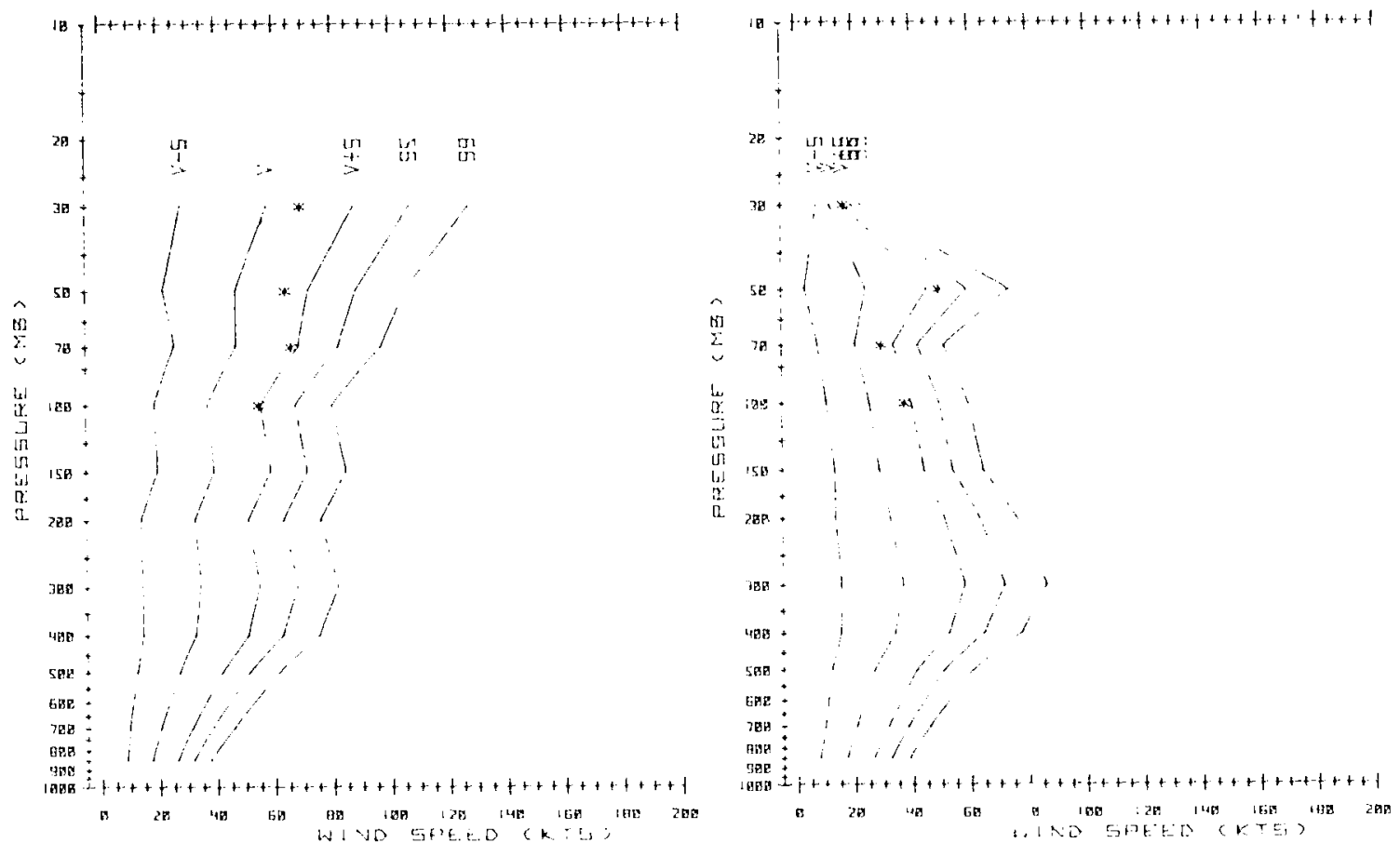

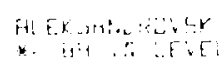

SL.MME.:

HI Frstra kit:

init.:

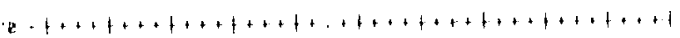

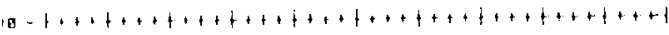
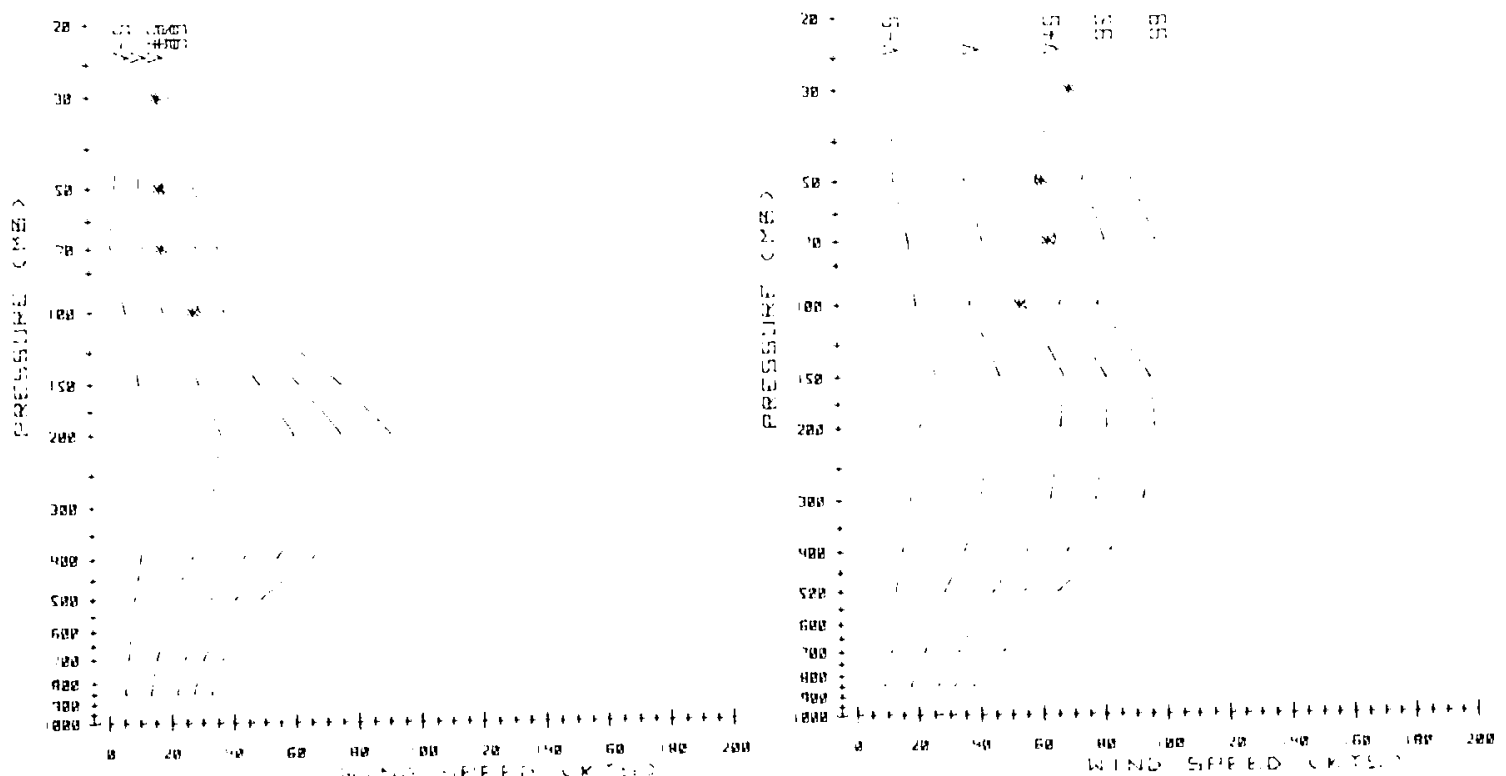


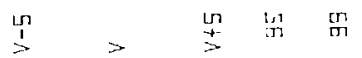

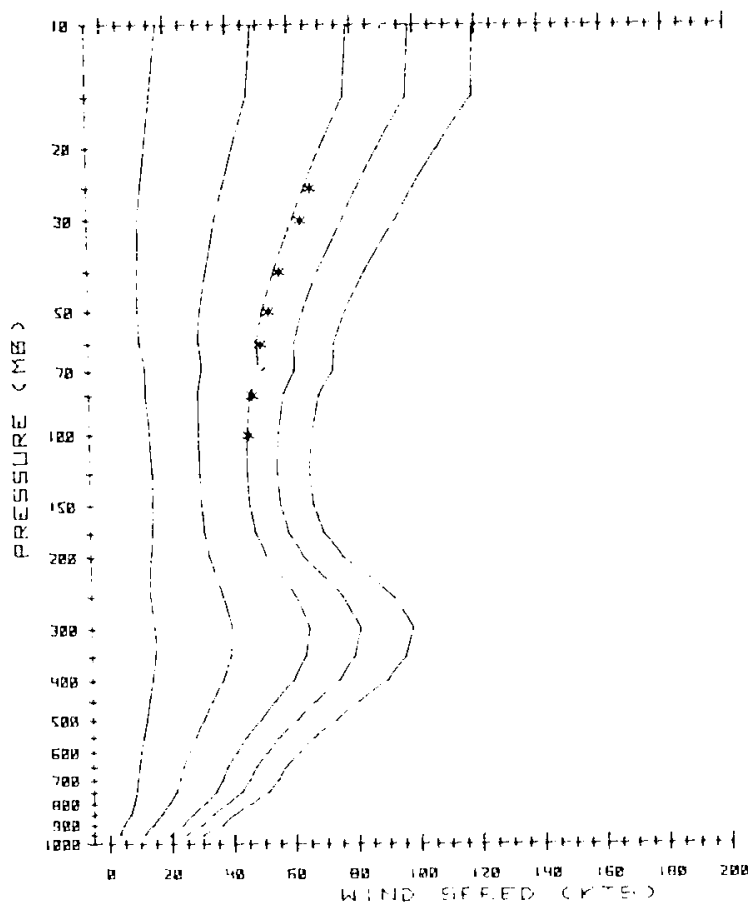

FNCHDRAGE *: BH IDLEVEL

SUMMER

10 triten

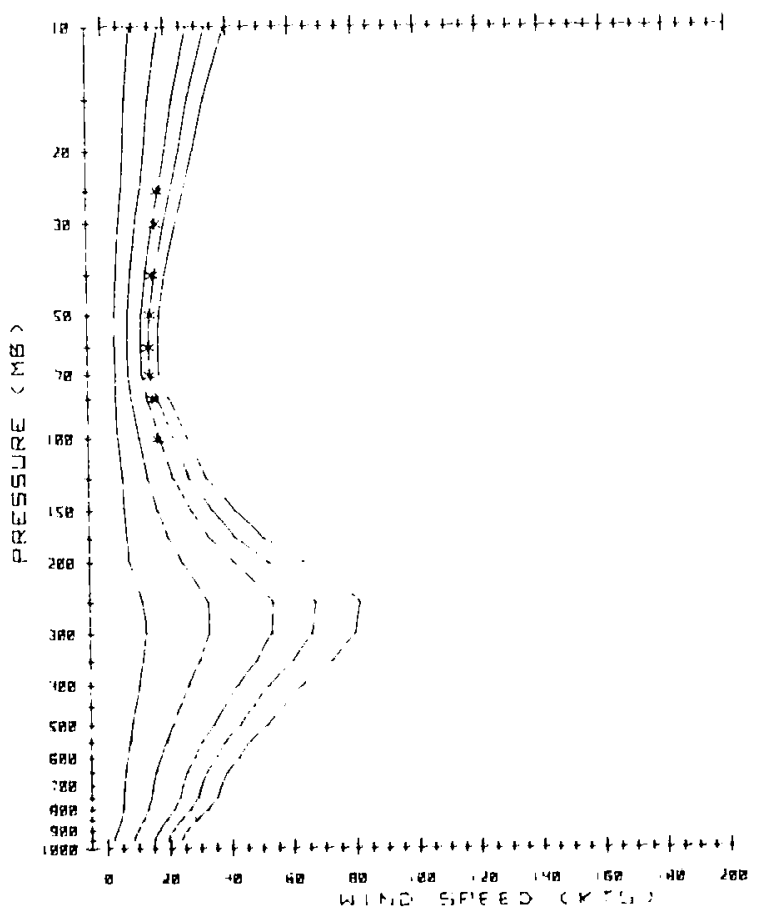

$\frac{1}{3}=\stackrel{4}{5}$ 界界

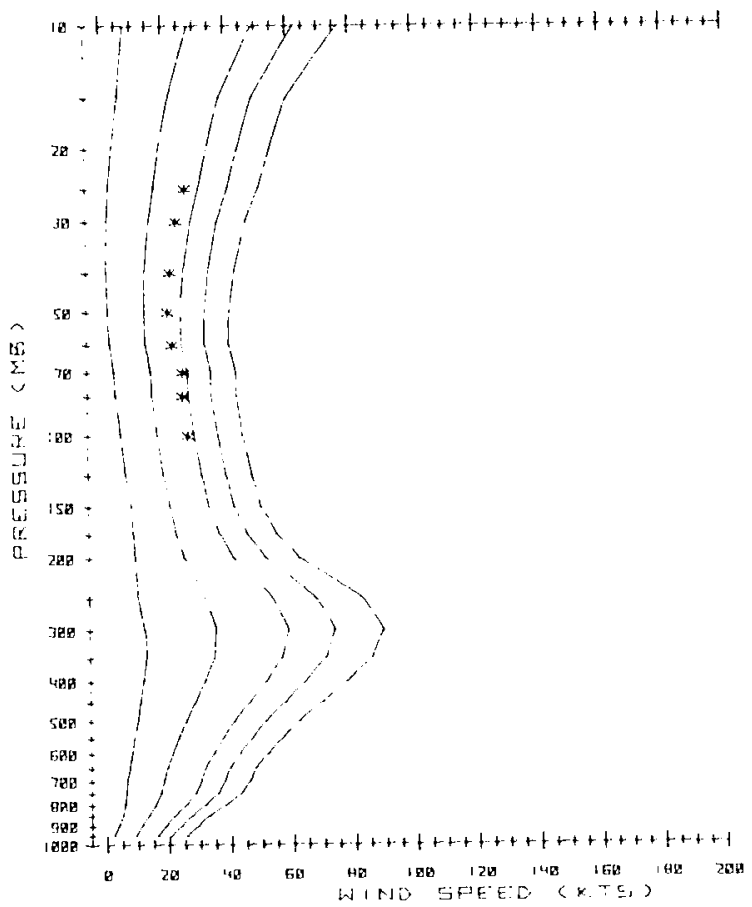

FNCHERATEE

* E 34 1\% LEVEL

FALL.

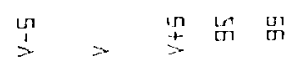

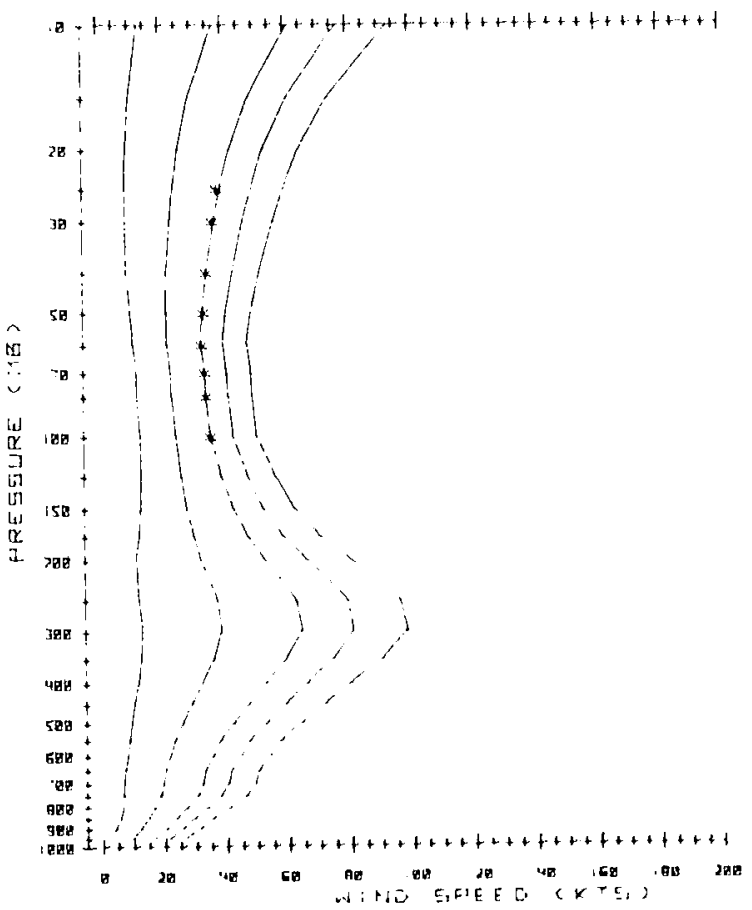




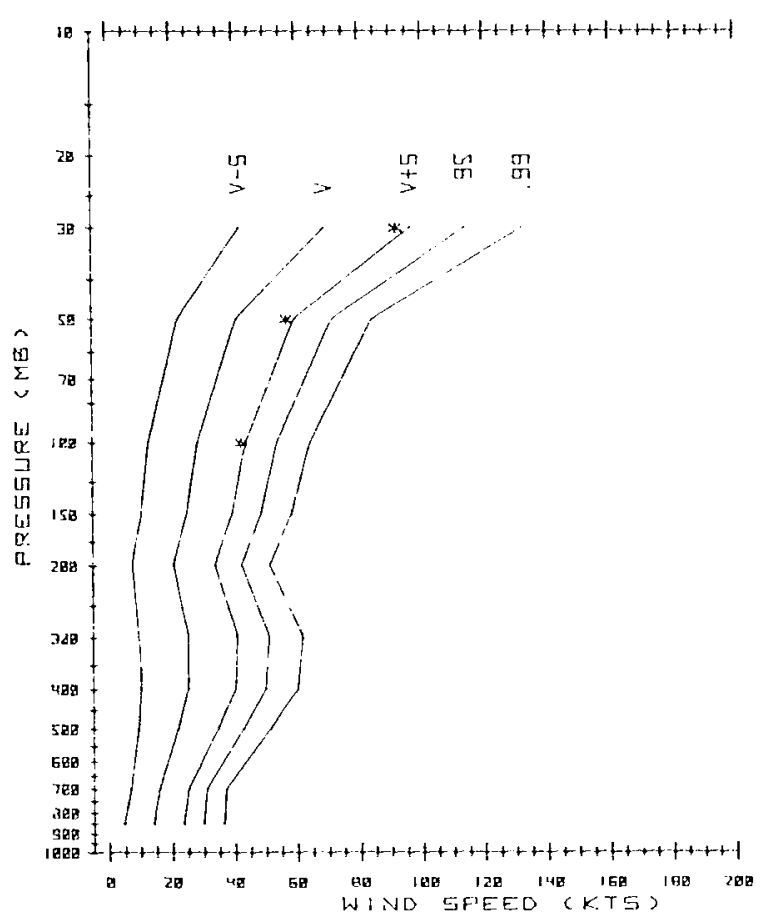

AYFN

$*=$ QU4 1\% LEVEL

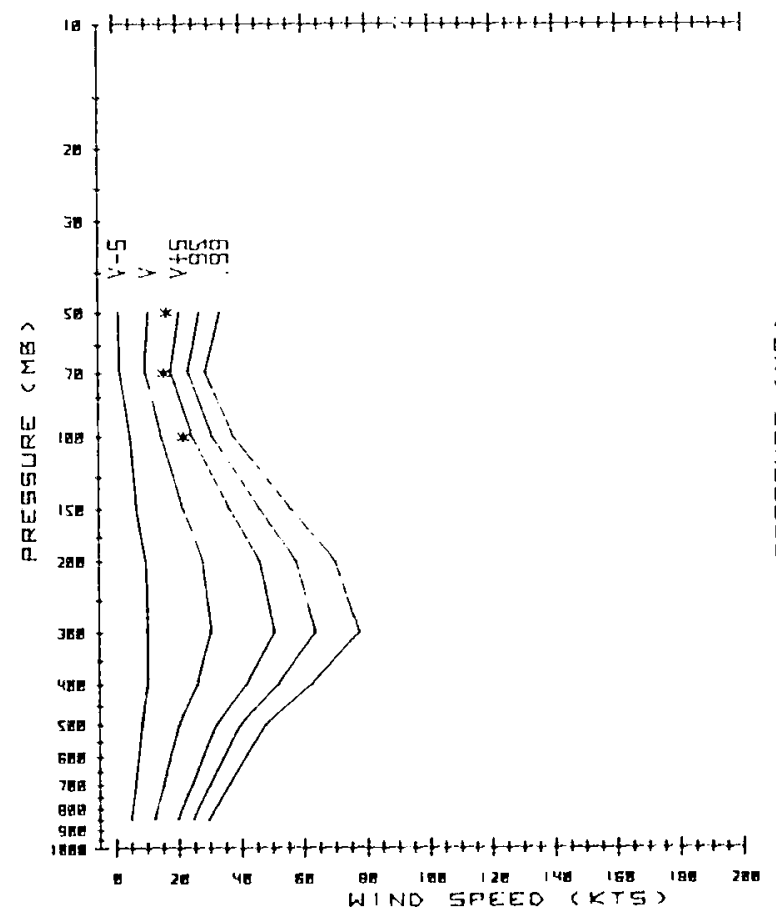

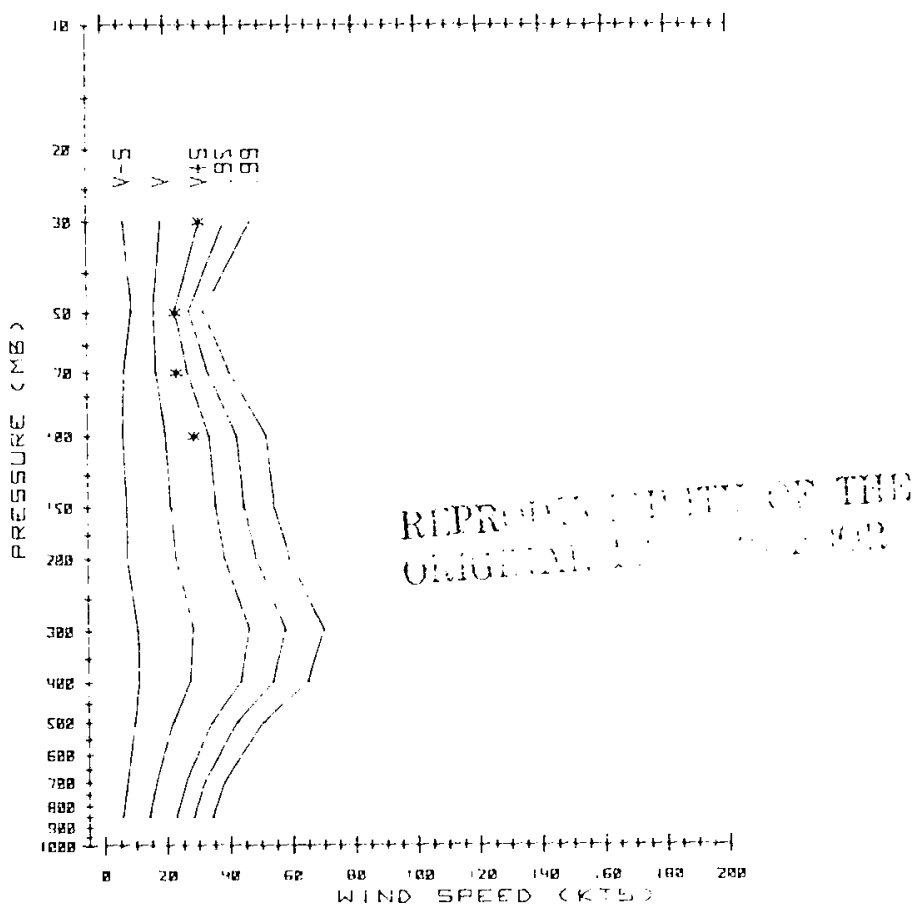

FYAN

$*=84.1 \%$ LEVEL

FRLL

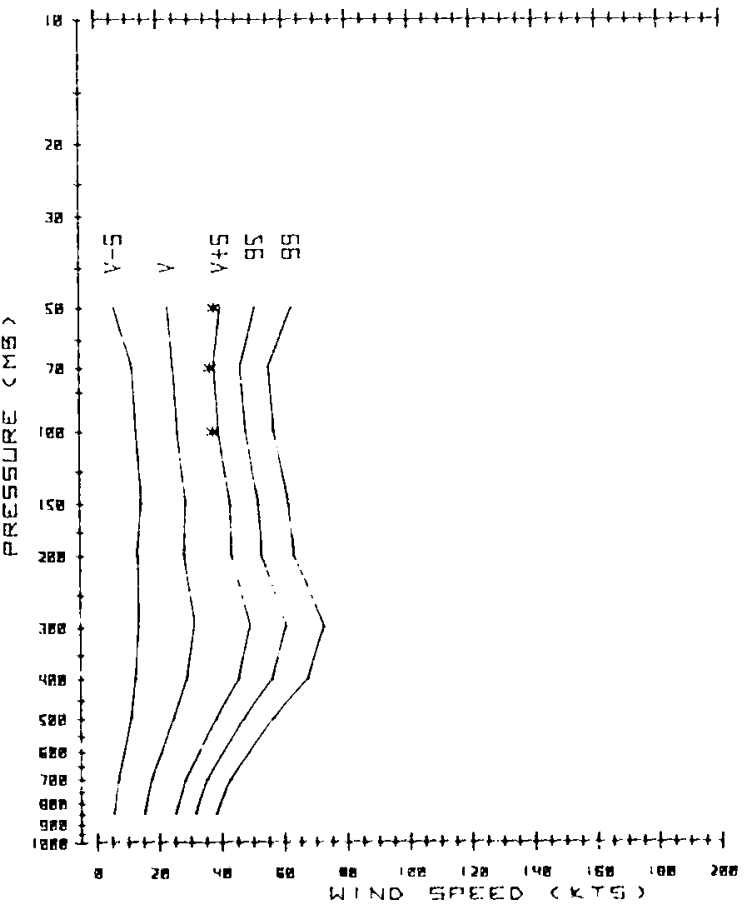


$K D R F$
$*=B^{4}, \pi, \%$ LEVEL.

WINTER

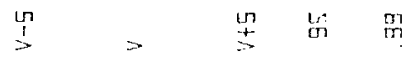

$10-1+t+t+t+1+t+1+t+1+t+t+t+1+t+t+t+1+t-t+t+t$

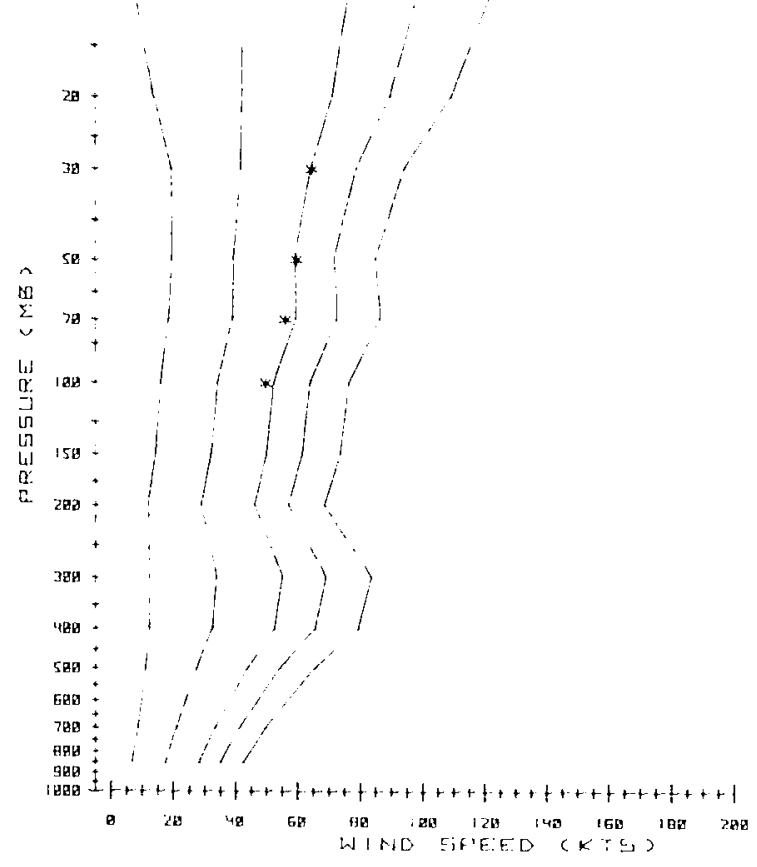

KOKF

$*=04.1 \%$ L.EVEL

SUMMER

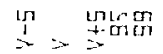

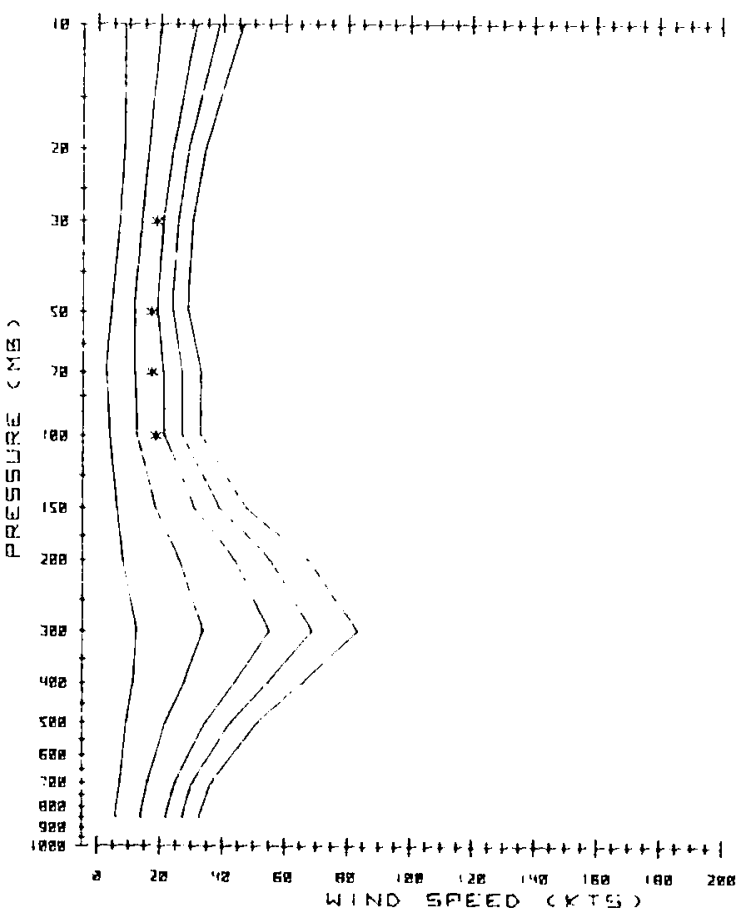

KLIRF

$*=\theta^{4} .1 \%$ LEVEL.

SPRING

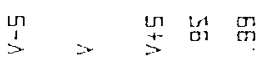

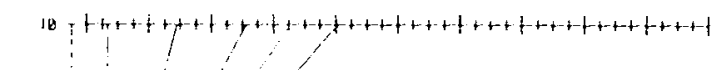

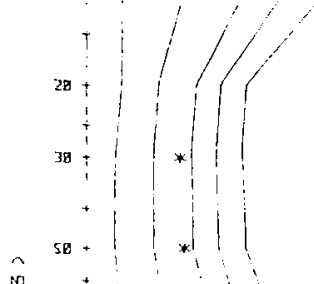

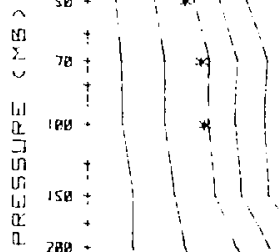

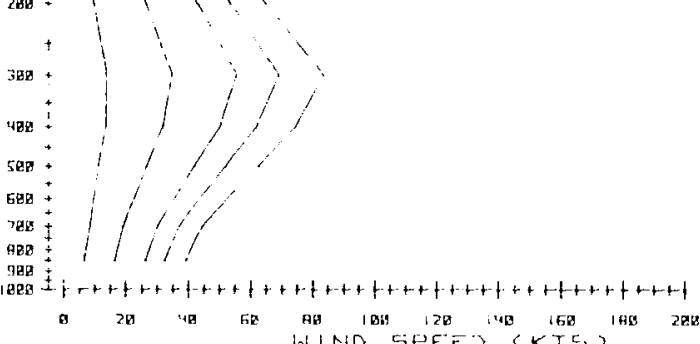

KDRF

$*=B^{4} \quad 1 \%$ LEVEL

FALL

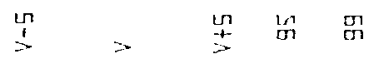

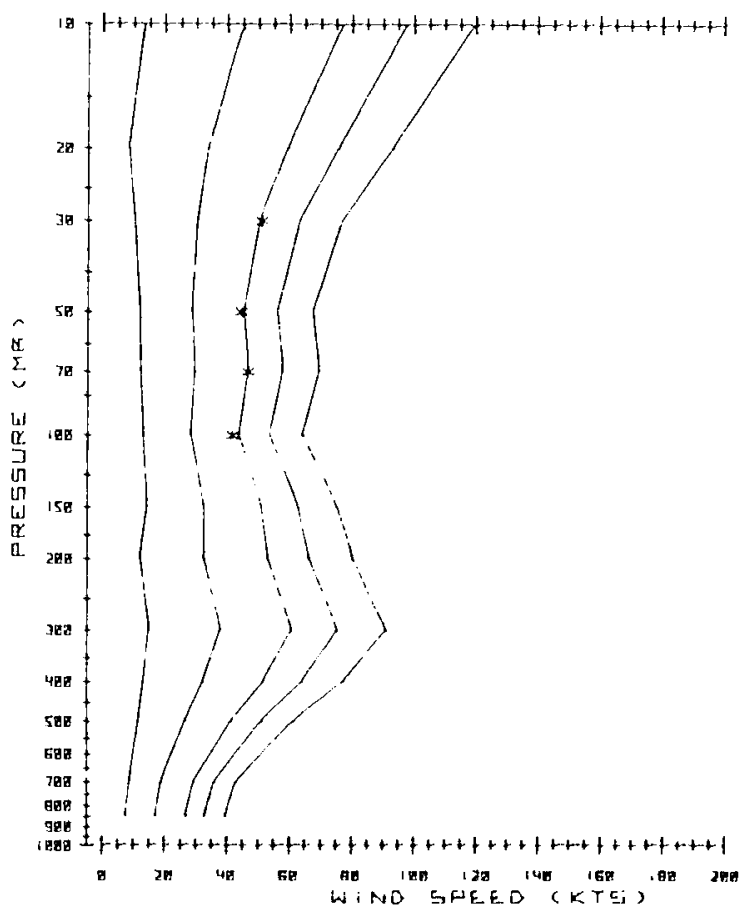



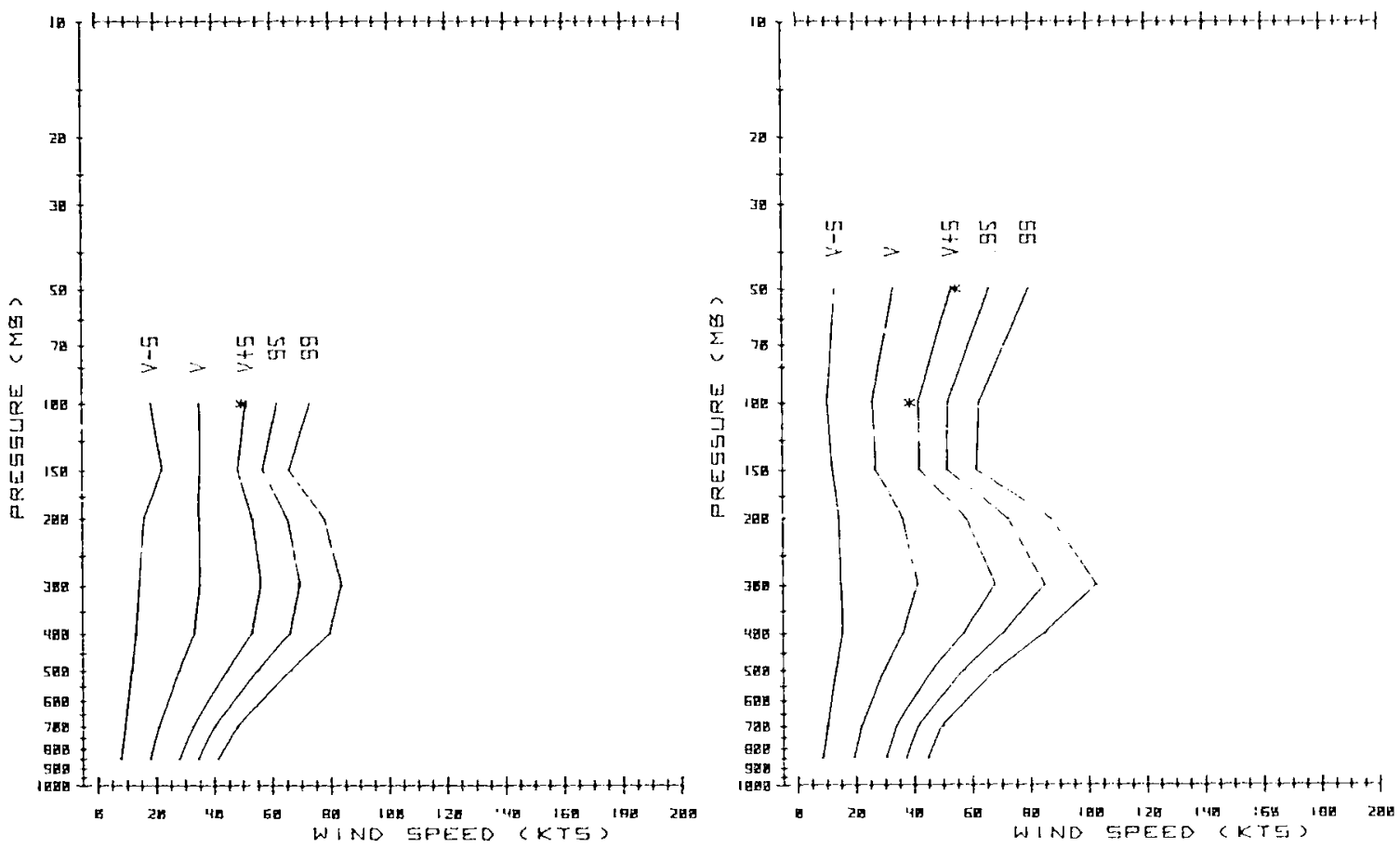

MYS, VASILYEVA $*=84.1 \%$ LEVEL

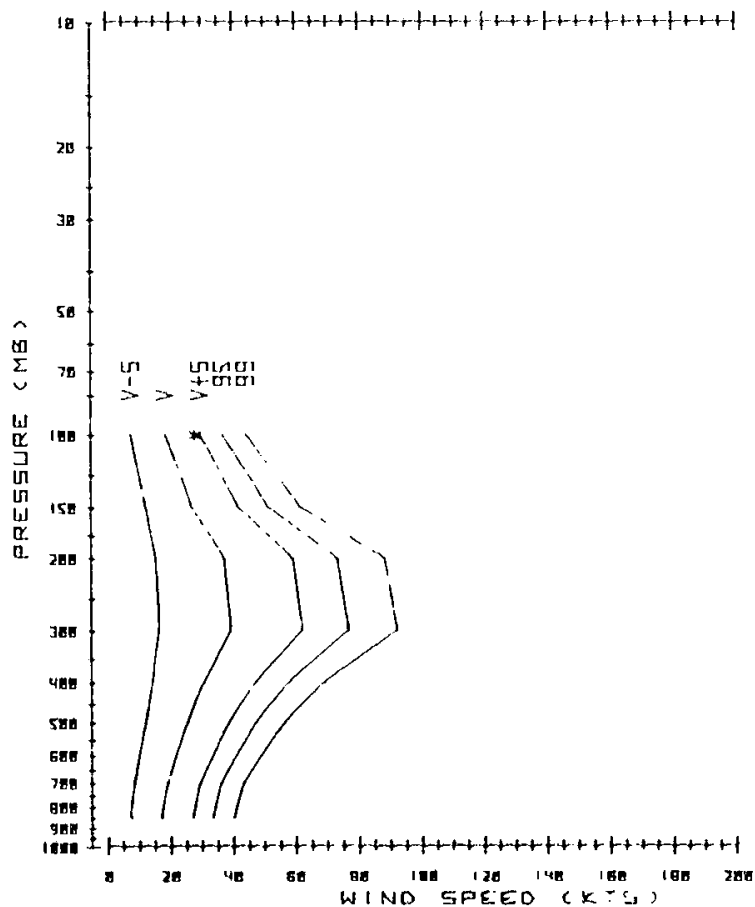

SUMMER
MYS VASILYEVH $x=841 \%$ LEVEL

FFLL

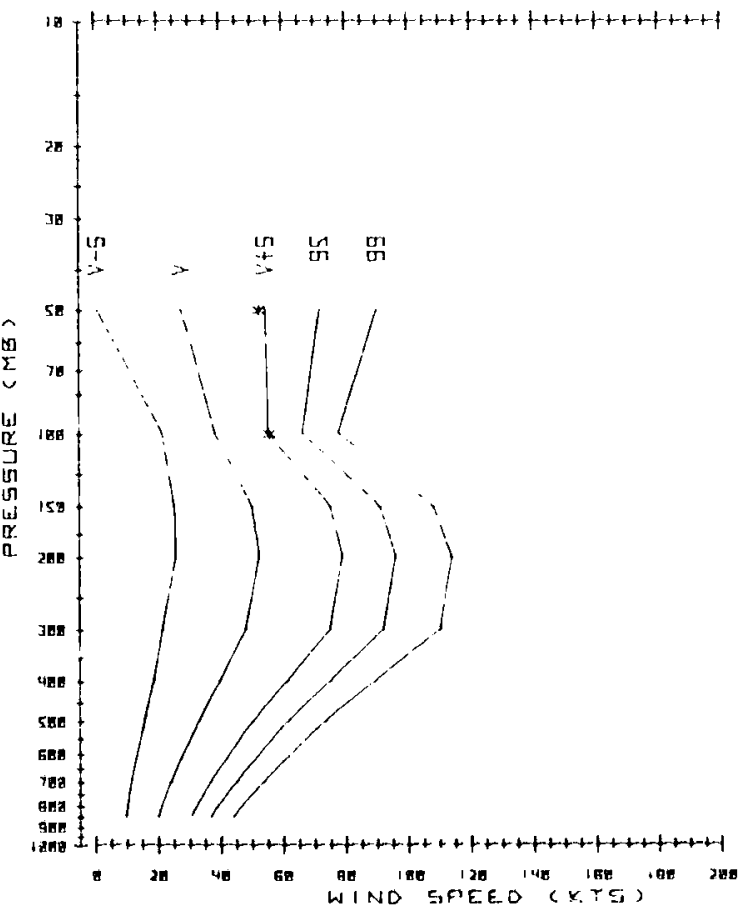


NDME

$*=U^{4}$, , \% LEVE!

WINTER

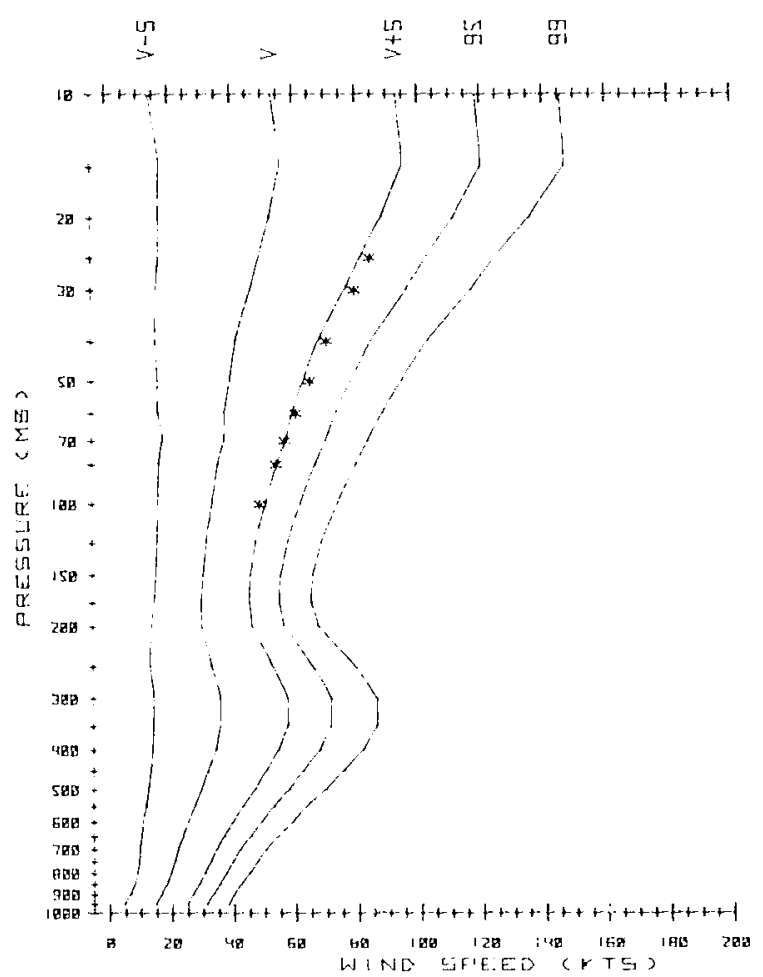

NDME
$*=B 4$ I\% LEVEL

SUMMER

$\ln _{x \rightarrow 3}^{\operatorname{tgntm}}$

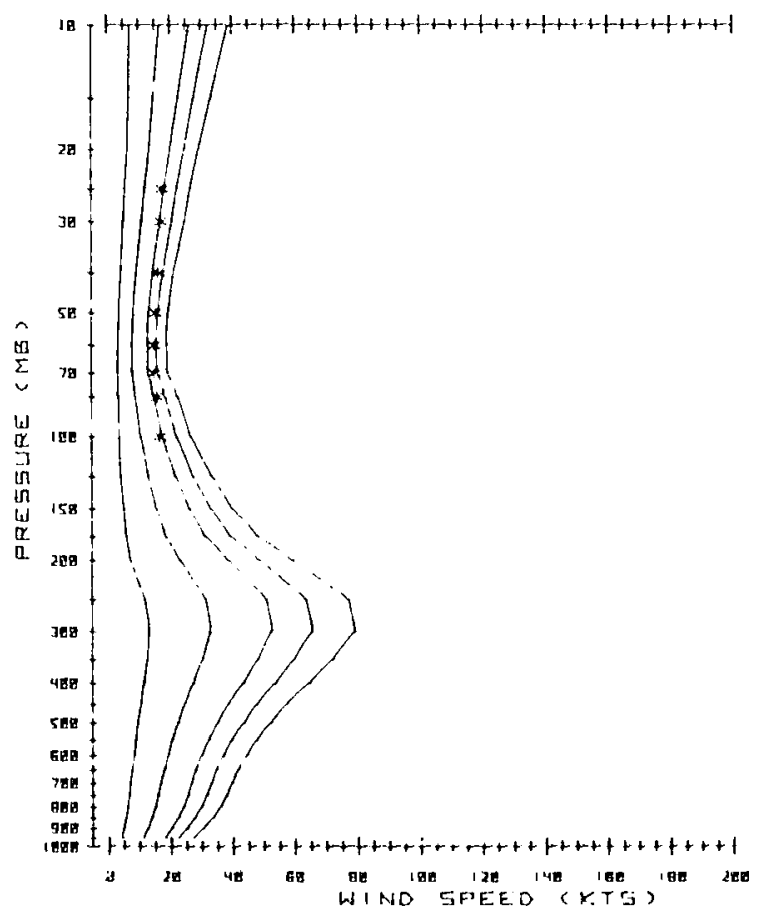

NDME

* = E4:\% LEVEL

SPR INE

$\stackrel{4}{\rightarrow} \quad \stackrel{4}{ \pm}$ 量

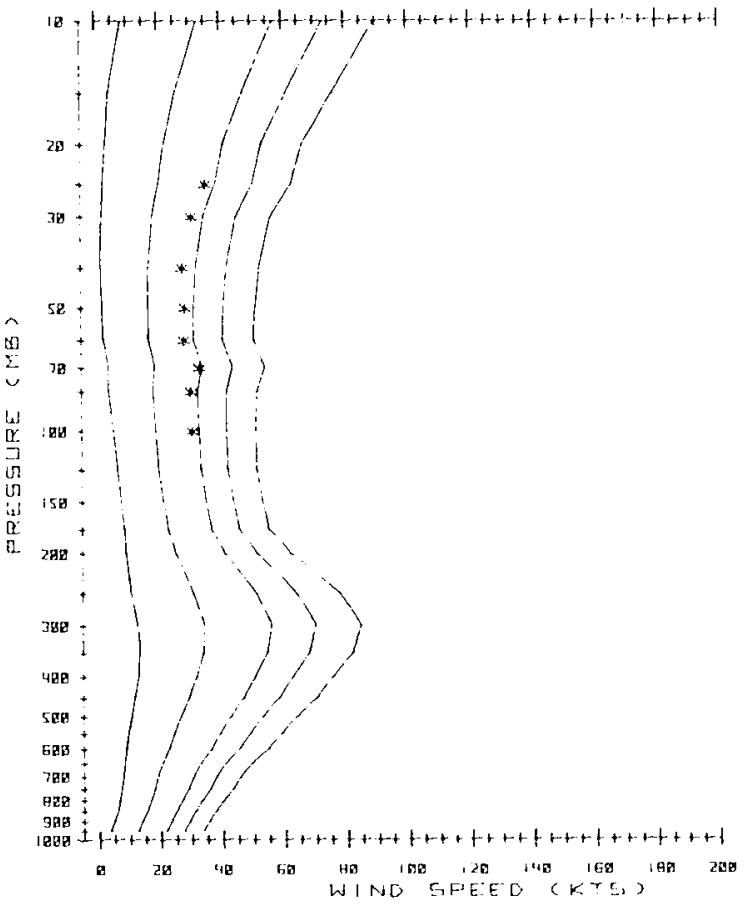

NDME

$*=$ G4 1\% LEVEL

FALL

$\stackrel{4}{>}=\stackrel{4}{\rightarrow}$ 湈

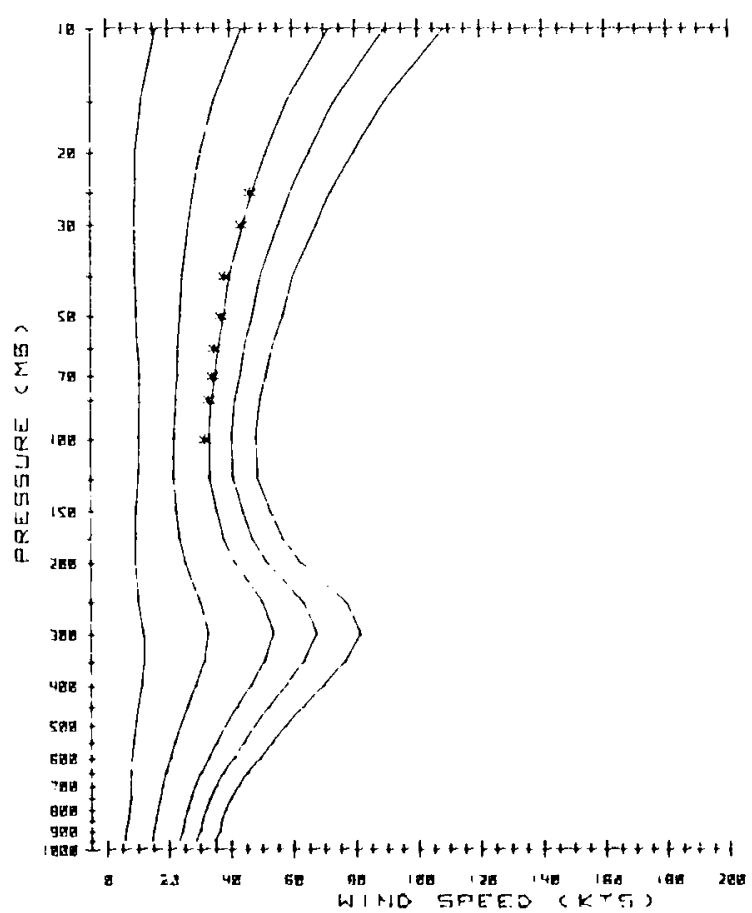



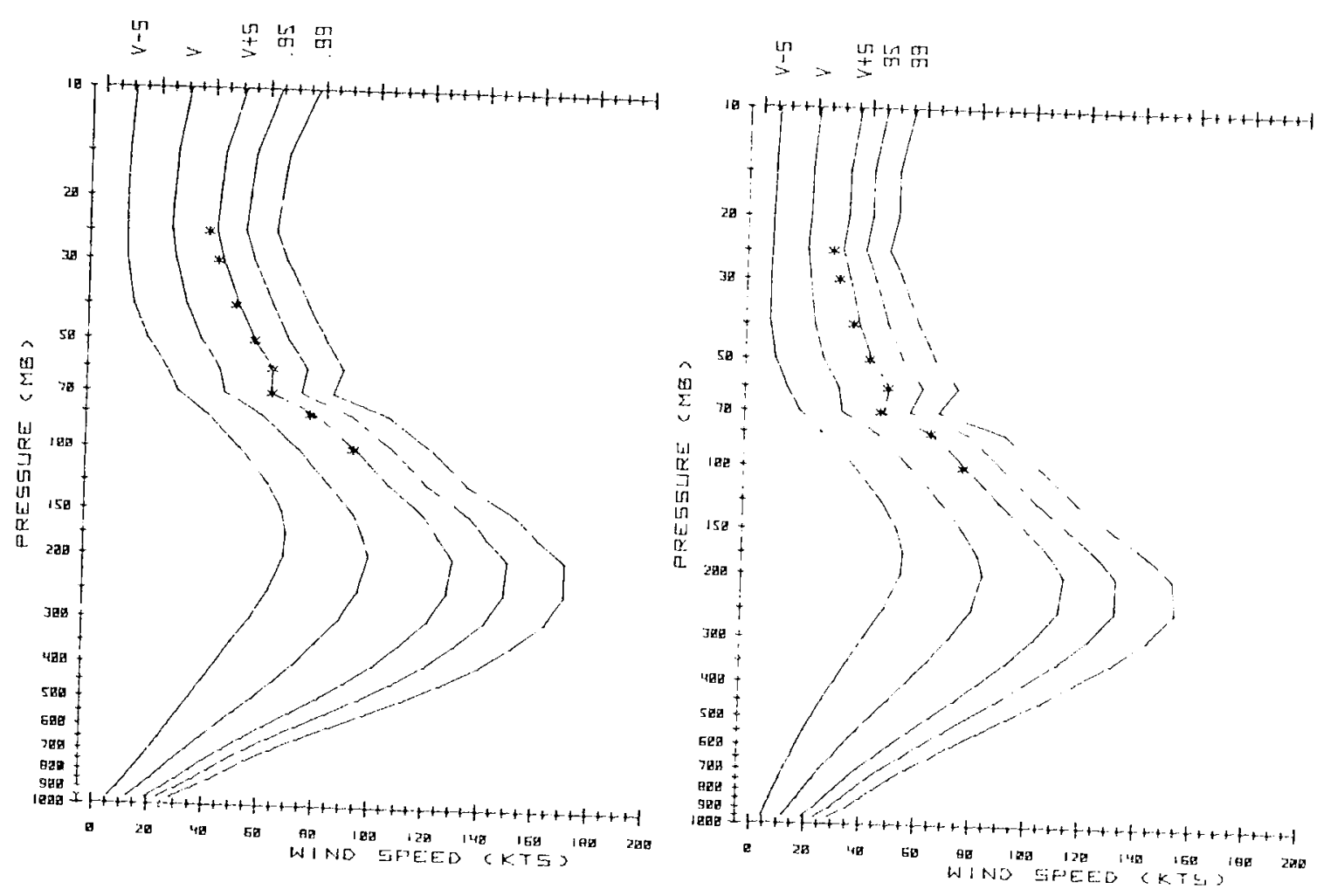

DSFN

*-= EU. 1\% LEVEL

SUMMER

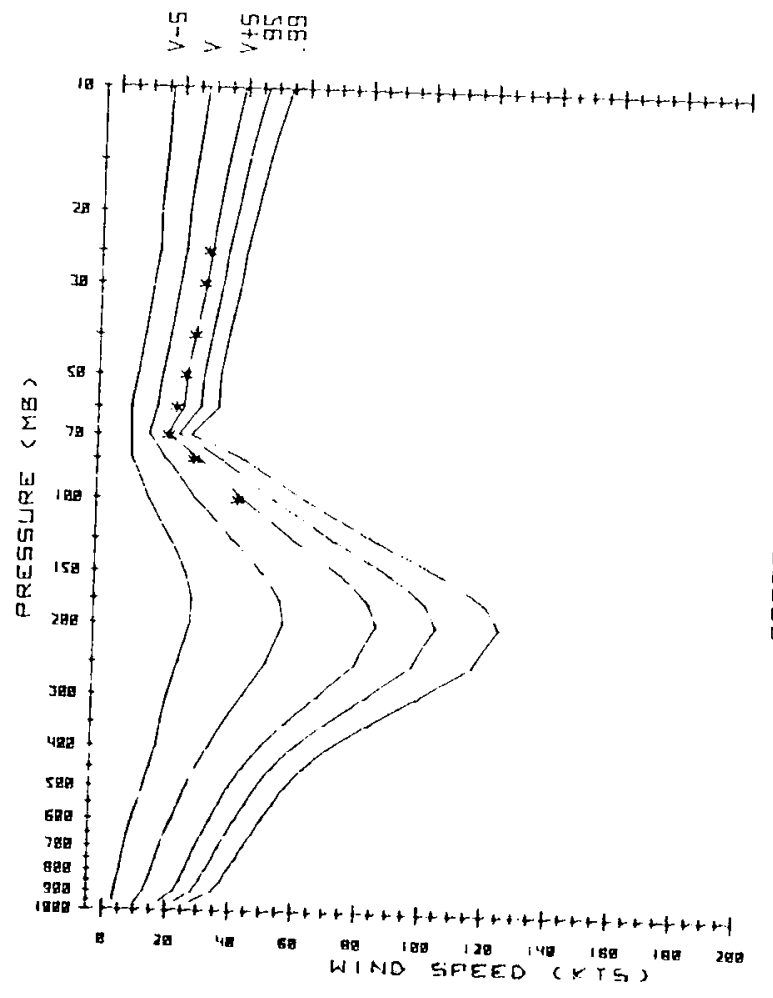

प5HN

$*=H 4 .: \%$ LEVEL

FFL.

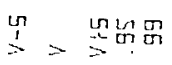

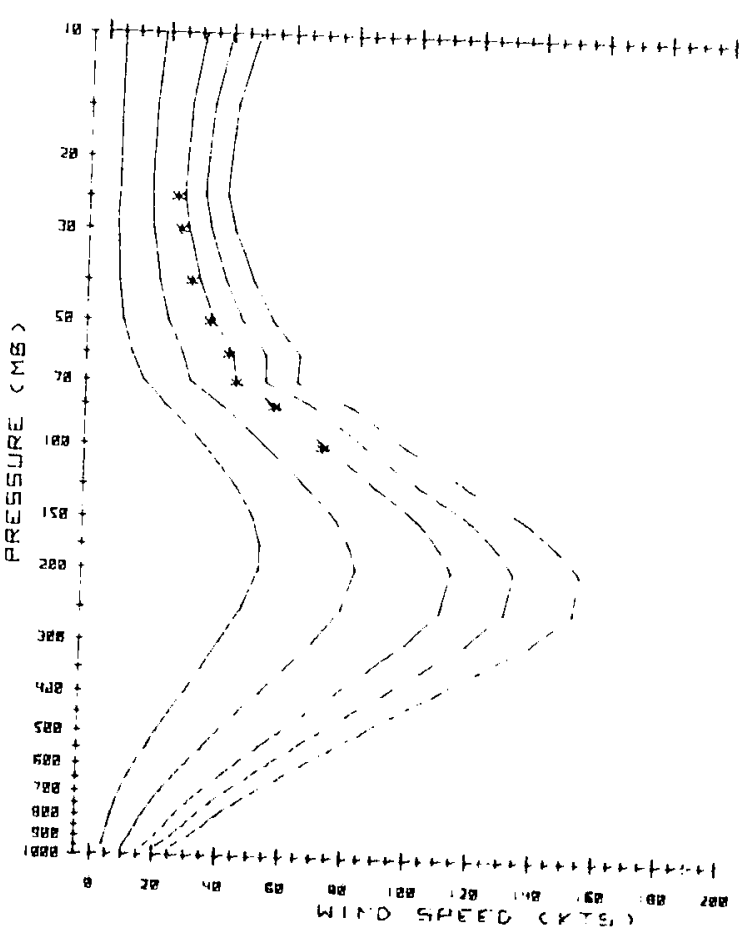



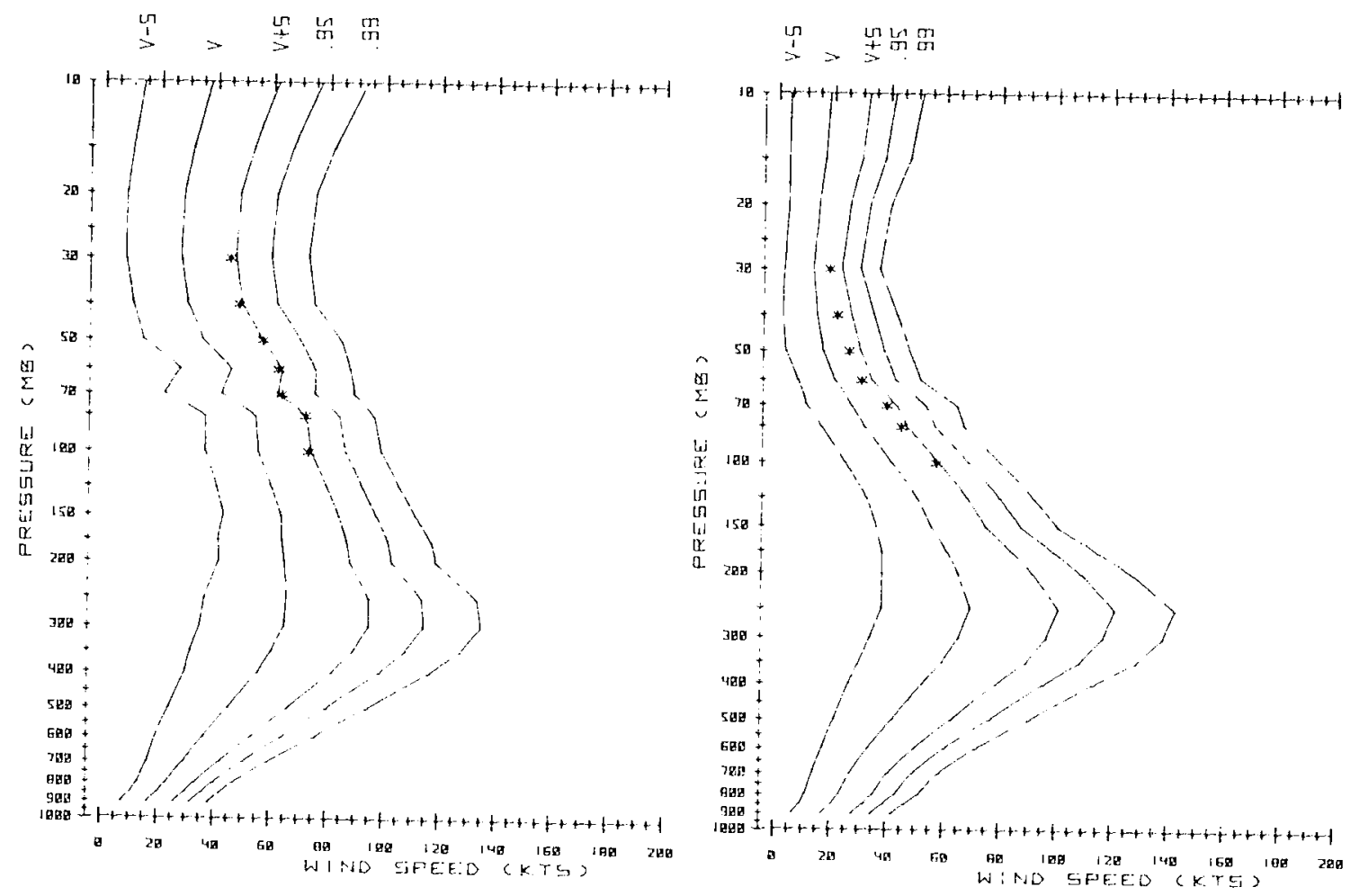

SHPPIRD

* $H^{4}$ i $\%$ LEVEL

SLMMER

5APPCRE

$*=G_{4}$ i\% LEVEL

FALL

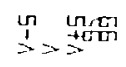

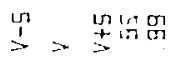
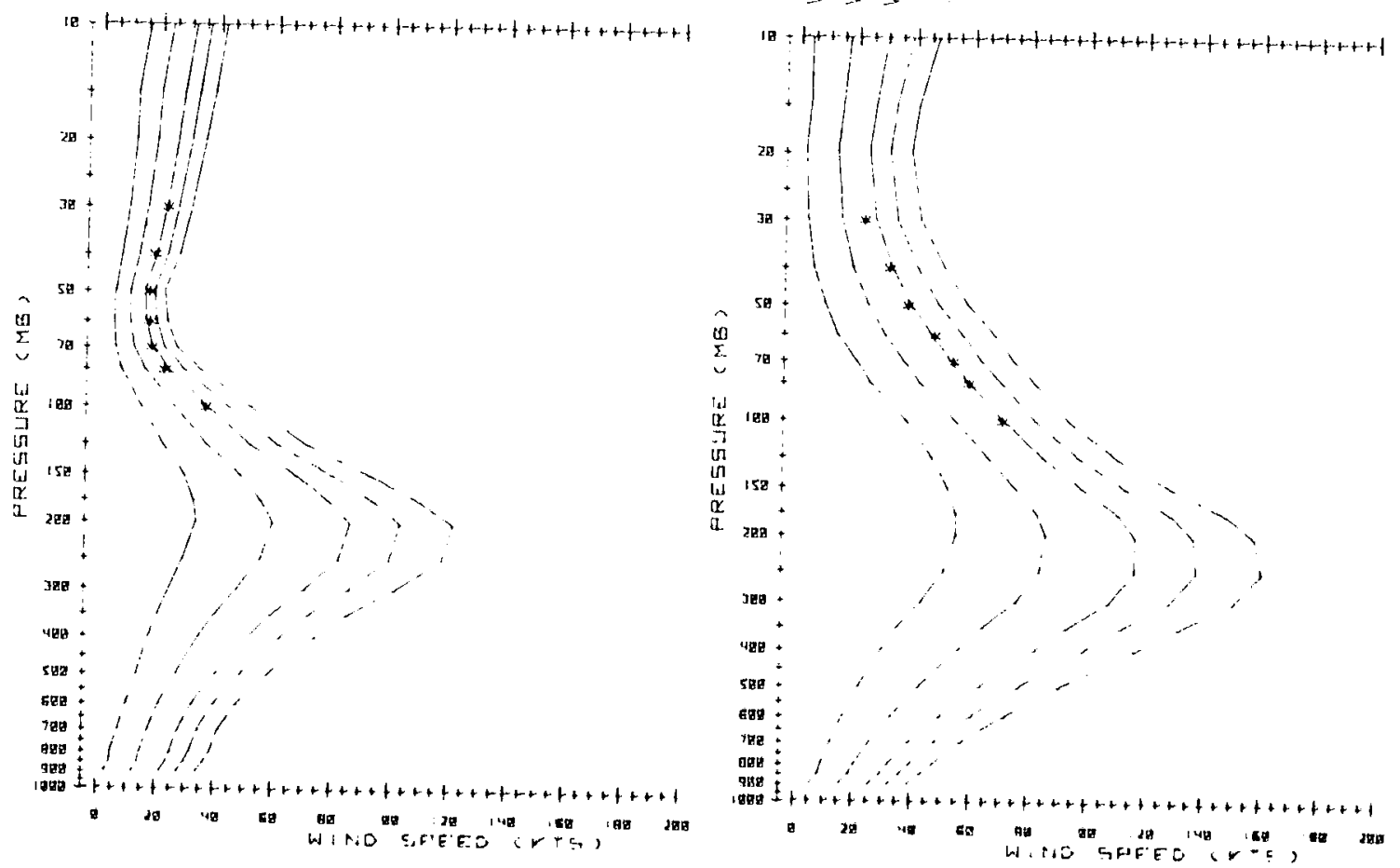


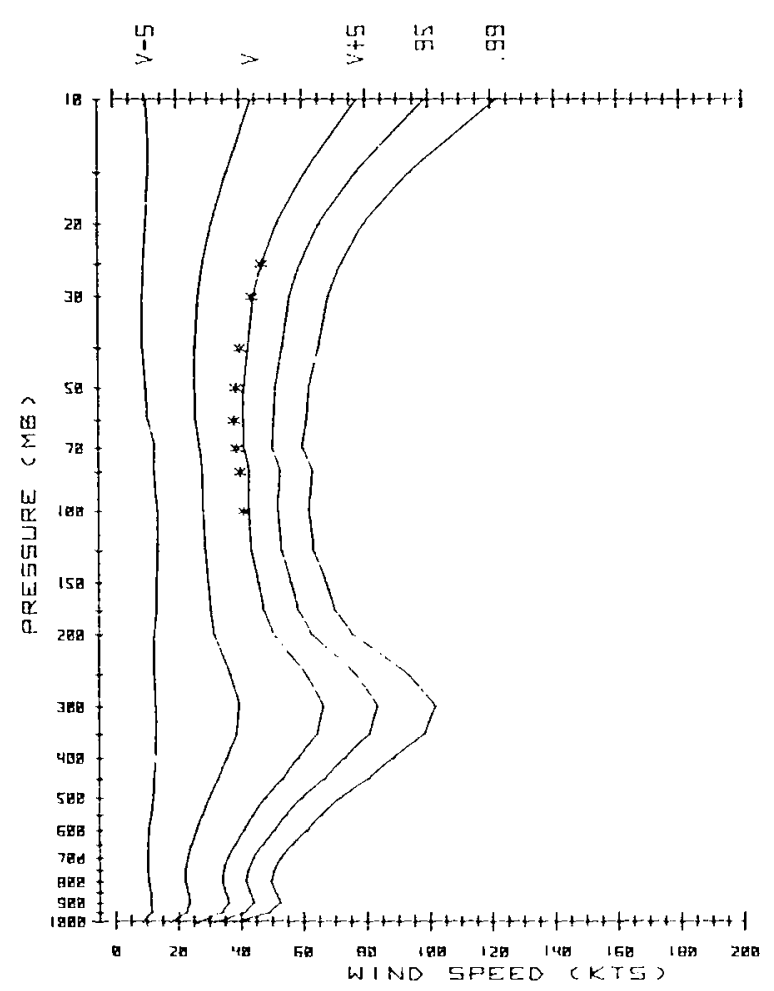

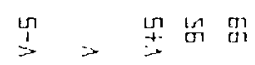

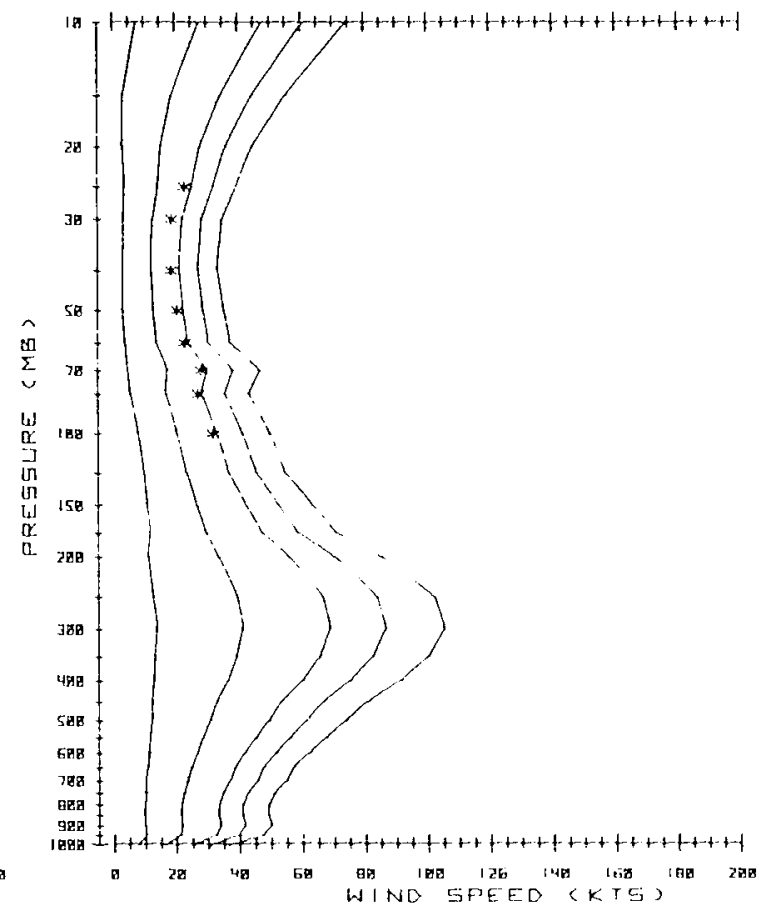

SHEMYA

* EH. 1\% LEVEL

SUMMER

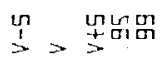

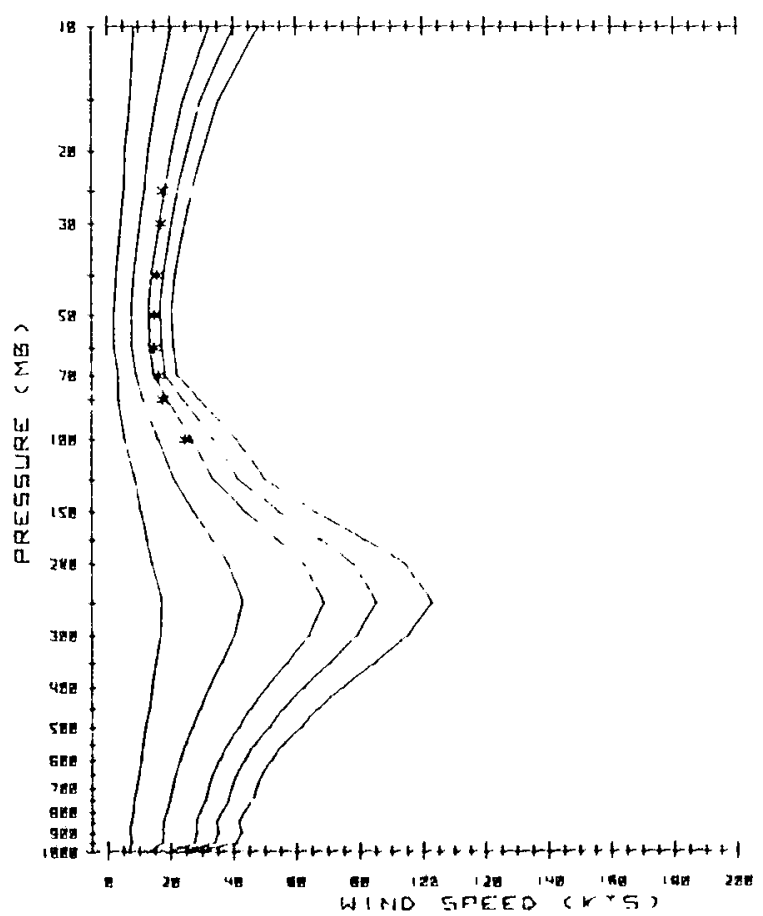

SHEMYA

$*=B^{4} 1 \%$ LEVEL

FALL

$\stackrel{10}{\rightarrow}>\stackrel{4}{\rightarrow} \stackrel{\ln m}{\mathrm{~m}}$

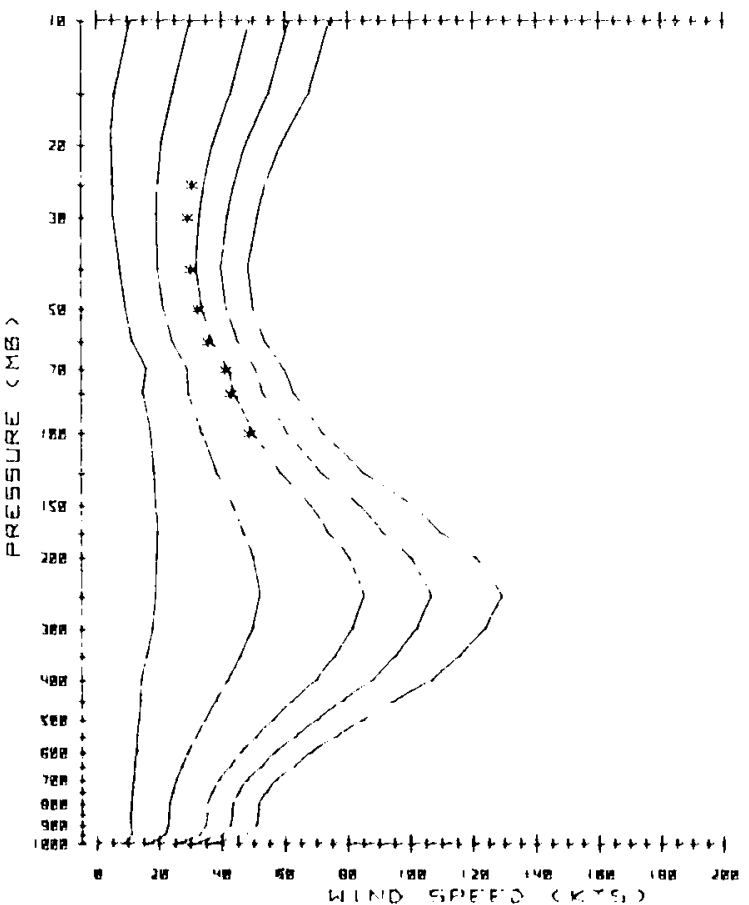



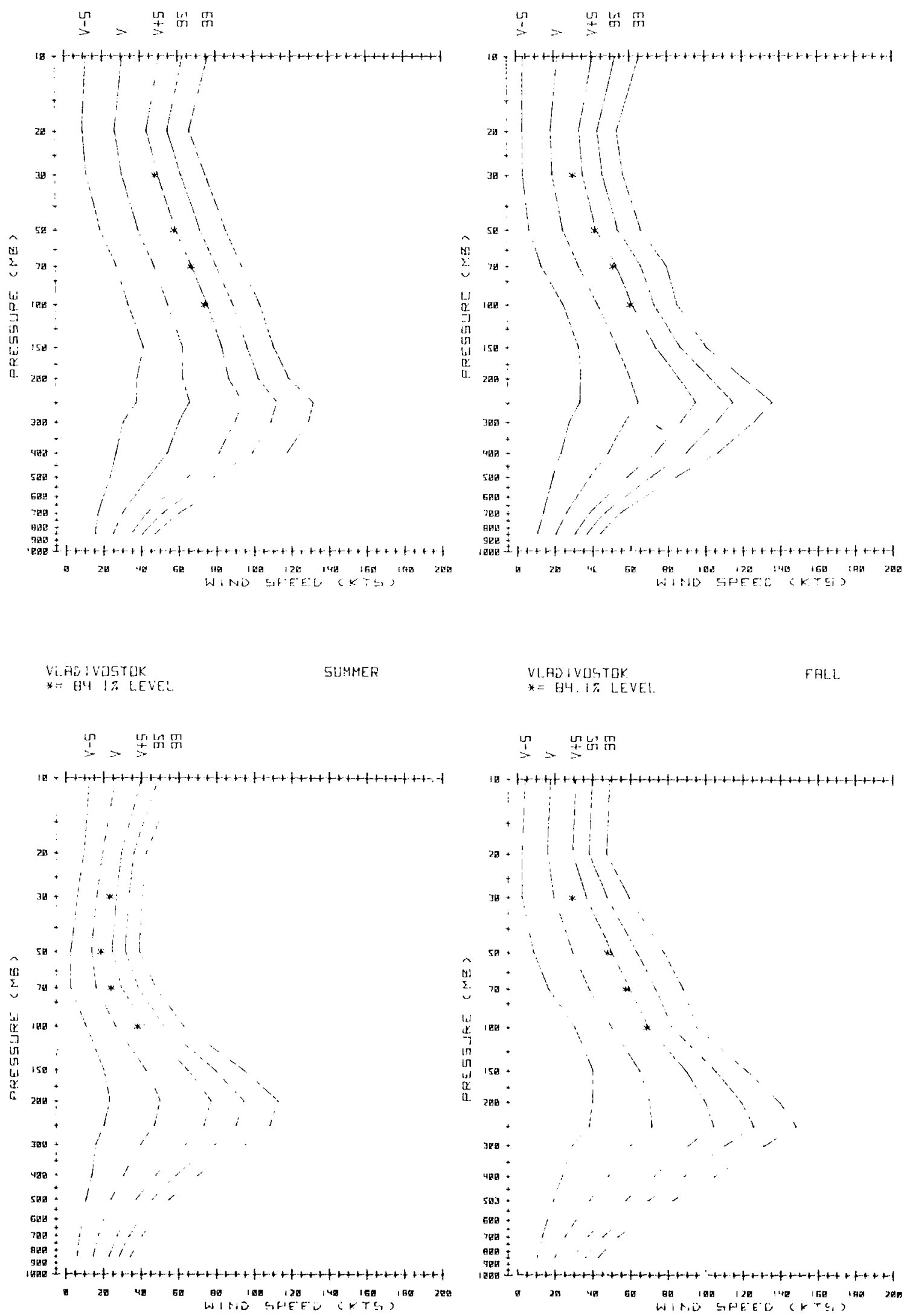
$\stackrel{1}{\rightarrow}>\stackrel{\oiiint}{\lessgtr}$ 台

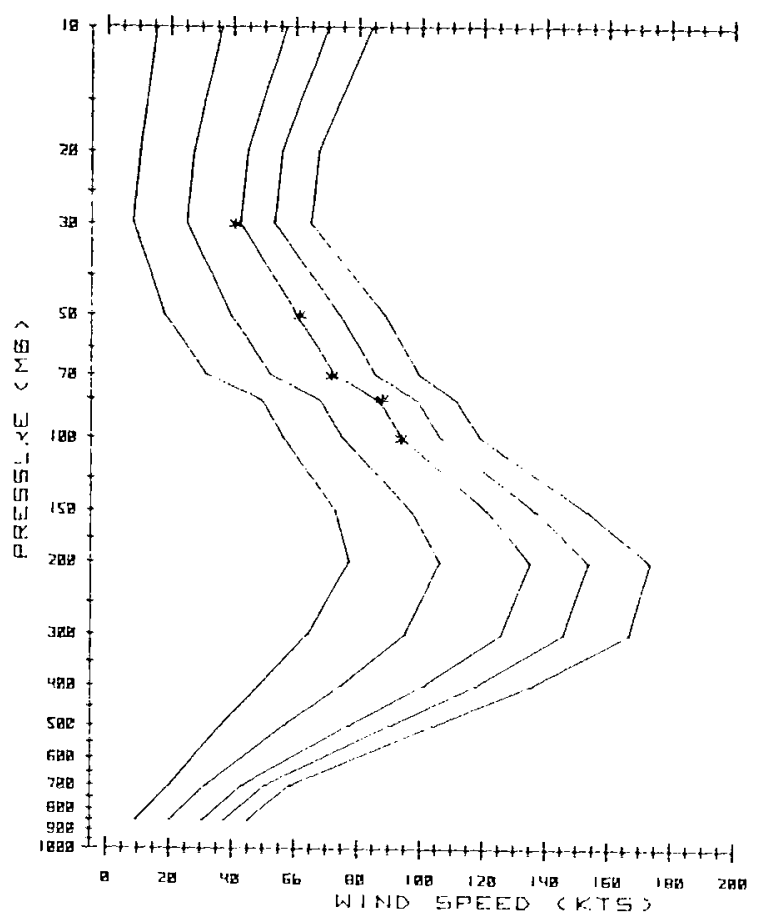

WhU!MA

* $-84.1 \%$ LEVEL

SUMMER

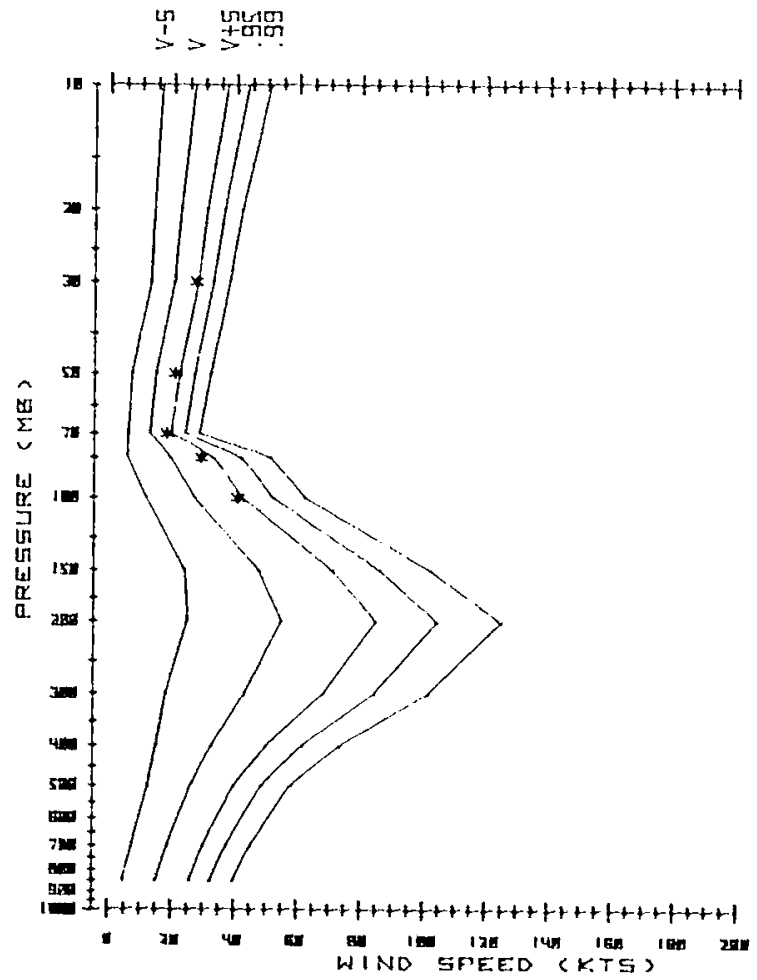

$\stackrel{4}{>}>\stackrel{40 \pi}{ \pm 00}$

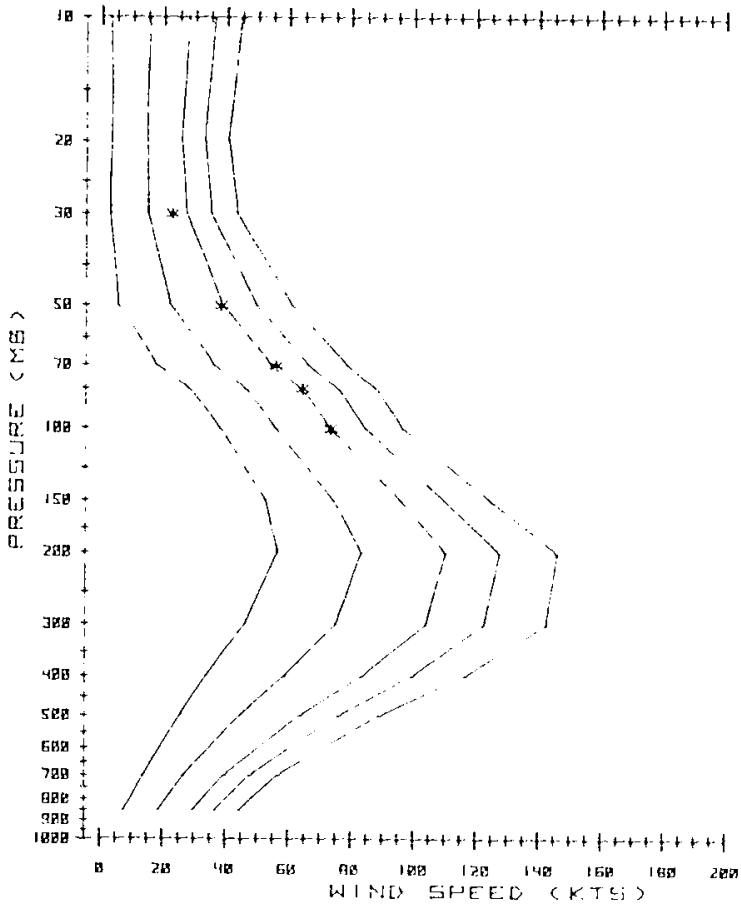

WHSIMA

* $=34$. 1\% L.EVEL

FHLL

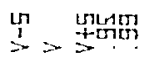

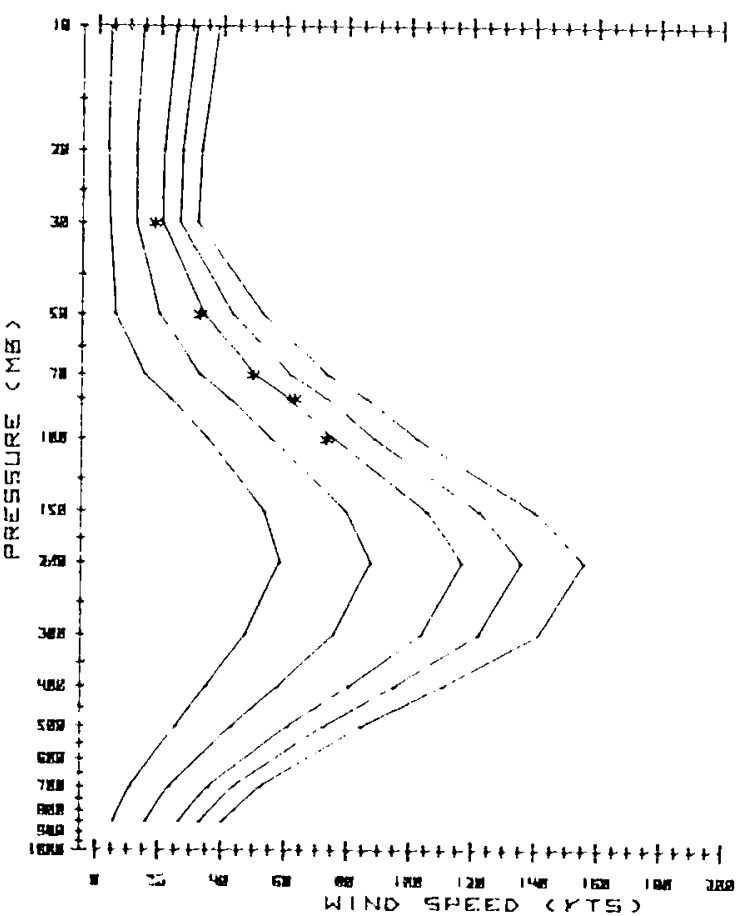



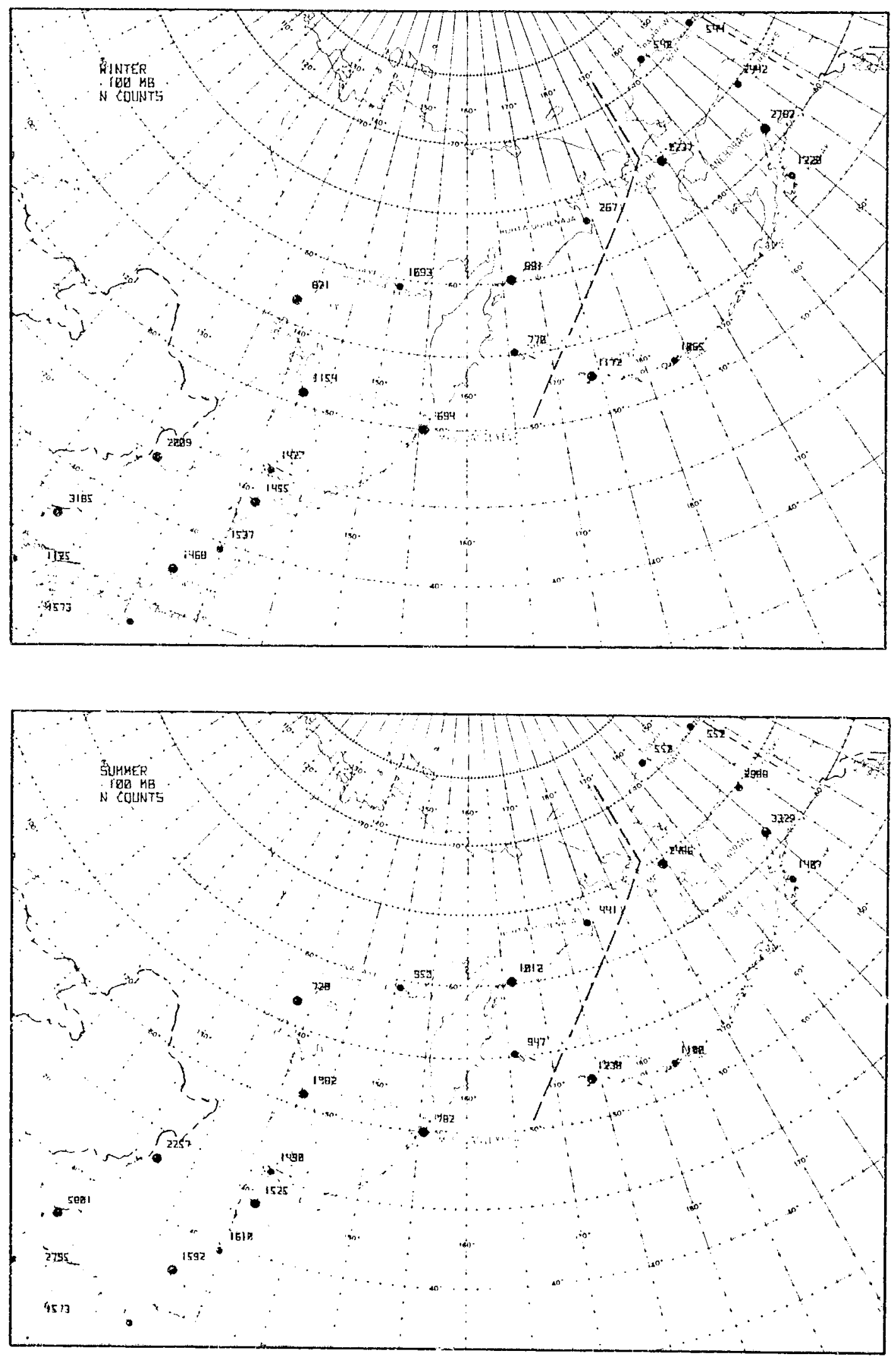

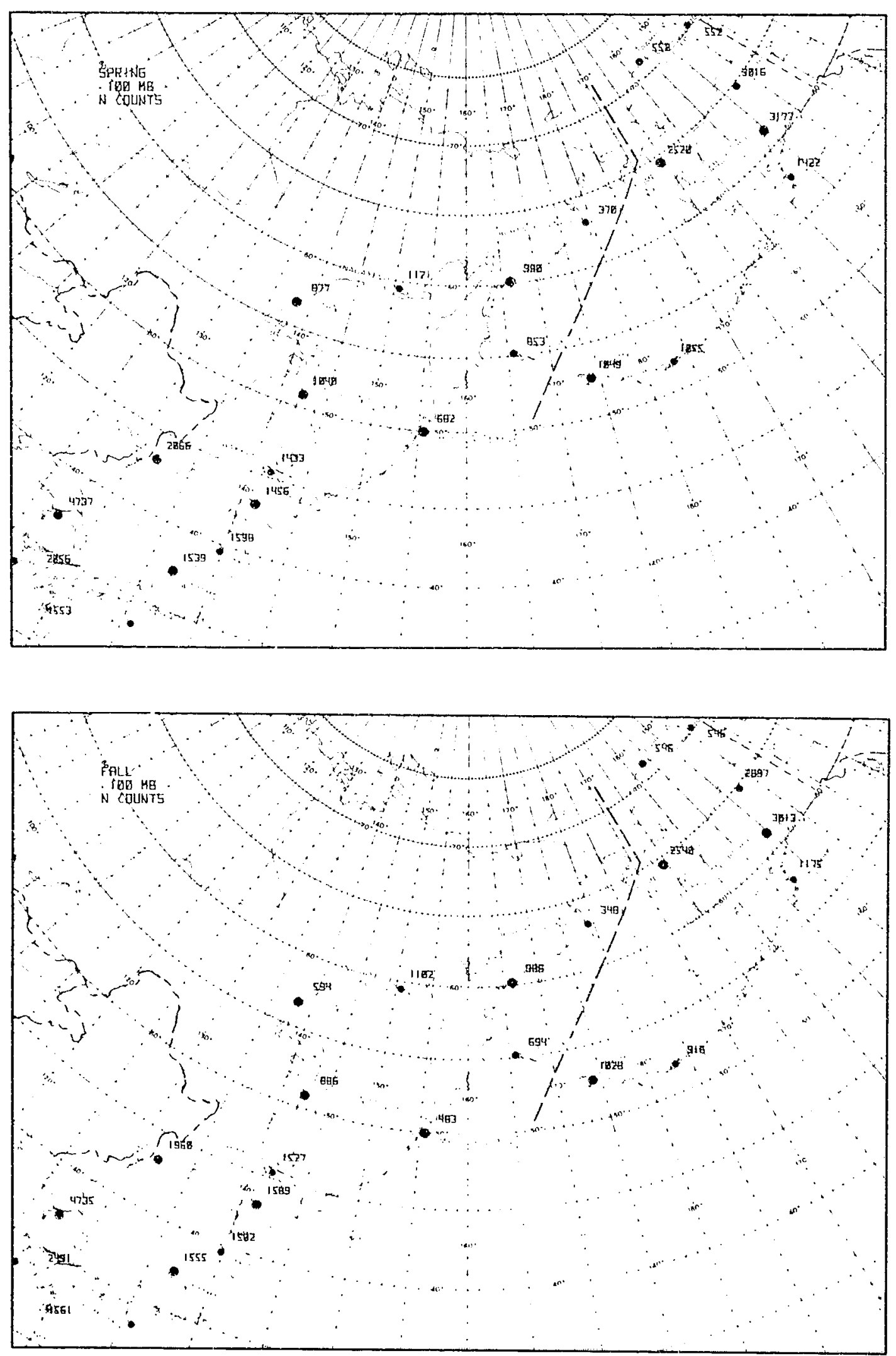

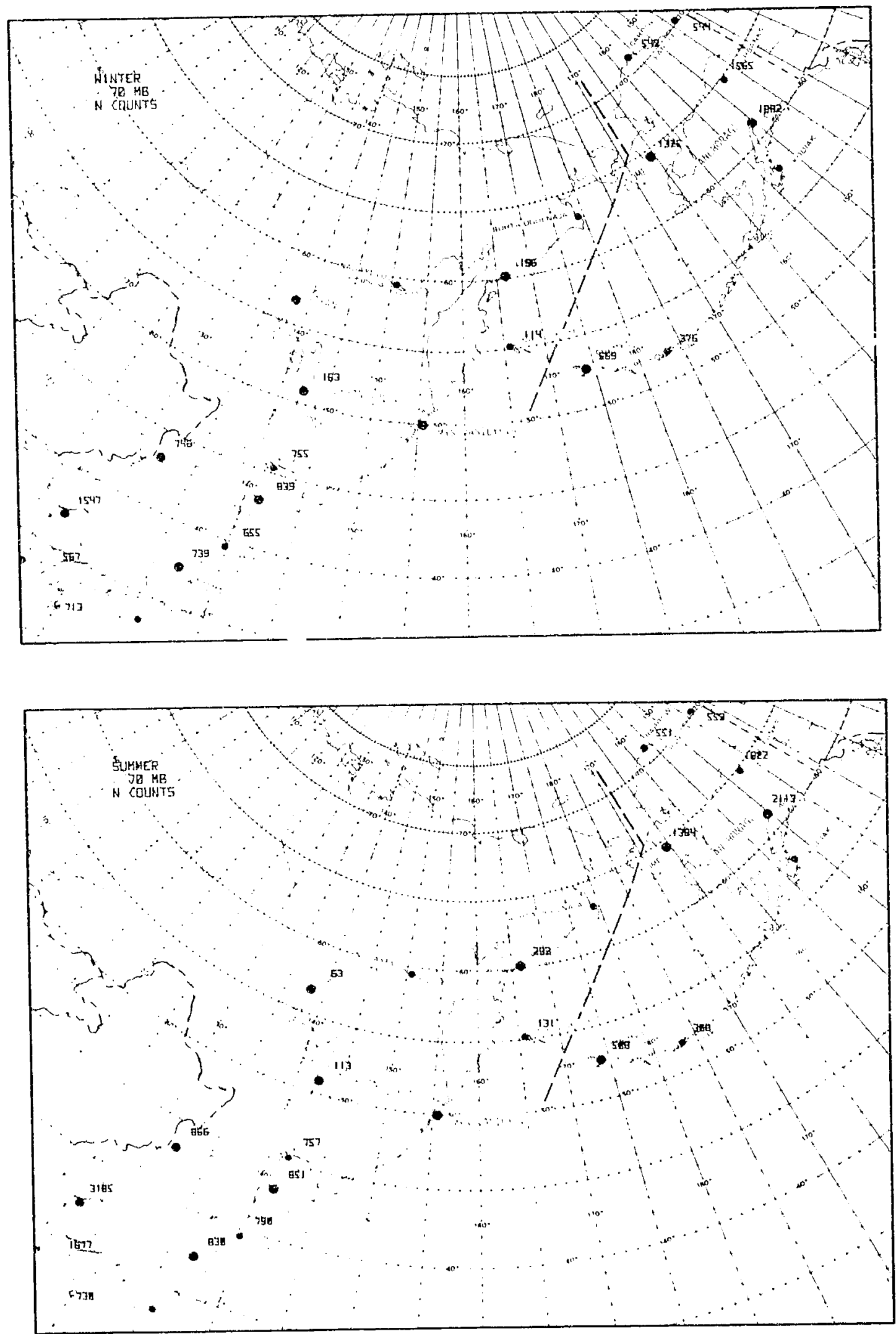

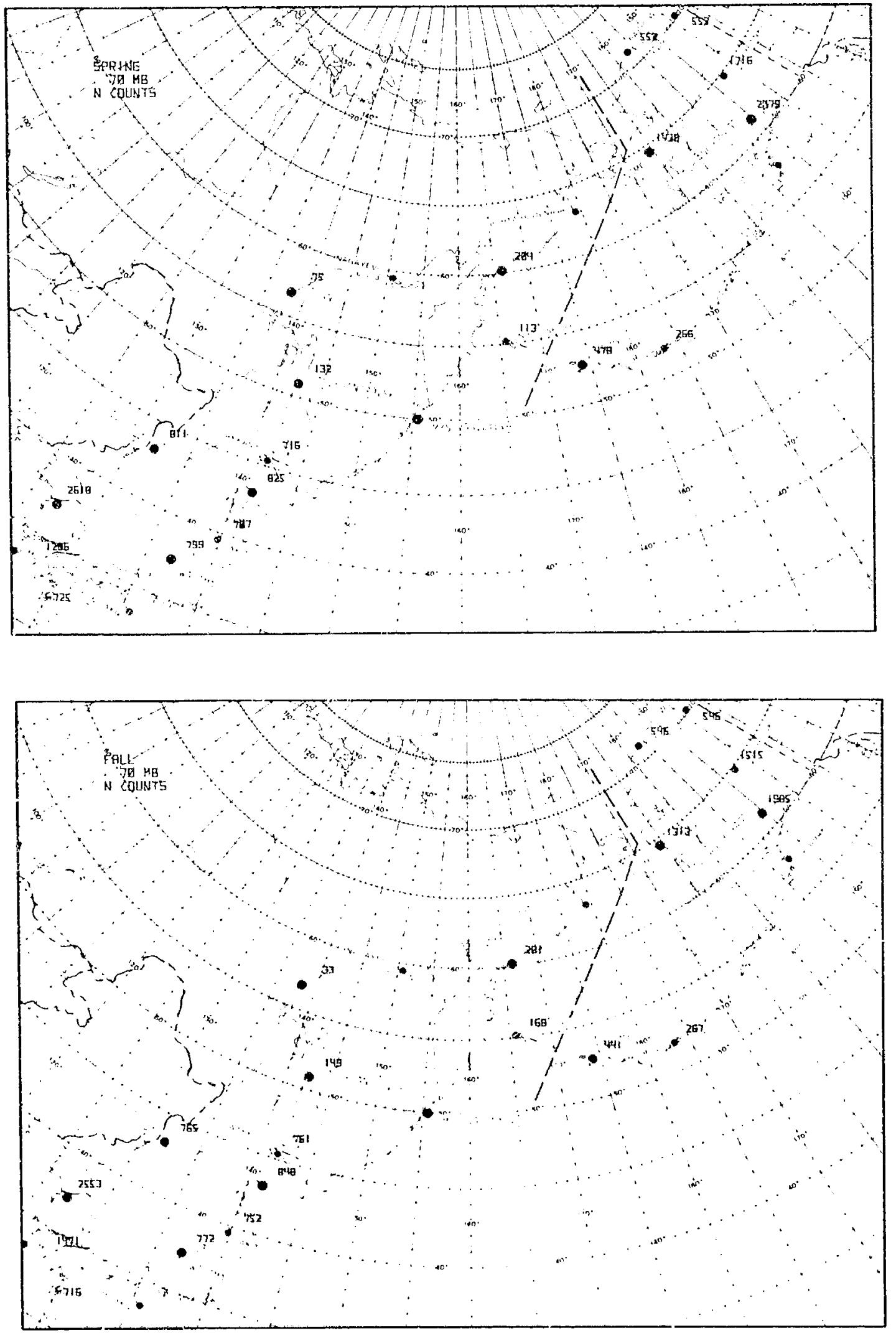

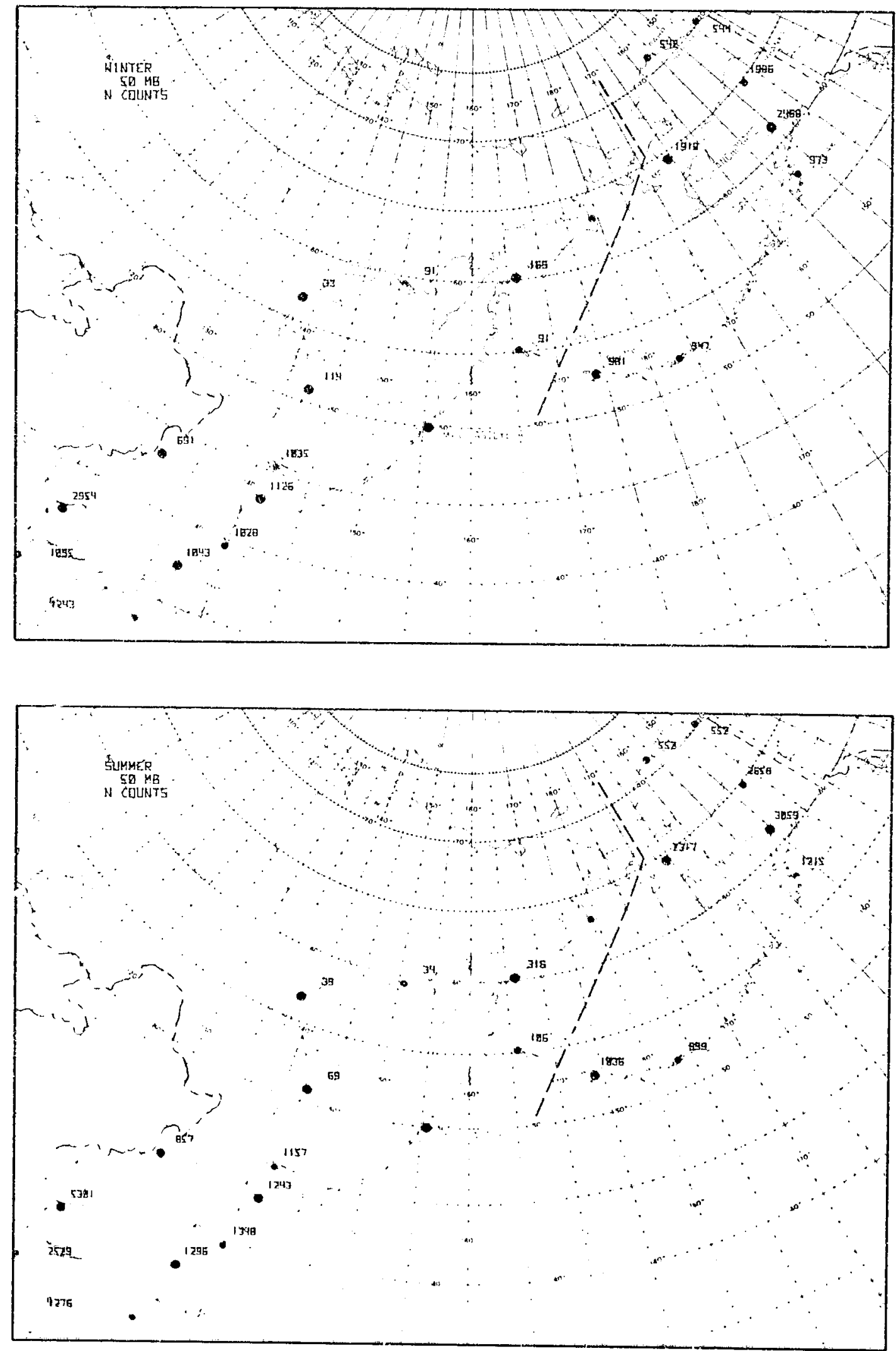

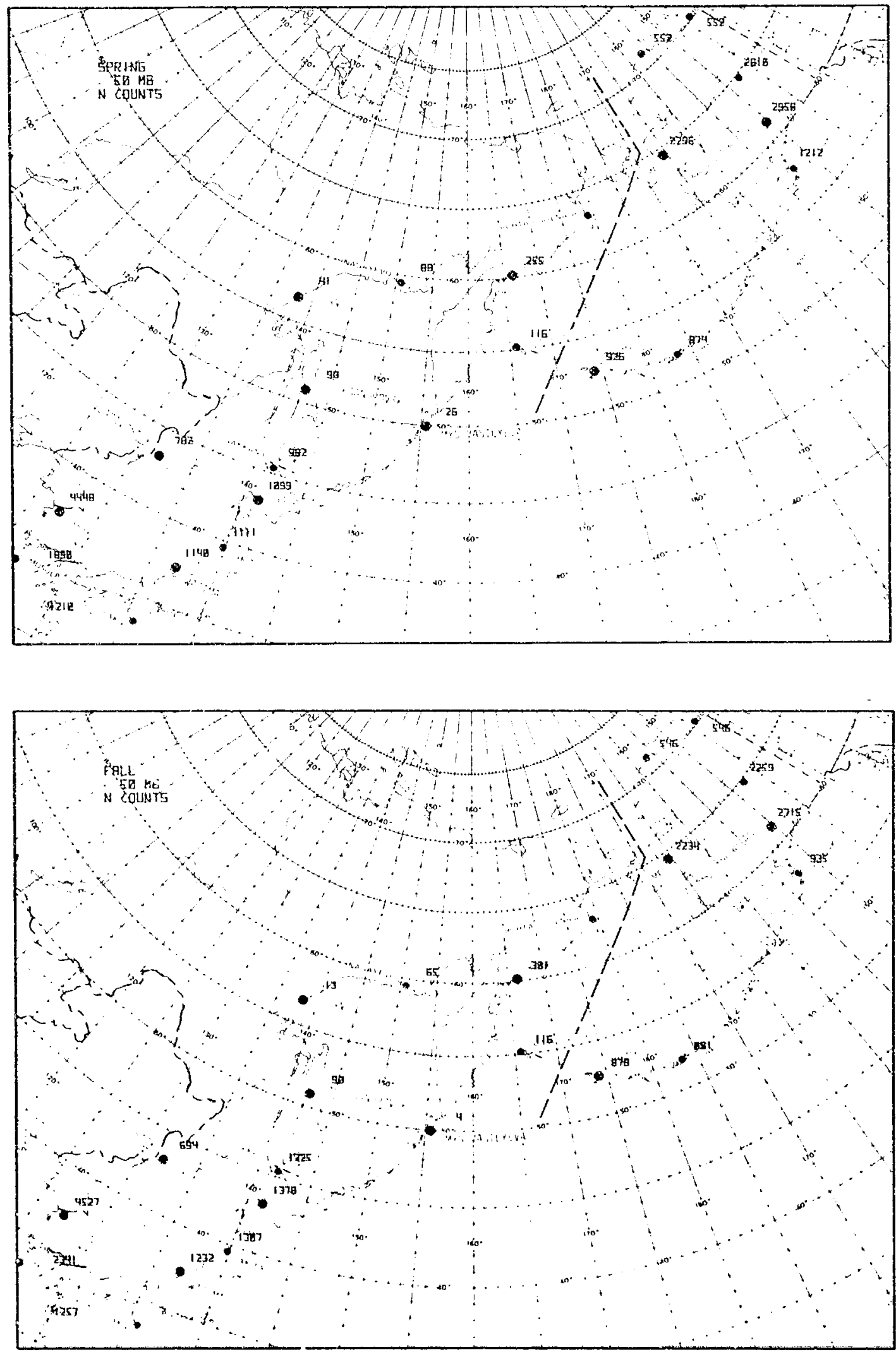

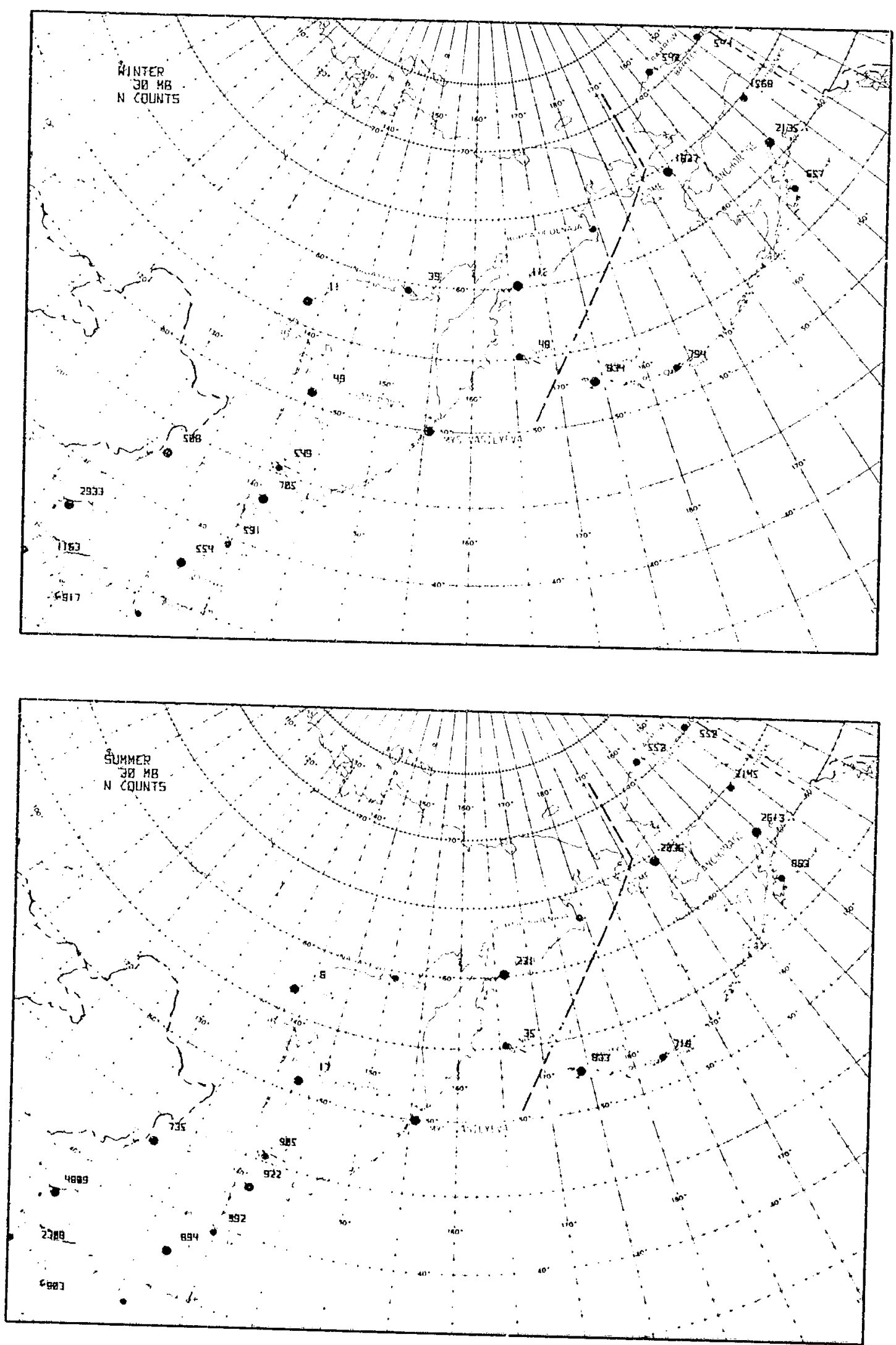

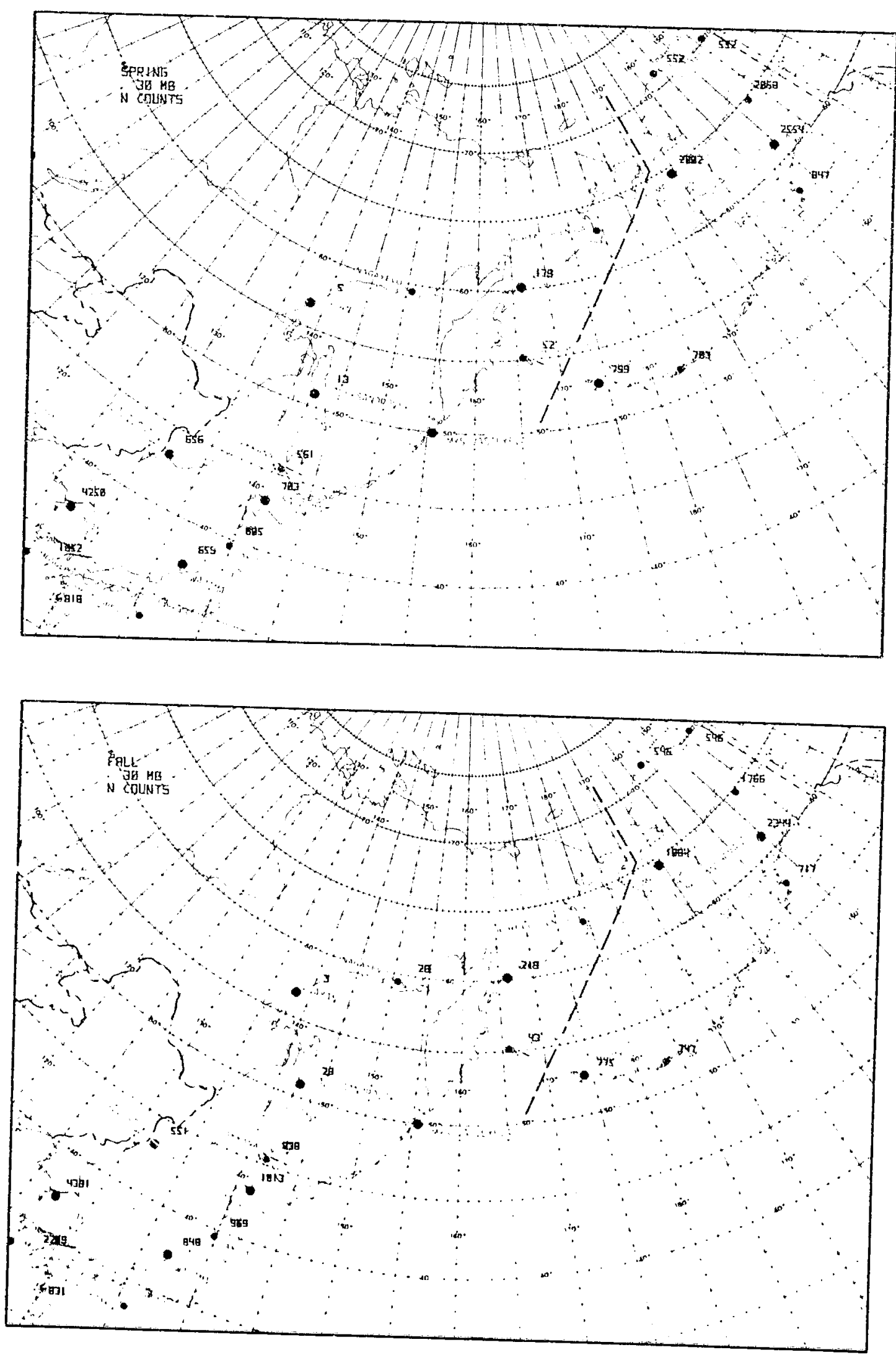

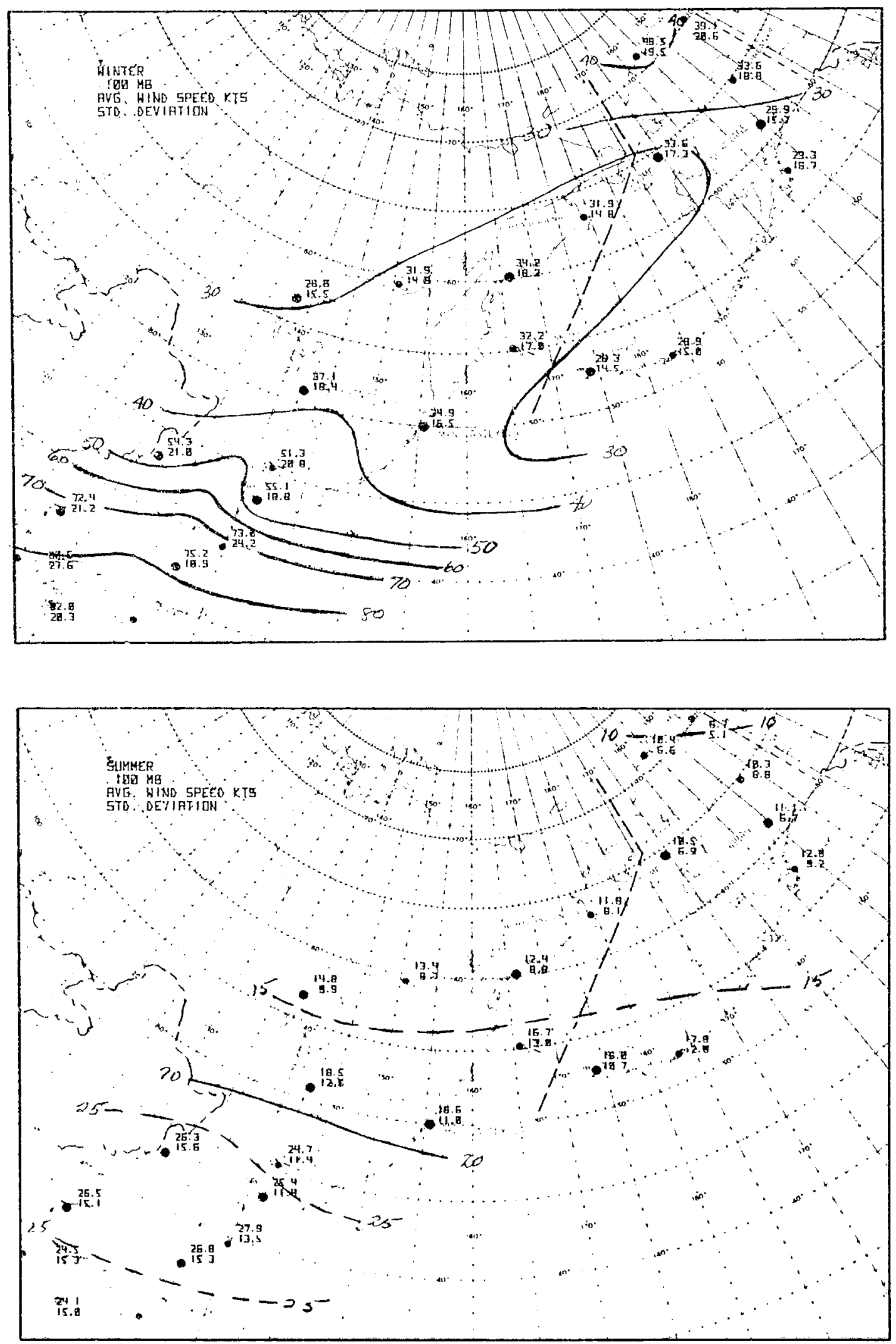


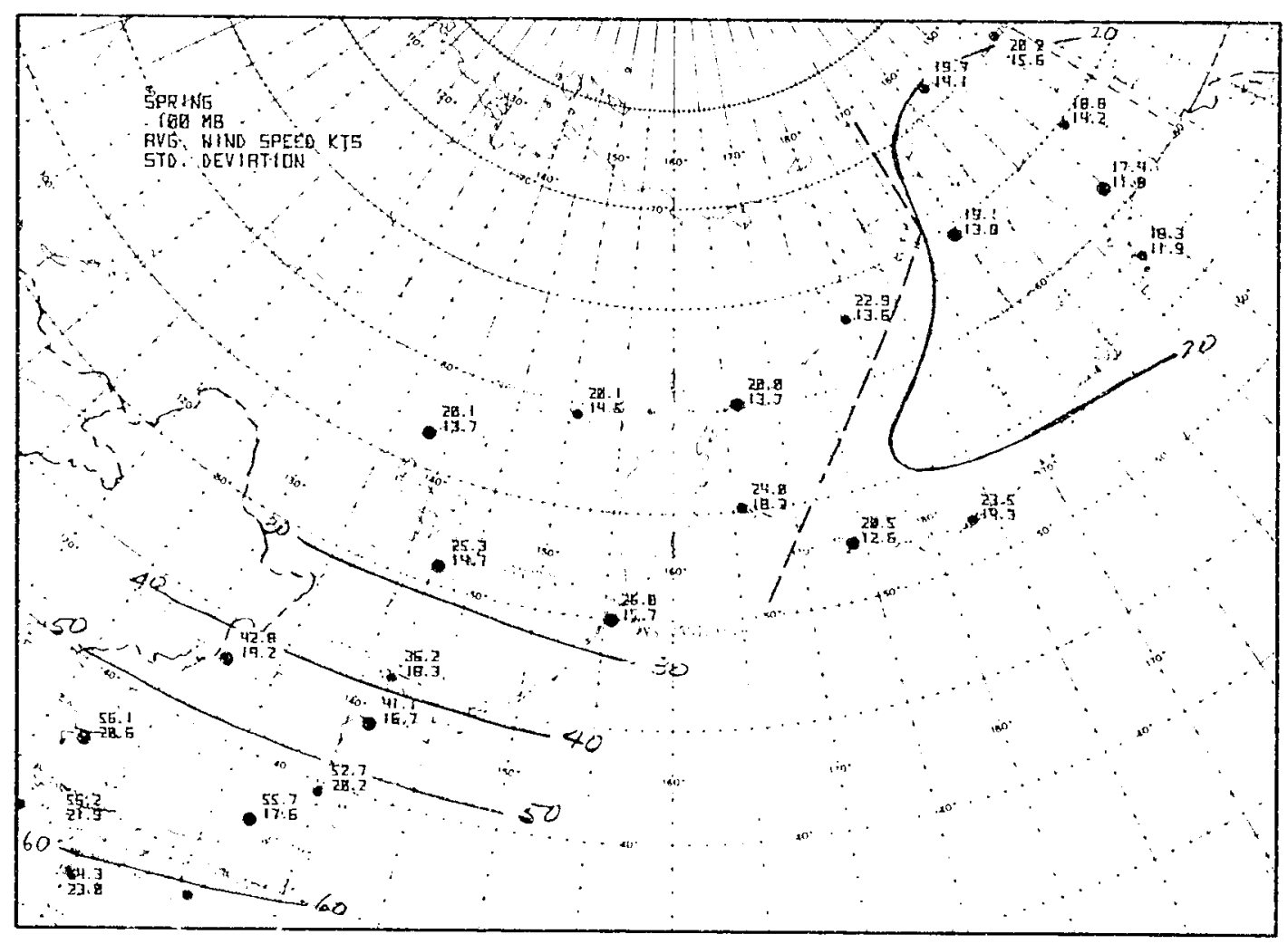

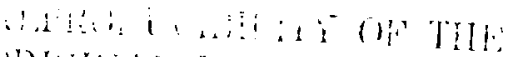

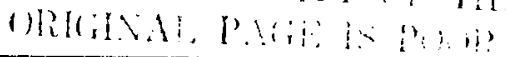

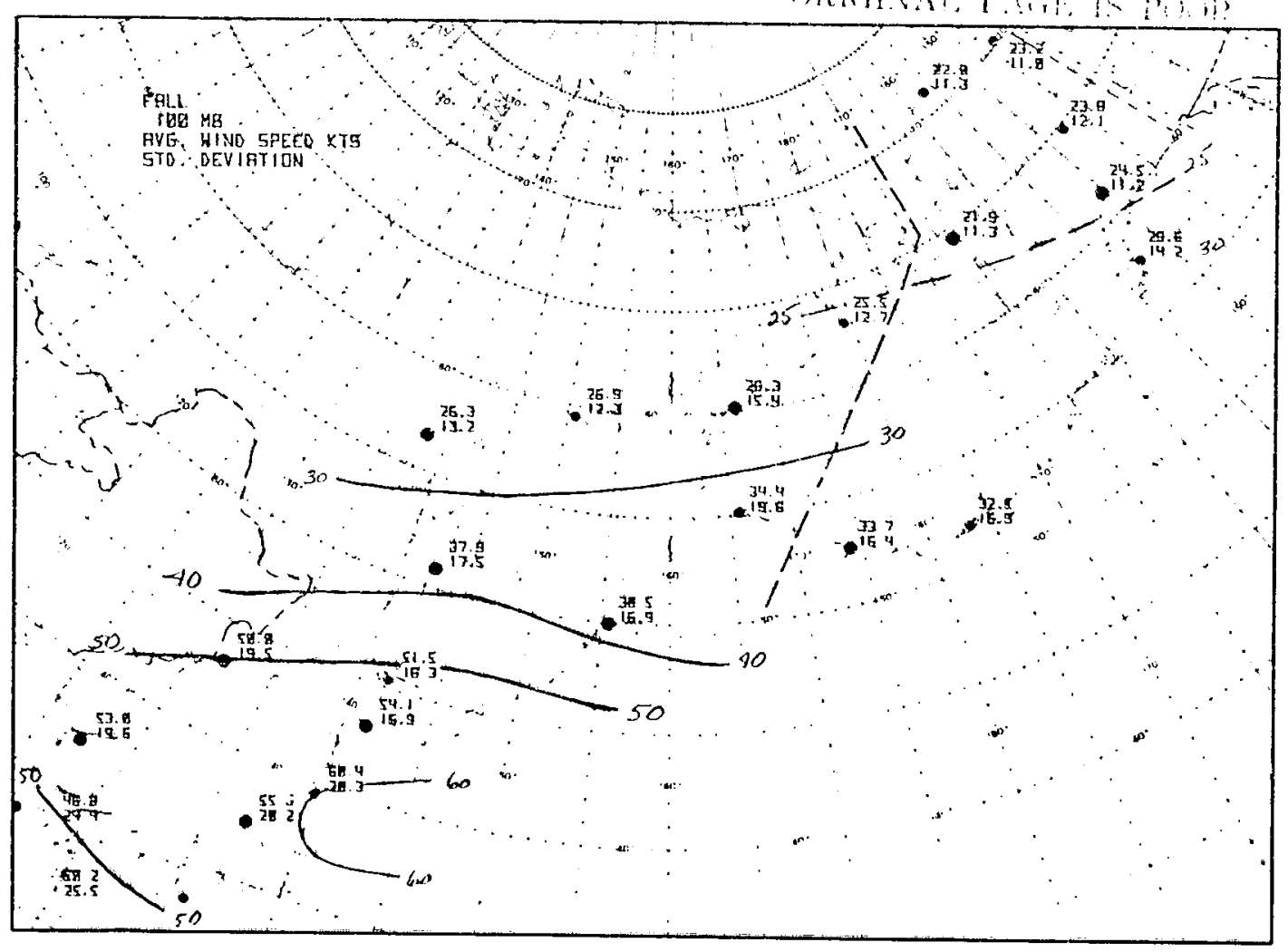



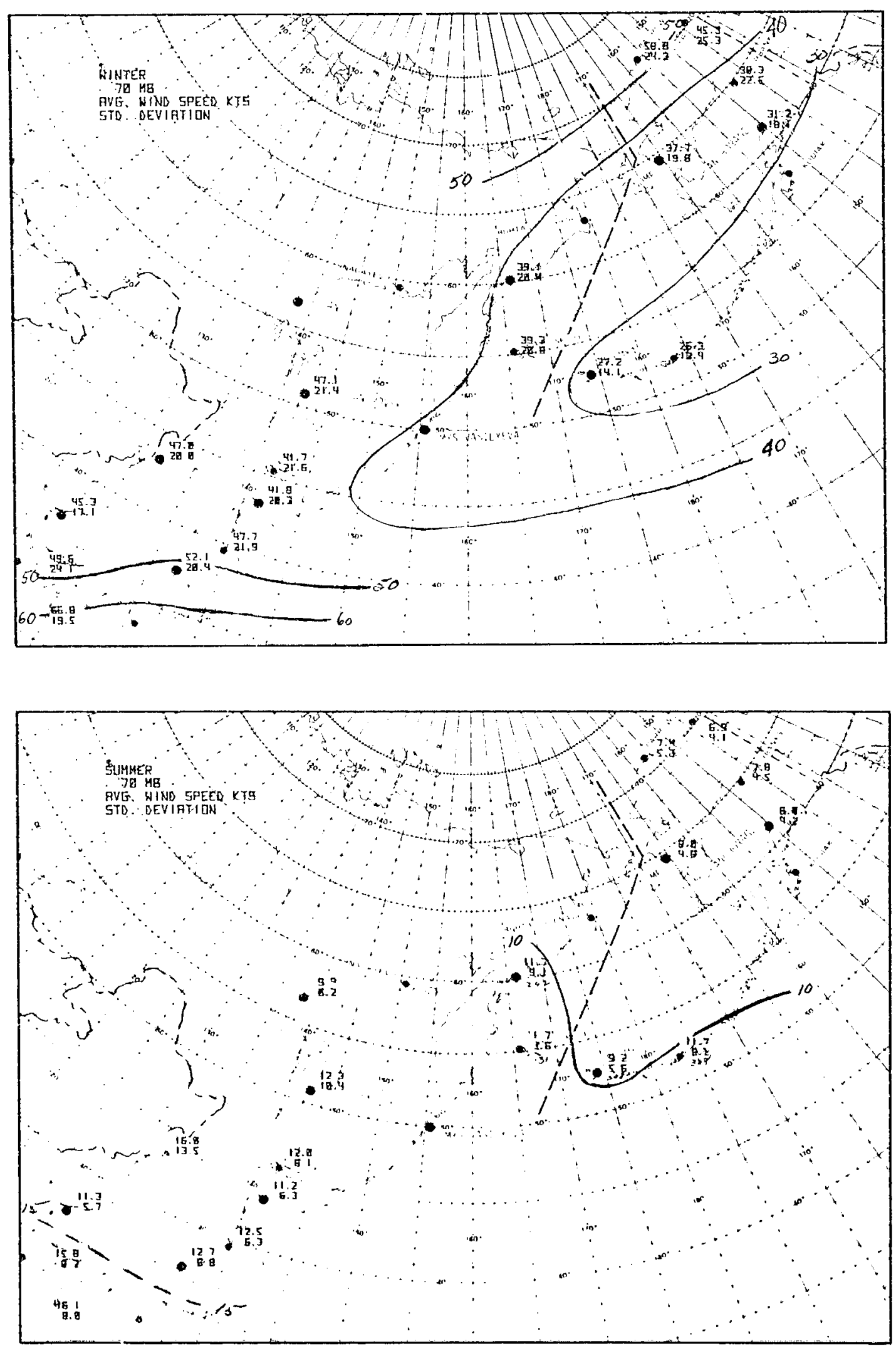

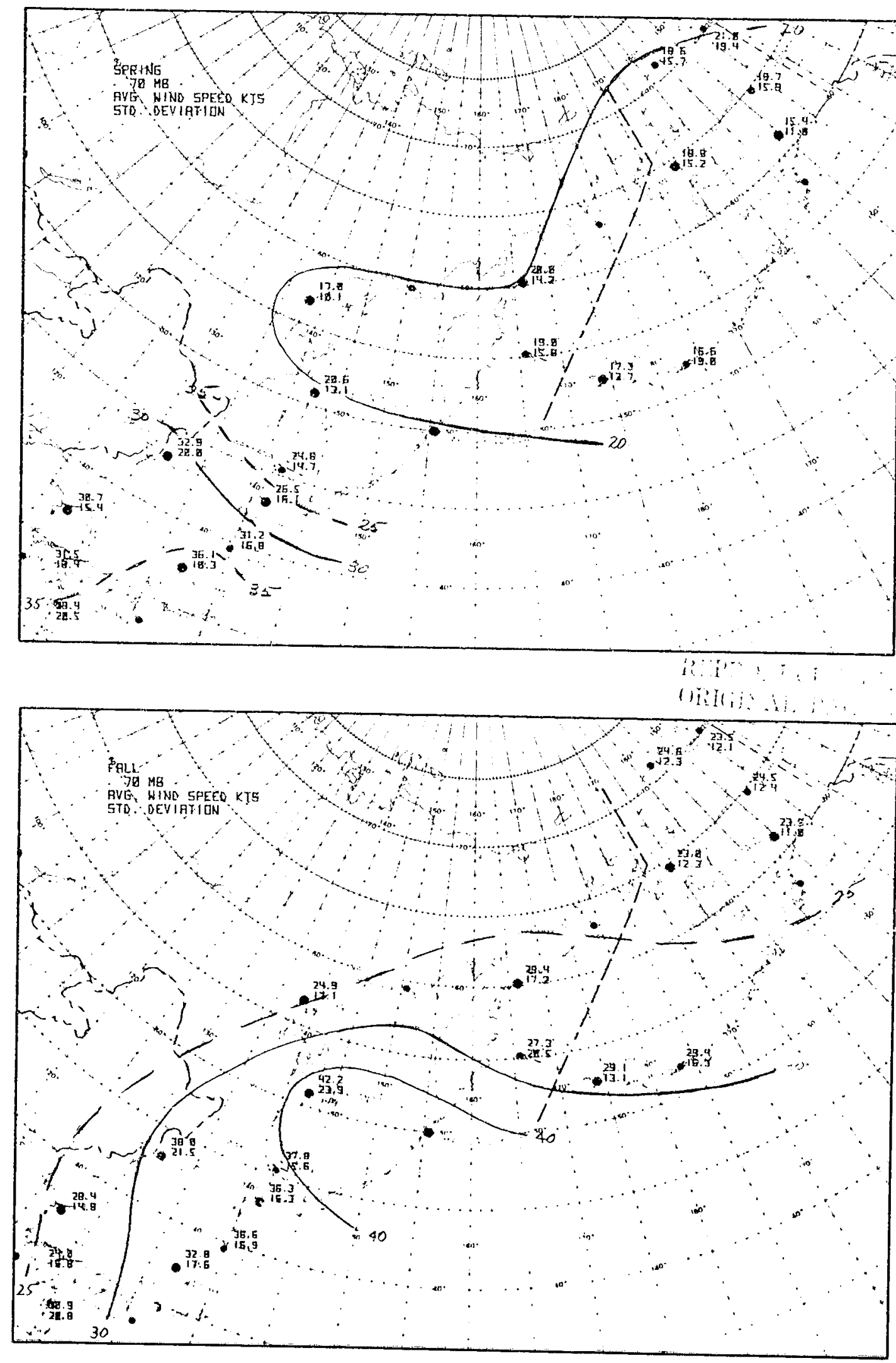

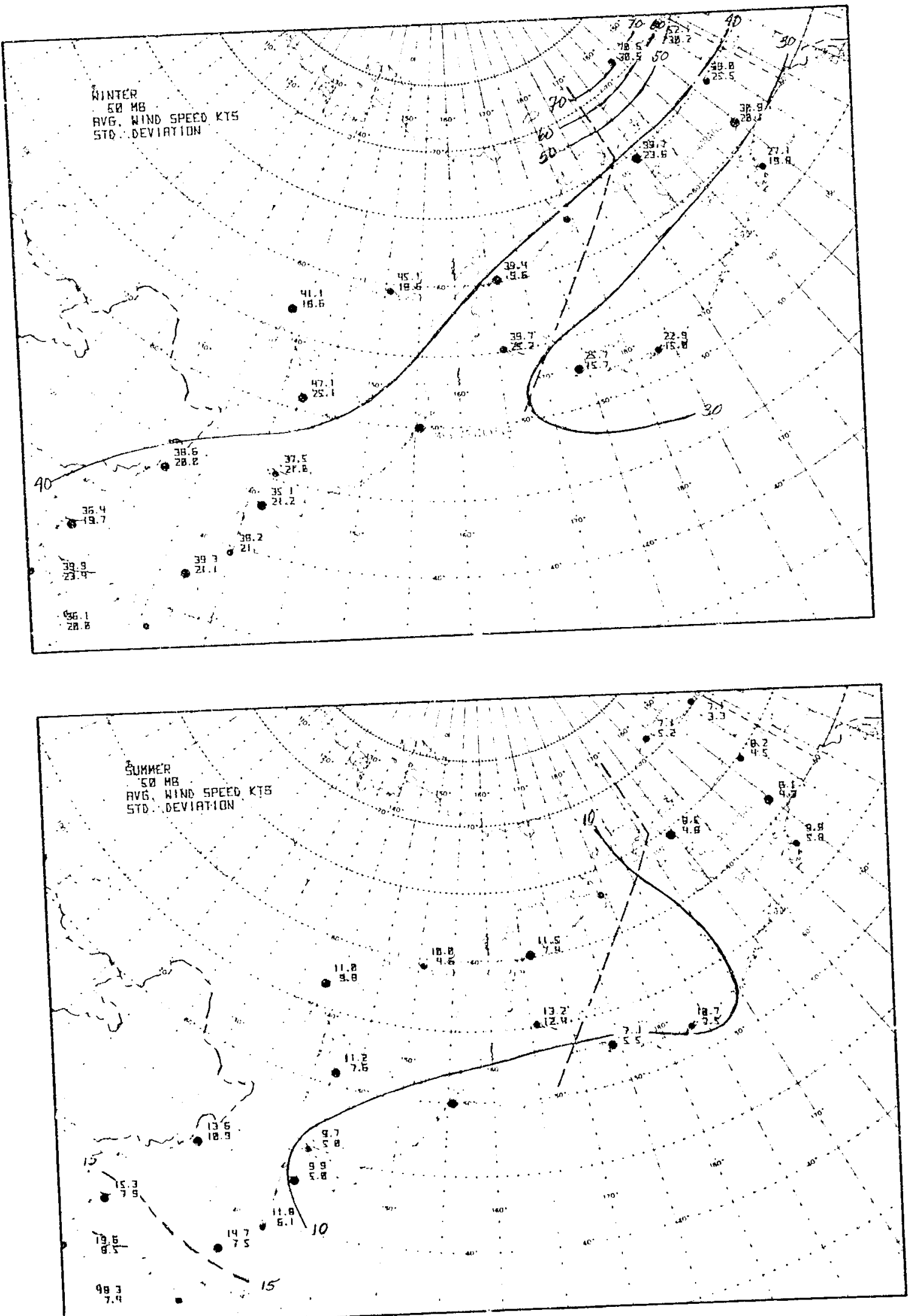

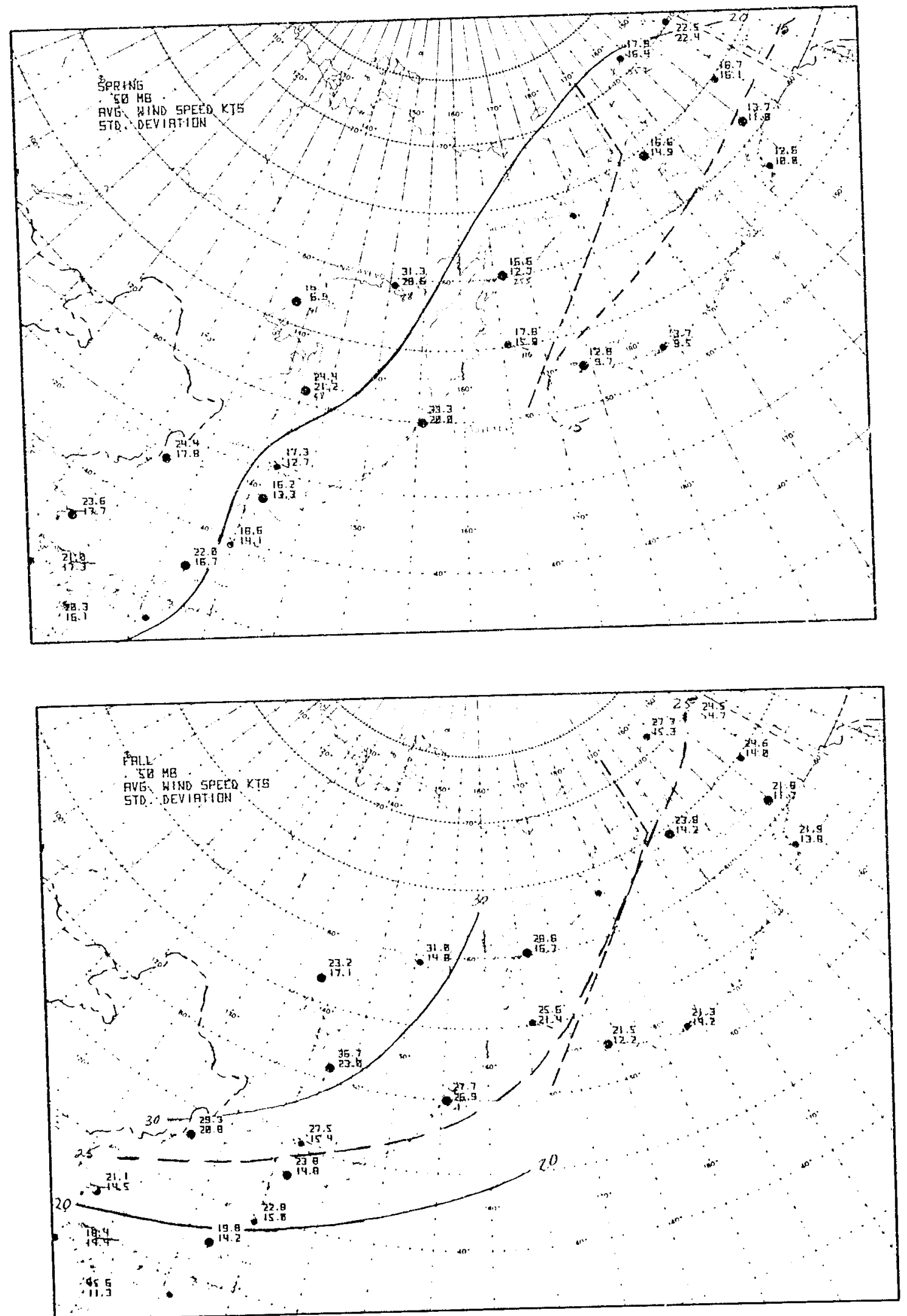

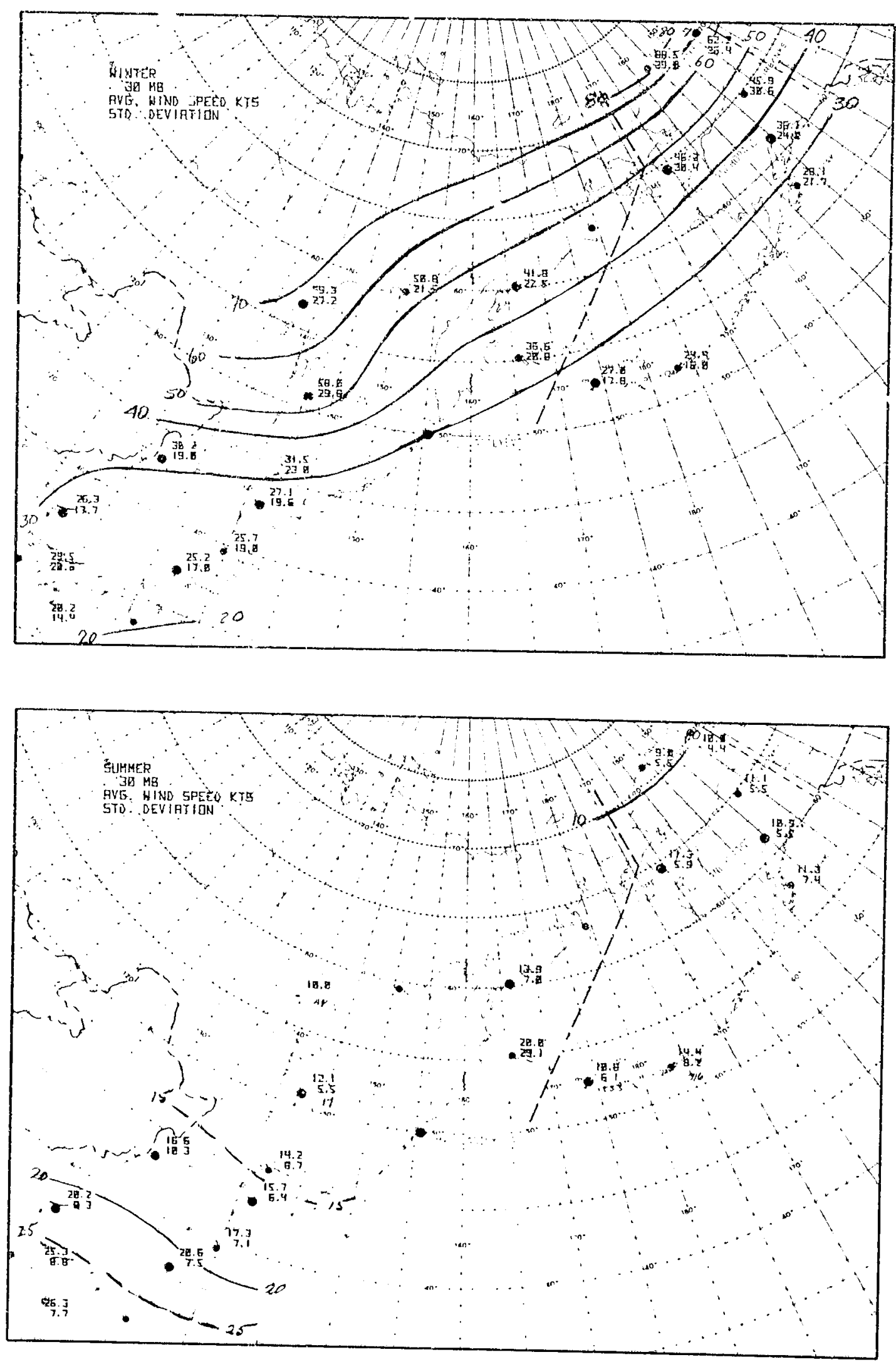

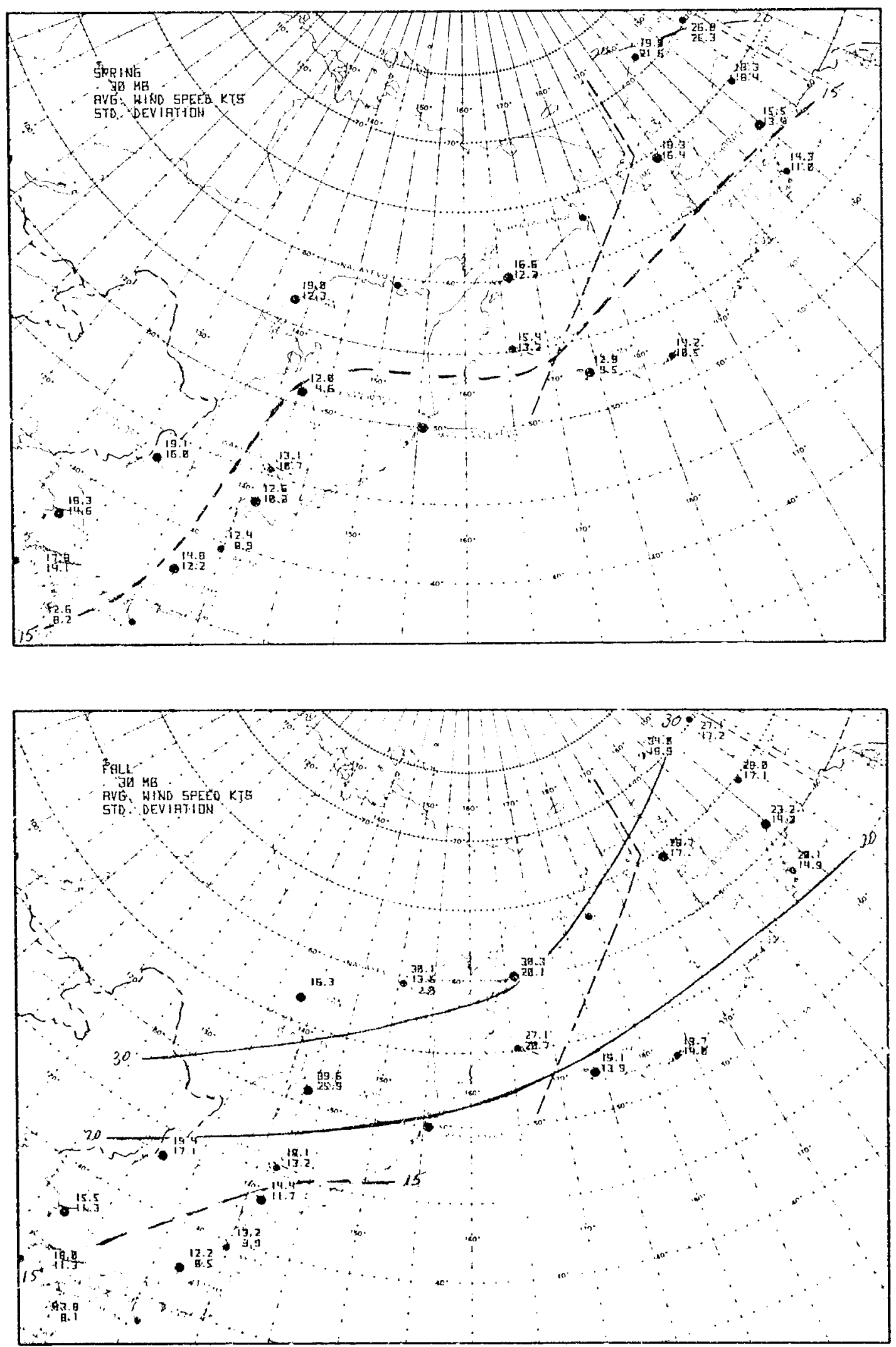

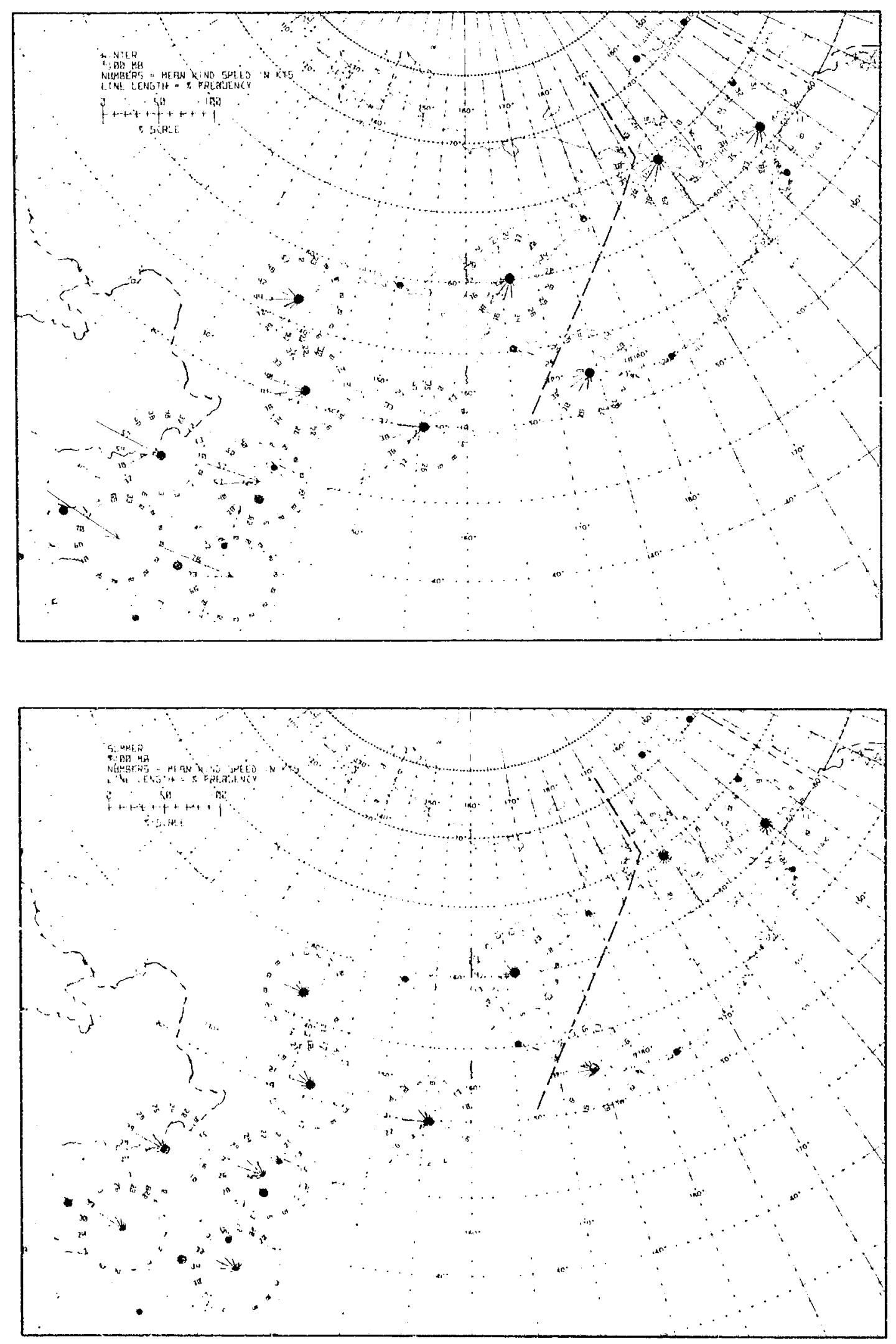

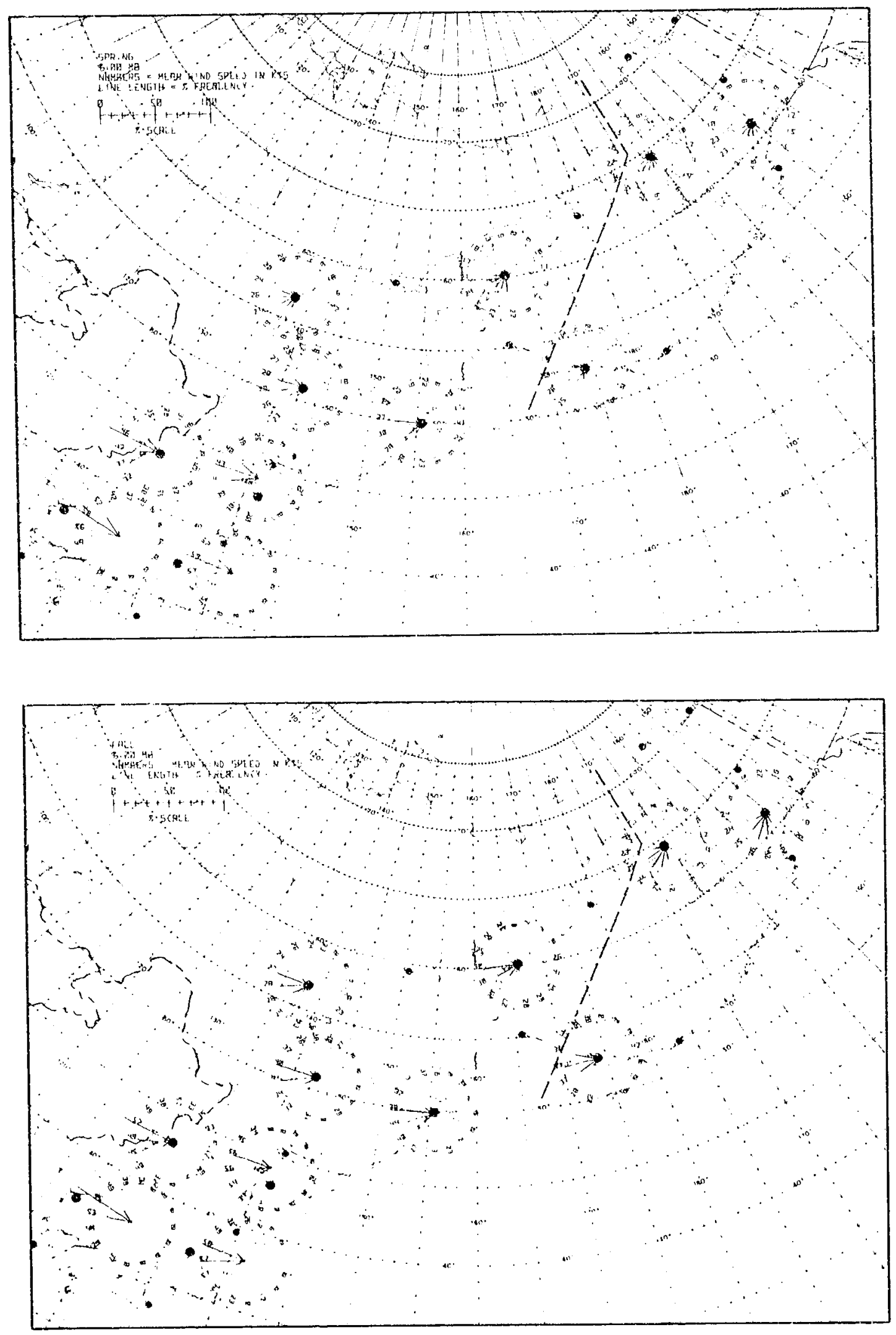

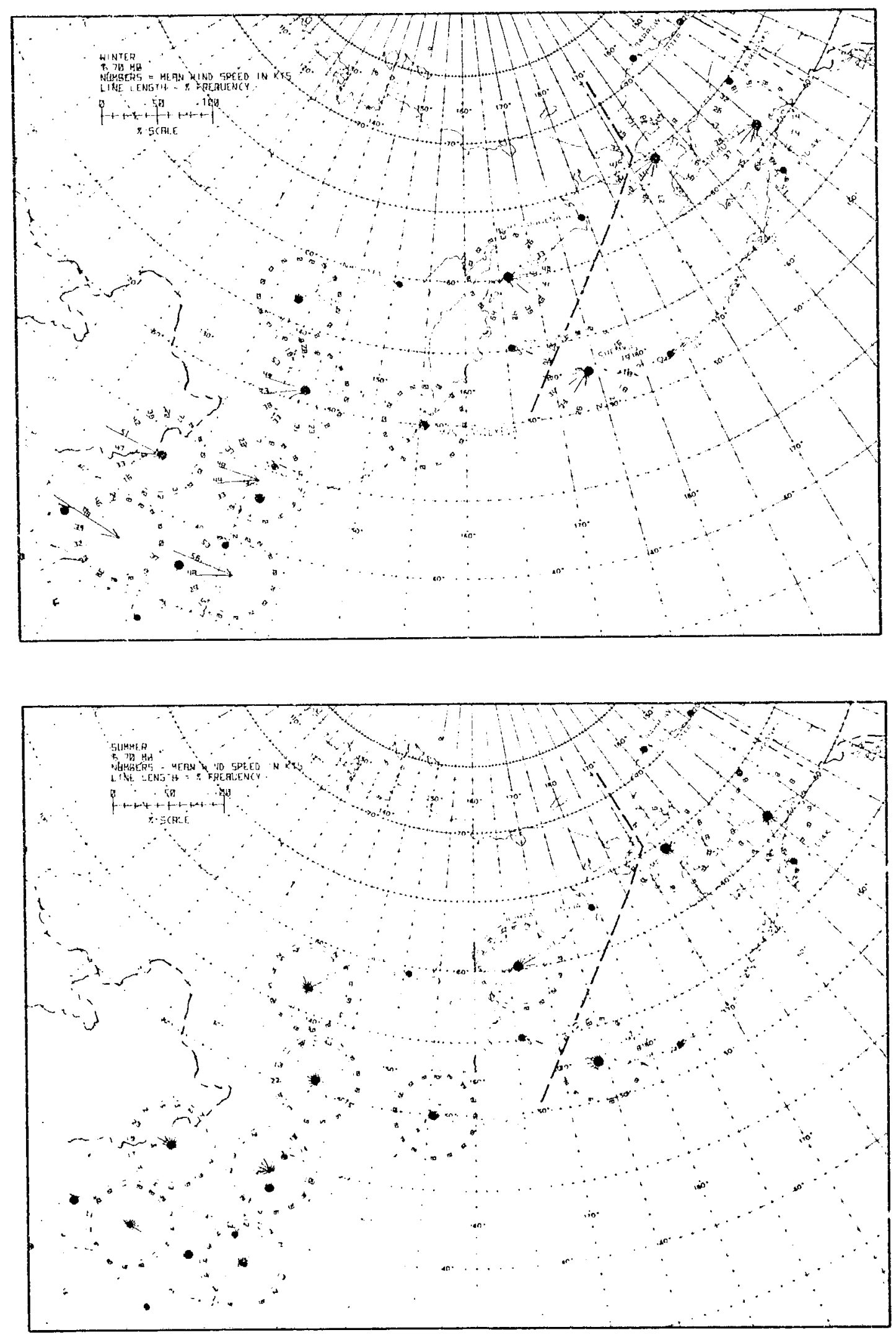

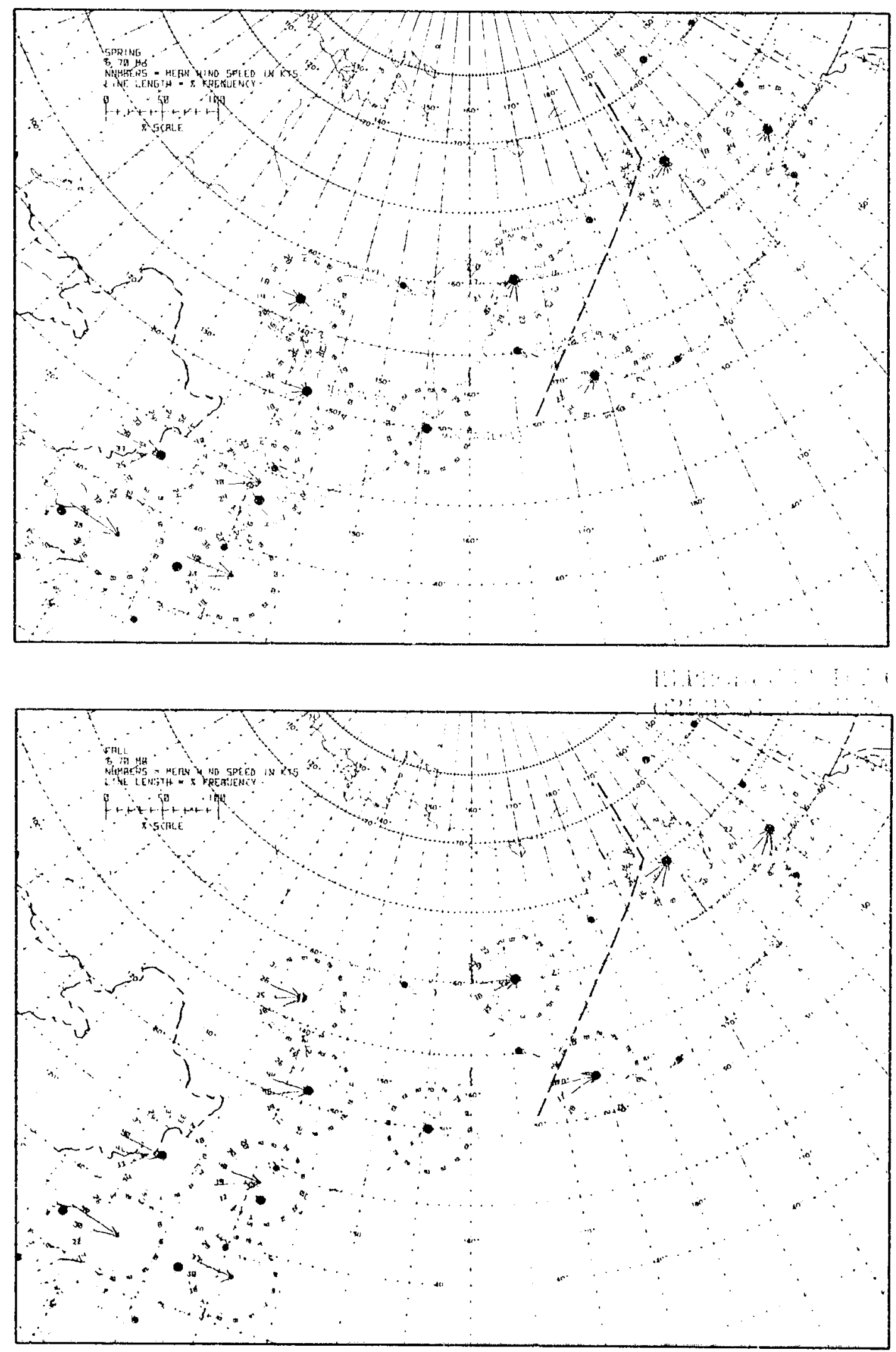

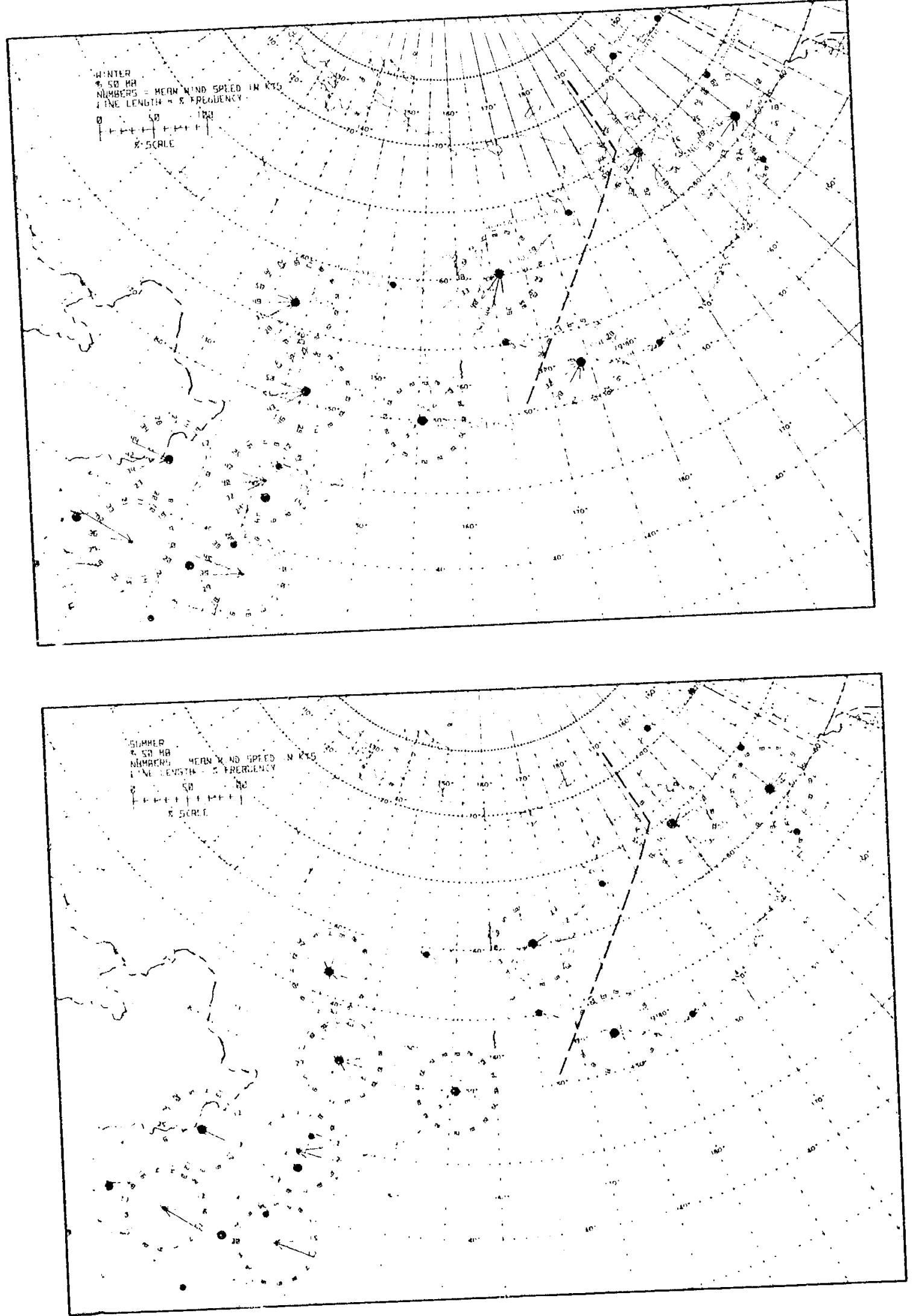

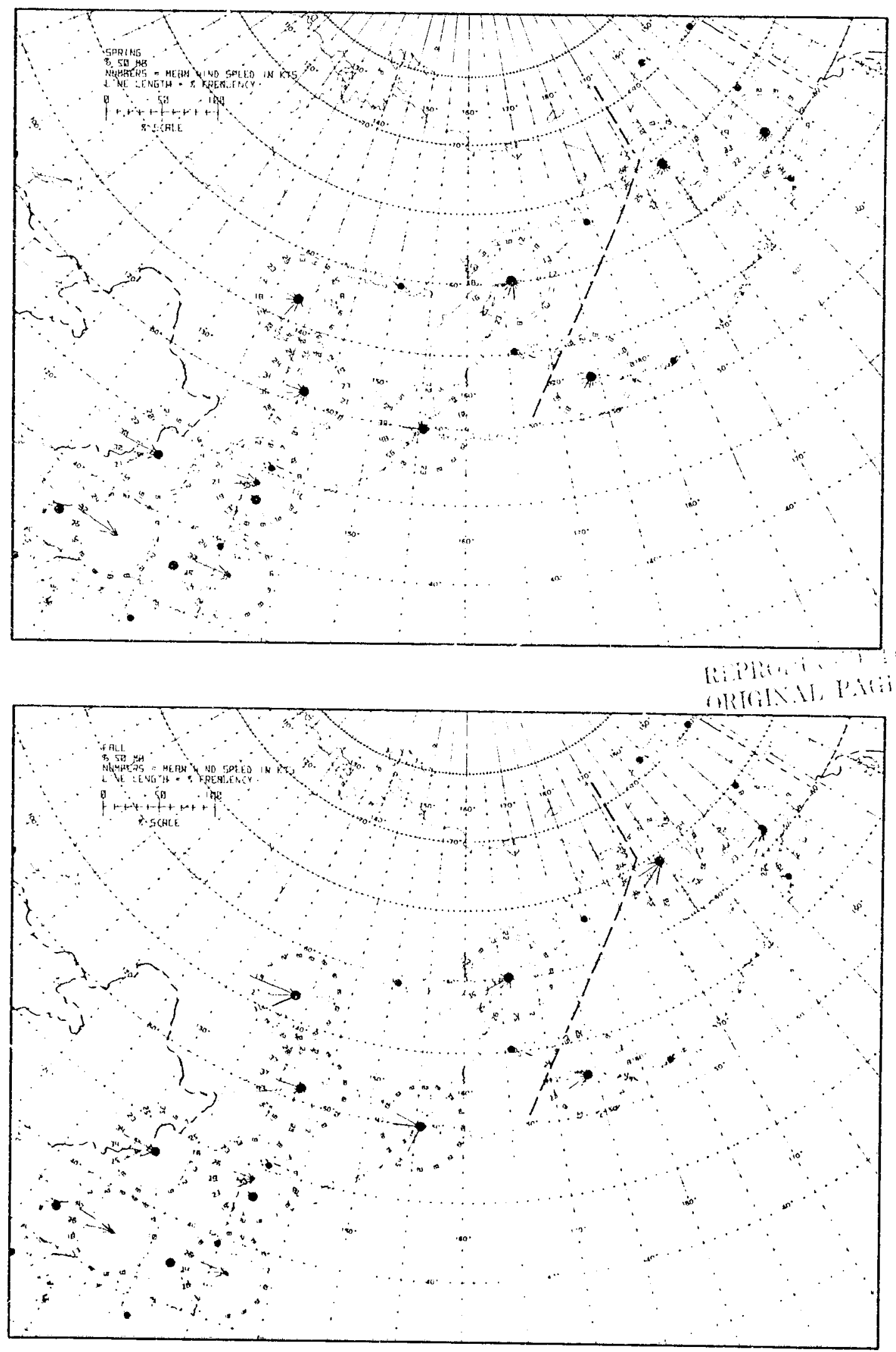

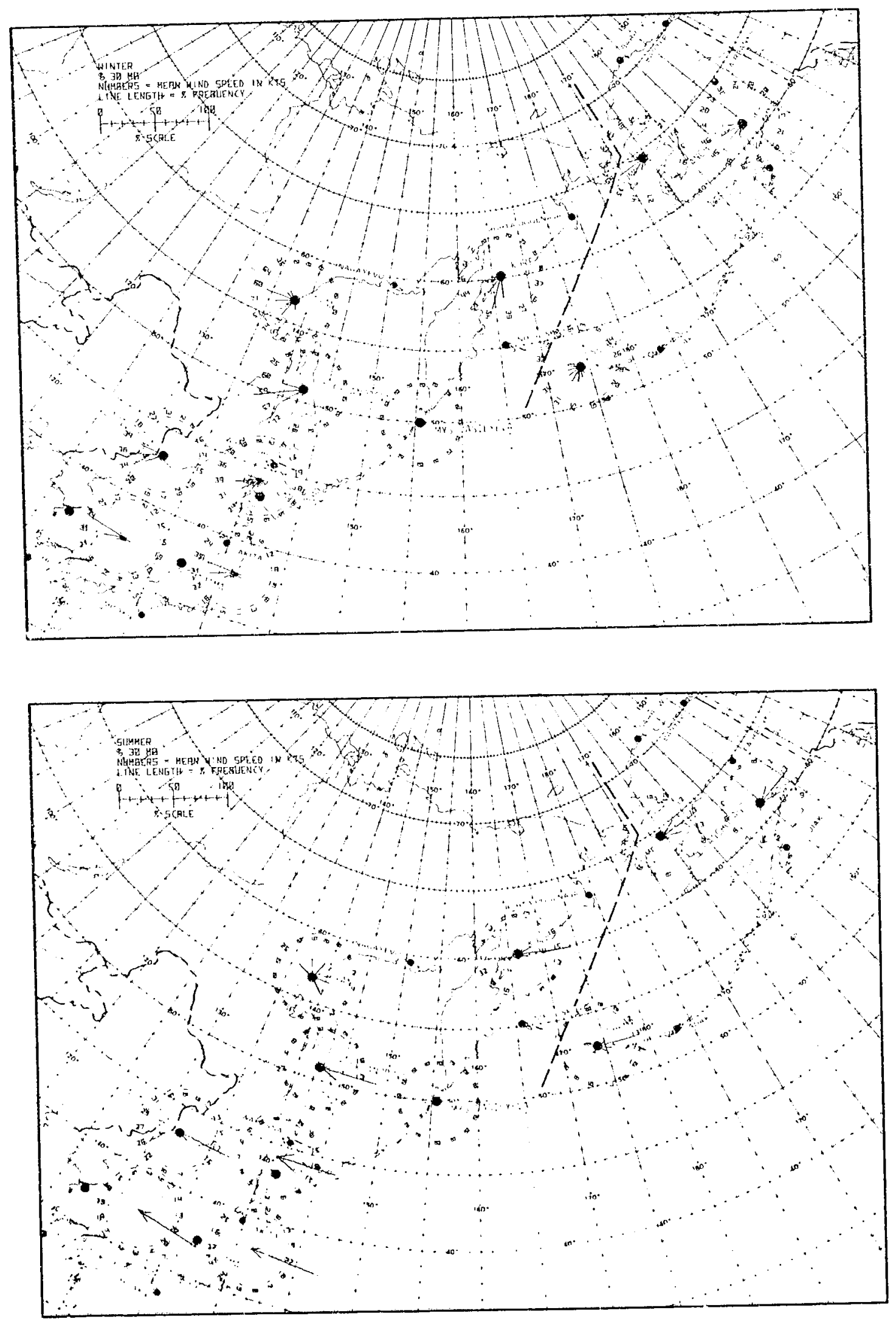


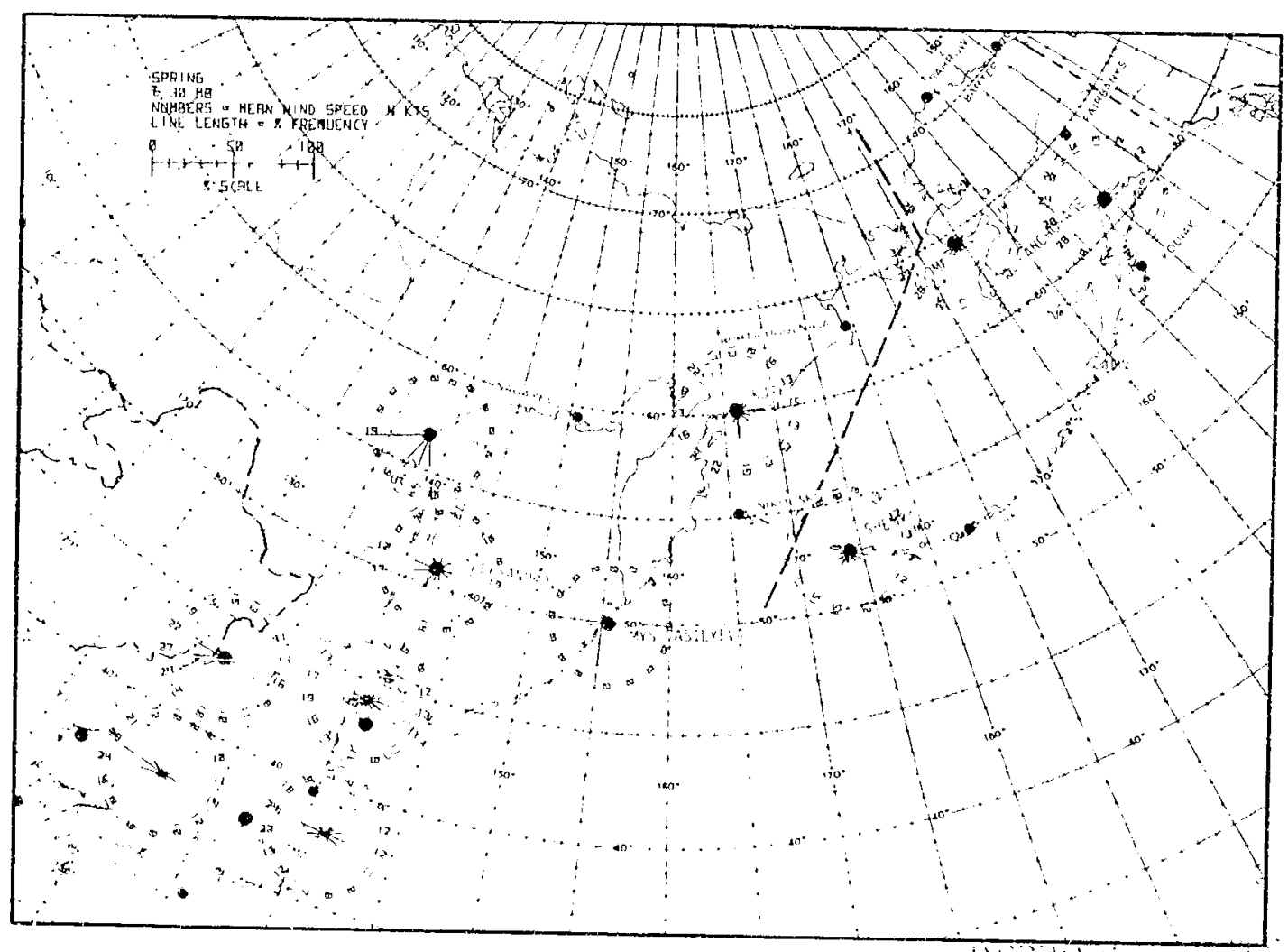

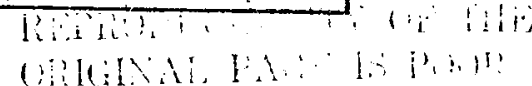

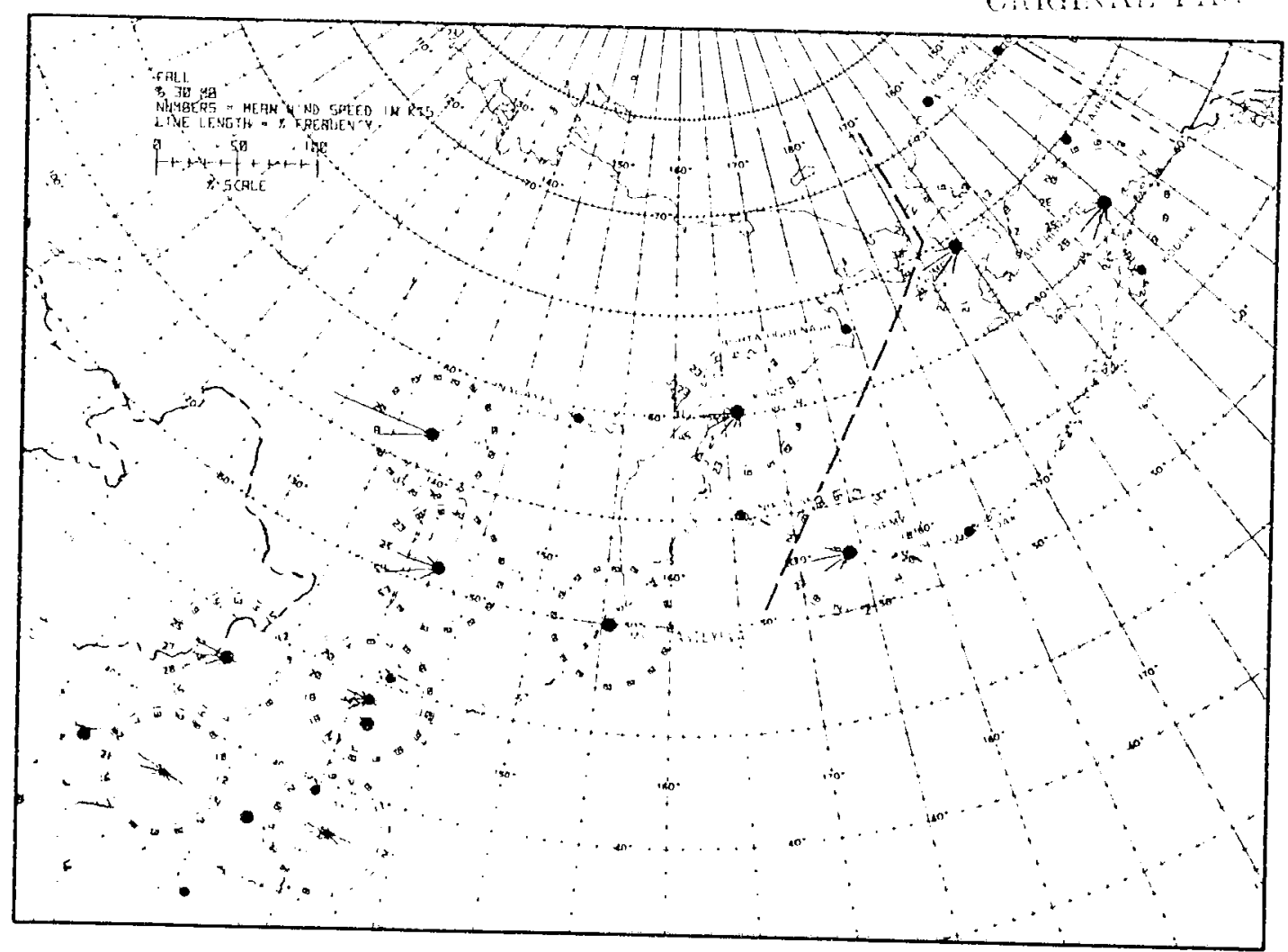



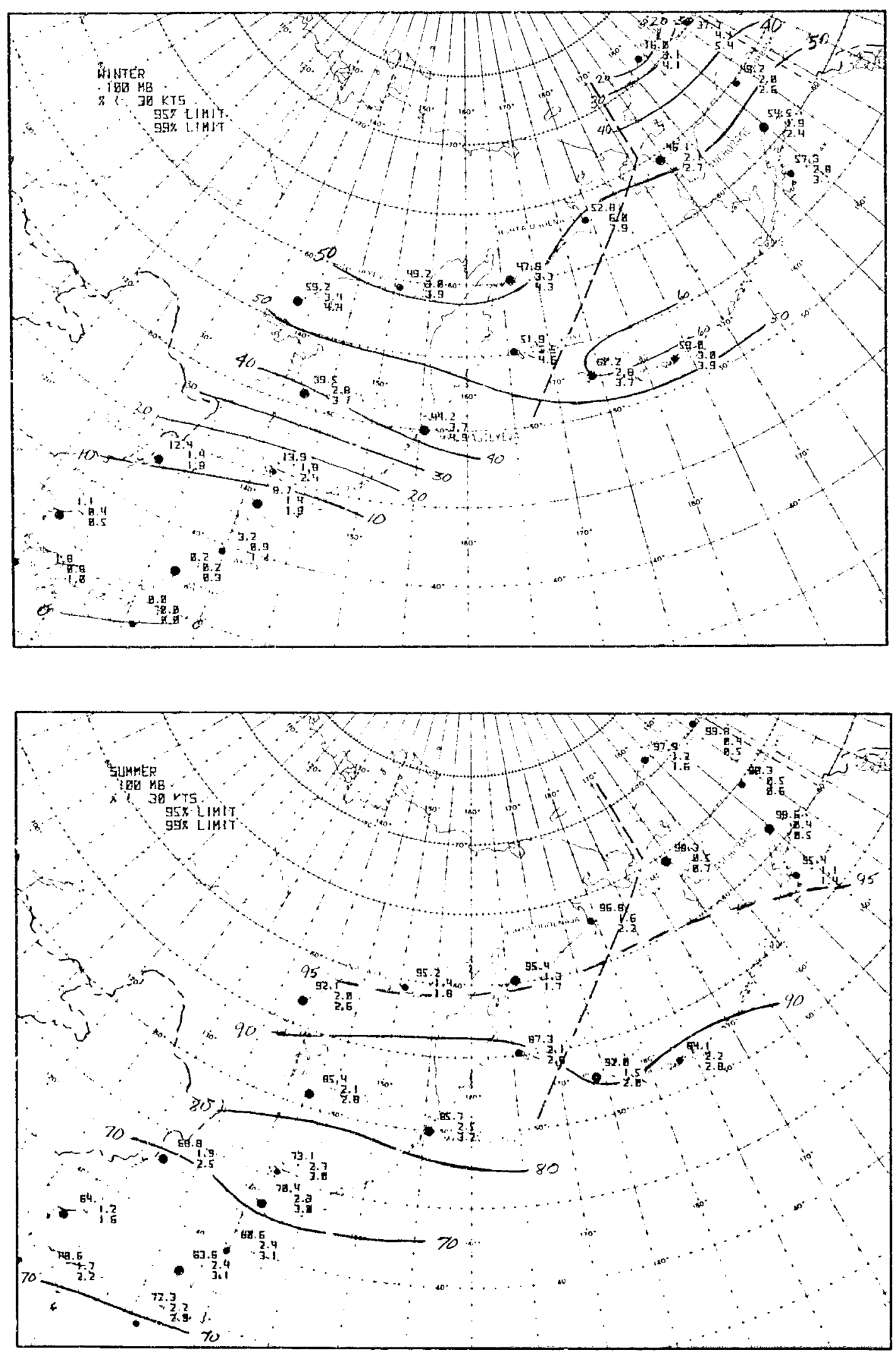

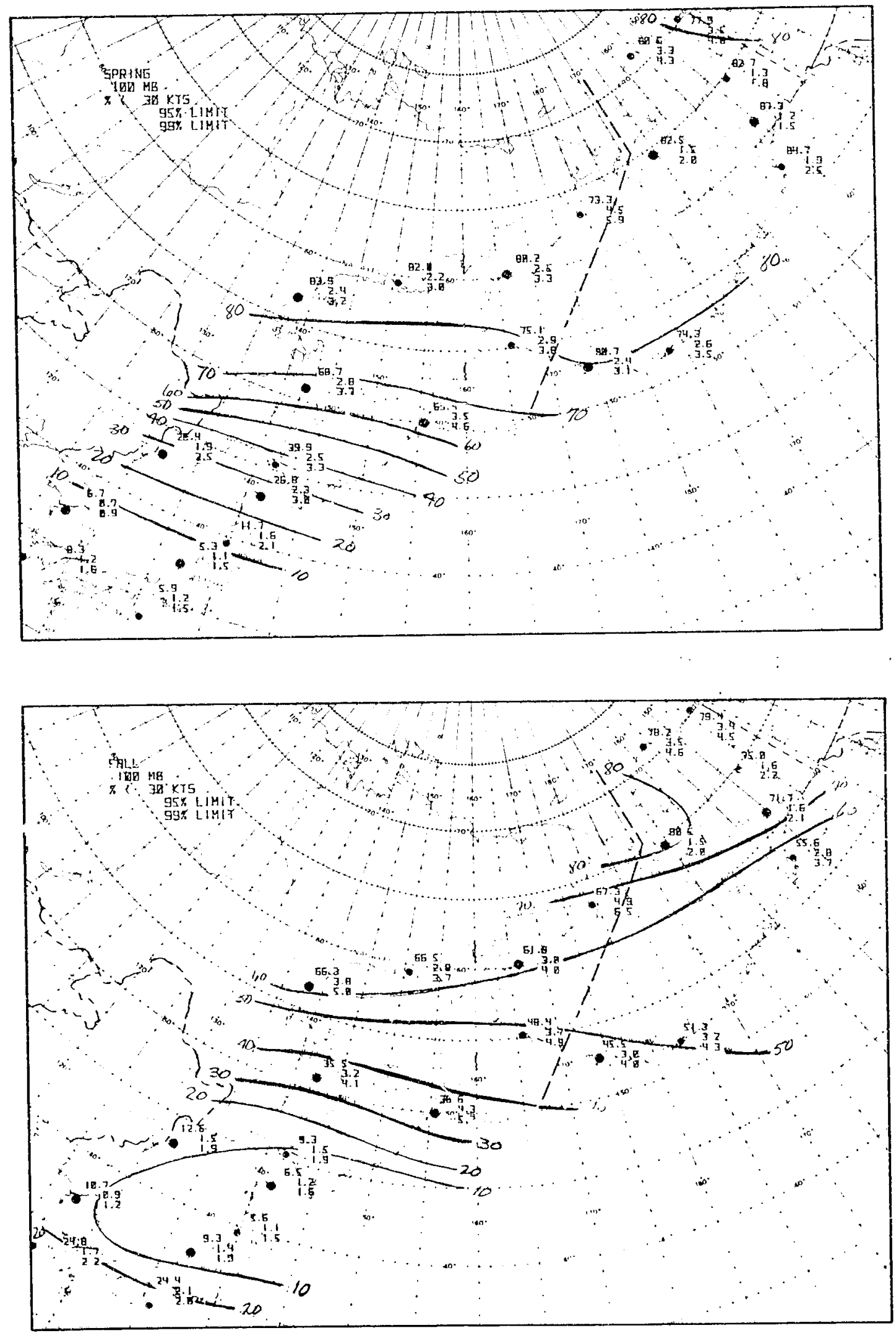

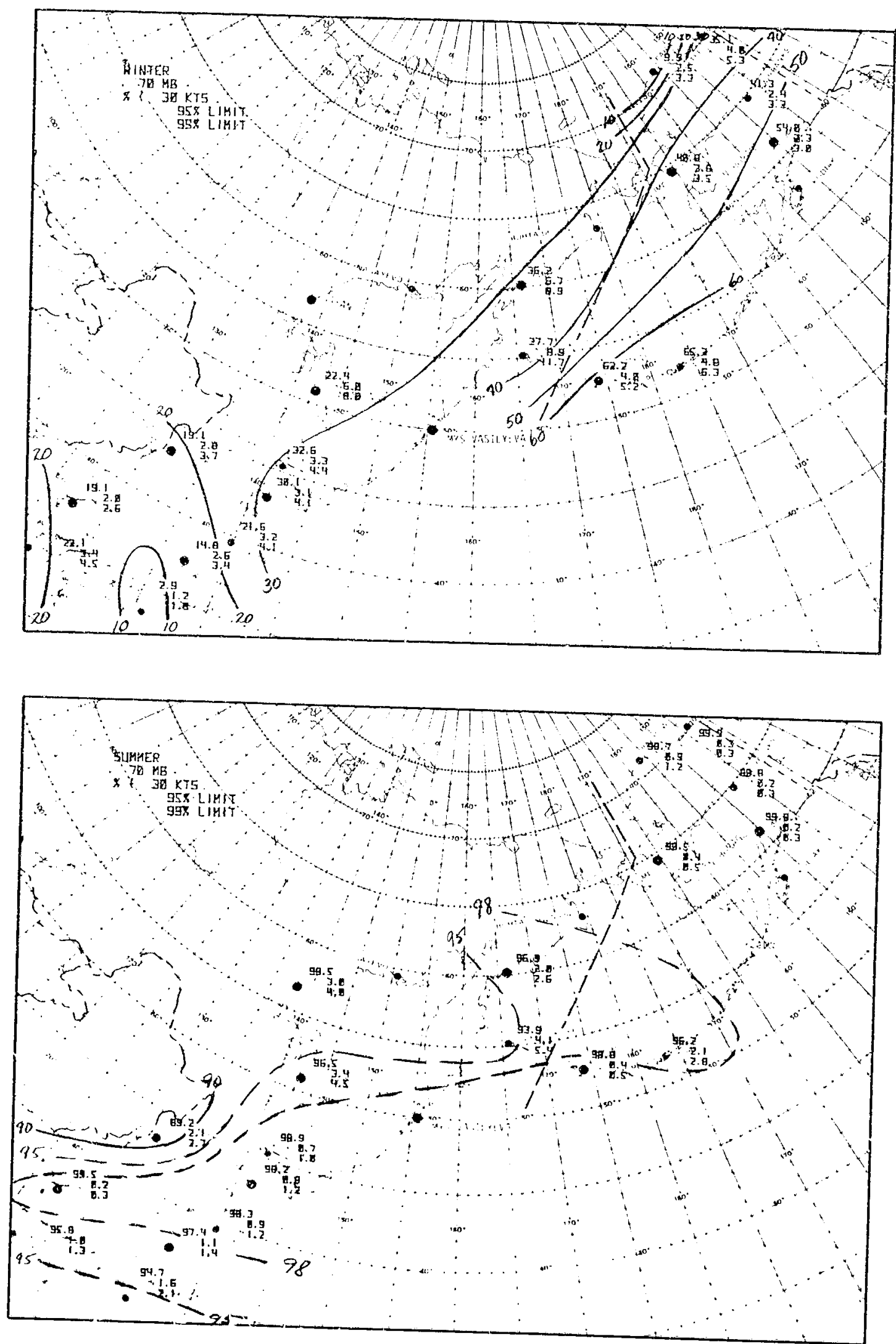


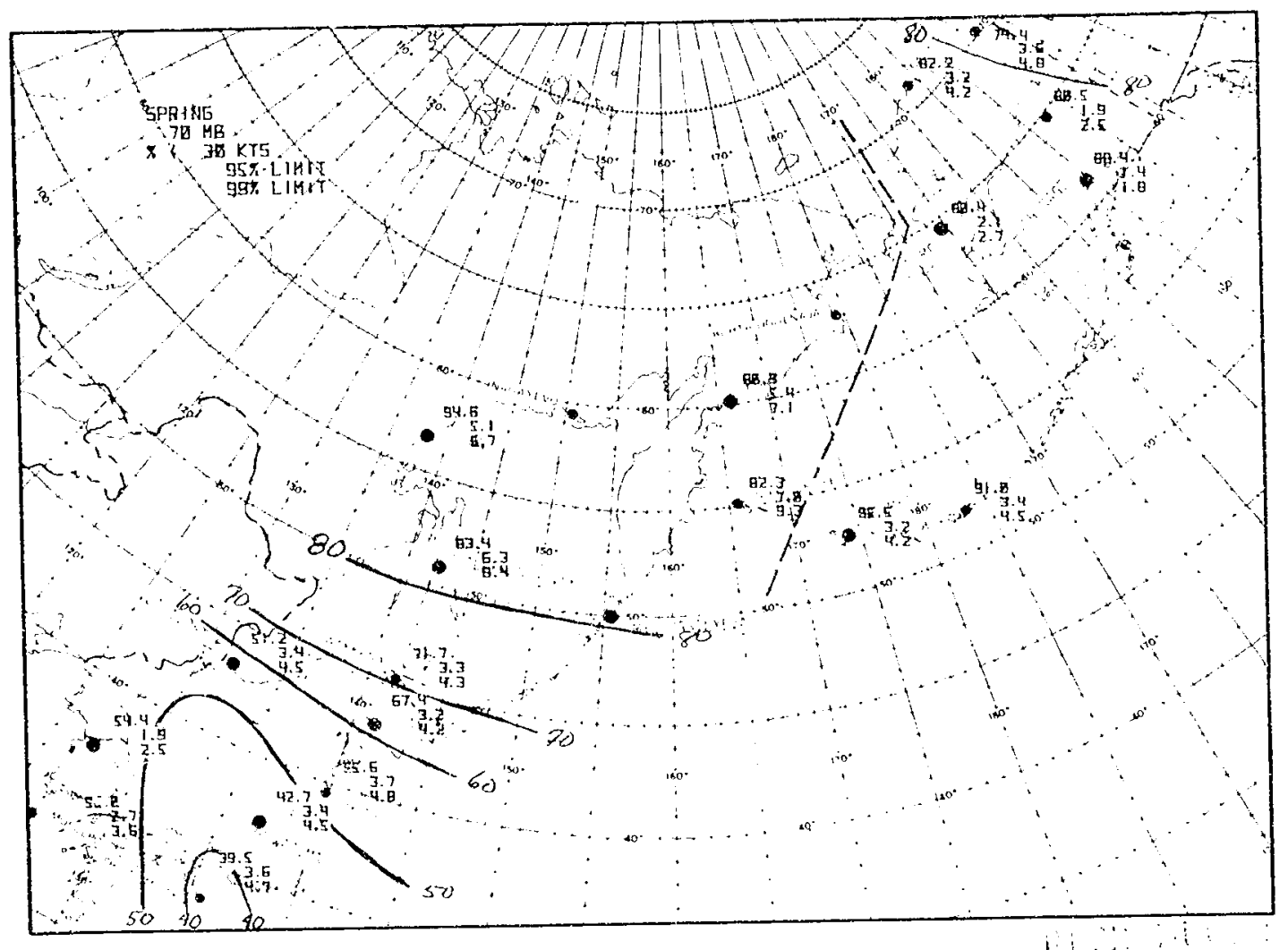

a Thll

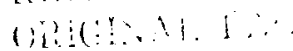

$\therefore$ In)

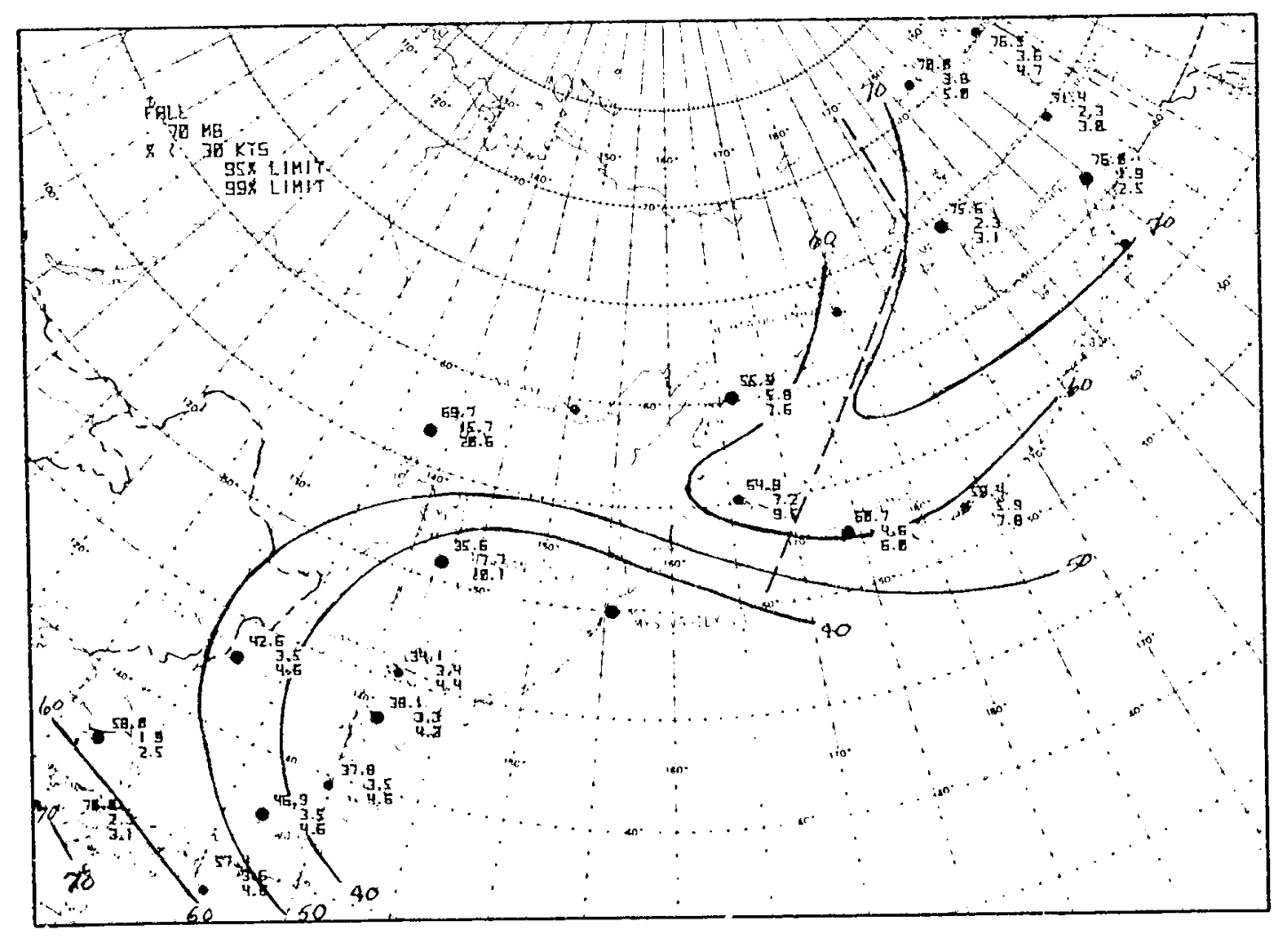



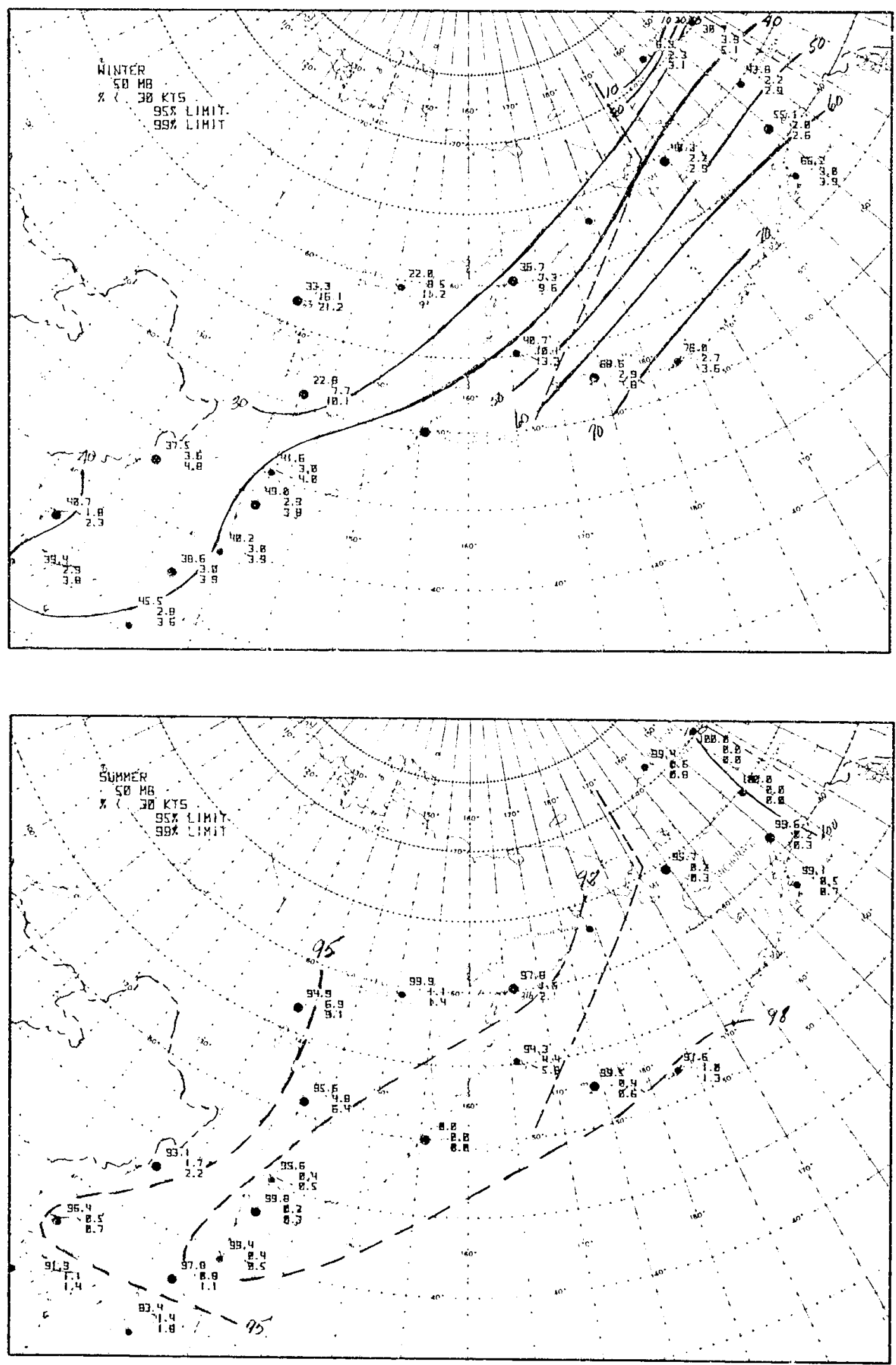


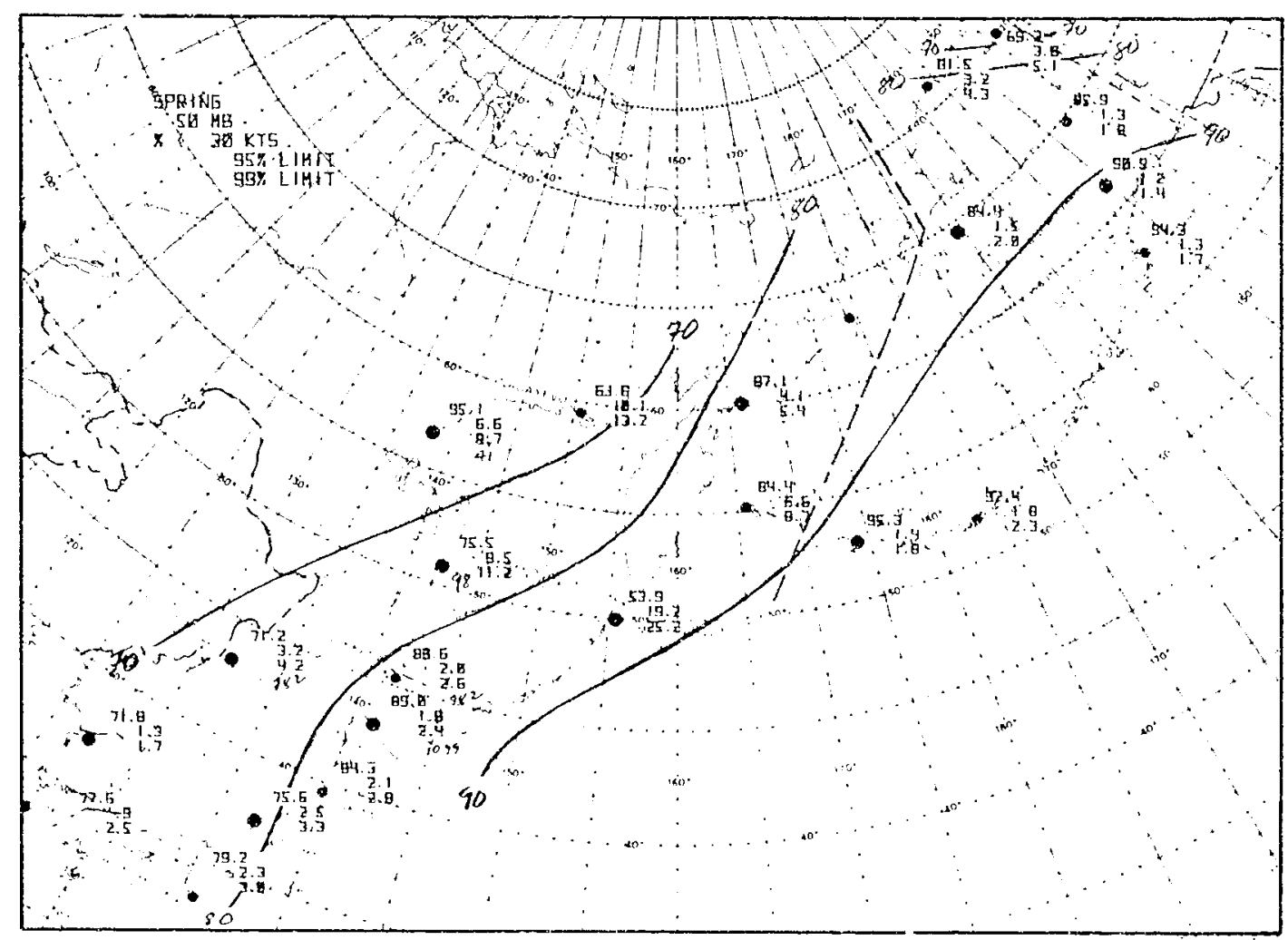

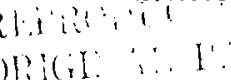

$\therefore \quad$ i P(): R

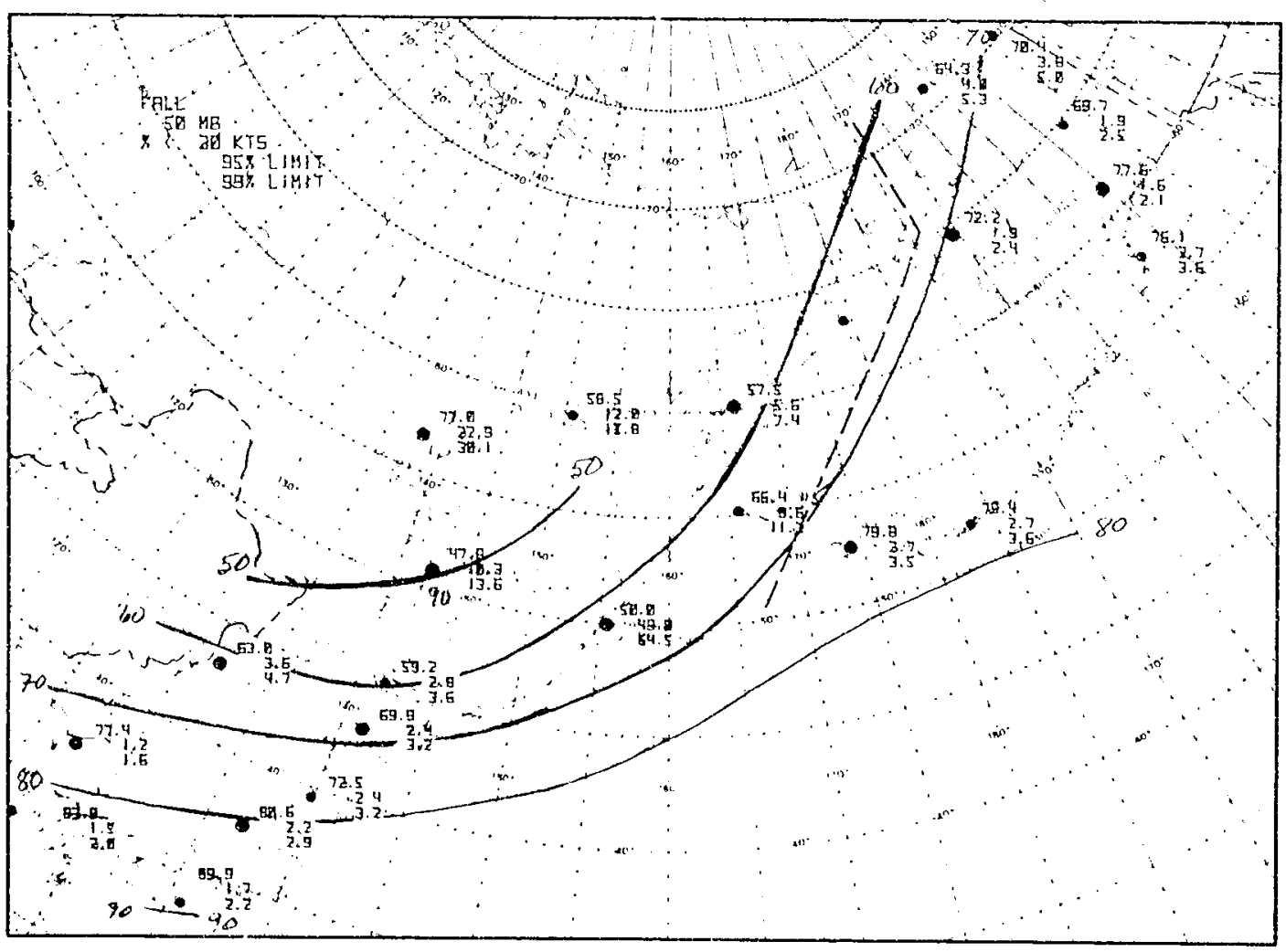



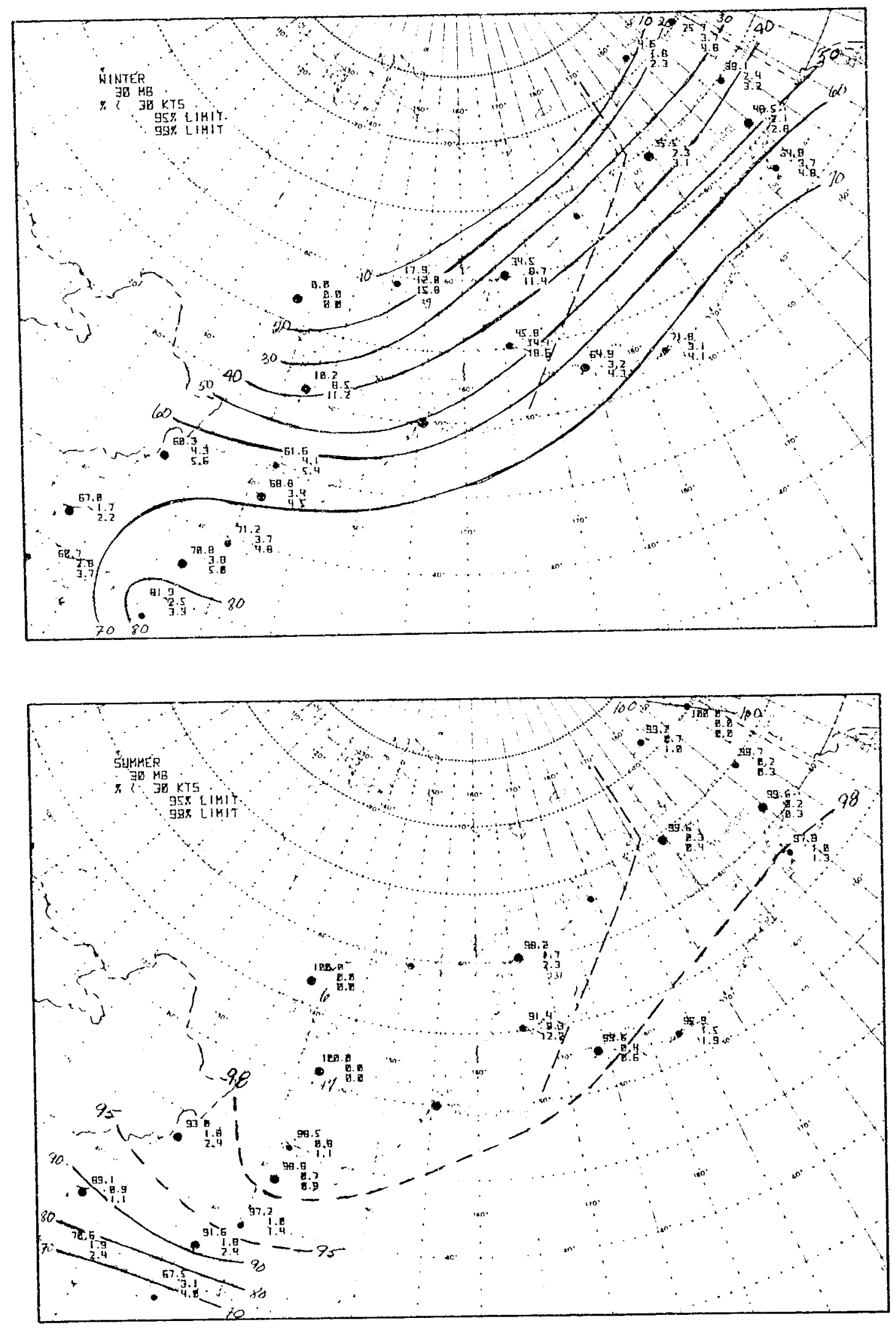


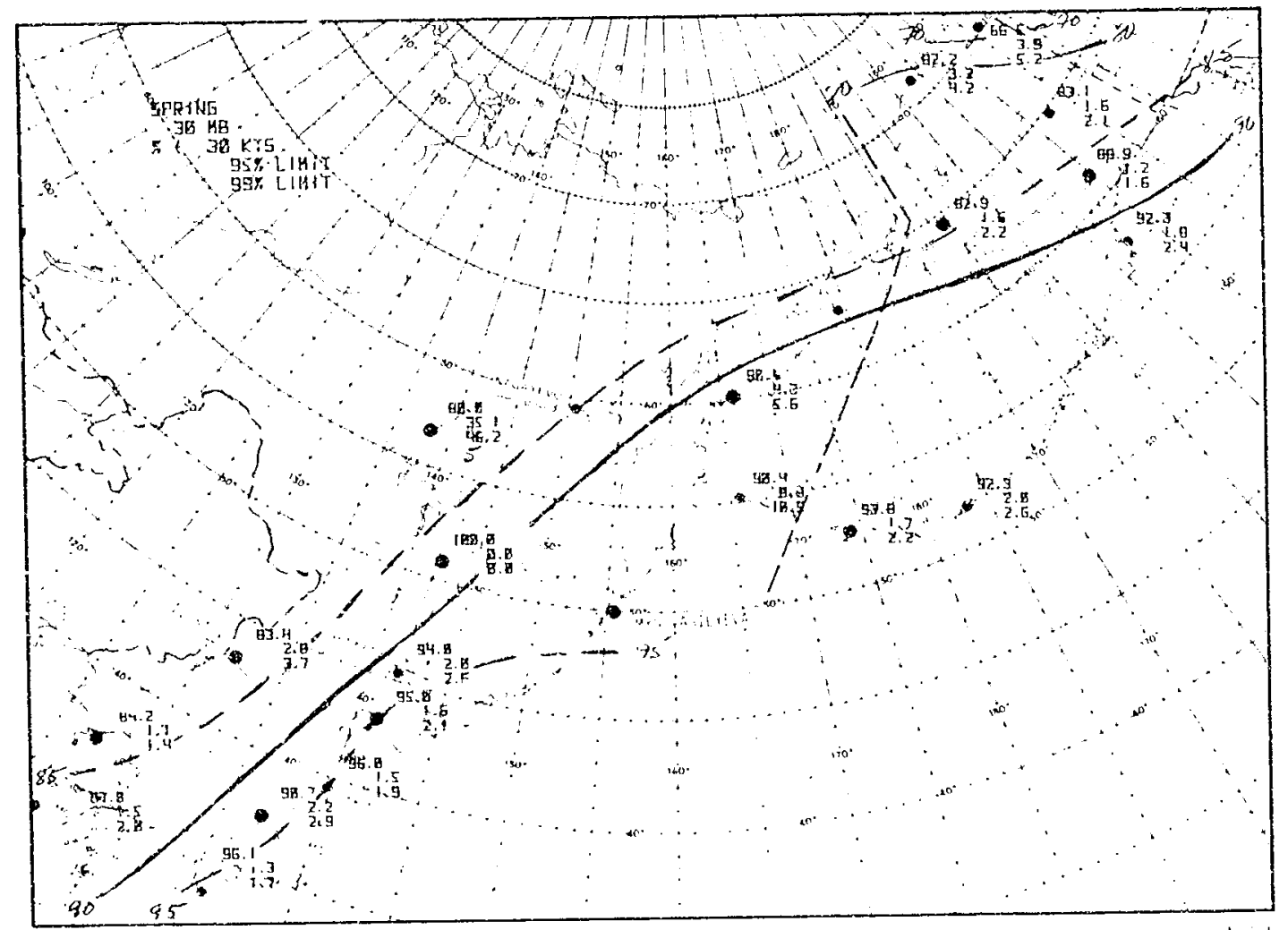

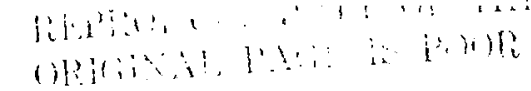

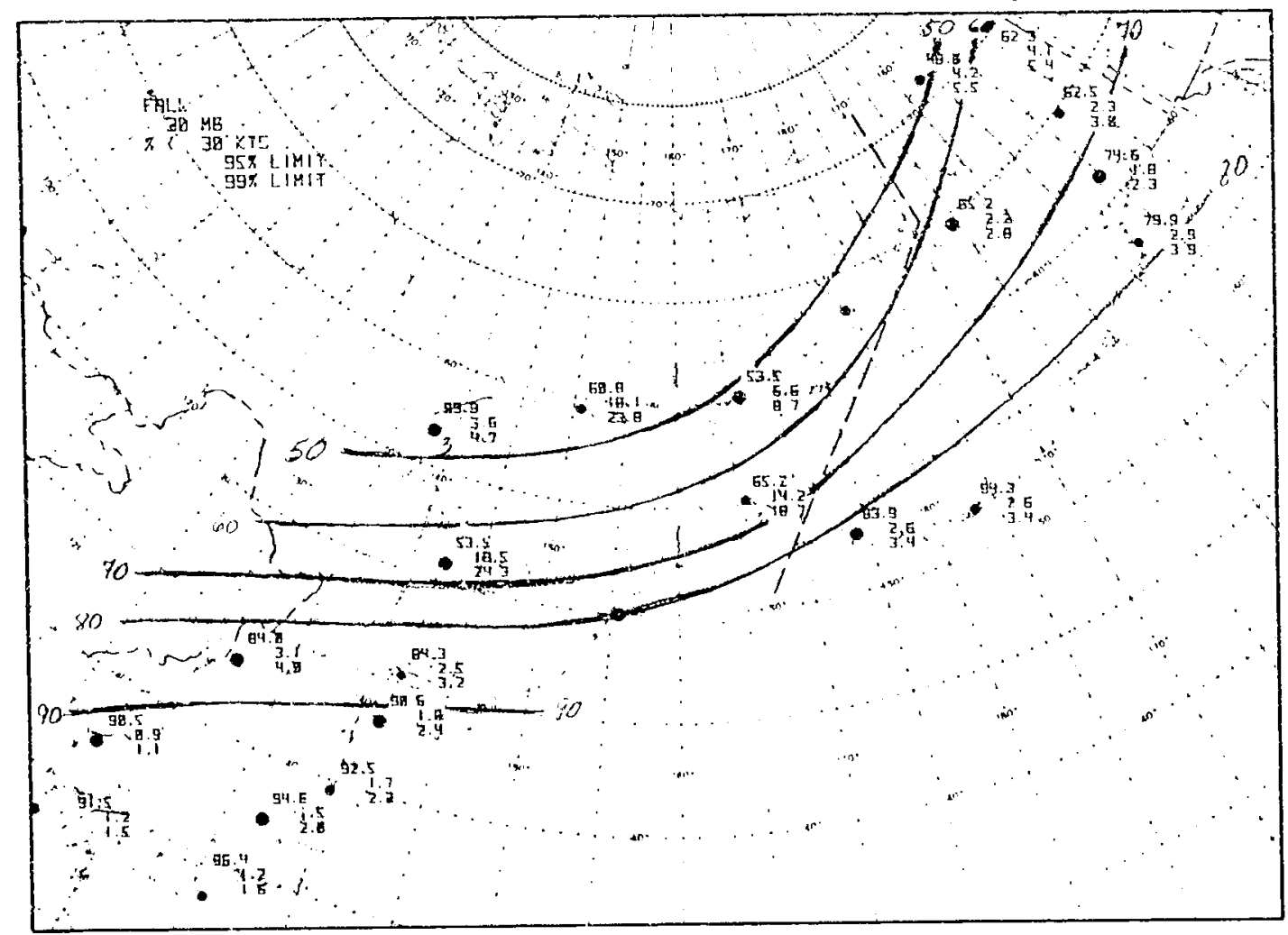



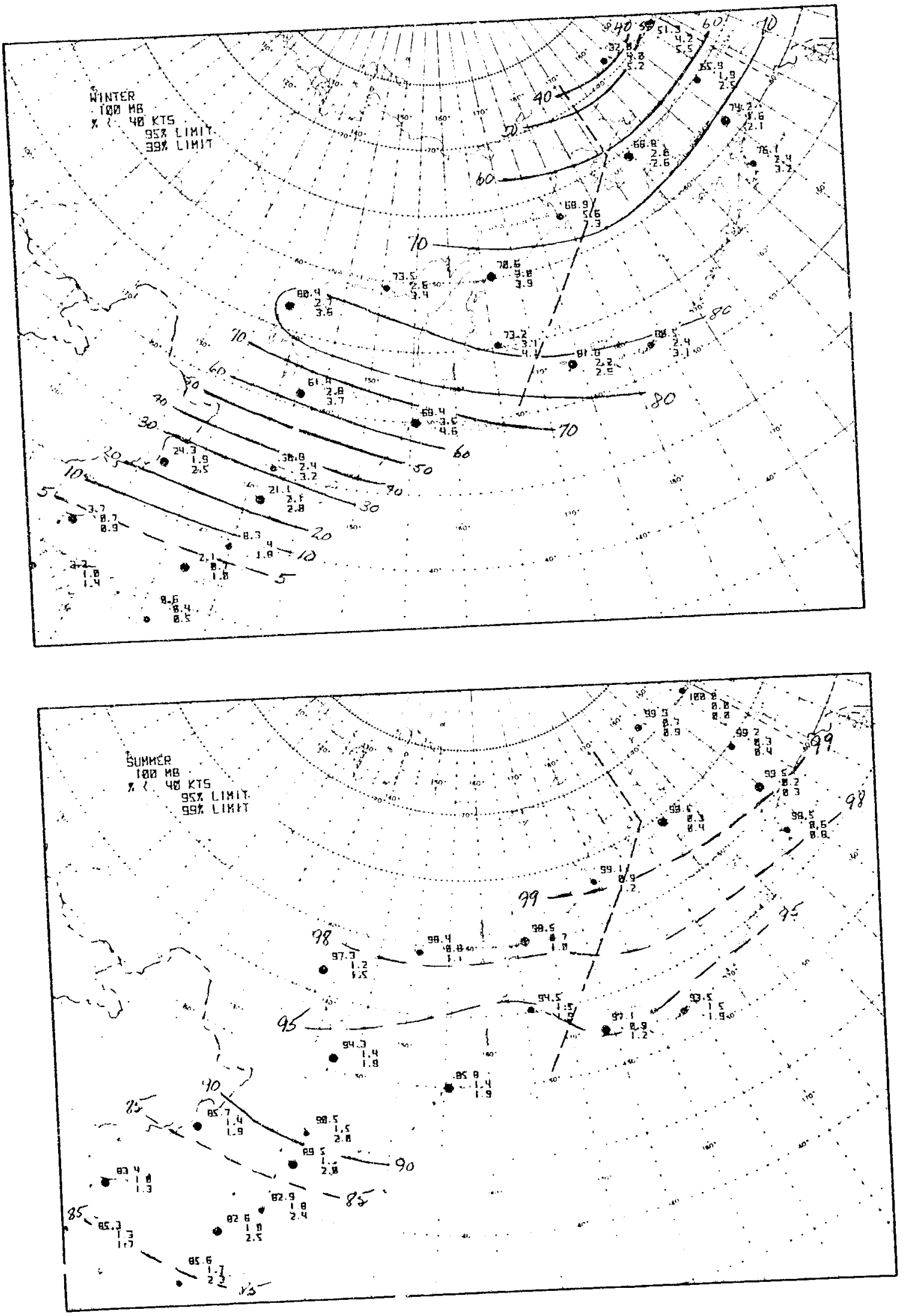


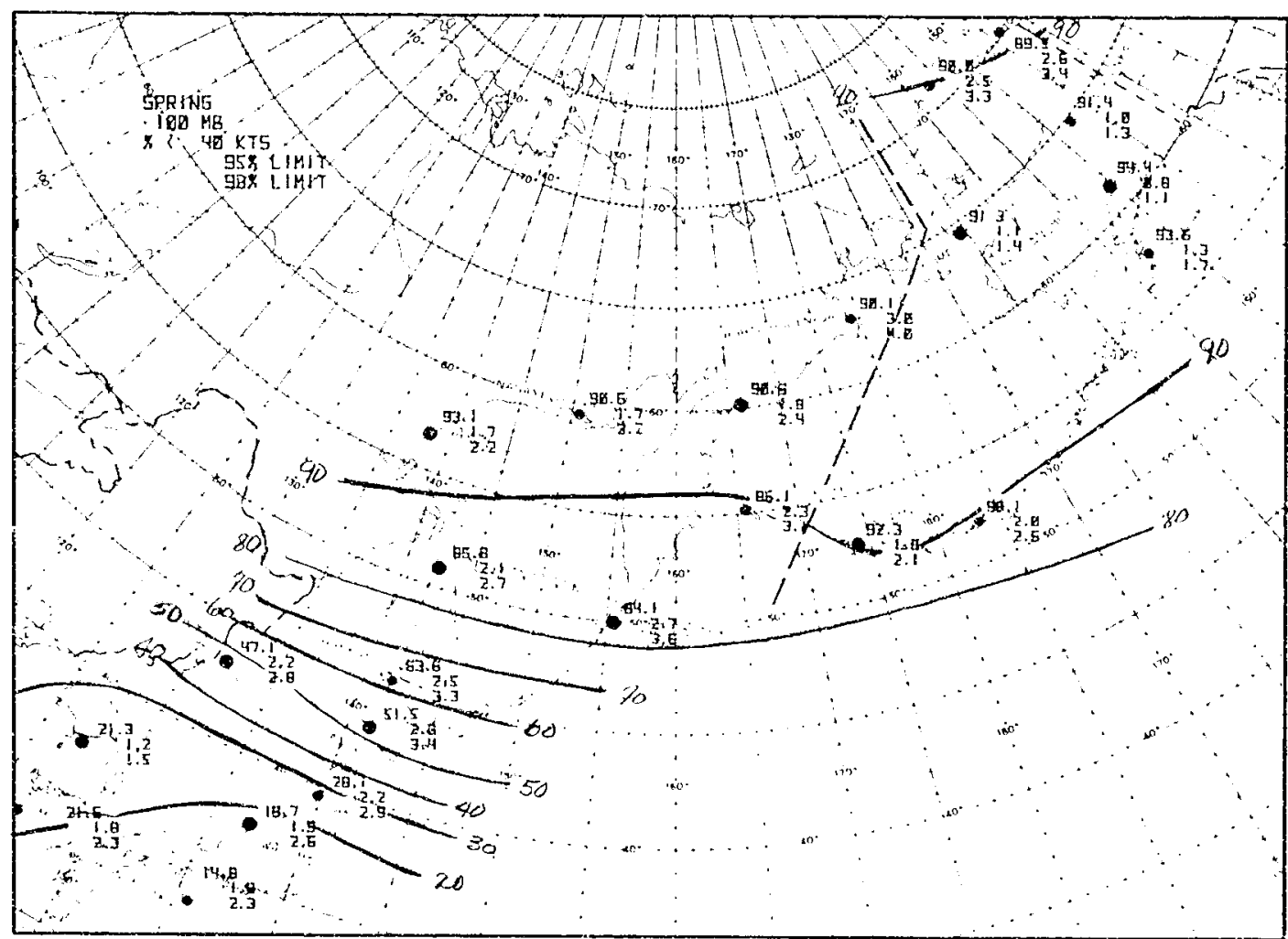

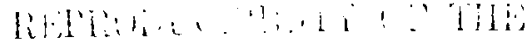

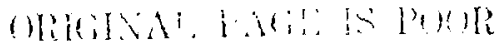

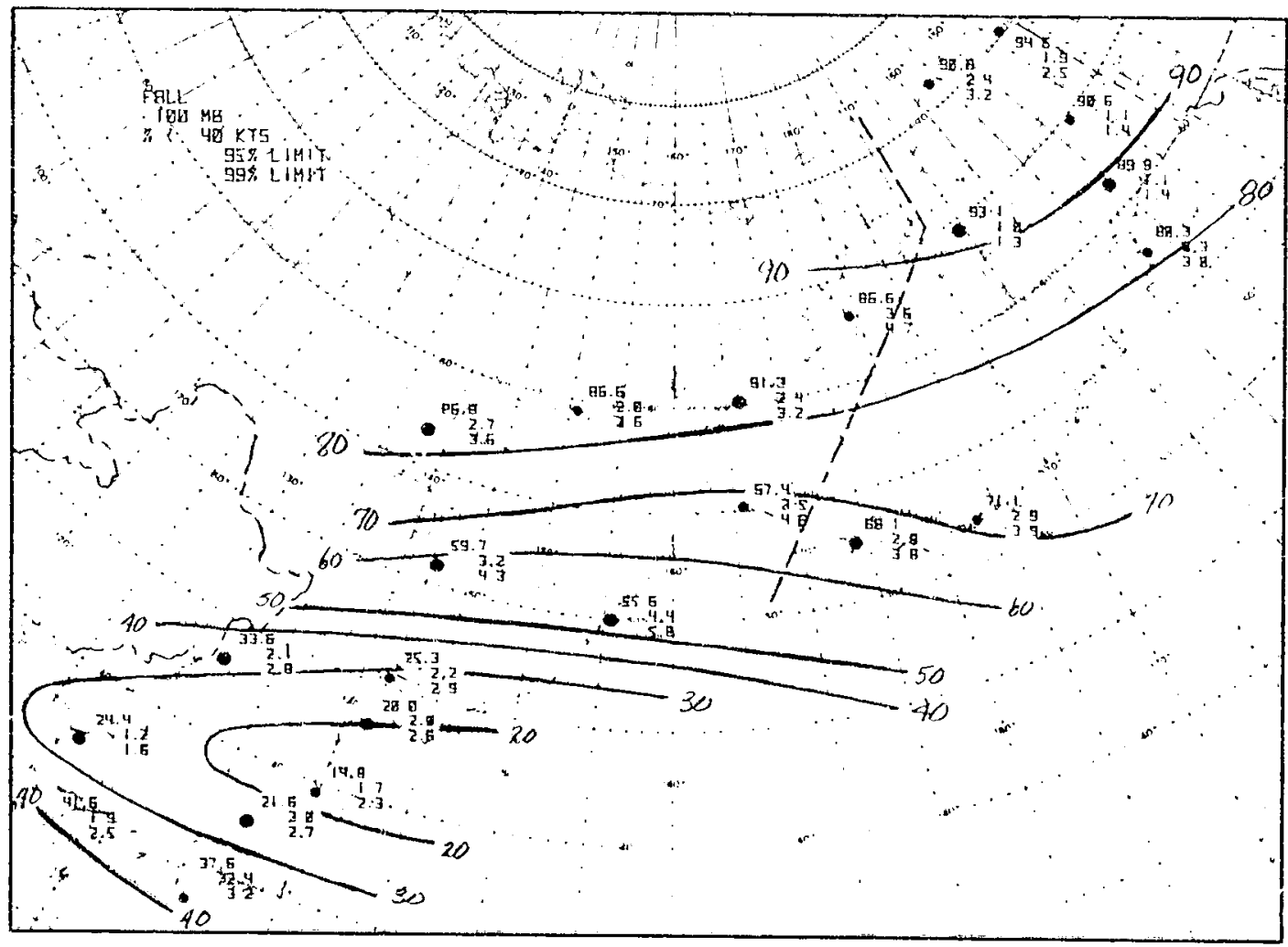



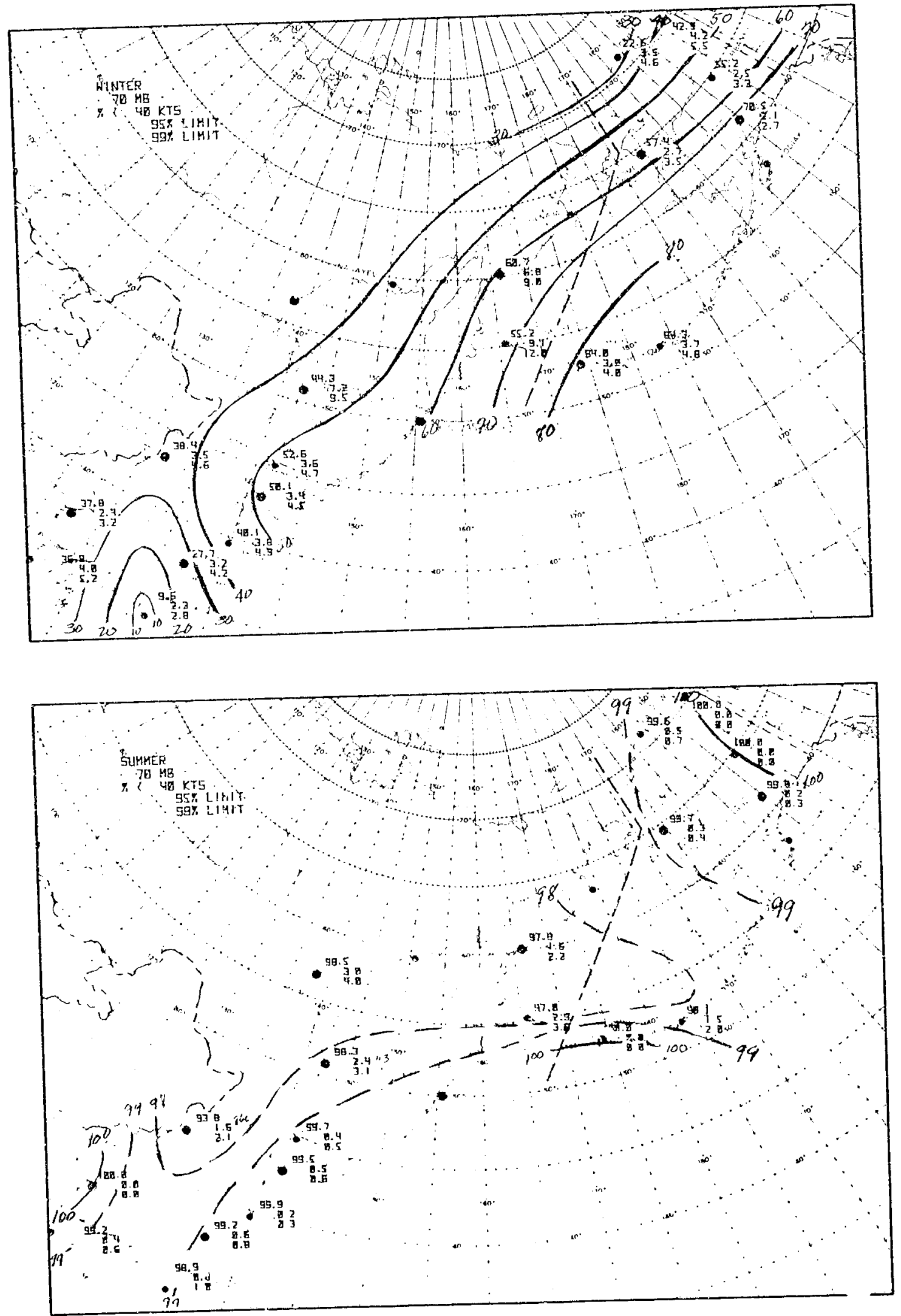

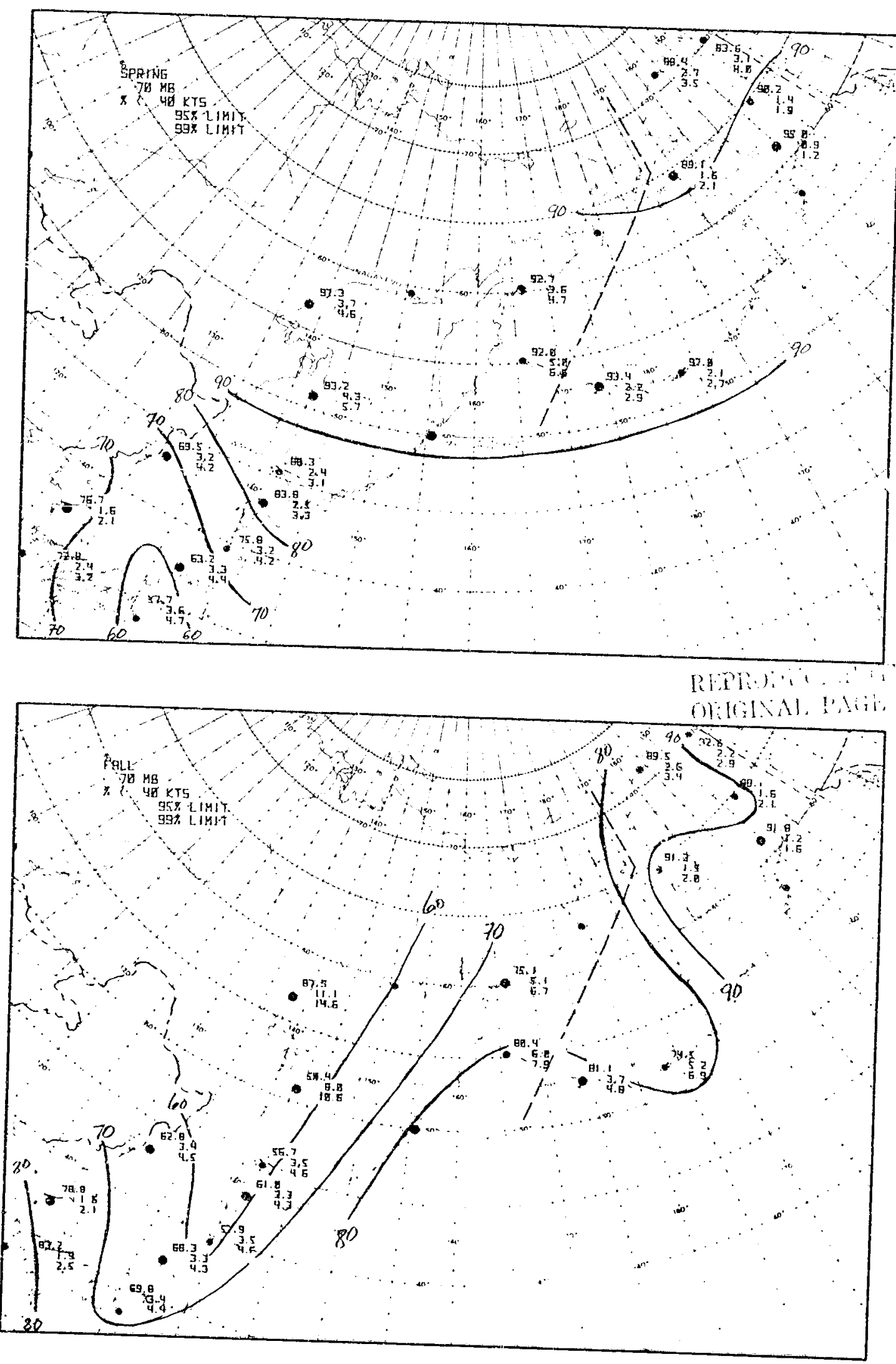

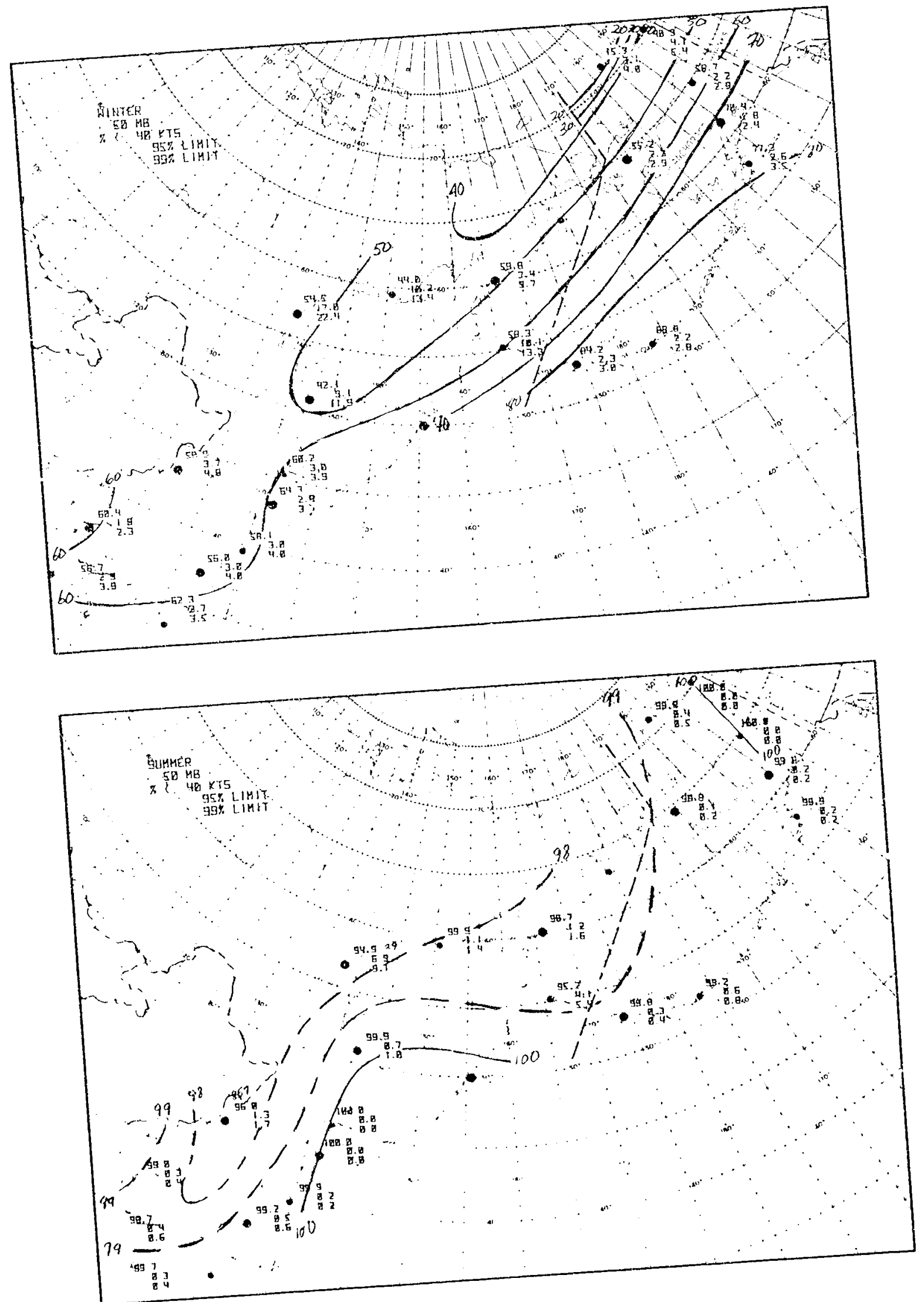

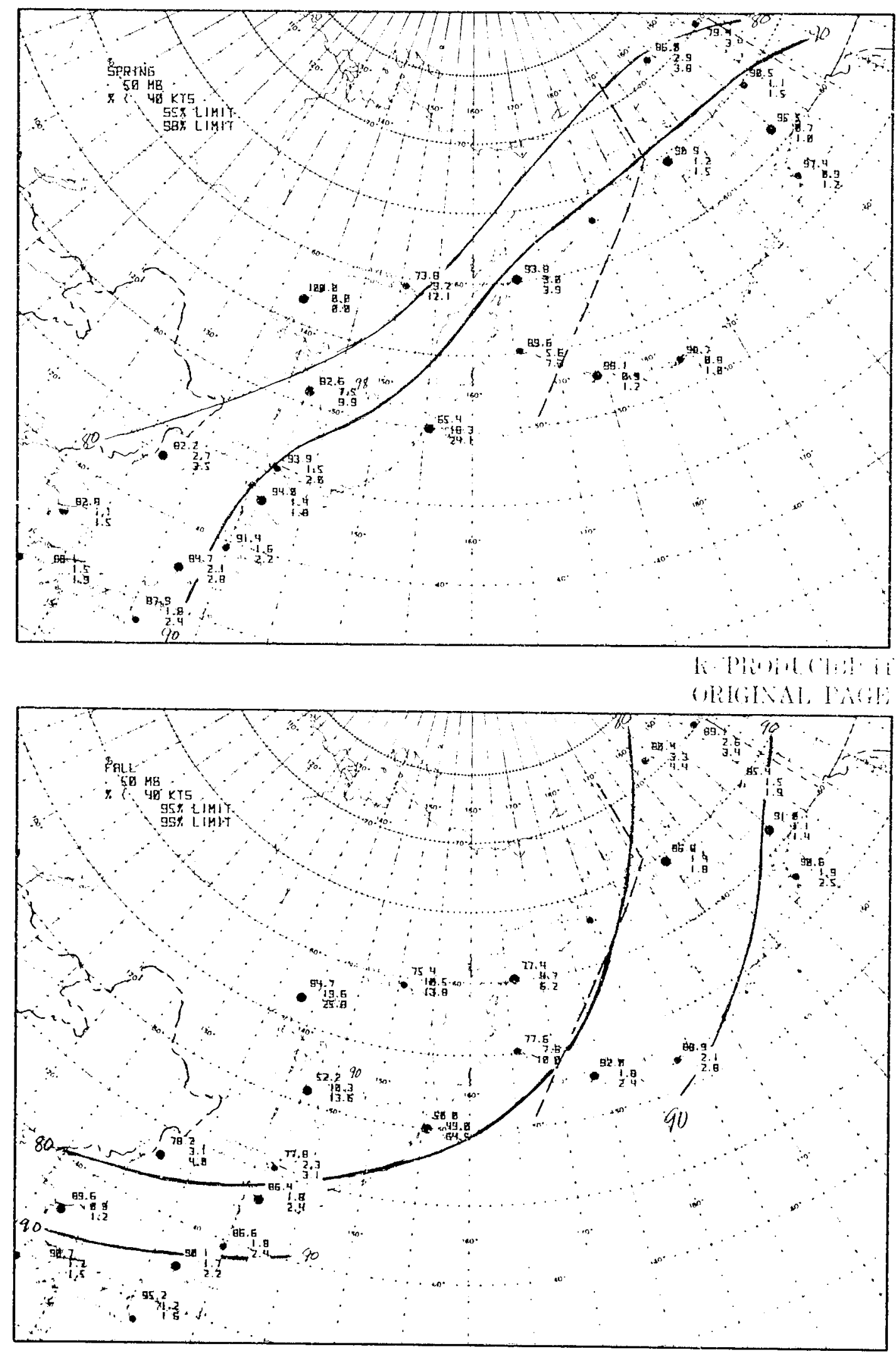

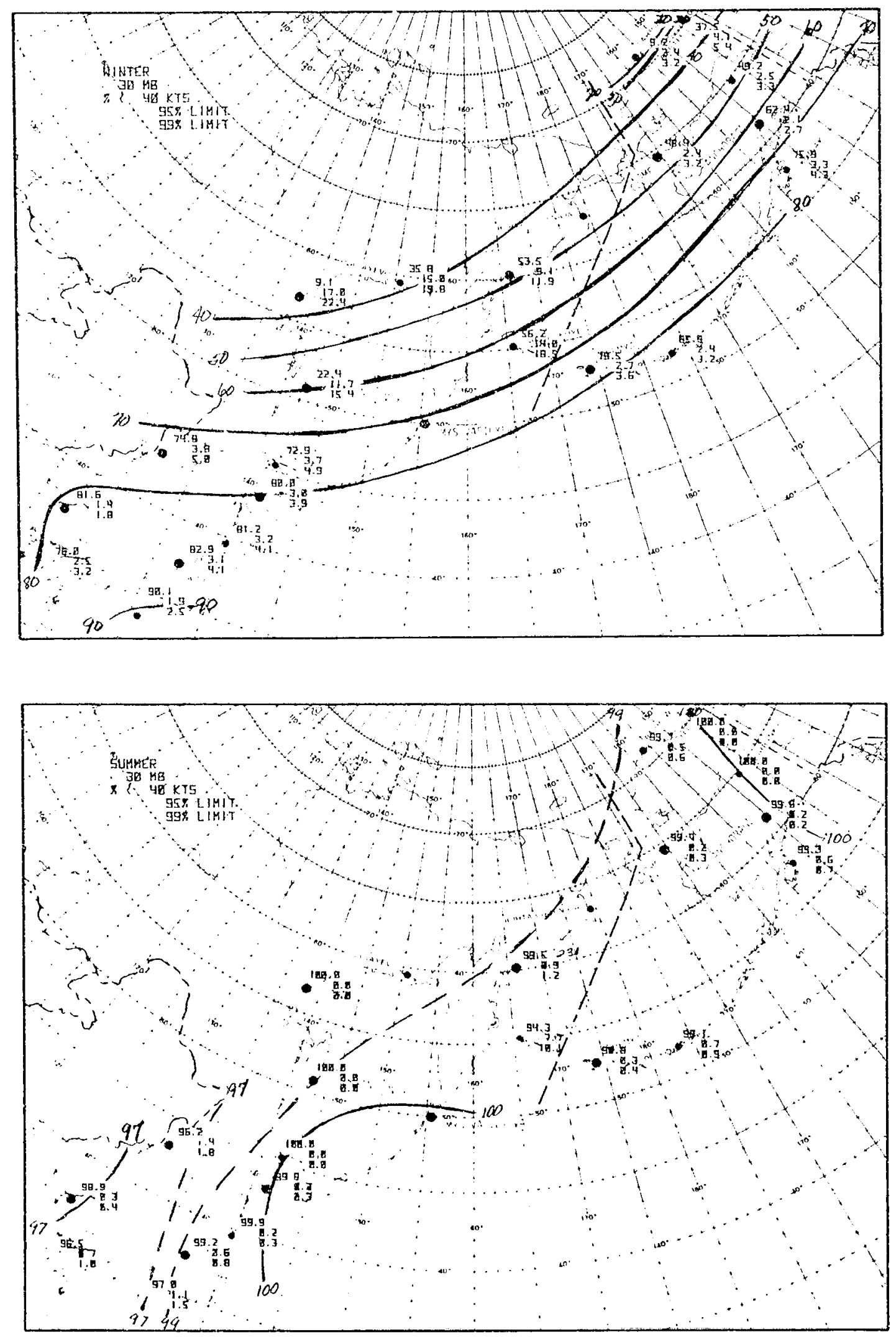

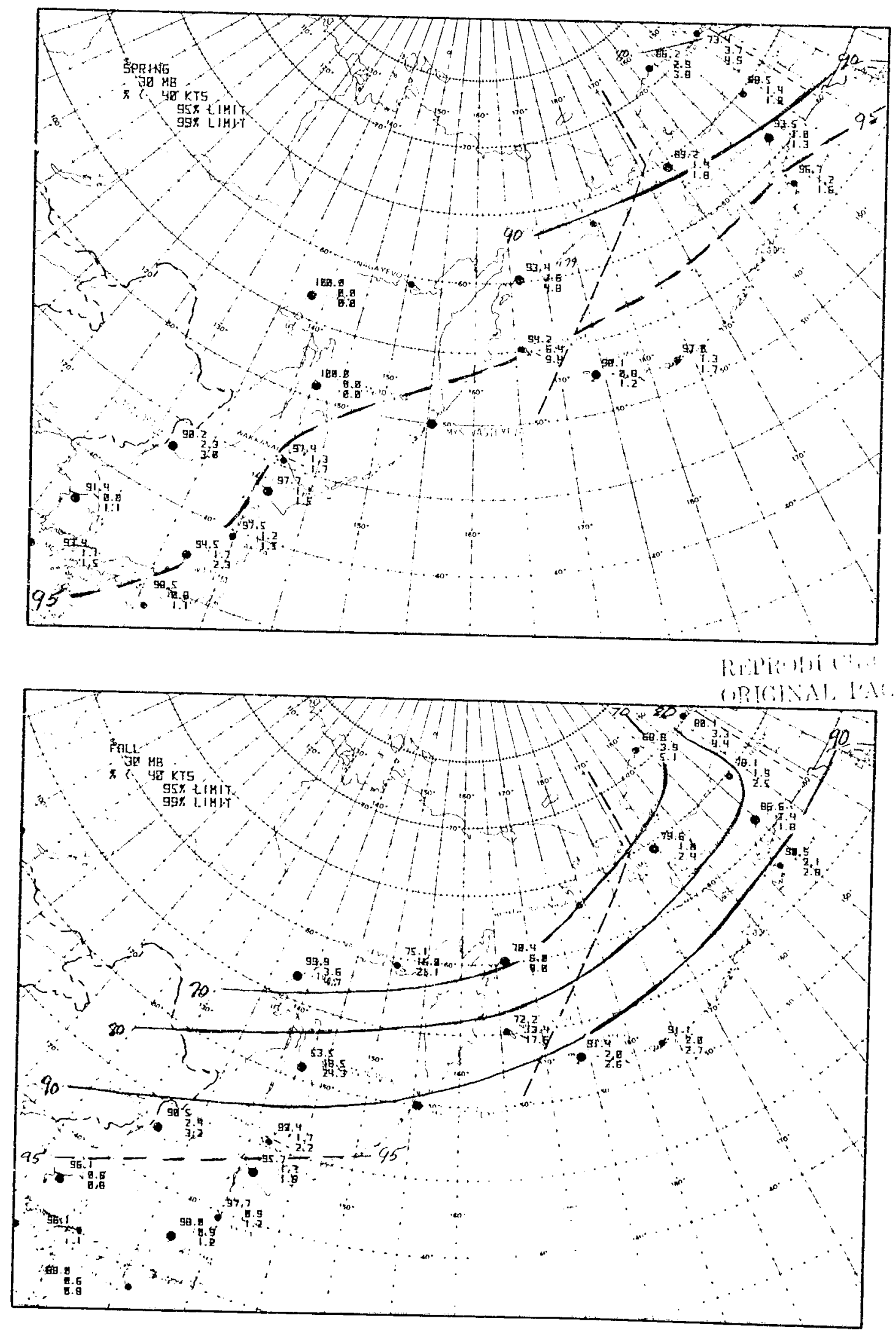

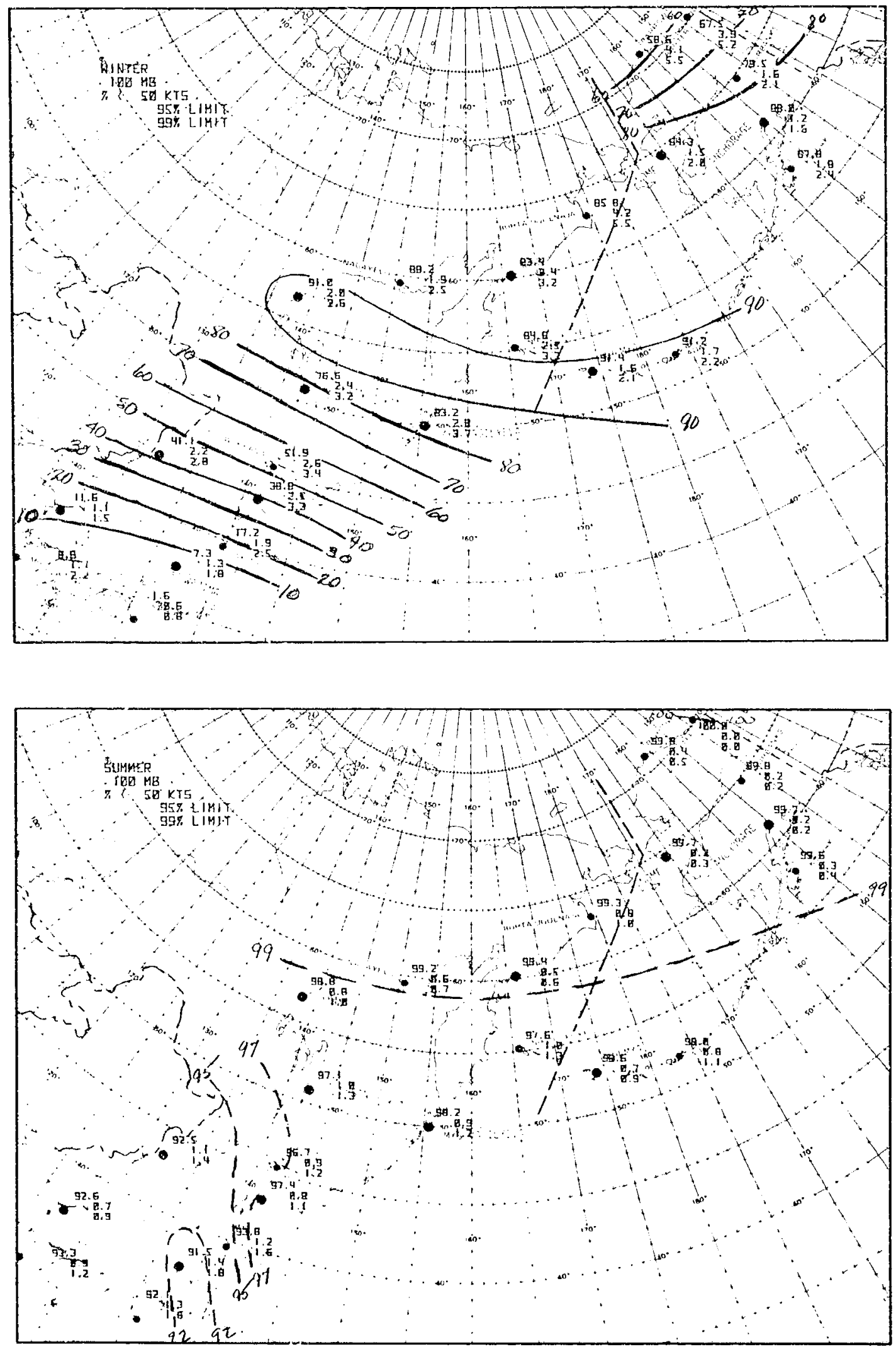


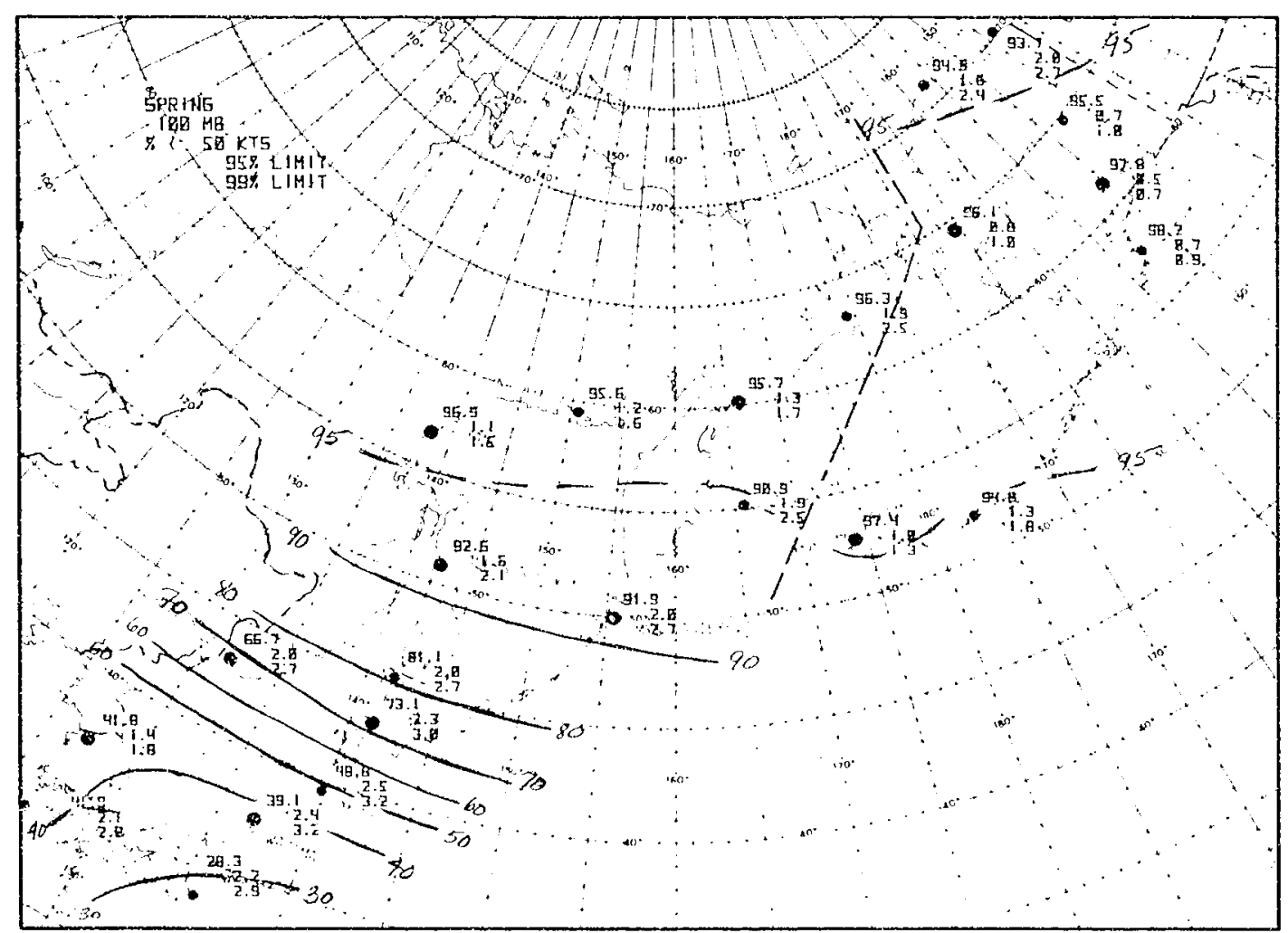

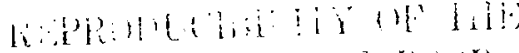

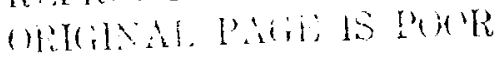

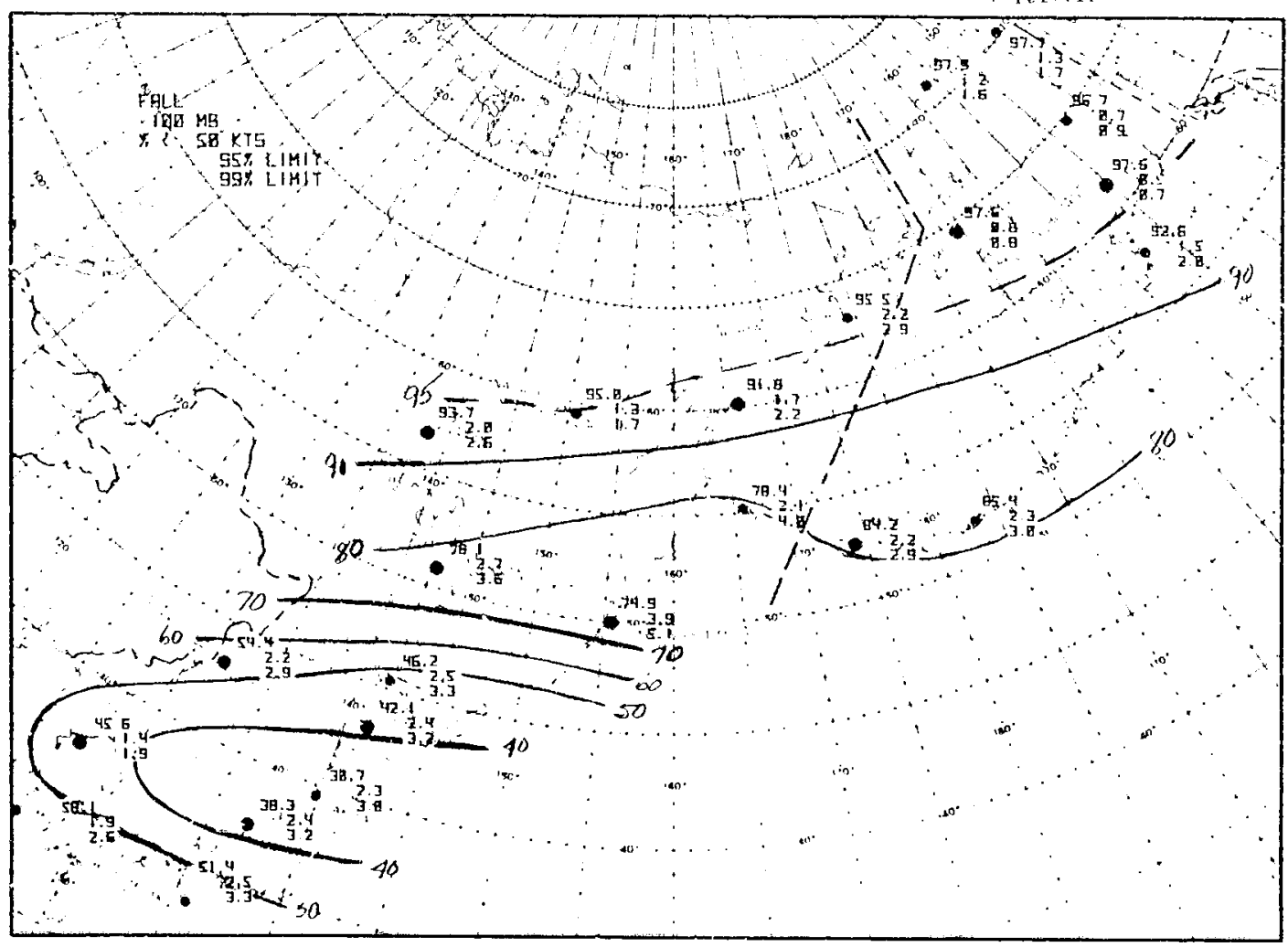



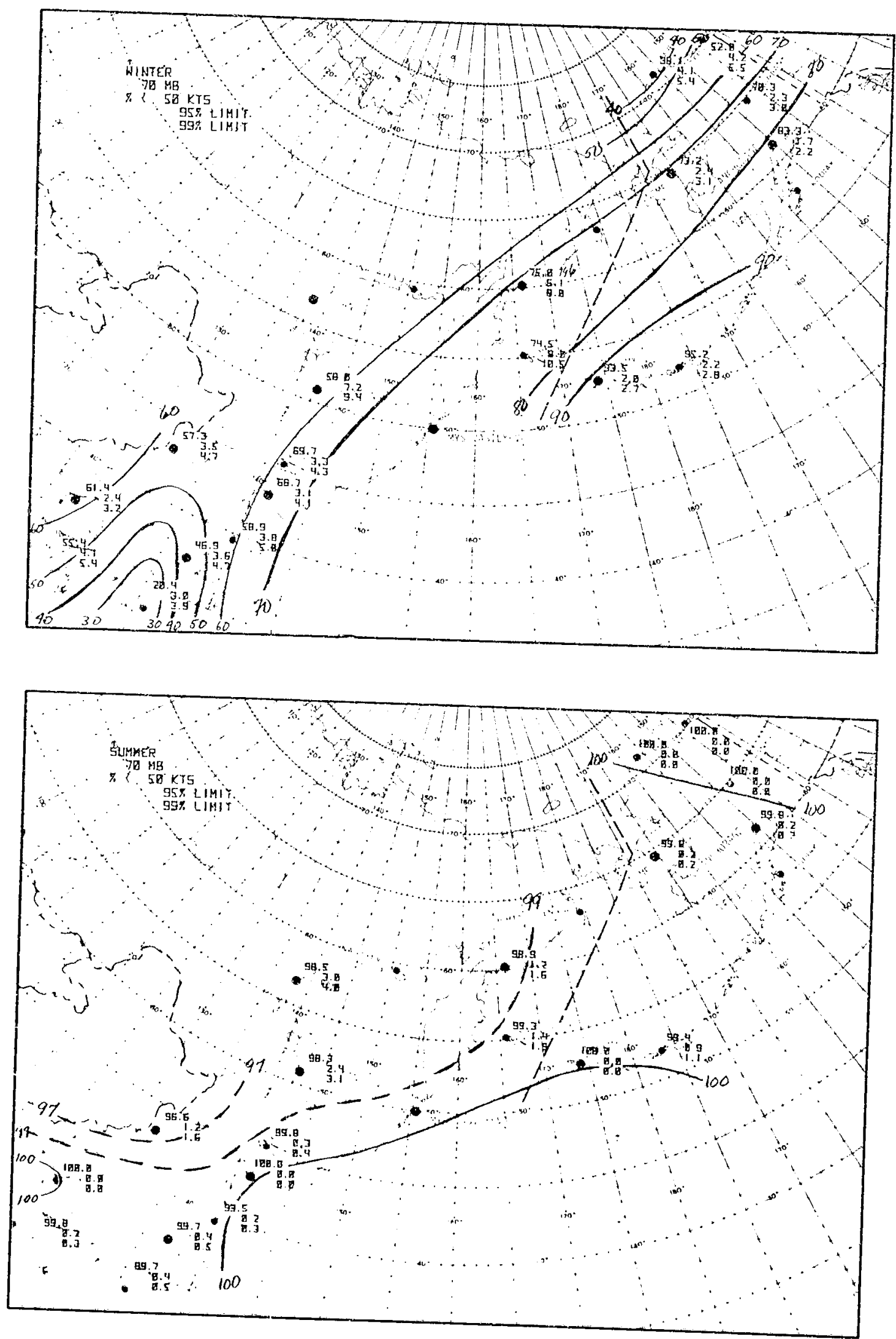

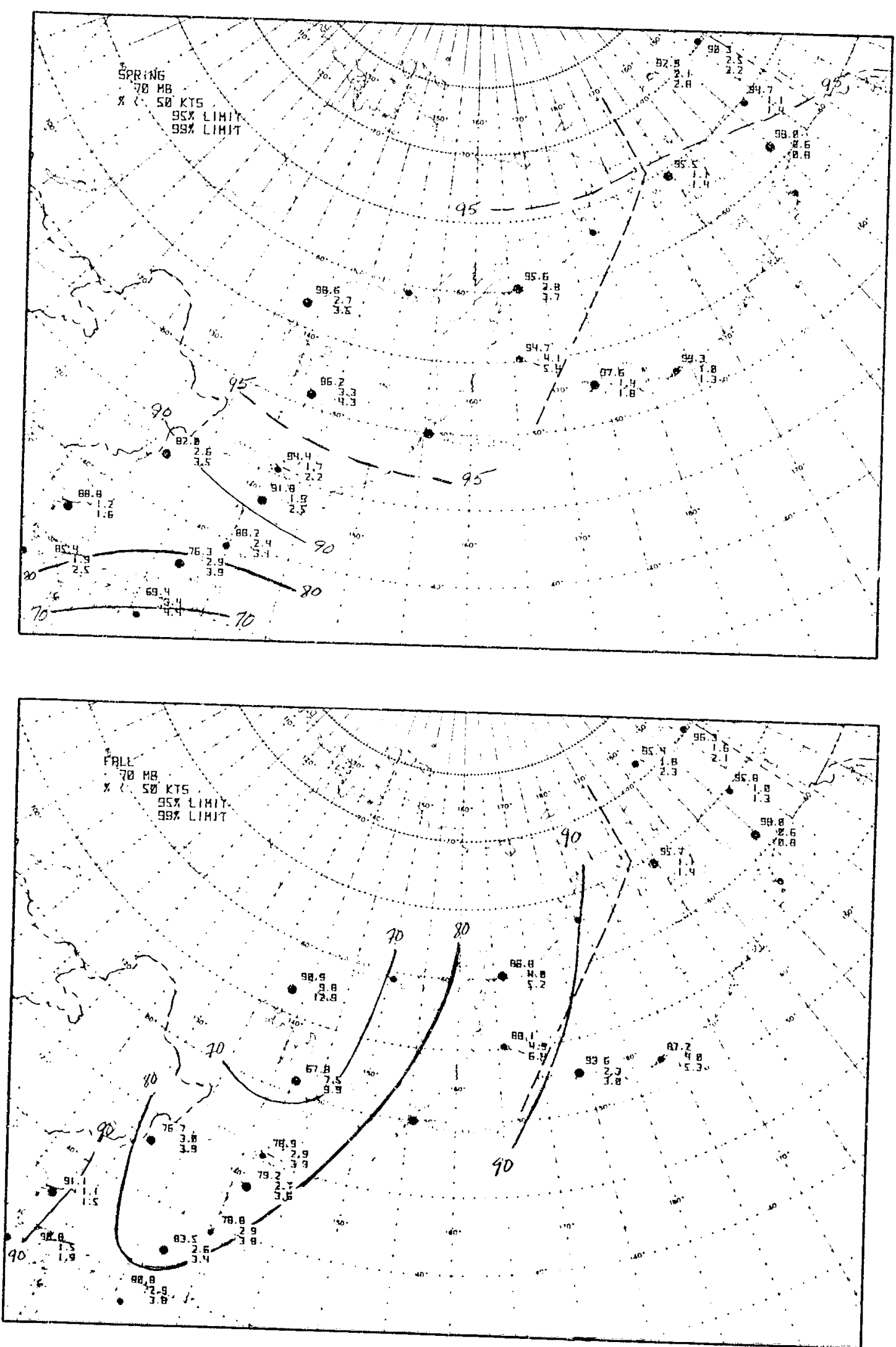

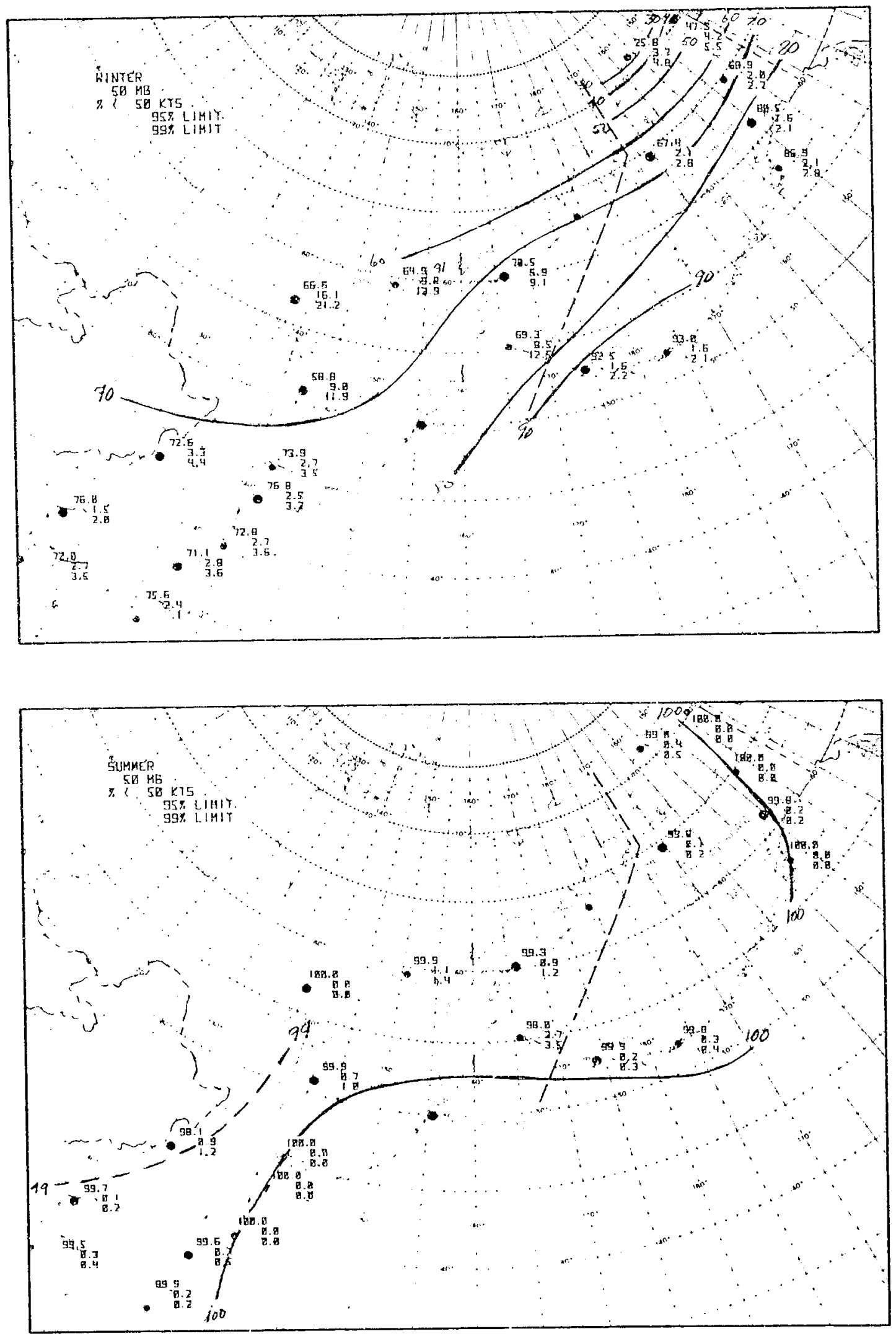


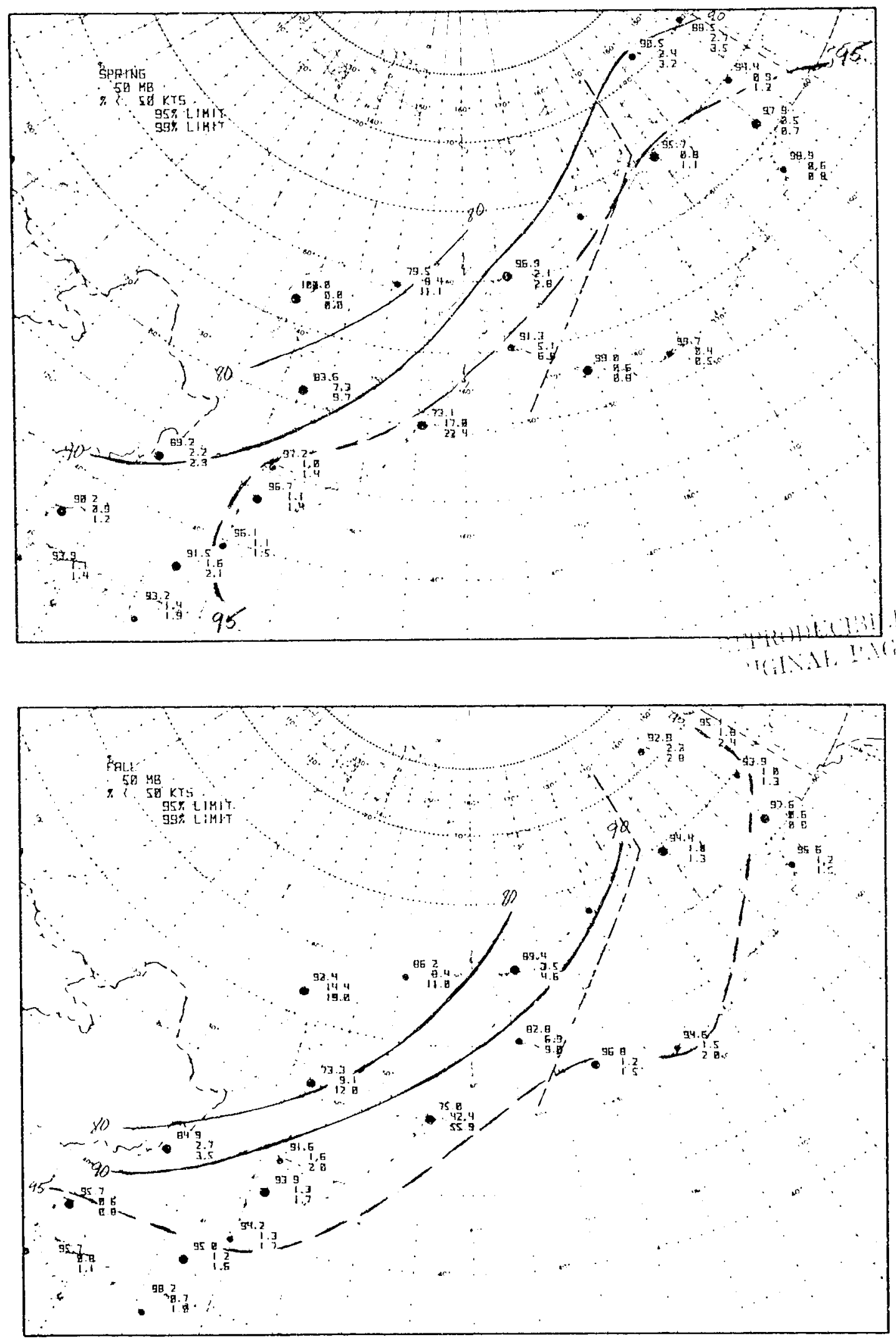



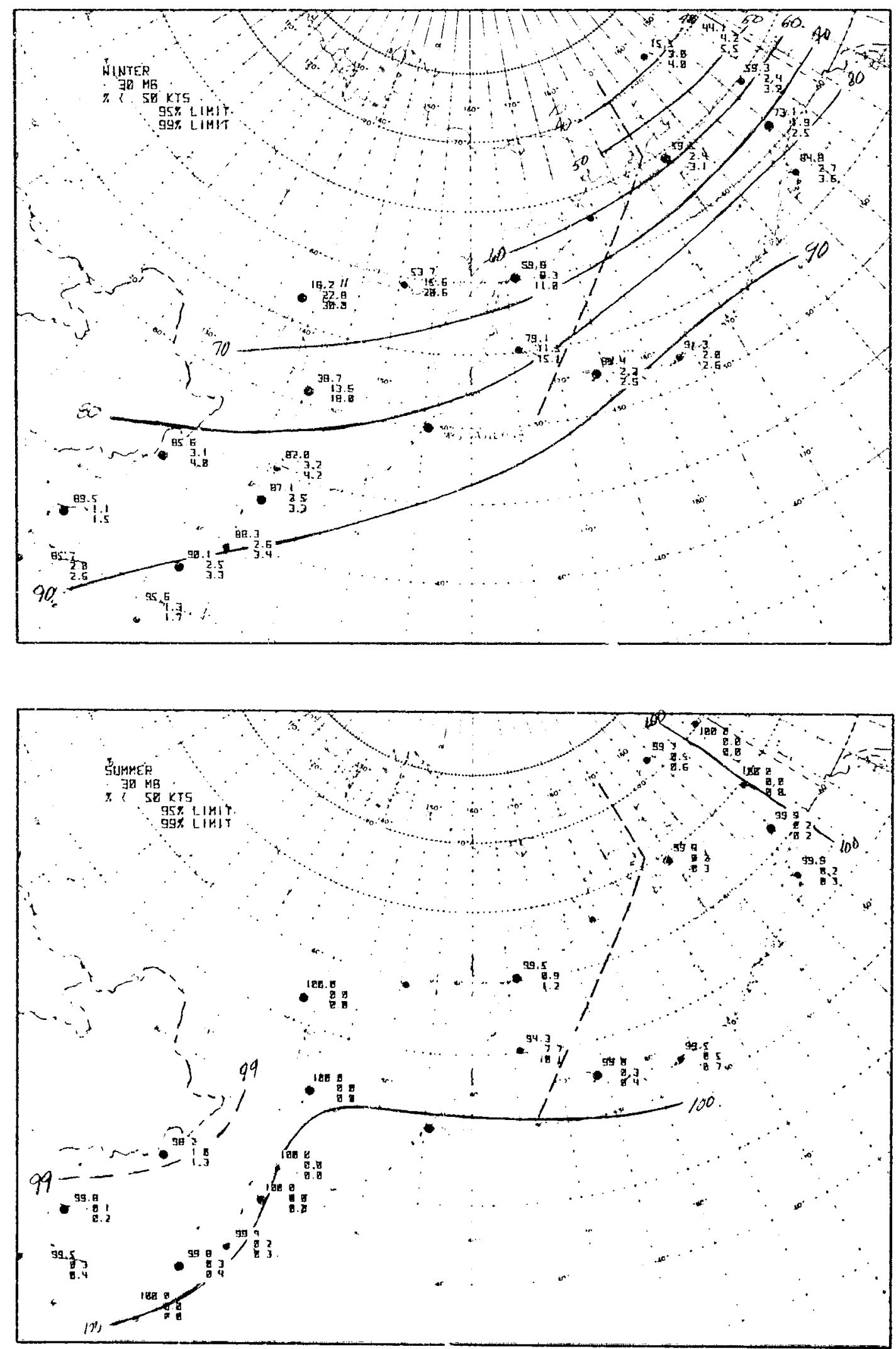


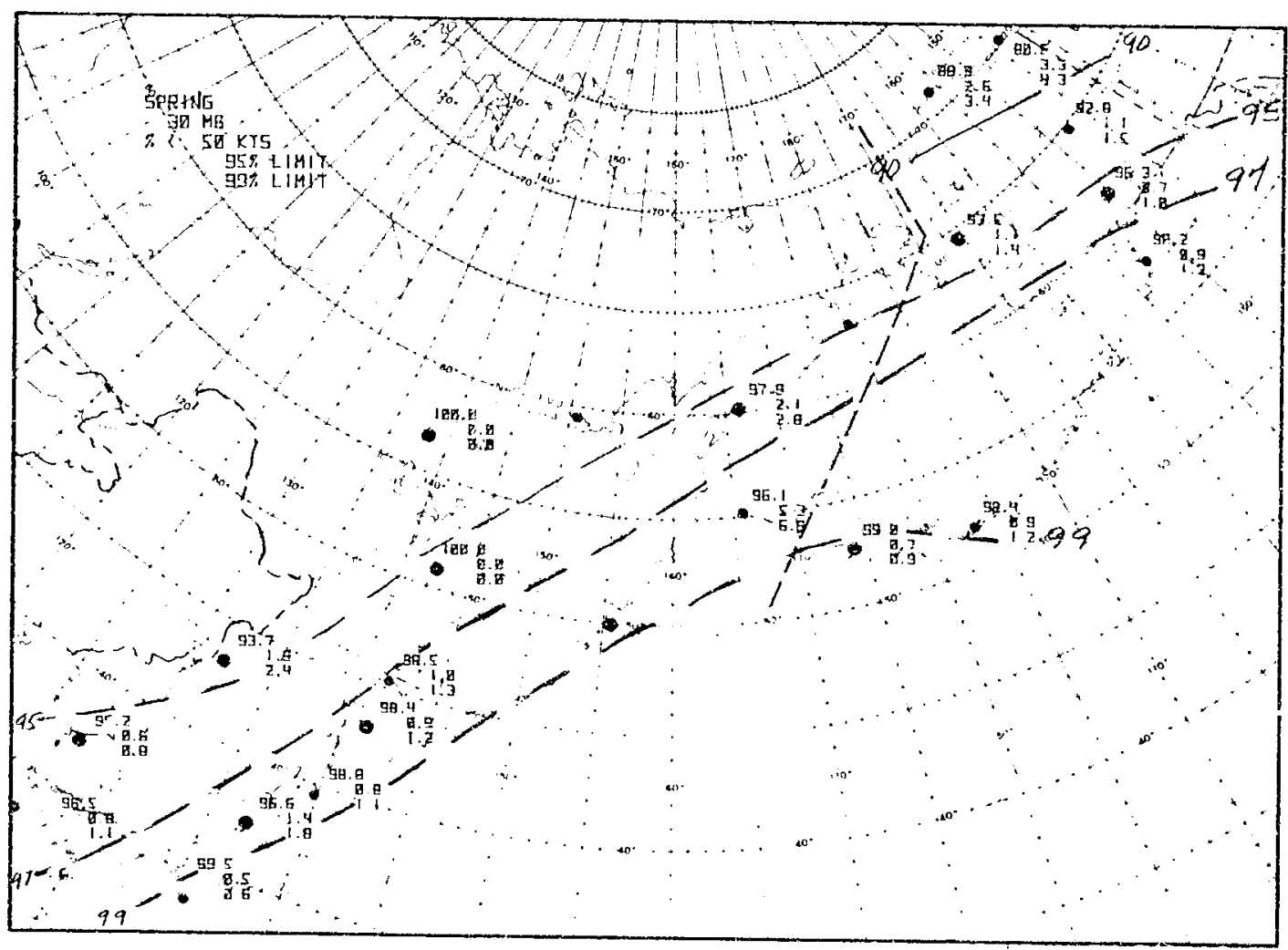

in

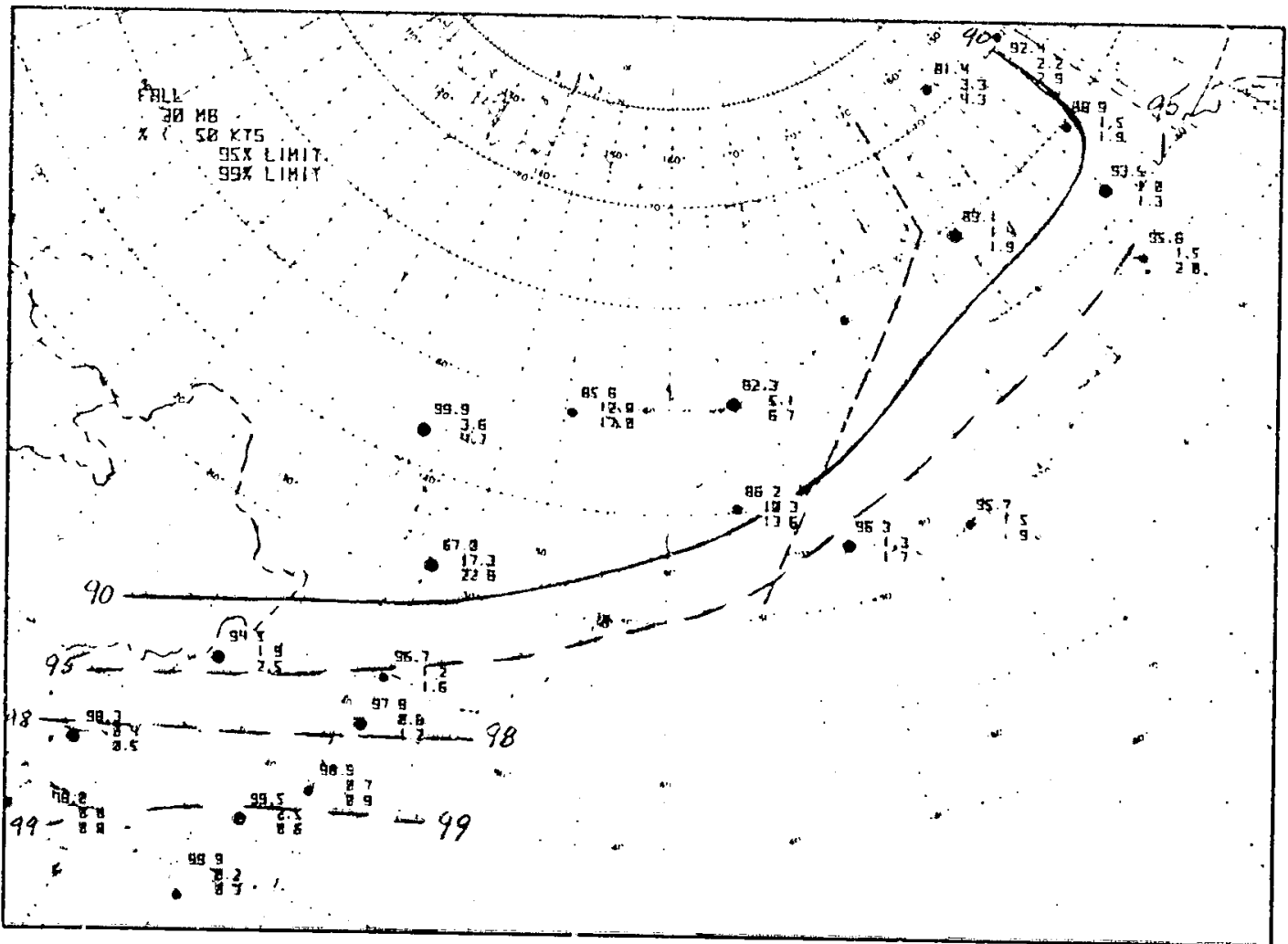



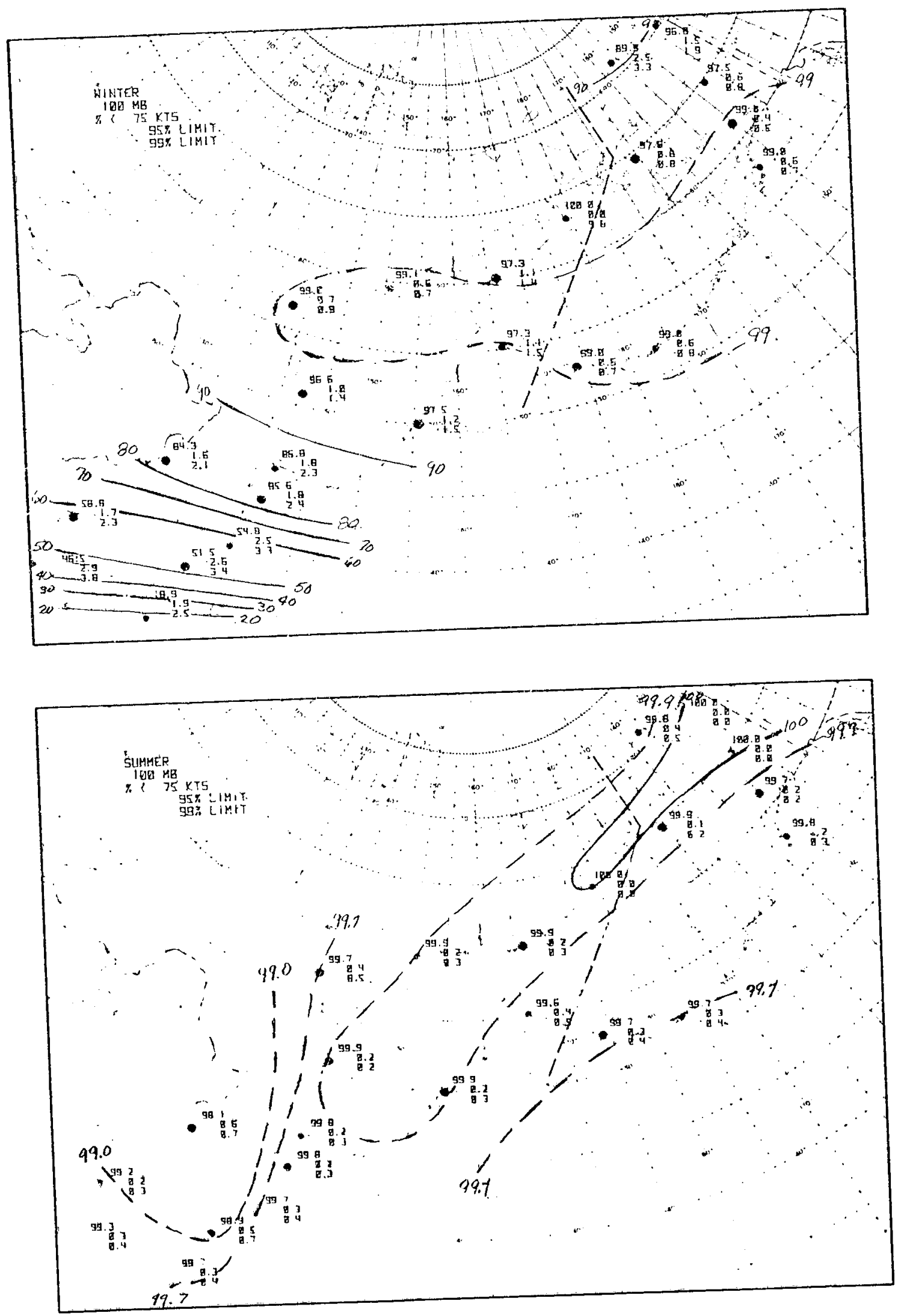

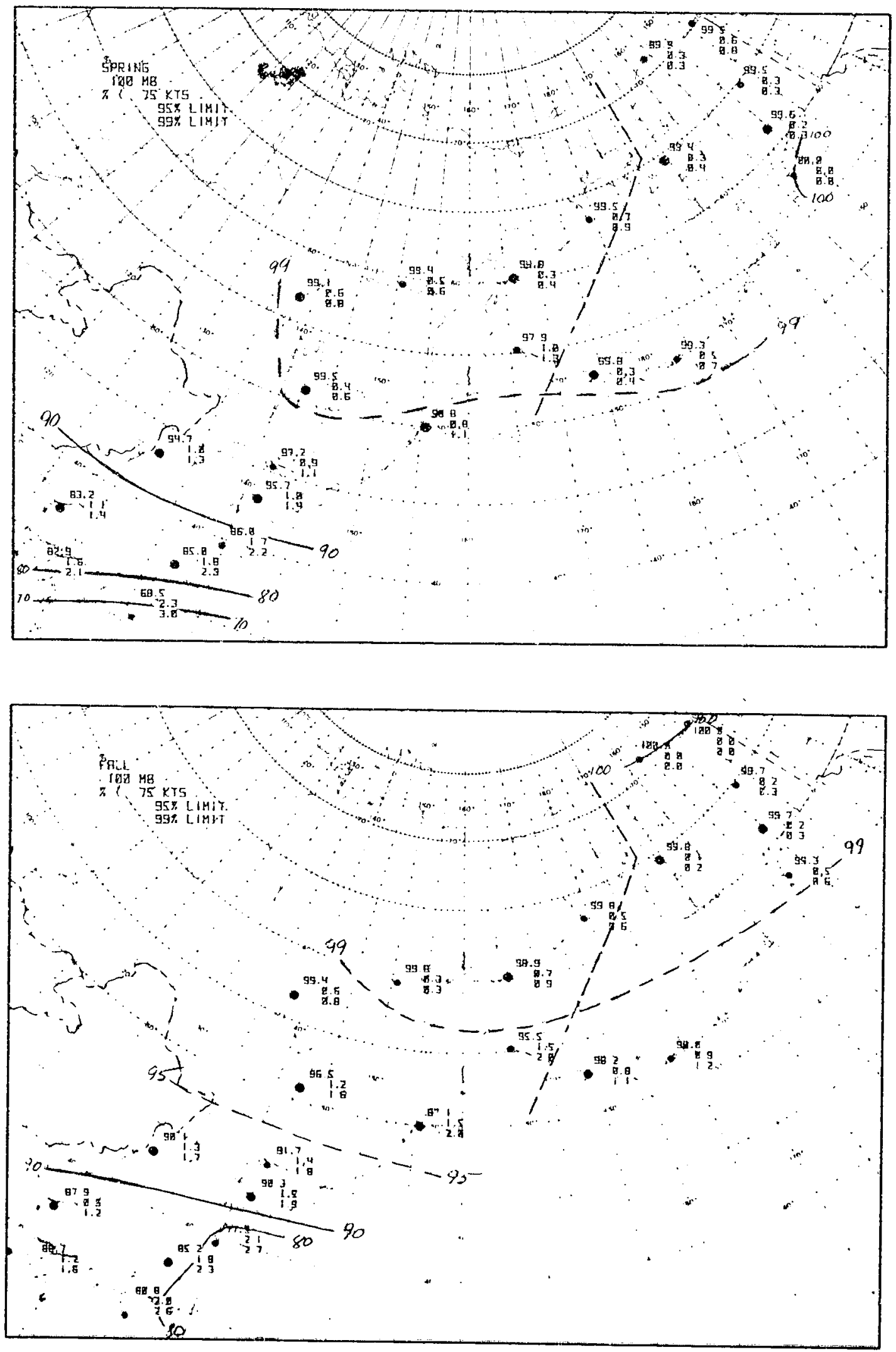

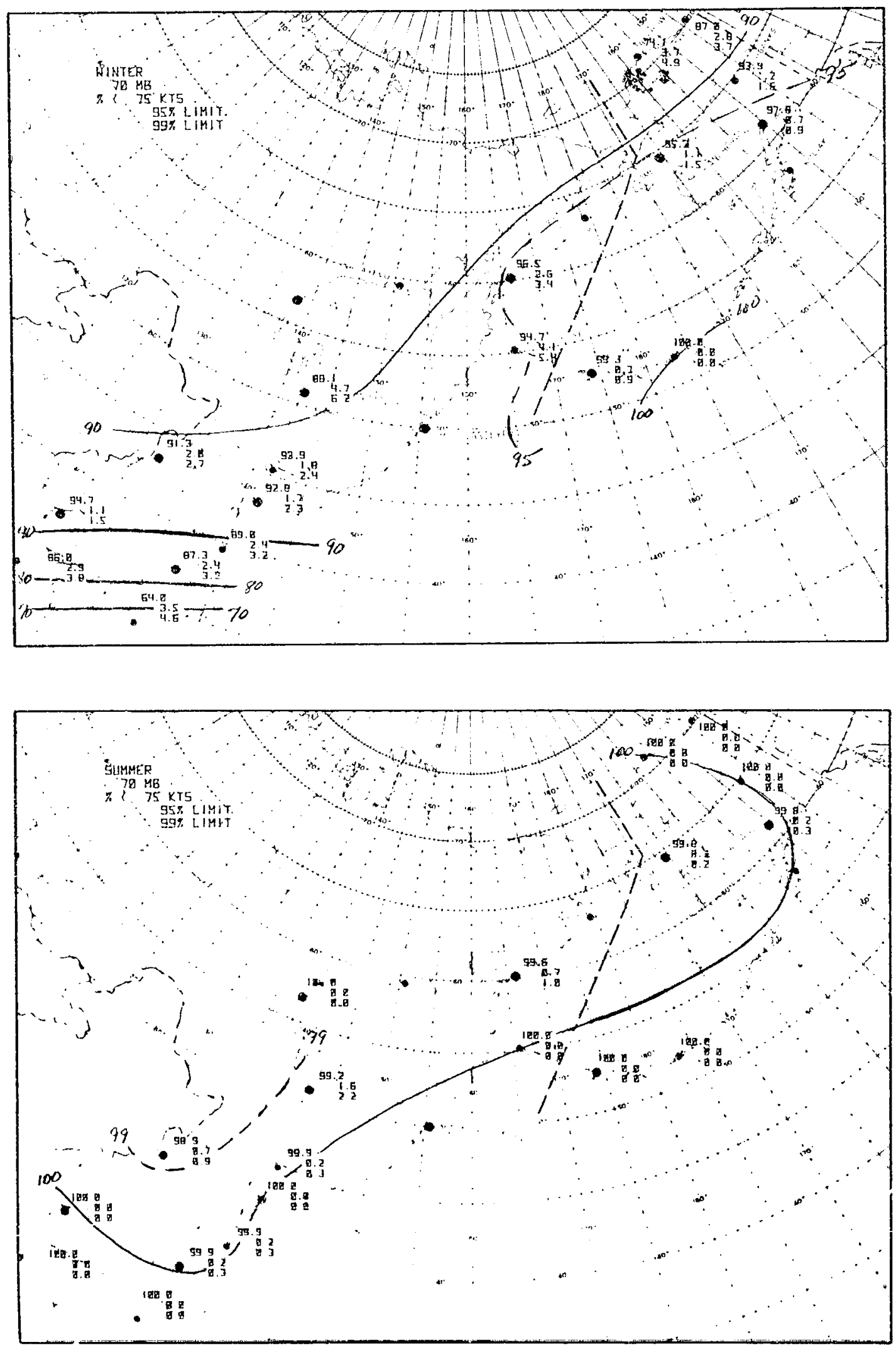

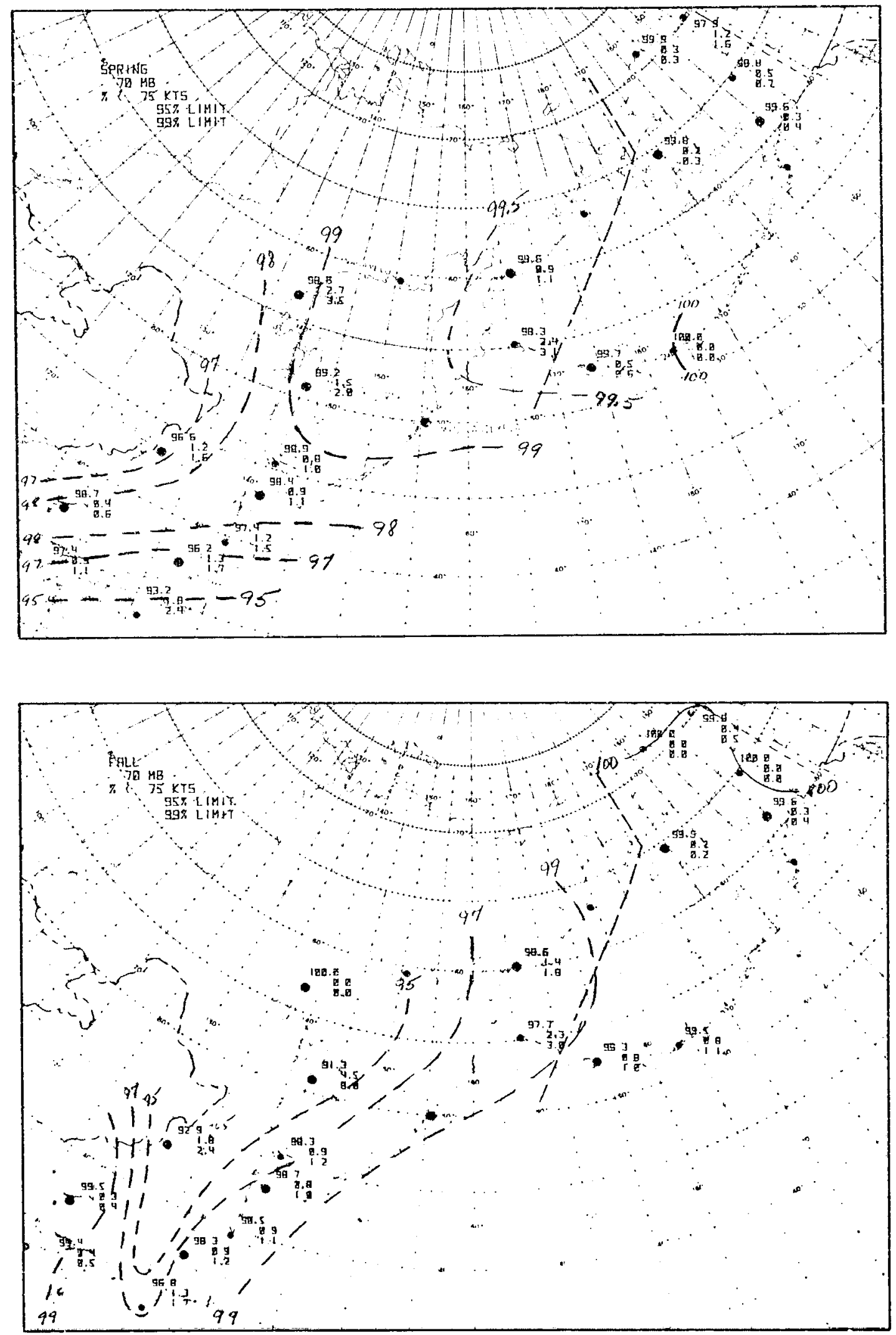

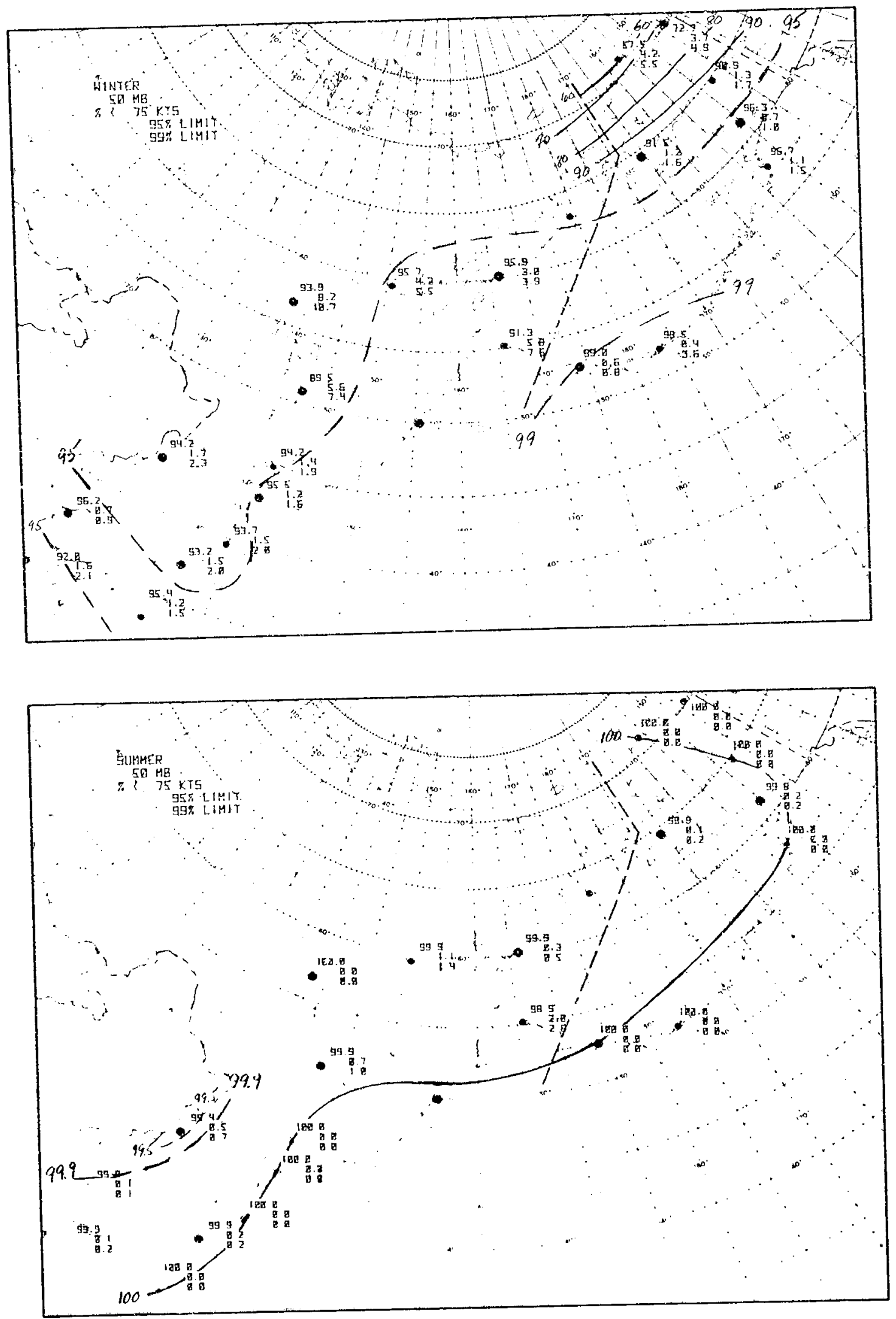

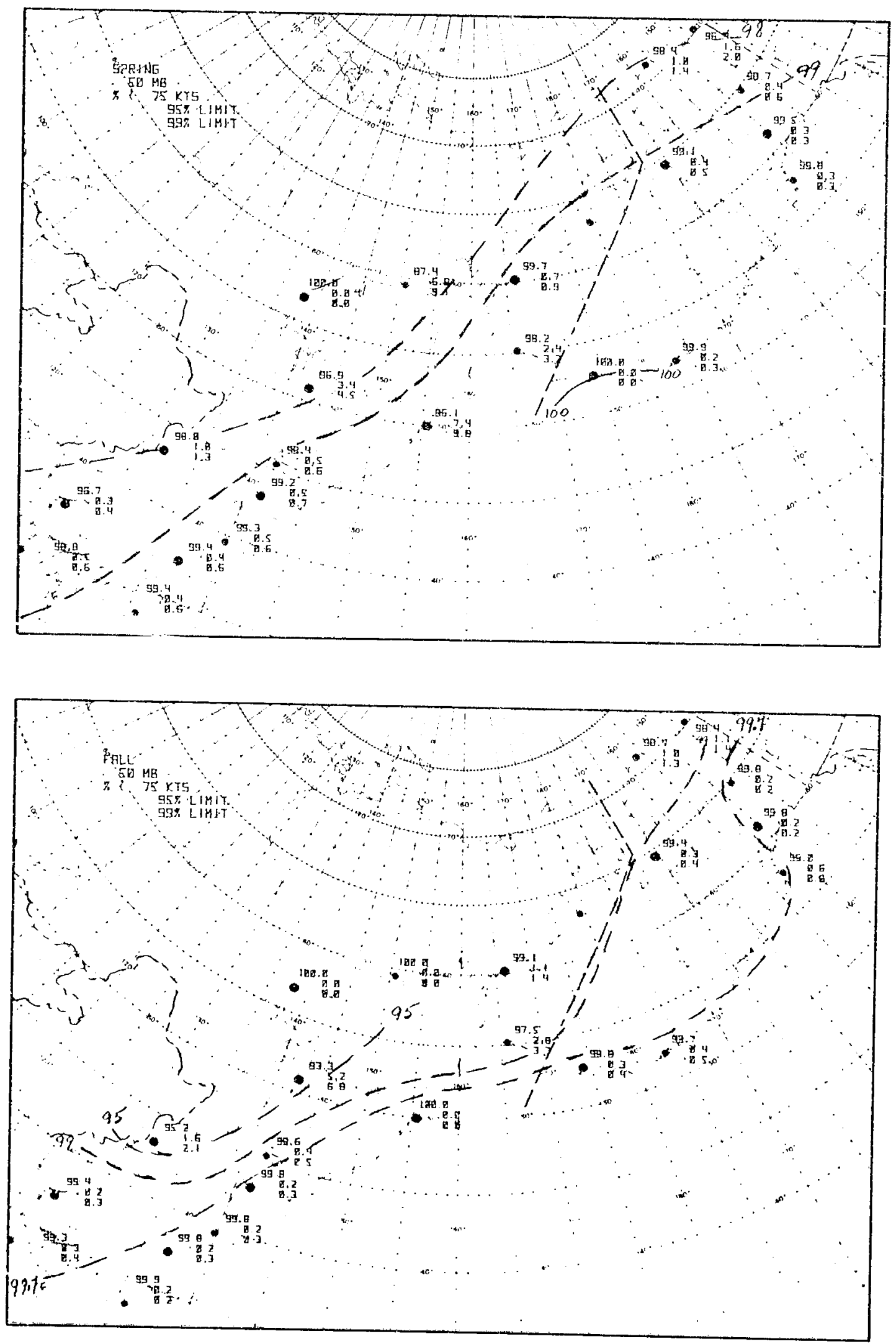

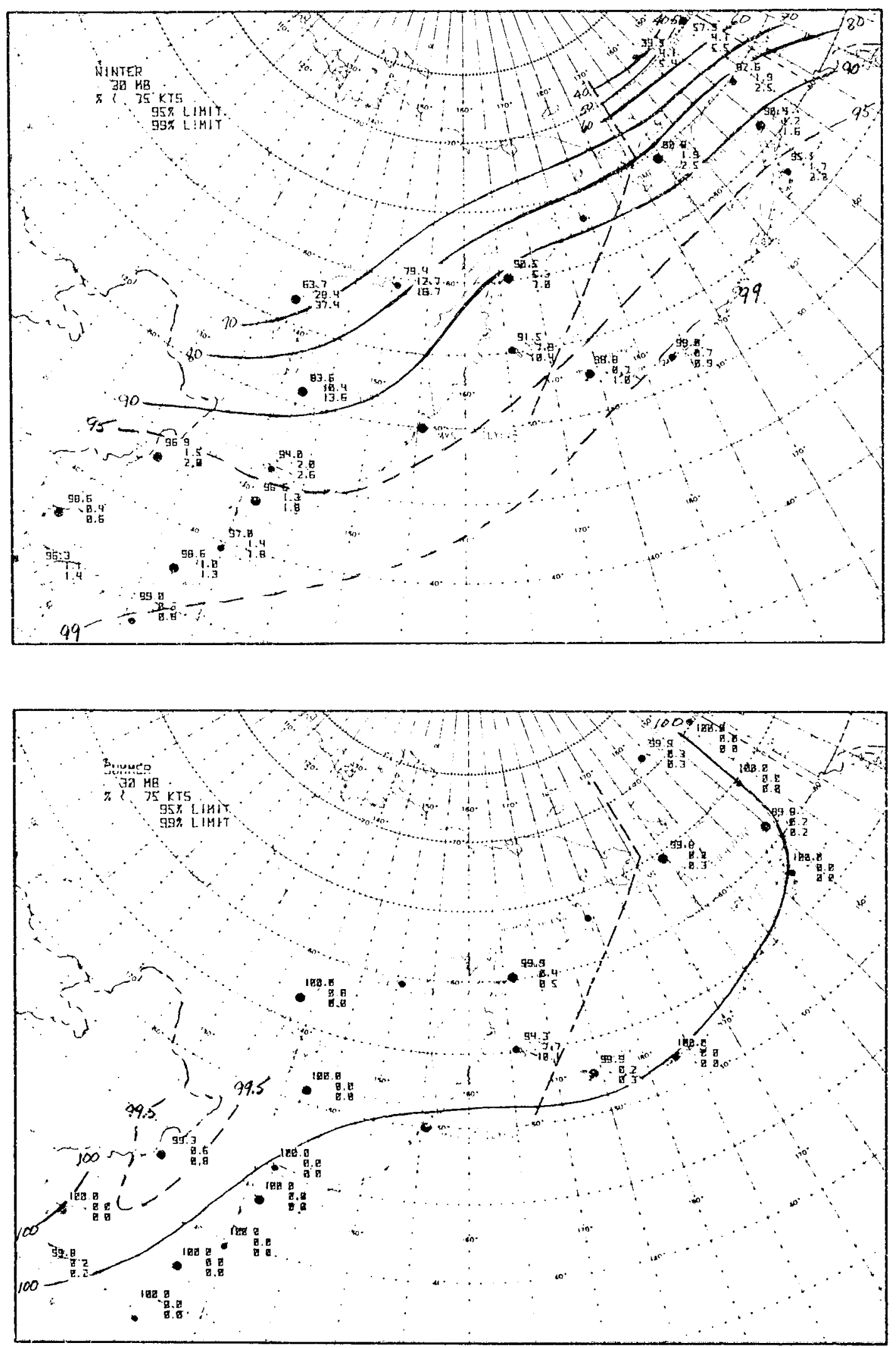

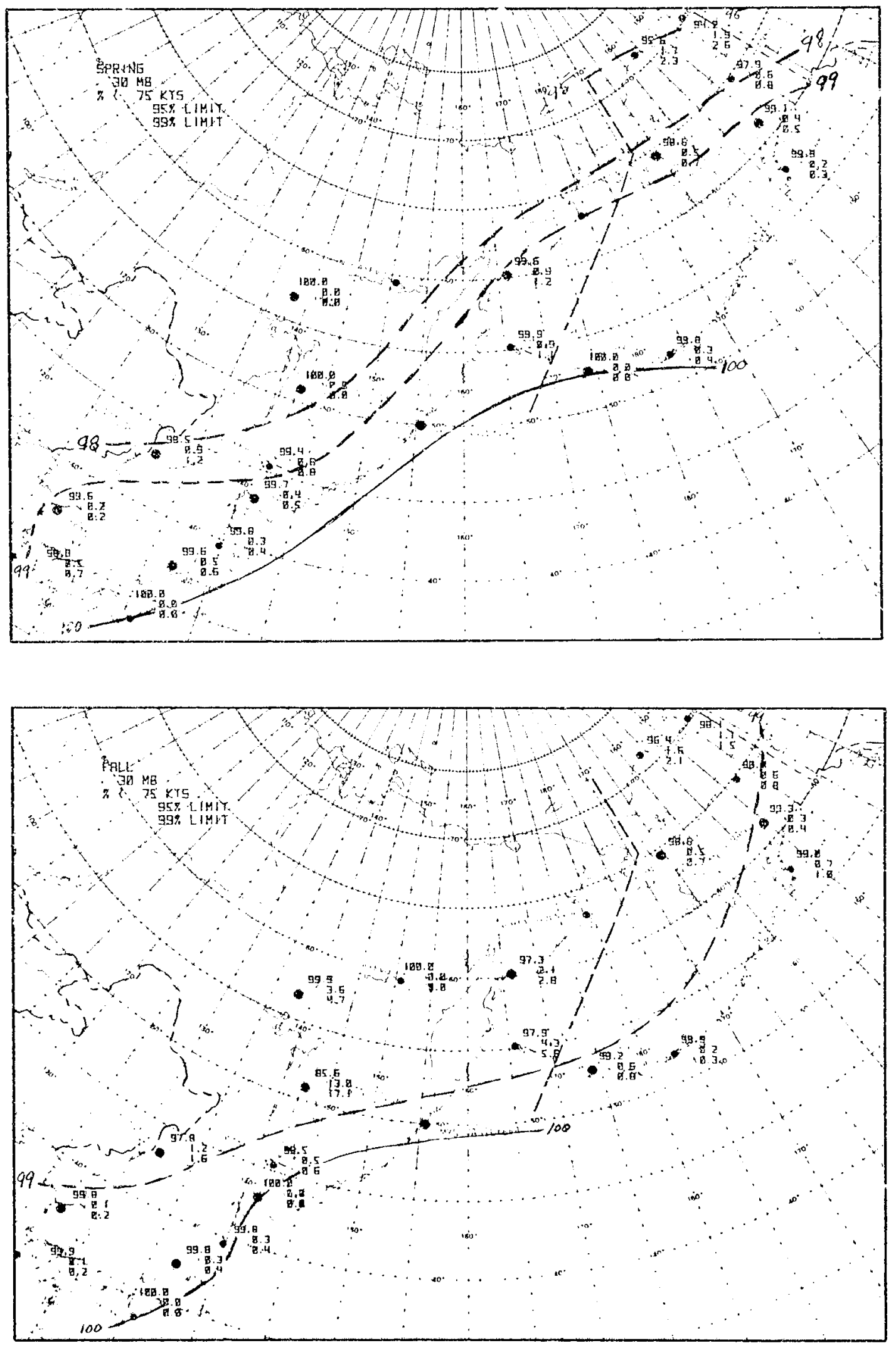


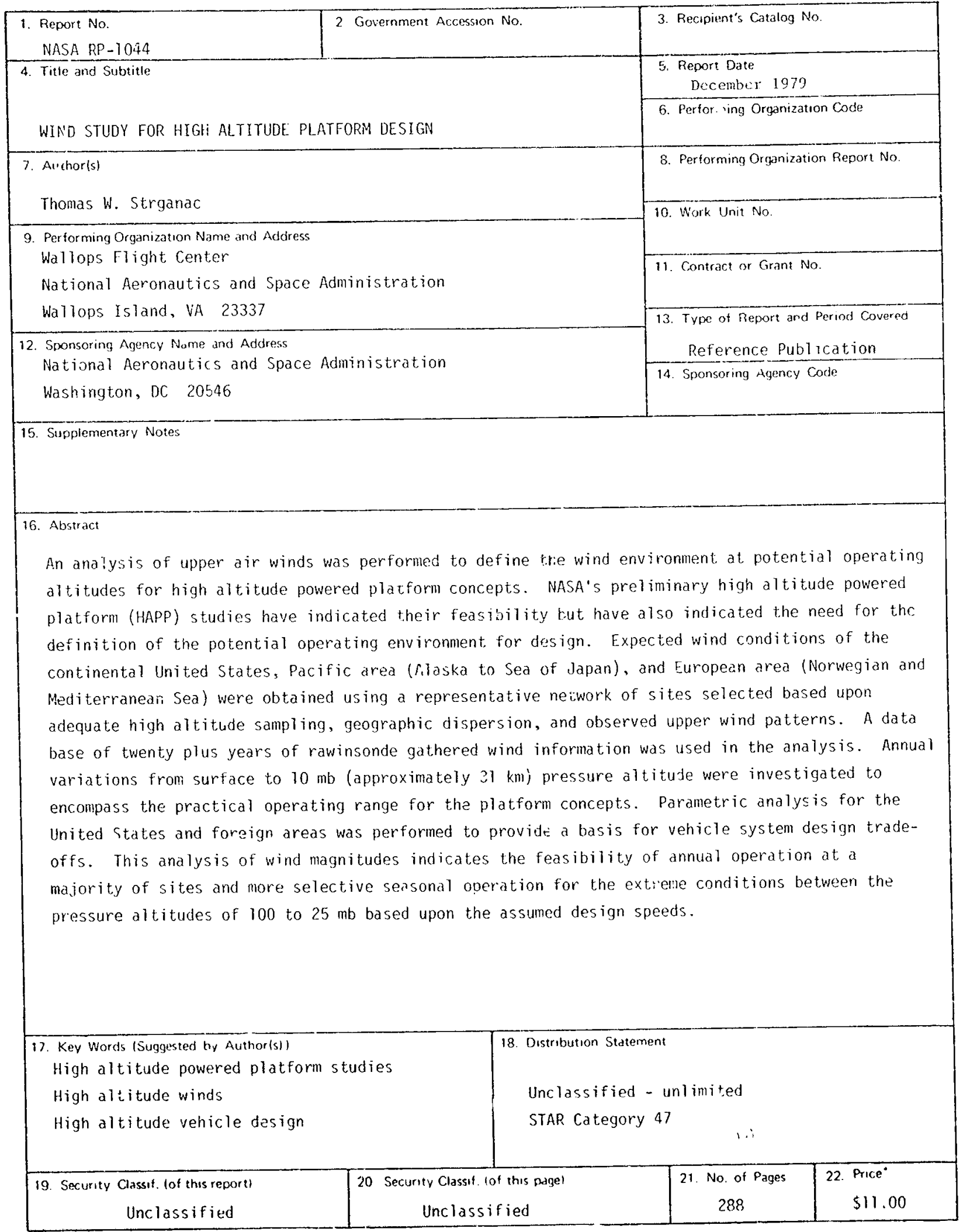

- For sale by the National Technical Intormation Service Sprenptipid Virenat 22161 